\title{
Potential Environmental Impacts of Hydrogen-based Transportation and Power Systems
}

Final Report

December 31, 2010

Tetra Tech, Inc.

Lafayette, CA

Stanford University

Palo Alto, $\mathrm{Ca}$

Potomac-Hudson Engineering

Bethesda, MD 



\section{TABLE OF CONTENTS}

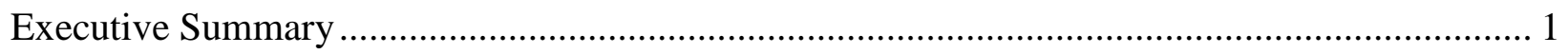

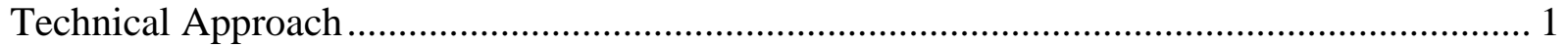

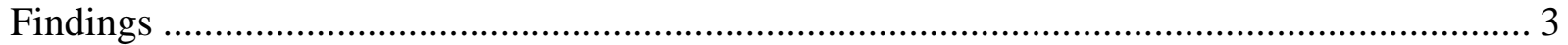

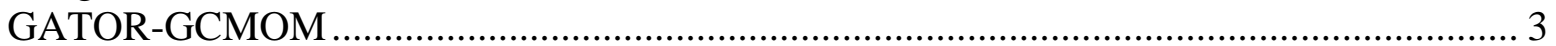

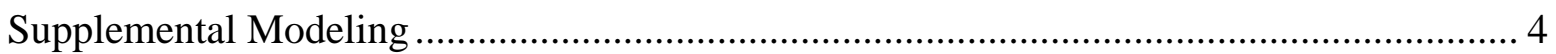

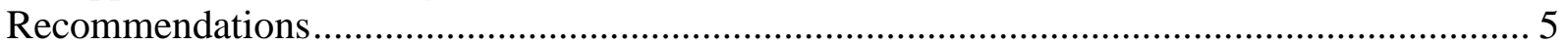

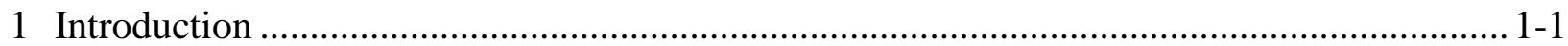

1.1 Technical Approach ............................................................................................1-1

$1.2 \quad$ Report Content and Organization.......................................................................... 1-3

2 GATOR-GCMOM Model Description Simulation Results ................................................2-1

2.1 GATOR-GCMOM and Rationale for Selection....................................................... 2-1

2.1.1 Model Description ....................................................................................... 2-1

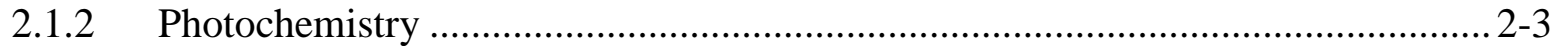

2.1.3 Dry Deposition.................................................................................... 2-3

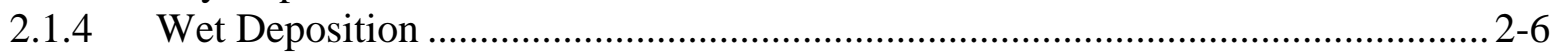

2.1.5 Estimates of Hydrogen Emissions and Leakage ...................................................... 2-6

2.1.6 Assumptions Used in GATOR-GCMOM Simulations..........................................2-8

2.2 GATOR-GCMOM Model Simulation Results ………………................................. 2-8

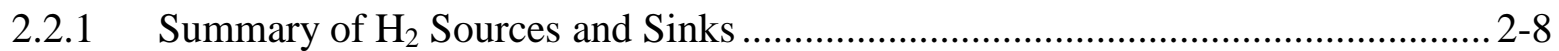

2.2.2 Effects of Converting from FFOVs to Wind-Powered HFCVs Today................ 2-10

2.2.3 Effects of Converting from FFOVs to Steam-Reforming-Powered HFCVs

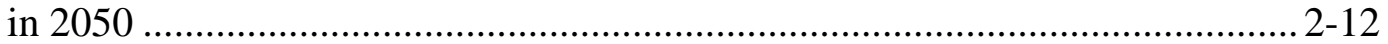

2.3 Estimation of Global Effects of $\mathrm{H}_{2}$ Economy ……................................................ 2-21

3 Emissions Input and Estimated Changes.......................................................................... 3-1

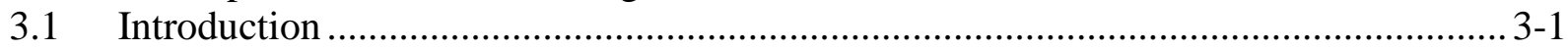

3.2 SRES Scenarios and Emission Estimates.................................................................. 3-2

3.2.1 SRES Scenario A1B Selection.................................................................. 3-8

3.2.2 Emission Estimates by Region for 2000 and 2050 A1B Base Cases .....................3-9

3.2.3 Emission Estimates Scale-up to 2050 ….......................................................... 3-10

3.3 Methods Used for Conversion to $\mathrm{H}_{2}$-based Transportation and Emission

Estimates ..................................................................................................... 3-11

3.3.1 Deriving Emission Growth Factors for Steam-reforming Method for $\mathrm{H}_{2}$ Production .......................................................................................... 3-11

3.3.2 Comparison of Emissions from GATOR-GCMOM for 2000, 2050 A1B,

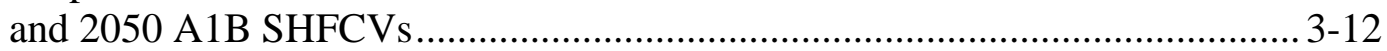

3.3.3 Wind-generated Method for $\mathrm{H}_{2}$ Production and Emission Changes .................... 3-17

3.4 Sensitivity Analysis ......................................................................................... 3-18 


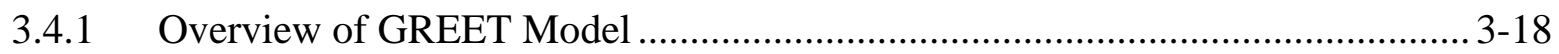

3.4.2 Sensitivity Analyses Using GREET Model in US........................................... 3-20

3.4.3 Sensitivity Analyses for US ......................................................................... 3-23

3.4.4 Sensitivity Analyses for Selected Countries ...................................................... 3-30

3.5 Summary and Conclusions ........................................................................................ 3-34

4 Simplified Global Hydrogen Cycle Model ....................................................................... 4-1

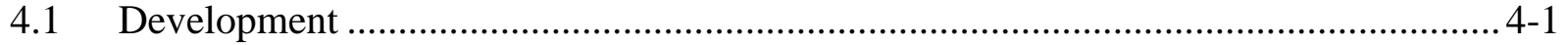

4.2 Applications .................................................................................................. 4-3

4.2.1 Sensitivity of Atmospheric Hydrogen Mixing Ratios to Deposition Velocity ...... 4-4

4.2.2 Time Frame Estimates for Atmospheric Response to Hydrogen Leakage Rates........................................................................................................ 4-6

4.2.3 Approximate Response of Tropospheric Hydrogen Burden to Net Changes in Hydrogen Input from Hydrogen Economy ...................................................... 4-7

4.2.4 Investigation of Time-variable Hydrogen Emission Rates .................................... 4-8

4.2.5 Recent Developments and Implications in Soil Uptake of Hydrogen .................... 4-8

5 Probabilistic Framework to Evaluate Hydrogen Uptake by Soils........................................... 5-1

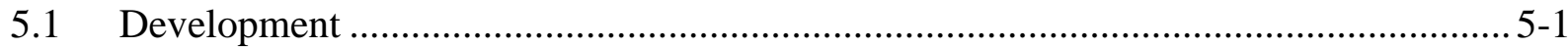

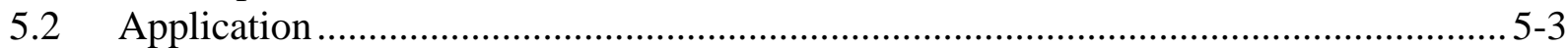

6 Potential Environmental Effects from Shift to HFCVs........................................................6-1

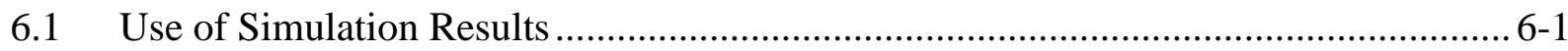

6.2 US Standards for Criteria Pollutants ......................................................................... 6-1

6.3 Comparison of Predicted Criteria Pollutants in US to Standards................................... 6-7

6.4 Potential Effects of Criteria Pollutants on Health ....................................................... 6-8

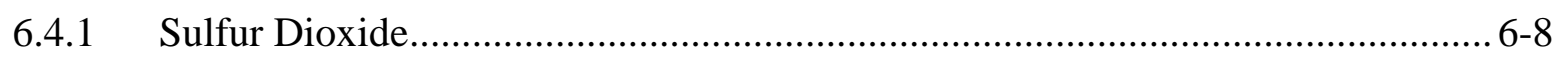

6.4.2 Carbon Monoxide ............................................................................................. 6-9

6.4.3 Nitrogen Dioxide ........................................................................................

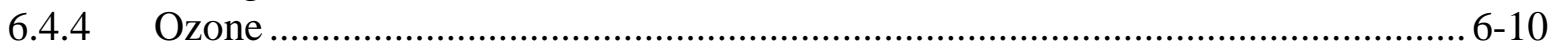

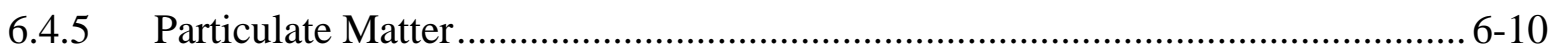

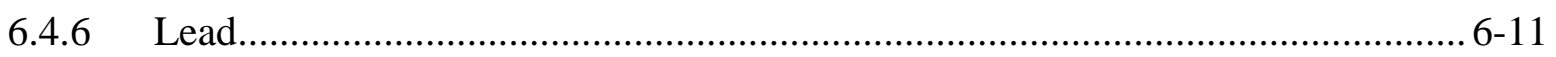

6.5 Potential Effects of Criteria Pollutants on Structures.................................................. 6-11

6.6 Summary of Potential Future Effects ....................................................................... 6-15

7 Summary, Conclusions and Recomendations ..............................................................

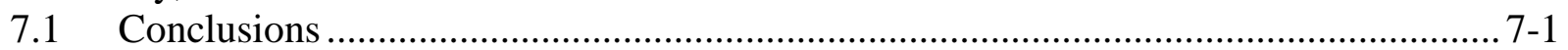

7.2 Recommendations ...........................................................................................

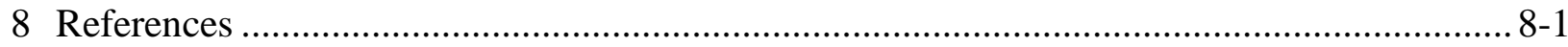

Appendix A Emission-related Tables ....................................................................................... A-1

Appendix B Effects on the Atmosphere of Converting to Hydrogen Fuel Cell Vehicles.

Stanford University, November 2009. ……………........................................................... B-1

Appendix C Development, Verification, and Applications of a Simplified Hydrogen

Model. Tetra Tech, Inc., January 2010................................................................................. C-1

Abstract 1

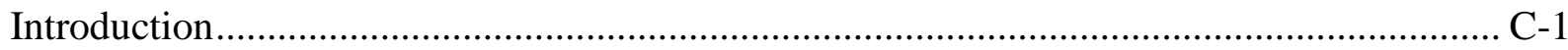

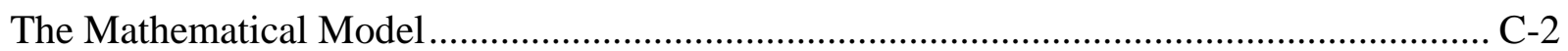

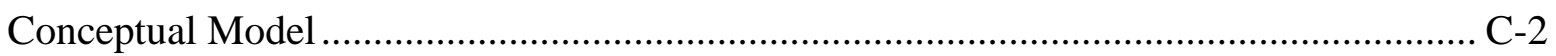

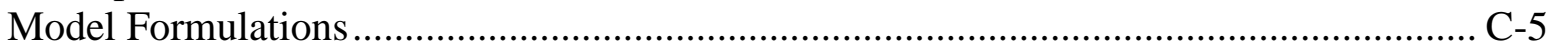

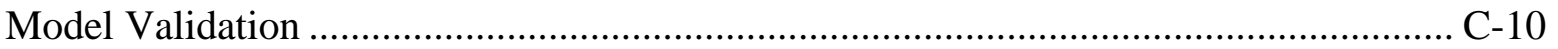




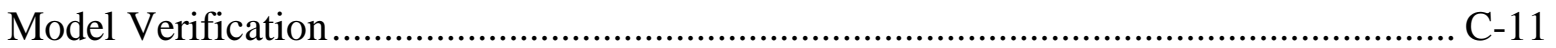

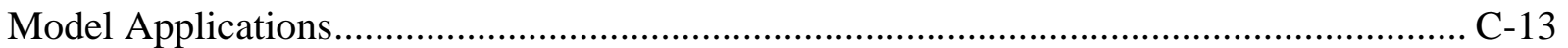

Sensitivity to Deposition Velocity ................................................................................ C-14

Time Frame Estimates for Atmospheric Response to Hydrogen Leakage Rates .............. C-17

Approximate Response of Tropospheric Hydrogen Burden to Net Changes in

Hydrogen Input from Hydrogen Economy …………....................................... C-18

Investigation of Time-variable Hydrogen Emission Rates .................................................. C-20

Recent Developments and Implications in Soil Uptake of Hydrogen .............................. C-21

Summary and Conclusions ................................................................................................ C-25

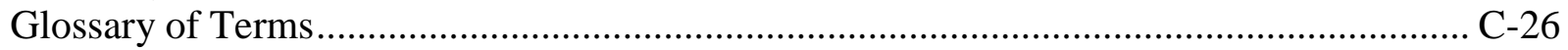

Addendum Typical Range of Model Input Variables....................................................... C-30

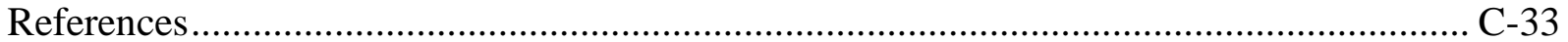

Appendix D Review of Methods of Predicting Soil Uptake of Hydrogen: Experimental and Modeling Approaches, With an Analysis of Uncertainties. Tetra Tech, Inc.,

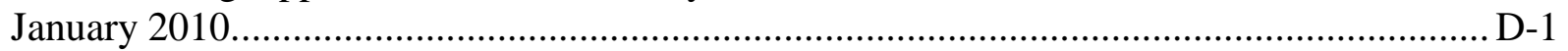

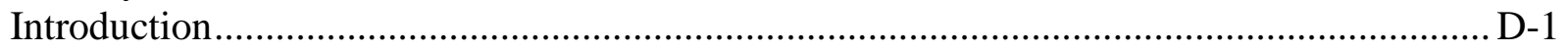

Laboratory and Field Studies of Atmospheric Hydrogen Uptake by Soils ............................ D-1

Modeling Techniques to Estimate Hydrogen Uptake by Soils ............................................... D-6

Development of Probabilistic Framework to Estimate Hydrogen Uptake by Soil................ D-11

Summary and Conclusions ……………………………………………………...... D-18

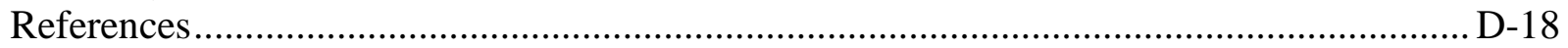

Appendix E Plots of ten-year zonal differences in Selected Constituents: maximum and minimum by altitude and latitude........................................................................................ 



\section{LIST OF FIGURES}

Figure 2-1 Studies of Hydrogen Deposition Velocity. .......................................................... 2-6

Figure 2-2 Annually-averaged dry deposition speeds of $\mathrm{H}_{2}$ from the model calculated with the method described herein ........................................................................ 2-9

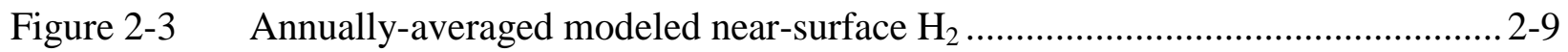

Figure 2-4 Zonally- and ten-year averaged differences in ozone due to converting all FFOV to WHFCVs today. ............................................................................. 2-11

Figure 2-5 Ten-year-average differences in hydrogen near the surface due to the conversion of FFOVs to SHFCVs in 2050 ................................................... 2-13

Figure 2-6 Zonally averaged and ten-year averaged temperature differences for two HFCV scenarios. ................................................................................. 2-14

Figure 2-7 Plots of 10-year zonal differences for ozone: Maximum and minimum by altitude (A) and latitude (B)..................................................................... 2-16

Figure 3-1 Map showing the 17 regions used by the IMAGE 2.2 modeling group and Greenland and Antarctica. .................................................................................... 3-3

Figure 3-2 Comparison of global annual $\mathrm{CO}_{2}$ emissions from all sources including energy, land uses, and industry for the SRES scenario families............................ 3-8

Figure 4-1 Global Hydrogen Cycle .............................................................................. 4-2

Figure 4-2 Sources and Sinks for Global Hydrogen Budget ................................................ 4-3

Figure 4-3 Field and Laboratory Studies of Hydrogen Uptake. Note: The recent modeling results of Jacobson are shown for comparison. .................................... 4-4

Figure 4-4 Sensitivity of Hydrogen Mixing Ratio to Deposition Velocity ............................. 4-5

Figure 4-5 Influence of hydrogen leakage rates on incremental tropospheric and stratospheric hydrogen mixing ratios

Figure 4-6 Effects of time variable source terms and hydrogen leakage on hydrogen mixing ratios in the troposphere. ....................................................................... 4-8

Figure 4-7 Relative soil uptake versus hydrogen concentration............................................. 4-9

Figure 4-8 Global soil uptake of hydrogen using two approaches: (a) linear uptake with respect to hydrogen concentration and; (b) Wuebbles-non-linear

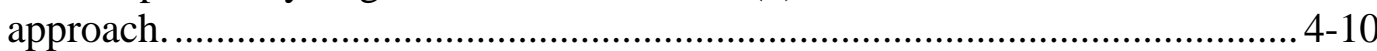

Figure 4-9 Projected Hydrogen Mixing Ratios During the $21^{\text {st }}$ Century for Hydrogen Uptake Governed by the Work of Wuebbles........................................................ 4-10

Figure 5-1 $\quad$ A) Soil temperature limitation function. B) Soil moisture limitation function

Figure 5-2 $\quad$ A) Truncated normal probability density of the temperature in the boreal forest. B) Truncated normal probability density of soil moisture in the boreal forest. C) Truncated normal probability density of the temperature 
in the Mojave Desert. D) Truncated normal probability density of soil moisture in the Mojave Desert.........................................................................5-5

Figure 5-3 $\quad$ A) Distribution of soil uptake of hydrogen in boreal forest. B) Distribution of soil uptake of hydrogen in Mojave Desert....................................................5-6

Figure 6-1 Graphs of Annual Mean Concentrations of Criteria Air Pollutants in the

U.S. from 1990-2008.................................................................................. 6-4

Figure C-1 Global Hydrogen Cycle …........................................................................ C-3

Figure C-2 Sources and Sinks for Global Hydrogen Budget .......................................... C-4

Figure C-3 Present and Projected Atmospheric Hydrogen mole fractions based on

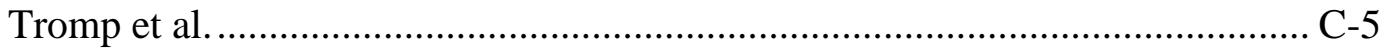

Figure C-4 Predicted Hydrogen Burden and Mixing Ratio in Troposphere under

Present Day Conditions............................................................................... C-11

Figure C-5 Predicted Hydrogen Burden and Mixing Ratios in Stratosphere under

Present Day Conditions.......................................................................... C-12

Figure C-6 Tropospheric Hydrogen Mixing Ratios from 1993-2008 in Tasmania and

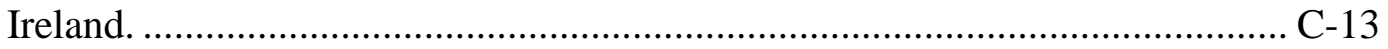

Figure C-7 Studies of Hydrogen Deposition Velocity. ................................................ C-14

Figure C-8 Studies of Hydrogen Uptake .................................................................... C-15

Figure C-9 Sensitivity of Hydrogen Mixing Ratio to Deposition Velocity. ...................... C-16

Figure C-10 Influence of hydrogen leakage rates on incremental tropospheric and

stratospheric hydrogen mixing ratios .......................................................... C-18

Figure C-11 Comparison of Exact and Approximate Changes of Hydrogen Mass in Troposphere

Figure C-12 Effects of time variable source terms and hydrogen leakage on hydrogen mixing ratios in the troposphere. ............................................................. -21

Figure C-13 Relative soil uptake versus hydrogen concentration.................................... C-22

Figure C-14 Global soil uptake of hydrogen using two approaches: (a) linear uptake with respect to hydrogen concentration and; (b) Wuebbles-non-linear approach........................................................................................... C-23

Figure C-15 Relative soil uptake versus hydrogen concentration: Wuebbles approach, and non-linear best fit Wuebbles data.

Figure C-16 Projected Hydrogen Mixing Ratios During the $21^{\text {st }}$ Century for Hydrogen Uptake Governed by the Work of Wuebbles................................................ C-25

Figure D-1 Representative time required for diffusion of hydrogen in soil ....................... D-9

Figure D-2 $\quad$ A) Hydrogen profile over depth for different soil temperatures. B) Hydrogen flux into soil under three soil moisture conditions.......................... D-10

Figure D-3 A) Hydrogen mixing ratio beneath snow cover for different snow cover depths. B) Hydrogen flux into soil beneath snow cover.

Figure D-4 A) Soil temperature limitation function. B) Soil moisture limitation function

Figure D-5 A) Truncated normal probability density of the temperature in the boreal forest. B) Truncated normal probability density of soil moisture in the boreal forest. C) Truncated normal probability density of the temperature in the Mojave Desert. D) Truncated normal probability density of soil moisture in the Mojave Desert. 
Figure D-6 A) Hydrogen uptake in boreal forest limited by soil moisture and temperature. B) Soil uptake of hydrogen in Mojave Desert limited by soil moisture and temperature.

D-17

Figure D-7 $\quad$ A) Distribution of soil uptake of hydrogen in boreal forest. B) Distribution of soil uptake of hydrogen in Mojave Desert. 



\section{LIST OF TABLES}

Table 2-1 Summary of GATOR-GCMOM Model Components ............................................2-1

Table 2-2 Summary of Emission Categories Used in GATOR-GCMOM.............................2-7

Table 2-3 Emission Factors of Hydrogen from Natural Fires by Vegetation Type .............. 2-8

Table 2-4 Summary of Atmospheric Response of Converting from FFOVs to WindPowered HFCVs today ............................................................................. 2-10

Table 2-5 Ten-Year Averaged Differences in Constituent Concentrations Near the Surface for Conversion from FFOVs to SHFCVs in 2050 ............................... 2-13

Table 2-6 (a) Summary of Ten-year Zonal Differences: WHFCV Results by Altitude .... 2-17

Table 2-6 (b) Summary of Ten-year Zonal Differences: WHFCV Results by Latitude .... 2-18

Table 2-6 $\quad$ (c) Summary of Ten-year Zonal Differences: SHFCV Results by Altitude..... 2-19

Table 2-6 $\quad$ (d) Summary of Ten-year Zonal Differences: SHFCV Results by Latitude ..... 2-20

Table 3-1 Population by Regions Used by the IMAGE 2.2 Modeling Group ....................... 3-5

Table 3-2 Gross Domestic Product Per Capita Income for 17 Regions used by IMAGE 2-2 Model....................................................................................... 3-6

Table 3-3 Major Factors Defining IPCC SRES A1 IMAGE Scenario ................................. 3-7

Table 3-4 Differences in Energy-related Factors for Six IPCC Scenario Families................3-8

Table 3-5 World Emissions by Sector and Chemical Species for 2000 Base Case .............. 3-9

Table 3-6 World Emissions by Sector and Chemical Species for 2050 A1B Base Case ......................................................................................................... 3-10

Table 3-7 Growth Factors by Region for Industry, Transportation, and Power Sectors from 2000 Base Case to 2050 A1B..................................................................... 3-13

Table 3-8 Vehicle Miles Traveled per Year by Region and Estimated Gasoline Used for Conventional Vehicles in 2050 ................................................................ 3-14

Table 3-9 Growth Factors by Region for Industry, Transportation, and Power Sectors from 2000 to 2050A1B with SHFCVs.................................................................. 3-15

Table 3-10 Comparison of Fossil-fuel related emission rates of key chemical components in 2000, 2050 A1B scenario, and 2050 A1B scenario with SHFCVs. ............................................................................................. 3-17

Table 3-11 Comparison of Global Emissions for 2000 Base Case and WHFCV Case ....... 3-18

Table 3-12 Fuel Economy from GREET for Vehicle Types................................................. 3-20

Table 3-13 Vehicle Miles Traveled in the USA................................................................ 3-21

Table 3-14 Projected Percentages of Vehicle Fuel Technology Types in the Vehicle Fleet in the US ................................................................................................ 3-21

Table 3-15 Vehicle Fuel Technology and Miles Traveled by Scenario in the US................ 3-21

Table 3-16 Generation Mixture of Electricity by Energy Source Type ................................. 3-22

Table 3-17 Emission Factors of Standard Vehicles for 2030 in US ...................................... 3-23

Table 3-18 Emission Factors of Standard Vehicles for 2050 in US ....................................... 3-24 
Table 3-19

Table 3-20

Table 3-21

Table 3-22

Table 3-23

Table 3-24

Table 3-25

Table 3-26

Table 3-27

Table 3-28

Table 3-29

Table 4-1

Table 6-1

Table 6-2

Table 6-3

Table 6-4

Table 6-5

Table A-1

Table A-2

Table A-3

Table A-4

Table C-1

Table C-2

Table C-3

Table C-4

Table C-5

Table D-1
Baseline Emission Factors for HFCVs for Passenger Cars $3-25$ Baseline Emission Factors for HFCVs for LDT1 ............................................. 3-26 Total Estimated Baseline Emissions without HFCVs in US .............................. 3-27 Net Estimated Change in Emissions in 2030 in US with HFCVs ...................... 3-27 Net Estimated Change in Emissions in 2050 in US with HFCVs ..................... 3-28 Percent Change in Emissions in 2030 and 2050 with HFCVs in US Vehicle Fleet 3-29 Energy Sources Used for Generating Electricity in GREET ............................... 3-31 Projected Methods to Produce Hydrogen in Selected Countries .......................... 3-31 Estimated Emissions with HFCVs for Scenario 1 in 2030 for Other Countries 3-32

Estimated Emissions for 2050 Scenario 2 without HFCVs for Other Countries. 3-33

Estimated Emissions with HFCVs for Scenario 2 in 2050 ............................... 3-33

Parameter-by-Parameter Sensitivity Analysis for Hydrogen Model .................... 4-6

National US Air Quality Standards for Criteria Pollutants.................................... 6-2 Annual Mean Concentrations of Criteria Air Pollutants in US, 1990-2008 ......... 6-3 Simulated Atmospheric Surface Concentrations for US Grid Cells ..................... 6-7

Building Materials and Air Pollutants of Concern .............................................. 6-13

Example of Tolerable $\mathrm{SO}_{2}$ Levels............................................................... 6-14

Emissions for 2000 A1B by Region ............................................................ A-2

Emissions from 2050 A1B by Region ......................................................... A-7

Growth Factors by Region from 2000 Base Case to 2050 A1B ........................ A-12

Parameter Definitions for Emission Growth Factor Tables................................ A-16

Estimates of Anthropogenic Hydrogen Generation and Leakage from

Anthropogenic Production, Distribution, and Storage Operations ....................... C-2

Atmospheric Burdens and Residence Time Estimates of Hydrogen from Various Researchers... C-4

Comparison of Predicted Hydrogen Results vs. Values Calculated by

Other Researchers Shown Previously in Table C-2.

Parameter-by-Parameter Sensitivity Analysis for Hydrogen Model ................. C-17

Typical Range of Model Input Variables............................................................ C-30

Studies to Determine Hydrogen Deposition Velocity and Hydrogen

Uptake by Soils..... D-3 


\section{EXECUTIVE SUMMARY}

Hydrogen $\left(\mathrm{H}_{2}\right)$ offers several advantages as an energy carrier: minimum discharge of pollutants when used, production from multiple types of sources, increased thermodynamic efficiencies compared to fossil fuels, and reduced dependence on foreign oil. However, potential impacts from the $\mathrm{H}_{2}$ generation processes, the transport and distribution of $\mathrm{H}_{2}$, and releases of $\mathrm{H}_{2}$ into the atmosphere have been put forward. Modeling results of Tromp et al., (2003), for example, predicted significant ozone $\left(\mathrm{O}_{3}\right)$ depletion and moisture increases in the stratosphere. The projected additional moisture was hypothesized to cause stratospheric cooling and increased formation of polar ice clouds that indirectly catalyze ozone destruction. Whereas $\mathrm{O}_{3}$ is a problem in the troposphere causing medical, ecological, and material problems, in the stratosphere $\mathrm{O}_{3}$ protectively absorbs ultraviolet radiation and protects the earth surface from bond breaking energy that can lead to health maladies such as skin cancer. However, numerous researchers were quick to note two major problems with the modeling and analysis presented in Tromp et al (2003): 1) the projected $\mathrm{H}_{2}$ leakage rates assumed were very high (i.e., 10 to 20 percent of production versus 1 to 3 percent projected by other investigators), and 2) the analysis did not incorporate the decreases in $\mathrm{CO}_{2}$ and priority pollutants that would accompany the shift to hydrogen. It is known that hydrogen can escape containment at rates about four times that of equally compressed air. Still, Tromp et al.'s assumed leakage rates were about a factor of ten times larger than those calculated by other investigators.

The goal of this project is to analyze the effects of emissions of hydrogen, the six criteria pollutants, and greenhouse gases on climate, human health, materials and structures. This project is part of a larger effort to assess the life-cycle costs and benefits and environmental impacts to inform decisions regarding future hydrogen research as described in the Department of Energy (DOE) Multi-Year Research, Development and Demonstration Plan: Planned Program Activities for 2005-2015. This project contributes to the achievement of DOE Systems Analysis Milestone 11: Complete environmental analysis of the technology environmental impacts for the hydrogen scenarios and technology readiness (http://www1.eere.energy.gov/hydrogenandfuelcells/mypp/).

\section{Technical Approach}

A modeling approach was developed and utilized to evaluate the potential environmental effects associated with the conversion of the on-road vehicle fleet from fossil-fuel vehicles to hydrogen fuel cell vehicles. GATOR-GCMOM (Global Gas Aerosol Transport Radiation General Circulation Mesoscale Ocean Model) was the primary tool used to predict atmospheric concentrations of gases and aerosols associated with the selected scenarios. GATOR-GCMOM, solves gas, aerosol, cloud, dynamical, transport, radiation, ocean, land surface, and sea ice processes [Jacobson et al., 2007; Jacobson, 2008a,b; Jacobson and Streets, 2009]. This fully 
coupled model accounts for all feedbacks among major atmospheric processes based on first principles.

The dominant sink for $\mathrm{H}_{2}$ in the troposphere is loss to soils. This accounts for about 80 percent of the total $\mathrm{H}_{2}$ sink (Rhee et al., 2006). The capabilities of the GATOR-GCMOM soil routine were extended to mechanistically represent hydrogen loss to soils in terms of an inverse sum of resistances, and weighted over land use types. The new expressions for $\mathrm{H}_{2}$ uptake by soils built on the previous work of other researchers over the past two decades such as reported in SmithDowney et al. (2006) and in Conrad and Seiler (1995).

The future scenarios and the emission rates selected for this analysis of hydrogen environmental effects are based on the scenarios developed by the Intergovernmental Panel on Climate Change (IPCC, 2000). The scenarios selected for the model simulations are a 2000 base case, a 2050 A1B base case, and a 2050 A1B case with hydrogen fuel cell vehicles (HFCVs). The hydrogen fuel cell scenario assumed conversion of $90 \%$ of fossil-fuel on-road vehicles (FFOV) in developed countries and $45 \%$ of FFOVs vehicles in other countries to hydrogen fuel cell vehicles, with the $\mathrm{H}_{2}$ produced by steam-reforming of natural gas (SHFCVs). A second set of simulations was conducted to examine the effect of converting the world's FFOVs to HFCVs, where the $\mathrm{H}_{2}$ is produced by wind-powered electrolysis (WHFCVs). In all scenarios a 3\% leakage of $\mathrm{H}_{2}$ consumed was assumed.

GATOR-GCMOM was used to predict tropospheric and stratospheric concentrations of gases and aerosols including $\mathrm{CO}_{2}, \mathrm{CH}_{4}, \mathrm{O}_{3}, \mathrm{H}_{2}$, water vapor, VOCs, and particulate matter. The predicted concentrations of $\mathrm{H}_{2}$, VOCs, and greenhouse gases are used to estimate effects on climate such as changes in air temperature, cloud production, ozone levels, and production of photochemical smog. The effects on air quality, human health, materials, and building structures are quantified by comparing the GATOR-GCMOM model output and accepted health and other effects levels, and ambient air quality criteria.

Because of the high resolution and computational requirements of the radiation, photochemical, cloud, aerosol and surface processes, the horizontal resolution was limited to $4^{\circ} \mathrm{S}-\mathrm{N} \times 5^{\circ} \mathrm{W}-\mathrm{E}$ global domain. Each scenario was simulated for 10 years to assess climate responses.

Two new models were developed that provide the ability to evaluate a wider range of conditions and address some of the uncertainties that exist in the evaluation of the effects of hydrogen emissions. One of these models is a simplified global hydrogen cycle model that simulates hydrogen dynamics in the troposphere and stratosphere and is intended to complement more complex three-dimensional models, with particular focus on GATOR-GCMOM. While this model is unable to simulate the wide array of processes parameterized in numerical threedimensional models, it can simulate multiple sources and sinks of hydrogen to predict atmospheric hydrogen mixing ratios, total atmospheric burden, and lifetime of hydrogen over time periods that extend from well into the past to well into the future (for example, from the beginning of the industrial revolution to the end of the 21st century) in a matter of minutes while at the other extreme, GATOR-GCMOM can take weeks of real time to simulate a decade.

Although atmospheric hydrogen uptake by soils has been studied for several decades, the number of studies is small, and relatively few uptake rates or deposition velocities have been estimated. Also no framework has been developed that can rigorously accommodate natural variability. The second new model provides a Monte Carlo framework to address this issue. While it is not feasible to include the Monte Carlo approach in GATOR-GCMOM due to that model's 
complexity, the application of the probabilistic approach with the simplified model provides valuable insight into the issue of uptake variability for different types of ecosystems.

\section{Findings}

The major findings of the project are presented in two parts: GATOR-GCMOM simulations and supplemental modeling.

\section{GATOR-GCMOM}

1. Converting $100 \%$ of current vehicles worldwide to WHFCVs is expected to reduce levels of $\mathrm{NO}_{\mathrm{x}}, \mathrm{CO}, \mathrm{CO}_{2}$, most organic gases, $\mathrm{OH}$, ozone, PAN, black carbon, and other particle components in the troposphere, but to increase tropospheric $\mathrm{CH}_{4}$ due to the lower $\mathrm{OH}$. However, by cooling the troposphere and warming the stratosphere, thereby stabilizing the stratosphere, reducing water vapor and $\mathrm{HO}_{\mathrm{x}}$ transport to it, and reducing the sizes and lifetimes of stratospheric aerosols and polar stratospheric clouds, WHFCVs are expected to increase upper tropospheric/lower stratospheric (UTLS) ozone, causing a net global ozone column increase, despite a slight upper stratospheric decrease in ozone. Thus, shifting to WHFCVs would benefit the environment by improving air quality and decreasing conditions that favor ozone destruction in the UTLS.

2. Converting vehicles worldwide in 2050 to SHFCVs at $90 \%$ penetration in developed countries and $45 \%$ penetration in other countries is expected to reduce $\mathrm{NO}_{\mathrm{x}}, \mathrm{CO}, \mathrm{CO}_{2}$, $\mathrm{CH}_{4}$, some other organic gases, ozone, PAN, black carbon, and other particle components in the troposphere, but may increase some other organic gases there, depending on the exact emission changes. Conversion to SHFCVs is also expected to cool the troposphere and warm the stratosphere, but to a lesser extent than WHFCVs. Finally, SHFCVs are expected to increase upper tropospheric/lower stratospheric ozone while decreasing upper stratospheric ozone, but to a lesser extent in both cases than WHFCVs. Conversion to SHFCVs would also benefit the environment, particularly if organic gas emissions were lower than simulated, which would result in less surface ozone and increased stratospheric ozone.

3. These results (with respect to WHFCVs and SHFCVs) will likely strengthen over longer simulation periods, as greater reductions in $\mathrm{CO}_{2}$ over a longer simulation period will trigger greater tropospheric cooling and stratospheric warming, causing greater reductions in surface ozone and greater net increases in stratospheric ozone.

4. The predicted criteria pollutant concentrations from the GATOR-GCMOM simulations indicate that near surface annual mean concentrations in the US are likely to increase from the 2000 base case to the $2050 \mathrm{~A} 1 \mathrm{~B}$ base case for $\mathrm{CO}_{2}$ and ozone due to increased economic activity, but to decrease for $\mathrm{CO}, \mathrm{NO}_{2}, \mathrm{SO}_{2}$, and $\mathrm{PM}_{10}$ due to improved pollution control equipment and energy efficiencies. The shift to SHFCVs in 2050 is predicted to result in decreased concentrations for all the criteria pollutants, except for $\mathrm{SO}_{2}$ and $\mathrm{PM}_{10}$. The higher predicted concentrations for $\mathrm{SO}_{2}$ and $\mathrm{PM}_{10}$ were attributed to increased emissions associated with the use of the steam-reforming method to generate $\mathrm{H}_{2}$. If renewable methods such as wind-based electrolysis were used to generate $\mathrm{H}_{2}$, the emissions of $\mathrm{SO}_{2}$ and $\mathrm{PM}_{10}$ would be lower. Because most of the key pollutants are predicted to decrease, shifting to HFCVs is considered to be beneficial to human health, and unlikely to result in damage to buildings and cultural or heritage sites. 
5. These results are thought to be robust for larger leakage rates of hydrogen and for greater penetrations of HFCVs, since we believe that the controlling factor for stratospheric ozone impacts is the reduction in fossil-fuel greenhouse gases and the resulting surface cooling, which reduces water vapor emissions, and stratospheric warming, which increases tropopause stability, reducing water vapor transport to the stratosphere. The reduction in water vapor (and ozone-destroying hydrogen oxides that is produced) to the stratosphere due to climate feedbacks should be larger than increases in water vapor and hydrogen oxides produced by leaked hydrogen, causing a net column ozone increase. Further, warmer stratospheric temperatures due to HFCVs should reduce aerosol and polar stratospheric cloud size and lifetime, reducing ozone loss further. While we do not know exactly what hydrogen leakage rate and vehicle penetration would cause net damage, we are confident, based on the results to date that indicate the dominance of climate feedbacks, that all realistic proposed future scenarios of HFCV fleets will not cause damage. As such, no disadvantage to the future large-scale penetration of HFCVs is indicated.

\section{Supplemental Modeling}

The simplified model is intended to check the plausibility of results from GATOR-GCMOM. Summarizing the model's capabilities, it predicts both tropospheric and stratospheric hydrogen mixing ratios, subject to hydrogen releases (from biomass burning, fossil fuel combustion, nitrogen fixation, soil uptake, and oceanic off gassing), and atmospheric sinks and sources (oxidation by the $\mathrm{OH}$ radical, and production by photolysis of HCHO, which is produced from atmospheric methane).

The model was validated by a series of analytical tests, and by comparison with known atmospheric burdens, mixing ratios, and residence times of hydrogen. Sensitivity analyses were also performed that confirmed the importance of soil uptake on the global budget.

The major conclusions of this supplemental work are as follows:

1. The time required for hydrogen mixing ratios to attain a steady state condition following initiation of a constant hydrogen leakage rate is over 10 years in the troposphere and over 50 years in the stratosphere. This suggests that the GCMs should be run for periods in excess of 10 years.

2. The hydrogen mixing ratios in the 21st century are likely to increase whether or not the hydrogen economy evolves. These increases may exceed those due to transformation to a hydrogen economy.

3. Hydrogen deposition velocity is an important contributor to the fate of hydrogen, since soil uptake is the single largest pathway of hydrogen loss from the atmosphere. On a global basis, a hydrogen deposition velocity of $0.041 \mathrm{~cm} \cdot \mathrm{s}^{-1}$ that is used by GATORGCMOM is consistent with the work by Novelli (1999). On a local basis, the deposition velocity can vary greatly due to such local changes in soil temperature and soil moisture. This behavior was shown by examining hydrogen uptake in two ecosystems: a boreal forest and the Mojave Desert.

4. Based on laboratory experiments performed by Smith-Downey (2006) under optimal soil temperature and soil moisture conditions, the upper limit of hydrogen uptake by soil was calculated to be approximately $35 \mathrm{nmol} \cdot \mathrm{m}^{-2} \cdot \mathrm{s}^{-1}$, which is equivalent to a deposition 
velocity of approximately $0.15 \mathrm{~cm}-\mathrm{s}^{-1}$. This value is slightly higher than deposition velocities reported from all previous studies reviewed here, and bounds the upper limit of hydrogen deposition.

5. Current developments in hydrogen uptake by soils were reported in Wuebbles (2009). Laboratory analysis implicated a non-linear dependence on hydrogen mixing rates. Algorithms to describe hydrogen uptake in the model were modified to incorporate these effects. Results showed that soil uptake would increase as molecular hydrogen mixing ratios increase, thereby tending to reduce mixing ratios. An example that was simulated showed that by mid-century mixing ratios would be $30 \mathrm{ppbv}$ lower, and by the end of the century 110 ppbv lower. These are significant differences, and suggest the importance of confirming the findings of Wuebbles (2009).

\section{Recommendations}

Based on the results of these studies several recommendations are made to extend the analysis of the effects of emissions of hydrogen and to address the uncertainties associated with the technical approach and the results from this study.

1. The GATOR-GCMOM model was used to perform simulations of future conditions for ten years. At the end of the ten year period, it is assumed that the atmospheric chemistry has attained a new steady-state condition, and that concentrations of important constituents have all stabilized. However, it has not been possible to demonstrate the validity of this assumption during the project. We recommend that longer simulation time periods be evaluated that would not only allow an assessment of this assumption, but also how longer-duration simulations would influence our conclusions. To accomplish this task, methods to make longer duration simulations feasible would be examined including running GATOR-GCMOM on faster computers, or streamlining the model for faster execution.

2. For this project, GATOR-GCMOM was initialized in a unique way, and the uncertainties in predictions associated with this single initialization were not examined. In general, data sets to uniquely initialize GATOR-GCMOM (or other GCMs) are incomplete, and climate modelers often use different initializations to create an ensemble of simulations. We recommend that tests be completed with multiple simulations of differing initializations to examine the significance on model predictions and project conclusions.

3. Surface concentrations of $\mathrm{SO}_{2}$ and $\mathrm{PM}_{10}$ in the US were predicted to increase for the 2050 A1B case with SHFCVs over the 2050 A1B base case. The predicted surface concentrations in the US were less than the annual mean standard for $\mathrm{SO}_{2}$, but more detailed simulations could be conducted to allow comparison to the 24-hour standards for $\mathrm{SO}_{2}$ and $\mathrm{PM}_{10}$. The ability to provide additional spatial and temporal data could be achieved by running GATOR-GCMOM in a nested grid configuration for the US and saving daily and seasonal concentration data for key criteria pollutants that have 24- or 8hour standards $\left(\mathrm{SO}_{2}, \mathrm{CO}, \mathrm{O}_{3}\right.$, and $\mathrm{PM}_{10}$ and $\left.\mathrm{PM}_{2.5}\right)$. The detailed results would then be compared to the shorter duration air quality standards for near surface atmospheric concentrations of the criteria pollutants.

4. The simplified hydrogen model developed during this project was limited to examining the fate of hydrogen emitted to the atmosphere, as well as sources and sinks of hydrogen. 
It is recommended that other atmospheric constituents be added to the model to further increase its utility, with a focus on those constituents that can be simulated with a limited number of chemical reactions and source/sink terms. Special emphasis should be placed on exploring ways to further examine the dominant effects of climate feedbacks that appear important to the results of the GATOR-GCMOM simulations.

5. Due to the potential significance of the work done by Wuebbles (2009) that suggests hydrogen uptake by soil is a non-linear function of atmospheric concentrations, we suggest further studies be conducted to examine this process. To our knowledge, there are no other uptake results that are consistent with these. The proposed studies should also include field experiments to determine deposition velocities for different biome types that will supplement the generally sparse data presently available. 


\section{INTRODUCTION}

Hydrogen $\left(\mathrm{H}_{2}\right)$ offers several advantages as an energy carrier: minimum discharge of pollutants when used, production from multiple types of sources, increased thermodynamic efficiencies compared to fossil fuels, and reduced dependence on foreign oil. However, potential impacts from the $\mathrm{H}_{2}$ generation processes, the transport and distribution of $\mathrm{H}_{2}$, and releases of $\mathrm{H}_{2}$ into the atmosphere have been put forward. Modeling results of Tromp et al., (2003), for example, predicted significant ozone $\left(\mathrm{O}_{3}\right)$ depletion and moisture increases in the stratosphere. The projected additional moisture was hypothesized to cause stratospheric cooling and increased formation of polar ice clouds that indirectly catalyze ozone destruction. Whereas $\mathrm{O}_{3}$ is a problem in the troposphere causing medical, ecological, and material problems, in the stratosphere $\mathrm{O}_{3}$ protectively absorbs ultraviolet radiation and protects the earth surface from bond breaking energy that can lead to health maladies such as skin cancer. However, numerous researchers were quick to note two major problems with the modeling and analysis presented in Tromp et al (2003): 1) the projected $\mathrm{H}_{2}$ leakage rates assumed were very high (i.e., 10 to 20 percent of production versus 1 to 3 percent projected by other investigators), and 2) the analysis did not incorporate the decreases in $\mathrm{CO}_{2}$ and priority pollutants that would accompany the shift to hydrogen. It is known that hydrogen can escape containment at rates about four times that of equally compressed air. Still, Tromp et al.'s assumed leakage rates were about a factor of ten times larger than those calculated by other investigators.

The goal of this project is to analyze the effects of emissions of hydrogen, the six criteria pollutants and greenhouse gases on climate, human health, materials and structures. This project is part of a larger effort to assess the life-cycle costs and benefits and environmental impacts to inform decisions regarding future hydrogen research as described in the Department of Energy (DOE) Multi-Year Research, Development and Demonstration Plan: Planned Program Activities for 2005-2015. This project contributes to the achievement of DOE Systems Analysis Milestone 11: Complete environmental analysis of the technology environmental impacts for the hydrogen scenarios and technology readiness (http://www1.eere.energy.gov/hydrogenandfuelcells/mypp/).

\subsection{Technical Approach}

There are five tasks associated with the overall technical approach:

- Develop Scenarios for Implementing a Shift to Hydrogen-based Vehicles and Corresponding Emission Rates. The future scenarios and the emission rates selected for this analysis of hydrogen environmental effects are based on the scenarios developed by the Intergovernmental Panel on Climate Change (IPCC, 2000). The scenarios selected for the model simulations are a 2000 base case, a 2050 A1B base case, a 2050 A1B case with hydrogen fuel cell vehicles (HFCVs) where the hydrogen fuel is generated by the steamreforming of natural gas, and a contemporary case with HFCVs with hydrogen generated 
by wind-powered electrolysis.

The basic steps performed to parameterize the emission inputs for the modeling task are:

o Compile emissions data for the selected scenarios by geographic region

o Estimate emission changes from fossil fuel vehicles to HFCVs

o Develop emission growth factors for change from 2000 to 2050 with HFCVs

o Use these growth factors to scale regional emissions to a global grid used for modeling

The results from the Special Report on Emissions Scenarios (SRES) (IPCC, 2000) are used to generate the basic emissions data. A variety of tools, including the GREET 1.8b model (ANL, 2008a), are then used to generate the emissions profiles of HFCV applications.

The complexity of the model used to predict atmospheric concentrations of gases and aerosols limited the number of simulations that could be conducted. Therefore, a series of sensitivity analyses were conducted to evaluate the effect on emissions of alternative methods for generating hydrogen fuel, alternative energy sources for electricity, different mixes of vehicle types, and different world-wide HFCV penetration scenarios.

\section{- Predict Changes in Atmospheric Concentrations of Hydrogen and Other} Constituents. GATOR-GCMOM (Global Gas Aerosol Transport Radiation General Circulation Mesoscale Ocean Model) was used as the primary tool to predict atmospheric concentrations of gases and aerosols associated with the selected scenarios. GATORGCMOM, solves gas, aerosol, cloud, dynamical, transport, radiation, ocean, land surface, and sea ice processes [Jacobson et al., 2007; Jacobson, 2008a,b; Jacobson and Streets, 2009] and is the "first fully-coupled online model to account for all major feedbacks among major atmospheric processes based on first principles” Zhang (2008, p. 1844). GATOR-GCMOM was used to predict tropospheric and stratospheric concentrations of gases and aerosols including $\mathrm{CO}_{2}, \mathrm{CH}_{4}, \mathrm{O}_{3}, \mathrm{H}_{2}$, water vapor, VOCs, and particulate matter. The predicted concentrations of $\mathrm{H}_{2}$, VOCs, and greenhouse gases are used to estimate effects on climate such as changes in air temperature, cloud production, ozone levels, and production of photochemical smog.

- Extend the GATOR-GCMOM Soils Module. The dominant sink for $\mathrm{H}_{2}$ in the troposphere is loss to soils. This accounts for about 80 percent of the total $\mathrm{H}_{2}$ sink (Rhee et al., 2006). The capabilities of the GATOR-GCMOM soil routine were extended to mechanistically represent hydrogen loss to soils in terms of an inverse sum of resistances, and weighted over land use types. The new expressions for $\mathrm{H}_{2}$ uptake by soils were based on the previous work of other researchers over the past two decades such as reported in Smith-Downey et al. (2006) and in Conrad and Seiler (1995).

- Develop Simplified Models. Two new models were developed to provide the ability to evaluate a wider range of conditions and address some of the uncertainties that exist in the evaluation of the effects of hydrogen emissions. One of these models is a simplified global hydrogen cycle model that simulates hydrogen dynamics in the troposphere and stratosphere and is intended to complement more complex three-dimensional models, with particular focus on GATOR-GCMOM (Jacobson, 2009). While this model is unable 
to simulate the wide array of processes parameterized in numerical three-dimensional models, it can simulate multiple sources and sinks of hydrogen to predict atmospheric hydrogen mixing ratios, total atmospheric burden, and lifetime of hydrogen over time periods that extend from well into the past to well into the future (for example, from the beginning of the industrial revolution to the end of the 21st century) in a matter of minutes while at the other extreme, GATOR-GCMOM can take weeks of real time to simulate a decade.

Although atmospheric hydrogen uptake by soils has been studied for several decades, the number of studies is small, and relatively few uptake rates or deposition velocities have been estimated. Also no framework has been developed that can rigorously accommodate natural variability. The second new model provides a Monte Carlo framework to address this issue. While it is not feasible to include the Monte Carlo approach in GATORGCMOM due to that model's complexity, the application of the probabilistic approach with the simplified model provides valuable insight into the issue of uptake variability for different types of ecosystems.

- Quantify Near and Long-term Environmental Effects. The effects on air quality, human health, ecosystem, and building structures are quantified using the GATORGCMOM model output and accepted health and ecosystem effects levels, and ambient air quality criteria.

\subsection{Report Content and Organization}

The results of the model simulations and the interpretation of the data from numerous analyses are presented in seven major sections. Each of the sections, with the exception of Appendix A and Appendix E, is intended to stand alone and to describe the major elements of this research project:

- Section 2. GATOR-GCMOM Simulations. GATOR-GCMOM was used to conduct ten-year simulations to examine the effect of converting $90 \%$ of fossil-fuel on-road vehicles (FFOV) in developed countries and $45 \%$ of FFOVs vehicles in other countries in 2050 to hydrogen fuel cell vehicles, where the $\mathrm{H}_{2}$ is produced by steam-reforming of natural gas (SHFCVs). A second set of ten-year simulations were conducted to examine the effect of converting the world's FFOV to hydrogen fuel cell vehicles (HFCVs), where the $\mathrm{H}_{2}$ is produced by wind-powered electrolysis (WHFCVs). The results of these simulations are described in detail. Tropospheric and stratospheric changes in the major emitted and produced chemicals (e.g., $\mathrm{CH}_{4}, \mathrm{CO}_{2}, \mathrm{CO}, \mathrm{H}_{2}, \mathrm{H}_{2} \mathrm{O}$-vapor, $\mathrm{HCHO}, \mathrm{NO}_{2}, \mathrm{NO}$, $\mathrm{O}_{3}$ and VOCs) are presented. The predicted concentrations of $\mathrm{H}_{2}$ and greenhouse gases are used to estimate effects on climate such as changes in air temperature, cloud production, ozone levels, and production of photochemical smog.

- Section 3. Emissions Input and Estimated Changes. Although the emissions data used as input to GATOR-GCMOM are described in Section 2, detailed information on the development of the data for the selected emission scenarios is described in Section 3. The tools used in the development of the model input data are described, and the differences between the alternative scenarios are discussed. The results of sensitivity analyses, that were conducted to evaluate the effect on emissions of alternative energy sources for hydrogen production and for alternative methods of generating electricity and different 
HFCV penetration scenarios, are also presented. The objective of this section is to provide a detailed description of the emissions data used and an assessment of the general applicability of the GATOR-GCMOM results that are based on a limited set of growth and energy-use scenarios.

- Section 4. Simplified Global Hydrogen Cycle Model. The newly developed simplified global hydrogen cycle model is described, and the results of several analyses that were conducted to assess the potential effects of the hydrogen economy are presented. These analyses are used, for example, to estimate how the burden (and therefore mixing ratio) of hydrogen will change in the troposphere at a future steady-state condition. The use of this new tool to vary a wide range of assumptions and to evaluate tropospheric hydrogen burden changes with and without a hydrogen economy is demonstrated.

- Section 5. Probabilistic Framework to Evaluate Atmospheric Hydrogen Uptake by Soils. The results of the newly developed Monte Carlo framework to examine natural variability of $\mathrm{H}_{2}$ deposition velocities or uptake rates are presented. Two ecosystem types, a boreal forest ecosystem and the Mojave Desert ecosystem, are examined in detail. The hydrogen uptake rates over the range of soil moisture and temperature conditions for the two ecosystems are presented, and these are compared with estimates of actual global uptake (50 to $90 \mathrm{Tg} / \mathrm{yr}$ ) and the estimates from the GATOR-GCMOM simulations.

- Section 6. Potential Environmental Effects From Shift to HFCVs on Human Health and Structures. The near-surface concentrations in the US for $\mathrm{CO}, \mathrm{SO}_{\mathrm{x}}, \mathrm{NO}_{2}$, ozone, and particulate matter from the GATOR-GCMOM results were compared to pertinent national air quality standards. Potential effects on human health, materials, and structures due to the predicted changes in criteria pollutants after a shift to HFCVs are discussed.

- Section 7. Summary, Conclusions, and Recommendations. The results from the GATOR-GCMOM simulations of the current and future (2050) emission inventories of all important anthropogenic gas and particle chemicals are summarized. Overall, these results, which are the cornerstone of this project, indicate that all proposed future scenarios for the development and expansion of HFCV fleets will not cause damage to the troposphere or stratosphere.

In addition to the examination of potential global atmospheric changes associated with conversion to HFCVs, the results from the GATOR-GCMOM simulations were used to compare the predicted surface atmospheric concentrations of hydrogen, the six criteria pollutants and greenhouse gases on climate, human health, materials, and structures to levels that may cause effects on human health and structures or materials. A summary of the potential for effects in the US is presented.

Based on these results, as well as predictions from the global hydrogen balance model that was developed to check the plausibility of results from GATOR-GCMOM and to simulate atmospheric conditions over longer periods of time, recommendations are presented to address identified uncertainties.

- Section 8. References. The literature cited in Sections 1-7 is listed. 
- Appendix A. Supporting Data Tables for Emissions Input and Estimated Changes. Numerous tables that provide back up to the results summarized in Section 3 are presented.

- Appendix B. Final Report by Stanford University: Effects on the Atmosphere of Converting to Hydrogen Fuel Cell Vehicles. The complete results of the GATORGCMOM Simulations are presented. The results of the analyses conducted by Stanford University are summarized in Section 2. Here the complete results of the simulations conducted by Professor Mark Z. Jacobson are presented. In addition to more detailed information on the model set up, the final report includes additional graphic presentations of the modeling results.

- Appendix C. Development, Verification, and Applications of a Simplified Hydrogen Model. Section 4 provided a summary of the results from a simplified model of hydrogen dynamics in the troposphere and stratosphere. Hypothetical market conversion scenarios are simulated, and predicted hydrogen mixing ratios have been simulated up to the end of the 21st century. The complete description of the model and the simulation results are presented in this appendix. The description includes the results of various verification and validation tests.

- Appendix D. Probabilistic Framework to Estimate Hydrogen Uptake by Soils. The results of the Monte Carlo framework that was developed for this project to examine natural variability of $\mathrm{H}_{2}$ deposition velocities or uptake rates are summarized in Section 5. The complete report is presented in this appendix. The report provides the details of the modeling techniques as well as the results of additional analyses.

- Appendix E. Plots of Ten-year Zonal Differences in Selected Constituents: Maximum and Minimum by Altitude and Latitude. Detailed plots of data and graphics described in Section 2 are presented. 



\section{GATOR-GCMOM MODEL DESCRIPTION AND SIMULATION RESULTS}

\subsection{GATOR-GCMOM and Rationale for Selection}

\subsubsection{Model Description}

The model used for this study was GATOR-GCMOM, which solves gas, aerosol, cloud, dynamical, transport, radiation, ocean, land surface, and sea ice processes (Jacobson et al., 2007; Jacobson, 2008a, b; Jacobson and Streets, 2009). It is fully-coupled to account for all major feedbacks among major atmospheric processes based on first principles (Zhang, 2008). It was used for this study due to its comprehensive set of capabilities needed to rigorously evaluate potential impacts of a hydrogen economy. An overview of the model is shown in Table 2-1, and described below. Details of GATOR-GCMOM and its applications for this project are shown in Appendix B. The materials in Appendix B consist of the detailed project report prepared by Mark Jacobson that describes his work for the past several years.

Table 2-1

Summary of GATOR-GCMOM Model Components

\begin{tabular}{|l|l|}
\hline \multicolumn{1}{|c|}{ Model Component } & \multicolumn{1}{c|}{ Description } \\
\hline Horizontal Global Grid Resolution & $4^{\circ} \mathrm{S}-\mathrm{N} \times 5^{\circ} \mathrm{W}-\mathrm{E}$ \\
\hline Atmospheric Representation & 47 layers up to $0.22 \mathrm{hPa}(60 \mathrm{~km})$ (higher resolution near surface) \\
\hline Soil Representation & 10 soil layers \\
\hline Ocean Representation & Two-dimensional ocean model of mixed surface layer, and 10 layers for deeper ocean \\
\hline Constituents and Reactions & $\begin{array}{l}\text { Gases (134), chemical reactions (347), including } 57 \text { photolysis reactions, aerosol size } \\
\text { distributions (2), hydrometeor distributions (3) }\end{array}$ \\
\hline Other Major Processes Simulated & $\begin{array}{l}\text { Cloud dynamics } \\
\text { Transport } \\
\text { Radiation } \\
\text { Land surface processes } \\
\text { Sea ice processes } \\
\text { Major feedback loops } \\
\text { Aerosol microphysics } \\
\text { Ocean chemistry }\end{array}$ \\
\hline Dry Deposition & $\begin{array}{l}\text { Inverse sum of series of resistances (aerodynamic, turbulent transfer, diffusion through } \\
\text { molecular sublayer, uptake in soil) }\end{array}$ \\
\hline Wet Deposition & $\begin{array}{l}\text { Wet deposition of hydrogen is included in the model, as hydrogen is slightly soluble in } \\
\text { rain water }\end{array}$ \\
\hline
\end{tabular}

Because of the high resolution and computational requirements of the processes modeled, the horizontal resolution was limited to a $4^{\circ} \mathrm{S}-\mathrm{N}$ x $5^{\circ} \mathrm{W}$-E global domain. A model run at higher horizontal resolution can do so only if it does not include several physical and chemical 
processes or sacrifices resolution in other processes, such as radiation, chemistry, aerosol microphysics, cloud processes, or surface processes. As such, the resolution among all processes here is the highest possible for a given set of computer resources, and this is reflected in the long time required to simulate climate responses for 10 years.

The model was run with 47 atmospheric layers up to $0.22 \mathrm{hPa}(\sim 60 \mathrm{~km})$, including 14 layers in the bottom $1 \mathrm{~km}$ (very high resolution), and 31 layers up to $15 \mathrm{~km}$. The model treated the evolution of 134 gases, 347 chemical reactions, two aerosol size distributions, and three hydrometeor distributions (liquid, ice, graupel). The model tracked both particle number and component mass for each size bin of each aerosol and hydrometeor size distribution. Processes affecting gases included emissions, photochemistry, dry deposition, wet deposition, gas-toparticle conversion, gas-cloud interactions, and transport. Radiative transfer was solved explicitly over 694 wavelengths and probability intervals for heating rates and 86 wavelengths for photolysis rate coefficients. The model included a subgrid surface module in each grid cell that treated 10 layers per soil class. It also included a 2-D ocean model of the mixed layer, and 10 layers of ocean for energy diffusion and ocean chemistry.

The model treated feedbacks among meteorological, gas, aerosol, cloud, radiative, land surface, and ocean surface processes. Since meteorology was coupled to the other processes, any process that affected meteorology was linked to the other processes and vice versa. The main coupling between gas, aerosol, and cloud processes and meteorology was through radiative transfer. A second coupling was through water vapor.

All gases that photolyzed in the model affected radiative heating rates since absorption cross sections of each gas at each wavelength were used both for actinic flux calculations for photolysis (when quantum yields were applied) and irradiance calculations (for heating rates). Aerosol particles, cloud drops, ice crystals, and graupel particles affected gas photolysis and radiative heating rates since particle absorption cross sections were determined as a function of wavelength and included in optical depth. Changes in radiative heating rates in turn affected temperatures, which affected the rates of gas and aerosol chemical reactions; water fluxes from the ocean; the relative humidity; air pressure; wind speeds; cloud and aerosol microphysical processes, etc.

Carbon dioxide, like other gases, affected irradiances and radiative heating rates as it is an IR absorber. Its absorption affected the temperature at all altitudes and horizontal locations, and changes in temperature affected local temperature and pressure gradients, evaporation rates of water from oceans, lakes, soils, and clouds, and the temperature-dependence of many physical and chemical processes in the model, including biogenic emissions. For example, an increase in $\mathrm{CO}_{2}$ increased water evaporation, and both higher temperature and water vapor increase ozone in the troposphere, but higher water vapor decreases ozone in parts of the stratosphere by enhancing the $\mathrm{HO}_{\mathrm{x}}$ photochemical destruction cycle of ozone and increasing the size and lifetime of polar stratospheric clouds.

The change in $\mathrm{CO}_{2}$ also affected $\mathrm{CO}_{2}$ photosynthesis (which depended on $\mathrm{CO}_{2}$ backpressure) in chlorophyll and green plants, thus chlorophyll and leaf respiration rates. Changes in $\mathrm{CO}_{2}$ further changed dissolution and evaporation rates of $\mathrm{CO}_{2}$ into the ocean (which were also affected by the changes in temperature due to $\mathrm{CO}_{2}$ ), $\mathrm{CO}_{2}$ weathering rates, ocean $\mathrm{pH}$ and chemical composition, sea spray $\mathrm{pH}$ and composition, and rainwater $\mathrm{pH}$ and composition. Changes in sea spray composition, in turn, affected the radiative properties of sea spray, thus radiative heating rates. 


\subsubsection{Photochemistry}

Hydrogen photochemical production and loss treated chemistry among 20 aerosol, liquid, ice, and graupel heterogeneous chemical reactions, 314 kinetic reactions, and 57 photolysis reactions. The reaction mechanism is given in Jacobson (2008b, supplemental information). The four chemical sources of $\mathrm{H}_{2}$ in the reaction mechanism were $\mathrm{H}+\mathrm{HO}_{2}, \mathrm{CH}_{4}+\mathrm{O}\left({ }^{1} \mathrm{D}\right.$ ), $\mathrm{H}_{2} \mathrm{COO}^{*}$ (excited formic acid) thermal decomposition, and $\mathrm{HCHO}$ photolysis. The three chemical sinks were reaction with $\mathrm{O}\left({ }^{1} \mathrm{D}\right), \mathrm{OH}$, and $\mathrm{Cl}$.

\subsubsection{Dry Deposition}

GATOR-GCMOM simulates hydrogen uptake in terms of an inverse sum of resistances, and weighted over land use types:

$$
\begin{aligned}
& \mathrm{V}_{\mathrm{d}}\left(\mathrm{z}_{\mathrm{r}}\right)=\sum_{\mathrm{l}} \mathrm{V}_{\mathrm{d}, \mathrm{l}}\left(\mathrm{z}_{\mathrm{r}}\right)=\sum_{\mathrm{l}} \frac{\mathrm{f}_{\mathrm{l}}}{\mathrm{R}_{\mathrm{a}}+\mathrm{R}_{\mathrm{b}}+\mathrm{R}_{\mathrm{s}, \mathrm{l}}} \\
& \text { where } \\
& \mathrm{R}_{\mathrm{a}} \quad \text { = aerodynamic resistance to turbulent transfer between the } \\
& \text { reference height } \mathrm{z}_{\mathrm{r}} \text { and the laminar sub-layer adjacent to the } \\
& \text { surface } \\
& \mathrm{R}_{\mathrm{b}} \quad \text { = resistance to molecular diffusion across a thin laminar sub-layer } \\
& \text { adjacent to the atmosphere-surface interface } \\
& \mathrm{R}_{\mathrm{s}, \mathrm{l}} \quad=\text { land use class } 1 \text { resistance to chemical, biological and physical } \\
& \text { interaction that occurs once hydrogen has collided with a surface } \\
& \mathrm{f}_{\mathrm{l}} \quad=\text { area fraction of land use class } \mathrm{l} \text { in discretized cell } \\
& \mathrm{Z}_{\mathrm{r}} \quad \text { = reference height } \\
& \mathrm{V}_{\mathrm{d}}\left(\mathrm{z}_{\mathrm{r}}\right) \quad=\text { deposition velocity over a discretized cell, considering all land } \\
& \text { uses in the cell }
\end{aligned}
$$

The summation in each cell is over all 11 land uses classes specified in Wesely [1989]: (1) urban land, (2) agricultural land, (3) rangeland, (4) deciduous forest, (5) coniferous forest, (6) mixed forest including wetland, (7) salt and fresh water, (8) barren land, mostly desert, (9) nonforested wetland, (10) mixed agricultural and range land, and (11) rocky open area with low-growing shrubs.

Prior to beginning this work, GATOR-GCMOM approximated the total surface resistance, $\mathrm{R}_{\mathrm{s}, \mathrm{l}}$, by:

$$
\mathrm{R}_{\mathrm{s}, \mathrm{l}}=\left(\frac{1}{\mathrm{R}_{\text {stom }}+\mathrm{R}_{\text {meso }}}+\frac{1}{\mathrm{R}_{\text {cut }}}+\frac{1}{\mathrm{R}_{\text {conv }}+\mathrm{R}_{\text {surf }}}+\frac{1}{\mathrm{R}_{\text {camp }}+\mathrm{R}_{\text {soil }}}\right)_{1}^{-1}
$$

where 


$$
\begin{array}{ll}
\mathrm{R}_{\text {stom }} & =\text { the leaf stomata resistance } \\
\mathrm{R}_{\text {meso }} & =\text { the leaf mesophyll resistance } \\
\mathrm{R}_{\text {cut }} & =\text { the leaf cuticle resistance } \\
\mathrm{R}_{\text {conv }} & =\text { the resistance due to buoyant convection in canopies } \\
\mathrm{R}_{\text {surf }} & \text { = the resistance due to leaves, twigs, bark, or other exposed } \\
\mathrm{R}_{\text {canp }} & =\text { the resistance due to canopy height and density } \\
\mathrm{R}_{\text {soil }} & =\text { the resistance due to soil and leaf litter at the ground surface }
\end{array}
$$

This equation assumes that land use class $l$ is fully vegetated. An improvement made to this equation is to allow only a fraction of land use type $\mathrm{l}$ to be vegetated. This results in a modification to Equation (2) as follows:

$$
\mathrm{R}_{\mathrm{s}, \mathrm{l}}=\left\{\left[\frac{1}{\mathrm{R}_{\text {stom }}+\mathrm{R}_{\text {meso }}}+\frac{1}{\mathrm{R}_{\text {cut }}}+\frac{1}{\mathrm{R}_{\text {conv }}+\mathrm{R}_{\text {surf }}}+\frac{1}{\mathrm{R}_{\text {camp }}+\mathrm{R}_{\text {soil, }, \mathrm{f}}}\right] \mathrm{f}_{\mathrm{v}, \mathrm{l}}+\frac{1}{\mathrm{R}_{\text {soil, }}}\left(1-\mathrm{f}_{\mathrm{v}, \mathrm{l}}\right)\right\}^{-1}
$$

where

$$
\mathrm{f}_{\mathrm{v}, \mathrm{l}} \quad=\text { fraction of land use type that is vegetated within a cell. }
$$

When $f_{v, l}=0, R_{s, l}=R_{s o i l, l}$, the total resistance to uptake is due to the soil, and

$$
\mathrm{R}_{\text {soil }}=1 / \mathrm{V}_{\mathrm{d}, 1}
$$

where

$$
\begin{aligned}
\mathrm{V}_{\mathrm{d}, \mathrm{I}} \quad & \text { hydrogen deposition velocity considering resistance based on } \\
& \text { soil surface only }
\end{aligned}
$$

A review of the literature on soil deposition velocities $V_{\mathrm{s}, \mathrm{l}}$ showed that the deposition velocity depends primarily on soil moisture content and soil temperature:

$$
\mathrm{V}_{\mathrm{d}, \mathrm{l}}=\mathrm{F}_{1}(\mathrm{~W}) \cdot \mathrm{G}(\mathrm{T})
$$

where

$$
\mathrm{F}_{1}(\mathrm{~W})=\text { soil moisture dependence of } \mathrm{V}_{\mathrm{d}, \mathrm{l}} \text { for land use type } \mathrm{l}, \mathrm{cm} \cdot \mathrm{s}^{-1}
$$


G(T) = soil temperature limitation function and is independent of land use type

For this project $\mathrm{F}_{\mathrm{l}}(\mathrm{W})$ was parameterized as:

$$
\mathrm{F}_{\mathrm{l}}(\mathrm{W})= \begin{cases}0.177-0.4139 \mathrm{w} & \text { grassland } \\ 0.197-0.4190 \mathrm{w} & \text { forests } \\ 0.01235-0.00472 \ln (\mathrm{w})+0.0027 \ln ^{2}(\mathrm{w}) & \text { savannah } \\ 0.0316-0.988 \mathrm{w} & \text { ag land (late Aut,Win) } \\ 0.218-0.548 \mathrm{w} & \text { ag land (rest of year) }\end{cases}
$$

where

$\mathrm{w} \quad=$ water content of soil, dimensionless

These expressions were obtained from previous work of other researchers over the past two decades such as reported in Smith-Downey et al. (2006) and in Conrad and Seiler (1995). $\mathrm{V}_{\mathrm{d}, \mathrm{l}}$ has an additional limitation imposed that is not reflected in Equation (6): deposition is constrained to approach zero at very low soil water content, or at very high soil moisture content. The temperature dependence term, G(T), is based on the work of Smith-Downey et al. (2006):

$$
G(T)=\left[\frac{1}{1+\exp (-0.1718 T+46.938)}\right]^{-1}
$$

where

$\mathrm{T}$

$$
\begin{aligned}
& =\text { soil temperature, Kelvin (typical temperature range is } 273 \mathrm{~K} \text { to } \\
& 313 \mathrm{~K} \text { ) }
\end{aligned}
$$

To see how GATOR-GCMOM compares to results from other researchers, see Figure 2-1. On this plot are deposition velocities from field studies conducted around the world; global average estimates from Novelli (1999); and the global average estimate over land $(0.041 \mathrm{~cm} / \mathrm{sec})$ by Jacobson's GATOR-GCMOM model. Jacobson's estimate is very similar to the average value calculated by Novelli (1999) of $0.04 \mathrm{~cm} \cdot \mathrm{s}^{-1}$, and is approximately the median value from the various field studies shown. 


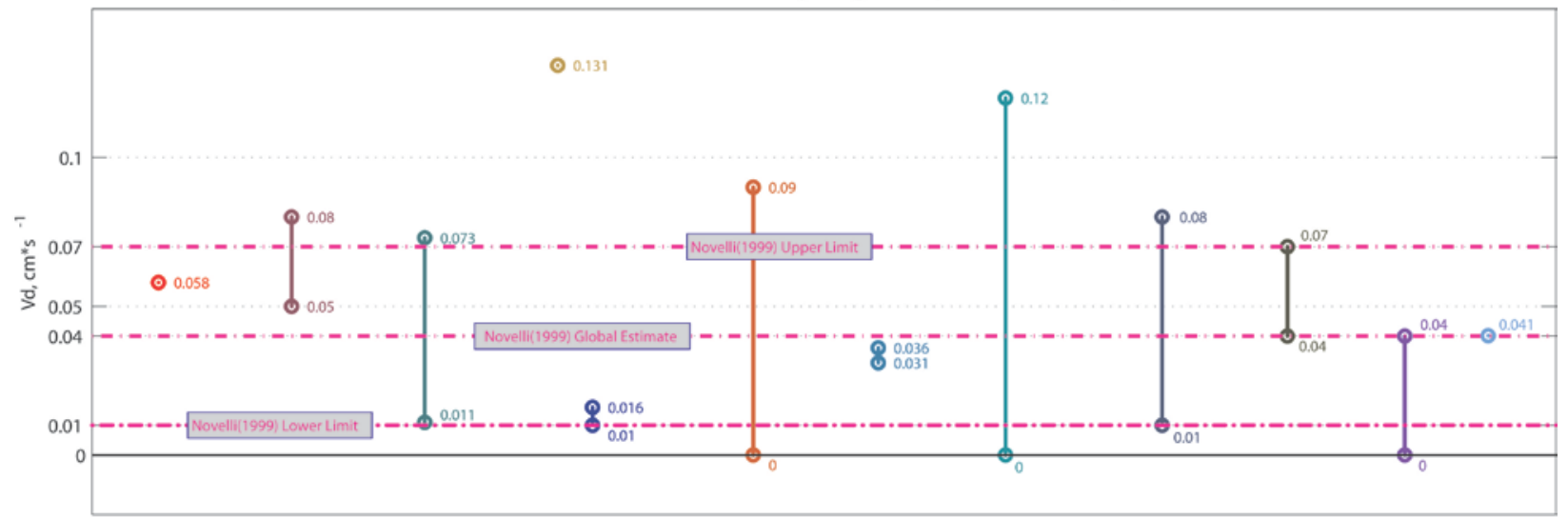

- - Gerst and Quay (2001): Second Growth Coniferous Forest, Seattle, WA

- - Yonemura et al. (2000): Deciduous Forest, Tsukuba, Japan

- - Rahn et al. (2002): Boreal Forest, AK

- Conrad and Seiler (1985): South Africa Savanna

- - Conrad and Seiler (1985): South Africa and Namibia, Desert Soils

$-0-$ Conrad and Seiler (1985): Arable Field, Japan

- - Conrad and Seiler (1985): Unplanted Field

- - Liebl and Seiler (1976): Various Savanna and Field Sites

- Yonemura et al. (1999) Andisol Field, Tsukaba, Japan

- Lallo et al. 2008; Boreal Forest Finland; Soil Chamber - snow free conditions.

- Lallo et al. 2008; Boreal Forest Finland; Soil Chamber - winter conditions.

- - Jacobson (2009) Global Average Over Land

Figure 2-1 Studies of Hydrogen Deposition Velocity. Note: The recent modeling results of Jacobson (2009) for global average deposition are shown for comparison.

\subsubsection{Wet Deposition}

Previous studies have not considered wet deposition of hydrogen because it is relatively insoluble in rainwater. Nevertheless, its removal rate was calculated with the method described in Jacobson (2003). The effective Henry’s constant used was $0.00078 \mathrm{~mol} / \mathrm{kg} / \mathrm{atm}$.

\subsubsection{Estimates of Hydrogen Emissions and Leakage}

A summary of the emissions categories used for GATOR-GCMOM is provided in Table 2-2. 
Table 2-2

Summary of Emission Categories Used in GATOR-GCMOM

\begin{tabular}{|l|l|}
\hline \multicolumn{1}{|c|}{ Category } & \multicolumn{1}{c|}{ Comments } \\
\hline \multirow{4}{*}{ Hydrogen Emissions } & Source Categories: \\
& Fossil \\
& Biofuel \\
& Biomass \\
& Ocean \\
& Nitrogen Fixation \\
& Volcanoes \\
\hline \multirow{5}{*}{$\begin{array}{l}\text { Emission of 27 Chemical } \\
\text { Species }\end{array}$} & Approach: \\
& Developed emissions factors for adjusting year 2000 emissions to year 2050 emissions. \\
& Emissions developed in 17 world regions. \\
& 82 source types. \\
\hline \multirow{5}{*}{ Emission Scenarios } & 2050 A1B base case. \\
& 2050 A1B scenario with 90\% penetration in developed countries and 45\% penetration in other \\
& countries ( $\mathrm{H}_{2}$ produced by steam reforming of natural gas). \\
& Present day emissions using wind generated electricity to produce hydrogen. \\
\hline
\end{tabular}

Hydrogen emissions from fossil fuel vehicles were estimated based on the $\mathrm{H}_{2}$ to $\mathrm{CO}$ ratio of $0.0285 \mathrm{~g} \mathrm{H}_{2} / \mathrm{g} \mathrm{CO}$, which is the mean value from Barnes et al., 2003. The same ratio was also used to estimate hydrogen emissions from ships, airplanes, and other fossil-fuel sources. The hydrogen emissions from natural fires were based on emission factors by vegetation type and 8day fuel burn data for five years from Giglio et al., 2006 (Table 2-3). The emission factors used for vegetation were as follows (Andrae and Merlet, 2002):

Hydrogen emissions from biomass burning were based on the global spatial distribution of the black carbon (BC) emission rate using 1996 estimates of biomass burning from Bond et al. (2004). However, the global burn rate was adjusted to a global burn rate of 4200 Tg-dry matter/yr, which was the mean value of Ludwig et al. (2003) then scaled by the ratio of the 2009 to 1995 population. The $\mathrm{BC}$ emission rate was then multiplied by the ratio of the biofuel $\mathrm{H}_{2}$ emission factor of $1.8 \mathrm{~g}-\mathrm{H}_{2} / \mathrm{kg}$-dm to the rate for $\mathrm{BC}$ of $0.59 \mathrm{~g}-\mathrm{BC} / \mathrm{kg}-\mathrm{dm}$ from Andrae and Merlet, 2002.

Hydrogen emissions from natural sources were also included in the model. Hydrogen emissions over the ocean were estimated as $3.5 \mathrm{Tg}-\mathrm{H}_{2} / \mathrm{yr}$ based on literature values and distributed spatially based on data for dimethylsulfide (DMS) concentrations (Kettle et al., 1999). Hydrogen emissions from soil due to nitrogen fixation were estimated as $3.2 \mathrm{Tg}-\mathrm{H}_{2} / \mathrm{yr}$, but spatially and temporally distributed based on NO emissions, which are a function of land use, surface vegetation fraction, wind speed, temperature, and canopy type. The method used is described in Jacobson and Streets (2009). Hydrogen emissions from volcanoes were estimated based on the percent of hydrogen in the total emissions for the highest of three sites (1.39\% of total gas emissions at Erta Ale in Ethiopia, Symonds et al., 1994), and then scaled using $\mathrm{SO}_{2}$ emission factors for other volcanoes from Andres and Kosgnoc (1998). Emission fractions of $\mathrm{CO}_{2}(11.3 \%)$ and $\mathrm{CO}(0.44 \%)$ were also derived using this approach. The $\mathrm{SO}_{2}$ emission fraction from Erta Ale was $8.34 \%$. The total $\mathrm{H}_{2}$ emissions from volcanoes were estimated as $0.05 \mathrm{Tg}-\mathrm{H}_{2} / \mathrm{yr}$.

An estimated hydrogen leakage rate in 2050 was 3.0 percent, the upper limit of Zittel et al., 1996 and Schultz et al., 2003. For comparison, the leakage rate for natural gas was estimated as 1 percent by Schultz et al., 2003, since hydrogen is a smaller molecule a higher leakage rate was 
considered appropriate. The total hydrogen leaked is based on the total volume of fuel used in the hydrogen fuel cell vehicles (HFCVs), which is estimated using the vehicle miles driven per year, heating values of gasoline versus hydrogen, tank to wheel efficiencies of both vehicle types, and fleet-averaged mileage of all onroad vehicles, as described in Jacobson, 2008. The estimated hydrogen leakage for the $2050 \mathrm{~A} 1 \mathrm{~B}$ with HFCVs case is $3.4 \mathrm{Tg}-\mathrm{H}_{2} / \mathrm{yr}$. Additional discussion of hydrogen leakage is included in Appendix B.

Table 2-3

Emission Factors of Hydrogen from Natural Fires by Vegetation Type

\begin{tabular}{|c|c|}
\hline Emission Factor, $\mathbf{g ~} \mathbf{H}_{2} / \mathbf{k g}$-dry matter & Vegetation Type \\
\hline 0.97 & Savannah \\
\hline 3.8 & Tropical Forest \\
\hline 1.8 & Extratropical Forest \\
\hline 2.4 & Agricultural Wastes. \\
\hline
\end{tabular}

\subsubsection{Assumptions Used in GATOR-GCMOM Simulations}

The major assumption and potential limitations associated with the GATOR-GCMOM modeling are summarized below. They are:

- The GATOR-GCMOM simulations are limited by the number of years that can be simulated because of the large computational time required (on the order of weeks to months). At the end of ten-year simulations it is assumed that the scenario being modeled has attained a new steady-state condition.

- Typically, ensembles of GCM's are used in climate change studies because a single simulation does not capture the response variability associated with multiple simulations. Ensembles were not run during this project.

- A rigorous sensitivity analysis was not undertaken during this project for GATORGCMOM (although sensitivity analyses were performed for GREET). However, best professional judgment was used to minimize impacts of uncertainties on model predictions.

- The leakage rate of hydrogen that results from moving to a hydrogen economy is not known with accuracy, and has been a source of uncertainty for over a decade. The leakage rates used in this study are consistent with estimates from recent research.

\subsection{GATOR-GCMOM Model Simulation Results}

Appendix B provides Mark Jacobson’s detailed project report that provides all simulation results and supplemental graphics. This section provides an overview of these results.

\subsubsection{Summary of $\mathrm{H}_{2}$ Sources and Sinks}

The hydrogen source and sink budgets from the present study are generally similar to those presented in previous studies, but the net atmospheric chemical change of $\mathrm{H}_{2}$ differs because the present study treats chemistry of the stratosphere and troposphere whereas all the other studies considered tropospheric chemistry only. One sink not included is escape from the stratosphere to higher altitudes or space. 
The global atmospheric burden up to $0.22 \mathrm{hPa}(\sim 60 \mathrm{~km})$ of hydrogen was calculated to be about $188 \mathrm{Tg}$ based on a mean well-mixed initial mixing ratio of $530 \mathrm{ppbv}$ and an Earth surface area of $5.10064 \times 10^{14} \mathrm{~m}^{2}$. Simmonds et al. (2000) estimates a burden on a single day (January 1, 1996) of $182 \mathrm{Tg}$, based on mean hemispheric mixing ratios of 504 and $520 \mathrm{ppbv}$ between the Northern and Southern Hemisphere, respectively, on that day.

Figure 2-2 shows annually-averaged dry deposition speeds (deposition speed is calculated as the hydrogen flux into soil divided by atmospheric concentration) worldwide for molecular hydrogen calculated by GATOR-GCMOM. The average over land $(0.041 \mathrm{~cm} / \mathrm{s})$ is very close to the estimate made by Novelli et al. (1999) of $0.04 \mathrm{~cm} / \mathrm{sec}$. The variability of deposition velocities over land are significant, and some patterns are discernable. Deposition velocities to the north of $60^{\circ}$ latitude are very small, as well as in very dry locations, such as North Africa or the interior of Australia.

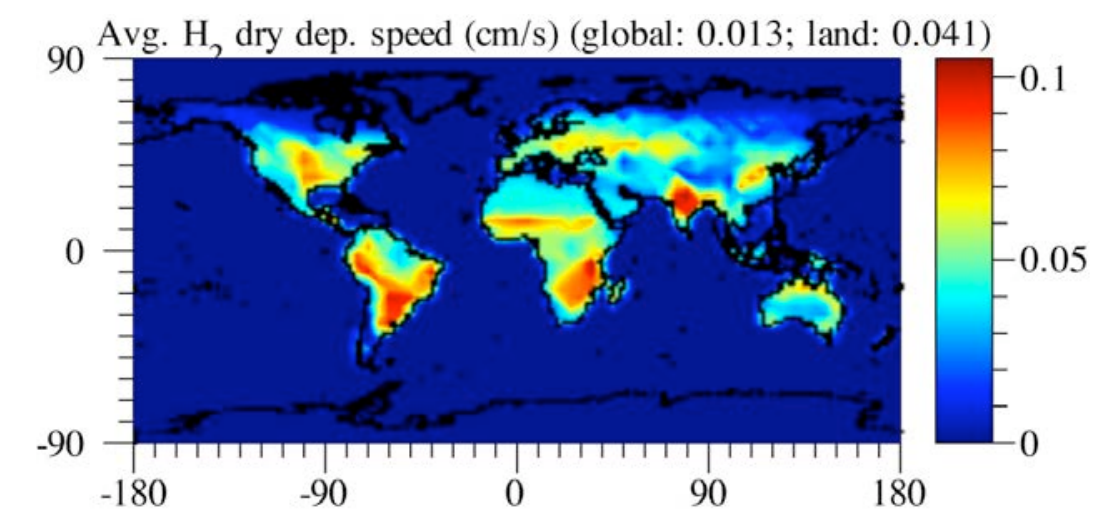

Figure 2-2 Annually-averaged dry deposition speeds $(\mathrm{cm} / \mathrm{s})$ of $\mathrm{H}_{2}$ from the model calculated with the method described herein. Numbers in parentheses are the globally- and land-averaged values, respectively.

Figure 2-3 shows annually-averaged modeled near surface hydrogen concentrations. Note that the concentrations are highest where deposition velocities are lowest, such as over oceans.

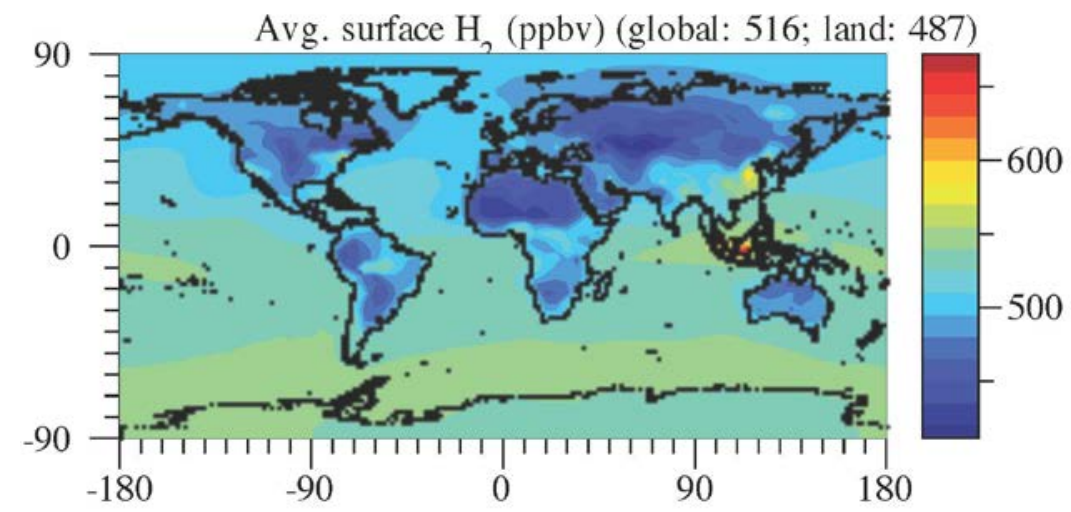

Figure 2-3 Annually-averaged modeled near-surface $\mathrm{H}_{2}$ (ppbv). Numbers in parentheses are the globally- and land-averaged values, respectively, from the figure. 


\subsubsection{Effects of Converting from FFOVs to Wind-Powered HFCVs Today}

Ten-year model simulations were performed examining the effect of converting the world's FFOV to hydrogen fuel cell vehicles (HFCVs), where the $\mathrm{H}_{2}$ is produced by wind-powered electrolysis (WHFCVs). Results were published in Jacobson (2008b). Table 3-11 summarizes emission changes for this set of scenarios.

Although complete climate responses (particularly for $\mathrm{CO}_{2}$ changes) require more than ten years, climate responses of short-lived gases, aerosol particles, and clouds stabilize substantially during years 6-10, as evidenced by the fact that 6-10 year simulations of the effects of black carbon on climate (Jacobson, 2004) have given similar global surface temperature responses to each other and to 100-year simulations of internally-mixed BC run independently (Chung and Seinfeld, 2005). Longer simulations would converge results more and account for greater changes in $\mathrm{CO}_{2}$ and energy exchange with the deep ocean. Thus, the results here are probably conservative (the results will strengthen due to a stronger climate response over a longer period).

Table 2-4 summarizes the atmospheric response of converting from FFOVs to wind-powered HFCVs to provide a comparison for a complete conversion under existing conditions. The conversion to WHFCV decreased the ambient global column of the vehicle-emitted chemicals, $\mathrm{H}_{2}, \mathrm{CO}_{2}, \mathrm{NO}, \mathrm{NO}_{2}, \mathrm{CO}, \mathrm{HCHO}, \mathrm{CH}_{3} \mathrm{CHO}$, benzene, toluene, black carbon (BC), and primary organic matter (POM) relatively proportionately to their emission reductions. WHFCV also decreased column secondary organic matter (SOM), $\mathrm{S}(\mathrm{VI}), \mathrm{HNO}_{3}$, and $\mathrm{NO}_{3}{ }^{-}$by $6 \%, 3 \%, 2 \%$, and $19 \%$, respectively due to reductions in aerosol-precursor gases.

Table 2-4

Summary of Atmospheric Response of Converting from FFOVs to Wind-Powered HFCVs today

\begin{tabular}{|l|l|}
\hline \multicolumn{1}{|c|}{ Category } & \multicolumn{1}{c|}{ Response } \\
\hline $\begin{array}{l}\text { Vehicle-emitted Chemicals } \\
\left(\mathrm{H}_{2}, \mathrm{CO}_{2}, \mathrm{NO}, \mathrm{NO}_{2}, \mathrm{CO}, \mathrm{HCHO}, \mathrm{BTEX}, \mathrm{BC}, \mathrm{POM}\right)\end{array}$ & $\begin{array}{l}\text { Concentrations generally decreased in proportion to emission } \\
\text { reductions (See Table 3-11, columns b and } \mathrm{c}) .\end{array}$ \\
\hline & $\mathrm{SOM}-6 \%$ decrease \\
& $\mathrm{S}(\mathrm{VI})-3 \%$ decrease \\
$\mathrm{HNO}_{3}-2 \%$ decrease & $\mathrm{NO}_{3}-19 \%$ decrease \\
Other Chemicals & $\begin{array}{l}\text { Formaldehyde -3.9\% decrease } \\
\mathrm{CH}_{4} 0.25 \% \text { increase }\end{array}$ \\
\hline Troposphere Ozone & $1-5$ ppbv-decrease (less than 5\%) \\
\hline \multirow{3}{*}{ UTLS Changes } & $\begin{array}{l}\text { Temperature: increases } \\
\text { Ozone: increase } \\
\text { OH: decrease }\end{array}$ \\
\hline Aerosols & Reduced concentrations; induces surface warming \\
\hline Water vapor & Reduced concentration in stratosphere; slight increase in \\
\hline
\end{tabular}

The decrease in tropospheric ozone precursors due to WHFCV decreased surface ozone by about $\sim 1$ ppbv globally and up to 5 ppbv regionally. WHFCV, though, increased column ozone by about $0.25 \%$, by increasing upper-tropospheric/lower-stratospheric (UTLS) ozone. Ozone increased in the UTLS between $200-50 \mathrm{hPa}(\sim 11.8-19.3 \mathrm{~km})$, peaking at $80 \mathrm{hPa}(\sim 17 \mathrm{~km})$, primarily in the Northern Hemisphere. The increase correlates very well with an up to $4 \% \mathrm{OH}$ decrease in the same region. Since $\mathrm{HO}_{\mathrm{x}}$ is the main family to destroy UTLS ozone, $\mathrm{OH}$ loss should increase ozone there. $\mathrm{OH}$ is produced primarily by aldehyde and HONO photolysis and $\mathrm{O}\left({ }^{1} \mathrm{D}\right)+\mathrm{H}_{2} \mathrm{O}$ reaction. WHFCV reduced column formaldehyde and acetaldehyde by $3.9 \%$ and 
$1.6 \%$, respectively, column HONO, and tropospheric $\mathrm{O}\left({ }^{1} \mathrm{D}\right)$ by reducing tropospheric ozone by $6 \%$. These reductions outweighed a slight (0.1\%) tropospheric $\mathrm{H}_{2} \mathrm{O}$ increase, causing a net $\mathrm{OH}$ loss.

Figure 2-4 shows a zonally and ten-year averaged plot for ozone, as an example. More plots can be found in Appendix B (Mark Jacobson's final report) and in Appendix E (graphical results for many constituents by altitude and latitude).
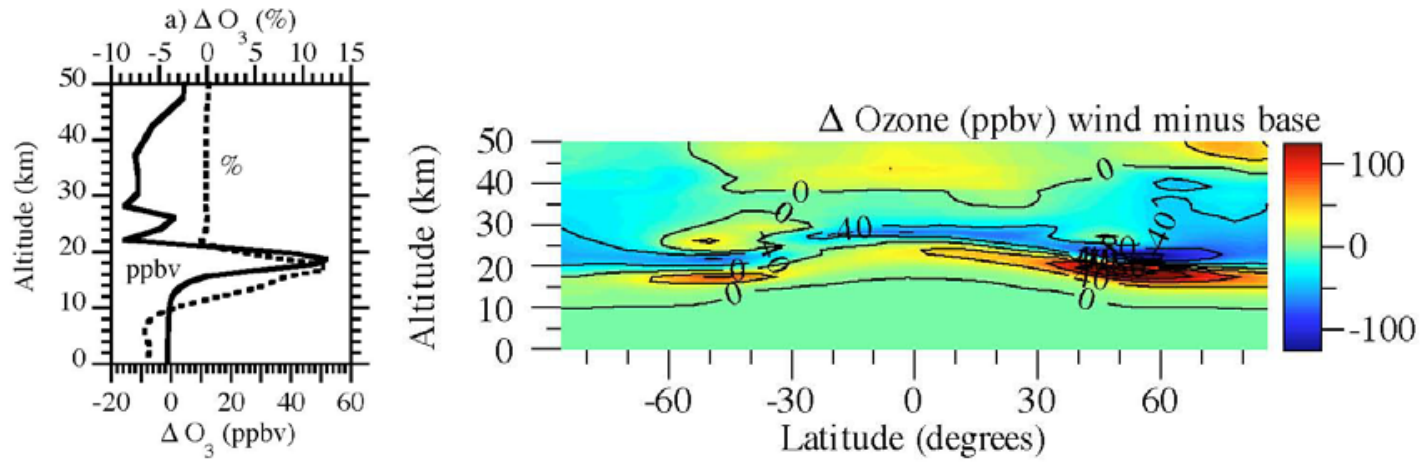

Figure 2-4 Zonally- and ten-year averaged differences in ozone due to converting all FFOV to WHFCVs today.

Although $\mathrm{CH}_{4}$ emissions decreased by $\sim 0.25 \%$, column $\mathrm{CH}_{4}$ increased slightly (+0.25\%) due primarily to a tropospheric $\mathrm{CH}_{4}$ increase caused by an $\mathrm{OH}$ loss. Tropospheric $\mathrm{OH}$ and $\mathrm{O}_{3}$ losses reduced chemical losses of isoprene and monoterpenes, increasing their concentrations and reducing secondary organic matter.

Greenhouse gases (GHGs) warm the surface and cool the stratosphere, thus their removal does the reverse, but over years to decades. Aerosol particles consist of warming components (e.g., $\mathrm{BC}$, some POM) and cooling components (e.g., S(VI), $\mathrm{NO}_{3}{ }^{-}$, most POM and SOM). Cooling components dominate, so overall, aerosol particles caused net surface cooling, and their removal (with WHFCV) caused surface warming by reducing aerosol and cloud optical depths and increasing surface solar radiation. WHFCV decreased both GHG and aerosol emissions, so the net impact depended on the period during which changes occurred. For the 10-y simulations, a slight surface cooling and stronger UTLS warming occurred, indicating that the GHG effect began to dominate by 10 years. UTLS warming occurred globally and was enhanced by the ozone increase there. Over a longer simulation, the surface cooling and stratospheric warming due to WHFCVs should strengthen.

Tropospheric cooling and stratospheric warming increases the stability of UTLS, reducing transport of water vapor to the stratosphere. This explains the decrease in upper tropospheric and stratospheric water vapor. Over longer simulations, surface cooling would also reduce lower tropospheric water vapor regionally to a greater extent, reducing water vapor transport to the stratosphere further.

In the present case, WHFCVs increased upper stratospheric temperatures, on average, thereby decreasing ozone there. The small percent decrease in water vapor in the stratosphere due to WHFCVs increased ozone less than higher temperature decreased ozone, resulting in a net ozone decrease, as shown in Figure 2-4. 
In the upper troposphere and lower stratosphere (UTLS), however, ozone increased. The increase was greater than was the upper-stratospheric ozone decrease, causing a net ozone column increase. UTLS ozone increases were consistent with results from Jacobson (2008a), where the effects of $\mathrm{CO}_{2}$ in isolation on ozone, particulate matter, and temperatures were examined. Most of the UTLS ozone increase here was due to the water vapor effect, as, water vapor decreased due to WHFCVs, enhancing ozone due to chemistry alone. The increase in ozone due to a reduction in water vapor is due to a reduction in $\mathrm{OH}$ and $\mathrm{HO}_{2}$ produced by water vapor, reducing the catalytic ozone loss due to these chemicals. Shindell and Grewe (2002) found that, for net increases in stratospheric water vapor, ozone column should decrease, implying that for net decreases in stratospheric water vapor, ozone column should increase, a result consistent with that found here.

In the UTLS, under low $\mathrm{NO}_{\mathrm{x}}$ and organic gas mixing ratios, higher temperatures have less effect on ozone than in the upper stratosphere, particularly since the $\mathrm{O}+\mathrm{O}_{3}$ reaction is less important than in the upper stratosphere (Evans et al., 1998).

A second, less significant reason for the UTLS ozone gains due to WHFCVs was that the warmer UTLS temperatures due to removing FFOVs reduced the prevalence of aerosol and ice cloud surface area on which ozone-destroying halogen gases could form and by reducing nitric acid available for nitric acid trihydrate (NAT) ice crystals to form. WHFCV reduced aerosol surface area by reducing BC, POM, and S(VI) emissions and increasing precipitation. The reduced UTLS aerosol surface area decreased heterogeneous reactions, decreasing ambient $\mathrm{Cl}_{2}$ and HOCl (Jacobson, 2008b), which would otherwise destroy ozone.

Fahey et al. (2001) observed large particles containing nitric acid sedimenting in the Arctic winter stratosphere. They hypothesized that greenhouse gases, which increase water vapor and cool the stratosphere, increase the prevalence of ice clouds on which ozone-destroying reactions occur and on the sedimentation rate of nitric acid particles, enhancing denitrification. The denitrification reduces the ability of active chlorine to combine with nitric acid to form chlorine nitrate $\left(\mathrm{ClONO}_{2}\right)$, thereby extending ozone loss. Their hypothesis, that an increase in greenhouse gases destroys stratospheric ozone through these mechanisms implies that the reverse, removal of greenhouse gases, should increase such ozone. This result is consistent with what was found here with respect to the effect of converting to WHFCVs.

\subsubsection{Effects of Converting from FFOVs to Steam-Reforming-Powered HFCVs in 2050}

Ten-year model simulations were performed examining the effect of converting $90 \%$ of fossil fuel occupied vehicles (FFOV) in developed countries and 45\% of FFOVs vehicles in other countries in 2050 to hydrogen fuel cell vehicles, where the $\mathrm{H}_{2}$ is produced by steam-reforming of natural gas (SHFCVs). Initial gas and particle mixing ratios for the 2050 case were assumed similar to the present day; however, given the short-lived nature of almost all gases (aside from greenhouse gases and $\mathrm{H}_{2}$ ) and particles, initial conditions should have little impact over the simulation.

Table 2-5 summarizes simulation-averaged differences in several modeled gases and aerosol components and temperature due to the conversion to SHFCVs. Most of the chemicals shown were emitted directly. Some, such as ozone and sulfate aerosol (S(VI)), formed in the atmosphere due to chemical reaction and gas-to-particle conversion. In general, concentrations of 
most emitted chemicals decreased in the global average. Decreases occurred primarily in North America and Europe, and for some chemicals, in China. Increases occurred in South America, Africa, and parts of Asia, including India. Some chemicals, such as $\mathrm{H}_{2}$, increased in the U.S. and Europe due to the higher penetration of SHFCVs.

Table 2-5

Ten-Year Averaged Differences in Constituent Concentrations Near the Surface for Conversion from FFOVs to SHFCVs in 2050

\begin{tabular}{|c|c|}
\hline Constituent & Ten-Year Average Differences \\
\hline Hydrogen & $+6 \mathrm{ppbv}$ \\
\hline $\mathrm{NO}$ & $-0.026 \mathrm{ppbv}$ \\
\hline $\mathrm{CO}$ & $-6.2 \mathrm{ppbv}$ \\
\hline $\mathrm{CO}_{2}$ & $-2470 \mathrm{ppbv}$ \\
\hline $\mathrm{CH}_{4}$ & $-2.7 \mathrm{pbv}$ \\
\hline $\mathrm{HCHO}$ & $-0.02 \mathrm{ppbv}$ \\
\hline $\mathrm{SO}_{2}$ & $-0.0014 \mathrm{ppbv}$ \\
\hline $\mathrm{O}_{3}$ & $-0.41 \mathrm{ppbv}$ \\
\hline $\mathrm{BC}$ & $-0.023 \mu \mathrm{g} / \mathrm{m}^{3}$ \\
\hline $\left.\mathrm{S}^{3} 1\right)$ & $-0.006 \mu \mathrm{g} / \mathrm{m}^{3}$ \\
\hline $\mathrm{NO}_{3}$ & $-0.031 \mu \mathrm{g} / \mathrm{m}^{3}$ \\
\hline $\mathrm{PM}_{2.5}$ & $-0.14 \mu \mathrm{g} / \mathrm{m}^{3}$ \\
\hline Temperature & $-0.04 \mathrm{~K}$ \\
\hline
\end{tabular}

Figure 2-5 illustrates the spatial distribution of near-surface hydrogen and shows the elevated levels in the United States and Europe.

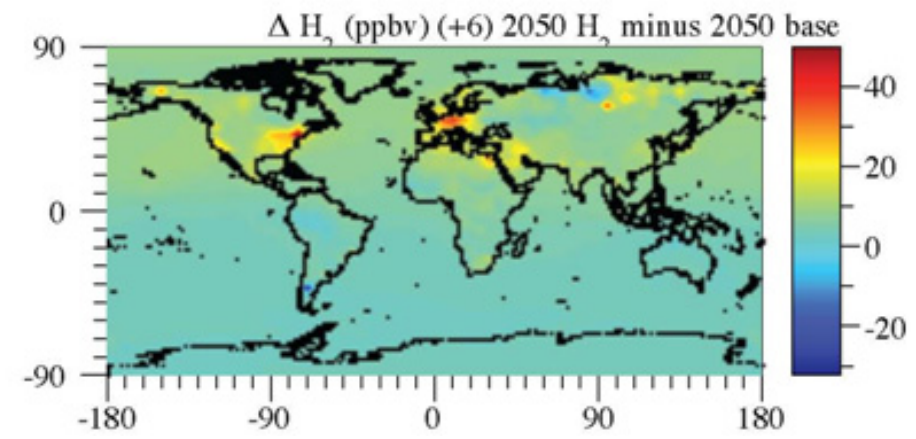

Figure 2-5 Ten-year-average differences in hydrogen near the surface due to the conversion of FFOVs to SHFCVs in 2050. Numbers in parentheses are globally-averaged changes in the figure.

Due to the decrease in $\mathrm{NO}_{\mathrm{x}}$ and organics in particular, surface ozone decreased in the global average due to the conversion to SHFCVs. Much of the decrease occurred in populated areas, and this resulted in an overall decrease in the ozone-related health effects (see section 6). Surface particulate matter, particularly black carbon, sulfate, and nitrate, decreased in the global average. Further, surface temperature decreased due to the conversion, with most decreases occurring at high latitudes. Decreases occurred primarily due to the reduction in $\mathrm{CO}_{2}$ and black carbon, both of which are strong global warming agents. 
Tropospheric changes in the major emitted chemicals, $\mathrm{H}_{2}, \mathrm{NO}, \mathrm{CO}, \mathrm{CO}_{2}, \mathrm{CH}_{4}, \mathrm{HCHO}$, toluene, $\mathrm{SO}_{2}$, and $\mathrm{BC}$, reflect changes, for the most part, in emissions of these chemicals. An exception was $\mathrm{CH}_{4}$, whose emissions did not change much but whose column abundance decreased in the global average due to a slight increase in $\mathrm{OH}$ in many regions, which itself was caused by a significant decrease in $\mathrm{CO}$ due to SHFCVs. $\mathrm{CO}$ is oxidized by $\mathrm{OH}$, removing $\mathrm{OH}$, so a reduction in $\mathrm{CO}$ increases OH. This result differs from Jacobson and Streets (2009), where OH decreased slightly due to a conversion to wind-powered HFCVs (WHFCVs), causing an increase in $\mathrm{CH}_{4}$. The reason $\mathrm{OH}$ decreased in that case was that, although $\mathrm{CO}$ emissions also decreased, so did aldehyde emissions, and aldehydes are significant sources of $\mathrm{OH}$, so reducing aldehydes decreased $\mathrm{OH}$. Also, a reduction in stratospheric water vapor reduced stratospheric $\mathrm{OH}$. In the present scenario, aldehyde emissions increased slightly, producing $\mathrm{OH}$ that offset $\mathrm{OH}$ reduction due to a reduction in water vapor. However, over a longer simulation period, it is expected that further cooling due to greater accumulated reductions in $\mathrm{CO}_{2}$ will reduce water vapor further, reducing $\mathrm{OH}$ causing a net increase in $\mathrm{CH}_{4}$.

See Figure 2-6 that shows zonally averaged temperature changes as a function of latitude, and shows temperature difference peaking at high positive and negative latitudes.

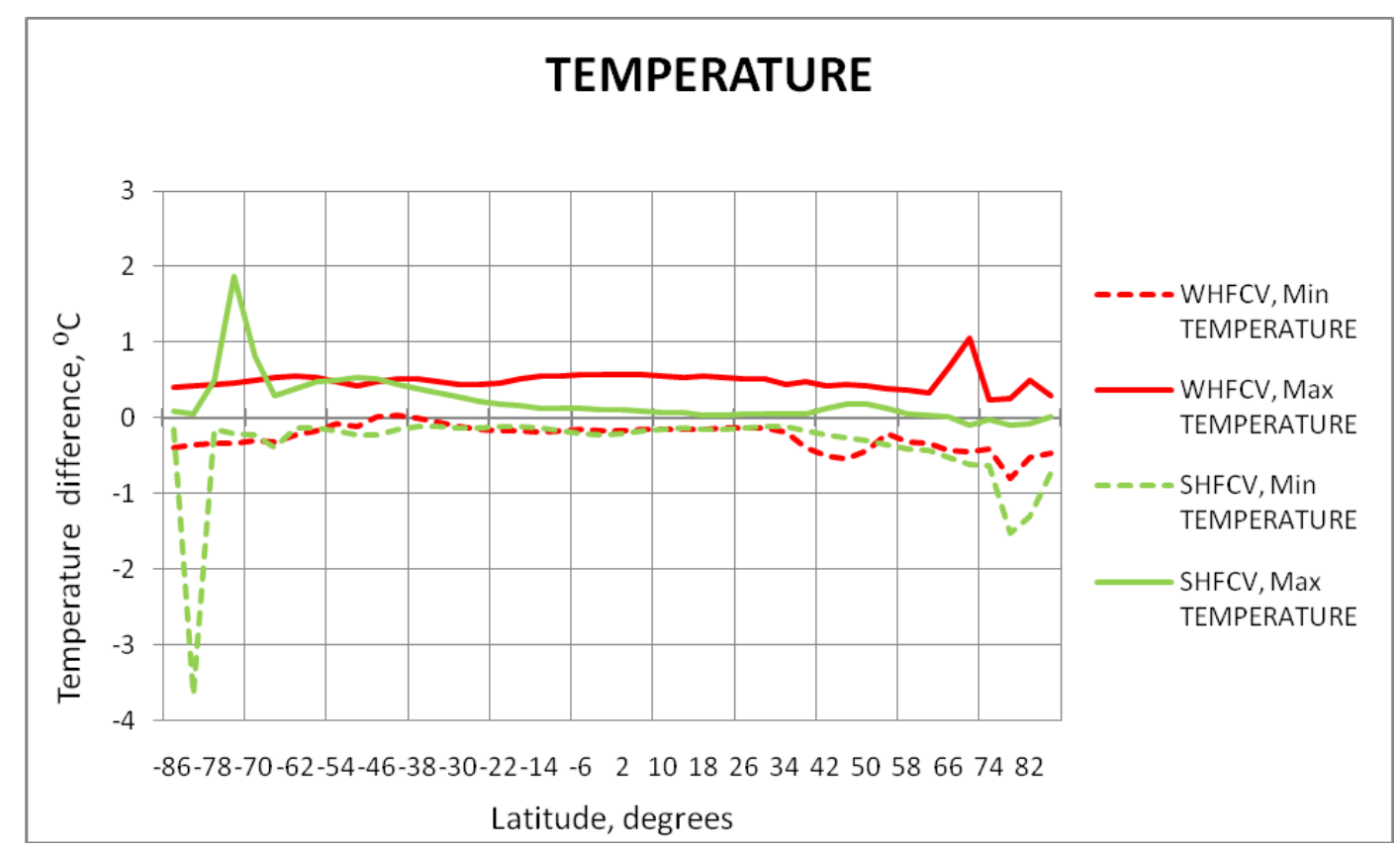

Figure 2-6

Zonally averaged and ten-year averaged temperature differences for two HFCV scenarios.

The stratospheric temperature inversion slows the transport of tropospheric gases to the stratosphere. Stratospheric warming and tropospheric cooling due to SHFCVs increased the stability of the lower stratosphere further, reducing hydrogen transport to the stratosphere. As the overall lifetime of $\mathrm{H}_{2}$ in the atmosphere is 2-3 years, much of the hydrogen emitted in the troposphere was removed from the atmosphere before reaching the stratosphere, causing little change in stratospheric hydrogen relative to tropospheric hydrogen.

Table 2-6 has been prepared to summarize the maximum and minimum ten-year zonal differences by altitude and by latitude for both the WHFCV and SHFCV cases for $\mathrm{CH}_{4}, \mathrm{CO}_{2}$, 
$\mathrm{CO}, \mathrm{H}_{2}, \mathrm{H}_{2} \mathrm{O}$-vapor, $\mathrm{HCHO}, \mathrm{NO}_{2}, \mathrm{NO}, \mathrm{O}_{3}, \mathrm{SO}_{2}$, toluene, and temperature. Table 2-6(a) and Table 2-6(c) show that the most extreme changes occur near the earth's surface (0 km altitude) or near the UTLS. For Table 2-6(b) and Table 2-6(d), which shows results by latitude, the most extreme cases of change for WHFCV scenario are in the northern hemisphere, while for the SHFCV scenario, more extreme changes occur in the southern hemisphere. Examples of constituents that tend to decease in concentrations near the surface are those such as $\mathrm{CO}_{2}$ and $\mathrm{NO}_{\mathrm{x}}$, where emissions are reduced during the conversion to HFCVs. Neither maximum nor minimum differences tend to occur in the upper stratosphere, but differences are typically well below those in the troposphere. An exception is ozone, where concentration changes are greatest in the UTLS.

Plots for $\mathrm{CH}_{4}, \mathrm{O}_{3}, \mathrm{CO}_{2}, \mathrm{H}_{2}, \mathrm{H}_{2} \mathrm{O}$-vapor, temperature, $\mathrm{SO}_{2}, \mathrm{CO}$, and $\mathrm{NO}_{2}$ differences by latitude and longitude are included in Appendix E. An example for ozone is shown in Figure 2-7. Very small differences in ozone levels occur in the lower $10 \mathrm{~m}$ of the troposphere, and the largest differences occur in the UTLS. Taken in their totality most plots show that the largest changes for most constituents also occur near the UTLS.

The decrease in $\mathrm{CO}$, and $\mathrm{CH}_{4}$ in particular decreased surface and mid-tropospheric ozone due to a conversion to SHFCVs. The conversion also increased upper-tropospheric/lower stratospheric ozone, on average, and decreased upper stratospheric ozone in a manner similar to in the WHFCV case and for similar reasons. Again, $\mathrm{O}_{3}$ changes in the WHFCV case were greater in magnitude than in the SHFCV case. In both cases, effects should strengthen over a longer simulation period as greater accumulated reductions in $\mathrm{CO}_{2}$ over a longer simulation will trigger greater tropospheric cooling and stratospheric warming, increasing stratospheric stability further, reducing surface evaporation of water, and reducing UTLS water vapor, causing greater increases in UTLS ozone and greater decreases in upper stratospheric ozone, and greater net increases in overall ozone. 
A

03

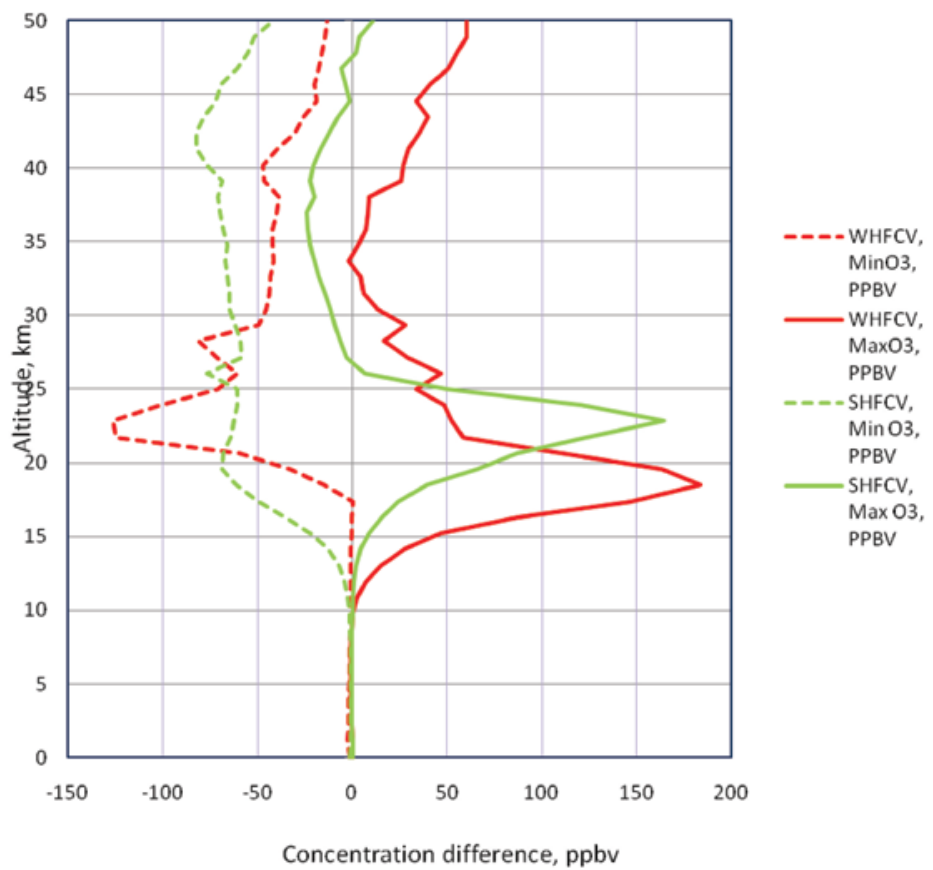

B

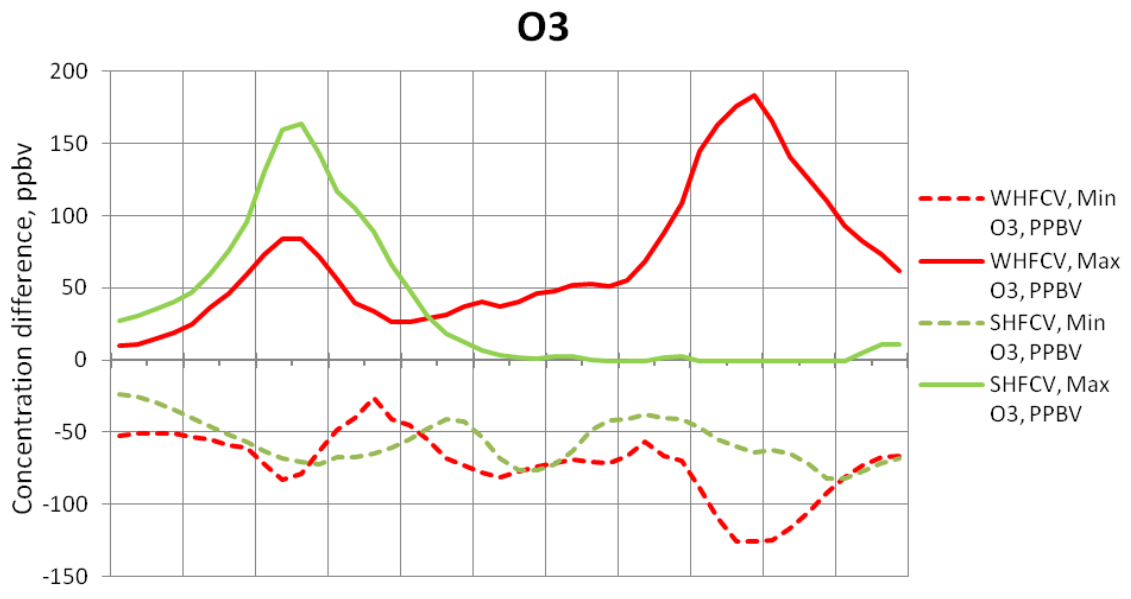

$-86-78-70-62-54-46-38-30-22-14 \quad-6 \quad 2 \quad 10182634425058667482$

Latitude, degrees

Figure 2-7 Plots of 10-year zonal differences for ozone: Maximum and minimum by altitude (A) and latitude (B). 
Table 2-6 (a)
Summary of Ten-year Zonal Differences: WHFCV Results by Altitude

\begin{tabular}{|c|c|c|c|c|c|c|c|c|c|c|c|c|c|c|c|c|c|c|c|c|c|c|c|c|}
\hline \multirow[b]{2}{*}{$\begin{array}{c}\text { Altitude, } \\
\mathrm{km}\end{array}$} & \multicolumn{2}{|c|}{$\mathrm{CH} 4$} & \multicolumn{2}{|c|}{$\mathrm{CO}$} & \multicolumn{2}{|c|}{ co } & \multicolumn{2}{|c|}{ H2 } & \multicolumn{2}{|c|}{ H2O } & \multicolumn{2}{|c|}{ HCHO } & \multicolumn{2}{|c|}{ NO2 } & \multicolumn{2}{|c|}{ No } & \multicolumn{2}{|c|}{03} & \multicolumn{2}{|c|}{ SO2 } & \multicolumn{2}{|c|}{ TOL } & TEMPE! & ATURE \\
\hline & $\begin{array}{c}\text { Min CH4, } \\
\text { PPBV }\end{array}$ & $\begin{array}{c}\text { Max CH4 } \\
\text { PPBV }\end{array}$ & $\begin{array}{c}\text { Min CO2, } \\
\text { PPBV }\end{array}$ & $\begin{array}{c}\text { Max CO2, } \\
\text { PPBV }\end{array}$ & $\begin{array}{c}\text { Min co, } \\
\text { PPBV }\end{array}$ & $\begin{array}{c}\text { Max CO, } \\
\text { PPBV }\end{array}$ & $\begin{array}{l}\text { Min H2, } \\
\text { PPBV }\end{array}$ & $\begin{array}{l}\text { Max H2, } \\
\text { PPBVV }\end{array}$ & $\begin{array}{l}\text { Min H2O, } \\
\text { PPBV }\end{array}$ & $\begin{array}{c}\max _{\mathrm{P}} \mathrm{H} 2 \mathrm{O}, \\
\mathrm{PPBV}\end{array}$ & \begin{tabular}{|c} 
Min HCHO, \\
PPBV
\end{tabular} & $\begin{array}{c}\text { Max HCHO, } \\
\text { PPBV }\end{array}$ & $\begin{array}{c}\text { Min NO2, } \\
\text { PPBV }\end{array}$ & $\begin{array}{c}\text { Max NO2, } \\
\text { PPBVV }\end{array}$ & $\begin{array}{l}\text { MinNo, } \\
\text { PPBV }\end{array}$ & $\begin{array}{l}\text { MaxNO, } \\
\text { PPBV }\end{array}$ & $\begin{array}{l}\text { MinO3, } \\
\text { PPBV }\end{array}$ & $\begin{array}{l}\text { MaxO3, } \\
\text { PPBV }\end{array}$ & $\begin{array}{l}\text { MinsO2, } \\
\text { PPBV }\end{array}$ & $\begin{array}{c}\text { MaxSO2, } \\
\text { PPBV }\end{array}$ & $\begin{array}{l}\text { MinTOL, } \\
\text { PPBV }\end{array}$ & $\begin{array}{l}\text { MaxTOL, } \\
\text { PPBVV }\end{array}$ & Min TEMP & Mах ТЕМР \\
\hline 0 & 0 & 6.7 & -3600 & 0 & -60.54 & 0 & $\begin{array}{l}-13.3 \\
\end{array}$ & 0 & -477000 & & -0.03216 & & $\begin{array}{l}-0.1011 \\
\end{array}$ & $\begin{array}{ll}0.01118 \\
\end{array}$ & -0.01168 & 0.006421 & -1.629 & 0 & -0.0028 & 0.001477 & -0.02734 & 0 & $\begin{array}{c}-0.81 \\
\end{array}$ & 1.06 \\
\hline 1.087 & 0 & 6 & -3590 & 0 & -59.37 & 0 & -12.7 & 0 & . -77000 & 171000 & -0.1165 & 0 & -0.10069 & 0 & -0.03955 & $5.81 \mathrm{E}-06$ & -2.49 & 0 & -0.00766 & & -0.02962 & 0 & -0.25 & 0.29001 \\
\hline 2.1739 & 4.2001 & 6 & -3380 & - -1630 & -56.88 & -12.45 & -12.7 & -9.7 & -72000 & 173000 & -0.0748 & 0.0002 & -0.02883 & -0.00014 & -0.00902 & 0.000113 & -2.248 & -0.462 & -0.00319 & 0.002449 & -0.02317 & -0.00036 & -0.24002 & 0.26999 \\
\hline 3.2609 & 4.2999 & 6 & -3190 & -1650 & -53.83 & -12.61 & -12.7 & -10.1 & -81000 & 181000 & -0.0428 & -0.00023 & -0.00727 & $-5.98 E-05$ & -0.00092 & $-9.25 E-06$ & -1.943 & -0.549 & -0.00081 & 0.001766 & -0.01939 & -0.00022 & -0.23001 & 0.22 \\
\hline 4.3478 & 4.2999 & 6.1 & -3060 & -1660 & -51.11 & -12.89 & -12.7 & -10.3 & -84000 & 155000 & -0.02593 & 0.0008 & -0.00341 & $-4.74 E-05$ & -0.00056 & $-5.23 \mathrm{E}-06$ & -1.772 & -0.5977 & -0.00063 & 0.001908 & -0.01603 & $-9.00 E-05$ & -0.23001 & 0.20001 \\
\hline 5.4348 & 4.2 & 6 & -2940 & -1670 & -48.82 & -13.24 & -12.6 & -10.3 & -59600 & 129900 & -0.01504 & 0.0008 & -0.0022 & $-3.42 E-05$ & -0.00067 & $1.35 E-06$ & -1.667 & -0.605 & -0.0006 & 0.001779 & -0.01315 & $1.73 \mathrm{E}-05$ & -0.22 & 0.20001 \\
\hline 6.5217 & 4.2 & 6.1001 & -2830 & - 1690 & -46.67 & -13.63 & -12.6 & -10.3 & -48700 & 105700 & -0.01056 & 0.00054 & -0.00109 & $-2.63 E-05$ & -0.0002 & $6.33 \mathrm{E}-06$ & -1.51 & -0.605 & -0.00035 & 0.001769 & -0.01068 & $3.53 \mathrm{E}-05$ & -0.22 & 0.20999 \\
\hline 7.6087 & 4.2 & 6.2001 & -2720 & - -1700 & -44.27 & -14.02 & -12.5 & -10.2 & -48600 & 97600 & -0.00817 & 0.00016 & -0.0006 & $-2.29 \mathrm{E}-05$ & $-9.44 E-05$ & $2.60 \mathrm{E}-06$ & -1.282 & -0.576 & 0.000401 & 0.001804 & -0.00803 & $2.81 \mathrm{E}-05$ & -0.19 & 0.21001 \\
\hline 8.6957 & 4.1 & 6.5 & -2590 & -1680 & -41.27 & -14.36 & -12.4 & -10 & -26700 & 79500 & -0.00664 & -0.00017 & -0.00029 & $-1.67 \mathrm{E}-05$ & $-4.57 E-05$ & $4.18 \mathrm{E}-05$ & -1.028 & -0.444 & 0.000729 & 0.00186 & -0.00558 & $2.32 \mathrm{E}-05$ & -0.15999 & 0.22 \\
\hline 9.7826 & 4.1 & 7.3 & -2460 & - -1610 & -38.01 & -14.55 & -12.6 & -9.1001 & - -11500 & 60900 & -0.00574 & -0.00021 & -0.00046 & $-1.02 E-05$ & $-4.94 E-05$ & $5.03 \mathrm{E}-05$ & -0.968 & 0.255 & 0.000826 & 0.001859 & -0.0033 & $3.10 \mathrm{E}-06$ & -0.12 & 0.23 \\
\hline 10.8696 & 2.7 & 9.2 & -240 & - 14440 & -36.34 & -14.1 & -13. & -6.2999 & -4800 & 43300 & -0.00537 & 0.000191 & -0.00062 & $-8.14 E-06$ & $-5.42 E-05$ & $5.35 \mathrm{E}-05$ & -0.94 & 2.77 & 0.000725 & 0.00195 & -0.00 & 0.000124 & & 22 \\
\hline 11.9565 & 0.19995 & 12.3 & -2300 & -1130 & -33.85 & -12.46 & -15.8 & -1.5 & -2020 & 21870 & -0.00477 & 0.000356 & -0.00058 & $-6.49 E-06$ & $-7.07 E-05$ & $3.10 \mathrm{E}-05$ & $-0.9 c$ & 7.1 & 0.000833 & 0.001961 & -0.00109 & & -0.17 & 19 \\
\hline 13.0435 & -3.1 & 19.5 & -2120 & -300 & -29.29 & -1.27 & -15.9 & 8 & -957 & 14700 & -0.004 & $8.60 \mathrm{E}-05$ & -0.00047 & $-1.11 \mathrm{E}-06$ & -0.0002 & $1.91 E-05$ & -0.746 & 14.88 & 0.000841 & 0.001911 & -0.00061 & 0.000158 & -0.2 & 0.14999 \\
\hline 14.1304 & -7.1001 & 26.7 & -2100 & & -27.72 & & -17.4 & 16.15 & -473 & 4670 & -0.00324 & $2.80 \mathrm{E}-05$ & -0.0013 & $9.17 \mathrm{E}-06$ & -0.0008 & $8.74 \mathrm{E}-05$ & -0.604 & 27.62 & 0.00061 & 0.002334 & -0.00057 & $9.47 \mathrm{E}-05$ & -0.12001 & 0.2 \\
\hline 15.2174 & -1 & 26.4 & -2060 & 340 & -27 & 4.32 & -14.3 & 14.02 & -269.9 & 1589 & -0.00309 & 0.00023 & -0.00272 & 0.000596 & -0.00175 & 0.000627 & -0.497 & 46.56 & 0.000364 & 0.002427 & -0.00065 & $6.67 \mathrm{E}-05$ & 0.009995 & 0.31999 \\
\hline 16.3043 & 1 & 26.93 & . & 330 & -26.01 & 2.86 & -13.3 & 15.41 & -214.7 & 466 & -0.00245 & 0.00082 & -0.00341 & 0.004608 & -0.00212 & 0.004018 & -0.354 & 86.57 & 0.000201 & 0.001994 & -0.00066 & $3.52 \mathrm{E}-05$ & 0.040009 & 0.45 \\
\hline 17.3913 & -3.84 & & -1770 & 400 & -24.05 & 2.062 & -12.4 & & -208.3 & 212 & -0.0015 & 0.000891 & -0.00271 & 0.006415 & -0.00174 & 0.005436 & 0.111 & 146.74 & 0.000112 & 0.001848 & -0.00038 & $2.29 \mathrm{E}-05$ & 0.019989 & 0.52 \\
\hline 18.4783 & -3.34 & 35.32 & -1100 & 310 & -17.67 & 1.58 & -11 & 14.46 & -207.5 & 106.1 & -0.00062 & 0.00129 & -0.00166 & 0.004155 & -0.00101 & 0.003438 & -15 & & $6.74 \mathrm{E}-05$ & 0.001501 & $-8.48 E-00$ & $2.11 \mathrm{E}-05$ & -0.04001 & 0.46001 \\
\hline 19.5652 & -2.28 & & -140 & 22 & -2.94 & 0.54 & -1.51 & 8.72 & -204. & 30. & $-7.30 \mathrm{E}-05$ & 0.00134 & -0.00061 & 0.0014 & -0.00 & 0.00 & -33 & 163.2 & & & $-3.50 \mathrm{E}-05$ & & 999 & \\
\hline 20.6522 & -1.73 & & -90 & 130 & -1.037 & 0.751 & -0.09998 & & - 199. & -15.3 & 0.000235 & 0.001022 & -0.00018 & 0.001023 & 0.00011 & & -59.4 & & & & & & & 0.57001 \\
\hline 21.7391 & -1.44 & 14.97 & .70 & 30 & -0.449 & 0.326 & 0.65002 & 4.22 & -195.3 & -46 & 0.000151 & 0.001011 & -0.00017 & 0.000385 & -0.00011 & 0.000144 & -124.5 & 58.3 & $2.24 \mathrm{E}-05$ & 0.000115 & $-1.93 E-06$ & 3.14E-06 & -0.29001 & 0.58 \\
\hline 22.8261 & -0.72998 & 11.4 & -60 & 20 & -0.187 & 0.376 & 1.15 & 3.55 & -194.9 & -62.8 & 0.000102 & 0.001039 & -0.00041 & 0.000258 & -0.0004 & 0.000198 & -126.1 & 52.5 & $1.79 \mathrm{E}-05$ & $9.31 \mathrm{E}-05$ & $-6.39 \mathrm{E}-07$ & $2.28 \mathrm{E}-06$ & -0.37 & 0.49001 \\
\hline 23.913 & -2.13 & 7.0 & -60 & 0 & -0.094 & 0.263 & 1.31 & 2.83 & -196.7 & -72.6 & $4.70 \mathrm{E}-05$ & 0.000877 & -0.00034 & 0.00096 & -0.00027 & 0.000792 & -100.7 & 48.1 & $1.60 \mathrm{E}-05$ & $7.75 \mathrm{E}-00$ & $-1.59 \mathrm{E}-07$ & $1.73 \mathrm{E}-00$ & -0.39999 & 0.39 \\
\hline 25 & -4.04 & 2.25 & -60 & 0 & -0.0754 & 0.238 & 1.15 & 2.5 & -199.5 & -77.7 & $-1.00 \mathrm{E}-05$ & 0.000581 & -0.00069 & 0.002369 & -0.00025 & 0.002203 & -71 & 33.4 & $1.40 \mathrm{E}-00$ & $6.62 \mathrm{E}-05$ & $-4.99 E-08$ & $1.36 \mathrm{E}-00$ & -0.35001 & 0.31999 \\
\hline 26.087 & -5.42 & 0.26001 & -60 & 0 & -0.0678 & 0.215 & 1.05 & 2.22 & -199.3 & -80.8 & $-6.20 \mathrm{E}-05$ & 0.000282 & -0.0011 & 0.00413 & -0.00031 & 0.004354 & -61 & 46.6 & $1.20 \mathrm{E}-05$ & $5.87 \mathrm{E}-05$ & $-4.03 E-09$ & $1.09 \mathrm{E}-06$ & -0.299 & 0.28 \\
\hline 27.1739 & $\begin{array}{l}-7.67 \\
\end{array}$ & -0.33002 & -60 & 0 & -0.0652 & 0.193 & 0.77002 & 2.11 & -195.1 & -83.2 & -0.00033 & 0.0002 & -0.0026 & 0.00566 & -0.00057 & 0.00652 & -71.7 & 29.1 & $1.01 \mathrm{E}-05$ & $5.31 \mathrm{E}-05$ & $-8.10 \mathrm{E}-09$ & $8.77 \mathrm{E}-07$ & -0.26001 & 0.31 \\
\hline 28.2609 & -9.38 & & -60 & 0 & -0.0525 & & 0.44 & 1.8 & -187. & -8 & -0.000 & & -0.003 & & & & -81.399 & & $9.49 \mathrm{E}-06$ & & $-6.17 E-08$ & & & 0.32001 \\
\hline 29.34 & -9.27 & -0.91998 & -60 & 0 & & & & & -17 & & -0.000 & & -0.00 & & & & -49. & & 8.50E-06 & & & & & 0.34 \\
\hline 30.4348 & -8.52 & -1.04 & -60 & 0 & -0.0549 & 0.129 & 0.099976 & 1.69 & -170.3 & -87 & -0.00077 & $6.00 \mathrm{E}-05$ & -0.0026 & & -0.00098 & 0.01018 & -45.5 & 13 & 7.60E-06 & $4.36 \mathrm{E}-05$ & $-9.52 \mathrm{E}-08$ & $.92 E-07$ & -0.25 & 0.32001 \\
\hline 31.5217 & -7.66 & -1.11 & -60 & 0 & -0.063 & 0.114 & 0.12997 & 1.66 & -163 & -87.1 & -0.00079 & $4.20 \mathrm{E}-05$ & -0.00121 & 0.00869 & -0.00 & 0.011 & -44 & 6 & $6.70 \mathrm{E}-06$ & $4.17 \mathrm{E}-05$ & $-9.41 \mathrm{E}-08$ & $5.34 \mathrm{E}-07$ & -0.8 & 0.3 \\
\hline 32.6087 & -6.55 & -1 . & -60 & 0 & & $0 . c$ & 0.17999 & 1.61 & -158.9 & -86.3 & -0.00077 & $9.30 \mathrm{E}-0$ & -0.00 & 0.01178 & $0.00 \mathrm{c}$ & 0.01083 & -43.5 & 4 & $6.16 \mathrm{E}-06$ & $4.00 \mathrm{E}-05$ & $-1.13 \mathrm{E}-07$ & $4.89 \mathrm{E}-07$ & & 0.39999 \\
\hline 33.6957 & -5.66 & -1. & -50 & 0 & & & 0.28 & 1.57 & -153 & -86 & -0.00081 & 0.000111 & -0.000 & 0.01 & 0.00 & 0.01 & -41. & -2 & $5.76 \mathrm{E}-00$ & $3.86 \mathrm{E}-05$ & $-1.26 \mathrm{E}-07$ & $4.46 \mathrm{E}-07$ & & 0.42 \\
\hline 34.7826 & -5.22 & -1. & -60 & -10 & -0.0982 & 0.073 & 0.39001 & 1.52 & -147.8 & -85.8 & -0.00099 & 0.00013 & -0.00033 & 0.0235 & 0.00374 & 0.01277 & -42.101 & 3 & $5.38 \mathrm{E}-00$ & $3.74 \mathrm{E}-05$ & $-1.20 \mathrm{E}-07$ & $4.04 \mathrm{E}-07$ & -0.18001 & 0.39 \\
\hline 35.8696 & -4.9 & -1. & -50 & -10 & -0.104 & 0.059999 & 0.45999 & 1.4 & -143. & -85 & -0.00112 & 0.000137 & -0.00151 & 0.02 & 0.00621 & 0.01465 & -42. & 7 & $5.22 \mathrm{E}-06$ & $3.62 \mathrm{E}-05$ & $-1.07 E-07$ & $3.63 \mathrm{E}-07$ & -0.14999 & 0.36 \\
\hline 36.9565 & -4.68 & -1.55 & -50 & -10 & -0.109 & 0.052 & 0.48001 & 1.4 & -138.8 & -85 & -0.00124 & 0.000176 & -0.00297 & 0.0314 & 0.00834 & 0.01723 & -39.7 & & $5.07 \mathrm{E}-06$ & $3.51 \mathrm{E}-05$ & $-9.48 \mathrm{E}-08$ & $3.22 \mathrm{E}-07$ & & 0.28999 \\
\hline 38.0435 & -4.5 & -1.68 & -66 & -1 & & 0.080999 & \begin{tabular}{|l|l|l}
0.51001 \\
\end{tabular} & & & & & & & & & & & & & & & & & 0.42999 \\
\hline 39.1304 & -4.42 & -1.7 & -60 & -10 & & 0.1 & \begin{tabular}{|l|l|}
0.54001 \\
\end{tabular} & & & & & & & & 0.010 & 0.02 & -46.8 & & & & & & & 0.5 \\
\hline 40.2174 & -4.34 & -1.71 & -60 & -10 & -0.13 & 0.13 & 0.56 & 1.3 & - 124 & -85. & $\begin{array}{l}-0.00 \\
-0.0\end{array}$ & & & & 0.01 & 0.0 & -47 & 27 & $4.80 \mathrm{E}-06$ & & $-5.00 E-08$ & 07 & & 52 \\
\hline 41.30 & -4. & & -60 & -10 & & & 0.5 & 1.3 & -119 & & -0.00 & & -0.01 & 0.03 & 0.0 & 0.0 & -39 & 29.801 & $4.77 \mathrm{E}-06$ & $3.00 \mathrm{E}-05$ & $-2.92 E-08$ & $1.78 \mathrm{E}$ & -0.18 & 0.53 \\
\hline 42.3913 & -4. & -1. & -50 & -16 & -0 & & 0.569 & 1.3 & -114 & -84 & -0.00 & -5.00 & -0.02 & 0.0 & 0.0 & 0.0 & -30. & 35.4 & $4.74 \mathrm{E}-06$ & $2.89 \mathrm{E}-05$ & $-1.10 \mathrm{E}-08$ & $1.59 \mathrm{E}-07$ & -0.26999 & 0.53 \\
\hline 43.4783 & -4.14 & -1.52 & -50 & -10 & -0.161 & 0.15 & 0.57999 & 1.38 & -110.9 & -84 & -0.00159 & -0.00034 & -0.0247 & 0.04 & 0.0135 & 0.031 & -25.9 & 40.1 & $4.71 \mathrm{E}-06$ & $2.79 \mathrm{E}-05$ & $-3.87 \mathrm{E}-09$ & $1.43 \mathrm{E}-07$ & -0.38 & 0.48001 \\
\hline 44.5652 & -4.12 & -1.47 & -50 & -10 & -0.162 & 0.128 & 0.57001 & 1.39 & -109 & -83. & -0.00154 & -0.00057 & -0.0271 & 0.0442 & 0.0134 & 0.0323 & -19.1 & 33.6 & $4.69 \mathrm{E}-06$ & $2.69 \mathrm{E}-05$ & $-3.45 E-09$ & $1.33 \mathrm{E}-07$ & -0.45 & 0.44998 \\
\hline 45.6522 & -4.08 & -1.39 & -60 & -10 & -0.162 & 0.10 & 0.54999 & 1.4 & -107.3 & -83 & -0.00159 & -0.00068 & -0.0304 & 0.0442 & 0.0129 & 0.033 & -20 & & $4.77 \mathrm{E}-06$ & $2.62 E-05$ & $-3.55 E-09$ & $1.26 \mathrm{E}-07$ & -0.43002 & 0.5 \\
\hline 46.7391 & -4.05 & -1.32 & -50 & -10 & -0.1 & 0.1 & 0.53998 & 1.4 & -105 & -8 & -0.00 & -0.00078 & -0.0 & 0.04 & & 0.0337 & -18 & & $4.71 \mathrm{E}-06$ & $2.56 \mathrm{E}-05$ & $-3.64 \mathrm{E}-09$ & 1.19E- -07 & -0.32 & 0.56 \\
\hline 47.8261 & -4.01 & -1.28 & -50 & -10 & -0.1 & & & 1.4 & -105 & -82 & & & & & & & & & & & & & & 0.54999 \\
\hline 48.913 & -4.01 & -1.25 & -50 & -10 & -0.154 & 0.101 & & 1.48 & $\begin{array}{l}-105.4 \\
\end{array}$ & -82.9 & -0.001 & - -0.00088 & -0.0 & 0.0447 & 0.0106 & 0.0341 & -14.5 & 60.1 & $4.73 \mathrm{E}-06$ & $2.45 E-05$ & $-3.22 \mathrm{E}-09$ & $1.14 \mathrm{E}-07$ & -0.25 & 0.53 \\
\hline 50 & -4 & -1.25 & -50 & -10 & -0.151 & 0.098 & 0.48999 & 1.5 & -105 & -83 & -0.00164 & -0.00088 & -0.0338 & & 0.011 & & -13.5 & 60 & $4.75 \mathrm{E}-06$ & $2.41 \mathrm{E}-05$ & $-3.33 \mathrm{E}-09$ & $1.14 \mathrm{E}-07$ & -0.51999 & 0.48001 \\
\hline & $\begin{array}{l}28.2609 \\
\text { cm, Alt } \rightarrow- \\
9.38\end{array}$ & $\begin{array}{l}17.3913 \mathrm{~km}, \\
\text { Aft }>35.97\end{array}$ & 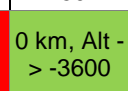 & $\begin{array}{l}4.1 .1304 \mathrm{~km} \\
\text { Alt } \rightarrow \text { a }\end{array}$ & $\underset{-60.54}{k m, \text { Alt } \rightarrow>}$ & $\begin{array}{l}14.1304 \\
\mathrm{~km}, \mathrm{Alt}=\mathrm{y}\end{array}$ & $\begin{array}{c}14.1304 \\
\text { km, Alt } \rightarrow- \\
17.4\end{array}$ & 17.391: & $\begin{array}{r}0 \mathrm{~km} \text {, Alt }-> \\
477000\end{array}$ & $\begin{array}{l}\mathrm{km} \text {, Alt }- \\
239000\end{array}$ & 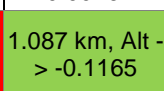 & $\begin{array}{l}0 \mathrm{~km} \text {, Alt-> } \\
0.00159\end{array}$ & $\begin{array}{c}0 \mathrm{~km} \text {, Alt -> } \\
0.1011\end{array}$ & 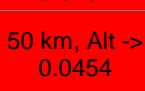 & $\begin{array}{l}1.087 \mathrm{~km} \text {, Alt } \\
>-0.039547\end{array}$ & $\begin{array}{l}0 \mathrm{~km}, \text { Alt-. } \\
0.0343\end{array}$ & $\begin{array}{l}22.8261 \mathrm{~km}, 1 \\
\text { Alt } \rightarrow-126.1\end{array}$ & $\begin{array}{l}18.4783 \mathrm{~km} \\
\text { Att } \rightarrow 183.2\end{array}$ & $\begin{array}{c}1.087 \mathrm{~km} \text {, Alt } \\
>-0.00766\end{array}$ & $\begin{array}{l}1.087 \mathrm{~km} \text {, Alt } \\
\rightarrow 0.00544\end{array}$ & $\begin{array}{l}1.087 \mathrm{~km} \text {, Alt - } \\
>-0.029662\end{array}$ & $\begin{array}{l}11.9565 \mathrm{~km} \\
\text { Att- }\end{array}$ & $\begin{array}{c}0 \mathrm{~km}, \text { Alt } \rightarrow- \\
0.81\end{array}$ & $\begin{array}{l}0 \mathrm{~km} \text {, Alt } \rightarrow \\
1.06\end{array}$ \\
\hline
\end{tabular}


Table 2-6 (b)

Summary of Ten-year Zonal Differences: WHFCV Results by Latitude

\begin{tabular}{|c|c|c|c|c|c|c|c|c|c|c|c|c|c|c|c|c|c|c|c|c|c|c|c|c|}
\hline \multirow[b]{2}{*}{$\begin{array}{l}\text { Latitude } \\
\text { degrees }\end{array}$} & \multicolumn{2}{|c|}{$\mathrm{CH} 4$} & \multicolumn{2}{|c|}{$\mathrm{CO2}$} & \multicolumn{2}{|c|}{ co } & \multicolumn{2}{|c|}{$\mathrm{H} 2$} & \multicolumn{2}{|c|}{$\mathrm{H} 2 \mathrm{O}$} & \multicolumn{2}{|c|}{ HCHO } & \multicolumn{2}{|c|}{ NO2 } & \multicolumn{2}{|c|}{ NO } & \multicolumn{2}{|c|}{03} & \multicolumn{2}{|c|}{ SO2 } & \multicolumn{2}{|c|}{ TOL } & \multicolumn{2}{|c|}{ TEMPERATURE } \\
\hline & 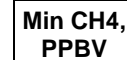 & Max CH4, & $\mid \begin{array}{c}\text { Min Co2, } \\
\text { PPBV }\end{array}$ & $\begin{array}{l}\operatorname{Max} \mathrm{CO}_{\mathrm{P}} \text {, } \\
\text { PPBV }\end{array}$ & $\begin{array}{c}\text { Min Co, } \\
\text { PPBV }\end{array}$ & $\begin{array}{l}\text { Max Co, } \\
\text { PPBV }\end{array}$ & $\begin{array}{l}\text { Min H2, } \\
\text { PPBV }\end{array}$ & $\underset{\text { MPBV }}{\text { Max }}$ & 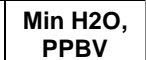 & $\underset{\text { PPBV }}{\operatorname{Max} \text { H2O, }}$ & $\begin{array}{l}\text { Min HCHO, } \\
\text { PPBV }\end{array}$ & $\underset{\text { PPBV }}{\operatorname{Max} \mathrm{HCH}}$ & $\begin{array}{l}\text { Min NO2, } \\
\text { PPBV }\end{array}$ & \begin{tabular}{|l} 
Max NO2, \\
PPBV
\end{tabular} & $\begin{array}{c}\text { Min NO, } \\
\text { PPBV }\end{array}$ & $\begin{array}{l}\text { Max NO, } \\
\text { PPBV }\end{array}$ & $\begin{array}{c}\text { Min 03, } \\
\text { PPBV }\end{array}$ & $\begin{array}{l}\text { Max O3, } \\
\text { PPBV }\end{array}$ & $\begin{array}{l}\text { Min So2, } \\
\text { PPBV }\end{array}$ & Max SO2, & $\begin{array}{c}\text { Min TOL, } \\
\text { PPBV }\end{array}$ & $\begin{array}{l}\text { Max TOL, } \\
\text { PPBV }\end{array}$ & Min TEMP & Max TEMP \\
\hline & -1.94 & 21.2 & -1700 & 0 & -14.55 & 0.065 & -10.3 & 8.01 & -6480 & 0 & -0.00093 & 0.000294 & -0.00194 & 0.02825 & -0.00259 & 0.0232 & -52.9 & 9.94 & 0 & 0.001064 & -0.00087 & 0.000108 & \begin{tabular}{|l|}
-0.39999 \\
\end{tabular} & 0.41 \\
\hline-82 & -2.08 & 22.6 & - -1710 & -50 & -14.79 & 0.073999 & -10.4 & 8.38 & -18500 & -102.9 & -0.00248 & 0.000261 & -0.00148 & 0.03241 & -0.00081 & 0.0201 & -51.2 & 10.6 & -0.00255 & 0.001291 & -0.00089 & 0.00014 & -0.36 & 0.42 \\
\hline-78 & -2.41 & 24.3 & - -1720 & -50 & -15.26 & 0.091 & -10.5 & 9.49 & -25700 & -100.3 & -0.00144 & 0.000356 & -0.00039 & 0.0383 & -0.0004 & 0.0187 & -51 & 15.21 & $1.55 \mathrm{E}-05$ & 0.00151 & -0.00091 & 0.00018 & -0.34 & 0.45001 \\
\hline-74 & -2.66 & 26.7 & - -1730 & -40 & -15.3 & 0.099 & -10.6 & 11.99 & -44340 & -93.5 & -0.00164 & 0.000249 & -0.00032 & 0.0423 & -0.00065 & 0.0176 & -51.2 & 18.68 & -0.0028 & 0.001682 & -0.00093 & 0.000214 & -0.34 & 0.45999 \\
\hline-70 & -2.89 & 26.4 & - -1730 & -40 & -15.1 & 0.106 & -10.6 & 11.92 & -47330 & -68 & -0.0016 & 0.00027 & 0.00025 & & -0.00024 & 0.019 & -53 & 24.8 & -0.0005 & 0.001481 & -0.00095 & 0.000234 & -0.31 & 0.5 \\
\hline-66 & -3.16 & 25.4 & -1730 & -30 & -15.32 & 0.131 & -10.6 & 11.28 & -84700 & 117 & -0.00164 & 0.00039 & 0.00039 & 0.0448 & -0.00047 & 0.02 & -54.7 & 36.26 & -0.00102 & 0.001431 & -0.00097 & & 0.32001 & 0.54001 \\
\hline-62 & -4.14 & 23.9 & -1740 & -10 & -15.63 & 0.155 & -10.6 & 10.6 & -40000 & 4700 & -0.00167 & 0.000541 & -0.0005 & 0.0423 & -0.00044 & 0.0295 & -58.7 & 46.4 & -0.00012 & 0.001507 & -0.001 & 0.000231 & -0.23 & 0.56 \\
\hline-58 & -5.18 & 21.61 & -1740 & 20 & -15.86 & 0.15 & -10.7 & 8.16 & -1000 & 8900 & -0.00209 & 0.00071 & -0.00066 & 0.0413 & -0.00086 & 0.0329 & -60.7 & 59.6 & -0.00049 & 0.001532 & -0.00102 & 0.000189 & -0.17 & 0.53 \\
\hline-54 & -5.94 & 24.31 & -1750 & 80 & -16.15 & 0.375 & -11 & 10.61 & -3700 & 18100 & -0.00346 & 0.001008 & -0.00073 & 0.0409 & -0.00027 & & -72.3 & 73.69 & -0.00053 & 0.001582 & -0.00105 & 0.000126 & -0.08 & 0.47 \\
\hline-50 & -6.37 & 26.93 & -1760 & 180 & -18.88 & 1.23 & -15.8 & 14.03 & -19000 & 28300 & -0.0057 & 0.001281 & -0.00142 & 0.0401 & -0.00032 & 0.0342 & -82.9 & 83.59 & -0.00042 & 0.001699 & -0.00113 & $8.72 \mathrm{E}-05$ & -0.11002 & 0.42999 \\
\hline-46 & -7.1001 & 33.07 & - 1780 & 270 & -20.85 & 1.231 & -17.4 & 15.41 & -15300 & 33600 & -0.00779 & \begin{tabular}{|l}
0.00129 \\
\end{tabular} & -0.00271 & 0.0388 & -0.00053 & 0.0337 & -79 & 83.75 & -0.00046 & 0.00177 & -0.00129 & $9.47 \mathrm{E}-05$ & 0.02002 & 0.48 \\
\hline-42 & -6.59 & & -1810 & 320 & -21.24 & 1.845 & -15.1 & 14.71 & -109.3 & 54000 & -0.00916 & 0.00134 & -0.00343 & & -0.00083 & 0.032 & -63.5 & 71.57 & -0.00044 & 0.001824 & -0.00134 & $7.89 \mathrm{E}-05$ & 0.029999 & 0.52 \\
\hline-38 & -6.6 & 33.91 & -1820 & & -21.3 & 2.062 & -12 & & -103 & 108800 & & & & & -0.0 & 3 & -48 & & & & & & -0.01001 & 0.50999 \\
\hline-34 & -6.77 & 35.32 & -1850 & 400 & -23.17 & 1.416 & -13.4 & 14.67 & -101.6 & 143000 & -0.01382 & 0.001132 & -0.00572 & 0.0376 & -0.00118 & 0.0298 & -40.6 & & -0.0013 & 0.001655 & -0.00163 & $5.67 \mathrm{E}-05$ & -0.06 & 0.47 \\
\hline-30 & -7.06 & 34.2 & -1890 & 340 & -25.11 & 1.58 & -15.2 & 14.46 & -100.2 & 111000 & -0.01851 & 0.001011 & -0.00871 & 0.0361 & -0.0023 & 0.0292 & -25.9 & 33.62 & -0.00139 & 0.001496 & -0.00163 & $2.29 \mathrm{E}-05$ & -0.11 & 0.44 \\
\hline-26 & $\begin{array}{l}-7.44 \\
\end{array}$ & 30.97 & -1950 & 310 & -25.92 & 0.67 & -15.4 & 13.77 & -98.9 & 95000 & -0.01953 & 0.00098 & -0.00529 & 0.0343 & -0.00126 & 0.028 & -41 & 26.3 & -0.001 & 0.001797 & -0.00134 & $2.32 \mathrm{E}-05$ & -0.14999 & 0.44 \\
\hline-22 & -7.89 & 29.4 & -1990 & 160 & -26.54 & -0.019 & -15.4 & 8.72 & -7000 & 75000 & -0.01643 & 0.000932 & -0.00782 & 0.0327 & -0.00208 & 0.0269 & -45.3 & 26.6 & -0.0007 & 0.002271 & -0.00131 & $2.81 \mathrm{E}-05$ & -0.17999 & 0.46001 \\
\hline-18 & -8.55 & 25.6 & -2000 & 190 & -26.12 & -0.038 & -14.3 & 8.1801 & -66000 & 69000 & -0.01796 & 0.000907 & -0.00425 & 0.0313 & -0.00119 & 0.0257 & -55.399 & 28.9 & -0.00019 & 0.002287 & -0.00098 & $3.53 \mathrm{E}-0$ & -0.18001 & 0.50999 \\
\hline-14 & -9.03 & 20.81 & -2010 & & -25.97 & -0.042 & -13.4 & 4.92 & -72000 & 15000 & -0.01927 & 0.000914 & -0.00413 & 0.0306 & -0.00115 & 0.0244 & -68.4 & 31.3 & $-7.00 E-06$ & 0.002449 & -0.00077 & $3.18 \mathrm{E}-0$ & -0.19 & 0.56001 \\
\hline-10 & -9.35 & & -2010 & & -25.72 & 0.133 & -12.6 & 4.8 & -84000 & 20 & -0.02085 & 0.000929 & & & & & -73.199 & & $-3.30 \mathrm{E}-05$ & & -0.00073 & & -0.17999 & 0.56 \\
\hline-6 & $\begin{array}{l}-9.38 \\
\end{array}$ & & & & -25.8 & 0.18501 & -12.5 & 5.3 & -61000 & & -0.0563 & 0.000974 & -0.00506 & 0.0288 & -0.00115 & 0.02 & -78 & 40.1 & -0.00011 & & & $4.82 E-05$ & & 0.58 \\
\hline-2 & -9.27 & 20.13 & -2050 & 180 & -26.34 & 0.414 & -13 & 5.59 & -15000 & 63000 & -0.0732 & 0.000987 & -0.00563 & 0.028 & -0.00114 & 0.0245 & -81.399 & 37.1 & $4.72 E-06$ & 0.001848 & -0.00219 & 4.39E-05 & 0.17001 & 0.57999 \\
\hline 2 & -8.72 & 18.57 & -2170 & 170 & -29.79 & 0.298 & -13.3 & 5.41 & -92.8 & 55000 & -0.0553 & & -0.00479 & 0.0281 & -0.0011 & 0.025 & -77.6 & 40.4 & $4.82 \mathrm{E}-06$ & 0.001845 & -0.0023 & $4.13 \mathrm{E}-0$ & -0.17001 & 0.57001 \\
\hline 6 & $\begin{array}{l}-7.95 \\
\end{array}$ & 17.31 & -2360 & 140 & -35.02 & 0.428 & -13.1 & 5.14 & -92.3 & 77800 & -0.0627 & 0.001039 & -0.00455 & 0.0284 & -0.00099 & 0.025 & $\begin{array}{r}-73.8 \\
\end{array}$ & 46.4 & -0.00017 & 0.001835 & -0.00299 & $3.42 E-05$ & -0.16 & 0.57001 \\
\hline 10 & -7.04 & 17.72 & -2510 & 130 & -38.53 & 0.751 & -12.6 & 5.91 & -91.7 & 135000 & -0.0985 & 0.001017 & -0.00729 & 0.0284 & -0.00083 & 0.0255 & -71.1 & 48.1 & -0.00212 & 0.001798 & -0.00446 & $2.42 E-05$ & -0.14999 & 0.56001 \\
\hline 14 & -6.21 & 17 & -2650 & 100 & -42.93 & 0.619 & -12.5 & 5.86 & -91.1 & 181000 & -0.0728 & 0.000974 & -0.00799 & 0.0285 & -0.0011 & 0.0252 & -69 & 51.9 & -0.00263 & 0.001765 & -0.00701 & $1.21 \mathrm{E}-05$ & -0.16 & 0.53999 \\
\hline 18 & -5.56 & 15.8 & -2770 & 70 & -45.02 & 0.395 & -12.3 & 5.58 & -90.6 & & -0.0654 & 0.000931 & -0.01748 & 0.0291 & -0.00331 & 0.0248 & -70.8 & 52.5 & -0.00323 & 0.001862 & -0.00851 & $2.18 \mathrm{E}-06$ & -0.14999 & 0.54999 \\
\hline 22 & -5.01 & 14.9 & -287 & 20 & -46.69 & 0.35 & -12 . & 4. & -90 & 211000 & -0.06695 & & & & & 0.02 & -71 & & 487 & & -0.01034 & $1.17 \mathrm{E}-0$ & -0.13998 & 0.53 \\
\hline 26 & -4.61 & 19 & -294 & 26 & -48 . & & -12 & 3. & -10 & & -0.0745 & & -0.02 & & & 0.0 & & & & & & & -0.13 & 0.51999 \\
\hline 30 & -4.41 & 20.6 & -2980 & 20 & -51.25 & 0.217 & -12.2 & 6.56 & -21200 & & -0.0864 & & -0.0 & 0. & -0.01115 & 0.0 & -56 & & & & 698 & 7.24E-08 & -0.14 & 0.50999 \\
\hline 34 & -4.38 & & & 230 & & 1.57 & -12.1 & 9 & & 180 & & & & & -0.01103 & 0.0 & -6 & & -0.00 & 0.002427 & -0.0 & & -0.19 & 0.45 \\
\hline 38 & -4.41 & $1 \varepsilon$ & -3110 & 33 & -56 & 2.51 & -12.1 & 8.51 & -410000 & & -0.0966 & 0.000 & -0.10 & & -0.03955 & 0.02 & -69.8 & 108.5 & -0.00023 & & -0.02664 & $9.50 \mathrm{E}-09$ & 9999 & 0.46999 \\
\hline 42 & -4.49 & 13 & -32 & 230 & -57.93 & 1.44 & -13.8 & 5.69 & -477000 & 2520 & -0.1 & 0.00 & -0.08 & 0.0 & -0.01467 & 0.02 & -89.1 & 145.17 & -0.00257 & 0.002 & -0.02797 & $1.23 \mathrm{E}-08$ & -0.51001 & 0.43001 \\
\hline 46 & -4.53 & 11.1 & -3350 & 220 & -59.16 & 3.04 & -15.9 & 5.1 & -419000 & -57 & -0.1137 & 0.000558 & -0.09783 & 0.0333 & -0.02087 & 0.0221 & -109.3 & 163.2 & -0.00766 & 0.002051 & -0.02962 & $2.38 \mathrm{E}-08$ & -0.53998 & 0.45 \\
\hline 50 & -4.38 & 11.4 & -3450 & 230 & -59.15 & 2.46 & -15.9 & 4.78 & -315000 & -85.6 & -0.10326 & 0.000503 & -0.07419 & 0.0341 & -0.01141 & 0.0212 & -126.1 & 175.83 & -0.00726 & 0.001914 & -0.02858 & $6.08 \mathrm{E}-08$ & -0.42999 & 0.42001 \\
\hline 54 & -4.02 & 12. & -3480 & 220 & -59.29 & 1.61 & -15.8 & 4.6 & - 163700 & -85.6 & -0.0748 & 0.000416 & -0.06326 & 0.0328 & -0.00784 & 0.0215 & -125.8 & & & & -0.02661 & $1.07 E-07$ & -0.21002 & 0.39 \\
\hline 58 & -3.42 & 12 & $-354 C$ & 160 & -59.37 & 1. & -14 & 4.5 & -201100 & -84.6 & & & -0.04788 & & & & -124.5 & 165 & -0.00 & & -0.02542 & & & 0.36 \\
\hline 62 & -3.23 & 16 & -3590 & 280 & -59.31 & 4.14 & -1 & & & 0 & & & -0.0 & & & & -11 & 14 & & & & & & \\
\hline 66 & -2.88 & 21 & -3600 & 430 & -60.54 & 5.71 & -10.7 & & -22 & 1961 & & & -0.1 & & & & - 104.9 & 125 & & & & & $\begin{array}{l}-0.43002 \\
\end{array}$ & 0.66998 \\
\hline 70 & -2.45 & 25 & -3250 & & -58.8 & 6.75 & -10.7 & 14. & $-23 !$ & 115600 & -0.0 & 0.00 & -0.026 & 0.00 & -0.00089 & 0.0 & -92.4 & 110 & -0.00043 & 0.001875 & -0.02363 & $3.74 \mathrm{E}-07$ & -0.45 & \\
\hline 74 & -2.15 & 26.6 & -3180 & 490 & -58.41 & & -10.6 & 16.15 & -58600 & -11 & -0.03055 & 0.000363 & -0.019 & 0.00379 & -0.00014 & 0.0168 & -81.6 & 93.2 & -0.00073 & 0.001787 & -0.02293 & $2.73 \mathrm{E}-05$ & -0.41 & 0.23999 \\
\hline 78 & -1.93 & 26.6 & -3310 & 410 & -57.42 & 6.21 & -10.7 & 16.03 & -66200 & 51 & -0.02802 & 0.000371 & -0.0261 & 0.00375 & -0.00314 & 0.015 & -72.8 & 82 & $2.21 E-05$ & 0.001767 & -0.02175 & $5.14 \mathrm{E}-05$ & -0.81 & 0.26001 \\
\hline 82 & -1.83 & 26 & -3140 & 320 & -57.05 & 5.07 & -10.6 & 15.45 & -7580 & 3200 & -0.02393 & 0.000369 & -0.0288 & 0.00229 & -0.00022 & 0.0146 & -67.1 & 73.5 & $2.34 \mathrm{E}-05$ & 0.001786 & -0.02094 & $5.05 E-05$ & -0.51999 & 0.48999 \\
\hline 86 & -1.71 & 26.1 & -3110 & 300 & -57.02 & 4.32 & -10.5 & 15.19 & -13300 & 20900 & -0.02181 & 0.000353 & -0.0338 & 0.00233 & -0.00064 & 0.0155 & -66.8 & 61.9 & $2.41 E-05$ & 0.001791 & $\begin{array}{r}-0.02008 \\
\end{array}$ & $3.75 E-05$ & -0.47 & 0.29001 \\
\hline & $\begin{array}{c}-6 \text { o, lat }-> \\
-9.38\end{array}$ & $\begin{array}{l}\text { o, lat } \\
35.97\end{array}$ & \begin{tabular}{|}
660 , lat - \\
-3600
\end{tabular} & $\begin{array}{c}074 \text { o, lat } \\
>490\end{array}$ & 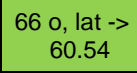 & $\begin{array}{l}40 \text {, lat } \\
6.94\end{array}$ & $\begin{array}{c}-46 \text { o, lat -> } \\
17.4\end{array}$ & $\begin{array}{r}38 \text { o, lat } \\
16.69\end{array}$ & $\begin{array}{r}42 \text { o lat }-> \\
477000\end{array}$ & $\begin{array}{l}18 \text { o, lat- } \\
239000\end{array}$ & $\begin{array}{c}34 \mathrm{o}, \text { lat }->- \\
0.1165\end{array}$ & $\begin{array}{l}\text { o, lat - }> \\
0.00159\end{array}$ & $\begin{array}{c}66,0, \text { lat } \rightarrow \\
0.1011 \\
\quad\end{array}$ & $\begin{array}{r}-70 \text { o, lat - } \\
0.0454\end{array}$ & $\begin{array}{r}38 \mathrm{o}, \text { lat }-\rightarrow \\
0.039547\end{array}$ & $\begin{array}{r}50,0 \text { lat } \\
0.0343\end{array}$ & $\begin{array}{c}50 \text { o, lat-s } \\
126.1\end{array}$ & 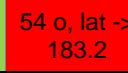 & $\begin{array}{r}46 \text { o, lat }-> \\
0.00766 \\
\end{array}$ & $\begin{array}{c}380 \text {, lat }-7 \\
0.00546\end{array}$ & $\begin{array}{r}46 \text { o, lat }-> \\
0.02962 \\
\end{array}$ & $\begin{array}{l}-660, \text {, lat }-7 \\
0.0002364\end{array}$ & $\begin{array}{c}78 \text { o, lat - } \\
0.81\end{array}$ & $\begin{array}{l}0,0 \text {, lat- } \\
1.06\end{array}$ \\
\hline
\end{tabular}


Table 2-6 (c)

Summary of Ten-year Zonal Differences: SHFCV Results by Altitude

\begin{tabular}{|c|c|c|c|c|c|c|c|c|c|c|c|c|c|c|c|c|c|c|c|c|c|c|c|c|}
\hline \multirow[b]{2}{*}{$\begin{array}{c}\text { Altitude, } \\
\mathrm{km}\end{array}$} & \multicolumn{2}{|c|}{$\mathrm{CH} 4$} & \multicolumn{2}{|c|}{$\mathrm{co2}$} & \multicolumn{2}{|c|}{ co } & \multicolumn{2}{|c|}{ H2 } & \multicolumn{2}{|c|}{ H2O } & \multicolumn{2}{|c|}{ HCHO } & \multicolumn{2}{|c|}{ NO2 } & \multicolumn{2}{|c|}{ NO } & \multicolumn{2}{|c|}{03} & \multicolumn{2}{|c|}{ SO2 } & \multicolumn{2}{|c|}{ TOL } & TEMPE & RATURE \\
\hline & $\begin{array}{l}\text { Min CH4, } \\
\text { PPBV }\end{array}$ & $\begin{array}{l}\text { Max CH4, } \\
\text { PPBV }\end{array}$ & $\begin{array}{c}\text { Min co2, } \\
\text { PPBV }\end{array}$ & $\begin{array}{c}\operatorname{Max} \mathrm{CO}^{2}, \\
\text { PPBV }\end{array}$ & \begin{tabular}{|c} 
Minco, \\
PPBV
\end{tabular} & $\begin{array}{c}\text { Maxco, } \\
\text { PPBV }\end{array}$ & $\begin{array}{l}\text { Min H2, } \\
\text { PPBV }\end{array}$ & $\begin{array}{l}\text { Max H2, } \\
\text { PPBV }\end{array}$ & $\begin{array}{l}\text { Min H2O, } \\
\text { PPBV }\end{array}$ & $\begin{array}{c}\text { Max H2O, } \\
\text { PPBV }\end{array}$ & $\underset{\text { PPBV }}{\text { Min HCO, }}$ & $\begin{array}{c}\text { Max HCHO, } \\
\text { PPBV }\end{array}$ & $\begin{array}{c}\text { Min NO2, } \\
\text { PPBV }\end{array}$ & \begin{tabular}{|c|} 
Max NO2, \\
PPBV
\end{tabular} & & & $\begin{array}{c}\text { Min 03, } \\
\text { PPBV }\end{array}$ & $\begin{array}{l}\text { Max 03, } \\
\text { PPBV }\end{array}$ & $\begin{array}{l}\text { Min SO2, } \\
\text { PPBV }\end{array}$ & $\begin{array}{l}\text { Max SO2, } \\
\text { PPBV }\end{array}$ & $\begin{array}{c}\text { Min TOL, } \\
\text { PPBV }\end{array}$ & $\begin{array}{c}\text { Max TOL, } \\
\text { PPBV }\end{array}$ & Min TEMP & Max TEMP \\
\hline 0 & -3.7 & 0 & -3030 & & -10.65 & 0 & 0 & 8.81 & -217400 & & -0.03812 & 0.000352 & -0.07265 & 0.001179 & -0.02341 & 0.000366 & -1.546 & 0.157 & -0.004697 & 0.002154 & 0 & & -3.66 & 1.87 \\
\hline 1.087 & -3.6 & 0 & -3040 & 0 & -9.43 & 0 & 0 & & -95500 & 26800 & -0.0859 & & -0.02425 & 0.00542 & -0.01237 & $3.65 \mathrm{E}-03$ & -0.956 & 0 & -0.004445 & 0.00936 & 0 & 0.0103 & -0.2 & 0.13 \\
\hline 2.1739 & -3.6 & -1.8 & -2980 & -2070 & -9.11 & -3.44 & 2.99 & 9.08 & -87600 & 16000 & -0.0653 & 0.0024 & -0.00559 & 0.0000052 & -0.000856 & 0.000106 & -0.987 & -0.177 & -0.002455 & & 0.0005586 & 0.00752 & -0.2 & 0.15 \\
\hline 3.2609 & -3.7 & -1.8 & -2930 & -2080 & -8.93 & -3.59 & 3.07 & 8.86 & -78000 & 15000 & -0.04544 & -0.0005 & -0.002321 & $2.98 \mathrm{E}-05$ & -0.0002101 & $8.31 E-05$ & -1.085 & -0.19 & -0.001036 & 0.00977 & 0.0004123 & 0.00569 & -0.2 & 0.13 \\
\hline 4.3478 & -3.8 & -1.8 & -2880 & -2080 & -8.68 & -3.71 & 3.14 & 8.67 & -78000 & 3100 & -0.02817 & -0.000706 & -0.001007 & $3.14 \mathrm{E}-05$ & -0.00005257 & $8.74 E-05$ & -1.122 & -0.216 & -0.000905 & 0.00589 & 0.0002797 & $4.41 E-03$ & -0.21 & 0.1 \\
\hline 5.4348 & -3.8 & -1.9 & -2830 & -2080 & -8.51 & -3.82 & 3.21 & 8.37 & -69300 & 4400 & -0.01905 & -0.000764 & -0.00057 & $2.22 \mathrm{E}-05$ & -0.0000489 & $5.40 \mathrm{E}-05$ & -1.054 & -0.224 & -0.000551 & 0.00274 & 0.0002215 & $3.59 \mathrm{E}-03$ & -0.23 & 0.09 \\
\hline 6.5217 & -3.9 & -1.9 & -2760 & -2080 & -8.34 & -3.84 & 3.27 & 7.97 & -55700 & 680 & -0.01522 & -0.00081 & -0.000334 & $1.31 E-05$ & -0.0000571 & $1.17 \mathrm{E}-04$ & -1.014 & -0.222 & -0.000178 & 0.001304 & 0.000192 & $2.82 \mathrm{E}-03$ & -0.25 & 0.06 \\
\hline 7.6087 & -4.1 & -1.8 & -2690 & -2090 & -8.11 & -3.87 & 3.28 & 7.56 & -38500 & 60 & -0.01164 & -0.000924 & -0.000258 & $7.70 \mathrm{E}-05$ & $-8.31 \mathrm{E}-05$ & $1.55 \mathrm{E}-04$ & -1.055 & -0.183 & -0.000241 & 0.000886 & 0.0001663 & $1.79 \mathrm{E}-03$ & -0.27 & 0.05 \\
\hline 8.6957 & -4.7 & -1.3 & -2580 & -2080 & -7.85 & -3.97 & 3.2 & 7.26 & -31100 & -168 & -0.00877 & -0.001045 & -0.00023 & $-8.40 E-07$ & $-1.18 E-04$ & $6.35 E-05$ & -1.2 & -0.1 & -0.000311 & 0.000838 & 0.0001178 & $1.32 E-03$ & & 0.08 \\
\hline 9.7826 & -5.7 & -0.8 & -2400 & -2050 & -7.46 & -4.05 & 2.94 & 7.06 & -20700 & -110 & -0.00666 & -0.000934 & -0.000274 & $-5.74 E-06$ & $-9.98 E-05$ & $9.11 \mathrm{E}-05$ & -1.62 & 0.0 & -0.000306 & 0.000636 & 0.0000601 & $1.05 E-03$ & -0.31 & 0.09 \\
\hline 10.8696 & -7 & -0.2 & -2340 & -1980 & -6.62 & -4.17 & 2.46 & 6.87 & -14900 & 6 & -0.00521 & -0.000599 & -0.0003 & $5.02 E-05$ & $-8.69 E-05$ & $7.63 E-05$ & -2.452 & 0.306 & -0.000188 & 0.000521 & -0.0000012 & 0.000732 & -0.33 & 0.05 \\
\hline 11.9565 & -9 & 2.6 & -2530 & -1690 & -6.23 & -4.1 & 1.63 & 6.66 & -7310 & 92 & -0.00481 & -0.000518 & -0.000349 & $8.17 \mathrm{E}-05$ & $-6.27 \mathrm{E}-05$ & $4.78 E-05$ & -4.225 & 1.03 & -0.000138 & 0.000384 & & 0.000495 & -0.37 & 0.07 \\
\hline 13.0435 & -19.1 & & -3210 & -1510 & -6.35 & -3.73 & 0.61 & 6.09 & -4090 & 136 & -0.00402 & $-7.42 E-04$ & -0.000489 & $1.44 \mathrm{E}-04$ & -0.00003659 & $1.35 E-04$ & -7.16 & 2.25 & -0.000158 & 0.000383 & -0.00002683 & 0.000475 & -0.39 & 0.19 \\
\hline 14.1304 & -45 & 0.9 & -3360 & -1080 & -10.85 & -3.65 & -7.4 & 5.44 & -1830 & 158 & -0.00301 & $-5.67 E-04$ & -0.000862 & 3.57E-04 & -0.00001362 & $5.58 \mathrm{E}-04$ & -12.87 & 4.13 & -0.0002053 & 0.000326 & -0.0000251 & 4.47E-04 & -0.42 & 0.28 \\
\hline 15.2174 & -49.7 & -1.6 & -2370 & -610 & -11.08 & -2.51 & -13.96 & 5.15 & -775 & 152.8 & $\begin{array}{l}-0.00279 \\
-\end{array}$ & -0.00041 & $\begin{array}{l}-0.0000752 \\
-\end{array}$ & 0.0010177 & $\begin{array}{l}-0.00000856 \\
\end{array}$ & 0.001255 & -22.37 & 8.65 & $\begin{array}{l}-0.0002353 \\
\end{array}$ & 0.000187 & -0.00001706 & $3.73 \mathrm{E}-04$ & -0.43 & 0.3 \\
\hline 16.3043 & -31.31 & -2.48 & -2340 & -340 & $\begin{array}{l}-7.107 \\
\end{array}$ & -1.65 & -11.28 & 4.68 & -293.9 & 142.5 & -0.00323 & -0.000295 & -0.000702 & 0.0017817 & -0.0001333 & 0.001745 & -35.48 & 15.69 & -0.000163 & 0.000102 & -0.00001329 & $2.01 E-04$ & & 0.32 \\
\hline 17.3913 & -19.97 & -1.4 & -2480 & -210 & -7.55 & -0.85 & -6.98 & 3.43 & -186.4 & 123.7 & -0.002169 & -0.000163 & -0.000251 & 0.0016969 & -0.0000207 & & -49 & 23. & & 7.67E-05 & -0.00000816 & $3.88 \mathrm{E}-05$ & & 0.34 \\
\hline 18.4783 & -24 & -0.56 & -2340 & -150 & -8.65 & -0.518 & -6.6 & -0.84 & -132.4 & 104.3 & -0.000624 & 0.000118 & $-1.01 E-05$ & 0.0006255 & -0.00001133 & 0.000425 & -61.3 & 39.5 & $-1.01 E-04$ & $6.23 \mathrm{E}-05$ & $-1.15 \mathrm{E}-05$ & $5.02 E-06$ & -0.42 & 0.38 \\
\hline 19.5652 & -23.86 & 0.25 & -1020 & -110 & -4.797 & $\begin{array}{l}-0.332 \\
-\end{array}$ & - -10.28 & -0.93 & -96.7 & 88.6 & $-4.75 \mathrm{E}-04$ & 0.00006 & $-2.27 E-05$ & 0.0001284 & -0.00002831 & 0.000118 & -68.5 & 65.6 & $-1.02 E-04$ & $5.92 \mathrm{E}-05$ & $-5.42 \mathrm{E}-06$ & $2.95 \mathrm{E}-06$ & -0.43 & 0.45 \\
\hline 20.6522 & -7.56 & 0.65 & -300 & -90 & -1.25 & -0.2198 & -5.19 & -1.01 & -71.5 & 74.5 & -0.000369 & 0.00005 & $-4.11 E-05$ & 0.0001776 & -0.0000528 & 0.000154 & -68.4 & 86.9 & $-1.10 \mathrm{E}-04$ & $6.14 E-05$ & $-1.78 E-06$ & $1.85 E-06$ & -0.48 & 0.43 \\
\hline 21.7391 & -2.76 & 1.01 & -190 & -80 & -0.409 & -0.1436 & -2.26 & -0.96 & -61.5 & 67.9 & -0.000304 & 0.0000349 & $-6.12 E-05$ & 0.0001588 & -0.0000783 & 0.000145 & -64.1 & 122.7 & $-1.22 E-04$ & $6.66 \mathrm{E}-05$ & $-1.34 E-06$ & $1.29 E-06$ & -0.52 & 0.42 \\
\hline 22.8261 & -1.43 & 1.39 & -160 & -70 & -0.279 & -0.1029 & -1.83 & -0.95 & -57.3 & 61.4 & -0.0002417 & 0.0000144 & -0.000128 & 0.0000879 & -0.0000873 & $6.45 E-05$ & -62.4 & & $-1.35 E-04$ & 8.56 E- -05 & $-9.16 E-07$ & $9.32 E-07$ & -0.49 & 0.54 \\
\hline 23.913 & -0.83 & & -140 & -60 & -0.233 & -0.088 & -1.78 & -0.95 & -56 & 58.8 & $-1.94 \mathrm{E}-04$ & 0.0000584 & -0.000239 & 0.0001874 & & & & 120.5 & $-1.51 E-04$ & $1.06 \mathrm{E}-04$ & $-6.28 \mathrm{E}-07$ & $6.99 \mathrm{E}-07$ & -0.5 & 0.5 \\
\hline 25 & -0.74 & 1. & -120 & -50 & -0.189 & -0.057 & -1.75 & -0.95 & -57.4 & 57. & $-1.63 \mathrm{E}-04$ & 0.0001178 & -0.00026 & 0.0003 & -0.0000822 & & -60.8 & & $-1.67 E-04$ & $1.22 \mathrm{E}-04$ & $-4.72 E-07$ & $5.24 \mathrm{E}-07$ & & 0.36 \\
\hline 26.087 & -0.7 & & -120 & -50 & -0.146 & & -1.83 & -0.95 & -60.7 & 56. & $-1.43 \mathrm{E}-04$ & 0.00 & & & & & & 6.5 & & & $-3.50 E-07$ & $4.21 \mathrm{E}-07$ & & 0.28 \\
\hline 27.1739 & -0.75 & 2.82 & -110 & -50 & -0.1271 & -0.0284 & -1.92 & -0.94 & -66.1 & 55.8 & -0.00013446 & 000214 & 0.000228 & 0.001476 & -0.0000011 & 0.002259 & -58.4 & -2.9 & $-1.85 E-04$ & $1.70 \mathrm{E}-04$ & $-2.86 \mathrm{E}-07$ & $3.45 \mathrm{E}-07$ & -0.48 & 0.23 \\
\hline 28.2609 & -0.69 & 2. & -110 & -40 & -0.1175 & -0.0134 & -2.01 & -0.94 & -71.7 & 55.5 & -0.00014 & 0.000247 & 0.00012 & 0.00329 & 0.000018 & 0.0043 & -59.1 & -6.4 & $-1.98 \mathrm{E}-04$ & $2.33 \mathrm{E}-04$ & $-2.34 E-07$ & $2.87 E-07$ & -0.49 & 0.2 \\
\hline 29.3478 & -0.69 & 3.0 & -110 & -50 & -0.1078 & -0.0005 & -2.05 & -0.92 & -75.8 & 55 & -0.00014 & 0.000282 & 0.00046 & 0.00532 & 0.000358 & 0.00686 & -62 & -9.4 & $-2.09 E-04$ & $2.86 \mathrm{E}-04$ & $-1.90 E-07$ & $2.35 E-07$ & -0.49 & 0.18 \\
\hline 30.4348 & -0.67 & 3. & -110 & -40 & -0.0996 & 0.0137 & -2.02 & -0.91 & -79.4 & 54.1 & -0.000149 & $3.32 E-04$ & 0.00195 & 0.00789 & 0.000657 & 0.00934 & -65 & -11.7 & $-2.24 E-04$ & $3.15 E-04$ & $-1.64 E-07$ & $1.90 E-07$ & -0.55 & 0.2 \\
\hline 31.5217 & -0.7 & & -110 & -40 & -0.093 & 0.0284 & -2 & -0.88 & -80.7 & 51.6 & -0.0002 & $3.95 E-04$ & 0.00149 & 0.00846 & 0.000757 & 0.01137 & -65 & & $-2.39 E-04$ & $3.58 \mathrm{E}-04$ & $-1.47 E-07$ & $1.55 E-07$ & -0.51 & 0.26 \\
\hline 32.6087 & -0.81 & 3.56 & -100 & -40 & -0.0856 & 0.0391 & -2 & -0.85 & -81.5 & & $\begin{array}{l}-0.000216 \\
-0\end{array}$ & $4.48 \mathrm{E}-04$ & 0.00206 & 0.01 & 0.00136 & 0.01 & -66 & & $-2.32 \mathrm{E}-04$ & $3.34 \mathrm{E}-04$ & $-1.37 E-07$ & $1.24 \mathrm{E}-07$ & $\begin{array}{l}-0.39 \\
-0.39\end{array}$ & 0.33 \\
\hline 33.6957 & -0.95 & 3. & -100 & -40 & -0.078 & 0.049 & -2.02 & $-0 . \varepsilon$ & -82.4 & 48. & -0.000248 & 0.000 & 0.00315 & 0.01226 & 0.001 & 0.01576 & -67 & -20 & $-2.36 E-04$ & $2.88 \mathrm{E}-04$ & $-1.27 E-07$ & $9.73 \mathrm{E}-08$ & -0.34 & 0.32 \\
\hline 34.7826 & -1.09 & & -100 & -40 & & & & & & & & & 0.00415 & & & & -66 & & & & $-1.14 E-07$ & $7.70 \mathrm{E}-08$ & & 0.26 \\
\hline 35.8696 & -1.22 & 3.8 & -100 & -40 & & & & & -86.7 & & & & & & & & -68 & & $-2.46 E-04$ & $2.39 E-04$ & $-1.06 E-07$ & $5.99 E-08$ & & 0.2 \\
\hline 36.9565 & -1.31 & 3.9 & -90 & -40 & & 0.06 & -2.07 & -0.6 & -88.4 & 46.2 & -0.000426 & 0. & 0.00 & 0.01 & 0.00 & & -70 & -24.1 & $-2.52 \mathrm{E}-04$ & $2.71 \mathrm{E}-04$ & $-9.80 \mathrm{E}-08$ & $4.44 E-08$ & -0.72 & 0.2 \\
\hline 38.0435 & -1. & & -100 & -40 & & 0.0 & -2. & -0. & -86.6 & 45.4 & -0.00 & 0.00 & 0.006 & 0.02 & 0.005 & 0.02 & -71 & -20 & $-2.60 \mathrm{E}-04$ & $2.38 \mathrm{E}-04$ & $-8.65 E-08$ & 3.44E-08 & -0.64 & 0.26 \\
\hline 39.1304 & -1.38 & & -90 & -40 & -0.0738 & 0.08 & -2.07 & -0.63 & -83.7 & 44.1 & -0.000655 & 0.00 & 0.00724 & 0.026 & 0.00698 & 0.03016 & -68.5 & -22.3 & $-2.78 E-04$ & $1.88 E-04$ & $-7.59 E-08$ & $2.63 \mathrm{E}-08$ & -0.47 & 0.32 \\
\hline 40.2174 & -1.39 & 4.0 & -90 & -40 & -0.0617 & 0.1018 & -2.05 & -0.61 & -82.1 & 42.7 & -0.000616 & 0.000922 & 0.00633 & 0.02902 & 0.00693 & 0.03505 & -76.4 & -20.8 & $-2.96 E-04$ & 1.49E-04 & $-6.72 \mathrm{E}-08$ & $1.93 \mathrm{E}-08$ & -0.34 & 0.38 \\
\hline 41.3043 & -1.33 & 4.0 & -90 & -30 & $\begin{array}{l}-0.0459 \\
-\end{array}$ & 0.118 & -2 & -0.59 & -80.5 & 42.1 & -0.000675 & 0.001005 & 0.00557 & 0.02854 & 0.00763 & 0.0393 & -82 & -16.5 & $-3.15 E-04$ & $1.20 \mathrm{E}-04$ & $-5.45 E-08$ & $1.59 \mathrm{E}-08$ & -0.29 & 0.37 \\
\hline 42.3913 & -1.23 & 4. & -90 & -30 & -0.046 & 0.135 & -1.96 & -0.57 & -78.7 & 41.9 & -0.000687 & $9.94 E-04$ & 0.00582 & 0.03017 & 0.00923 & 0.0421 & -82.3 & -12.4 & $-3.35 E-04$ & $1.42 E-04$ & $-4.37 \mathrm{E}-08$ & $1.39 E-08$ & -0.41 & 0.34 \\
\hline 43.4783 & -1.1 & & -90 & -30 & & & & & & 42 & & & & & & & -78.3 & & & & & & & 0.26 \\
\hline 44.5 & -0.9 & & -80 & -30 & & & & & -75 & & & & & 0.03 & & & -72 & -1 & $-3.89 E-04$ & $1.11 \mathrm{E}-04$ & $-3.41 \mathrm{E}-08$ & & & 0.24 \\
\hline 45.6: & -0.82 & 3.9 & -80 & -30 & & 0.1 & -1.76 & -0 & -73.9 & & & & & & & & -69.2 & -3. & $-3.70 \mathrm{E}-04$ & $1.06 \mathrm{E}-04$ & $-2.85 E-08$ & & -0.63 & 0.34 \\
\hline 46.7391 & -0.78 & 3.8 & -80 & -30 & -0.00 & $0.18 \varepsilon$ & -1.72 & -0.61 & -71.8 & 41.8 & & 0.00 & 0.00341 & 0.03012 & 0.00942 & 0.0463 & -60.7 & -5.7 & $-3.90 E-04$ & $1.10 \mathrm{E}-04$ & $-2.57 \mathrm{E}-08$ & $1.03 E-08$ & -0.54 & 0.42 \\
\hline 47.8261 & -0.77 & 3.74 & -80 & -30 & -0.0047 & 0.196 & -1.7 & -0.63 & -69.7 & 41.7 & -0.001094 & 0.000942 & 0.00307 & 0.0298 & 0.00971 & 0.0473 & -55 & 1.9 & $-4.16 E-04$ & $1.07 E-04$ & $-2.41 E-08$ & 9.94E-09 & -0.35 & 0.47 \\
\hline 48.913 & -0.74 & 3.72 & -80 & -30 & -0.0134 & & -1.69 & -0.65 & -68.8 & 41.7 & -0.001178 & 0.000892 & 0.00292 & 0.02933 & 0.00982 & 0.0478 & -51.8 & 3.8 & $-4.26 E-04$ & $1.02 E-04$ & $-2.18 \mathrm{E}-08$ & $9.72 \mathrm{E}-09$ & -0.19 & 0.49 \\
\hline 50 & -0.71 & 3.72 & -80 & -30 & & & & -0.65 & -69 & 41.5 & -0.001276 & 0.000864 & 0.00295 & 0.02905 & 0.00946 & & -41.3 & 10.9 & $-4.25 \mathrm{E}-04$ & $1.03 \mathrm{E}-04$ & $-2.03 \mathrm{E}-08$ & $9.63 \mathrm{E}-09$ & -0.31 & 0.47 \\
\hline & $\begin{array}{l}15.2174 \mathrm{~km}, \\
\text { Alt } \rightarrow-49.7\end{array}$ & $30435 \mathrm{k}$ & $\begin{array}{c}14.1304 \\
\mathrm{~km}, \mathrm{Alt}-\mathrm{-} \\
3360\end{array}$ & $\begin{array}{l}1.087 \mathrm{~km} \\
\text { Alt } \rightarrow 0\end{array}$ & $\begin{array}{c}15.2174 \\
\mathrm{~km} \text {, Alt-> } \\
11.08\end{array}$ & $\begin{array}{l}48.91350 \\
\text { km, Alt } \\
0.198 \\
0.78\end{array}$ & $\begin{array}{c}15.2174 \\
\text { km Alt } \rightarrow- \\
13.96\end{array}$ & $\begin{array}{ll}1.087 \mathrm{~km} \\
\mathrm{Att} \rightarrow 9.26\end{array}$ & $\begin{array}{l}0 \mathrm{~km}, \text { Alt }-> \\
-217400\end{array}$ & & $\begin{array}{c}1.087 \mathrm{~km} \text {, Alt } \\
-0.0859\end{array}$ & $\begin{array}{l}087 \mathrm{kmm} \text { Alt } \\
>0.0086\end{array}$ & $\begin{array}{c}0 \mathrm{~km} \text {, Alt -> } \\
0.07265\end{array}$ & & $\begin{array}{c}0 \mathrm{~km}, \mathrm{Alt} \rightarrow- \\
0.02341\end{array}$ & $\begin{array}{l}0 \mathrm{~km}, \text { Alt } \\
0.0481\end{array}$ & $\begin{array}{l}\begin{array}{l}42.3913 \mathrm{~km}, \\
\text { Alt }>-82.3\end{array}\end{array}$ & & $\begin{array}{c}0 \mathrm{~km}, \text { Alt } \rightarrow- \\
0.004697\end{array}$ & & $\begin{array}{l}11.9565 \mathrm{~km}, \\
\text { Alt }->-2.87 \mathrm{e}- \\
0.05\end{array}$ & $\begin{array}{l}0 \mathrm{~km}, \text { Alt-> } \\
0.01134\end{array}$ & $\begin{array}{c}0 \mathrm{~km}, \text { Alt-> } \\
3.66\end{array}$ & $\begin{array}{l}\mathrm{km}, \text { Alt } \\
1.87\end{array}$ \\
\hline
\end{tabular}


Table 2-6 (d)

Summary of Ten-year Zonal Differences: SHFCV Results by Latitude

\begin{tabular}{|c|c|c|c|c|c|c|c|c|c|c|c|c|c|c|c|c|c|c|c|c|c|c|c|c|}
\hline \multirow[b]{2}{*}{$\begin{array}{l}\text { Latitude, } \\
\text { degrees }\end{array}$} & \multicolumn{2}{|c|}{$\mathrm{CH} 4$} & \multicolumn{2}{|c|}{$\mathrm{CO} 2$} & \multicolumn{2}{|c|}{ co } & \multicolumn{2}{|c|}{ H2 } & \multicolumn{2}{|c|}{ H2O } & \multicolumn{2}{|c|}{ HCHO } & \multicolumn{2}{|c|}{ NO2 } & \multicolumn{2}{|c|}{ No } & \multicolumn{2}{|c|}{03} & \multicolumn{2}{|c|}{ so2 } & \multicolumn{2}{|c|}{ TOL } & \multicolumn{2}{|c|}{ TEMPERATURE } \\
\hline & $\begin{array}{l}\text { Min } \mathrm{CH} \text {, } \\
\text { PPBV }\end{array}$ & $\begin{array}{c}\operatorname{Max} \mathrm{CH} 4, \\
\text { PPBV }\end{array}$ & $\begin{array}{l}\text { Min co2, } \\
\text { PPBV }\end{array}$ & $\begin{array}{c}\text { Max Co2, } \\
\text { PPBV }\end{array}$ & $\begin{array}{l}\text { Min Co, } \\
\text { PPBV }\end{array}$ & $\begin{array}{c}\text { Max co, } \\
\text { PPBV }\end{array}$ & $\begin{array}{l}\text { Min H2, } \\
\text { PPBV }\end{array}$ & $\begin{array}{c}\text { Max H2, } \\
\text { PPBV }\end{array}$ & $\begin{array}{c}\text { Min H2O, } \\
\text { PPBV }\end{array}$ & $\begin{array}{l}\text { Max H2O, } \\
\text { PPBV }\end{array}$ & $\underset{\text { PPBV }}{\text { Min HCHO, }}$ & $\begin{array}{c}\text { Max HCHO, } \\
\text { PPBV }\end{array}$ & \begin{tabular}{|c} 
Min NO2, \\
PPBV
\end{tabular} & $\begin{array}{c}\text { Max NO2, } \\
\text { PPBV }\end{array}$ & $\begin{array}{l}\text { Min NO, } \\
\text { PPBV }\end{array}$ & $\begin{array}{c}\text { Max NO, } \\
\text { PPBV }\end{array}$ & $\begin{array}{l}\text { Min O3, } \\
\text { PPBV }\end{array}$ & $\begin{array}{l}\text { Max O3, } \\
\text { PPBV }\end{array}$ & $\begin{array}{l}\text { Min SO2, } \\
\text { PPBV }\end{array}$ & $\begin{array}{l}\text { Max SO2, } \\
\text { PPBV }\end{array}$ & $\begin{array}{l}\text { Min TOL, } \\
\text { PPBV }\end{array}$ & $\begin{array}{l}\text { Max TOL, } \\
\text { PPBV }\end{array}$ & Min TEMP & Max TEMP \\
\hline & -10.1 & 4.04 & \begin{tabular}{|l|}
-2090 \\
\end{tabular} & & -4.73 & & -1.12 & 3.28 & -8440 & 158 & -0.001082 & \begin{tabular}{|l|}
0.000773 \\
\end{tabular} & -0.000239 & 0.00987 & -0.0000396 & & -24.1 & 27.6 & -0.002455 & 0.000487 & 0 & 0.001002 & -0.16 & 0.09 \\
\hline-82 & -9.6 & 3.99 & -2140 & -30 & -4.63 & 0.187 & -1.66 & 3.3 & -179200 & 10900 & -0.005212 & 0.000797 & -0.000249 & 0.0104 & -0.00003755 & 0.0435 & -25.6 & 30.9 & -0.004697 & 0.000511 & 7.989E-09 & 0.001029 & -3.66 & 0.05 \\
\hline-78 & -8.9 & 3.81 & 2090 & -30 & -4.36 & 0.186 & -2.14 & 3.37 & -10700 & 54200 & -0.001298 & 0.000828 & -0.00026 & 0.01117 & -0.00011394 & 0.0372 & -29.3 & 35.1 & $-3.92 \mathrm{E}-03$ & 0.000516 & $5.292 \mathrm{E}-09$ & 0.00108 & -0.16 & 0.5 \\
\hline-74 & -9.5 & 3.75 & -2110 & -30 & -4.27 & 0.189 & -2.4 & 3.46 & -300 & & -0.001104 & 0.000924 & -0.0001839 & 0.0135 & -0.00024639 & 0.03324 & -34.2 & 40 & -0.004172 & 0.000562 & $2.787 \mathrm{E}-09$ & 0.00115 & -0.2 & \\
\hline-70 & -10.5 & 3.8 & -2120 & -40 & -4.37 & 0.187 & -2.63 & 3.46 & -1860 & 149200 & -0.00131 & 0.000939 & -0.0006926 & 0.01579 & -0.0003727 & 0.02938 & -39.9 & 46.8 & -0.002046 & 0.000604 & 1.2219E-09 & 0.001146 & -0.22 & 0.82 \\
\hline-66 & -13.7 & 3.81 & -2140 & -40 & -4.65 & 0.171 & -3.93 & 3.51 & -7700 & 21900 & -0.00144 & 0.000977 & -0.0001793 & 0.01717 & -0.0000483 & 0.02621 & -46.1 & 59.5 & -0.002047 & 0.000644 & $4.268 \mathrm{E}-10$ & 0.001158 & -0.39 & 0.3 \\
\hline-62 & -21.4 & 3.81 & -2150 & -40 & -6.06 & 0.154 & -6.21 & 3.65 & -4540 & 58500 & -0.00146 & 0.001003 & -0.0004377 & 0.01706 & -0.0002963 & 0.02282 & -52.1 & 75.5 & -0.001501 & 0.000665 & $1.0003 E-10$ & 0.001225 & -0.14 & 0.39 \\
\hline-58 & -31.4 & 3.7 & -2530 & -40 & -7.82 & 0.149 & -9.39 & 3.72 & -12000 & 50 & -0.00185 & 0.001005 & -0.0003199 & 0.01737 & -0.0000892 & 0.02094 & -57 & 95.3 & -0.000441 & 0.000633 & -0.00000101 & 0.001316 & -0.13 & 0.47 \\
\hline-54 & -40.8 & 3.42 & -2950 & -40 & -9.75 & 0.1399 & -12.5 & 3.68 & -45500 & 42.8 & -0.00278 & 0.000968 & -0.0004589 & 0.01715 & -0.0001244 & 0.01919 & -63 & 130.9 & -0.000367 & 0.000684 & -0.00001434 & 0.00151 & -0.17 & 0.49 \\
\hline-50 & -47.19 & 3.08 & -3210 & -40 & -10.85 & 0.1103 & -13.96 & 3.77 & -67800 & 39.1 & -0.00394 & 0.000937 & -0.0003 & 0.01691 & -0.0001364 & 0.01806 & -68 & 160 & -0.00055 & 0.000776 & -0.0000287 & $1.76 E-03$ & -0.22 & 0.54 \\
\hline-46 & -49.7 & 2.69 & -3360 & -40 & -11.08 & 0.0945 & -12.56 & 3.91 & -86000 & 35.7 & -0.00476 & 0.000884 & -0.0002858 & 0.01685 & -0.0001065 & 0.01735 & -71 & & -0.000329 & 0.000831 & -0.00002683 & $1.65 E-03$ & -0.22 & 0.51 \\
\hline-42 & -41.7 & 2.4 & -3080 & -40 & -10.24 & 0.0852 & -10.3 & 4.16 & -93000 & 4000 & -0.00487 & 0.000819 & -0.001654 & 0.01688 & -0.000275 & 0.0169 & -72.2 & 143.5 & -0.00031 & 0.000964 & -0.0000099 & $1.32 E-03$ & & \\
\hline-38 & -27.7 & 2.16 & -2690 & -40 & -8.46 & 0.0716 & -7.47 & 4.38 & -45000 & 4400 & -0.00527 & 0.000753 & -0.00171 & 0.01731 & -0.0005122 & 0.01634 & -67 & 116.6 & -0.000128 & 0.001149 & 0.000000551 & $1.60 \mathrm{E}-03$ & & \\
\hline-34 & -19.9 & 2.02 & -2540 & -40 & -7.4 & 0.0635 & -6.29 & 4.52 & -55900 & 37.7 & -0.00567 & 0.000702 & -0.002487 & 0.0174 & -0.001179 & 0.01569 & -67 & 105.1 & -0.000098 & 0.00302 & 0.000000706 & $1.06 E-03$ & -0.11 & 0.33 \\
\hline-30 & -19.97 & 1.94 & -2470 & -40 & -6.9 & 0.0602 & -6.6 & 4.59 & -61400 & 26000 & -0.00827 & 0.000661 & -0.00267 & 0.01742 & -0.000721 & 0.0149 & -65 & 89.2 & -0.000085 & 0.0057 & -0.000000975 & $9.52 E-04$ & -0.14 & 0.28 \\
\hline-26 & -21.46 & 1.95 & -2400 & -40 & -6.53 & 0.0596 & -6.51 & 4.63 & - 77700 & 29000 & -0.01008 & 0.000616 & -0.001194 & 0.01738 & -0.0006552 & 0.01447 & -61 & 65.5 & -0.000084 & 0.01491 & -0.000000891 & $8.89 E-04$ & -0.14 & 0.22 \\
\hline-22 & -21.03 & 2.06 & -2320 & -40 & -6.62 & 0.0594 & -6.51 & 4.69 & -67000 & 35000 & -0.00748 & 0.000615 & -0.001288 & 0.01717 & -0.000619 & 0.01362 & -55 & 48.5 & -0.000104 & & -0.000001061 & $1.07 E-03$ & -0.12 & 0.19 \\
\hline-18 & -20 & 2.12 & -2290 & -40 & -7.01 & 0.0588 & -6.96 & 4.78 & -68000 & 28 & -0.0054 & 0.000578 & -0.00261 & 0.01701 & -0.000972 & 0.01351 & -48 & 30.2 & -0.000134 & 0.00919 & -0.000001027 & $6.63 E-04$ & -0.11 & 0.16 \\
\hline-14 & -19.7 & 2.02 & -2300 & -40 & -7.24 & 0.06 & -7.01 & 4.85 & -85000 & 27.1 & -0.00436 & 0.000546 & -0.000907 & 0.0166 & -0.0005809 & 0.0133 & -41 & 18.5 & $-1.83 E-04$ & 0.00376 & -0.000001559 & $8.08 E-04$ & -0.13 & 0.13 \\
\hline-10 & -20.16 & 1.81 & -2350 & -40 & -7.31 & 0.064 & -7.8 & 4.91 & -64000 & 25.8 & -0.0084 & 0.000491 & -0.001449 & 0.0169 & -0.0004457 & 0.01375 & -42.4 & 12.8 & $-2.32 E-04$ & 0.00375 & -0.00000261 & $7.66 E-04$ & -0.17 & 0.12 \\
\hline-6 & -22.31 & 1.52 & -2410 & -50 & -8.11 & 0.066 & -8.74 & 4.99 & -67000 & 25 & -0.0215 & 0.000441 & -0.0009 & 0.01768 & -0.0004814 & 0.01429 & -53 & 6.4 & -0.000281 & 0.000888 & 0.00000719 & $8.96 E-04$ & -0.21 & 0.12 \\
\hline-2 & -23.4 & 1.32 & -2450 & -50 & -8.62 & 0.07 & -9.32 & 5.08 & -64000 & 23.7 & -0.0171 & 0.000385 & -0.00114 & 0.01816 & -0.0006423 & 0.01489 & -68.3 & 3.1 & $-3.14 \mathrm{E}-04$ & 0.000819 & 0.00001126 & $1.17 \mathrm{E}-03$ & -0.22 & 0.1 \\
\hline 2 & -23.86 & 1.11 & -2480 & -50 & -8.65 & 0.072 & -10.28 & 5.4 & -72000 & 23.3 & -0.0115 & 0.000356 & -0.000989 & 0.0182 & -0.0008178 & 0.01503 & -76 & 1.7 & $-3.48 E-04$ & 0.000869 & -0.0000115 & $1.67 E-03$ & -0.2 & 0.1 \\
\hline 6 & -24 & 0.93 & -2450 & -50 & -8.6 & 0.07 & -10.04 & 5.91 & -78000 & 22.6 & -0.0042 & & -0.000406 & 0.01771 & -0.001214 & 0.01463 & -76.6 & 0.9 & -0.000386 & 0.002892 & -0.00000812 & $3.17 \mathrm{E}-03$ & -0.17 & 0.09 \\
\hline 10 & -21.7 & 0.77 & -2450 & -50 & -7.69 & 0.068 & -9.49 & 6.39 & -74000 & 20.7 & -0.00433 & 0.000278 & -0.00255 & 0.01714 & -0.00173 & 0.01445 & -71.9 & 2.8 & -0.000414 & 0.002329 & -0.000004 & 4.06E-03 & -0.16 & 0.07 \\
\hline 14 & -19.4 & 0.57 & -2520 & -50 & -7.14 & 0.066 & -8.92 & 7.09 & -78000 & 16.3 & -0.0237 & 0.000207 & -0.00217 & 0.01654 & -0.00228 & 0.01449 & -63.4 & 2.3 & -0.000425 & 0.00314 & -0.00000385 & $2.33 E-03$ & -0.14 & 0.07 \\
\hline 18 & -17.3 & 0.41 & -2660 & -50 & -7.47 & 0.063 & -8.26 & 7.63 & -52000 & 12.4 & -0.0253 & 0.000159 & -0.00349 & 0.01615 & -0.002983 & 0.01445 & -48.7 & -0.301 & -0.000425 & 0.002004 & -0.000000671 & $3.09 E-03$ & -0.16 & 0.03 \\
\hline 22 & -16.1 & 0.28 & -2740 & -50 & -7.99 & 0.06 & -7.67 & 7.98 & -21000 & 16000 & -0.0262 & 0.000149 & -0.00379 & 0.01642 & -0.002972 & & -42 & -0.402 & -0.000695 & 0.00225 & -0.00000583 & $4.46 E-03$ & -0.16 & 0.04 \\
\hline 26 & -16.16 & 0.14 & -2820 & -50 & -8.23 & $0.05 \varepsilon$ & -6.62 & 8.3 & -18500 & 33000 & -0.0202 & 0.000112 & -0.003989 & 0.01695 & -0.002211 & 0.0148 & -41 & -0.44 & -0.000412 & 0.009 & 0.00000624 & $6.89 \mathrm{E}-03$ & -0.14 & 0.05 \\
\hline 30 & -14.69 & 0 & -2810 & -60 & -8.6 & 0.061 & -5.96 & 8.52 & -18900 & 35000 & -0.02821 & 0.000085 & -0.00749 & 0.01713 & -0.003835 & 0.0146 & -38 & -0.45 & -0.001294 & 0.009 & .00000453 & $6.89 \mathrm{E}$ & -0.12 & 0.05 \\
\hline 34 & -13.17 & -0.07 & -2850 & -60 & -8.94 & 0.067 & -6.08 & 8.84 & -29000 & 7000 & -0.0613 & 0.000041 & -0.007268 & 0.01748 & -0.004181 & 0.0148 & -40.2 & 2 & -0.000052 & 0.0017 & & $6.34 \mathrm{E}$ & -0.12 & 0.06 \\
\hline 38 & - 14.42 & 0.2 & -2900 & -60 & -9.14 & 0.073 & -5.92 & & -52000 & 6.1 & -0.0585 & 0.000031 & -0.02425 & 0.01841 & -0.01237 & 0.01494 & -40.9 & 2.3 & -0.00217 & 0.000376 & -0.00000215 & 7.37E-03 & -0.17 & 0.06 \\
\hline 42 & -16.7 & 0.3 & -2990 & -60 & -9.32 & 0.081 & -6.26 & 9.02 & -81000 & 6 & -0.0611 & 0.00006 & -0.01745 & 0.02048 & -0.009977 & 0.01537 & -47 & -0.6 & -0.001829 & 0.000427 & -0.00000186 & 7.43E-03 & -0.22 & 0.13 \\
\hline 46 & -18.6 & 3.1 & -2990 & -60 & -9.35 & 0.086 & -6.77 & 8.88 & -61000 & 6.1 & -0.0635 & 0.000118 & -0.02248 & 0.02369 & -0.011736 & 0.01661 & -54.7 & -0.617 & -0.001037 & 0.000296 & -0.00000347 & $7.23 E-03$ & -0.27 & 0.19 \\
\hline 50 & -16.48 & & -3020 & -60 & -9.41 & 0.092 & -6.42 & 8.9 & -52000 & 6.5 & -0.0626 & 0.000076 & -0.02202 & 0.02675 & -0.010556 & 0.01893 & -59.6 & -0.637 & -0.002967 & 0.000183 & -0.00000156 & $7.03 E-03$ & -0.3 & 0.19 \\
\hline 54 & -15.41 & 3.9 & -3040 & -60 & -9.33 & 0.088 & -6.03 & 8.92 & -71700 & 6.8 & -0.0702 & 0.000028 & -0.02302 & 0.02944 & -0.008422 & 0.02126 & -64.2 & -0.61 & -0.001434 & 0.000112 & 0000089 & $7.96 E-03$ & -0.35 & 0.12 \\
\hline 58 & -13.7 & 1.9 & -3040 & -60 & -9.43 & & -6.19 & 9.04 & - 1208000 & 6.2 & -0.0776 & -0.0000222 & -0.02027 & & -0.0027 & 0.02248 & -62.5 & -0.6 & -0.000541 & 0.000009 & 0000424 & & & \\
\hline 62 & -14.85 & 0.28 & -3010 & -70 & -9.76 & & -6.2 & 9.0 & -1466 & 3.1 & -0.08 & & -0.02092 & 0.03018 & & & -64. & & & & & & & 4 \\
\hline 66 & -13.52 & 0.22 & -3030 & -70 & -10.39 & & -5.94 & 9.17 & & -3.5 & -0.08 & & -0.07265 & & & & -72.6 & -0.67 & & & & $9.84 \mathrm{E}$ & -0.52 & 0.02 \\
\hline 70 & -11.09 & -0.05 & -2970 & -70 & -10.23 & 0.006 & -5.53 & 9.1 & -82200 & -14.7 & -0.0556 & -0.0000603 & -0.02344 & 0.02519 & -0.002895 & 0.01195 & -82.3 & -0.725 & -0.001571 & -0.0000746 & -0.0000251 & $1.04 E-02$ & -0.62 & -0.09 \\
\hline 74 & -9.19 & -0.03 & -2950 & -70 & -10.65 & 0.0011 & -4.68 & 9.04 & -74700 & -29.2 & -0.0423 & -0.0000855 & -0.00358 & 0.01939 & -0.001633 & 0.01045 & -82 & -0.752 & -0.001456 & 0.000035 & -0.0000127 & $1.10 \mathrm{E}-02$ & -0.63 & -0.03 \\
\hline 78 & -7.53 & 0.4 & -3030 & -70 & -10.53 & -0.0026 & -3.94 & 9.08 & -217400 & -43.5 & -0.03331 & -0.000101 & -0.002181 & 0.0158 & -0.0003439 & 0.01036 & -77.5 & 5.3 & $-2.08 E-04$ & 0.000185 & -0.00001152 & & -1.53 & -0.09 \\
\hline 82 & -6.91 & 1 & -2910 & .70 & -10.16 & -0.0007 & -3.43 & 9.07 & -135100 & -50.5 & -0.03043 & -0.000118 & -0.002903 & 0.01574 & -0.0006098 & 0.01056 & -71.11 & 10.4 & $-2.18 \mathrm{E}-04$ & 0.000261 & -0.00001357 & 1.04E-02 & -1.31 & -0.07 \\
\hline 86 & -6.8 & 0.36 & -2860 & -70 & -10.36 & -0.0012 & -3.24 & 9 & -70900 & 8900 & -0.02575 & -0.000083 & -0.001633 & 0.01728 & -0.00011336 & 0.00987 & -68.1 & 10.9 & $-2.66 \mathrm{E}-04$ & 0.0001197 & -0.00001706 & $1.03 E-02$ & -0.72 & 0.02 \\
\hline & $\begin{array}{c}-46 \text { o, lat - } \\
>-49.7\end{array}$ & $\begin{array}{l}0, \text { lat } \\
\text { 4.4. }\end{array}$ & $\begin{array}{l}-46 \text { o, lat - } \\
>-3360\end{array}$ & $\begin{array}{l}60 \text {, lat } \\
>0\end{array}$ & $\begin{array}{r}-46 \text { o, lat }-> \\
-11.08\end{array}$ & $\begin{array}{l}60 \text { o lat - }-> \\
0.198\end{array}$ & $\begin{array}{c}-50 \text { o, lat - } \\
-13.96\end{array}$ & $\begin{array}{l}\text { o, lat } \\
9.26\end{array}$ & $\begin{array}{l}78 \text { o, lat }->- \\
217400-\end{array}$ & 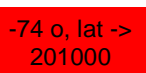 & $\begin{array}{c}66 \text { o, lat - }- \\
0.0859\end{array}$ & $\begin{array}{c}60, \text { lat }-\rightarrow \\
0.0086\end{array}$ & $\begin{array}{c}66 \text { o, lat }->- \\
0.07265\end{array}$ & $\begin{array}{l}8.03173 \\
0.03173\end{array}$ & $\begin{array}{c}66 \text { o, lat } \rightarrow>- \\
0.02341\end{array}$ & $\begin{array}{l}60.0481- \\
0.048\end{array}$ & 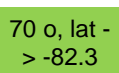 & 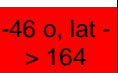 & $\begin{array}{r}-82 \text { o, lat - } \rightarrow- \\
0.004697\end{array}$ & $\begin{array}{c}22, \text { alat- } \\
0.0175\end{array}$ & $\begin{array}{c}-50 \text { o , lat } \rightarrow>- \\
2.87 \mathrm{e}-005\end{array}$ & $\begin{array}{c}78, \text { o, lat }->> \\
0.01134\end{array}$ & $\begin{array}{l}82 \text { o, lat }> \\
3.66->\end{array}$ & $\begin{array}{l}0 . \text { lat } \\
1.87\end{array}$ \\
\hline
\end{tabular}




\subsection{Estimation of Global Effects of $\mathrm{H}_{2}$ Economy}

The GATOR-GCMOM model used the emissions data discussed in Section 2.2 and other information on land use, soil and vegetation characteristics, and meteorology to predict the atmospheric concentrations of GHGs, $\mathrm{H}_{2}$, VOCs, and particulates across the globe on a $4^{\circ} \mathrm{S}-\mathrm{N}$ by $5^{\circ} \mathrm{W}$-E grid basis from the ground surface to an altitude of $60 \mathrm{~km}$. Vertically, the model is divided into 47 layers, which span the troposphere and stratosphere. The model includes chemical and photolytic processes for gases, aerosols, and hydrometeor distributions, as described in Section 2.1. The model allows for hydrogen leakage into the stratosphere and reaction with hydroxyl radicals, other chemicals, and polar ice. The model then predicts the concentrations of GHGs, $\mathrm{H}_{2}$, VOCs, and particulates in the atmosphere after 10 years for the 2050 A1B base case and the 2050A1B case with SHFCVs. The changes in these two cases after 10 years are then computed. Model results are presented as the change between the two cases in the near surface atmospheric concentrations as a function of latitude and longitude and as vertical profiles from the surface to $60 \mathrm{~km}$ as a function of latitude. The profile plots (e.g., Figure 2-7a) are used to determine the effect of the hydrogen economy on ozone in the troposphere and stratosphere and changes in concentrations of GHGs that could influence climate (see Appendix E). 



\section{EMISSIONS INPUT AND ESTIMATED CHANGES}

\subsection{Introduction}

Emissions data are key inputs to GATOR-GCMOM. The scenarios simulated for this project with this model included a 2000 base case, a 2050 A1B base case, a 2050 A1B case with hydrogen fuel cell vehicles where the hydrogen fuel is generated using steam-reforming of natural gas, and a contemporary case with HFCVs where the hydrogen was generated by windpowered electrolysis. This section describes the emission scenarios developed for the Intergovernmental Panel on Climate Change (IPCC), the underlying factors that influence the projected emissions, the rationale for selecting the A1B scenario for these simulations, the emissions data for 2000 and the 2050 A1B cases, and how the emissions were adjusted to represent a 2050 A1B case with HFCVs.

The steps required to parameterize the emission inputs to GATOR-GCMOM, described in this section, include:

- Compile emissions data for selected scenario by region for 2000 and 2050 A1B case

- Develop emission growth factors for change from 2000 to 2050 A1B case

- Use GREET model to estimate emission changes from fossil fuel vehicles to HFCVs

- Use SPECIATE model to subdivide total VOCs into specific compounds

- Develop emission growth factors for change from 2000 to 2050 with HFCVs

- Use growth factors to scale region emissions to global grid basis used in model.

The emission growth factors and total global emissions of key constituents for the 2000 and 2050 cases are compared in this section and key assumptions are discussed.

The GATOR-GCMOM model simulates a large number of processes and climate feedbacks, as described in Section 2. The complexity of the model limits the number of scenarios that can be evaluated, and only one set of 2050 scenarios was simulated for this project. The steam-methane reforming (SMR) process using natural gas was selected as the method for generating the hydrogen fuel for the 2050 A1B case with HFCVs. The SMR method was selected, since it is currently used in existing refineries to generate hydrogen, and thus is the most likely method to be used in the future. However, the emissions associated with multiple population - growth and energy-use scenarios were estimated to provide a comparison to the 2050 A1B scenario that was selected for the detailed analyses. Sensitivity analyses were conducted using the GREET model to evaluate differences in emission estimates when other methods for generating hydrogen fuel for the vehicles were used. Additional sensitivity analyses were conducted for the US to evaluate the effect on emissions of alternative energy sources for electricity and of different types of 
vehicles. Simulations were also made to estimate the effect of shifting to HFCVs in six other countries using a combination of methods of generating hydrogen. Findings from the GREET simulations are discussed with respect to the general applicability of the GATOR-GCMOM results and the sensitivity analyses.

\subsection{SRES Scenarios and Emission Estimates}

In 1996, the Plenary of the Intergovernmental Panel on Climate Change (IPCC) requested development of a Special Report on Emissions Scenarios (SRES) and a series of scenario families incorporating a wide range of driving factors from 1990 to 2100 (IPCC, 2000). Four storylines were developed referred to as the A1, A2, B1, B2 families. The A1 family was further subdivided into three scenario groups, the A1FI, A1T, and A1B. For each of these groups plus the other families, a total of 40 scenarios were developed for use in global climate models. The intent was to provide scenarios where some factors were kept constant such as population growth, but other factors such as technology development were varied. For example, the A1 and B1 scenarios used the same population growth projections, but different proportions of energy sources. Within the A1 family, the A1FI scenario assumed a primary dependence on fossil fuels, while the A1T scenario assumed a more renewable energy-based supply and the A1B scenario used a balanced mix with respect to energy sources. These three scenarios predicted increased economic growth and reduced differences in per capita income, relative to other scenario families such as the slower economic growth and larger regional differences of the A2 family.

The main driving forces that influence greenhouse gas (GHG) emissions and sulfur emissions were projected at ten-year intervals from 1990 to 2100, although the base year for the population projection was 1995. The main driving forces were considered to be: population, gross domestic product ( $\$ / \mathrm{yr}$ ), per capita income (for developed countries and for economies in transition to developing countries) and the rate and type of technological changes (IPCC, 2000). The major secondary factors were considered to include: energy intensity, primary energy used, share of coal used for primary energy, and share of zero carbon for primary energy used (IPCC, 2000). Land uses, particularly the amount of land used for agriculture and food production, were also considered.

The original SRES scenarios divided the world into only four regions. Later, the SRES scenarios were downscaled into regions and countries for use by seven different global climate modeling groups. The use of multiple groups to downscale the data resulted in minor differences between these separate downscaled data sets, since some of the modeling groups used a different number of regions and countries. The data used in GATOR-GCMOM for this project were obtained from the Integrated Model to Assess the Global Environment (IMAGE) 2.2 from the National Institute for Public Health and the Environment Research for Man and Environment (RIVM) in Bilthoven, The Netherlands. The IMAGE modelers downscaled the world data for population, other driving forces, and emissions into 17 regions (IMAGE Team, 2001). The 17 regions used in GATOR-GCMOM are listed below; three of the regions are distinct countries (Figure 3-1):

1. Canada

2. USA

3. Central America

4. South America

5. Northern Africa

6. Western Africa 
7. Eastern Africa

8. Southern Africa

9. OECD Europe

10. Eastern Europe

11. Former USSR

12. Middle East

13. South Asia

14. East Asia

15. South East Asia

16. Oceania

17. Japan

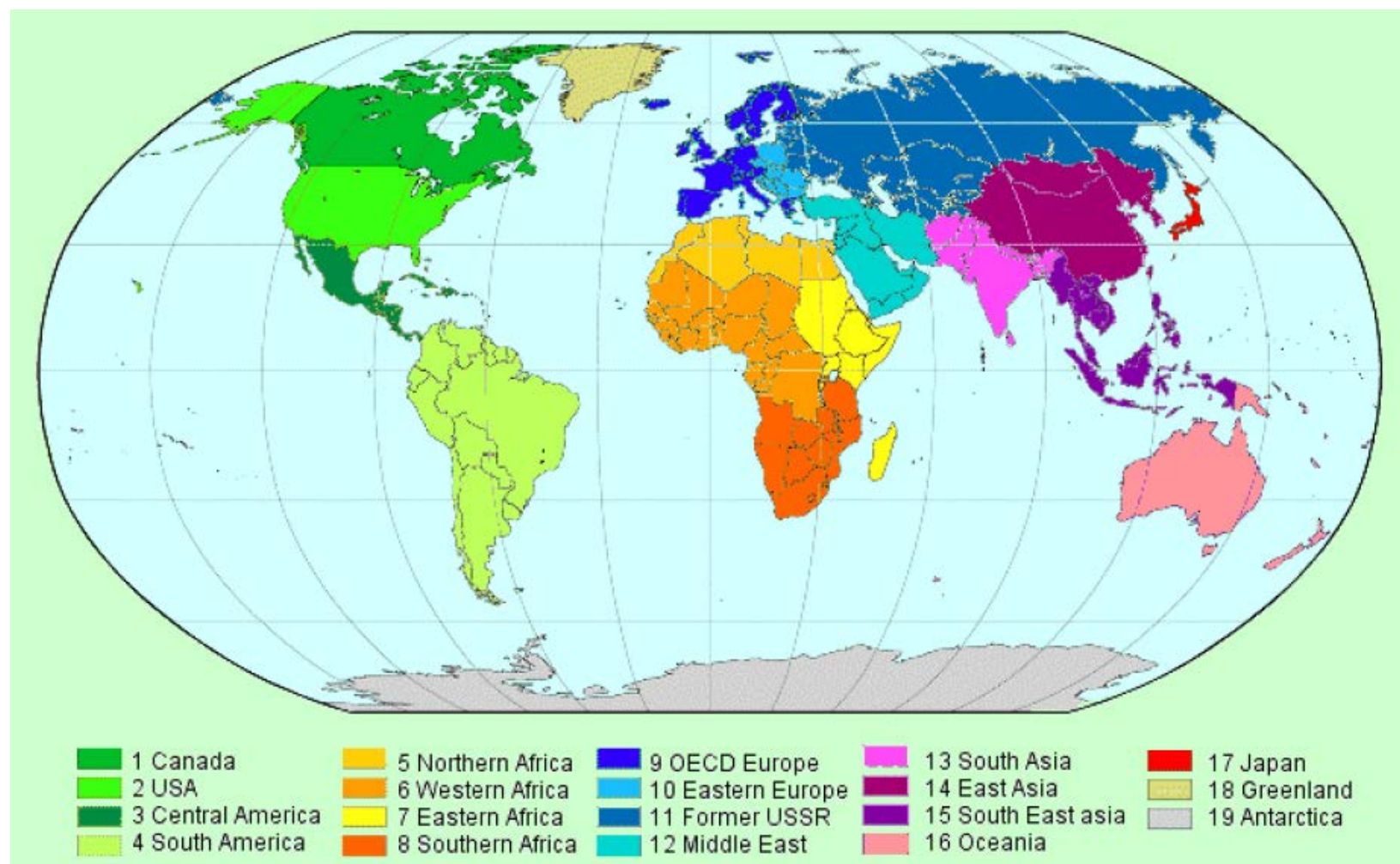

Figure 3-1 Map showing the 17 regions used by the IMAGE 2.2 modeling group and Greenland and Antarctica (IMAGE Team, 2001).

Two additional regions Greenland and Antarctica are included in Figure 3-1, but were not simulated in GATOR-GCMOM. The regions were also downscaled into a total of 224 countries, but this detailed data set was not used in the GATOR-GCMOM model for this project.

The methods used for downscaling to region, country, and global grids were described in a report by van Vuuren et al., 2006. The population and economic data were also downscaled to a $0.5^{\circ}$ by $0.5^{\circ}$ global grid basis (e.g. CIESIN, 2003). The population projections to 2100 for the A1-B1 SRES scenarios were made by the International Institute for Applied Systems Analysis (IIASA) based on data for 1995 and used a rapid fertility transition projection that had low fertility and low mortality rates (Lutz, 1996), which resulted in an estimated population of 8.7 billion people in 2050. The A2 SRES scenario had high fertility and high mortality rates with an estimated 
population in 2050 of 11.2 billion people. Technological change and economic growth in the A2 scenario were projected to be slower than in the other scenarios, and more heterogeneous among the regions. The original population projections by IIASA were estimated for 13 regions, as described in a summary of the projections (IIASA, 2007). The results were then downscaled to country level based on the latest year with data for a given country and the closest United Nations 2000 Revision of population projections to a given SRES scenario. The country level SRES A1 and B1 scenarios used the UN medium variant that estimated a 2050 population in the world of 9.3 billion, compared to the regional SRES projection for the A1 and B1 scenarios of 8.7 billion in 2050 . The UN country age-specific populations were used to estimate an age structure at 5-year intervals from 1990 to 2050. After 2050, the age group shares of each country were kept constant out to 2100. The detailed population projections made for the SRES by IIASA were provided for 5-year intervals by age group in each region for 1995 to 2100 . As an example, the projected population data for the 17 regions used by the IMAGE 2.2 modeling group and for the GATOR-GCMOM modeling are shown in Table 3-1 for the years 2000 to 2050. While the total population for the world in 2050 was the same as the IMAGE 2.2 data set, there were differences between the datasets due to downscaling to varying numbers of regions and countries.

The key economic driving force that influences GHG emissions was considered to be gross domestic product (GDP) per capita income. The IMAGE model used GDP data from 1995, expressed in constant US\$, from the World Bank’s World Development Indicators (World Bank, 2004). These data were then downscaled to the country and grid level making sure that the regional totals were the same as in the original projections. The A1 scenarios had higher annual per capita income growth rates among the countries (2-8\%) than the A2 scenarios (1-6\%) (van Vuuren, 2006). The GDP per capita income for the 17 regions is shown in Table 3-2 from 2000 to 2050 .

Energy sources and technology changes were considered to be an important influence on emissions. The A1B scenario used a mix of primary fuel sources with technological improvement for all types of energy supply and end uses (IPCC, 2000). The A2 scenario assumed less economic growth and more fragmented technological change. The B1 scenario used the same population as the A1B scenario but was less material and energy intensive. The B2 scenario assumed a smaller population than A2, an intermediate level of economic development and more emphasis on environmental protection and social equity. The major factors related to energy and land uses for the composite A1 IMAGE scenario are listed in Table 3-3 for the world from 2000 to 2050. Energy use and sources between the six scenario families are compared in Table 3-4. There were some differences between the data sets due to handling of non-commercial renewable energy and rounding. The A1B scenario used more energy than the A1T, A2, B1 or B2 scenarios, but less than the A1F1 scenario. By 2050, the A1B scenario used less coal than the B1 or A2 scenarios, and more renewable energy. The A1B scenario represented a middle ground between the coal-intensive A1F1 scenario and the renewableintensive A1T scenario. 
Table 3-1
Population by Regions Used by the IMAGE 2.2 Modeling Group

\begin{tabular}{|c|c|c|c|c|c|c|c|c|c|c|c|c|c|c|c|c|c|}
\hline Year & Canada & USA & $\begin{array}{l}\text { Central } \\
\text { America }\end{array}$ & $\begin{array}{c}\text { South } \\
\text { America }\end{array}$ & $\begin{array}{c}\text { Northern } \\
\text { Africa }\end{array}$ & $\begin{array}{c}\text { Western } \\
\text { Africa }\end{array}$ & $\begin{array}{c}\text { Eastern } \\
\text { Africa }\end{array}$ & $\begin{array}{c}\text { Southern } \\
\text { Africa }\end{array}$ & $\begin{array}{l}\text { OECD } \\
\text { Europe }\end{array}$ & $\begin{array}{l}\text { Eastern } \\
\text { Europe }\end{array}$ & $\begin{array}{c}\text { Former } \\
\text { USSR }\end{array}$ & Middle East & South Asia & East Asia & $\begin{array}{l}\text { South East } \\
\text { Asia }\end{array}$ & Oceania & Japan \\
\hline 2000 & $3.08 \mathrm{E}+07$ & $2.80 \mathrm{E}+08$ & $1.73 E+08$ & $3.45 \mathrm{E}+08$ & $1.47 \mathrm{E}+08$ & $3.25 \mathrm{E}+08$ & $1.98 \mathrm{E}+08$ & $1.55 E+08$ & $3.93 E+08$ & $1.22 \mathrm{E}+08$ & $2.96 \mathrm{E}+08$ & $2.45 \mathrm{E}+08$ & $1.36 \mathrm{E}+09$ & $1.38 \mathrm{E}+09$ & $5.10 \mathrm{E}+08$ & $2.94 \mathrm{E}+07$ & $1.28 \mathrm{E}+08$ \\
\hline 2005 & $3.21 \mathrm{E}+07$ & $2.91 \mathrm{E}+08$ & $1.85 \mathrm{E}+08$ & $3.69 \mathrm{E}+08$ & $1.64 \mathrm{E}+08$ & $3.71 E+08$ & $2.26 \mathrm{E}+08$ & $1.77 E+08$ & $4.00 \mathrm{E}+08$ & $1.23 E+08$ & $2.99 \mathrm{E}+08$ & $2.73 E+08$ & $1.48 \mathrm{E}+09$ & $1.42 \mathrm{E}+09$ & $5.38 \mathrm{E}+08$ & $3.04 \mathrm{E}+07$ & $1.31 \mathrm{E}+08$ \\
\hline 2010 & $3.33 \mathrm{E}+07$ & $3.03 E+08$ & $1.97 E+08$ & $3.93 E+08$ & $1.81 \mathrm{E}+08$ & $4.19 E+08$ & $2.56 \mathrm{E}+08$ & $2.00 E+08$ & $4.06 \mathrm{E}+08$ & $1.24 E+08$ & $3.03 E+08$ & $3.03 E+08$ & $1.59 \mathrm{E}+09$ & $1.45 \mathrm{E}+09$ & $5.66 \mathrm{E}+08$ & $3.13 E+07$ & $1.33 E+08$ \\
\hline 2015 & $3.47 \mathrm{E}+07$ & $3.15 \mathrm{E}+08$ & $2.08 \mathrm{E}+08$ & $4.15 \mathrm{E}+08$ & $1.99 \mathrm{E}+08$ & $4.69 \mathrm{E}+08$ & $2.86 \mathrm{E}+08$ & $2.24 E+08$ & $4.11 \mathrm{E}+08$ & $1.24 E+08$ & $3.07 E+08$ & $3.34 \mathrm{E}+08$ & $1.70 \mathrm{E}+09$ & $1.48 \mathrm{E}+09$ & $5.93 \mathrm{E}+08$ & $3.20 \mathrm{E}+07$ & $1.34 \mathrm{E}+08$ \\
\hline 2020 & $3.60 \mathrm{E}+07$ & $3.27 E+08$ & $2.19 \mathrm{E}+08$ & $4.36 \mathrm{E}+08$ & $2.16 \mathrm{E}+08$ & $5.19 \mathrm{E}+08$ & $3.16 \mathrm{E}+08$ & $2.47 E+08$ & $4.16 \mathrm{E}+08$ & $1.24 E+08$ & $3.09 \mathrm{E}+08$ & $3.65 E+08$ & $1.80 E+09$ & $1.51 \mathrm{E}+09$ & $6.17 E+08$ & $3.26 \mathrm{E}+07$ & $1.35 \mathrm{E}+08$ \\
\hline 2025 & $3.73 \mathrm{E}+07$ & $3.39 \mathrm{E}+08$ & $2.28 \mathrm{E}+08$ & $4.55 E+08$ & $2.32 \mathrm{E}+08$ & $5.65 E+08$ & $3.44 \mathrm{E}+08$ & $2.69 E+08$ & $4.21 \mathrm{E}+08$ & $1.24 \mathrm{E}+08$ & $3.11 E+08$ & $3.95 E+08$ & $1.89 \mathrm{E}+09$ & $1.52 \mathrm{E}+09$ & $6.39 \mathrm{E}+08$ & $3.31 \mathrm{E}+07$ & $1.36 \mathrm{E}+08$ \\
\hline 2030 & $3.86 \mathrm{E}+07$ & $3.50 \mathrm{E}+08$ & $2.36 \mathrm{E}+08$ & $4.70 \mathrm{E}+08$ & $2.47 E+08$ & $6.06 \mathrm{E}+08$ & $3.69 \mathrm{E}+08$ & $2.89 \mathrm{E}+08$ & $4.25 \mathrm{E}+08$ & 1.23E+08 & $3.12 E+08$ & $4.22 \mathrm{E}+08$ & $1.96 \mathrm{E}+09$ & $1.52 \mathrm{E}+09$ & $6.56 \mathrm{E}+08$ & $3.36 \mathrm{E}+07$ & $1.36 \mathrm{E}+08$ \\
\hline 2035 & $3.97 \mathrm{E}+07$ & $3.61 E+08$ & $2.42 \mathrm{E}+08$ & $4.83 \mathrm{E}+08$ & $2.60 \mathrm{E}+08$ & $6.37 E+08$ & $3.89 E+08$ & $3.04 E+08$ & $4.28 \mathrm{E}+08$ & $1.22 \mathrm{E}+08$ & $3.13 E+08$ & $4.45 E+08$ & $2.01 E+09$ & $1.51 \mathrm{E}+09$ & $6.69 \mathrm{E}+08$ & $3.39 \mathrm{E}+07$ & $1.36 \mathrm{E}+08$ \\
\hline 2040 & $4.07 \mathrm{E}+07$ & $3.70 \mathrm{E}+08$ & $2.47 E+08$ & $4.92 \mathrm{E}+08$ & $2.73 E+08$ & $6.68 \mathrm{E}+08$ & $4.07 E+08$ & $3.19 E+08$ & $4.29 \mathrm{E}+08$ & $1.20 \mathrm{E}+08$ & $3.13 E+08$ & $4.68 \mathrm{E}+08$ & $2.06 \mathrm{E}+09$ & $1.49 \mathrm{E}+09$ & $6.78 \mathrm{E}+08$ & $3.41 \mathrm{E}+07$ & $1.36 \mathrm{E}+08$ \\
\hline 2045 & $4.16 \mathrm{E}+07$ & $3.78 \mathrm{E}+08$ & $2.50 \mathrm{E}+08$ & $4.99 \mathrm{E}+08$ & $2.84 \mathrm{E}+08$ & $6.97 \mathrm{E}+08$ & $4.25 \mathrm{E}+08$ & $3.32 \mathrm{E}+08$ & $4.29 \mathrm{E}+08$ & $1.18 \mathrm{E}+08$ & $3.11 \mathrm{E}+08$ & $4.90 E+08$ & $2.09 E+09$ & $1.46 \mathrm{E}+09$ & $6.82 \mathrm{E}+08$ & $3.40 \mathrm{E}+07$ & $1.35 \mathrm{E}+08$ \\
\hline 2050 & $4.23 \mathrm{E}+07$ & $3.85 E+08$ & $2.52 \mathrm{E}+08$ & $5.03 E+08$ & $2.94 \mathrm{E}+08$ & $7.22 \mathrm{E}+08$ & $4.40 \mathrm{E}+08$ & $3.44 \mathrm{E}+08$ & $4.27 \mathrm{E}+08$ & $1.16 \mathrm{E}+08$ & $3.07 E+08$ & $5.10 \mathrm{E}+08$ & $2.11 E+09$ & $1.42 \mathrm{E}+09$ & $6.81 \mathrm{E}+08$ & $3.39 \mathrm{E}+07$ & $1.34 \mathrm{E}+08$ \\
\hline
\end{tabular}


Table 3-2

Gross Domestic Product (GDP) Per Capita Income for 17 Regions used by IMAGE 2-2 Model

\begin{tabular}{|c|c|c|c|c|c|c|c|c|c|c|c|c|c|c|c|c|c|}
\hline Year & Canada & USA & $\begin{array}{c}\text { Central } \\
\text { America } \\
\end{array}$ & $\begin{array}{c}\text { South } \\
\text { America } \\
\end{array}$ & $\begin{array}{c}\text { Northern } \\
\text { Africa }\end{array}$ & $\begin{array}{c}\text { Western } \\
\text { Africa }\end{array}$ & $\begin{array}{c}\text { Eastern } \\
\text { Africa } \\
\end{array}$ & $\begin{array}{c}\text { Southern } \\
\text { Africa }\end{array}$ & $\begin{array}{c}\text { Oecd } \\
\text { Europe }\end{array}$ & $\begin{array}{l}\text { Eastern } \\
\text { Europe }\end{array}$ & $\begin{array}{c}\text { Former } \\
\text { USSR }\end{array}$ & $\begin{array}{c}\text { Middle } \\
\text { East }\end{array}$ & $\begin{array}{l}\text { South } \\
\text { Asia }\end{array}$ & $\begin{array}{l}\text { East } \\
\text { Asia }\end{array}$ & $\begin{array}{c}\text { South East } \\
\text { Asia }\end{array}$ & Oceania & Japan \\
\hline 2000 & 21,152 & 31,210 & 2,801 & 4,518 & 1,289 & 302 & 218 & 1,171 & 23,769 & 3,290 & 1,600 & 3,516 & 422 & 1,778 & 1,502 & 17,187 & 42,385 \\
\hline 2005 & 23,420 & 35,212 & 3,309 & 5,231 & 1,534 & 343 & 254 & 1,262 & 26,462 & 4,088 & 1,981 & 3,985 & 554 & 2,478 & 1,865 & 19,010 & 44,998 \\
\hline 2010 & 25,565 & 38,812 & 4,030 & 6,245 & 1,909 & 420 & 318 & 1,471 & 29,563 & 5,469 & 2,658 & 4,727 & 778 & 3,495 & 2,387 & 20,755 & 47,815 \\
\hline 2015 & 27,555 & 42,343 & 5,019 & 7,626 & 2,424 & 536 & 415 & 1,788 & 32,890 & 7,348 & 3,633 & 5,732 & 1,109 & 4,873 & 3,108 & 22,399 & 50,688 \\
\hline 2020 & 29,712 & 45,756 & 6,335 & 9,438 & 3,130 & 702 & 555 & 2,230 & 36,531 & 9,936 & 4,992 & 7,074 & 1,595 & 6,721 & 4,103 & 24,216 & 53,955 \\
\hline 2025 & 32,456 & 49,190 & 8,052 & 11,764 & 4,084 & 937 & 754 & 2,833 & 40,395 & 13,365 & 6,889 & 8,832 & 2,303 & 9,150 & 5,458 & 26,556 & 57,912 \\
\hline 2030 & 35,821 & 52,704 & 10,300 & 14,762 & 5,372 & 1,270 & 1,039 & 3,654 & 44,332 & 17,703 & 9,455 & 11,128 & 3,272 & 12,211 & 7,165 & 29,454 & 62,476 \\
\hline 2035 & 39,514 & 56,646 & 13,162 & 18,506 & 7,120 & 1,759 & 1,463 & 4,821 & 48,162 & 22,911 & 12,809 & 14,141 & 4,552 & 15,838 & 9,264 & 32,685 & 67,162 \\
\hline 2040 & 43,237 & 61,366 & 16,729 & 23,080 & 9,403 & 2,422 & 2,045 & 6,319 & 52,204 & 28,544 & 17,071 & 17,921 & 6,205 & 20,037 & 11,844 & 36,029 & 71,722 \\
\hline 2045 & 46,926 & 66,823 & 21,066 & 28,521 & 12,325 & 3,274 & 2,805 & 8,133 & 56,880 & 34,401 & 22,220 & 22,558 & 8,282 & 24,836 & 14,944 & 39,444 & 75,988 \\
\hline 2050 & 51,187 & 72,531 & 26,037 & 34,597 & 15,832 & 4,285 & 3,720 & 10,134 & 62,065 & 40,162 & 28,318 & 27,849 & 10,775 & 30,163 & 18,414 & 43,404 & 80,871 \\
\hline
\end{tabular}

Values are expressed in 1995 US $\$$ and have been rounded to nearest whole $\$$.

IMAGE 2.2 Data, 2001RIVM publication 481508018 
Table 3-3

Major Factors Defining IPCC SRES A1 IMAGE Scenario

\begin{tabular}{|c|c|c|c|c|c|c|c|c|}
\hline & & 1990 & 2000 & 2010 & 2020 & 2030 & 2040 & 2050 \\
\hline World Population & Millions & 5,280 & 6,122 & 6,892 & 7,618 & 8,196 & 8,547 & 8,708 \\
\hline \multirow{2}{*}{ GNP/GDP } & Trillion US\$ & 21.0 & 26.7 & 37.9 & 55.9 & 81.2 & 116.2 & 163.5 \\
\hline & 1990 US\$/cap & 3971.0 & 4357.0 & 5503.0 & 7342.0 & 9907.0 & 13598.0 & 18772.0 \\
\hline \multirow[t]{8}{*}{ Final Energy } & EJ & & & & & & & \\
\hline & Non-commercial & 54 & 59 & 65 & 63 & 59 & 50 & 40 \\
\hline & Solids & 43 & 44 & 45 & 52 & 59 & 66 & 69 \\
\hline & Liquids & 106 & 119 & 146 & 177 & 198 & 213 & 209 \\
\hline & Gas & 46 & 55 & 73 & 84 & 90 & 100 & 119 \\
\hline & Electricity & 39 & 55 & 88 & 147 & 220 & 307 & 373 \\
\hline & Others & 2 & 4 & 11 & 29 & 50 & 68 & 85 \\
\hline & Total & 289 & 336 & 429 & 551 & 677 & 804 & 895 \\
\hline \multirow[t]{8}{*}{ Primary Energy } & EJ & & & & & & & \\
\hline & Coal & 105 & 111 & 129 & 170 & 245 & 298 & 301 \\
\hline & Oil & 129 & 143 & 187 & 242 & 285 & 300 & 348 \\
\hline & Gas & 62 & 73 & 117 & 163 & 188 & 222 & 259 \\
\hline & Non-Fossil Electric & 8 & 14 & 23 & 39 & 61 & 91 & 128 \\
\hline & Biomass & 3 & 4 & 12 & 35 & 69 & 102 & 129 \\
\hline & Other Renewables & 61 & 69 & 77 & 76 & 74 & 68 & 59 \\
\hline & Total & 368 & 416 & 544 & 725 & 923 & 1080 & 1224 \\
\hline \multirow[t]{7}{*}{ Land Use } & Million ha & & & & & & & \\
\hline & Cropland & 1435 & 1382 & 1450 & 1524 & 1573 & 1571 & 1530 \\
\hline & Grasslands & 3435 & 3295 & 3313 & 3362 & 3381 & 3271 & 3064 \\
\hline & Energy Biomass & 8 & 10 & 26 & 82 & 177 & 274 & 374 \\
\hline & Forest & 4277 & 4266 & 4224 & 4251 & 4147 & 4132 & 4173 \\
\hline & Others & 3916 & 4119 & 4058 & 3853 & 3793 & 3824 & 3931 \\
\hline & Total & 13071 & 13071 & 13071 & 13071 & 13071 & 13071 & 13071 \\
\hline
\end{tabular}

Cropland is arable land for crops excluding energy crops and grass \& fodder species

Permanent pasture: FAO category 'land for grass \& fodder species'

IPCC SRES Emissions Scenarios - Version 1.1 Appendix I, 2000

Emissions of $\mathrm{CO}_{2}, \mathrm{SO}_{2}, \mathrm{CH}_{4}, \mathrm{~N}_{2} \mathrm{O}, \mathrm{CO}, \mathrm{NO}_{\mathrm{x}}, \mathrm{CFC} / \mathrm{HFC} / \mathrm{HCFC}, \mathrm{PFC}, \mathrm{SF}_{6}$, and NMVOCs were projected for each of the SRES scenarios for the four world regions (IPCC, 2000). Hydrogen emissions were not projected for the SRES scenarios. However, hydrogen emissions can be estimated for fossil fuel-based sources by using a scaling factor in combination with the CO emissions such as described in Barnes et al., 2003 and a method for estimating hydrogen leakage. Estimation of hydrogen emissions for this project is discussed in more detail in Section 2. For $\mathrm{CO}_{2}$, separate projections were made for emissions related to fossil fuels and land uses. The projected emissions for $\mathrm{CO}_{2}$ and the other gases spanned a narrower range up to 2050 then for the future years out to 2100, as shown in Figure 3-2. The SRES emissions data were then downscaled to 17 regions and to the country level by the IMAGE modeling group (van Vuuren, 2006). Grid-based results were also generated. 
Table 3-4

Differences in Energy-related Factors for Six IPCC Scenario Families

\begin{tabular}{|c|c|c|c|c|c|c|c|c|}
\hline Factor & $\begin{array}{c}1990 \\
\text { Base Case }\end{array}$ & Year & A1B & A1F1 & A1T & A2 & B1 & B2 \\
\hline \multirow{2}{*}{ Final Energy Intensity, MJ/US\$ } & \multirow{2}{*}{16.7} & 2020 & 9.4 & 9.4 & 8.7 & 12.1 & 8.8 & 8.5 \\
\hline & & 2050 & 5.5 & 6.3 & 4.8 & 9.5 & 4.5 & 6 \\
\hline \multirow{2}{*}{ Primary Energy, $10^{18} \mathrm{~J} / \mathrm{yr}$} & \multirow{2}{*}{$351^{*}$} & 2020 & 711 & 669 & 649 & 595 & 606 & 566 \\
\hline & & 2050 & 1,347 & 1,431 & 1,213 & 971 & 813 & 869 \\
\hline \multirow{2}{*}{ Percent of Coal as Primary Energy Source } & \multirow{2}{*}{24} & 2020 & 23 & 29 & 23 & 22 & 22 & 17 \\
\hline & & 2050 & 14 & 33 & 10 & 30 & 21 & 10 \\
\hline \multirow{2}{*}{ Percent of Zero Carbon as Primary Energy Source } & \multirow{2}{*}{18} & 2020 & 16 & 15 & 21 & 8 & 21 & 18 \\
\hline & & 2050 & 36 & 19 & 43 & 18 & 30 & 30 \\
\hline
\end{tabular}

*Includes non-commercial energy; IMAGE scenarios do not include non-commercial renewable energy.

IPCC, 2000. Emissions Scenarios Summary for Policymakers.

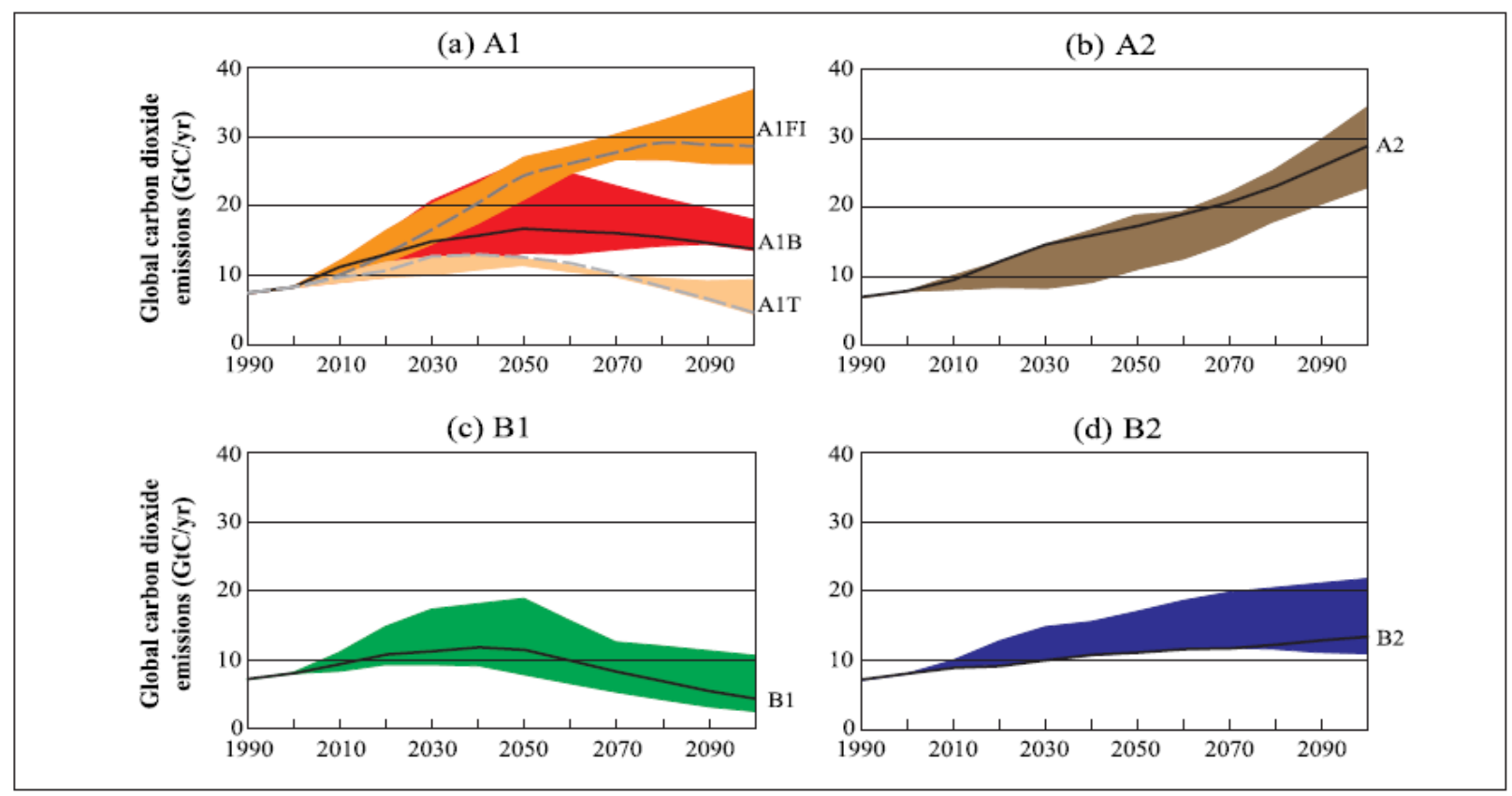

Figure 3-2 Comparison of global annual $\mathrm{CO}_{2}$ emissions from all sources including energy, land uses, and industry for the SRES scenario families (IPCC, 2000). The lines for each family represent illustrative scenarios.

\subsubsection{SRES Scenario A1B Selection}

The A1B scenario was selected as the basis for this project, since it included a balance of both fossil fuel and renewable energy sources with increased technological development. The population for this scenario was based on the low International Institute for Applied Systems Analysis (IIASA) 1996 population projection, which estimated the population in 2050 as 8.7 billion. This scenario was energy intensive with a mix of energy sources, but did not require development options that could be considered unrealistic. This scenario while not specifically designed as a median or average case, in general did tend toward the mid-range for most factors 
and emission levels, as seen in Figure 3-2. The population and hence emissions among the scenarios diverged more between 2050 and 2100.

\subsubsection{Emission Estimates by Region for 2000 and 2050 A1B Base Cases}

The IMAGE down-scaled emissions data for 27 chemicals or species for the 17 regions were used to derive input data for GATOR-GCMOM. Total emissions by region and source type were compiled for several key chemicals: $\mathrm{CO}, \mathrm{CO}_{2}, \mathrm{CH}_{4}, \mathrm{NO}, \mathrm{NO}_{2}, \mathrm{~N}_{2} \mathrm{O}, \mathrm{SO}_{2}$, Ethene, Toluene, and Xylenes. The sector types include domestic fossil fuel, domestic biofuel, industry, transport, power, natural biomass burning, other anthropogenic emissions, and biogenic emissions such as sea salt emissions and nitrogen fixation on land. Table 3-5 shows total emissions for the world by sector type for the 2000 base case. The emissions subdivided by region and sector type are shown in Appendix A. There were clear differences in the importance of sectors between the regions. For example, domestic biomass burning was a larger contributor of $\mathrm{CO}$ and $\mathrm{CO}_{2}$ in most Asian and African areas than in the US, Canada, or Europe. Transportation was a larger contributor than industry in the US for $\mathrm{CO}, \mathrm{CO}_{2}, \mathrm{NO}$, and $\mathrm{NO}_{2}$. The power sector contributed more $\mathrm{CO}_{2}$ and $\mathrm{SO}_{2}$ in the US than industry or transportation. Table 3-6 shows total emissions for the world by sector type for the 2050 A1B base case without HFCVs. The emissions subdivided by region for the 2050 A1B base case are shown in Appendix A.

Table 3-5

World Emissions by Sector and Chemical Species for 2000 Base Case

\begin{tabular}{|c|c|c|c|c|c|c|c|c|}
\hline \multirow[b]{2}{*}{ Species } & \multicolumn{2}{|c|}{ Domestic } & \multirow[b]{2}{*}{ Industry } & \multirow[b]{2}{*}{ Transport } & \multirow[b]{2}{*}{ Power } & \multirow[b]{2}{*}{ Biomass Burning } & \multirow{2}{*}{$\begin{array}{c}\text { Other } \\
\text { Anthropo- } \\
\text { genic }\end{array}$} & \multirow[b]{2}{*}{ Biogenic } \\
\hline & Biofuel & $\begin{array}{c}\text { Fossil } \\
\text { Fuel }\end{array}$ & & & & & & \\
\hline CO (Unit: Tg) & 173.46 & 27.00 & 31.37 & 205.43 & 1.48 & 473.46 & 0 & 0 \\
\hline $\mathrm{CO}_{2}$ (Unit: TgC) & 2451.35 & 799.0 & 2114.0 & 1412.0 & 2008.0 & & 257.0 & \\
\hline $\mathrm{CH}_{4}$ (Unit: $\mathrm{Tg}$ ) & & 10.46 & 1.94 & 89.35 & 1.24 & 0.00 & 16.77 & 186.75 \\
\hline NO (Unit: Tg) & 3.138 & 1.642 & 11.898 & 21.655 & 13.278 & 10.835 & 0.000 & 0.000 \\
\hline $\mathrm{NO}_{2}$ (Unit: Tg) & 0.535 & 0.280 & 2.027 & 3.689 & 2.262 & 1.846 & 0.000 & 0.000 \\
\hline $\mathrm{N}_{2} \mathrm{O}$ (Unit: $\mathrm{GgN}$ ) & & 12.100 & 498.100 & 96.900 & 53.500 & & 7319.300 & \\
\hline $\mathrm{SO}_{2}$ (Unit:Tg) & 0.468 & 6.207 & 37.730 & 5.498 & 43.972 & 2.692 & 0.000 & 0.000 \\
\hline Ethene (Unit:Tg) & 3.528 & 0.000 & 0.182 & 3.026 & 0.000 & 7.608 & 0.000 & 0.000 \\
\hline Toluene (Unit: Gg) & 830.0911 & 109.37305 & 2813.174 & 4131.226 & 16.21053 & 1305.839666 & 0 & 0 \\
\hline Xylenes (Unit: Gg) & 502.37 & 166.68 & 1113.47 & 4064.70 & 56.26 & 588.00 & 0 & 0 \\
\hline
\end{tabular}

Biomass burning refers to natural biomass burning.

Biogenic refers to natural emissions such as emissions from the ocean and nitrogen fixation over land.

$\mathrm{CO}_{2}$ emissions for biomass burning and biogenic emissions are not shown.

Data were compiled from RIVM by Streets in 2008. 
Table 3-6

World Emissions by Sector and Chemical Species for 2050 A1B Base Case

\begin{tabular}{|c|c|c|c|c|c|c|c|c|}
\hline \multirow[b]{2}{*}{ Species } & \multicolumn{2}{|c|}{ Domestic } & \multirow[b]{2}{*}{ Industry } & \multirow[b]{2}{*}{ Transport } & \multirow[b]{2}{*}{ Power } & \multirow[b]{2}{*}{$\begin{array}{l}\text { Biomass } \\
\text { Burning }\end{array}$} & \multirow[b]{2}{*}{$\begin{array}{c}\text { Other } \\
\text { Anthropogenic }\end{array}$} & \multirow[b]{2}{*}{$\begin{array}{c}\text { Biogeni } \\
\text { c }\end{array}$} \\
\hline & Biofuel & $\begin{array}{l}\text { Fossil } \\
\text { Fuel }\end{array}$ & & & & & & \\
\hline CO (Unit: Tg) & 170.05 & 17.17 & 62.76 & 179.77 & 7.20 & 407.42 & 0 & 0 \\
\hline $\mathrm{CO}_{2}$ (Unit: $\mathrm{TgC}$ ) & $\begin{array}{c}2170.3 \\
4\end{array}$ & $\begin{array}{c}1662.7 \\
0\end{array}$ & $\begin{array}{c}3585.7 \\
0\end{array}$ & 3948.70 & $\begin{array}{c}10459.1 \\
0\end{array}$ & & 183.40 & \\
\hline $\mathrm{CH}_{4}$ (Unit: Tg) & 10.25 & 1.76 & 215.53 & 3.67 & 0.00 & 24.47 & 330.64 & \\
\hline NO (Unit: Tg) & 4.67 & 5.83 & 37.47 & 28.60 & 59.47 & 7.95 & 0.00 & 0.00 \\
\hline $\mathrm{NO}_{2}$ (Unit: Tg) & 0.796 & 0.993 & 6.384 & 4.872 & 10.132 & 1.355 & 0 & 0 \\
\hline $\mathrm{N}_{2} \mathrm{O}$ (Unit: $\mathrm{GgN}$ ) & & 23.30 & 464.60 & 302.30 & 201.00 & & 10902.60 & \\
\hline $\mathrm{SO}_{2}$ (Unit: $\mathrm{Tg}$ ) & 0.452 & 1.760 & 69.455 & 7.136 & 52.082 & 4.074 & 0 & 0 \\
\hline Ethene (Unit: Tg) & 3.459 & 0.003 & 0.161 & 2.277 & 0.000 & 7.883 & 0 & 0 \\
\hline $\begin{array}{l}\text { Toluene (Unit: } \\
\text { Gg) }\end{array}$ & 813.68 & 66.28 & $\begin{array}{l}3009.3 \\
8\end{array}$ & 3293.26 & 74.86 & 1324.08 & 0 & 0 \\
\hline Xylene (Unit:Gg) & 492.44 & 98.80 & $\begin{array}{c}1200.5 \\
3\end{array}$ & 3052.06 & 179.84 & 597.69 & 0 & 0 \\
\hline
\end{tabular}

Biomass burning refers to natural biomass burning.

Biogenic refers to natural emissions such as emissions from the ocean and nitrogen fixation over land.

$\mathrm{CO}_{2}$ emissions for biomass burning and biogenic emissions are not shown.

Data were compiled from RIVM by Streets in 2008.

Due to the increased population and industrial activities of the 2050 A1B scenario, emissions of most chemicals were predicted to increase between 2000 and 2050. However, emissions of some chemicals such as CO were expected to decline as controls on fossil fuel-based vehicles increased. As the use of biomass as fuel for domestic heating and cooking declined by 2050, there were also predicted decreases in emissions associated with this sector.

\subsubsection{Emission Estimates Scale-up to 2050}

Development of the emissions data for 2050 for use in GATOR-GCMOM was a two-step process. The first step involved using the A1B scenario emissions data for the 17 regions for 2000 and 2050 to derive emission growth factors. Emission growth factors were developed by comparing data for a base year to a future year, in this case 2050. The base year for the monthly emissions of $\mathrm{NO}_{\mathrm{x}}, \mathrm{N}_{2} \mathrm{O}, \mathrm{CO}, \mathrm{CO}_{2}, \mathrm{SO}_{2}$, and $\mathrm{CH}_{4}$ was 1995 and 1990 for speciated organic gases (Olivier et al., 1996) and 1990 for ammonia (Bouwman et al., 1997). The 1990 organic gases were scaled to 1995 using the ratio of organic gases to total non-methane VOCs. The baseline data were then scaled to represent the year 2000. The changes between the baseline and future emissions were represented as emission growth factors, which were then used to multiply the emissions data on a $1^{\circ}$ by $1^{\circ}$ global grid basis from the EDGAR v2.0 global emission inventory (Olivier et al., 1996). These data were then aggregated to the global grid detail used in the model simulations, a $4^{\circ} \mathrm{S}$ to $\mathrm{N}$ by $5^{\circ} \mathrm{W}$ to $\mathrm{E}$ grid.

The A1B scenario emissions data for the 17 regions were obtained from the IMAGE modeling group for $\mathrm{CO}_{2}, \mathrm{CH}_{4}, \mathrm{NO}_{\mathrm{x}}, \mathrm{N}_{2} \mathrm{O}, \mathrm{CO}, \mathrm{SO}_{2}$, and VOCs (IMAGE Team, 2001). Because of the need to speciate the VOCs and particulate emissions and to aggregate the data to the model's grid, the A1B emission projections for 2050 from the IMAGE modeling group were not used directly in the model. The emission growth factors were derived by David Streets of Argonne National Laboratory using a similar method as used to scale-up to 2030 for previous GATOR-GCMOM 
simulations (Jacobson and Streets, 2009). Two sets of growth factors were derived: one set for changes from 2000 to the 2050 A1B scenario and one set for changes from 2000 to the 2050 A1B scenario with HFCVs.

Emissions growth factors were developed for twenty-seven species and carbon-bond IV groups for GATOR-GCMOM, as listed below:

- Gases - NO, $\mathrm{NO}_{2}, \mathrm{~N}_{2} \mathrm{O}, \mathrm{NH}_{3}, \mathrm{SO}_{2}, \mathrm{H}_{2} \mathrm{SO}_{4}, \mathrm{CO}, \mathrm{CO}_{2}, \mathrm{CH}_{4}$

- VOCs $-\mathrm{C}_{2} \mathrm{H}_{4}, \mathrm{HCHO}$, higher aldehydes, $\mathrm{C}_{5} \mathrm{H}_{8}$, terpenes, nonreactive VOCs, paraffins, olefins, ketones, alcohols, toluene, xylene)

- Aerosol components (BC, POC, sulfate, nitrate, fine PM, and coarse PM)

- Carbon-bond IV groups - used for VOCs that are not modeled explicitly such as alkanes and trimethylbenzenes.

The VOCs were speciated for 82 source types by Streets using the methodology described for China (Klimont et al., 2002) and for Asia (Streets et al., 2003), which used VOC profiles from the EPA model SPECIATE (US EPA, 2000) and other references. The speciation of nonmethane VOCs was conducted on a per country basis based on chemical reactivity, functional group, anthropogenic source for given VOC, and the type of emission controls, if present.

The emission growth factors for the changes from the 2000 base case to the 2050 A1B scenario are shown in Table 3-7 for the three sectors related to HFCVs, industry, transportation, and power. All emission growth factors for changes from 2000 to the 2050A1B scenario are included in Appendix A. A value of 1 means there is no change in a given chemical for that sector and region. While most chemicals increase, there are some organic chemicals and particulate species that decline due to increased emission controls for industries and transportation in the developed countries. The growth factors were capped at 100, where there were low emissions previously for a given chemical due to low industrial activity in a region such as parts of Africa, to avoid a situation where the change would be large but with a high uncertainty. The growth factors for a given region were then multiplied by the 2000 base case global emissions in the appropriate grid cell(s).

\subsection{Methods Used for Conversion to $\mathrm{H}_{2}$-based Transportation and Emission Estimates}

\subsubsection{Deriving Emission Growth Factors for Steam-reforming Method for $\mathrm{H}_{2}$ Production}

Once the emission factors were derived for the 2050 A1B case, the emission growth factors were adjusted to represent a 2050 A1B scenario with $90 \%$ penetration of hydrogen fuel cell vehicles in developed countries and 45\% penetration in other countries. All hydrogen for the vehicles in 2050 was generated using steam-reforming of natural gas. This case is referred to as $2050 \mathrm{~A} 1 \mathrm{~B}$ SHFCV. The change in emissions for conversion from gasoline-powered to hydrogen-powered vehicles was estimated using the GREET model (ANL, 2008) by David Streets based on the vehicle miles driven per year, energy of gasoline versus hydrogen, tank to wheel efficiencies of both vehicle types, and fleet-averaged mileage of all onroad vehicles. The gasoline used and vehicle miles driven by region are provided in Table 3-8. The standard GREET model provides only total VOCs. The EPA model SPECIATE allows emissions of total VOCs from some 
sources to be divided into specific chemicals based on a profile of VOCs from a given source (EPA, 2000). The changes in emissions from the 2050 A1B base case to the 2050 A1B case with SHFCV are expressed as growth factors by source type and region, which are then multiplied by the base emissions in the global grid cells.

Emission growth factors for key chemicals from the 2000 base case to the 2050 A1B case with SHFCVs are shown in Table 3-9 for the sectors where changes occurred, which were industry, transportation, and power. Changes occurred in all three sectors, but the larger changes occurred for transportation where all the chemicals decreased, except some organic compounds that remained the same. Due to the need for increased power to produce the hydrogen, there were some increases in this sector for $\mathrm{CO}, \mathrm{CO}_{2}, \mathrm{NO}, \mathrm{NO}_{2}, \mathrm{~N}_{2} \mathrm{O}$, and some particulates. The emission growth factors were capped at 100, as explained previously. The growth factors for a given region were multiplied by the 2000 base case global emissions in the appropriate grid cell(s), as was done for the 2050 A1B scenario without HFCVs.

The estimated changes after conversion to SHFCVs were consistent with expected changes based on the processes, except possibly for the total emissions of organic gases. The shift to SHFCVs based on Street's results predicted decreases in both $\mathrm{CO}_{2}$ and some organic gases after conversion to SHFCVs. Using data for the US for a 45 percent conversion to hydrogen-based vehicles as an example, the change in emissions of xylenes and formaldehyde were smaller than expected (12 and 2 percent, respectively) based on the decrease in $\mathrm{CO}_{2}$ emissions for the transportation sector, 37 percent. There was no sequestration of $\mathrm{CO}_{2}$ in this example. One hypothesis is that the organic gases were higher due to emissions from trucks delivering the hydrogen, although another possible explanation is that the increased emissions are from the steam-reforming process. If the cause is due to truck transportation, the emissions could be decreased if the hydrogen is produced in distributed local refueling stations, rather than centralized stations, or if transported by pipeline. Additional discussion of emissions from other methods of generating hydrogen is presented in Section 3.4 on Sensitivity Analyses.

\subsubsection{Comparison of Emissions from GATOR-GCMOM for 2000, 2050 A1B, and 2050 A1B SHFCVs}

A comparison of the 2000 base case, 2050 A1B scenario, and the 2050A1B with HFCVs scenario for the total fossil fuel emissions in the world for key chemicals is shown in Table 3-10. Most chemicals increase between the 2000 base case and the 2050A1B case due to an increase in population and industrial activity. Exceptions include $\mathrm{N}_{2} \mathrm{O}$, the base fraction of black carbon particles and particulate organic matter. However, emissions of many of these chemicals are expected to decrease regionally, particularly over North America and Europe, where emissions are expected to decline.

A comparison of the 2050 A1B and 2050 A1B+SHFCV columns in Table 3-10 indicates that a partial conversion to HFCVs, with $\mathrm{H}_{2}$ produced by steam-reforming of natural gas, is expected to decrease emissions of $\mathrm{NO}, \mathrm{NO}_{2}, \mathrm{~N}_{2} \mathrm{O}, \mathrm{CO}, \mathrm{CO}_{2}$, methane, and the fine fraction of black carbon in particulate matter compared with no conversion. However, $\mathrm{H}_{2}, \mathrm{SO}_{2}$, and the non-methane VOCs (e.g. ethene, toluene) may increase due to increased emissions for power and due to producing, transporting, and compressing the $\mathrm{H}_{2}$. 
Table 3-7

Growth Factors by Region for Industry, Transportation, and Power Sectors from 2000 Base Case to 2050 A1B

\begin{tabular}{|c|c|c|c|c|c|c|c|c|c|c|c|c|c|c|c|c|c|c|c|c|c|c|c|c|c|c|c|}
\hline & ALD2 & $\mathrm{CO}$ & ETH & FORM & ISOP & $\mathrm{NH} 3$ & NO & NO2 & NR & OLE & PAR & PEC & PMC & PMFINE & PNO3 & POA & PSO4 & SO2 & SULF & TERPB & TOL & XYL & KET & ALC & $\mathrm{CO2}$ & $\mathrm{CH} 4$ & N2O \\
\hline \multicolumn{28}{|l|}{ Industry } \\
\hline Canada & 0.77 & 1.23 & 0.79 & 0.66 & 1.00 & 1.00 & 1.59 & 1.59 & 0.78 & 0.82 & 0.49 & 0.91 & 1.09 & 1.09 & 1.09 & 1.36 & 1.09 & 0.35 & 0.35 & 1.00 & 0.79 & 0.82 & 0.82 & 0.79 & 0.66 & 0.84 & 0.29 \\
\hline USA & 0.90 & 1.02 & 0.91 & 0.74 & 1.00 & 1.00 & 1.62 & 1.62 & 0.37 & 0.91 & 0.48 & 0.74 & 1.86 & 1.86 & 1.86 & 3.73 & 1.86 & 0.24 & 0.24 & 1.00 & 0.90 & 0.91 & 0.91 & 0.91 & 0.64 & 0.37 & 0.28 \\
\hline Central America & 0.90 & 3.78 & 0.90 & 1.26 & 1.00 & 1.00 & 4.26 & 4.26 & 1.86 & 1.08 & 1.14 & 2.14 & 0.86 & 0.86 & 0.86 & 0.48 & 0.86 & 2.28 & 2.28 & 1.00 & 0.97 & 1.08 & 1.08 & 0.90 & 1.83 & 2.04 & 1.82 \\
\hline South America & 1.00 & 3.57 & 1.00 & 1.33 & 1.00 & 1.00 & 4.85 & 4.85 & 4.57 & 1.10 & 3.86 & 1.10 & 0.40 & 0.40 & 0.40 & 0.25 & 0.40 & 9.60 & 9.60 & 1.00 & 1.03 & 1.10 & 1.10 & 1.00 & 2.01 & 4.66 & 2.44 \\
\hline Northern Africa & 2.02 & 10.82 & 1.69 & 3.77 & 1.00 & 1.00 & 8.96 & 8.96 & 1.95 & 2.99 & 1.12 & 2.04 & 2.84 & 2.84 & 2.84 & 3.81 & 2.84 & 8.65 & 8.65 & 1.00 & 2.42 & 2.34 & 2.34 & 1.69 & 4.42 & 2.15 & 4.56 \\
\hline Western Africa & 4.82 & 12.03 & 3.59 & 5.64 & 1.00 & 1.00 & 19.41 & 19.41 & 7.84 & 4.83 & 3.17 & 1.81 & 0.49 & 0.49 & 0.49 & 0.30 & 0.49 & 10.66 & 10.66 & 1.00 & 4.83 & 4.82 & 4.82 & 3.59 & 6.68 & 14.20 & 9.80 \\
\hline Eastern Africa & 5.21 & 35.20 & 3.82 & 7.46 & 1.00 & 1.00 & 24.66 & 24.66 & 100.00 & 5.47 & 8.29 & 5.00 & 2.08 & 2.08 & 2.08 & 1.32 & 2.08 & 10.20 & 10.20 & 1.00 & 5.23 & 5.26 & 5.26 & 3.82 & 15.45 & 100.00 & 15.40 \\
\hline Southern Africa & 1.29 & 4.15 & 1.19 & 1.57 & 1.00 & 1.00 & 4.74 & 4.74 & 12.91 & 2.20 & 10.59 & 1.78 & 1.19 & 1.19 & 1.19 & 1.03 & 1.19 & 9.50 & 9.50 & 1.00 & 1.68 & 1.84 & 1.84 & 1.19 & 2.71 & 12.90 & 3.27 \\
\hline OECD Europe & 0.73 & 0.76 & 0.79 & 0.61 & 1.00 & 1.00 & 1.21 & 1.21 & 0.83 & 0.78 & 0.92 & 0.72 & 0.80 & 0.80 & 0.80 & 0.95 & 0.80 & 0.40 & 0.40 & 1.00 & 0.74 & 0.76 & 0.76 & 0.79 & 0.54 & 0.79 & 0.25 \\
\hline Eastern Europe & 0.49 & 1.20 & 0.49 & 0.71 & 1.00 & 1.00 & 2.42 & 2.42 & 0.40 & 0.55 & 1.08 & 1.45 & 1.33 & 1.33 & 1.33 & 1.19 & 1.33 & 0.27 & 0.27 & 1.00 & 0.54 & 0.57 & 0.57 & 0.49 & 1.23 & 0.39 & 0.57 \\
\hline Former USSR & 0.52 & 1.84 & 0.56 & 0.69 & 1.00 & 1.00 & 2.93 & 2.93 & 2.21 & 0.61 & 1.40 & 1.34 & 1.36 & 1.36 & 1.36 & 1.40 & 1.36 & 0.70 & 0.70 & 1.00 & 0.60 & 0.60 & 0.60 & 0.56 & 1.47 & 2.23 & 0.96 \\
\hline Middle East & 1.48 & 5.89 & 1.47 & 1.31 & 1.00 & 1.00 & 6.22 & 6.22 & 7.17 & 1.67 & 2.56 & 5.20 & 4.72 & 4.72 & 4.72 & 4.07 & 4.72 & 1.37 & 1.37 & 1.00 & 1.93 & 1.63 & 1.63 & 1.47 & 2.89 & 7.60 & 1.89 \\
\hline South Asia & 2.52 & 7.94 & 2.34 & 6.56 & 1.00 & 1.00 & 10.12 & 10.12 & 2.39 & 3.19 & 2.47 & 7.31 & 2.66 & 2.66 & 2.66 & 1.21 & 2.66 & 2.94 & 2.94 & 1.00 & 2.82 & 2.79 & 2.79 & 2.34 & 6.24 & 2.37 & 5.40 \\
\hline East Asia & 0.66 & 1.67 & 0.68 & 1.81 & 1.00 & 1.00 & 2.54 & 2.54 & 2.21 & 0.99 & 4.09 & 0.79 & 0.66 & 0.66 & 0.66 & 0.52 & 0.66 & 1.03 & 1.03 & 1.00 & 0.83 & 0.90 & 0.90 & 0.68 & 1.62 & 2.03 & 2.96 \\
\hline Southeast Asia & 1.74 & 6.34 & 1.72 & 2.18 & 1.00 & 1.00 & 5.26 & 5.26 & 2.19 & 1.90 & 1.44 & 1.33 & 0.95 & 0.95 & 0.95 & 0.73 & 0.95 & 2.37 & 2.37 & 1.00 & 1.86 & 1.89 & 1.89 & 1.72 & 2.34 & 2.24 & 5.30 \\
\hline Oceania & 0.66 & 0.58 & 0.76 & 0.68 & 1.00 & 1.00 & 1.23 & 1.23 & 1.85 & 0.80 & 0.42 & 0.65 & 0.80 & 0.80 & 0.80 & 0.99 & 0.80 & 1.18 & 1.18 & 1.00 & 0.68 & 0.72 & 0.72 & 0.76 & 0.81 & 1.92 & 0.74 \\
\hline Japan & 0.83 & 0.67 & 0.85 & 0.61 & 1.00 & 1.00 & 1.01 & 1.01 & 0.30 & 0.82 & 0.81 & 0.25 & 0.33 & 0.33 & 0.33 & 0.47 & 0.33 & 0.19 & 0.19 & 1.00 & 0.83 & 0.84 & 0.84 & 0.85 & 0.47 & 0.29 & 0.29 \\
\hline World & 0.85 & 2.00 & 0.88 & 1.24 & 1.00 & 1.00 & 3.15 & 3.15 & 2.42 & 1.04 & 2.01 & 1.68 & 1.17 & 1.11 & 1.12 & 0.81 & 1.12 & 1.84 & 1.84 & 1.00 & 1.07 & 1.08 & N/A & N/A & 1.70 & 2.41 & 0.93 \\
\hline \multicolumn{28}{|l|}{ Transportation } \\
\hline Canada & 0.30 & 0.43 & 0.30 & 1.06 & 1.00 & 1.00 & 0.68 & 0.68 & 0.85 & 0.30 & 0.41 & 0.49 & 0.54 & 0.54 & 1.00 & 0.59 & 0.54 & 0.14 & 0.14 & 1.00 & 0.33 & 0.30 & 1.00 & 0.30 & 1.28 & 1.33 & 0.82 \\
\hline USA & 0.24 & 0.37 & 0.25 & 1.61 & 1.00 & 1.00 & 0.56 & 0.56 & 0.83 & 0.25 & 0.44 & 0.44 & 0.43 & 0.43 & 1.00 & 0.43 & 0.43 & 0.12 & 0.12 & 1.00 & 0.29 & 0.25 & 1.00 & 0.25 & 1.09 & 1.09 & 0.67 \\
\hline Central America & 0.56 & 0.70 & 0.57 & 1.79 & 1.00 & 1.00 & 1.56 & 1.56 & 2.40 & 0.59 & 0.74 & 2.06 & 0.97 & 0.97 & 1.00 & 0.58 & 0.97 & 2.32 & 2.32 & 1.00 & 0.61 & 0.57 & 1.00 & 0.57 & 4.20 & 4.77 & 15.56 \\
\hline South America & 0.54 & 0.68 & 0.55 & 1.72 & 1.00 & 1.00 & 1.32 & 1.32 & 2.32 & 0.57 & 0.71 & 1.13 & 0.84 & 0.84 & 1.00 & 0.61 & 0.84 & 1.92 & 1.92 & 1.00 & 0.59 & 0.55 & 1.00 & 0.55 & 3.65 & 4.49 & 13.06 \\
\hline Northern Africa & 4.04 & 4.43 & 4.08 & 7.55 & 1.00 & 1.00 & 8.02 & 8.02 & 7.72 & 4.14 & 4.42 & 7.44 & 2.89 & 2.89 & 1.00 & 1.42 & 2.89 & 7.02 & 7.02 & 1.00 & 4.18 & 4.08 & 1.00 & 4.08 & 14.00 & 12.84 & 39.67 \\
\hline Western Africa & 3.57 & 4.31 & 3.62 & 10.78 & 1.00 & 1.00 & 8.02 & 8.02 & 8.04 & 3.68 & 4.48 & 7.67 & 2.81 & 2.81 & 1.00 & 1.47 & 2.81 & 6.72 & 6.72 & 1.00 & 3.83 & 3.61 & 1.00 & 3.61 & 12.89 & 13.82 & 56.00 \\
\hline Eastern Africa & 7.99 & 9.53 & 8.08 & 23.20 & 1.00 & 1.00 & 17.03 & 17.03 & 17.69 & 8.20 & 9.83 & 17.77 & 10.14 & 10.14 & 1.00 & 5.71 & 10.14 & 14.13 & 14.13 & 1.00 & 8.52 & 8.07 & 1.00 & 8.07 & 26.00 & 30.26 & 76.00 \\
\hline Southern Africa & 2.23 & 2.69 & 2.26 & 6.51 & 1.00 & 1.00 & 5.21 & 5.21 & 5.00 & 2.31 & 2.81 & 5.45 & 2.10 & 2.10 & 1.00 & 1.06 & 2.10 & 4.13 & 4.13 & 1.00 & 2.39 & 2.26 & 1.00 & 2.26 & 7.86 & 8.59 & 34.33 \\
\hline OECD Europe & 0.35 & 0.48 & 0.35 & 1.25 & 1.00 & 1.00 & 0.71 & 0.71 & 1.03 & 0.35 & 0.45 & 0.44 & 0.38 & 0.38 & 1.00 & 0.30 & 0.38 & 0.17 & 0.17 & 1.00 & 0.37 & 0.35 & 1.00 & 0.35 & 1.40 & 1.73 & 1.72 \\
\hline Eastern Europe & 0.42 & 0.50 & 0.43 & 1.13 & 1.00 & 1.00 & 1.13 & 1.13 & 2.09 & 0.44 & 0.53 & 1.42 & 1.33 & 1.33 & 1.00 & 1.21 & 1.33 & 0.37 & 0.37 & 1.00 & 0.45 & 0.43 & 1.00 & 0.43 & 4.15 & 4.84 & 14.75 \\
\hline Former USSR & 0.93 & 1.14 & 0.97 & 2.89 & 1.00 & 1.00 & 2.65 & 2.65 & 3.87 & 1.01 & 1.30 & 1.94 & 2.20 & 2.20 & 1.00 & 2.67 & 2.20 & 0.74 & 0.74 & 1.00 & 1.03 & 0.96 & 1.00 & 0.96 & 6.15 & 6.41 & 20.78 \\
\hline Middle East & 0.84 & 0.92 & 0.84 & 1.71 & 1.00 & 1.00 & 1.62 & 1.62 & 2.69 & 0.84 & 0.91 & 1.31 & 0.60 & 0.60 & 1.00 & 0.28 & 0.60 & 1.91 & 1.91 & 1.00 & 0.87 & 0.84 & 1.00 & 0.84 & 5.44 & 5.08 & 16.64 \\
\hline South Asia & 2.99 & 3.23 & 2.95 & 6.50 & 1.00 & 1.00 & 3.29 & 3.29 & 6.75 & 2.91 & 3.13 & 2.06 & 1.92 & 1.92 & 1.00 & 1.75 & 1.92 & 2.61 & 2.61 & 1.00 & 3.06 & 2.96 & 1.00 & 2.96 & 9.21 & 15.75 & 36.20 \\
\hline East Asia & 0.75 & 0.93 & 0.80 & 2.53 & 1.00 & 1.00 & 1.99 & 1.99 & 2.65 & 0.86 & 1.10 & 2.24 & 1.93 & 1.93 & 1.00 & 1.60 & 1.93 & 1.44 & 1.44 & 1.00 & 0.85 & 0.79 & 1.00 & 0.79 & 4.27 & 4.90 & 19.19 \\
\hline Southeast Asia & 1.10 & 1.32 & 1.11 & 2.58 & 1.00 & 1.00 & 2.14 & 2.14 & 2.69 & 1.12 & 1.27 & 2.30 & 1.25 & 1.25 & 1.00 & 0.71 & 1.25 & 1.81 & 1.81 & 1.00 & 1.15 & 1.11 & 1.00 & 1.11 & 5.10 & 6.34 & 23.90 \\
\hline Oceania & 0.29 & 0.38 & 0.29 & 0.80 & 1.00 & 1.00 & 0.63 & 0.63 & 0.74 & 0.29 & 0.35 & 0.97 & 0.88 & 0.88 & 1.00 & 0.73 & 0.88 & 0.26 & 0.26 & 1.00 & 0.30 & 0.29 & 1.00 & 0.29 & 1.24 & 1.28 & 0.79 \\
\hline Japan & 0.47 & 0.71 & 0.46 & 1.61 & 1.00 & 1.00 & 0.74 & 0.74 & 0.83 & 0.45 & 0.57 & 0.26 & 0.23 & 0.23 & 1.00 & 0.19 & 0.23 & 0.12 & 0.12 & 1.00 & 0.50 & 0.46 & 1.00 & 0.46 & 1.00 & 1.13 & 0.73 \\
\hline World & 0.75 & 0.88 & 0.75 & 2.20 & 1.00 & 1.00 & 1.32 & 1.32 & 1.91 & 0.77 & 0.94 & 1.48 & 1.10 & 1.10 & 1.00 & 0.79 & 1.10 & 1.30 & 1.30 & 1.00 & 0.80 & 0.75 & 1.00 & N/A & 2.80 & 2.97 & 3.12 \\
\hline
\end{tabular}

Parameter definitions are provided in Table A-4 of Appendix A. 
Table 3-7 (continued)

Growth Factors by Region for Industry, Transportation, and Power Sectors from 2000 Base Case to 2050 A1B

\begin{tabular}{|c|c|c|c|c|c|c|c|c|c|c|c|c|c|c|c|c|c|c|c|c|c|c|c|c|c|c|c|}
\hline & ALD2 & $\mathrm{co}$ & $\overline{\text { ETH }}$ & FORM & ISOP & $\mathrm{NH3}$ & NO & NO2 & NR & OLE & PAR & PEC & PMC & PMFINE & PNO3 & POA & PSO4 & SO2 & SULF & TERPB & TOL & $\mathrm{XYL}$ & KET & ALC & $\mathrm{CO2}$ & $\mathrm{CH} 4$ & $\mathrm{~N} 2 \mathrm{O}$ \\
\hline \multicolumn{28}{|l|}{ Power } \\
\hline Canada & 3.07 & 1.92 & 1.00 & 3.07 & 1.00 & 1.00 & 1.25 & 1.25 & 2.81 & 1.23 & 2.90 & 0.17 & 0.08 & 0.08 & 1.00 & 0.05 & 0.08 & 0.25 & 0.25 & 1.00 & 2.10 & 1.23 & 3.07 & 1.00 & 1.87 & 1.00 & 1.42 \\
\hline USA & 2.34 & 1.54 & 1.00 & 2.34 & 1.00 & 1.00 & 1.05 & 1.05 & 1.62 & 1.26 & 1.72 & 0.09 & 0.05 & 0.05 & 1.00 & 0.04 & 0.05 & 0.27 & 0.27 & 1.00 & 1.42 & 1.26 & 2.34 & 1.00 & 1.57 & 1.00 & 1.40 \\
\hline Central America & 5.34 & 8.82 & 1.00 & 5.34 & 1.00 & 1.00 & 7.89 & 7.89 & 17.63 & 16.13 & 12.01 & 4.56 & 3.32 & 3.32 & 1.00 & 2.52 & 3.32 & 1.31 & 1.31 & 1.00 & 17.40 & 16.13 & 5.34 & 1.00 & 8.30 & 1.00 & 7.33 \\
\hline South America & 17.12 & 17.35 & 1.00 & 17.12 & 1.00 & 1.00 & 18.07 & 18.07 & 17.89 & 16.61 & 17.65 & 1.46 & 0.65 & 0.65 & 1.00 & 0.41 & 0.65 & 4.49 & 4.49 & 1.00 & 17.69 & 16.61 & 17.12 & 1.00 & 20.26 & 1.00 & 19.25 \\
\hline Northern Africa & 8.99 & 12.24 & 1.00 & 8.99 & 1.00 & 1.00 & 13.05 & 13.05 & 13.18 & 42.97 & 12.12 & 5.65 & 5.49 & 5.49 & 1.00 & 6.74 & 5.49 & 6.20 & 6.20 & 1.00 & 14.47 & 42.97 & 8.99 & 1.00 & 13.75 & 1.00 & 14.00 \\
\hline Western Africa & 36.30 & 45.60 & 1.00 & 36.30 & 1.00 & 1.00 & 41.83 & 41.83 & 52.60 & 100.00 & 48.09 & 13.65 & 13.38 & 13.38 & 1.00 & 16.67 & 13.38 & 15.17 & 15.17 & 1.00 & 54.30 & 100.00 & 36.30 & 1.00 & 46.53 & 1.00 & 1.00 \\
\hline Eastern Africa & 59.23 & 100.00 & 1.00 & 59.23 & 1.00 & 1.00 & 89.13 & 89.13 & 100.00 & 100.00 & 100.00 & 45.00 & 41.88 & 41.88 & 1.00 & 45.94 & 41.88 & 41.46 & 41.46 & 1.00 & 100.00 & 100.00 & 59.23 & 1.00 & 100.00 & 1.00 & 1.00 \\
\hline Southern Africa & 100.00 & 6.88 & 1.00 & 100.00 & 1.00 & 1.00 & 6.28 & 6.28 & 9.63 & 5.84 & 11.29 & 0.05 & 0.05 & 0.05 & 1.00 & 0.04 & 0.05 & 4.98 & 4.98 & 1.00 & 6.79 & 5.84 & 100.00 & 1.00 & 7.25 & 1.00 & 6.28 \\
\hline OECD Europe & 2.38 & 2.05 & 1.00 & 2.38 & 1.00 & 1.00 & 1.72 & 1.72 & 2.57 & 1.63 & 2.57 & 0.61 & 0.36 & 0.3 & 1.00 & 0.24 & 0.36 & 0.43 & 0.43 & 1.00 & 2.08 & 1.63 & 2.38 & 1.00 & 2.25 & 1.00 & 1.84 \\
\hline Eastern Europe & 4.58 & 2.71 & 1.00 & 4.58 & 1.00 & 1.00 & 4.19 & 4.19 & 4.70 & 1.93 & 4.85 & 0.79 & 0.78 & 0.78 & 1.00 & 0.96 & 0.78 & 0.23 & 0.23 & 1.00 & 3.11 & 1.93 & 4.58 & 1.00 & 2.87 & 1.00 & 2.24 \\
\hline Former USSR & 2.23 & 2.49 & 1.00 & 2.23 & 1.00 & 1.00 & 1.44 & 1.44 & 2.53 & 2.93 & 2.48 & 0.79 & 0.81 & 0.81 & 1.00 & 1.11 & 0.81 & 0.24 & 0.24 & 1.00 & 2.58 & 2.93 & 2.23 & 1.00 & 2.81 & 1.00 & 2.81 \\
\hline Middle East & 8 & 17 & 1.00 & 8.4 & 1.00 & 1.00 & 7.06 & 7.06 & 12.44 & 9.60 & 11.57 & 3.39 & 1.66 & 1.66 & 1.00 & 0.98 & 1.66 & 0.75 & 0.75 & 1.00 & 12.23 & 9.60 & 8.48 & 1.00 & 9.71 & 1.00 & 7.54 \\
\hline South Asia & 43.70 & 16.38 & 1.00 & 43.70 & 1.00 & 1.00 & 16.47 & 16.47 & 27.85 & 11.16 & 31.02 & 4.01 & 2.58 & 2.58 & 1.00 & 1.83 & 2.58 & 5.81 & 5.81 & 1.00 & 16.57 & 11.16 & 43.70 & 1.00 & 15.84 & 1.00 & 12.60 \\
\hline East Asia & 17.91 & 5.32 & 1.00 & 17.91 & 1.00 & 1.00 & 4.73 & 4.73 & 12.39 & 2.88 & 14.19 & 0.68 & 0.74 & 0.74 & 1.00 & 1.27 & 0.74 & 0.87 & 0.87 & 1.00 & 5.49 & 2.88 & 17.91 & 1.00 & 5.21 & 1.00 & 3.55 \\
\hline Southeast A & 7.90 & 11.60 & 1.00 & 7.90 & 1.00 & 1.00 & 15.33 & 15.33 & 12.39 & 22.17 & 11.25 & 6.76 & 3.33 & 3.33 & 1.00 & 1.97 & 3.33 & 5.52 & 5.52 & 1.00 & 14.04 & 22.17 & 7.90 & 1.00 & 13.19 & 1.00 & 1.00 \\
\hline Oceania & 4.64 & 1.87 & 1.00 & 4.64 & 1.00 & 1.00 & 1.49 & 1.49 & 2.57 & 1.44 & 2.81 & 0.07 & 0.03 & 0.03 & 1.00 & 0.02 & 0.03 & 0.27 & 0.27 & 1.00 & 1.83 & 1.44 & 4.64 & 1.00 & 17.13 & 1.00 & 1.57 \\
\hline Japan & 1.25 & 1.56 & 1.00 & 1.25 & 1.00 & 1.00 & 1.36 & 1.36 & 1.60 & 1.76 & 1.54 & 0.49 & 0.45 & 0.45 & 1.00 & 0.47 & 0.45 & 0.34 & 0.34 & 1.00 & 1.66 & 1.76 & 1.25 & 1.00 & 1.65 & 1.00 & 1.74 \\
\hline World & 14.23 & 4.87 & 1.00 & 5.96 & 1.00 & 1.00 & 4.48 & 4.48 & 5.98 & 3.20 & 6.08 & 1.39 & 0.88 & 0.88 & 1.00 & 0.62 & 0.88 & 1.18 & 1.18 & 1.00 & 4.62 & 3.20 & N/A & 1.00 & 5.21 & 1.00 & 3.76 \\
\hline
\end{tabular}

Data were compiled from RIVM by Streets in 2008 .

Table 3-8

Vehicle Miles Traveled per Year by Region and Estimated Gasoline Used for Conventional Vehicles in 2050

\begin{tabular}{|c|c|c|c|c|c|c|c|c|c|c|c|c|c|c|c|c|c|c|c|}
\hline \multicolumn{2}{|l|}{$2050 \mathrm{~A} 1 \mathrm{~B}$} & Canada & USA & $\begin{array}{l}\text { Central } \\
\text { America }\end{array}$ & $\begin{array}{l}\text { South } \\
\text { America }\end{array}$ & $\begin{array}{c}\text { Northern } \\
\text { Africa }\end{array}$ & $\begin{array}{l}\text { Western } \\
\text { Africa }\end{array}$ & $\begin{array}{l}\text { Eastern } \\
\text { Africa }\end{array}$ & $\begin{array}{c}\text { Southern } \\
\text { Africa }\end{array}$ & $\begin{array}{l}\text { OECD } \\
\text { Europe }\end{array}$ & $\begin{array}{l}\text { Eastern } \\
\text { Europe }\end{array}$ & $\begin{array}{l}\text { Former } \\
\text { USSR }\end{array}$ & $\begin{array}{c}\text { Middle } \\
\text { East }\end{array}$ & $\begin{array}{c}\text { South } \\
\text { Asia }\end{array}$ & $\begin{array}{l}\text { East } \\
\text { Asia }\end{array}$ & $\begin{array}{c}\text { Southeast } \\
\text { Asia }\end{array}$ & Oceania & Japan & World \\
\hline \multirow{2}{*}{$\begin{array}{l}\text { IMAGE transportation sector energy } \\
\text { use }(\mathrm{PJ})\end{array}$} & Light oil & 1371 & 13957 & 4919 & 7160 & 4999 & 3246 & 2221 & 3093 & 9301 & 2028 & 6228 & 9836 & 7436 & 10895 & 6099 & 939 & 1685 & 95411 \\
\hline & Heavy oil & 677 & 5874 & 2621 & 5246 & 2829 & 1722 & 1252 & 1507 & 6375 & 1292 & 3934 & 6090 & 10575 & 6786 & 4655 & 455 & 1112 & 63000 \\
\hline \multicolumn{2}{|c|}{$\begin{array}{l}\text { Fraction of light oil that is vehicle gasoline (from } \\
\text { SPEW 2050 A1B) }\end{array}$} & 0.850 & 0.817 & 0.885 & 0.846 & 0.774 & 0.769 & 0.567 & 0.818 & 0.776 & 0.912 & 0.785 & 0.832 & 0.683 & 0.817 & 0.700 & 0.768 & 0.815 & 0.791 \\
\hline \multicolumn{2}{|c|}{$\begin{array}{l}\text { IMAGE transportation sector vehicle gasoline use in } \\
2050 \mathrm{~A} 1 \mathrm{~B}(\mathrm{PJ})\end{array}$} & 1165 & 11400 & 4351 & 6059 & 3867 & 2497 & 1259 & 2531 & 7214 & 1850 & 4887 & 8182 & 5077 & 8899 & 4269 & 721 & 1372 & 75452 \\
\hline \multicolumn{2}{|c|}{$\begin{array}{l}\text { Miles driven by conventional gasoline vehicles at } \\
0.194 \mathrm{mi} / \mathrm{MJ}\left(10^{\wedge} 12 \mathrm{mi} / \mathrm{yr}\right)\end{array}$} & 0.226 & 2.212 & 0.844 & 1.175 & 0.750 & 0.484 & 0.244 & 0.491 & 1.399 & 0.359 & 0.948 & 1.587 & 0.985 & 1.726 & 0.828 & 0.140 & 0.266 & 14.666 \\
\hline
\end{tabular}

Data were provided by David Streets of Argonne National Laboratory in 2008. 
Table 3-9
Growth Factors by Region for Industry, Transportation, and Power Sectors from 2000 to 2050A1B with SHFCV

\begin{tabular}{|c|c|c|c|c|c|c|c|c|c|c|c|c|c|c|c|c|c|c|c|c|c|c|c|c|c|c|c|}
\hline & ALD2 & co & ETH & FORM & ISOP & $\mathrm{NH3}$ & NO & NO2 & NR & OLE & PAR & PEC & PMC & PMFINE & PNO3 & POA & PSO4 & SO2 & SULF & TERPB & TOL & XYL & KET & ALC & $\mathrm{CO} 2$ & $\mathrm{CH} 4$ & $\mathrm{~N} 2 \mathrm{O}$ \\
\hline \multicolumn{28}{|l|}{ Industry } \\
\hline Canada & 0.75 & 1.23 & 0.69 & 0.58 & 1.00 & 1.00 & 1.35 & 1.35 & 0.78 & 0.10 & 0.46 & 1.11 & 1.11 & 1.11 & 1.11 & 1.11 & 1.11 & 0.33 & 0.33 & 1.00 & 0.76 & 0.78 & 0.75 & 0.69 & 0.79 & 0.83 & 0.29 \\
\hline USA & 0.88 & 1.02 & 0.77 & 0.67 & 1.00 & 1.00 & 1.46 & 1.46 & 0.37 & 0.10 & 0.36 & 1.90 & 1.90 & 1.90 & 1.90 & 1.90 & 1.90 & 0.22 & 0.22 & 1.00 & 0.88 & 0.88 & 0.88 & 0.77 & 0.80 & 0.36 & 0.28 \\
\hline Central America & 0.57 & 3.77 & 0.66 & 1.03 & 1.00 & 1.00 & 3.93 & 3.93 & 1.86 & 0.02 & 1.11 & 0.88 & 0.88 & 0.88 & 0.88 & 0.88 & 0.88 & 2.27 & 2.27 & 1.00 & 0.85 & 0.98 & 0.57 & 0.66 & 2.03 & 2.01 & 1.79 \\
\hline South America & 0.85 & 3.57 & 0.89 & 1.18 & 1.00 & 1.00 & 4.61 & 4.61 & 4.57 & 0.64 & 3.83 & 0.41 & 0.41 & 0.41 & 0.41 & 0.41 & 0.41 & 9.60 & 9.60 & 1.00 & 0.98 & 1.06 & 0.85 & 0.89 & 2.17 & 4.63 & 2.43 \\
\hline Northern Africa & 1.24 & 10.81 & 1.00 & 3.37 & 1.00 & 1.00 & 8.54 & 8.54 & 1.95 & 1.00 & 1.10 & 2.91 & 2.91 & 2.91 & 2.91 & 2.91 & 2.91 & 8.64 & 8.64 & 1.00 & 2.22 & 2.16 & 1.24 & 1.00 & 4.71 & 2.14 & 4.53 \\
\hline Western Africa & 3.96 & 11.93 & 1.00 & 5.29 & 1.00 & 1.00 & 18.32 & 18.32 & 7.84 & 1.88 & 3.17 & 0.50 & 0.50 & 0.50 & 0.50 & 0.50 & 0.50 & 10.63 & 10.63 & 1.00 & 4.75 & 4.75 & 3.96 & 1.00 & 7.37 & 14.17 & 9.79 \\
\hline Eastern Africa & 4.15 & 34.93 & 1.00 & 6.93 & 1.00 & 1.00 & 22.37 & 22.37 & 100.00 & 1.38 & 7.54 & 2.15 & 2.15 & 2.15 & 2.15 & 2.15 & 2.15 & 10.16 & 10.16 & 1.00 & 5.13 & 5.16 & 4.15 & 1.00 & 17.03 & 100.00 & 15.34 \\
\hline Southern Africa & 0.81 & 4.15 & 1.00 & 1.39 & 1.00 & 1.00 & 4.52 & 4.52 & 12.91 & 0.10 & 10.26 & 1.21 & 1.21 & 1.21 & 1.21 & 1.21 & 1.21 & 9.49 & 9.49 & 1.00 & 1.53 & 1.73 & 0.81 & 1.00 & 2.88 & 12.89 & 3.26 \\
\hline OECD Europe & 0.72 & 0.75 & 0.68 & 0.54 & 1.00 & 1.00 & 1.03 & 1.03 & 0.83 & 0.02 & 0.85 & 0.83 & 0.83 & 0.83 & 0.83 & 0.83 & 0.83 & 0.39 & 0.39 & 1.00 & 0.73 & 0.74 & 0.72 & 0.68 & 0.68 & 0.75 & 0.25 \\
\hline Eastern Europe & 0.40 & 1.20 & 0.46 & 0.63 & 1.00 & 1.00 & 2.36 & 2.36 & 0.40 & 0.38 & 1.02 & 1.36 & 1.36 & 1.36 & 1.36 & 1.36 & 1.36 & 0.26 & 0.26 & 1.00 & 0.51 & 0.55 & 0.40 & 0.46 & 1.29 & 0.38 & 0.56 \\
\hline Former USSR & 0.48 & 1.84 & 0.50 & 0.61 & 1.00 & 1.00 & 2.84 & 2.84 & 2.21 & 0.36 & 1.37 & 1.40 & 1.40 & 1.40 & 1.40 & 1.40 & 1.40 & 0.70 & 0.70 & 1.00 & 0.57 & 0.58 & 0.48 & 0.50 & 1.55 & 2.23 & 0.95 \\
\hline Middle East & 0.86 & 5.88 & 0.97 & 1.09 & 1.00 & 1.00 & 5.96 & 5.96 & 7.17 & 0.10 & 2.53 & 4.84 & 4.84 & 4.84 & 4.84 & 4.84 & 4.84 & 1.37 & 1.37 & 1.00 & 1.80 & 1.51 & 0.86 & 0.97 & 3.07 & 7.60 & 1.86 \\
\hline South Asia & 2.20 & 7.94 & 1.59 & 6.37 & 1.00 & 1.00 & 10.00 & 10.00 & 2.39 & 2.20 & 2.36 & 2.67 & 2.67 & 2.67 & 2.67 & 2.67 & 2.67 & 2.94 & 2.94 & 1.00 & 2.77 & 2.75 & 2.20 & 1.59 & 6.34 & 2.36 & 5.39 \\
\hline East Asia & 0.32 & 1.67 & 0.38 & 1.65 & 1.00 & 1.00 & 2.49 & 2.49 & 2.21 & 0.46 & 4.02 & 0.67 & 0.67 & 0.67 & 0.67 & 0.67 & 0.67 & 1.03 & 1.03 & 1.00 & 0.77 & 0.87 & 0.32 & 0.38 & 1.67 & 2.02 & 2.95 \\
\hline Southeast Asia & 1.58 & 6.33 & 1.61 & 2.04 & 1.00 & 1.00 & 5.07 & 5.07 & 2.19 & 1.43 & 1.40 & 0.97 & 0.97 & 0.97 & 0.97 & 0.97 & 0.97 & 2.36 & 2.36 & 1.00 & 1.81 & 1.86 & 1.58 & 1.61 & 2.47 & 2.23 & 5.28 \\
\hline Oceania & 0.64 & 0.58 & 0.29 & 0.59 & 1.00 & 1.00 & 1.01 & 1.01 & 1.85 & 0.10 & 0.30 & 0.81 & 0.81 & 0.81 & 0.81 & 0.81 & 0.81 & 1.17 & 1.17 & 1.00 & 0.65 & 0.68 & 0.64 & 0.29 & 0.96 & 1.91 & 0.72 \\
\hline Japan & 0.82 & 0.67 & 0.81 & 0.59 & 1.00 & 1.00 & 0.93 & 0.93 & 0.30 & 0.52 & 0.70 & 0.34 & 0.34 & 0.34 & 0.34 & 0.34 & 0.34 & 0.19 & 0.19 & 1.00 & 0.83 & 0.83 & 0.82 & 0.81 & 0.52 & 0.24 & 0.29 \\
\hline World & 0.75 & 2.00 & 0.71 & 1.11 & 1.00 & 1.00 & 3.01 & 3.01 & 2.42 & 0.44 & 1.96 & 1.13 & 1.13 & 1.13 & 1.13 & 1.13 & 1.13 & 1.84 & 1.84 & 1.00 & 1.03 & 1.04 & 0.75 & 0.71 & 1.81 & 2.40 & 0.93 \\
\hline \multicolumn{28}{|l|}{ Transportation } \\
\hline Canada & 0.29 & 0.29 & 0.28 & 1.03 & 1.00 & 1.00 & 0.56 & 0.56 & 0.85 & 0.20 & 0.24 & 0.50 & 0.50 & 0.50 & 0.50 & 0.50 & 0.50 & 0.12 & 0.12 & 1.00 & 0.30 & 0.28 & 1.00 & 0.28 & 0.80 & 1.27 & 0.47 \\
\hline USA & 0.24 & 0.26 & 0.22 & 1.58 & 1.00 & 1.00 & 0.46 & 0.46 & 0.83 & 0.12 & 0.22 & 0.40 & 0.40 & 0.40 & 0.40 & 0.40 & 0.40 & 0.11 & 0.11 & 1.00 & 0.26 & 0.22 & 1.00 & 0.22 & 0.67 & 1.05 & 0.40 \\
\hline Central America & 0.55 & 0.57 & 0.54 & 1.75 & 1.00 & 1.00 & 1.31 & 1.31 & 2.39 & 0.48 & 0.53 & 0.96 & 0.96 & 0.96 & 0.96 & 0.96 & 0.96 & 2.31 & 2.31 & 1.00 & 0.58 & 0.54 & 1.00 & 0.54 & 3.32 & 4.67 & 12.33 \\
\hline South America & 0.54 & 0.56 & 0.53 & 1.69 & 1.00 & 1.00 & 1.15 & 1.15 & 2.31 & 0.47 & 0.53 & 0.83 & 0.83 & 0.83 & 0.83 & 0.83 & 0.83 & 1.91 & 1.91 & 1.00 & 0.56 & 0.53 & 1.00 & 0.53 & 3.00 & 4.40 & 10.68 \\
\hline Northern Africa & 4.02 & 4.08 & 4.00 & 7.44 & 1.00 & 1.00 & 7.52 & 7.52 & 7.68 & 3.84 & 3.87 & 2.86 & 2.86 & 2.86 & 2.86 & 2.86 & 2.86 & 6.99 & 6.99 & 1.00 & 4.10 & 4.00 & 1.00 & 4.00 & 11.33 & 12.54 & 31.07 \\
\hline Western Africa & 3.56 & 3.99 & 3.54 & 10.68 & 1.00 & 1.00 & 7.55 & 7.55 & 8.00 & 3.41 & 3.98 & 2.78 & 2.78 & 2.78 & 2.78 & 2.78 & 2.78 & 6.68 & 6.68 & 1.00 & 3.75 & 3.54 & 1.00 & 3.54 & 10.40 & 13.55 & 47.68 \\
\hline Eastern Africa & 7.97 & 9.02 & 7.96 & 23.04 & 1.00 & 1.00 & 16.30 & 16.30 & 17.64 & 7.76 & 9.02 & 10.07 & 10.07 & 10.07 & 10.07 & 10.07 & 10.07 & 14.08 & 14.08 & 1.00 & 8.40 & 7.96 & 1.00 & 7.96 & 22.24 & 29.83 & 67.61 \\
\hline Southern Africa & 2.22 & 2.48 & 2.22 & 6.44 & 1.00 & 1.00 & 4.88 & 4.88 & 4.97 & 2.13 & 2.47 & 2.08 & 2.08 & 2.08 & 2.08 & 2.08 & 2.08 & 4.10 & 4.10 & 1.00 & 2.34 & 2.22 & 1.00 & 2.22 & 6.24 & 8.41 & 28.71 \\
\hline OECD Europe & 0.34 & 0.33 & 0.32 & 1.22 & 1.00 & 1.00 & 0.57 & 0.57 & 1.03 & 0.26 & 0.29 & 0.36 & 0.36 & 0.36 & 0.36 & 0.36 & 0.36 & 0.16 & 0.16 & 1.00 & 0.35 & 0.33 & 1.00 & 0.32 & 0.92 & 1.67 & 1.13 \\
\hline Eastern Europe & 0.41 & 0.39 & 0.40 & 1.10 & 1.00 & 1.00 & 0.92 & 0.92 & 2.07 & 0.35 & 0.36 & 1.32 & 1.32 & 1.32 & 1.32 & 1.32 & 1.32 & 0.36 & 0.36 & 1.00 & 0.42 & 0.40 & 1.00 & 0.40 & 3.32 & 4.74 & 11.67 \\
\hline Former USSR & 0.92 & 0.97 & 0.91 & 2.83 & 1.00 & 1.00 & 2.33 & 2.33 & 3.85 & 0.80 & 0.93 & 2.17 & 2.17 & 2.17 & 2.17 & 2.17 & 2.17 & 0.73 & 0.73 & 1.00 & 0.98 & 0.91 & 1.00 & 0.91 & 5.20 & 6.29 & 17.16 \\
\hline Middle East & 0.84 & 0.75 & 0.80 & 1.65 & 1.00 & 1.00 & 1.37 & 1.37 & 2.67 & 0.70 & 0.64 & 0.59 & 0.59 & 0.59 & 0.59 & 0.59 & 0.59 & 1.90 & 1.90 & 1.00 & 0.83 & 0.81 & 1.00 & 0.80 & 4.40 & 4.96 & 12.75 \\
\hline South Asia & 2.99 & 2.93 & 2.92 & 6.46 & 1.00 & 1.00 & 3.10 & 3.10 & 6.73 & 2.79 & 2.93 & 1.90 & 1.90 & 1.90 & 1.90 & 1.90 & 1.90 & 2.61 & 2.61 & 1.00 & 3.03 & 2.93 & 1.00 & 2.92 & 8.26 & 15.55 & 32.82 \\
\hline East Asia & 0.75 & 0.81 & 0.77 & 2.49 & 1.00 & 1.00 & 1.77 & 1.77 & 2.64 & 0.76 & 0.90 & 1.91 & 1.91 & 1.91 & 1.91 & 1.91 & 1.91 & 1.43 & 1.43 & 1.00 & 0.82 & 0.77 & 1.00 & 0.77 & 3.50 & 4.81 & 16.37 \\
\hline Southeast Asia & 1.09 & 1.19 & 1.09 & 2.56 & 1.00 & 1.00 & 1.95 & 1.95 & 2.68 & 1.06 & 1.16 & 1.25 & 1.25 & 1.25 & 1.25 & 1.25 & 1.25 & 1.80 & 1.80 & 1.00 & 1.13 & 1.09 & 1.00 & 1.09 & 4.36 & 6.24 & 21.05 \\
\hline Oceania & 0.28 & 0.26 & 0.27 & 0.78 & 1.00 & 1.00 & 0.51 & 0.51 & 0.74 & 0.22 & 0.23 & 0.85 & 0.85 & 0.85 & 0.85 & 0.85 & 0.85 & 0.25 & 0.25 & 1.00 & 0.29 & 0.27 & 1.00 & 0.27 & 0.77 & 1.23 & 0.46 \\
\hline Japan & 0.47 & 0.53 & 0.45 & 1.59 & 1.00 & 1.00 & 0.61 & 0.61 & 0.82 & 0.38 & 0.46 & 0.22 & 0.22 & 0.22 & 0.22 & 0.22 & 0.22 & 0.11 & 0.11 & 1.00 & 0.48 & 0.45 & 1.00 & 0.45 & 0.66 & 1.09 & 0.45 \\
\hline World & 0.75 & 0.73 & 0.72 & 2.17 & 1.00 & 1.00 & 1.16 & 1.16 & 1.89 & 0.66 & 0.75 & 1.09 & 1.09 & 1.09 & 1.09 & 1.09 & 1.09 & 1.29 & 1.29 & 1.00 & 0.77 & 0.72 & 1.00 & 0.72 & 2.18 & 2.90 & 2.45 \\
\hline
\end{tabular}


Table 3-9 (continued)

Growth Factors by Region for Industry, Transportation, and Power Sectors from 2000 to 2050A1B with SHFCVs

\begin{tabular}{|c|c|c|c|c|c|c|c|c|c|c|c|c|c|c|c|c|c|c|c|c|c|c|c|c|c|c|c|}
\hline & ALD2 & co & ETH & FORM & ISOP & $\mathrm{NH3}$ & No & NO2 & NR & OLE & PAR & PEC & PMC & PMFINE & PNO3 & POA & PSO4 & so2 & SULF & TERPB & TOL & XYL & KET & ALC & $\mathrm{CO} 2$ & $\mathrm{CH} 4$ & N2O \\
\hline \multicolumn{28}{|l|}{ Power } \\
\hline Canada & 3.07 & 1.95 & 1.00 & 3.10 & 1.00 & 1.00 & 1.34 & 1.34 & 2.81 & 1.29 & 2.98 & 0.31 & 0.31 & 0.31 & 0.31 & 0.31 & 0.31 & 0.26 & 0.26 & 1.00 & 2.12 & 1.26 & 3.07 & 1.00 & 1.90 & 1.00 & 1.45 \\
\hline USA & 2.34 & 1.56 & 1.00 & 2.36 & 1.00 & 1.00 & 1.10 & 1.10 & 1.62 & 1.28 & 1.76 & 0.12 & 0.12 & 0.12 & 0.12 & 0.12 & 0.12 & 0.27 & 0.27 & 1.00 & 1.42 & 1.27 & 2.34 & 1.00 & 1.59 & 1.00 & 1.42 \\
\hline Central America & 5.41 & 8.90 & 1.00 & 5.34 & 1.00 & 1.00 & 8.09 & 8.09 & 17.65 & 16.93 & 12.11 & 3.43 & 3.43 & 3.43 & 3.43 & 3.43 & 3.43 & 1.32 & 1.32 & 1.00 & 17.52 & 16.49 & 5.41 & 1.00 & 8.37 & 1.00 & 7.45 \\
\hline South America & 17.18 & 17.46 & 1.00 & 17.12 & 1.00 & 1.00 & 18.42 & 18.42 & 17.90 & 17.25 & 17.75 & 0.84 & 0.84 & 0.84 & 0.84 & 0.84 & 0.84 & 4.55 & 4.55 & 1.00 & 17.77 & 16.89 & 17.18 & 1.00 & 20.38 & 1.00 & 19.50 \\
\hline Northern Africa & 9.20 & 12.32 & 1.00 & 9.00 & 1.00 & 1.00 & 13.33 & 13.33 & 13.18 & 45.18 & 12.18 & 5.89 & 5.89 & 5.89 & 5.89 & 5.89 & 5.89 & 6.23 & 6.23 & 1.00 & 14.53 & 43.96 & 9.20 & 1.00 & 13.83 & 1.00 & 14.22 \\
\hline Western Africa & 44.92 & 46.01 & 1.00 & 36.31 & 1.00 & 1.00 & 43.39 & 43.39 & 52.63 & 100.00 & 48.37 & 15.82 & 15.82 & 15.82 & 15.82 & 15.82 & 15.82 & 15.49 & 15.49 & 1.00 & 54.61 & 100.00 & 44.92 & 1.00 & 46.94 & 1.00 & 1.00 \\
\hline Eastern Africa & 70.91 & 100.00 & 1.00 & 59.25 & 1.00 & 1.00 & 91.84 & 91.84 & 100.00 & 100.00 & 100.00 & 48.33 & 48.33 & 48.33 & 48.33 & 48.33 & 48.33 & 41.69 & 41.69 & 1.00 & 100.00 & 100.00 & 70.91 & 1.00 & 100.00 & 1.00 & 1.00 \\
\hline Southern Africa & 100.00 & 6.91 & 1.00 & 100.00 & 1.00 & 1.00 & 6.33 & 6.33 & 9.63 & 5.88 & 11.39 & 0.31 & 0.31 & 0.31 & 0.31 & 0.31 & 0.31 & 4.99 & 4.99 & 1.00 & 6.81 & 5.86 & 100.00 & 1.00 & 7.27 & 1.00 & 6.30 \\
\hline OECD Europe & 2.38 & 2.09 & 1.00 & 2.40 & 1.00 & 1.00 & 1.84 & 1.84 & 2.57 & 1.67 & 2.64 & 0.50 & 0.50 & 0.50 & 0.50 & 0.50 & 0.50 & 0.45 & 0.45 & 1.00 & 2.09 & 1.65 & 2.38 & 1.00 & 2.27 & 1.00 & 1.88 \\
\hline Eastern Europe & 4.59 & 2.72 & 1.00 & 4.58 & 1.00 & 1.00 & 4.25 & 4.25 & 4.71 & 1.95 & 4.86 & 0.86 & 0.86 & 0.86 & 0.86 & 0.86 & 0.86 & 0.23 & 0.23 & 1.00 & 3.12 & 1.94 & 4.59 & 1.00 & 2.88 & 1.00 & 2.25 \\
\hline Former USSR & 2.24 & 2.50 & 1.00 & 2.23 & 1.00 & 1.00 & 1.47 & 1.47 & 2.53 & 3.03 & 2.49 & 0.89 & 0.89 & 0.89 & 0.89 & 0.89 & 0.89 & 0.24 & 0.24 & 1.00 & 2.59 & 2.97 & 2.24 & 1.00 & 2.82 & 1.00 & 2.83 \\
\hline Middle East & 8.55 & 10.23 & 1.00 & 8.48 & 1.00 & 1.00 & 7.24 & 7.24 & 12.45 & 10.36 & 11.62 & 1.76 & 1.76 & 1.76 & 1.76 & 1.76 & 1.76 & 0.76 & 0.76 & 1.00 & 12.28 & 9.94 & 8.55 & 1.00 & 9.76 & 1.00 & 7.64 \\
\hline South Asia & 43.70 & 16.40 & 1.00 & 43.70 & 1.00 & 1.00 & 16.51 & 16.51 & 27.85 & 11.19 & 31.07 & 2.72 & 2.72 & 2.72 & 2.72 & 2.72 & 2.72 & 5.82 & 5.82 & 1.00 & 16.58 & 11.17 & 43.70 & 1.00 & 15.85 & 1.00 & 12.62 \\
\hline East Asia & 17.91 & 5.34 & 1.00 & 17.91 & 1.00 & 1.00 & 4.77 & 4.77 & 12.39 & 2.91 & 14.25 & 0.86 & 0.86 & 0.86 & 0.86 & 0.86 & 0.86 & 0.88 & 0.88 & 1.00 & 5.51 & 2.89 & 17.91 & 1.00 & 5.23 & 1.00 & 3.56 \\
\hline Southeast Asia & 7.93 & 11.65 & 1.00 & 7.90 & 1.00 & 1.00 & 15.46 & 15.46 & 12.39 & 22.49 & 11.29 & 3.43 & 3.43 & 3.43 & 3.43 & 3.43 & 3.43 & 5.53 & 5.53 & 1.00 & 14.07 & 22.31 & 7.93 & 1.00 & 13.24 & 1.00 & 1.00 \\
\hline Oceania & 4.64 & 1.89 & 1.00 & 4.68 & 1.00 & 1.00 & 1.54 & 1.54 & 2.58 & 1.46 & 2.86 & 0.11 & 0.11 & 0.11 & 0.11 & 0.11 & 0.11 & 0.27 & 0.27 & 1.00 & 1.84 & 1.45 & 4.64 & 1.00 & 17.14 & 1.00 & 1.59 \\
\hline Japan & 1.25 & 1.58 & 1.00 & 1.26 & 1.00 & 1.00 & 1.40 & 1.40 & 1.60 & 1.78 & 1.56 & 0.50 & 0.50 & 0.50 & 0.50 & 0.50 & 0.50 & 0.34 & 0.34 & 1.00 & 1.67 & 1.77 & 1.25 & 1.00 & 1.66 & 1.00 & 1.76 \\
\hline World & 14.23 & 4.90 & 1.00 & 5.96 & 1.00 & 1.00 & 4.55 & 4.55 & 5.99 & 3.25 & 6.12 & 0.99 & 0.99 & 0.99 & 0.99 & 0.99 & 0.99 & 1.19 & 1.19 & 1.00 & 4.64 & 3.22 & 14.23 & 1.00 & 5.23 & 1.00 & 3.79 \\
\hline
\end{tabular}

Data were compiled from RIVM by Streets (2008). 
Table 3-10

Comparison of Fossil-fuel related emission rates (Tg/yr) of key chemical components in 2000, 2050 A1B scenario, and 2050 A1B scenario with SHFCVs.

\begin{tabular}{|c|c|c|c|}
\hline Chemical Component & 2000 & 2050 A1B & 2050 A1B+SHFCV \\
\hline $\mathrm{H}_{2}$ & 8.4 & 14.6 & 17.2 \\
\hline NO & 48.2 & 153 & 149 \\
\hline $\mathrm{NO}_{2}$ & 8.21 & 26.1 & 25.4 \\
\hline $\mathrm{N}_{2} \mathrm{O}$ & 11.1 & 9.7 & 9.6 \\
\hline $\mathrm{CO}$ & 294 & 514 & 484 \\
\hline $\mathrm{CO}_{2}$ & 25,560 & 95,900 & 93,200 \\
\hline Methane & 284 & 357 & 356 \\
\hline Methanol & 4.52 & 13.0 & 13.8 \\
\hline Ethene & 4.42 & 12.6 & 13.4 \\
\hline Formaldehyde & 0.97 & 6.69 & 7.38 \\
\hline Higher aldehydes & 2.91 & 9.14 & 9.29 \\
\hline Toluene & 4.42 & 8.1 & 8.8 \\
\hline Xylene & 6.13 & 9.42 & 10.3 \\
\hline $\mathrm{SO}_{2}$ & 129 & 212.5 & 213 \\
\hline FF-BC & 3.8 & 6.7 & 5.1 \\
\hline FF-POM & 5.5 & 6.0 & 7.6 \\
\hline BF-BC & 4.1 & 1.5 & 1.5 \\
\hline BF-POM & 38 & 14.6 & 14.6 \\
\hline
\end{tabular}

\subsubsection{Wind-generated Method for $\mathrm{H}_{2}$ Production and Emission Changes}

In addition to the 2050 A1B case with SHFCVs, another simulation was conducted with GATOR-GCMOM to compare a contemporary 2000 base case to a case where all onroad vehicles were converted to HFCVs where the hydrogen for the vehicles was generated from electrolysis using wind power. For this case, no emissions of any gases or particulates were considered, except for hydrogen from leakage and chemically-produced water vapor (Jacobson, 2008). Thus, the case represents the most optimistic scenario with respect to decreased emissions after conversion to hydrogen-based transportation. This case considered that the hydrogen was generated by electrolysis of water at local refueling stations where the electricity was provided by wind-powered electricity at wind farms transported via transmission lines to the local stations. The differences in life-cycle emissions of vehicle and equipment manufacturing and their transport compared to gasoline refineries and fuel transport were not considered.

A similar methodology to develop emission growth factors as described in Section 3.3.1 was used to derive emission growth factors for changes from a contemporary 2000 base case to a case using HFCVs where the hydrogen was produced using wind-generated electrolysis, referred to as WHFCVs as described in Jacobson, 2008. Table 3-11 shows the global emissions by sector for key chemicals for the base case, the emissions from WHFCVs, and the estimated total global emissions after the shift to WHFCVs. All chemicals are projected to decrease, except for ammonia which remained the same. The changes for this case represent a best case scenario, in that there were no emissions associated with the distribution of the hydrogen from the generating facilities to local fueling stations. The changes in full life-cycle emissions were also not considered. 
Table 3-11

Comparison of Global Emissions for 2000 Base Case and WHFCV Case

\begin{tabular}{|c|c|c|c|c|c|c|c|}
\hline Species & $\begin{array}{c}\text { (a) } \\
\text { Non- } \\
\text { vehicle } \\
\text { fossil-fuel } \\
\text { (Tg/yr) }\end{array}$ & $\begin{array}{c}\text { (b) } \\
\text { FFOV } \\
\text { (Tg/yr) }\end{array}$ & $\begin{array}{c}\text { (c) } \\
\text { WHFC } \\
\text { (Tg/yr) }\end{array}$ & $\begin{array}{c}\text { (d) } \\
\text { Biomass } \\
\text { burning } \\
\text { (Tg/yr) }\end{array}$ & $\begin{array}{c}\text { (e) } \\
\text { Biofuel } \\
\text { Burning } \\
\text { (Tg/yr) }\end{array}$ & $\begin{array}{c}(\mathbf{f}) \\
\text { Baseline } \\
\text { Total } \\
(a+b+d+e) \\
(\mathrm{Tg} / \mathrm{yr})\end{array}$ & $\begin{array}{c}(g) \\
\text { WHFCV } \\
\text { Total } \\
(a+c+d+e) \\
(T g / y r)\end{array}$ \\
\hline \multicolumn{8}{|c|}{ Inorganic Gases } \\
\hline Carbon monoxide & 119.1 & 195.7 & 0 & 420 & 216 & 950.8 & 755.1 \\
\hline Carbon dioxide & 21,010 & 3760 & 0 & $3200^{*}$ & $170^{*}$ & 28,140 & 24,380 \\
\hline Nitric oxide & 37 & 16 & 0 & 14 & 2.7 & 69.7 & 53.7 \\
\hline Nitrogen dioxide & 6.35 & 2.75 & 0 & 2.2 & 0.42 & 11.72 & 8.97 \\
\hline Nitrous acid & 0.523 & 0.224 & 0 & 0.25 & 0.048 & 1.045 & 0.821 \\
\hline Nitrous oxide & 11.02 & 0.10 & 0 & 1.1 & 0.17 & 12.39 & 12.29 \\
\hline Sulfur dioxide & 136.2 & 4.0 & 0 & 2.5 & 0.72 & 143.4 & 139.4 \\
\hline Sulfur trioxide & 5.34 & 0.14 & 0 & 0.078 & 0.022 & 5.58 & 5.44 \\
\hline Sulfuric acid & 2.18 & 0.06 & 0 & 0.026 & 0.0074 & 2.27 & 2.21 \\
\hline Ammonia & 58.2 & 0 & 0 & 6.0 & 3.6 & 67.8 & 67.8 \\
\hline Molec. hydrogen & 3.38 & 5.58 & 4.82 & 9.8 & 5.0 & 23.76 & 23 \\
\hline Water vapor & 9590 & 1420 & 1390 & 2770 & 1460 & 15,240 & 15,210 \\
\hline \multicolumn{8}{|c|}{ Organic Gases } \\
\hline Methane & 275.9 & 0.8 & 0 & 19.7 & 20.2 & 316.6 & 315.8 \\
\hline Paraffin bond grp & 38.0 & 14.7 & 0 & 7.0 & 7.3 & 67 & 52.3 \\
\hline Ethene & 2.54 & 1.83 & 0 & 6.0 & 5.0 & 15.37 & 13.54 \\
\hline Olefin bond grp & 2.75 & 2.10 & 0 & 2.2 & 4.1 & 11.15 & 9.05 \\
\hline Methanol & 2.65 & 1.85 & 0 & 8.3 & 4.2 & 17 & 15.15 \\
\hline Formaldehyde & 0.57 & 0.41 & 0 & 4.9 & 0.36 & 6.24 & 5.83 \\
\hline Higher aldehydes & 1.67 & 1.20 & 0 & 2.8 & 0.39 & 6.06 & 4.86 \\
\hline Benzene & 1.47 & 1.04 & 0 & 1.6 & 5.3 & 9.41 & 8.37 \\
\hline Toluene bond grp & 2.67 & 1.96 & 0 & 1.0 & 3.0 & 8.63 & 6.67 \\
\hline Xylene bond grp & 3.69 & 2.77 & 0 & 0.36 & 1.5 & 8.32 & 5.55 \\
\hline Total Organic Gas & 331.1 & 28.7 & 0 & 53.9 & 51.4 & 465.1 & 436.4 \\
\hline
\end{tabular}

\subsection{Sensitivity Analysis}

\subsubsection{Overview of GREET Model}

GREET is a full life cycle public domain spreadsheet model, in Microsoft Excel, developed by Argonne National Laboratory for the U.S. Department of Energy's Office of Energy Efficiency and Renewable Energy, first released in 1996. The complete life cycle assessment includes emissions due to mining and/or production of the raw materials, manufacturing and assembling the vehicles, production of fuel for the vehicles, vehicle recycling or disposal, and the emissions from use for transportation. The GREET model has two separate components:

- GREET1 Series for the fuel cycle from well-to-wheels, which refers to the production, manufacture, and distribution of automotive fuel and using the fuel in the vehicles.

- GREET2 Series for the vehicle life cycle including the energy and emissions associated with vehicle material recovery and production, vehicle component manufacturing and 
assembly, and vehicle disposal and recycling. The existing version for vehicle cycle analysis is GREET 2.7a (Argonne, 2007). This model was not used for this project.

The GREET spreadsheet version for fuel-cycle analysis, GREET 1.8b (Argonne, 2008a), was used for this project to evaluate alternative emission factors for transportation fuel and vehicle technology combinations. An updated version of this model, GREET 1.8c, was released in March 2009 to enhance the simulation of emission factors for plug-in hybrid electric vehicles. This version includes updated fuel economies based on Argonne's Powertrain Systems Analysis Toolkit (PSAT) model (Argonne, 2008b) and other information from the US EPA and Energy Information Administration (EIA) and alternate electricity generation mixes for the US, California, and the northeastern US based on EIA's 2009 Annual Energy Outlook. GREET 1.8c can be run from a graphic user interface, called GREETGUI (Argonne, 2009). For a given transportation fuel/vehicle technology combination, GREET calculates consumption of total energy, emissions of $\mathrm{CO}_{2}$ - equivalent greenhouse gases including $\mathrm{CO}_{2}$, methane, and $\mathrm{N}_{2} \mathrm{O}$ and emissions for five criteria pollutants $\left(\mathrm{CO}, \mathrm{NO}_{\mathrm{x}}, \mathrm{SO}_{\mathrm{x}}, \mathrm{PM}_{10}, \mathrm{PM}_{2.5}\right)$.

The GREET 1.8b model has three sections: the well-to-pump energy use and emissions, well-towheels energy use and emissions, and well-to-wheel energy use and emission changes relative to gasoline vehicles. For this project, the well-to wheels sections were used. While GREET 1.8b has 70 vehicle/fuel systems and over 100 fuel production pathways, a subset of fuel types and production pathways was used for this project. Fuel types used for this project were:

- Petroleum: gasoline and diesel

- Hydrogen: gaseous hydrogen

- Electricity: mix of sources by country.

GREET1.8b computes energy use and emissions for passenger cars (PC) and light-duty trucks (LDT1), although other shipping modes can be included for fuel transport. The vehicle technology types included for this project were:

- Gasoline operated vehicle

o Spark ignition (SI)

o Grid -independent hybrid electric vehicle spark ignition engine (GH GI)

o Grid-connected hybrid electric vehicle spark ignition engine (GH GC)

- Diesel operated vehicle

\section{o Compression-ignition direct ignition engine (CIDI)}

- Hydrogen fuel cell vehicle.

The model allows a user-specified mix of methods for generating hydrogen as fuel for the vehicles and for delivering the fuel such as by truck or pipeline. Users specify the number of vehicles by type and the fuel economy of each vehicle type. Output of the model used for this project included total emissions for specified years for $\mathrm{PM}_{10}, \mathrm{PM}_{2.5}, \mathrm{NO}_{\mathrm{x}}, \mathrm{N}_{2} \mathrm{O}, \mathrm{SO}_{\mathrm{x}}$, total VOCs, $\mathrm{CO}, \mathrm{CO}_{2}$ and $\mathrm{CH}_{4}$. Emission factors generated as $\mathrm{g} / \mathrm{mile}$ and as emissions in metric tons by vehicle type and fuel generation method were also used to compare vehicle/fuel combinations. The model also provides the percent contribution from the feedstock production, fuel production, and vehicle operation, although this capability was not used for this project. 


\subsubsection{Sensitivity Analyses Using GREET Model in US}

\subsubsection{Set-up of GREET Model Simulations}

Two scenarios using a combination of methods to generate hydrogen fuel for vehicles based on the IPCC A1B case were simulated for 2030 and 2050 for the US based on the report for DOE by Greene et al. (2007) in the US for a no-carbon-control policy and a carbon-control policy. The input parameters were developed using downscaled population data for the IPCC A1B case in 2030 and 2050. The number of hydrogen vehicles in the US in 2030 and 2050 was derived from the projected number of vehicles in the US to 2025 from the above report (Green, et al., 2007).

The estimated types of vehicles (e.g. cars and light-duty trucks), vehicle ownership rates, and miles traveled per year were projected to 2050 for the US and other regions based on the IEA/SMP model (Fulton and Eads, 2004). The average vehicle miles traveled per year was estimated as 10,900. The GREET $1.8 \mathrm{~b}$ model includes a 2020 base case that was used for parameters such as fuel economy that were scaled up by 5\% in 2030 and by another $5 \%$ in 2050 . The fuel economy by vehicle type is shown in Table 3-12.

Table 3-13 shows the population values, LDV ownership-rates, numbers of vehicle (determined by population and LDV rates in the study area) and average vehicle miles traveled (VMT).

The estimated split between cars (PC) and trucks (LDT1) by vehicle type for each scenario in 2030 and 2050 are shown in Table 3-14. As a comparison, a case with a low percent of hybrid vehicles was also simulated for both years. It is projected that gasoline vehicles would not be commonly used in 2050 Scenario 2 and that the number of gas hybrids would increase by 2050 . The projected annual vehicle miles traveled for the 2030 and 2050 scenarios based on the vehicle types without HFCVs are listed in Table 3-15. This information is used to determine how the emissions would change based on the emission factors by vehicle/fuel technology combination.

Table 3-12

Fuel Economy from GREET for Vehicle Types

\begin{tabular}{|l|l|l|l|c|c|c|}
\hline \multicolumn{2}{|c|}{} & Gas & Diesel & GH GI & GH GC & HFCV \\
\hline \multirow{4}{*}{ Passenger Cars } & Baseline & 27.8 & 33.4 & 41.7 & 83.4 & 65.6 \\
\cline { 2 - 8 } & 2030 & 29.2 & 35.0 & 43.8 & 87.6 & 68.9 \\
\cline { 2 - 8 } & 2050 & 30.6 & 36.7 & 45.9 & 91.7 & 72.2 \\
\hline \multirow{3}{*}{ Light-duty Trucks } & Baseline & 19.8 & 23.8 & 29.7 & 59.4 & 46.7 \\
\cline { 2 - 8 } & 2030 & 20.8 & 24.9 & 31.2 & 62.4 & 49.1 \\
\cline { 2 - 8 } & 2050 & 21.8 & 26.1 & 32.7 & 65.3 & 51.4 \\
\hline
\end{tabular}

Units are in grams per mile. The baseline values are for 2020. GHGI = gas hybrid grid independent, $\mathrm{GH}$ GC = gas hybrid grid connected, HFCV = hydrogen fuel cell vehicle. 
Table 3-13

Vehicle Miles Traveled in the USA

\begin{tabular}{|c|c|c|c|c|c|}
\hline Year & $\begin{array}{l}\text { Population }^{1} \text { (in } \\
1,000 \text { s) }\end{array}$ & $\begin{array}{l}\text { LDV Rates }{ }^{2} \text { per } 1,000 \\
\text { persons }\end{array}$ & $\begin{array}{l}\text { Number of Vehicles }{ }^{3} \\
\text { (in 1,000s) }\end{array}$ & $\begin{array}{l}\text { Average Vehicle } \\
\text { Miles }^{2} / \text { year }\end{array}$ & $\begin{array}{c}\text { Total VMT in } \\
1,000,000 \mathrm{~s}\end{array}$ \\
\hline 2030 & 347,000 & 750 & 261,000 & 10,900 & $2,840,000$ \\
\hline 2050 & 383,000 & 760 & 291,000 & 10,900 & $3,170,000$ \\
\hline
\end{tabular}

1 Source: (IPCC, 2002)

2 Source: (Fulton and Eads, 2004)

3 This value obtained by (population $x$ Light duty Vehicles (LDV) Ownership Rates per 1,000 persons

Table 3-14

Projected Percentages of Vehicle Fuel Technology Types in the Vehicle Fleet in the US

\begin{tabular}{|c|c|c|c|c|c|c|c|c|c|c|c|c|c|}
\hline \multirow[b]{2}{*}{ Year } & \multirow[b]{2}{*}{ Scenario } & \multicolumn{3}{|c|}{ Gas LDV } & \multicolumn{3}{|c|}{ Diesel LDV } & \multicolumn{3}{|c|}{$\begin{array}{l}\text { Gas Hybrid-Grid } \\
\text { Independent }\end{array}$} & \multicolumn{3}{|c|}{$\begin{array}{l}\text { Gas Hybrid-Grid } \\
\text { Connected }\end{array}$} \\
\hline & & $\begin{array}{l}\text { Gas } \\
\text { LDV } \\
\text { Total }\end{array}$ & PC & LDT1 & $\begin{array}{c}\text { Diesel } \\
\text { LDV } \\
\text { Total }\end{array}$ & PC & LDT1 & $\begin{array}{c}\text { Gas } \\
\text { Hybrid } \\
\text { Total }\end{array}$ & PC & LDT1 & $\begin{array}{c}\text { Gas } \\
\text { Hybrid } \\
\text { Total }\end{array}$ & PC & LDT1 \\
\hline \multirow{3}{*}{2030} & $\begin{array}{l}\text { Low } \\
\text { Hybrid }\end{array}$ & 95.1 & 50 & 50 & 3.5 & 50 & 50 & 1.4 & 50 & 50 & 0 & 50 & 50 \\
\hline & Scenario 1 & 87.5 & 60 & 40 & 3.5 & 60 & 40 & 10 & 60 & 40 & 0 & 60 & 40 \\
\hline & Scenario 2 & 20 & 60 & 40 & 3.5 & 60 & 40 & 50 & 60 & 40 & 27 & 60 & 40 \\
\hline \multirow{3}{*}{2050} & $\begin{array}{l}\text { Low } \\
\text { Hybrid }\end{array}$ & 93 & 50 & 50 & 5.2 & 50 & 50 & 1.8 & 50 & 50 & 0 & 50 & 50 \\
\hline & Scenario 1 & 80 & 60 & 40 & 5.2 & 60 & 40 & 14.8 & 60 & 40 & 0 & 60 & 40 \\
\hline & Scenario 2 & 0 & 60 & 40 & 5 & 60 & 40 & 45 & 60 & 40 & 50 & 60 & 40 \\
\hline
\end{tabular}

Table 3-15

Vehicle Fuel Technology and Miles Traveled by Scenario in the US

\begin{tabular}{|c|c|c|c|c|c|c|c|c|c|c|}
\hline \multirow{2}{*}{ Year } & \multicolumn{2}{|c|}{ Gas LDV } & \multicolumn{2}{c|}{ Diesel LDV } & \multicolumn{2}{c|}{$\begin{array}{c}\text { Gas Hybrid-Grid } \\
\text { Independent }\end{array}$} & \multicolumn{2}{c|}{$\begin{array}{c}\text { Gas Hybrid-Grid } \\
\text { Connect }\end{array}$} & $\begin{array}{c}\text { Total } \\
\text { Vehicle } \\
\text { Miles } \\
\text { Traveled }\end{array}$ \\
\cline { 3 - 12 } & Scenario & Car & LDT1 & Car & LDT1 & Car & LDT1 & Car & LDT1 \\
\hline \multirow{4}{*}{2030} & Low Hybrid & $1,350,000$ & $1,350,000$ & 49,700 & 49,700 & 19,900 & 19,900 & 0 & 0 & $2,840,000$ \\
\cline { 2 - 12 } & Scenario 1 & $1,470,000$ & 983,000 & 59,600 & 39,800 & 170,000 & 114,000 & 0 & 0 & $2,840,000$ \\
\cline { 2 - 12 } & Scenario 2 & 341,000 & 227,000 & 59,600 & 39,800 & 852,000 & 568,000 & 452,000 & 301,000 & $2,840,000$ \\
\hline \multirow{3}{*}{2050} & Low Hybrid & $1,470,000$ & $1,470,000$ & 82,400 & 82,400 & 28,500 & 28,500 & 0 & 0 & $3,170,000$ \\
\cline { 2 - 12 } & Scenario 1 & $1,520,000$ & $1,010,000$ & 98,900 & 65,900 & 281,000 & 188,000 & 0 & 0 & $3,170,000$ \\
\cline { 2 - 12 } & Scenario 2 & 0 & 0 & 95,100 & 63,400 & 856,000 & 570,000 & 951,000 & 634,000 & $3,170,000$ \\
\hline
\end{tabular}

Vehicle miles traveled are in the 1,000,000s.

The electricity was generated based on the mix of energy sources in 2005 (IEA 2008). The sources used for the base case are shown in Table 3-16. Alternative sources of electricity were also evaluated including the mix used in the GATOR-GCMOM simulations for 2030 and 2050. 
Table 3-16

Generation Mixture of Electricity by Energy Source Type

\begin{tabular}{|c|c|}
\hline Energy Source & Percent \\
\hline Coal & 48.6 \\
\hline Natural gas & 24.3 \\
\hline Oil & 2.6 \\
\hline Nuclear & 16.3 \\
\hline Biomass & 1.4 \\
\hline Hydro/Renewables & 6.8 \\
\hline
\end{tabular}

\subsubsection{Alternative Scenarios Selected for $\mathrm{H}_{2}$ Production}

Two alternative scenarios based on the IPCC A1B case were simulated for the US in 2030 and 2050 for this project using the well-to-wheels section of the GREET model 1.8b. The mix of methods to generate the hydrogen fuel in the US were based on two scenarios for hydrogen production methods that are projected out to 2050 in a report for DOE by Greene et al. (2007) in the US for a no-carbon-control policy and a carbon-control policy. The two scenarios were:

- Scenario 1: (20\% Hydrogen Fuel Cell Vehicles [HFCVs] in 2030 and 90\% HFCVs in 2050).

Assumed hydrogen production from steam reforming of natural gas in 2030 and from the no carbon policy source mix for 2050:

o Biomass without sequestration 5\%;

o Coal gasification without sequestration $66 \%$;

o Steam reforming using natural gas without sequestration $28 \%$;

o Renewable energy $1 \%$.

- Scenario 2: (50\% HFCVs in 2030 and 95\% HFCVs in 2050).

Assumed hydrogen production from steam reforming of natural gas in 2030 and from the carbon policy source mix for 2050:

o Biomass with sequestration of all $\mathrm{CO}_{2}$ from process $42 \%$;

o Coal gasification with sequestration of all $\mathrm{CO}_{2}$ from process $45 \%$;

o Steam reforming using natural gas $10 \%$;

o Renewable energy 3\%.

In 2030, the hydrogen was assumed to be generated mostly by steam methane reforming (SMR) in distributed units for the no-carbon-control policy. In 2050 under a carbon-control policy, the hydrogen was assumed to be produced from coal or biomass with sequestration and less SMR. The percent using natural gas for SMR was reduced by 2 percent and added to the percent for renewable energy, given the large increase in wind capacity that occurred in 2007 and that was envisioned by 2030. The distribution methods were also projected to 2050 and included mostly trucks by 2030, but increased pipelines by 2050, particularly under the carbon-control policy. Hydrogen production by renewables, e.g., distributed electrolysis using wind power was included, and renewables were expected to make a small contribution by 2050 . 
The emission sensitivity analyses were conducted for the US using downscaled population data for the IPCC A1B case in 2030 and 2050, estimated vehicle type and ownership rates, fuel types and methods for generating hydrogen, and methods for producing electricity. The number of hydrogen vehicles in the US in 2030 was derived from the transportation scenarios from a DOE report "Integrated Analysis of Market Transformation Scenarios with Hytrans" (Green, et al., 2007).

The energy sources for electricity in the US were obtained for the baseline using 2005 energy statistics (IEA, 2008). Natural gas was assumed to be the primary source in 2030 for hydrogen fuel production in the US from steam reforming of North American natural gas.

\subsubsection{Sensitivity Analyses for US}

Using the above inputs for the US, the GREET model provides emission factors for HFCVs based on the method used to generate the hydrogen and for standard vehicle types. The projected emission factors for non-HFCVs in 2030 (Table 3-17) and 2050 (Table 3-18) take into account estimated improvements in fuel economy and pollution control equipment. The emission factors for HFCVs by generation method are shown in Table 3-19 and Table 3-20.

Table 3-17

Emission Factors of Standard Vehicles for 2030 in US

\begin{tabular}{|c|c|c|c|c|c|c|c|c|}
\hline \multirow[b]{3}{*}{ Pollutant } & \multicolumn{8}{|c|}{ Emission Factors 2030} \\
\hline & \multicolumn{2}{|c|}{ Gasoline } & \multicolumn{2}{|c|}{ Diesel } & \multicolumn{2}{|c|}{ GH GI } & \multicolumn{2}{|c|}{ GH GC } \\
\hline & PC & LDT1 & PC & LDT1 & PC & LDT1 & PC & LDT1 \\
\hline$P M_{10}$ & 0.083 & 0.098 & 0.061 & 0.072 & 0.064 & 0.076 & 0.187 & 0.221 \\
\hline$P M_{2.5}$ & 0.036 & 0.044 & 0.028 & 0.035 & 0.029 & 0.035 & 0.058 & 0.069 \\
\hline$N O_{x}$ & 0.299 & 0.373 & 0.240 & 0.312 & 0.211 & 0.265 & 0.258 & 0.318 \\
\hline VOC & 0.273 & 0.328 & 0.08704 & 0.096 & 0.189 & 0.226 & 0.137 & 0.164 \\
\hline $\mathrm{CO}$ & 3.387 & 3.358 & 0.557 & 0.448 & 3.364 & 3.330 & 2.284 & 2.268 \\
\hline $\mathrm{SO}_{x}$ & 0.121 & 0.145 & 0.080 & 0.096 & 0.080 & 0.096 & 0.302 & 0.362 \\
\hline $\mathrm{CO}_{2}$ & 431 & 516 & 363 & 435 & 287 & 344 & 301 & 360 \\
\hline $\mathrm{CH}_{4}$ & 0.525 & 0.629 & 0.406 & 0.485 & 0.348 & 0.417 & 0.386 & 0.461 \\
\hline $\mathrm{N}_{2} \mathrm{O}$ & 0.020 & 0.021 & 0.012 & 0.013 & 0.017 & 0.018 & 0.013 & 0.014 \\
\hline
\end{tabular}

Units are in grams per mile 
Table 3-18

Emission Factors of Standard Vehicles for 2050 in US

\begin{tabular}{|l|c|c|c|c|c|c|c|c|}
\hline \multirow{3}{*}{ Pollutant } & \multicolumn{9}{|c|}{ Emission Factors 2050 } & \multicolumn{3}{c|}{ GH GI } & \multicolumn{3}{c|}{ GH GC } \\
\cline { 2 - 10 } & \multicolumn{2}{|c|}{ Gasoline } & \multicolumn{2}{|c|}{ Diesel } & LDT1 & PC & LDT1 & \multicolumn{2}{c|}{ PC } & LDT1 \\
\hline $\mathrm{PM}_{10}$ & 0.079 & 0.093 & 0.058 & 0.069 & 0.061 & 0.072 & 0.178 & 0.211 \\
\hline $\mathrm{PM}_{2.5}$ & 0.036 & 0.042 & 0.027 & 0.034 & 0.027 & 0.033 & 0.055 & 0.066 \\
\hline $\mathrm{NO}_{x}$ & 0.314 & 0.356 & 0.229 & 0.298 & 0.201 & 0.253 & 0.247 & 0.304 \\
\hline $\mathrm{VOC}$ & 0.009 & 0.313 & 0.083 & 0.091 & 0.180 & 0.216 & 0.130 & 0.156 \\
\hline $\mathrm{CO}$ & 2.30 & 3.21 & 0.083 & 0.427 & 3.21 & 3.18 & 2.18 & 2.16 \\
\hline $\mathrm{SO}_{x}$ & 0.086 & 0.138 & 0.532 & 0.092 & 0.077 & 0.092 & 0.288 & 0.345 \\
\hline $\mathrm{CO}_{2}$ & 322 & 492 & 347 & 415 & 274 & 328 & 287 & 344 \\
\hline $\mathrm{CH}_{4}$ & 0.000 & 0.600 & 0.387 & 0.463 & 0.332 & 0.398 & 0.368 & 0.440 \\
\hline $\mathrm{N}_{2} \mathrm{O}$ & 0.000 & 0.021 & 0.012 & 0.012 & 0.016 & 0.017 & 0.012 & 0.014 \\
\hline
\end{tabular}

Units are in grams per mile 
Table 3-19

Baseline Emission Factors for HFCVs for Passenger Cars

\begin{tabular}{|c|c|c|c|c|c|c|c|c|c|}
\hline \multirow[b]{2}{*}{ Pollutant } & \multirow{2}{*}{$\begin{array}{c}\text { Dispersed } \\
\text { Natural Gas }\end{array}$} & \multicolumn{8}{|c|}{ Central Production $^{1}$} \\
\hline & & Natural Gas & Solar & $\begin{array}{l}\text { Nuclear } \\
\text { TCWC }\end{array}$ & $\begin{array}{l}\text { Nuclear } \\
\text { HTGR }\end{array}$ & Coal $^{2}$ & Coal $^{3}$ & Biomass $^{2}$ & Biomass $^{3}$ \\
\hline$P M_{10}$ & 0.094 & 0.107 & 0.080 & 0.08 & 0.086 & 0.63 & 0.65 & 0.09 & 0.13 \\
\hline$P M_{2.5}$ & 0.046 & 0.049 & 0.023 & 0.02 & 0.025 & 0.16 & 0.16 & 0.03 & 0.04 \\
\hline$N O_{x}$ & 0.145 & 0.166 & 0.051 & 0.06 & 0.065 & 0.06 & 0.08 & 0.12 & 0.16 \\
\hline VOC & 0.025 & 0.024 & 0.004 & 0.01 & 0.005 & 0.03 & 0.03 & 0.01 & 0.01 \\
\hline $\mathrm{CO}$ & 0.060 & 0.060 & 0.013 & 0.02 & 0.018 & 0.03 & 0.03 & 0.04 & 0.05 \\
\hline $\mathrm{SO}_{x}$ & 0.117 & 0.139 & 0.107 & 0.12 & 0.119 & 0.16 & 0.20 & 0.16 & 0.23 \\
\hline $\mathrm{CO}_{2}$ & 218 & 226 & 46.7 & 51.7 & 53 & 411 & 103 & 40.6 & -300 \\
\hline $\mathrm{CH}_{4}$ & 0.719 & 0.448 & 0.066 & 0.07 & 0.077 & 0.45 & 0.47 & 0.090 & 0.13 \\
\hline $\mathrm{N}_{2} \mathrm{O}$ & 0.001 & 0.001 & 0.001 & 0.00 & 0.001 & 0.001 & 0.001 & 0.004 & 0.01 \\
\hline
\end{tabular}

1.Units are in grams per mile

2.Without carbon sequestration

3. With carbon sequestration 
Table 3-20

Baseline Emission Factors for HFCVs for LDT1

\begin{tabular}{|c|c|c|c|c|c|c|c|c|c|}
\hline \multirow[b]{2}{*}{ Pollutant } & \multirow{2}{*}{$\begin{array}{c}\text { Dispersed } \\
\text { Natural Gas }\end{array}$} & \multicolumn{8}{|c|}{ Central Production $^{1}$} \\
\hline & & Natural Gas & Solar & $\begin{array}{l}\text { Nuclear } \\
\text { TCWC }\end{array}$ & $\begin{array}{l}\text { Nuclear } \\
\text { HTGR }\end{array}$ & Coal $^{2}$ & Coal $^{3}$ & Biomass $^{2}$ & Biomass $^{3}$ \\
\hline$P M_{10}$ & 0.109 & 0.124 & 0.091 & 0.098 & 0.099 & 0.750 & 0.769 & 0.106 & 0.128 \\
\hline$P M_{2.5}$ & 0.053 & 0.058 & 0.026 & 0.028 & 0.028 & 0.190 & 0.195 & 0.032 & 0.038 \\
\hline$N O_{x}$ & 0.174 & 0.199 & 0.060 & 0.074 & 0.078 & 0.070 & 0.099 & 0.140 & 0.159 \\
\hline VOC & 0.030 & 0.029 & 0.005 & 0.006 & 0.006 & 0.040 & 0.041 & 0.013 & 0.014 \\
\hline $\mathrm{CO}$ & 0.072 & 0.072 & 0.016 & 0.020 & 0.021 & 0.030 & 0.039 & 0.046 & 0.051 \\
\hline $\mathrm{SO}_{x}$ & 0.140 & 0.167 & 0.128 & 0.139 & 0.142 & 0.190 & 0.234 & 0.191 & 0.232 \\
\hline $\mathrm{CO}_{2}$ & 261 & 271 & 55.9 & 61.9 & 63.4 & 492 & 124 & 48.6 & -300 \\
\hline $\mathrm{CH}_{4}$ & 0.861 & 0.536 & 0.079 & 0.090 & 0.093 & 0.540 & 0.565 & 0.107 & 0.133 \\
\hline $\mathrm{N}_{2} \mathrm{O}$ & 0.001 & 0.002 & 0.001 & 0.001 & 0.001 & 0.003 & 0.001 & 0.005 & 0.005 \\
\hline
\end{tabular}

1.Units are in grams per mile

2.Without carbon sequestration

3.With carbon sequestration 
Using the above information, the estimated future total emissions without HFCVs are shown in Table 3-21 for the US. It is important to note that emissions would increase between 2030 and 2050 even without conversion to HFCVS. For the two scenarios described previously in Section 3.3.2 with HFCVs generated by a combination of methods, the net change in total emissions is shown for 2030 in Table 3-22.

Table 3-21

Total Estimated Baseline Emissions without HFCVs in US

\begin{tabular}{|l|c|c|c|c|}
\hline \multirow{2}{*}{ Pollutant } & \multicolumn{2}{|c|}{2030} & \multicolumn{2}{|c|}{2050} \\
\cline { 2 - 5 } & Scenario 1 & Scenario 2 & Scenario 1 & Scenario 2 \\
\hline$P M_{10}$ & 245,000 & 306,000 & 256,000 & 407,000 \\
\hline$M_{2.5}$ & 107,000 & 116,000 & 115,000 & 141,000 \\
\hline$N_{x}$ & 900,000 & 756,000 & 985,000 & 784,000 \\
\hline$V O C$ & 792,000 & 577,000 & 437,000 & 514,000 \\
\hline $\mathrm{CO}$ & $9,300,000$ & $8,440,000$ & $8,290,000$ & $8,040,000$ \\
\hline $\mathrm{SO}_{x}$ & 353,000 & 451,000 & 368,000 & 668,000 \\
\hline $\mathrm{CO}_{2}$ & $1,270,000,000$ & $988,000,000$ & $1,190,000,000$ & $972,000,000$ \\
\hline $\mathrm{CH}_{4}$ & $1,540,000$ & $1,210,000$ & 846,000 & $1,210,000$ \\
\hline $\mathrm{N}_{2} \mathrm{O}$ & 57,600 & 47,878 & 30,600 & 46,000 \\
\hline
\end{tabular}

Units are in metric tons

Baseline emission reductions are derived from baseline emission factors to estimate the effect of the reduced miles traveled using non-HFCVs. The change in emissions results from the elimination of fossil-fuel based vehicle emissions and the replacement with HFCVs emissions.

Table 3-22

Net Estimated Change in Emissions in 2030 in US with HFCVs

\begin{tabular}{|c|c|c|c|c|c|c|}
\hline \multirow[b]{3}{*}{ Pollutant } & \multicolumn{6}{|c|}{2030} \\
\hline & \multicolumn{3}{|c|}{ Scenario 1} & \multicolumn{3}{|c|}{ Scenario 2} \\
\hline & $\begin{array}{c}\text { Eliminated } \\
\text { Baseline } \\
\text { Emissions }\end{array}$ & $\begin{array}{c}\text { Added } \\
\text { Emissions } \\
\text { from HFCVs }\end{array}$ & $\begin{array}{l}\text { Change in } \\
\text { Emissions }\end{array}$ & $\begin{array}{l}\text { Eliminated } \\
\text { Baseline } \\
\text { Emissions }\end{array}$ & $\begin{array}{c}\text { Added } \\
\text { Emissions from } \\
\text { HFCVs }\end{array}$ & $\begin{array}{l}\text { Change in } \\
\text { Emissions }\end{array}$ \\
\hline$P M_{10}$ & 6,120 & 6,770 & 649 & 39,700 & 35,200 & $-4,560$ \\
\hline$P M_{2.5}$ & 2,680 & 3,300 & 619 & 15,100 & 17,200 & 2,080 \\
\hline$N O_{x}$ & 22,500 & 10,600 & $-11,900$ & 98,200 & 55,000 & $-43,200$ \\
\hline VOC & 19,800 & 1,800 & $-18,000$ & 75,000 & 9,380 & $-65,600$ \\
\hline $\mathrm{CO}$ & 232,000 & 4,360 & $-228,000$ & $1,100,000$ & 22,700 & $-1,070,000$ \\
\hline $\mathrm{SO}_{x}$ & 8,830 & 8,530 & -296 & 58,700 & 44,400 & $-14,300$ \\
\hline $\mathrm{CO}_{2}$ & $31,800,000$ & $16,000,000$ & $-15,800,000$ & $128,000,000$ & $82,900,000$ & $-45,500,000$ \\
\hline $\mathrm{CH}_{4}$ & 38,600 & 52,500 & 13,940 & 158,000 & 273,000 & 115,000 \\
\hline $\mathrm{N}_{2} \mathrm{O}$ & 1,410 & 78 & $-1,340$ & 6,220 & 407 & $-5,820$ \\
\hline
\end{tabular}

Units are in metric tons

A decrease in emissions is estimated to occur when replacing the baseline emissions with HFCV emissions for all pollutants except $\mathrm{PM}_{10}, \mathrm{PM}_{2.5}$, and $\mathrm{CH}_{4}$ for Scenario 1 and $\mathrm{PM}_{2.5}$ and $\mathrm{CH}_{4}$ for Scenario 2 in 2030. The methane increases are due to use of the steam reforming process for producing the hydrogen. The increased particulates in Scenario 1 in 2030 are due to the steam reforming generation process and trucks for fuel delivery. Methane or particulates are not 
emitted from the HFCVs during operation. A 16 million metric ton decrease would result for $\mathrm{CO}_{2}$ emissions for Scenario 1 in 2030. Under Scenario 2 in 2030, converting a larger fraction to HFCVs is estimated to reduce $\mathrm{CO}_{2}$ emissions by 46 million metric tons. Another difference between the two scenarios in 2030 is that there are more grid-connected hybrids under Scenario 2 , where the mix of electricity generation methods would influence the total emissions. Total VOCs are less for the two scenarios in 2030, even though the method used to generate the hydrogen is steam reforming of methane from natural gas at distributed refueling stations. The specific VOCs are not provided by the GREET model, but can be speciated using VOC profiles from the EPA model SPECIATE, described in the database documentation report (EPA, 2006). Total VOCs were speciated using this model for input to GATOR-GCMOM, but were not for the sensitivity analyses.

A decrease in emissions is expected when replacing the baseline emissions with HFCV emissions for all pollutants except $\mathrm{PM}_{10}, \mathrm{PM}_{2.5}, \mathrm{SO}_{\mathrm{x}}$, and $\mathrm{CH}_{4}$ for Scenario 1 and $\mathrm{PM}_{10}$ and $\mathrm{PM}_{2.5}$ for Scenario 2 in 2050, as shown in Table 3-23. The increase in SOx is thought to be due to the increased use of coal with sequestration for generating the hydrogen. Large decreases in $\mathrm{CO}_{2}$ emissions with HFCVs are estimated for both scenarios for 2050, but especially for Scenario 2. This is partly an artifact of the method of accounting for use of biomass with sequestration where the $\mathrm{CO}_{2}$ that would be released on combustion of the biomass is counted as carbon neutral for the without sequestration case, and a $\mathrm{CO}_{2}$ reduction for the with sequestration case. Emissions are higher for coal with sequestration than without due to addition of energy required for capture, transport, and storage. As the efficiency of carbon capture methods improve, energy requirements would be expected to decrease.

Table 3-23

Net Estimated Change in Emissions in 2050 in US with HFCVs

\begin{tabular}{|c|c|c|c|c|c|c|}
\hline \multirow[b]{3}{*}{ Pollutant } & \multicolumn{6}{|c|}{2050} \\
\hline & \multicolumn{3}{|c|}{ Scenario 1} & \multicolumn{3}{|c|}{ Scenario 2} \\
\hline & $\begin{array}{l}\text { Eliminated } \\
\text { Baseline } \\
\text { Emissions }\end{array}$ & $\begin{array}{c}\text { Added } \\
\text { Emissions } \\
\text { from HFCVs }\end{array}$ & $\begin{array}{l}\text { Change in } \\
\text { Emissions }\end{array}$ & $\begin{array}{l}\text { Eliminated } \\
\text { Baseline } \\
\text { Emissions }\end{array}$ & $\begin{array}{c}\text { Added } \\
\text { Emissions } \\
\text { from HFCVs }\end{array}$ & $\begin{array}{l}\text { Change in } \\
\text { Emissions }\end{array}$ \\
\hline$P M_{10}$ & 180,000 & 968,000 & 789,000 & 358,000 & 964,000 & 605,000 \\
\hline$P M_{2.5}$ & 80,800 & 259,000 & 178,000 & 124,000 & 257,000 & 132,000 \\
\hline$N O_{x}$ & 690,000 & 190,000 & $-501,000$ & 691,000 & 316,000 & $-375,000$ \\
\hline VOC & 306,000 & 63,900 & $-242,000$ & 453,000 & 65,000 & $-388,000$ \\
\hline $\mathrm{CO}$ & $5,810,000$ & 78,700 & $-5,730,000$ & $7,080,000$ & 112,000 & $-6,970,000$ \\
\hline $\mathrm{SO}_{x}$ & 253,000 & 319,000 & 66,100 & 590,000 & 530,000 & $-60,100$ \\
\hline $\mathrm{CO}_{2}$ & $834,000,000$ & $730,000,000$ & $-104,000,000$ & $858,000,000$ & $-129,000,000$ & $-987,000,000$ \\
\hline $\mathrm{CH}_{4}$ & 593,000 & $1,100,000$ & 504,000 & $1,060,000$ & 927,000 & $-138,000$ \\
\hline $\mathrm{N}_{2} \mathrm{O}$ & 21,4000 & 3,280 & $-18,100$ & 40,700 & 7,230 & $-33,400$ \\
\hline
\end{tabular}

Units are in metric tons

Emission reductions, by percent, for the US hydrogen fuel vehicle fleet are listed in Table 3-24. These percentages were derived from the baseline emissions resulting from a non-hydrogen vehicle fleet compared to the HFCV emissions replacement. Methodology for producing hydrogen fuel does affect the well-to-wheels cycle for vehicle emissions from using HFCVs. Compared to the same number of vehicle miles traveled without HFCVs, there are small 
increases in particulates and methane in the 2030 scenarios, but large particulate increases by 2050 for both scenarios, but only in one scenario for methane and SOx.

Table 3-24

Percent Change in Emissions in 2030 and 2050 with HFCVs in US Vehicle Fleet

\begin{tabular}{|l|c|c|c|c|}
\hline \multirow{2}{*}{ Pollutant } & \multicolumn{2}{|c|}{2030} & \multicolumn{2}{c|}{2050} \\
\cline { 2 - 5 } & Scenario 1 & Scenario 2 & Scenario 1 & Scenario 2 \\
\hline$P M_{10}$ & 0.27 & -1.49 & 307 & 149 \\
\hline $\mathrm{NO}_{2.5}$ & 0.58 & 1.79 & 154 & -47.9 \\
\hline $\mathrm{VOC}$ & -1.32 & -5.72 & 50.8 & -75.5 \\
\hline $\mathrm{CO}$ & -2.27 & -11.4 & -55.4 & -86.6 \\
\hline $\mathrm{SO}_{x}$ & -2.45 & -12.7 & -69.1 & -9 \\
$\mathrm{CO}_{2}$ & -0.08 & -3.17 & 17.9 & -101 \\
\hline $\mathrm{CH}_{4}$ & -1.24 & -4.60 & -8.74 & -11.4 \\
\hline $\mathrm{N}_{2} \mathrm{O}$ & 0.9 & -9.52 & 59.7 & -72.5 \\
\hline
\end{tabular}

\subsubsection{Changes in Emissions for Alternative Hydrogen Production Methods}

The emission factors on a g/mile basis from HFCVs with the hydrogen generated using a variety of methods were shown in Table 3-19 for cars and in Table 3-20 for light-duty trucks. For example, if steam reforming using natural gas is conducted at dispersed facilities instead of centralized facilities, there is a slight increase in emissions of VOCs, $0.025 \mathrm{~g} / \mathrm{mile}$ instead of $0.024 \mathrm{~g} / \mathrm{mile}$, but a larger increase in methane, $0.719 \mathrm{~g} / \mathrm{mile}$ instead of $0.448 \mathrm{~g} / \mathrm{mile}$, which could be attributed to the methane in fuel used for trucks to transport fuel or to decreased efficiencies of the smaller process units compared to the larger, centralized facilities. One difference between the emissions factors used for the wind-based case with GATOR-GCMOM and those from the GREET model are that GREET includes emissions from transportation of the fuel in the renewables case (e.g. solar). In general, the emission factors for solar-produced hydrogen were the lowest of the options. The benefit to $\mathrm{CO}_{2}$ emissions is considered when sequestration is included, although there are small increases in particulates, $\mathrm{SO}_{\mathrm{x}}$, and methane due to the increased energy needed. Production of hydrogen using coal has the highest emission factors for most of the parameters compared to the other methods included in GREET. Dispersed natural gas has the highest emission factors for methane, $\mathrm{NO}_{\mathrm{x}}$, and $\mathrm{CO}$.

Sensitivity analyses for the 2050 Scenario 2 case showed that use of coal for generating hydrogen fuel is a strong influence on particulate emissions. If the amount of hydrogen produced by coal is increased from 45 percent to 87 percent to represent the case with no production using biomass, $\mathrm{PM}_{10}$ would increase significantly from 146 percent to 287 percent. If the coal was sequestered, a small increase in $\mathrm{PM}_{10}$ is predicted due to the additional energy needed for compressing the $\mathrm{CO}_{2}$, transporting it, and sequestrating it. The increase in particulates could be mitigated by additional flue gas controls. The changes in $\mathrm{PM}_{2.5}$ exhibit a similar response, but also could be reduced by flue gas controls. The benefit of sequestrating the $\mathrm{CO}_{2}$ was estimated as a decrease of 56 percent. Using biomass reduces the particulates by 27 to 31 percent and methane emissions by about 54 percent. Emissions of $\mathrm{NO}_{\mathrm{X}}, \mathrm{N}_{2} \mathrm{O}$, VOCs, and $\mathrm{CO}$ are similar for the cases using coal or biomass. These results confirm the influence of the method used to generate the hydrogen fuel for the HFCVs on total estimated emissions. 


\subsubsection{Changes in Emissions for Alternative Electricity Production Methods}

Sensitivity analyses were conducted for Scenario 1 in 2050 using different sources of electricity such as 0-55 percent coal, 2.6-6 percent oil, 0-24.3 \% natural gas, 16.3-33\% nuclear, 0-10\% biomass, and 6-46.8 \% hydro and other renewables. The results showed that the share based on coal has the largest influence, especially on the particulates and $\mathrm{SO}_{\mathrm{x}}$. However, overall the percent changes in emissions with HFCVs were similar regardless of method used for electricity, except for $\mathrm{SO}_{\mathrm{x}}$ and particulates. The differences in emissions between the cases were less than 0.5 percent for particulates and 1 percent for $\mathrm{SO}_{\mathrm{x}}$. Thus, the methods used for electricity have a minor influence on the total emissions.

\subsubsection{Changes in Emissions for Different Vehicle Types}

Sensitivity analyses were conducted to estimate the effect of having grid-independent hybrids or grid-connected hybrids for Scenario 1 in 2030. When the hybrid vehicles are all grid-connected, increased electricity is used, which increases particulates and $\mathrm{SO}_{\mathrm{x}}$. The other parameters remained essentially unaffected. There were small differences in emission factors between these two vehicle types as seen in Table 3-18, but the largest differences were for particulates and $\mathrm{SO}_{\mathrm{x}}$.

\subsubsection{Sensitivity Analyses for Selected Countries}

In addition, to the US sensitivity analyses, separate GREET-based analyses were conducted for Western Europe and six other countries actively developing hydrogen vehicles (Canada, Australia, China, Japan, South Korea, and New Zealand). The input parameters for each country were developed using downscaled population data for the IPCC A1B case in 2030 and 2050, estimated vehicle type and ownership rates, fuel types and methods for generating hydrogen, and methods for producing electricity. Estimates for the penetration of hydrogen vehicles for these countries were estimated as projected percentages of US hydrogen vehicle penetration rates. Both Scenarios for 2030 have a low percent conversion to HFCVs, 2.5 percent for Scenario 1 and 13 percent for Scenario 2, except for China. In 2050, the conversion to HFCVs was 70 percent for Scenario 1 and 88 percent for Scenario 2. The conversion rate used in China was half of the value used for other countries.

Electricity energy supply for each country was based on the 2005 baseline energy statistics as shown in Table 3-25 (IEA, 2008). The predicted methods used to produce hydrogen in these countries are shown in Table 3-26 for 2030 and 2050. Canada and the US were projected to use North American natural gas, while the other countries were projected to use natural gas from other areas. In Australia and China, the feedstocks used to produce hydrogen in 2030 are expected to be equally divided between natural gas and coal due to the primary use of coal for energy and its plentiful supply in those countries. Nuclear energy is an important source of electricity in Japan, South Korea, and Western Europe. Thus, it was projected to be used to generate some hydrogen in the future for those countries. In 2050, one scenario simulated use of all dispersed steam reforming of natural gas, while a second scenario simulated use of all centralized steam reforming of natural gas. Inputs for vehicle and fuel types, and annual miles traveled by vehicle type for the countries are included in Appendix A. 
Table 3-25

Energy Sources Used for Generating Electricity in GREET

\begin{tabular}{|l|c|c|c|c|c|c|}
\hline \multirow{2}{*}{\multicolumn{1}{c|}{ Country }} & \multicolumn{7}{c|}{ 2005 Energy Market Share Percentage } \\
\cline { 2 - 8 } & Oil & Natural Gas & Coal & Nuclear & Biomass & Other \\
\hline Australia & 0.8 & 11.7 & 80.1 & 0.0 & 4.3 & 3.1 \\
\hline Canada & 3.4 & 10.2 & 16.0 & 13.9 & 1.4 & 55.1 \\
\hline China $^{2}$ & 3.2 & 2.1 & 84.9 & 1.1 & 0.3 & 8.4 \\
\hline Japan & 13.0 & 21.8 & 27.5 & 27.0 & 2.3 & 8.4 \\
\hline New Zealand & 0.0 & 21.8 & 13.4 & 0.0 & 1.6 & 63.2 \\
\hline South Korea & 21.7 & 18.9 & 31.6 & 25.2 & 1.6 & 1.0 \\
\hline Western Europe & 4.7 & 27.2 & 26.1 & 14.8 & 6.5 & 20.7 \\
\hline
\end{tabular}

${ }^{1}$ IEA, 2008

${ }^{2}$ APERC, 2004)

Table 3-26

Projected Methods to Produce Hydrogen in Selected Countries

\begin{tabular}{|l|c|c|c|c|c|c|c|}
\hline $\begin{array}{c}\text { Proposed H2 Production } \\
\text { Methods 2030 Scenarios 1/2* }\end{array}$ & Canada & Australia & China & Japan & $\begin{array}{c}\text { New } \\
\text { Zealand }\end{array}$ & $\begin{array}{c}\text { South } \\
\text { Korea }\end{array}$ & $\begin{array}{c}\text { Western } \\
\text { Europe }\end{array}$ \\
\hline NG dispersed & $100 \%$ & - & - & $70 \%$ & - & - & - \\
\hline NG central & - & $50 \%$ & $20 \%$ & - & $80 \%$ & $70 \%$ & $70 \%$ \\
\hline Solar & - & - & - & - & $20 \%$ & - & - \\
\hline N-TCWC & - & - & - & $30 \%$ & - & $30 \%$ & $30 \%$ \\
\hline $\begin{array}{l}\text { Coal Gasification w/o } \\
\text { Sequestration }\end{array}$ & - & $50 \%$ & $80 \%$ & - & - & - & - \\
\hline Total & $100 \%$ & $100 \%$ & $100 \%$ & $100 \%$ & $100 \%$ & $100 \%$ & $100 \%$ \\
\hline
\end{tabular}

*In 2050, Scenario 1 used distributed natural gas for all countries; Scenario 2 used centralized natuaral gas facilities.

NG = natural gas; N-TCWC = nuclear thermo-chemical water cracking; w/o refers to without carbon sequestration

Projected methods for producing hydrogen were based on information from IEA, 2008 and APERC, 2004

The estimated emissions in 2030 and the predicted changes from the GREET model by country are shown in Table 3-27. The differences between countries are a function of the number of vehicles and rate of conversion, as well as the methods used to produce the hydrogen. For Canada, emissions are predicted to decrease for most compounds, but not $\mathrm{PM}_{2.5}$ or methane due to the increased combustion of natural gas. For Japan and South Korea, there was a predicted increase in methane and $\mathrm{SO}_{\mathrm{x}}$ emissions in both countries, but smaller changes in particulates when the hydrogen is produced at centralized plants rather than distributed plants. In Australia and China where coal gasification without sequestration were projected to be used to generate hydrogen, particulates and $\mathrm{SO}_{\mathrm{x}}$ were predicted to increase, along with methane from the natural gas production. In New Zealand where centralized natural gas plants and electrolysis by solar facilities were projected to produce hydrogen, there were decreases in all compounds, except methane and no change in $\mathrm{PM}_{2.5}$ emissions. As shown in Table 3-19, using solar-powered electricity to generate hydrogen results in less emissions on a g/mile basis, but the GREET model includes emissions from transportation of the hydrogen so the emissions are not zero. 
Table 3-27
Estimated Emissions with HFCVs for Scenario 1 in 2030 for Other Countries

\begin{tabular}{|c|c|c|c|c|c|c|c|c|c|c|c|c|c|c|}
\hline \multirow[b]{2}{*}{ Compound } & \multicolumn{2}{|c|}{ Canada } & \multicolumn{2}{|c|}{ Western Europe } & \multicolumn{2}{|c|}{ Japan } & \multicolumn{2}{|c|}{ Australia } & \multicolumn{2}{|c|}{ New Zealand } & \multicolumn{2}{|c|}{ South Korea } & \multicolumn{2}{|c|}{ China } \\
\hline & 2030 Base Case & Change* $^{*}$ & 2030 Base Case & Change & 2030 Base Case & Change & 2030 Base Case & Change & 2030 Base Case & Change & 2030 Base Case & Change & 2030 Base Case & Change \\
\hline $\mathrm{PM}_{10}$ & 19,800 & -100 & 137,000 & 0 & 34,100 & -100 & 9,090 & 640 & 1,140 & -10 & 14,300 & 0 & 78,000 & 4,500 \\
\hline $\mathrm{PM}_{2.5}$ & 9,300 & 20 & 64,300 & 200 & 15,600 & 0 & 3,690 & 160 & 540 & 0 & 6,460 & 10 & 31,500 & 1,000 \\
\hline $\mathrm{NO}_{x}$ & 81,200 & $-1,200$ & 562,000 & $-4,000$ & 137,000 & $-1,000$ & 28,000 & -200 & 4,830 & -40 & 56,700 & -400 & 238,000 & $-2,000$ \\
\hline VOC & 72,600 & $-1,700$ & 380,000 & $-9,000$ & 118,000 & $-3,000$ & 23,700 & -500 & 4,170 & -100 & 48,300 & $-1,200$ & 205,000 & $-2,000$ \\
\hline co & 852,000 & $-22,000$ & $4,210,000$ & $-100,000$ & $1,400,000$ & $-30,000$ & 277,000 & $-7,000$ & 48,100 & $-1,200$ & 577,000 & $-15,000$ & $2,400,000$ & $-30,000$ \\
\hline $\mathrm{SO}_{\mathrm{x}}$ & 28,200 & -200 & 194,000 & 1,000 & 54,400 & 100 & 12,400 & 200 & 1,580 & -10 & 24,800 & 300 & 109,000 & 1,000 \\
\hline $\mathrm{CO}_{2}$ & $1.16 \mathrm{E}+08$ & $-1,000,000$ & $7.93 E+08$ & $-12,000,000$ & $1.90 E+08$ & $-2,000,000$ & $3.90 \mathrm{E}+07$ & $-300,000$ & $6.81 E+06$ & $-100,000$ & $7.81 \mathrm{E}+07$ & $-1,100,000$ & $3.36 \mathrm{E}+08$ & 0 \\
\hline $\mathrm{CH}_{4}$ & 144,000 & 1,000 & 969,000 & 4,000 & 239,000 & 2,000 & 48,200 & 200 & 8,570 & 30 & 97,600 & 100 & 405,000 & 0 \\
\hline $\mathrm{N}_{2} \mathrm{O}$ & 5,170 & -120 & 32,500 & -700 & 8,460 & -210 & 1,700 & -40 & 299 & -8 & 3,490 & -80 & 14,600 & -200 \\
\hline
\end{tabular}

*Change is the 2030 Base Case minus the 2030 Scenario 1 with HFCVs Case 
The emissions for the 2050 base case without HFCVs are shown in Table 3-28 for the seven countries simulated with the GREET model. Table 3-29 lists emission estimates for the 2050 Scenario 2 case with HFCVs generated by centralized natural gas plants for the same countries.

Table 3-28

Estimated Emissions for 2050 Scenario 2 without HFCVs for Other Countries

\begin{tabular}{|l|c|c|c|c|c|c|c|}
\hline \multicolumn{1}{|c|}{ Pollutant } & Canada & $\begin{array}{c}\text { Western } \\
\text { Europe }\end{array}$ & Japan & Australia & New Zealand & South Korea & China \\
\hline $\mathrm{PM}_{10}$ & 36,500 & 265,000 & 57,000 & 15,000 & 2,020 & 24,400 & 286,000 \\
\hline $\mathrm{PM}_{2.5}$ & 12,800 & 92,200 & 19,900 & 5,130 & 713 & 8,510 & 97,800 \\
\hline $\mathrm{NO}_{x}$ & 72,800 & 522,000 & 113,000 & 28,000 & 4,150 & 48,600 & 529,000 \\
\hline$V O C$ & 48,600 & 345,000 & 74,300 & 18,000 & 2,420 & 31,600 & 342,000 \\
\hline $\mathrm{CO}$ & 761,000 & $5,610,000$ & $1,20,000$ & 282,000 & 36,800 & 508,000 & $5,340,000$ \\
\hline $\mathrm{SO}_{x}$ & 60,300 & 449,000 & 98,600 & 24,400 & 3,360 & 43,300 & 469,000 \\
\hline $\mathrm{CO}_{2}$ & $9.06 \mathrm{E}+07$ & $6.48 \mathrm{E}+08$ & $1.40 \mathrm{E}+08$ & $3.44 \mathrm{E}+07$ & $5.24 \mathrm{E}+06$ & $5.97 \mathrm{E}+07$ & $6.54 \mathrm{E}+08$ \\
\hline $\mathrm{CH}_{4}$ & 113,000 & 817,000 & 176,000 & 43,000 & 6,520 & 74,900 & 805,000 \\
\hline $\mathrm{N}_{2} \mathrm{O}$ & 4,350 & 31,800 & 6,780 & 1,620 & 233 & 2,880 & 30,700 \\
\hline
\end{tabular}

Units are metric tons.

Table 3-29

Estimated Emissions with HFCVs for Scenario 2 in 2050

\begin{tabular}{|l|c|c|c|c|c|c|c|}
\hline \multicolumn{1}{|c|}{ Pollutant } & Canada & $\begin{array}{c}\text { Western } \\
\text { Europe }\end{array}$ & Japan & Australia & New Zealand & South Korea & China \\
\hline $\mathrm{PM}_{10}$ & 39,800 & 500,000 & 108,000 & 40,900 & 2,920 & 43,500 & 700,000 \\
\hline $\mathrm{PM}_{2.5}$ & 12,700 & 139,000 & 30,500 & 11,100 & 910 & 12,200 & 193,000 \\
\hline $\mathrm{NO}_{x}$ & 31,900 & 172,000 & 57,500 & 17,200 & 2,220 & 24,900 & 409,000 \\
\hline $\mathrm{VOC}$ & 10,600 & 26,700 & 16,800 & 4,690 & 572 & 6,810 & 220,000 \\
\hline $\mathrm{CO}$ & 98,700 & 634,000 & 157,000 & 38,000 & 4,960 & 66,100 & $3,030,000$ \\
\hline $\mathrm{SO}_{x}$ & 25,800 & 44,700 & 72,800 & 25,000 & 1,430 & 36,500 & 519,000 \\
\hline $\mathrm{CO}_{2}$ & $4.14 \mathrm{E}+07$ & $6.13 \mathrm{E}+07$ & $5.58 \mathrm{E}+07$ & $1.70 \mathrm{E}+07$ & $2.17 \mathrm{E}+06$ & $4.03 \mathrm{E}+07$ & $4.78 \mathrm{E}+08$ \\
\hline $\mathrm{CH}_{4}$ & 65,400 & 683,000 & 175,000 & 45,500 & 6,830 & 60,900 & 839,000 \\
\hline $\mathrm{N}_{2} \mathrm{O}$ & 1,160 & 0 & 1,220 & 422 & 46 & 499 & 18,600 \\
\hline
\end{tabular}

Units are metric tons.

Particulate emissions, both $\mathrm{PM}_{10}$ and $\mathrm{PM}_{2.5}$, are predicted to increase in all countries. The increases would be less if the hydrogen was generated using dispersed plants, since there would not be truck transportation or a combination of trucks and pipelines to deliver the hydrogen. Emissions of $\mathrm{NO}_{\mathrm{x}}, \mathrm{N}_{2} \mathrm{O}$, VOCs, and $\mathrm{CO}$ were predicted to decrease in all the countries. Other pollutants differ between countries, depending on the numbers of HFCVs. For example, methane is estimated to decrease in most countries, but to increase in Australia, New Zealand, and China due to greater use of natural gas. Considering all the countries evaluated with the GREET model, the predicted changes in emissions in 2050 with the largest number of HFCVs (Scenario 2), only particulates are predicted to increase when the hydrogen is generated using steam reforming of natural gas in centralized plants. For the case with distributed natural gas plants to produce hydrogen and fewer HFCVs, particulates, methane, and $\mathrm{SO}_{\mathrm{X}}$ are predicted to increase. The predicted emissions in a particular country are influenced by the energy source for electricity, the 
method used to generate the hydrogen, and the number and type of vehicles that are replaced by hydrogen.

\subsection{Summary and Conclusions}

Shifting from fossil-fueled vehicles to hydrogen-based vehicles is predicted to decrease emissions of most GHGs and criteria pollutants. Using the SMR method for producing hydrogen for the $2050 \mathrm{~A} 1 \mathrm{~B}$ case resulted in decreases in emissions for $\mathrm{NO}, \mathrm{NO}_{2}, \mathrm{~N} 2 \mathrm{O}, \mathrm{CO}, \mathrm{CO}_{2}$, methane, and the fine fraction of black carbon particles. The emissions of $\mathrm{SO}_{2}$, non-methane VOCs, and fine particulate organic matter were estimated to increase due to the shift to SHFCVs. Using wind-based electrolysis for a contemporary case with a shift to HFCVs resulted in decreases in emissions for $\mathrm{CO}, \mathrm{CO}_{2}$, most nitrogen and sulfur components, and organic gases. Only ammonia emissions were estimated to increase, although particulate emissions were not available for this case. The emissions used for WHFCVs were only from hydrogen leakage and chemicallyproduced water vapor, which is considered a best case scenario. The emissions from the full lifecycle emissions of vehicle and equipment manufacturing, the power needed and the subsequent transport were not considered.

The sensitivity analyses using the GREET1.8b model showed that the emission changes varied depending on the method used to generate the hydrogen. Emissions of methane and other VOCs were greater by a factor of 1.6 and 1.04, respectively, if dispersed facilities were used to generate hydrogen using the SMR process instead of centralized facilities. The renewable methods such as solar had the lowest emissions on a g/mile basis for all compounds, except $\mathrm{PM}_{2.5}$ which was lowest for the nuclear thermo-chemical water conversion (TCWC) process. For example, $\mathrm{NO}_{\mathrm{x}}$ emissions for solar-generated $\mathrm{H}_{2}$ were estimated to be a factor of 3.2 lower and methane was a factor of 6.8 times lower than for centralized SMR. Coal-based methods without sequestration had higher emissions on a g/mile basis for particulates (a factor of 5.9 times greater than centralized SMR), $\mathrm{SO}_{\mathrm{x}}$ (a factor of 1.15 times greater), and $\mathrm{CO}_{2}$ (a factor of 1.8 times greater than SMR). The particulates for coal with sequestration were slightly higher than coal without sequestration due to the additional power to capture and compress the $\mathrm{CO}_{2}$.

The sensitivity analyses for the US showed that shifting to HFCVs using a mix of methods with sequestration in 2050 decreased estimated emissions of all compounds except particulates. $\mathrm{SO}_{\mathrm{x}}$ and methane were predicted to increase if coal without sequestration was used in the US in 2050. The methods used to generate electricity affected the particulate and $\mathrm{SO}_{\mathrm{x}}$ emissions, but had a small effect for the US case simulated. Use of more grid-connected hybrid vehicles resulted in small differences in emissions; particulates and $\mathrm{SO}_{\mathrm{x}}$ increased due to use of more electricity.

The sensitivity analyses in other countries used a wider range of methods for generating hydrogen than SMR. These simulations showed that the percent of coal used for generating hydrogen is an important factor in estimating the changes in future emissions after shifting to HFCVs in 2050. $\mathrm{CO}_{2}, \mathrm{CO}, \mathrm{NO}_{\mathrm{x}}, \mathrm{N}_{2} \mathrm{O}$, and VOCs were predicted to decrease after the shift to HFCVs, while particulate emissions were predicted to increase in the countries evaluated. Other factors that influenced the emissions in other countries were the number and types of vehicles.

The major conclusions of the emission analyses were as follows:

1. There were large predicted emission increases for most chemicals between 2000 and the 2050 A1B scenario on a global basis. The A1B scenario represents a middle ground between the coal-intensive A1F1 scenario and the renewable-intensive A1T scenario and 
used a mid-range estimate for world population in 2050. The A1B scenario is considered to be more likely than these two extreme scenarios. Estimated $\mathrm{CO}_{2}$ emissions for the 2050 A1B scenario were in the middle of the range of predicted $\mathrm{CO}_{2}$ emissions, as shown previously in Figure 3-2.

2. There was considerable variability for the specific emission growth factors on a regional and country level basis between 2000 and the 2050 A1B scenario, depending on the predicted increase in industrial activity. The estimated changes in energy use were much larger for the less developed countries where a larger percentage growth in industrial production is anticipated. Similar differences in emission growth factors between countries and regions were observed for the 2050 A1B case with SHFCVs. Additional investigation would be needed to evaluate the reasons for the differences.

3. Shifting from fossil-fueled vehicles to hydrogen-based vehicles is predicted to decrease emissions of most GHGs and criteria pollutants. The GATOR-GCMOM simulation used the SMR method for producing hydrogen for the 2050 A1B case with HFCVs. Emissions were predicted to decrease for $\mathrm{NO}, \mathrm{NO}_{2}, \mathrm{~N}_{2} \mathrm{O}, \mathrm{CO}, \mathrm{CO}_{2}$, methane, and the fine fraction of black carbon particles. The emissions of $\mathrm{SO}_{2}$, non-methane VOCs, and fine particulate organic matter were estimated to increase due to the shift to SHFCVs. If a renewable method such as solar or wind-based electrolysis were used instead of SMR, the particulate, $\mathrm{SO}_{2}$, and methane would be estimated to decrease for the same number of SHFCVs.

4. Sensitivity analyses using the GREET model showed that emission factors on a g/mile basis differ significantly, up to a factor of 9, depending on the source of the hydrogen. The GREET model includes emissions from associated transportation, which means that renewables method such as solar or wind-based electrolysis have low level emissions of particulates, $\mathrm{SO}_{\mathrm{x}}$, and $\mathrm{NO}_{\mathrm{x}}$ and VOCs. The WHFCVs case simulated with GATORGCMOM included only emissions of hydrogen leakage and water vapor. 



\section{SIMPLIFIED GLOBAL HYDROGEN CYCLE MODEL}

\subsection{Development}

A model of hydrogen dynamics in the troposphere and stratosphere has been developed, and is intended to complement more complex three-dimensional models, with particular focus on GATOR-GCMOM (Jacobson, 2009). The model developed here, while unable to simulate the wide array of processes parameterized in numerical three-dimensional models, can simulate atmospheric hydrogen mixing ratios over time periods that extend from well into the past to well into the future (for example, from the beginning of the industrial revolution to the end of the $21^{\text {st }}$ century) in a matter of minutes while at the other extreme, GATOR-GCMOM can take weeks of real time to simulate a decade.

The simplified model can predict how atmospheric hydrogen mixing ratios will be affected by conversion to an alternative hydrogen economy (e.g., to hydrogen fuel cell vehicles). Model verification and validation tests have been completed, and are reported in Appendix C. Multiple sources and sinks of hydrogen are included in the global model.

The model also predicts the total atmospheric burden and lifetime of hydrogen. The historical period from 1992 to present shows that the model can predict the recent hydrogen mixing ratios in the troposphere, (approximately 531 ppbv globally averaged).

Figure 4-1 illustrates a global conceptual model of the hydrogen cycle. The atmosphere is subdivided into the troposphere and stratosphere. Within the troposphere and stratosphere the predicted hydrogen mixing ratios are assumed to be spatially constant but temporally variable. Major sources of hydrogen to the troposphere include sources at the earth's surface (biomass burning, fossil fuel combustion, nitrogen fixation, and oceanic off-gassing), as well as hydrogen produced in the atmosphere from reactions involving methane $\left(\mathrm{CH}_{4}\right)$ and non-methane hydrocarbons (NMHC) (Novelli et al. 1999). In the troposphere, hydrogen is removed by reaction with the hydroxyl radical, insertion (diffusion) into the stratosphere, and uptake at the soil-atmosphere interface. In the stratosphere, processes similar to those in the troposphere both produce and destroy hydrogen.

A number of researchers have developed global tropospheric hydrogen budgets in an attempt to quantify sources and sinks of hydrogen. Examples are shown in Figure 4-2, and include the work of Novelli (1999), Rhee (2006), Hauglustaine and Ehhalt (2002), Price (2007), Xiao et al. (2007), and Jacobson (2009). Jacobson did not include separate categories for photochemical production and oxidation by $\mathrm{OH}$ radicals, but rather combined them (40.3 Tg/yr). Also, uptake rates calculated by Smith-Downey et al. (2006) for a boreal forest and the Mohave Desert were extrapolated to a global uptake rate to compare with the other investigated results. Not unexpectedly, hydrogen uptake from Mohave Desert soils were lower than from other global sources, but still high enough to show that uptake of hydrogen in desert soils is not insignificant. 


\section{SIMPLIFIED GLOBAL HYDROGEN CYCLE}

\section{STRATOSPHERE}

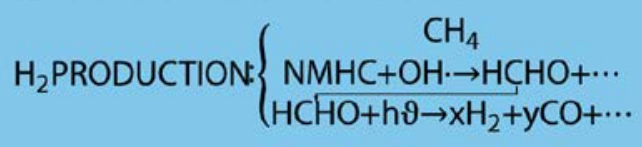

$\mathrm{H}_{2}$ Sink: $\mathrm{H}_{2}+\mathrm{OH} \cdot \rightarrow \mathrm{H}_{2} \mathrm{O}+\cdots$

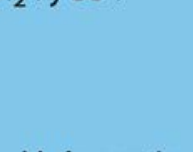

$\mathrm{H}_{2}$ Insertion

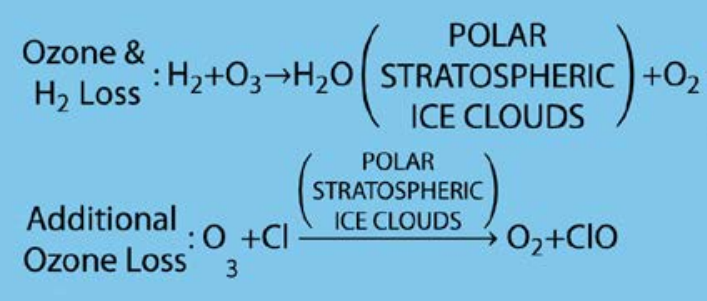

\section{TROPOSPHERE}

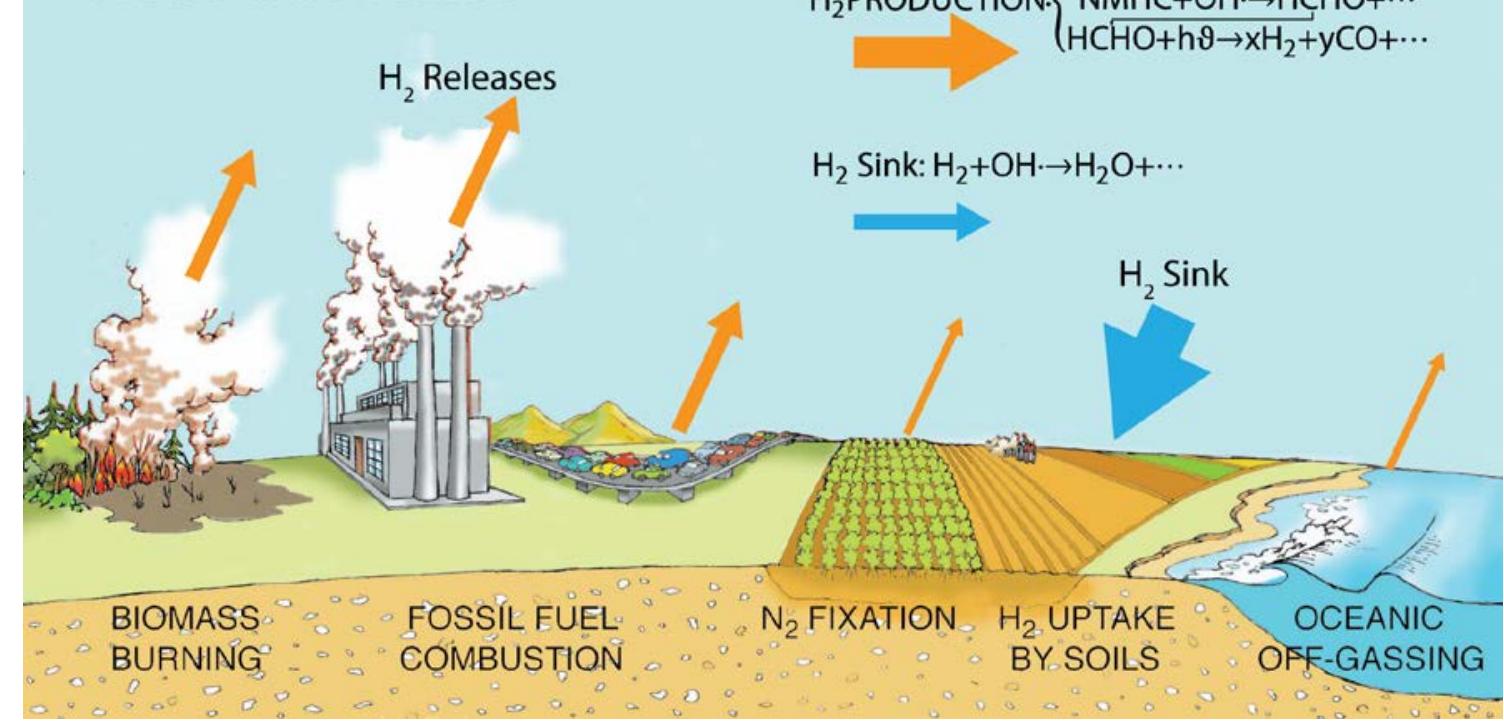

\section{Figure 4-1 Global Hydrogen Cycle}

Five source categories are shown in Figure 4-2 (photochemical production is the sum of production from methane and non-methane hydrocarbons). The two loss terms are by $\mathrm{OH}$ oxidation and by soil uptake. The soil uptake rate is a much greater loss rate than is oxidation by hydroxyl radicals, and research continues to better characterize this loss mechanism (for example, Smith-Downey et al. (2006, 2008) and Jacobson (2009).

The mathematical model solves for the total mass or burden of hydrogen in the troposphere and stratosphere over time, and assumes that both the troposphere and stratosphere are well-mixed with respect to hydrogen mixing ratio. This assumption was made based on the work of researchers such as Novelli et al. (1999) who analyzed tropospheric hydrogen concentrations from approximately 1990 to 1996 at 50 locations around the world. They found that the globally averaged tropospheric hydrogen mixing ratio was $530 \pm 6$ ppbv, with a tropospheric lifetime of about two years. Other researchers (e.g., Tromp et al. 2003) have demonstrated the uniformity of 
hydrogen mixing ratios at altitudes of up to $25 \mathrm{~km}$, and a slight decrease above that level up to 40 kms. Warneck (1999) and Ehhalt et al. (1977) also examined the vertical distribution of molecular hydrogen based on data from a number of investigations and found the vertical distribution of hydrogen was also uniform up to nearly $30 \mathrm{~km}$. The model presented here does not differentiate between the northern and southern hemispheres where hydrogen mass differs by about 3\%.

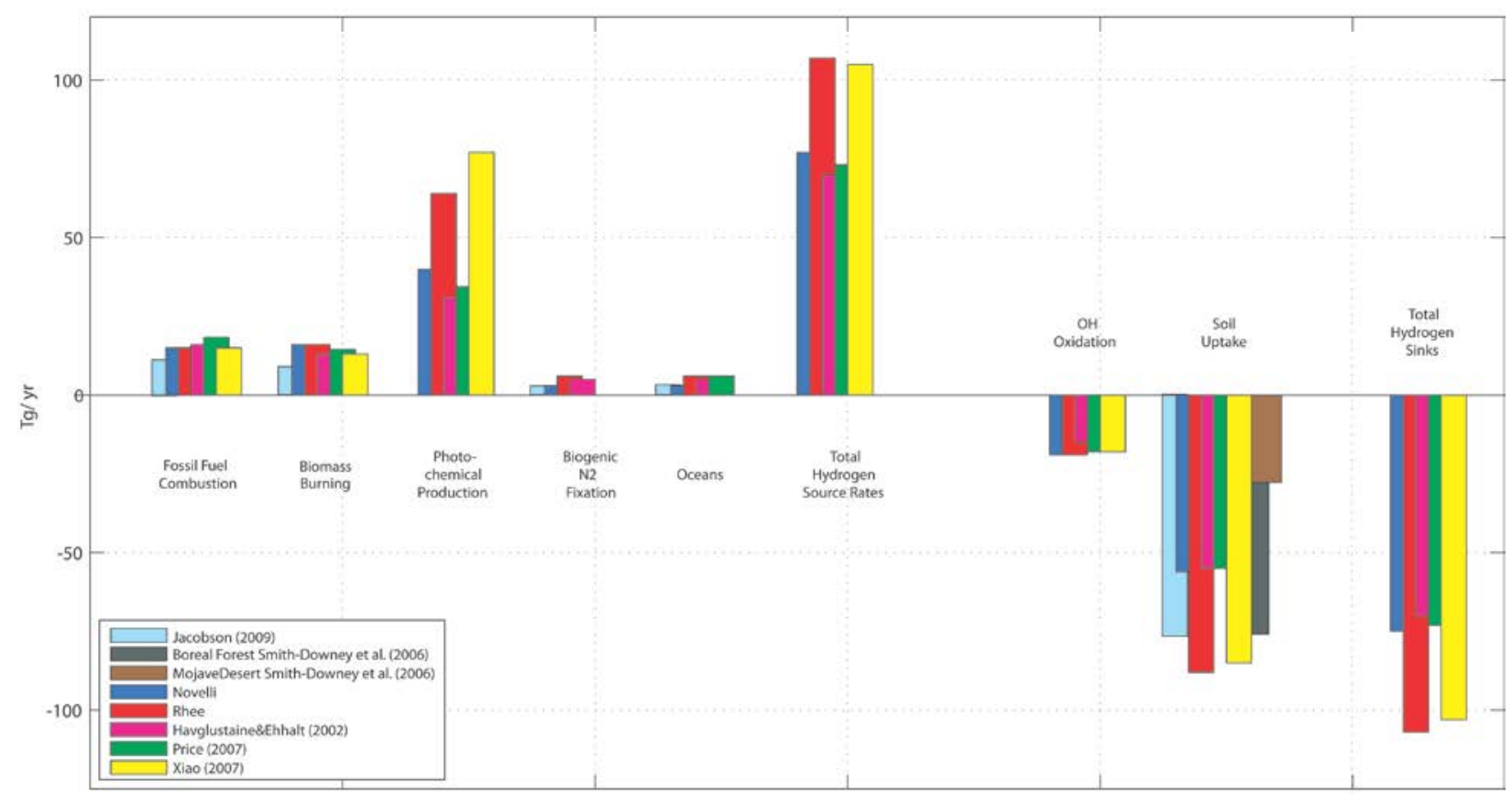

Figure 4-2 Sources and Sinks for Global Hydrogen Budget

As shown subsequently, the model is used to answer such questions as:

- What is the sensitivity of hydrogen mixing ratios to deposition velocity?

- How quickly do hydrogen mixing ratios respond to hydrogen leakage into the stratosphere? Is the time less than, or greater than, a decade?

- Can the model be used to check GATOR-GCMOM predictions of mixing ratios changes?

- Can the model be used to predict hydrogen mixing ratios at the end of the $21^{\text {st }}$ century, with or without a hydrogen economy?

- How plausible are new experimental data presented by Wuebbles (2009) on hydrogen uptake?

- What has been learned about hydrogen uptake rates and deposition velocities from field studies compared with model predictions? Is there one 'maximum' global uptake rate, and what is it? How can it be used in future studies?

\subsection{Applications}

The simplified hydrogen model has been used to address a number of questions that GATORGCMOM did not address due to its complexity (see above). These simulations are intended to 
provide additional insights into the global hydrogen cycle and how transformation to a global hydrogen economy might influence the hydrogen cycle.

\subsubsection{Sensitivity of Atmospheric Hydrogen Mixing Ratios to Deposition Velocity}

To begin the analyses we examine the deposition velocity, $\mathrm{V}_{\mathrm{d}}$. The deposition velocity, based on results of previous research, has a wide range (0 to $0.131 \mathrm{~cm} / \mathrm{sec}$ ), and prior researchers have shown that the soil uptake process is the largest hydrogen sink, as shown previously in Figure 4-2. Estimates of hydrogen uptake by the soil (and associated surface processes) range from 50 to $100 \mathrm{Tg} / \mathrm{yr}$, while the remaining largest sink (oxidation by the $\mathrm{OH}$ radical in the atmosphere) is approximately $20 \mathrm{Tg} / \mathrm{yr}$.

Since hydrogen uptake studies are designed to represent various land use types, variability is expected. Added to the plot are the global estimate and global upper and lower limits proposed by Novelli (1999). These estimates are very consistent with the field studies (when taken in their entirety), and add validity to the choice used $(0.04 \mathrm{~cm} / \mathrm{sec})$ for the global hydrogen cycle simulations presented here. A second set of researchers has also developed estimates of soil uptake, but expressed their results as $\mathrm{nmol} / \mathrm{m}^{2} / \mathrm{sec}$ (Figure $4-3$ ). Novelli's global estimate of 0.04 $\mathrm{cm} / \mathrm{sec}$ is equivalent to approximately $9.7 \mathrm{nmol} / \mathrm{m}^{2} / \mathrm{sec}$ and is plotted on Figure $4-3$. Novelli's estimate once again was generally between the upper and lower limits of the study results.

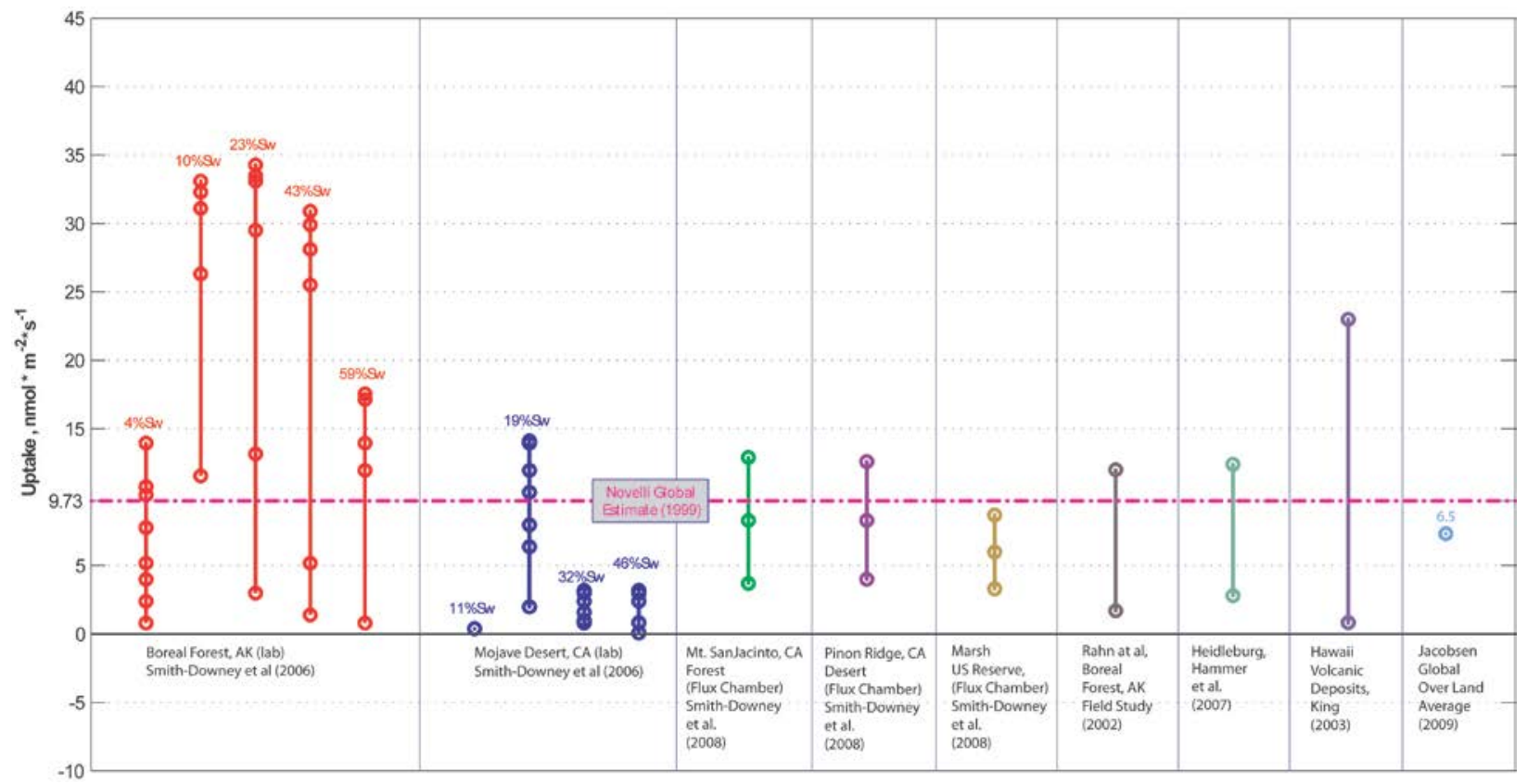

Figure 4-3 Field and Laboratory Studies of Hydrogen Uptake. Note: The recent modeling results of Jacobson (2009) are shown for comparison.

The sensitivity of predicted tropospheric and stratospheric hydrogen mixing ratios to deposition velocity is shown in Figure 4-4. Predictions are shown for deposition velocities of $0.01 \mathrm{~cm} / \mathrm{sec}$, $0.04 \mathrm{~cm} / \mathrm{sec}$ (global average as estimated by several researchers), and $0.07 \mathrm{~cm} / \mathrm{sec}$. The predicted hydrogen mixing ratios are quite sensitive to the deposition velocity. Both ends of the range of 
$\mathrm{V}_{\mathrm{d}}$ produce predictions that are well outside the present day hydrogen mixing ratios, indicating such deposition velocities are not realistic on a global scale.
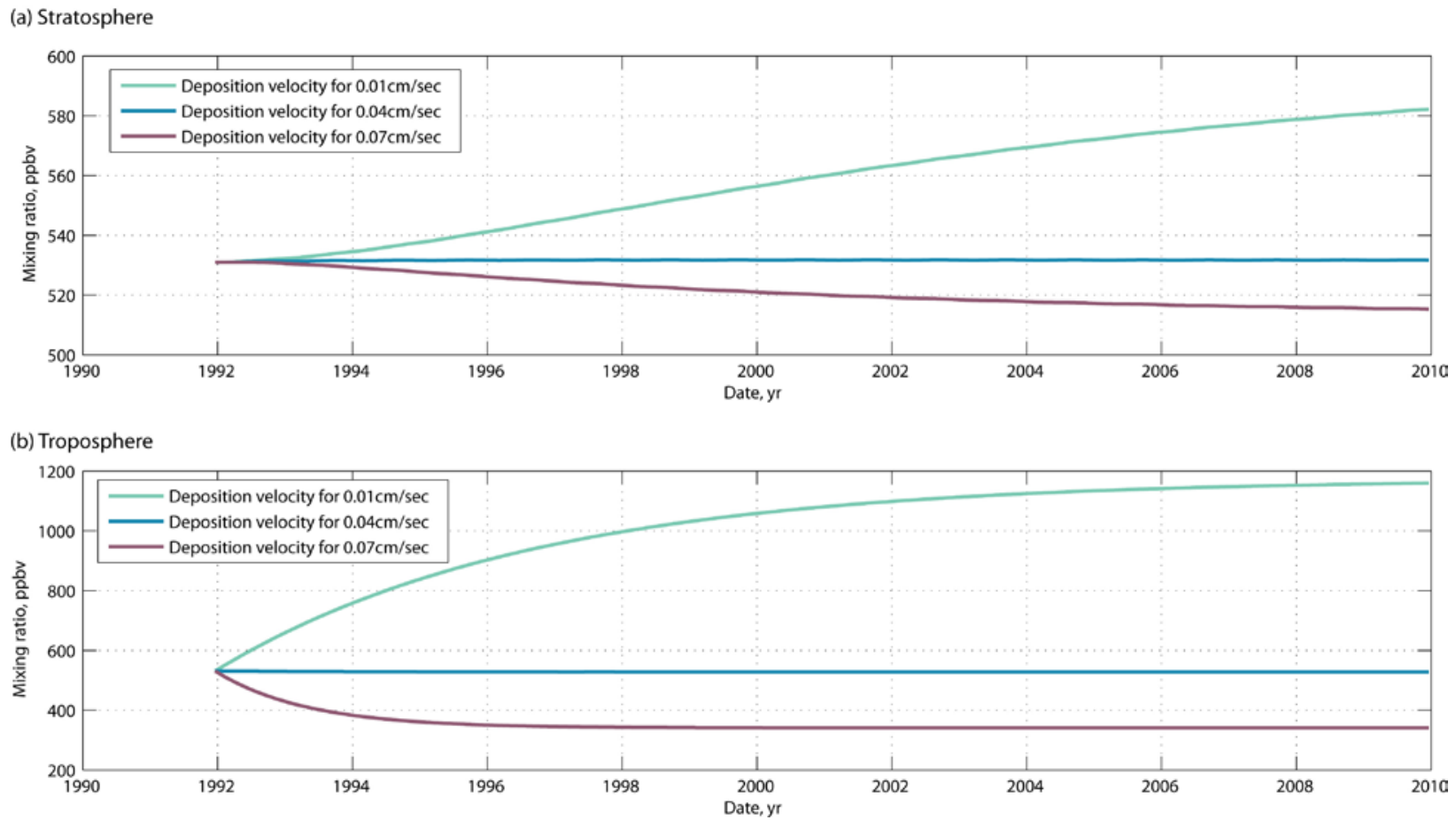

Figure 4-4 Sensitivity of Hydrogen Mixing Ratio to Deposition Velocity. Note: On a global scale, a deposition velocity of $0.04 \mathrm{~cm} \cdot \mathrm{s}^{-1}$ generates predications of hydrogen mixing ratios that are comparable with measured global averages. On a local scale, however, deposition velocities of $0.01 \mathrm{~cm} \cdot \mathrm{s}^{-1}$ and $0.07 \mathrm{~cm} \cdot \mathrm{s}^{-1}$ are plausible.

Results of more complete sensitivity analyses are shown in Table 4-1. Each variable is perturbed one at a time, with $+-10 \%$ change from a base case. The sensitivity analyses shows how atmospheric hydrogen mixing ratios are changed as each variable is perturbed. Not unexpectedly, hydrogen response is most sensitive to deposition velocity change, but a number of other variables are also of importance, particularly $\mathrm{k}_{1}$ (rate constant for loss of hydrogen by reaction with the $\mathrm{OH}$ radical). These results help to focus on those variables most important to know accurately in order to simulate the fate of atmospheric hydrogen. 
Table 4-1

Parameter-by-Parameter Sensitivity Analysis for Hydrogen Model (Once Steady-state Conditions are Attained)

\begin{tabular}{|c|c|c|c|c|c|c|c|}
\hline \multirow[b]{2}{*}{ Variable Perturbed } & \multirow[b]{2}{*}{ Base Case Value } & \multirow{2}{*}{$\begin{array}{l}\text { Base Case } \\
-10 \%\end{array}$} & \multirow{2}{*}{$\begin{array}{l}\text { Base Case } \\
\quad+10 \%\end{array}$} & \multicolumn{2}{|c|}{$\begin{array}{c}\text { Tropospheric } \\
\text { Response } \\
\text { (ppbv) }\end{array}$} & \multicolumn{2}{|c|}{$\begin{array}{c}\text { Stratospheric } \\
\text { Response } \\
\text { (ppbv) }\end{array}$} \\
\hline & & & & $-10 \%$ & $+10 \%$ & $-10 \%$ & $+10 \%$ \\
\hline $\begin{array}{l}\text { Initial Hydrogen Mixing Ratio in } \\
\text { Troposphere }\end{array}$ & $528 \mathrm{ppbv}$ & $478 \mathrm{ppbv}$ & 584 ppbv & 0 & 0 & 0 & 0 \\
\hline $\begin{array}{l}\text { Initial Hydrogen Mixing Ratio in } \\
\text { Stratosphere }\end{array}$ & 531 ppbv & 478 ppbv & 584 & 0 & 0 & 0 & 0 \\
\hline Deposition Velocity & $0.04 \mathrm{~cm} \cdot \mathrm{s}^{-1}$ & $0.036 \mathrm{~cm} \cdot \mathrm{s}^{-1}$ & $0.044 \mathrm{~cm} \cdot \mathrm{s}^{-1}$ & +52 & -46 & +5 & -3 \\
\hline $\mathrm{k}_{1}$ (troposphere) & $4.02 \cdot 10^{-15} \mathrm{~cm}^{3} \cdot$ molecule $^{-1} \cdot \mathrm{s}^{-1}$ & $3.6 \cdot 10^{-15}$ & $4.422 \cdot 10^{-15}$ & \multirow{2}{*}{+43} & \multirow{2}{*}{-17} & \multirow{2}{*}{+59} & \multirow{2}{*}{-51} \\
\hline $\mathrm{k}_{1}$ (stratosphere) & $1.03 \cdot 10^{-15} \mathrm{~cm}^{3} \cdot$ molecule $^{-1} \cdot \mathrm{s}^{-1}$ & $0.927 \cdot 10^{-15}$ & $1.13 \cdot 10^{-5}$ & & & & \\
\hline $\mathrm{k}_{5}$ (troposphere) & $4.04 \cdot 10^{-15} \mathrm{~cm}^{3} \cdot$ molecule $^{-1} \cdot \mathrm{s}^{-1}$ & $3.64 \cdot 10^{-15}$ & $4.44 \cdot 10^{-15}$ & \multirow{2}{*}{-19} & \multirow{2}{*}{+12} & \multirow{2}{*}{-45} & \multirow{2}{*}{+50} \\
\hline $\mathrm{k}_{5}$ (stratosphere) & $1.2 \cdot 10^{-15} \mathrm{~cm}^{3} \cdot$ molecule $^{-1} \cdot \mathrm{s}^{-1}$ & $1.08 \cdot 10^{-15}$ & $1.32 \cdot 10^{-15}$ & & & & \\
\hline $\mathrm{OH}$ (troposphere) & $9.70 \cdot 10^{5}$ molecule $\cdot \mathrm{cm}^{-3}$ & $8.77 \cdot 10^{5}$ & $1.07 \cdot 10^{6}$ & \multirow{2}{*}{-2.3} & \multirow{2}{*}{+2.6} & \multirow{2}{*}{+6} & \multirow{2}{*}{-4} \\
\hline $\mathrm{OH}$ (stratosphere) & $4.00 \cdot 10^{6}$ molecule $\cdot \mathrm{cm}^{-3}$ & $3.6 \cdot 10^{6}$ & $4.4 \cdot 10^{6}$ & & & & \\
\hline $\begin{array}{l}\text { Initial Methane Concentration in } \\
\text { Troposphere }\end{array}$ & $1660 \mathrm{ppbv}$ & 1494 & 1826 & -15 & +20 & -52 & +44 \\
\hline $\begin{array}{l}\text { All Sources of Hydrogen Emitted } \\
\text { to Troposphere }\end{array}$ & $37 \mathrm{Tg} / \mathrm{yr}$ & $33.3 \mathrm{Tg} / \mathrm{yr}$ & $40.7 \mathrm{Tg} / \mathrm{yr}$ & -27 & +31 & -2 & +4 \\
\hline $\begin{array}{l}\text { Insertion of Hydrogen into } \\
\text { Stratosphere (Reference Flux) }\end{array}$ & $0.6 \mathrm{Tg} / \mathrm{yr}$ & $0.54 \mathrm{Tg} / \mathrm{yr}$ & $0.66 \mathrm{Tg} / \mathrm{yr}$ & $<+1$ & $\sim-0.3$ & -4.3 & +6 \\
\hline
\end{tabular}

\subsubsection{Time Frame Estimates for Atmospheric Response to Hydrogen Leakage Rates}

As hydrogen leaks into the troposphere as a result of production, transport, and usage during transition to a hydrogen economy, important questions arise including these two:

- What will be the future mixing ratios of hydrogen in the troposphere and stratosphere?

- How long will it take for mixing ratios to stabilize, given a constant emissions rate?

By answering these questions, the significance of potentially increased hydrogen emissions can be assessed.

To answer these questions, three different hydrogen leakage rates were examined: $4.5 \mathrm{Tg} / \mathrm{yr}, 50$ $\mathrm{Tg} / \mathrm{yr}$, and $120 \mathrm{Tg} / \mathrm{yr}$. These are intended to represent a potential range of hydrogen emissions. The emissions were assumed to increase gradually over a 10 year period to each of the three amounts specified and to remain steady after that. The results are presented in Figure 4-5 for both the troposphere and stratosphere. All results are presented as differences with respect to the no leakage case (that is, the model was run twice, and the results were subtracted). In the troposphere, the response time to attain a steady tropospheric mixing ratio is about 15 years (from 2020 to 2035), while in the stratosphere the response time is over 30 years (that is, by 2050 hydrogen levels are increasing, but slowly).

Increases in mixing ratios in the troposphere range from about $10 \mathrm{ppbv}$ to over $800 \mathrm{ppbv}$ depending on the leakage rate. The increase to $800 \mathrm{ppbv}$ is very significant, as today's tropospheric concentrations are $531 \mathrm{ppbv}$. For the stratosphere, mixing ratio concentrations at 
steady-state are considerably smaller, and range from 2 ppbv to over $80 \mathrm{ppbv}$. Based on recent estimates of hydrogen leaking rates by Jacobson (2009), the lower end of leakage (4.5 Tg/yr) is the more realistic estimate. However, regardless of the leakage rate, the time to transition to a new steady-state condition is predicted to exceed 10 years.
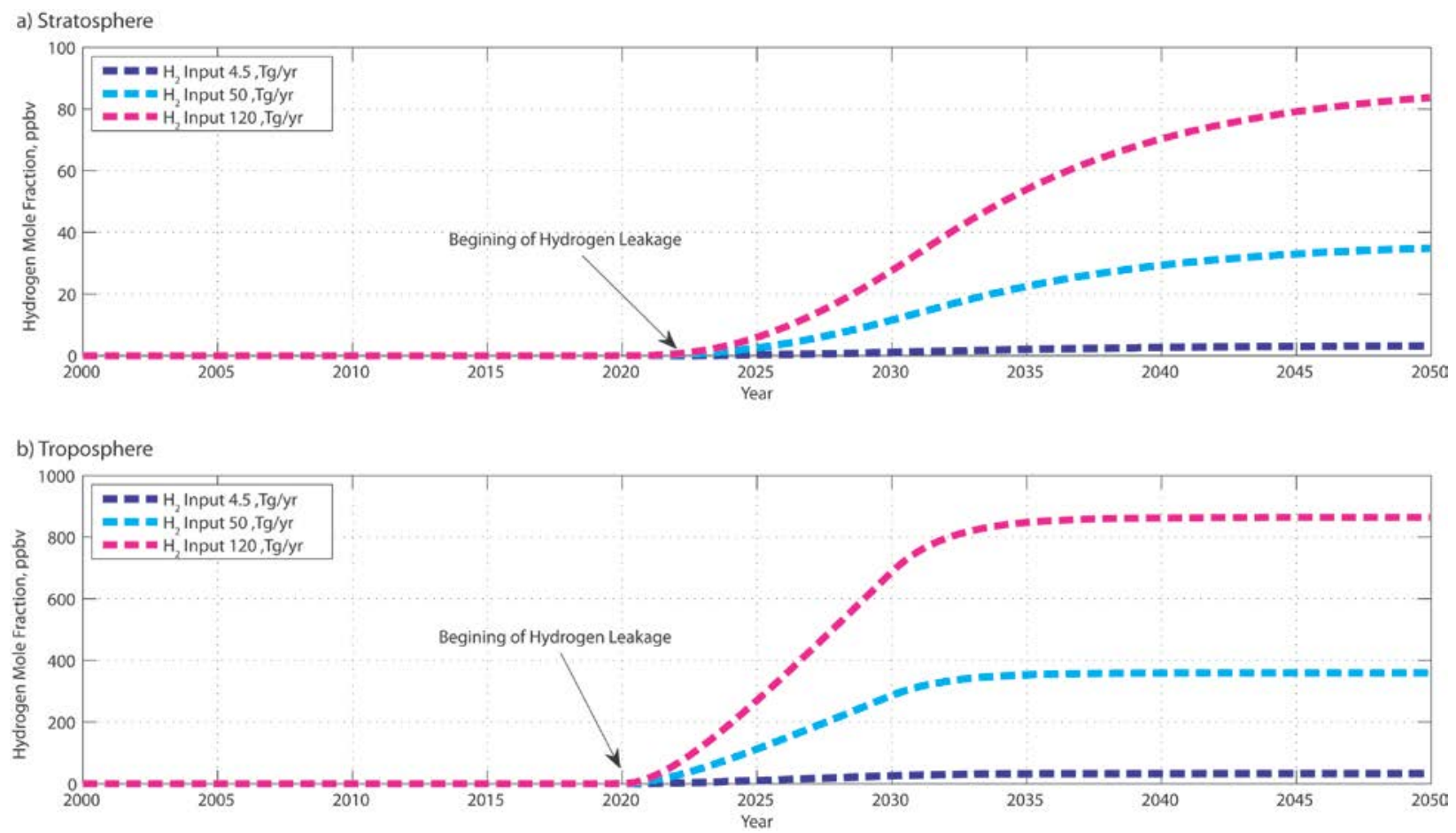

Figure 4-5 Influence of hydrogen leakage rates on incremental tropospheric and stratospheric hydrogen mixing ratios. Note: Hydrogen leakage was assumed to increase linearly over a 10 year period, and to remain constant thereafter.

\subsubsection{Approximate Response of Tropospheric Hydrogen Burden to Net Changes in Hydrogen Input from Hydrogen Economy}

An important metric of the hydrogen economy is how the burden (and therefore mixing ratio) of hydrogen will change in the troposphere at a future steady-state condition. We approximate the steady-state response using a set of simplifying assumptions that include:

- The major changes in sources of hydrogen in the hydrogen economy are the leakage associated with anthropogenic activities, and the change in fossil fuel emissions.

- The major changes in loss terms from the troposphere are limited to soil deposition and oxidation by the hydroxyl radical.

By making these assumptions and evaluating two conditions (without a hydrogen economy and with a hydrogen economy), the tropospheric hydrogen burden changes can be predicted. Details are shown in Appendix B.

This approach can be used to compare with Wuebbles (2009) results. In going to an A1FI hydrogen economy Wuebbles projects that the increase in hydrogen emissions between the two A1FI scenarios is $45 \mathrm{Tg} / \mathrm{yr}$ (see page 16 of Wuebbles (2009)). Assuming steady-state, we calculate the increase in mixing ratios of hydrogen to be $280 \mathrm{ppbv}$. This is at the lower end of the 
range predicted by Wuebbles (300-600 ppbv; see page 19). Given the simplicity of the approach used when comparing to Wuebbles (2009), the comparison generally validates the predictions by Wuebbles. As a cross check, the simulation results shown in Figure 4-4(b) were used. For an increase in hydrogen emissions of $45 \mathrm{Tg} / \mathrm{yr}$, the increase in hydrogen mixing ratios is $320 \mathrm{ppbv}$.

\subsubsection{Investigation of Time-variable Hydrogen Emission Rates}

We do not expect emissions of hydrogen to the atmosphere to remain constant over the $21^{\text {st }}$ century as our economy grows, whether or not a hydrogen economy evolves. This is illustrated in Figure 4-6, where hydrogen emissions from fossil fuel sources and biomass are assumed to increase by 1\%/yr and 0.5\%/yr, respectively. At the year 2050, $4.8 \mathrm{Tg} / \mathrm{yr}$ of hydrogen are assumed to leak into the atmosphere as a result of the initiation of a hydrogen economy. The only difference between Figure 4-6(a) and Figure 4-6(b) is that Figure 4-6(b) includes a compensating reduction in hydrogen emissions associated with a reduction in fossil fuel vehicles, while no such compensation is included in Figure 4-6(a). The effects of this difference are evident after 2050, when the hydrogen leakage is assumed to begin. The increased hydrogen mixing ratio associated with the hydrogen economy is about 15 ppbv when compensation is considered, but about twice that when compensation is not considered. Relative to the projected increase of hydrogen mixing ratios from $530 \mathrm{ppbv}$ to $715 \mathrm{ppbv}$ without a hydrogen economy, the increases in mixing ratios is small.
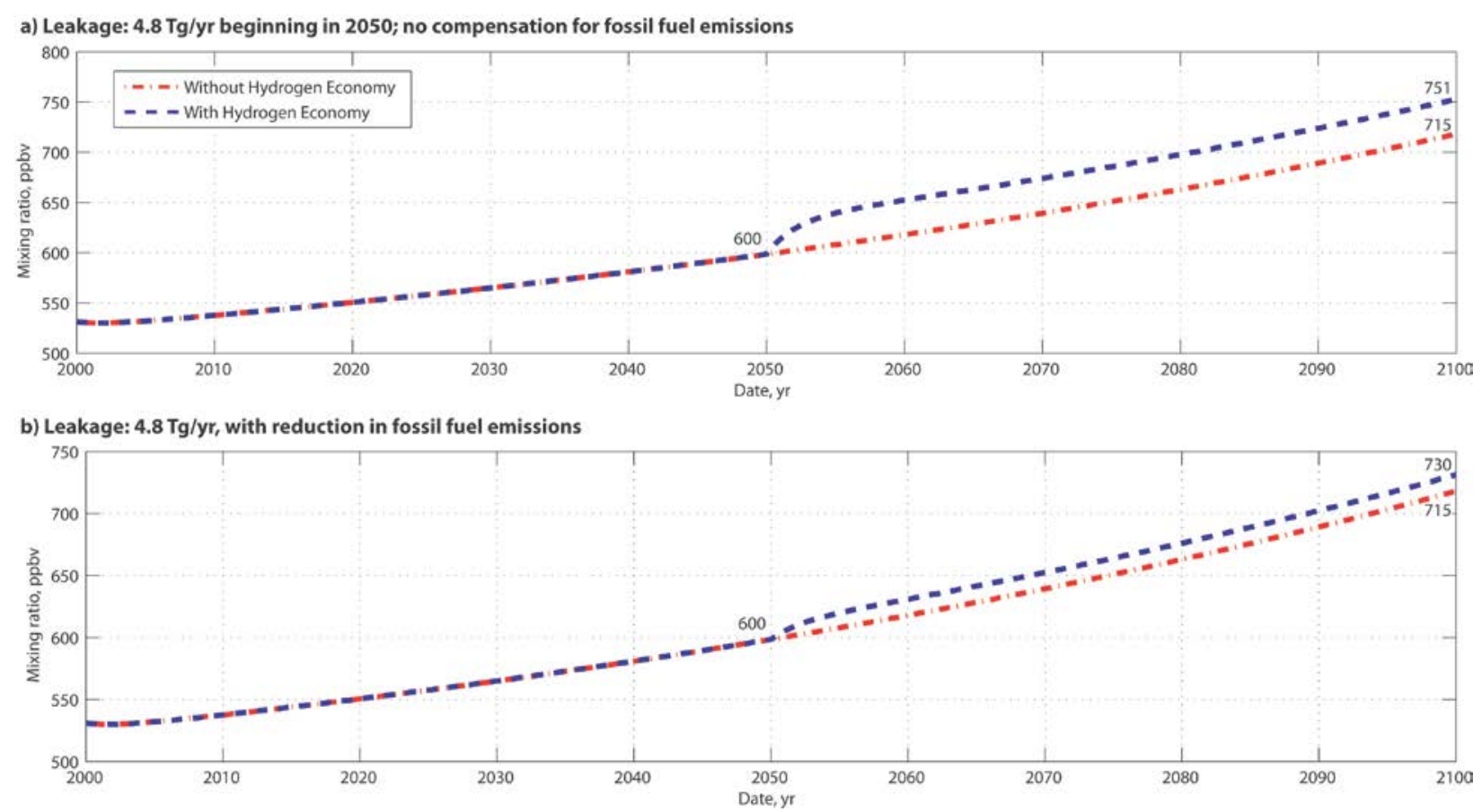

Figure 4-6 Effects of time variable source terms and hydrogen leakage on hydrogen mixing ratios in the troposphere.

\subsubsection{Recent Developments and Implications in Soil Uptake of Hydrogen}

The work presented in this paper up to this point, and by other researchers as well, assumes that hydrogen uptake by soil (and uptake by other near-surface features) is linearly proportional to the hydrogen mixing ratios at the atmospheric-soil interface. All results presented to this point are based on this assumption. 
Only a few researchers are known to have examined the effect of hydrogen mixing ratios on soil uptake of hydrogen. Schuler and Conrad (1991) examined hydrogen uptake at $10^{3} \mathrm{ppbv}$ and $3 \cdot 10^{6}$ ppbv for two soil types. The mixing ratios used are well above those in the troposphere ( $\sim 31 \mathrm{ppbv}$ ). For an acidic cambisol soil, the ratio of peak uptake rates (for the $3 \cdot 10^{6} \mathrm{ppbv}$ concentration to the $10^{3}$ ppbv concentration) was 1600:1. For a composite soil, the ratio of peak uptake rates was 1200:1 at the two hydrogen mixing ratios. In both cases uptake increases were less than linear (3000:1), indicating the lack of non-linear enhancement in uptake. However, the range of hydrogen mixing ratios used in the analysis is very large, and there is no indication of whether an intermediate peak would have been attained.

Trevors (1985) examined the hydrogen consumption in aerobic and anaerobic soils at a range of hydrogen mixing ratios that varied by a factor of 5 . In both cases, hydrogen consumed increased with hydrogen concentrations, and also over time. After about 72 hours a linear relationship was attained between hydrogen consumed and hydrogen concentration applied. The experiments did not provide evidence of non-linear uptake from exposure to higher hydrogen mixing ratios.

However, a recent study by Wuebbles (2009) has shown that hydrogen uptake by soils is a nonlinear function of the atmospheric hydrogen mixing ratios. Figure 4-7 shows the relative soil uptake developed by Wuebbles, and it is compared to the value used by other investigators.

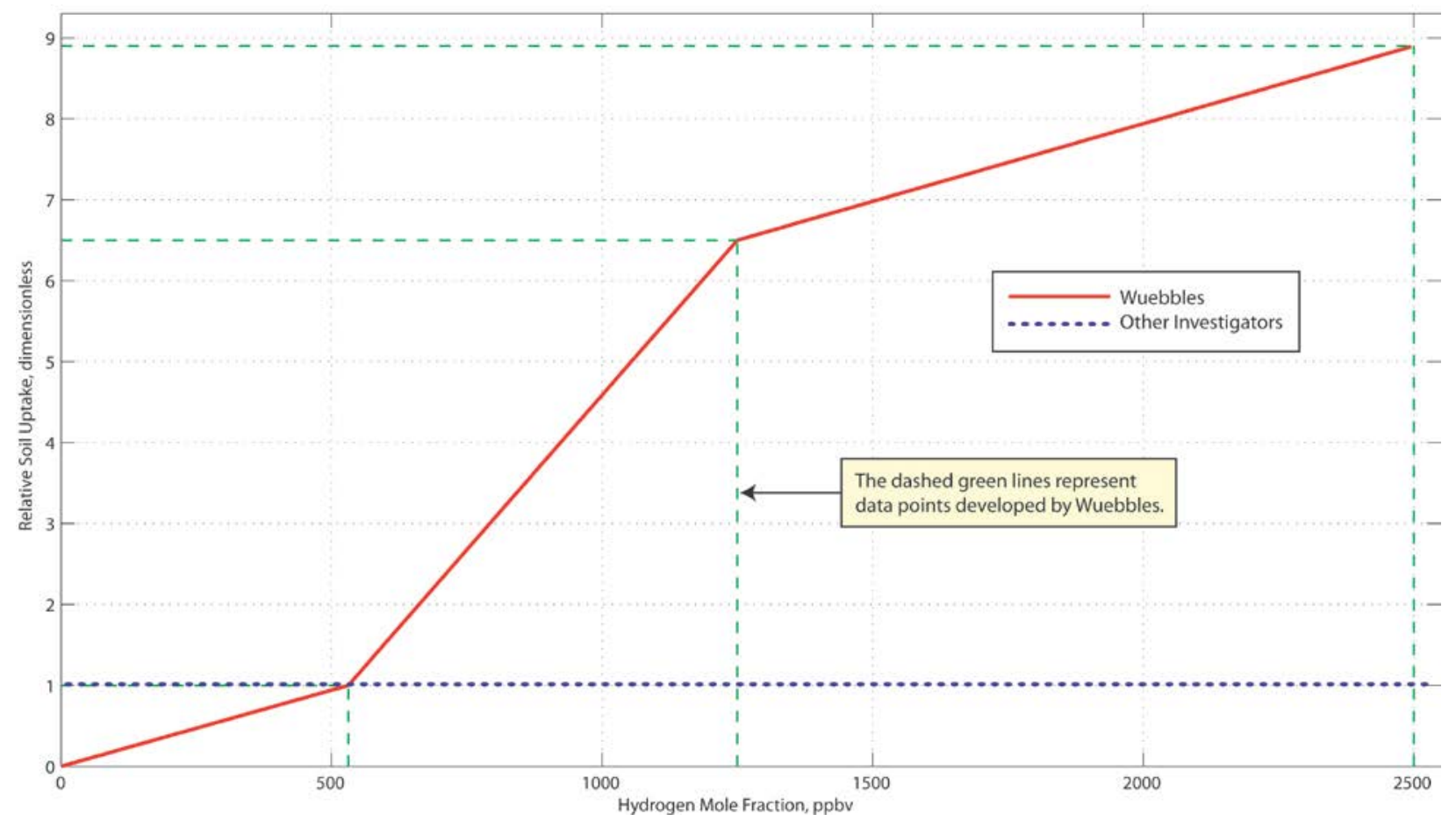

Figure 4-7 Relative soil uptake versus hydrogen concentration.

There is a significant difference in uptake as the hydrogen mixing ratio moves away from today's present value of about 531 ppbv. Since hydrogen concentrations are likely to increase in the future rather than decrease, the curve to the right of $531 \mathrm{ppbv}$ is of most interest. The uptake rate would double if the hydrogen mole fraction were to increase to $650 \mathrm{ppbv}$. The hydrogen uptake rates (both linear and non-linear approaches) are shown in Figure 4-8. They are only identical to each other at 531 ppbv (where the global uptake is about $54 \mathrm{Tg} / \mathrm{yr}$ ). At the hydrogen 
mole fraction where uptake doubles to $108 \mathrm{Tg} / \mathrm{yr}$ for non-linear uptake, the predicted linear uptake rate has increased to about $70 \mathrm{Tg} / \mathrm{yr}$.

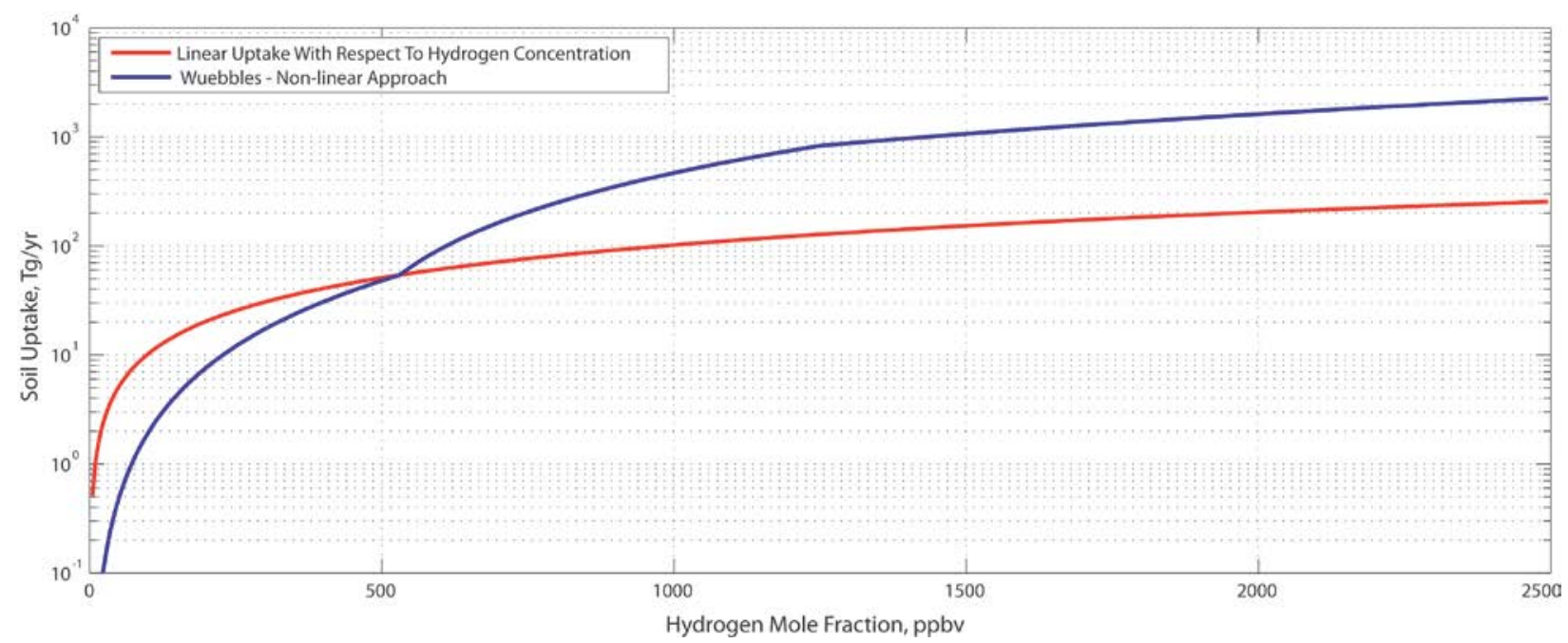

Figure 4-8 Global soil uptake of hydrogen using two approaches: (a) linear uptake with respect to hydrogen concentration and; (b) Wuebbles-non-linear approach.

Because of the anticipated importance of the non-linear uptake response, this feature was added to the global hydrogen model as an optional approach. Details are provided in Appendix A. To demonstrate the significance of this alternative formulation, Figure 4-6(a) was re-created using the alternative uptake rate in Equation (12a). The results are shown in Figure 4-9.

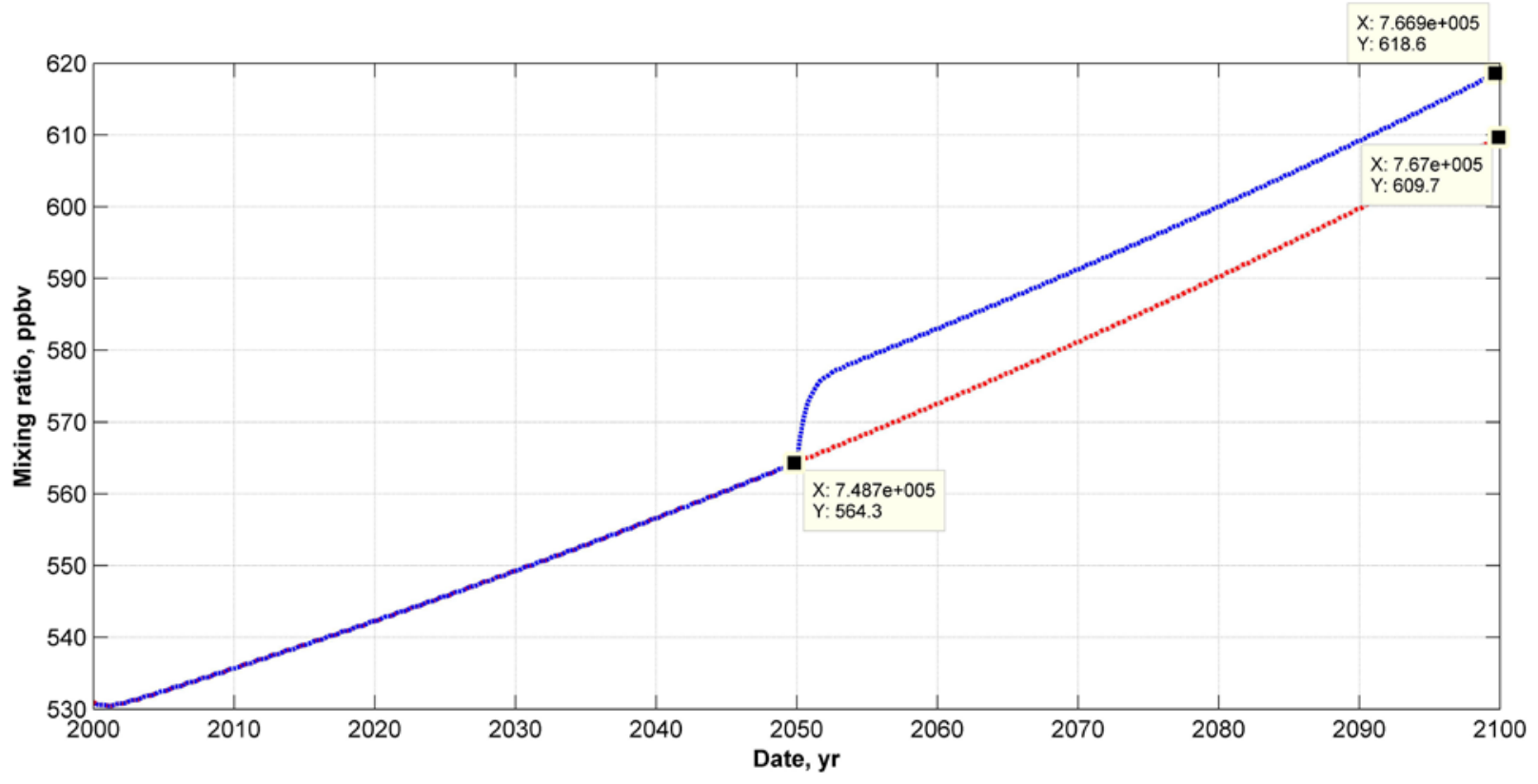

Figure 4-9 Projected Hydrogen Mixing Ratios During the $21^{\text {st }}$ Century for Hydrogen Uptake Governed by the Work of Wuebbles (2009). 
When the results of Figure 4-9 are compared against the results in Figure 4-6(b), where the only difference between the two simulations is the uptake algorithm, it is seen that hydrogen mixing ratios are predicted to decrease by about 35 ppbv in mid century (compared to the traditional linear uptake approach) and 110 ppbv by the end of the century. This is a significant effect, and indicates more work is needed to confirm this response. 



\section{PROBABILISTIC FRAMEWORK TO EVALUATE HYDROGEN UPTAKE BY SOILS}

\subsection{Development}

Although atmospheric hydrogen uptake by soils has been studied for several decades, the number of studies is small, and relatively few uptake rates or deposition velocities have been estimated. Also no framework has been developed that can rigorously accommodate natural variability. Here a Monte Carlo framework is presented that begins to address this issue. While it is not feasible to include the Monte Carlo approach in GATOR-GCMOM due to that model's complexity, the approach does provide valuable insight into the issue of uptake variability for different types of ecosystems.

The following formula is used to calculate uptake, and was motivated by the work of SmithDowney et at. (2006):

$$
\begin{aligned}
& M_{\mathrm{H}_{2} \text {,soil }}=\mathrm{G}\left(\mathrm{S}_{\mathrm{w}}\right) \mathrm{F}\left(\mathrm{T}_{\mathrm{k}}\right) \mathrm{M}_{\mathrm{H}_{2} \text {, soil,max }}^{*} \cdot \frac{\left[\mathrm{H}_{2}\right]_{\text {trop }}}{\left[\mathrm{H}_{2}^{*}\right]_{\text {trop }}} \\
& \text { where } \\
& \mathrm{G}\left(\mathrm{S}_{\mathrm{w}}\right) \quad \text { = soil moisture limitation expression, dimensionless } \\
& \mathrm{F}\left(\mathrm{T}_{\mathrm{k}}\right) \quad \text { = soil temperature limitation expression, dimensionless } \\
& \mathrm{M}_{\mathrm{H}_{2} \text {,soil,max }}^{*} \quad=\text { hydrogen uptake at optimal conditions, } \mathrm{nmol} \cdot \mathrm{m}^{-2} \cdot \mathrm{s}^{-1} \\
& {\left[\mathrm{H}_{2}\right]_{\text {trop }} \quad \text { =hydrogen concentration in troposphere, ppbv }} \\
& {\left[\mathrm{H}_{2}{ }^{*}\right]_{\text {trop }} \quad=\text { hydrogen concentration used to calculate the maximum uptake }} \\
& \text { rate (e.g., at optimal conditions in laboratory), ppbv }
\end{aligned}
$$

The limiting function $\mathrm{G}\left(\mathrm{S}_{\mathrm{w}}\right)$ is formulated to include moisture limitations at both low and high soil moisture content, consistent with the findings of previous researchers. The expression is:

$$
\mathrm{G}\left(\mathrm{S}_{\mathrm{w}}\right)=\alpha\left(\frac{\mathrm{S}_{\mathrm{w}}-\mathrm{S}_{\min }}{\mathrm{S}_{\mathrm{w}}+\mathrm{S}_{\mathrm{h} 1}}\right)\left(\frac{\mathrm{S}_{\mathrm{max}}-\mathrm{S}_{\mathrm{w}}}{\mathrm{S}_{\mathrm{w}}+\mathrm{S}_{\mathrm{h} 2}}\right)\left(\frac{\mathrm{S}_{\mathrm{h} 2}}{\mathrm{~S}_{\max }}\right)
$$


where

$$
\alpha=\left\{\max \left(\frac{\mathrm{S}_{\mathrm{w}}-\mathrm{S}_{\min }}{\mathrm{S}_{\mathrm{w}}+\mathrm{S}_{\mathrm{h} 1}}\right)\left(\frac{\mathrm{S}_{\mathrm{max}}-\mathrm{S}_{\mathrm{w}}}{\mathrm{S}_{\mathrm{w}}+\mathrm{S}_{\mathrm{h} 2}}\right)\left(\frac{\mathrm{S}_{\mathrm{h} 2}}{\mathrm{~S}_{\max }}\right)\right\}^{-1}
$$

and

$\mathrm{F}\left(\mathrm{T}_{\mathrm{k}}\right)=\left[1+\exp \left(-0.1718 \mathrm{~T}_{\mathrm{k}}+46.938\right)\right]^{-1}$

and $\mathrm{S}_{\mathrm{w}}$ and $\mathrm{T}_{\mathrm{k}}$ are treated as random variables. The random variables are assumed to be truncated normal distributions, denoted by these probability density functions:

$$
\begin{aligned}
& \operatorname{pdf}\left(\mathrm{S}_{\mathrm{w}}\right)=\delta_{\mathrm{s}} \operatorname{normpdf}\left(\mathrm{S}_{\mathrm{w}} ; \mu_{\mathrm{sw}}, \sigma_{\mathrm{sw}}\right) \\
& \mathrm{S}_{\min }<\mathrm{S}_{\mathrm{w}}<\mathrm{S}_{\max } \\
& \operatorname{pdf}\left(\mathrm{T}_{\mathrm{k}}\right)=\delta_{\mathrm{T}} \operatorname{normpdf}\left(\mathrm{T}_{\mathrm{k}} ; \mu_{\mathrm{T}_{\mathrm{k}}}, \sigma_{\mathrm{T}_{\mathrm{k}}}\right) \\
& \mathrm{T}_{\mathrm{k} \min }<\mathrm{T}_{\mathrm{k}}<\mathrm{T}_{\mathrm{k} \max }
\end{aligned}
$$

where

$$
\begin{array}{ll}
\operatorname{pdf}\left(\mathrm{S}_{\mathrm{w}}\right) \text {, pdf }\left(\mathrm{T}_{\mathrm{k}}\right) & =\text { probability density functions for } \mathrm{S}_{\mathrm{w}} \text { and } \mathrm{T}_{\mathrm{k}} \text {, respectively } \\
\mu_{\mathrm{Sw}}, \mu_{\mathrm{T}_{\mathrm{k}}} & =\text { mean values of the distributions } \\
\sigma_{\mathrm{Sw}}, \sigma_{\mathrm{T}_{\mathrm{k}}} & =\text { standard deviations of the distributions }
\end{array}
$$

In order to ensure that the cumulative probabilities of $\mathrm{S}_{\mathrm{w}}$ and $\mathrm{T}_{\mathrm{k}}$ are unity, $\delta_{\mathrm{s}}$ and $\delta_{\mathrm{T}_{\mathrm{k}}}$ are set as follows:

$$
\begin{aligned}
& \delta_{\mathrm{s}}=\left[\int_{\mathrm{S}_{\min }}^{\mathrm{S}_{\max }} \operatorname{normpdf}\left(\mathrm{S}_{\mathrm{w}} ; \mu_{\mathrm{Sw}}, \sigma_{\mathrm{Sw}}\right) \mathrm{dS} \mathrm{S}_{\mathrm{w}}\right]^{-1} \\
& =\left[\operatorname{cdfnorm}\left(\mathrm{S}_{\max } ; \mu_{\mathrm{Sw}}, \sigma_{\mathrm{Sw}}\right)-\operatorname{cdfnorm}\left(\mathrm{S}_{\min } ; \mu_{\mathrm{Sw}}, \sigma_{\mathrm{Sw}}\right)\right]^{-1} \\
& \delta_{\mathrm{T}_{\mathrm{k}}}=\left[\int_{\mathrm{T}_{\min }}^{\mathrm{T}_{\max }} \operatorname{normpdf}\left(\mathrm{T}_{\mathrm{k}} ; \mu_{\mathrm{T}_{\mathrm{k}}}, \sigma_{\mathrm{T}_{\mathrm{k}}}\right) \mathrm{d} \mathrm{T}_{\mathrm{k}}\right]^{-1} \\
& =\left[\operatorname{cdfnorm}\left(\mathrm{T}_{\mathrm{kmax}}, \mu_{\mathrm{T}_{\mathrm{k}}}, \sigma_{\mathrm{T}_{\mathrm{k}}}\right)-\operatorname{cdfnorm}\left(\mathrm{T}_{\mathrm{kmin}}, \mu_{\mathrm{T}_{\mathrm{k}}}, \sigma_{\mathrm{T}_{\mathrm{k}}}\right)\right]^{-1}
\end{aligned}
$$

where

$$
\text { cdfnorm = cumulative normal distribution function }
$$




\subsection{Application}

An uncertainty analysis was conducted with the simplified model to illustrate the variability of hydrogen uptake for two ecosystem types. Since soil uptake by hydrogen is an important sink, it is important to identify the controlling uptake factors, and to then quantify them. To begin, expressions for $\mathrm{G}\left(\mathrm{S}_{\mathrm{w}}\right)$ (soil moisture limitation function) and $\mathrm{F}\left(\mathrm{T}_{\mathrm{k}}\right)$ (soil temperature limitation function) are needed. Examples of $G\left(S_{w}\right)$ and $F\left(T_{k}\right)$ are shown in Figure 5-1. As mentioned earlier $F\left(T_{k}\right)$ is from Smith-Downey (2006), but the expression for $G\left(S_{w}\right)$ was developed for this work. While $F\left(T_{k}\right)$ is applicable globally, the expression for $G\left(S_{w}\right)$ depends on site specific conditions. Two expressions for $\mathrm{G}_{\mathrm{w}}$ are shown in Figure 5-1b: a boreal forest ecosystem and the Mojave Desert ecosystem. Both exhibit the same general behavior of having a peak value, and minimal values at both very low soil moisture contents and high soil moisture contents. Based on soil temperature and moisture data appropriate for the boreal forest ( $63^{\circ} 53^{\prime} \mathrm{N}, 145^{\circ} 44^{\prime} \mathrm{W}$ ) and Mojave Desert ( $34^{\circ} 08^{\prime} \mathrm{N}, 116^{\circ} 27^{\prime} \mathrm{W}$, Mojave, CA) (Smith-Downey et al. 2006), the density functions have been created, and are shown in Figure 5-2. There are significant differences in the probability density functions for the two ecosystems. Temperatures in the Mojave Desert are infrequently below freezing, while in the Alaskan boreal forest temperatures are more often below freezing than not. The soil moisture content in the Mojave Desert is typically lower than in the boreal forest, and exhibits a more narrow range.

The hydrogen uptake rates over the range of soil moisture and temperature conditions for the two ecosystems are shown in Figure 5-3. The hydrogen uptake rates, functions of both temperature and moisture, for the boreal forest are significantly higher than in the Mojave Desert. The units of the uptake rates are expressed in $\mathrm{Tg} / \mathrm{yr}$, assuming each of the ecosystems has global coverage. This helps to put into perspective the significance of the uptake from each ecosystem compared with estimates of actual global uptake (50 to $90 \mathrm{Tg} / \mathrm{yr}$ ). The lower end of predicted uptake rates in the boreal forest ( $50 \mathrm{Tg} / \mathrm{yr}$ ) are approximately comparable to the maximum uptake rates shown for the Mojave Desert (45 Tg/yr). During extremely low or extremely high soil moisture levels, uptake becomes very small $(\sim 5 \mathrm{Tg} / \mathrm{yr})$. 

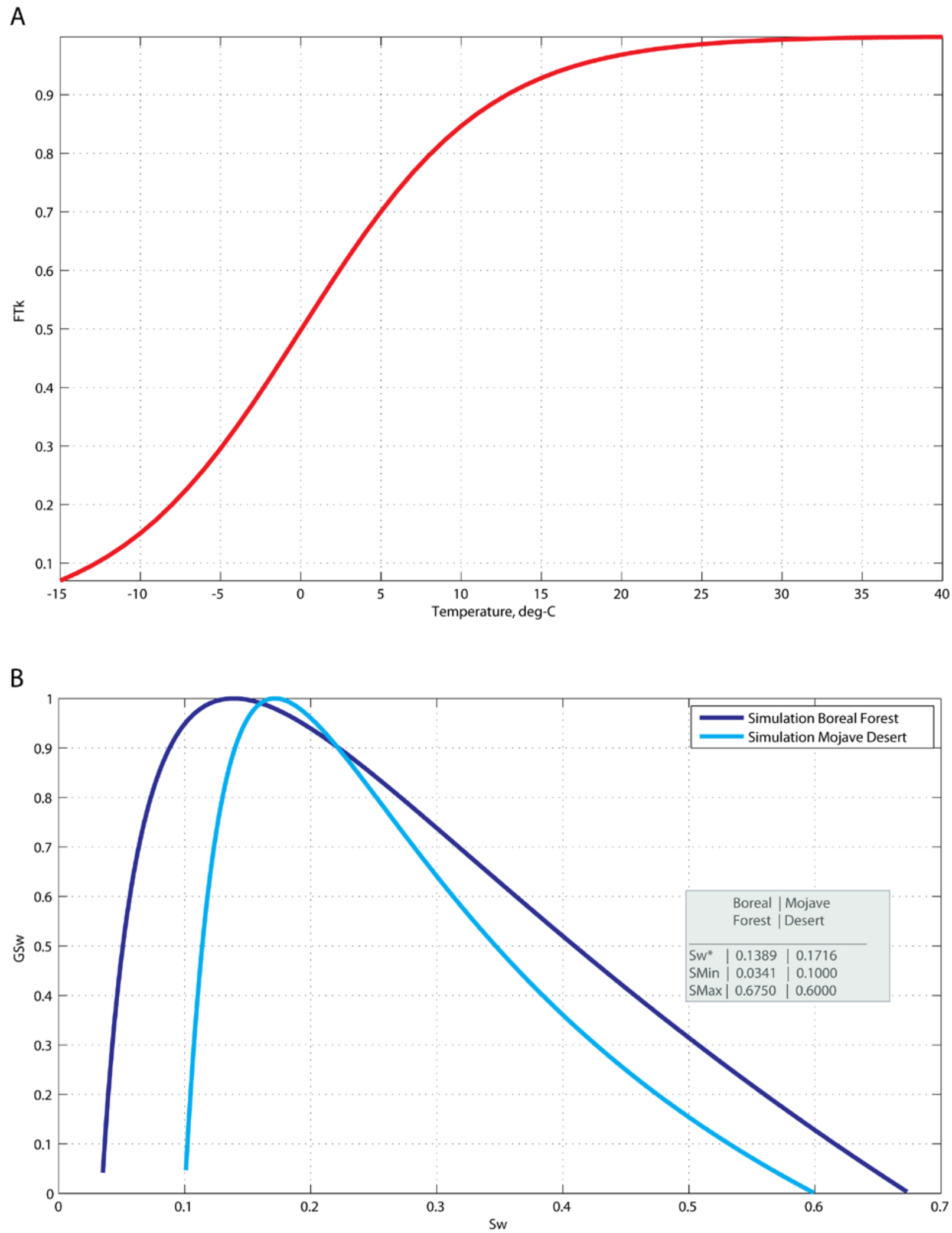

Figure 5-1 A) Soil temperature limitation function. B) Soil moisture limitation function 

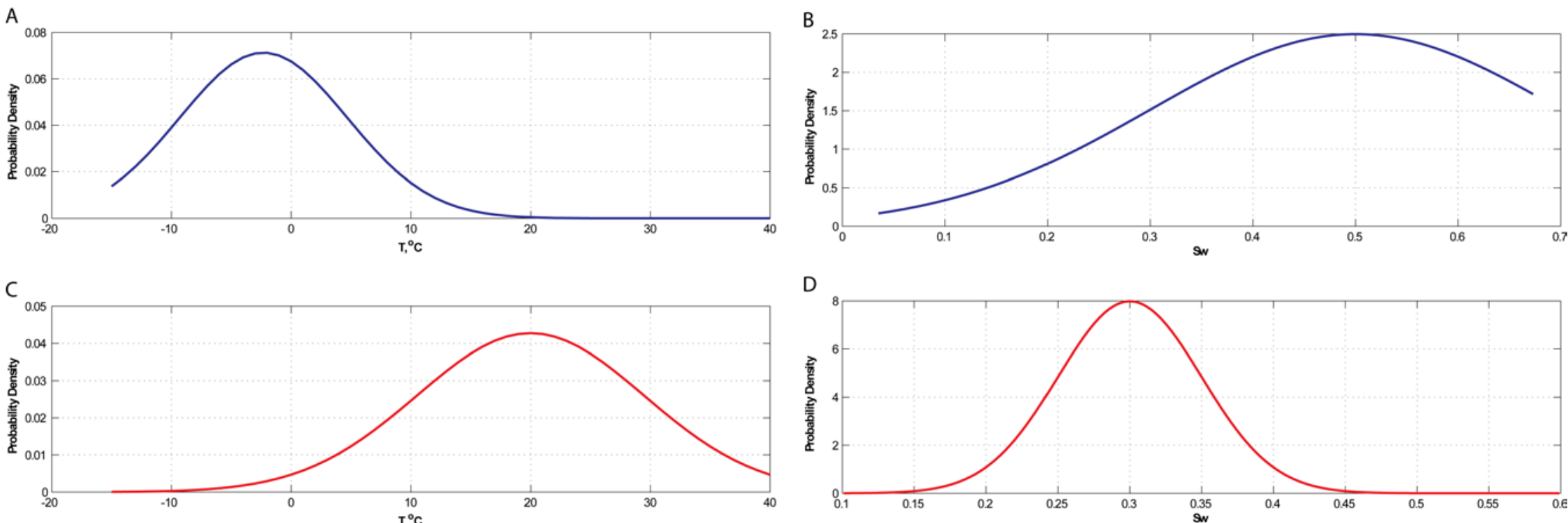

Figure 5-2

A) Truncated normal probability density of the temperature in the boreal forest. B) Truncated normal probability density of soil moisture in the boreal forest. C) Truncated normal probability density of the temperature in the Mojave Desert. D) Truncated normal probability density of soil moisture in the Mojave Desert. 


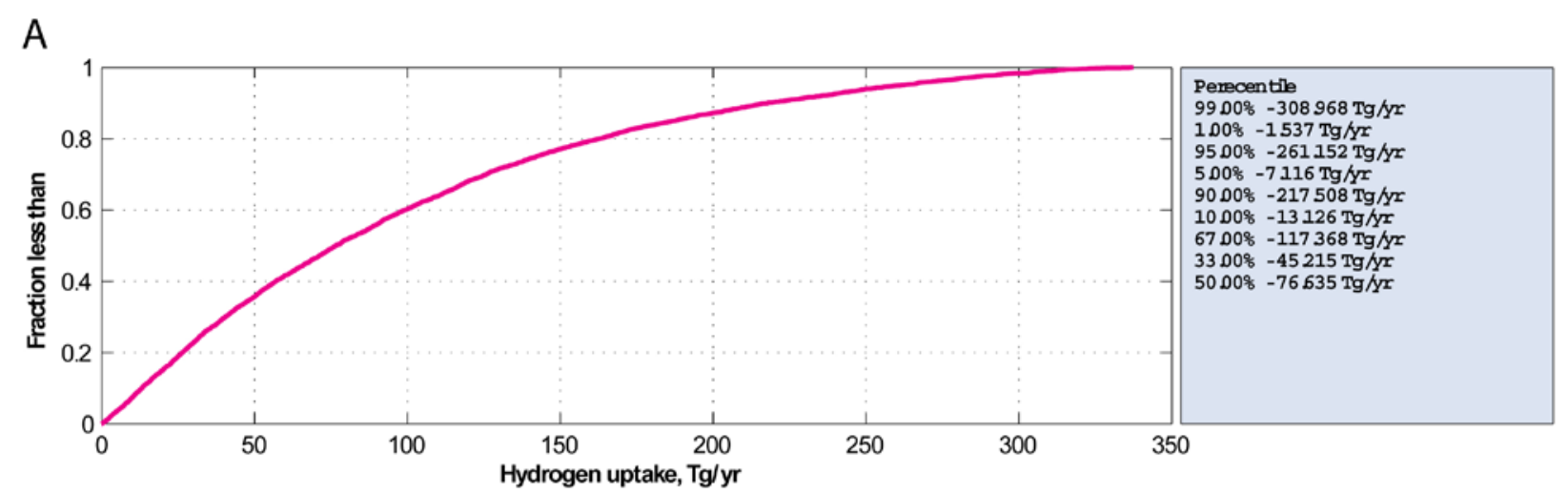

B

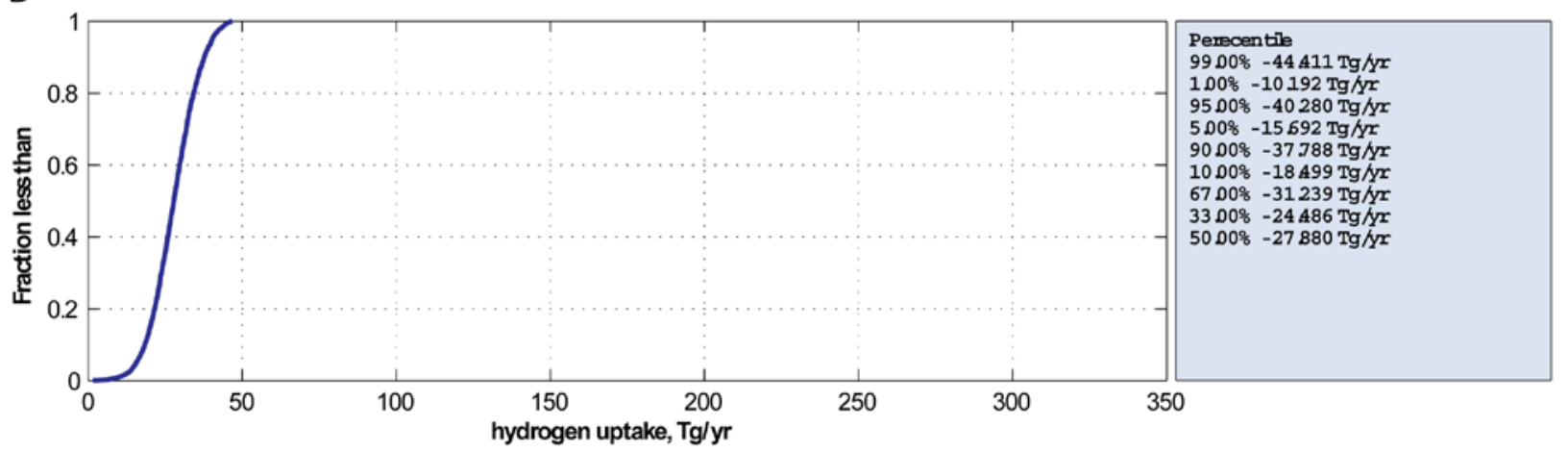

Figure 5-3 A) Distribution of soil uptake of hydrogen in boreal forest. B) Distribution of soil uptake of hydrogen in Mojave Desert.

Given that the global uptake rate reported by Novelli et al. (1999) is $54 \mathrm{Tg} / \mathrm{yr}$, the results are very plausible in that they bound Novelli's estimate. (The 50 percentile values for the Mojave Desert and boreal forest are $28 \mathrm{Tg} / \mathrm{yr}$ and $77 \mathrm{Tg} / \mathrm{yr}$, respectively.) The results generated for this project then match up well with the work of previous researchers, which lend a level of confidence to both sets of results. 


\section{POTENTIAL ENVIRONMENTAL EFFECTS FROM SHIFT TO HFCVS}

The GATOR-GCMOM results provide predicted changes in near-surface concentrations of $\mathrm{H}_{2}$, GHGs, VOCs, and particulate matter as black carbon, POM, $\mathrm{PM}_{10}$, and $\mathrm{PM}_{2.5}$. The near-surface changes in concentrations for $\mathrm{CO}, \mathrm{SO}_{\mathrm{X}}, \mathrm{NO}_{2}$, and ozone in the US have been used to estimate whether violations of national air quality criteria are more or less likely to occur. For particulate matter, the criteria are expressed as $\mathrm{PM}_{10}$ and $\mathrm{PM}_{2.5}$. The effect on atmospheric concentrations of lead of shifting to SHFCVs is discussed qualitatively based on the changes in emissions from vehicles and the steam-reforming process.

\subsection{Use of Simulation Results}

One objective of this project is to compare the predicted air quality for the six criteria pollutants $\left(\mathrm{CO}, \mathrm{SO}_{\mathrm{X}}, \mathrm{NO}_{2}\right.$, particulate matter, ozone, and lead) and greenhouse gases from the GATORGCMOM simulation results for the US to the appropriate national air quality standards. The next step is to compare the predicted surface atmospheric concentrations of these pollutants in the US to levels that may cause effects on human health and structures or materials. The focus of these efforts is to estimate the potential for effects from a shift to hydrogen-based vehicles by 2050. A summary of the potential for effects based on the global average concentrations are also presented.

\subsection{US Standards for Criteria Pollutants}

The US EPA has set national air quality standards for six criteria pollutants: carbon monoxide, ozone, nitrogen dioxide, sulfur dioxide, particulate matter (as $\mathrm{PM}_{10}$ and $\mathrm{PM}_{2.5}$ ), and lead (Table 6-1). Depending on the pollutant, there are annual means, 24-hour, 8-hour, or 1-hour maximum standards. The primary standards are intended to protect human health including the health of sensitive populations such as asthmatics, children, and the elderly. Secondary standards are designed to protect against damage to animals, crops, vegetation, or buildings and decreased visibility. The GATOR-GCMOM model was used to simulate the world at a global grid resolution of $4^{\circ} \mathrm{S}-\mathrm{N}$ by $5^{\circ} \mathrm{W}$-E. Because the model is computationally intensive, only annual average results by grid cell were saved, instead of 24-hour and hourly results. Therefore, only the annual air quality standards were compared for the 2050 A1B and 2050 A1B SHFCV cases. Other standards are discussed qualitatively based on the predicted changes in emissions for the future scenarios.

The US EPA maintains the Air Quality System (AQS) database for ambient air quality data collected by federal, state, local, and tribal air pollution control agencies from thousands of monitoring stations around the US. An annual summary of the data for the criteria air pollutants is prepared by EPA, and the data are also used to identify trends. The annual mean 
concentrations from 1990-2008 for carbon monoxide, ozone, nitrogen dioxide, sulfur dioxide, $\mathrm{PM}_{10}, \mathrm{PM}_{2.5}$, and lead in the United States are shown in Table 6-2.

Table 6-1

National US Air Quality Standards for Criteria Pollutants

\begin{tabular}{|c|c|c|c|c|c|c|}
\hline \multirow[b]{2}{*}{ Pollutant } & \multicolumn{3}{|c|}{ Primary Standard } & \multicolumn{3}{|c|}{ Secondary Standard } \\
\hline & Level, ppm & Level, $\mathrm{mg} / \mathrm{m}^{3}$ & Averaging Time & Level, ppm & Level, $\mathrm{mg} / \mathrm{m}^{3}$ & Averaging Time \\
\hline \multirow{2}{*}{ Carbon Monoxide } & 9 & 10 & 8-hour ${ }^{1}$ & None & & \\
\hline & 35 & 40 & 1-hour ${ }^{1}$ & None & & \\
\hline \multirow{2}{*}{ Sulfur Dioxide } & 0.03 & & Annual Arithmetic Mean & Same & & \\
\hline & 0.14 & & $24-$ hour $^{1}$ & 0.5 & 1.3 & 3-hour ${ }^{1}$ \\
\hline Nitrogen Dioxide & 0.053 & 0.1 & Annual Arithmetic Mean & Same & & \\
\hline \multicolumn{7}{|l|}{ Particulate Matter } \\
\hline $\mathrm{PM}_{10}$ & & 0.15 & 24-hour ${ }^{3}$ & Same & & \\
\hline \multirow{2}{*}{$\mathrm{PM}_{2.5}$} & & 0.015 & Annual Arithmetic Mean ${ }^{4}$ & Same & & \\
\hline & & 0.035 & 24-hour ${ }^{5}$ & Same & & \\
\hline \multirow{2}{*}{ Ozone } & 0.075 & & 8-hour ${ }^{6}$ & Same & & \\
\hline & 0.12 & & 1-hour ${ }^{7}$ & Same & & \\
\hline \multirow[t]{2}{*}{ Lead } & & 0.00015 & Rolling 3-month average ${ }^{8}$ & Same & & \\
\hline & & 0.0015 & Quarterly average $^{9}$ & Same & & \\
\hline
\end{tabular}

${ }^{1}$ Not to be exceeded more than once per year

${ }^{2}$ Final effective 10/15/2008

${ }^{3}$ Not to be exceeded more than once per year on average over 3 years

${ }^{4} 3$-year average of weighted annual mean $\mathrm{PM}_{2.5}$ concentrations from single or multiple community-oriented monitors

${ }^{5} 3$-year average of 98 th percentile of $24-\mathrm{hr} \mathrm{PM}_{2.5}$ concentrations at each population monitor

${ }^{6} 3$-year average of $4^{\text {th }}$-highest daily maximum 8-hr average ozone concentration at each monitor over each year (effective 5/27/2008); old standard was 0.08 ppm, EPA will issues rules for transition to new standard.

${ }^{7}$ Applies only to ozone nonattainment Early Action Compact Areas

${ }^{8} \mathrm{New}$ criteria applies to maximum 3-month average for 3 year period (CFR 67052 v73, no219. 11/12/2008); measured as lead concentration in Total Suspended Particles (TSP); criteria required to be met by 1/2017. Final Rule signed 10/15/2008.

${ }^{9}$ Previous standard

Reference: US EPA National Ambient Air Quality Standards accessed on 5/22/2009 at http://epa.gov/air/criteria.html. 
Table 6-2

Annual Mean Concentrations of Criteria Air Pollutants in US, 1990-2008

\begin{tabular}{|c|c|c|c|c|c|c|c|}
\hline Year & $\mathrm{CO}(\mathrm{ppm})^{1}$ & $\mathrm{O}_{3}(\mathrm{ppm})^{2}$ & $\mathrm{SO}_{2}(\mathrm{ppm})^{3}$ & $\mathrm{NO}_{2}(\mathrm{ppm})^{3}$ & $\mathrm{PM}_{10}(\mathrm{ug} / \mathrm{m} 3)^{4}$ & $\mathrm{PM}_{2.5}(\mathrm{ug} / \mathrm{m} 3)^{5}$ & Lead (ug/m3) \\
\hline 1990 & 6.02 & 0.086 & 0.0080 & 0.020 & 80.8 & - & 0.285 \\
\hline 1991 & 5.90 & 0.086 & 0.0079 & 0.020 & 79.5 & - & 0.213 \\
\hline 1992 & 5.47 & 0.082 & 0.0073 & 0.019 & 71.4 & - & 0.144 \\
\hline 1993 & 5.17 & 0.084 & 0.0072 & 0.019 & 70.7 & - & 0.130 \\
\hline 1994 & 5.34 & 0.084 & 0.0069 & 0.020 & 68.1 & - & 0.171 \\
\hline 1995 & 4.78 & 0.088 & 0.0055 & 0.019 & 67.7 & - & 0.111 \\
\hline 1996 & 4.44 & 0.084 & 0.0055 & 0.019 & 62.1 & - & 0.124 \\
\hline 1997 & 4.23 & 0.084 & 0.0054 & 0.018 & 62.0 & - & 0.121 \\
\hline 1998 & 4.03 & 0.088 & 0.0053 & 0.018 & 60.2 & - & 0.098 \\
\hline 1999 & 3.90 & 0.087 & 0.0051 & 0.019 & 65.2 & - & 0.119 \\
\hline 2000 & 3.51 & 0.081 & 0.0049 & 0.018 & 62.6 & 17.6 & 0.092 \\
\hline 2001 & 3.28 & 0.082 & 0.0046 & 0.017 & 61.7 & 17.1 & 0.089 \\
\hline 2002 & 2.97 & 0.087 & 0.0044 & 0.017 & 61.8 & 16.2 & 0.084 \\
\hline 2003 & 2.78 & 0.081 & 0.0043 & 0.016 & 62.4 & 15.8 & 0.114 \\
\hline 2004 & 2.57 & 0.074 & 0.0041 & 0.015 & 53.6 & 15.3 & 0.120 \\
\hline 2005 & 2.32 & 0.079 & 0.0042 & 0.015 & 57.2 & 16.8 & 0.094 \\
\hline 2006 & 2.22 & 0.077 & 0.0037 & 0.014 & 56.4 & 14.8 & 0.085 \\
\hline 2007 & 2.00 & 0.078 & 0.0036 & 0.013 & 58.3 & 15.3 & 0.107 \\
\hline 2008 & 1.88 & 0.074 & 0.0033 & 0.012 & 55.7 & 13.8 & 0.111 \\
\hline
\end{tabular}

Source: U.S. EPA's AQS Database

${ }^{1}$ Based on annual 2nd maximum 8-hour average.

${ }^{2}$ Based on annual 4th maximum 8-hour average.

${ }^{3}$ Based on annual arithmetic average.

${ }^{4}$ Based on annual 2nd maximum 24-hour average.

${ }^{5}$ Based on seasonally - weighted annual average.

${ }^{6}$ Based on annual maximum 3-month average.

Annual mean 8-hour concentrations for carbon monoxide were calculated using data collected from 206 sites, which ranged from 1.86 to $9.95 \mathrm{ppm}$. The annual 8-hour mean of $9 \mathrm{ppm}$ can be exceeded only once per year; therefore the second highest value is used to determine compliance and trends. Carbon monoxide (CO) concentrations in the United States have decreased by over 66 percent since 1990 (Figure 6-1a). The annual mean CO concentration across the US in 2007 was 2 ppm, which is 78 percent less than the standard of 9 ppm, and 1.88 ppm in 2008. In 2007, the $\mathrm{CO}$ averages by county did not exceed the 8-hour standard, although there were three counties, all in California, with about 15,000 people where the CO concentration was greater than 4.5 to 9 ppm (EPA, 2009a). In 2007, the 1-hour standard of 35 ppm was not exceeded in any of the counties with CO monitors. However, over 150 million people live in counties with no monitors. 
a)

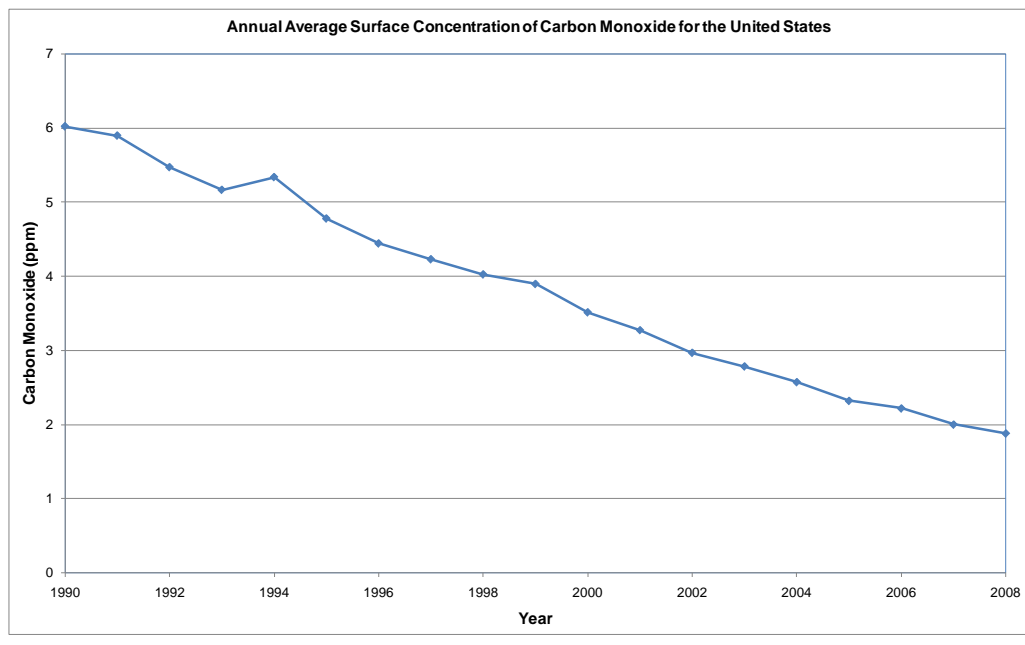

c)

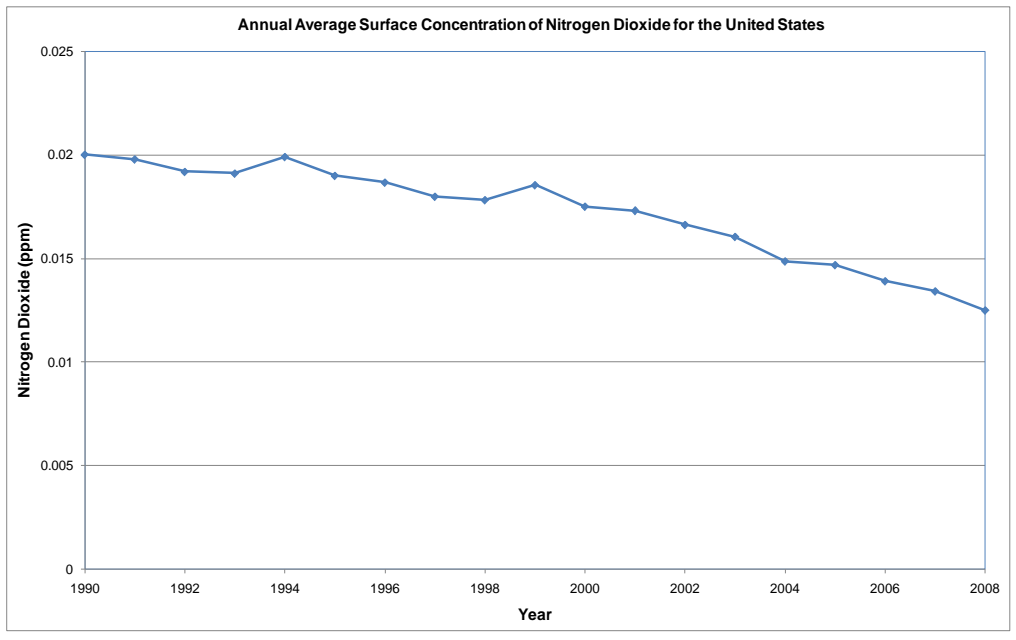

b)

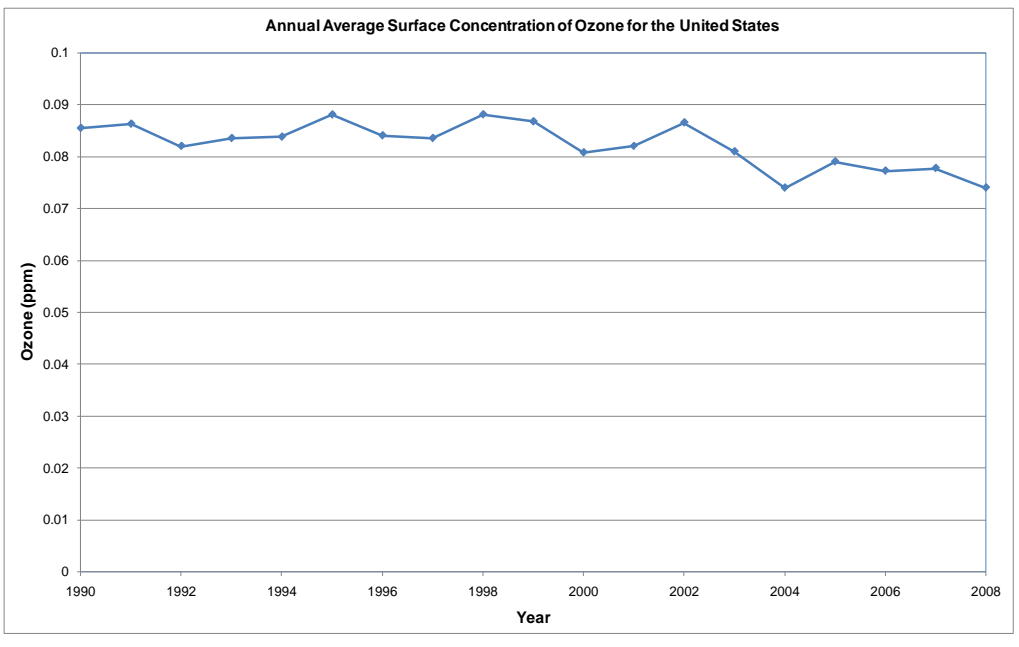

d)

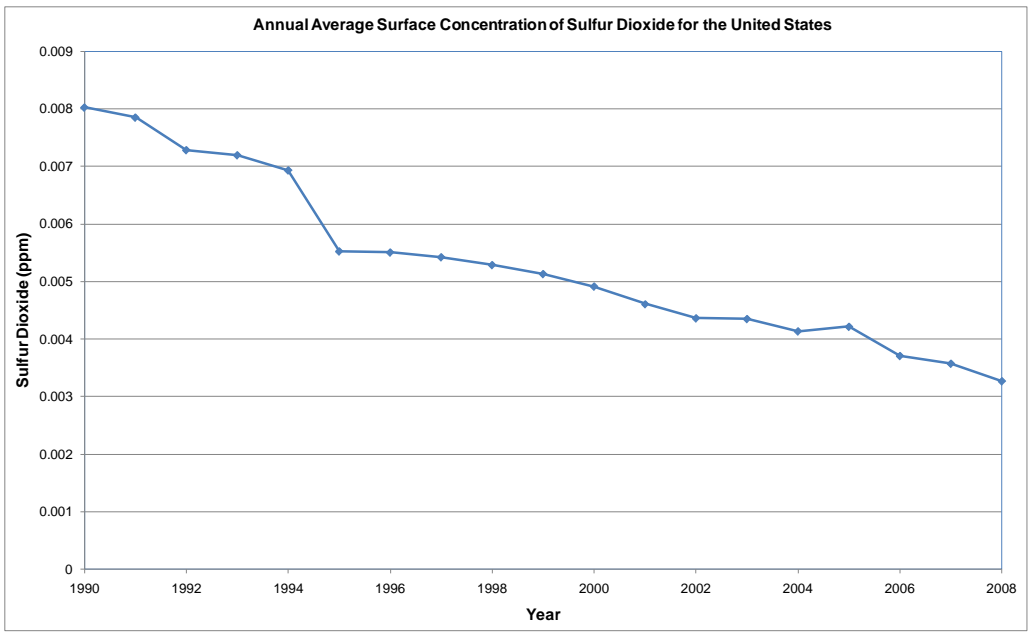

Figure 6-1 Graphs of Annual Mean Concentrations of Criteria Air Pollutants in the U.S. from 1990-2008, a) CO, b) Ozone, c) $\mathrm{NO}_{2}$, d) $\mathrm{SO}_{2}$, e) $\left.\mathrm{PM}_{10}, \mathrm{f}\right) \mathrm{PM}_{2.5}$, and g) Lead.

6-4 

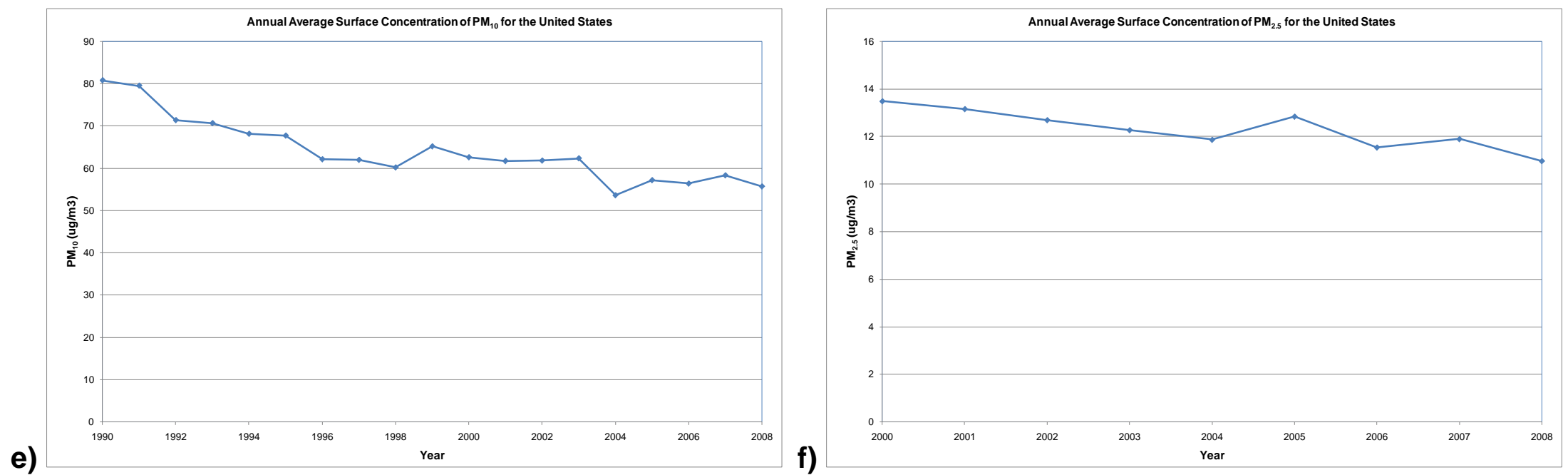

e) rear

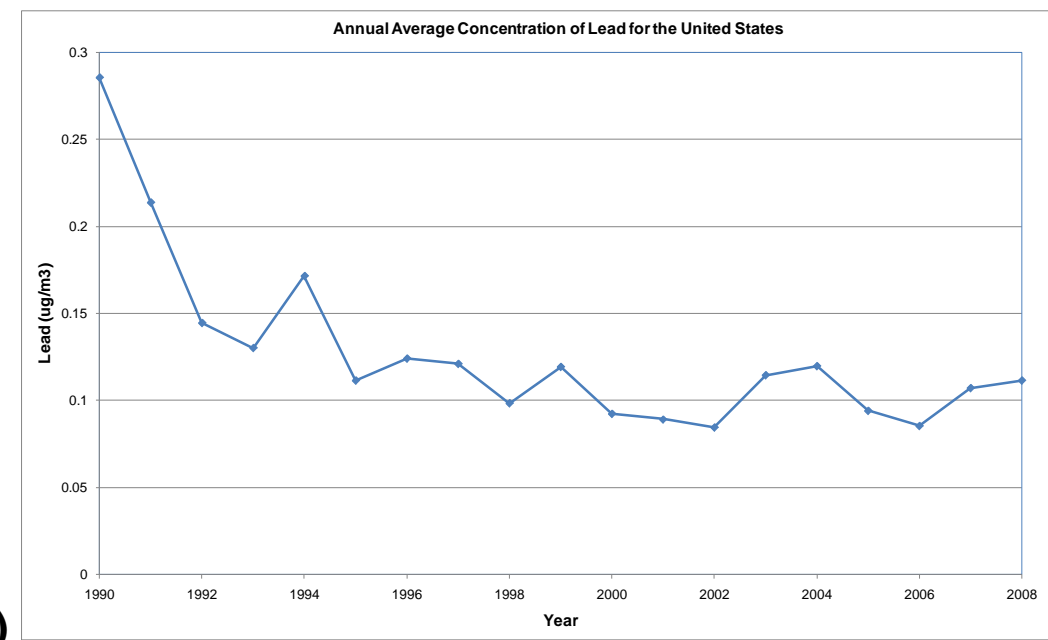

Figure 6-1 (continued) Graphs of Annual Mean Concentrations of Criteria Air Pollutants in the U.S. from 1990-2008, a) CO, b) Ozone, c) $\mathrm{NO}_{2}$, d) $\mathrm{SO}_{2}$, e) $\mathrm{PM}_{10}$, f) $\mathrm{PM}_{2.5}$, and g) Lead. 
Ozone is not emitted directly, but instead forms in the presence of sunlight from $\mathrm{NO}_{\mathrm{x}}$ and VOCs released by motor vehicles and industrial sources, as well as some natural sources. Because ozone forms more readily at higher temperatures, it is more likely to reach higher concentrations in the summer. Ozone at ground level is a major constituent of smog. However, ozone in the stratosphere is beneficial, as it provides protection against solar ultraviolet radiation. The annual mean 8-hour concentrations for ground level ozone were calculated using data collected from 547 sites and ranged from 0.074 to 0.088 ppm (EPA, 2009a). Ground level ozone concentrations in the United States remained fairly stable from 1990-2002, but have shown a notable decline since 2002 (Figure 6-1b). However, the overall 8-hour mean ozone in all years exceeded the 8hour standard of 0.075 ppm except for 2004 and 2008.

The annual mean concentrations for nitrogen dioxide were calculated using data from 151 sites and ranged from 0.012 to $0.02 \mathrm{ppm}$ (EPA, 2009a). Thus, all the sites were less than the standard for $\mathrm{NO}_{2}$ of $0.053 \mathrm{ppm}$. Nitrogen dioxide concentrations in the US have decreased by over $40 \%$ since 1990 (Figure 6-1c).

The annual mean concentrations for sulfur dioxide were calculated using data from 266 sites and ranged from 0.0033 to $0.008 \mathrm{ppm}$. Annual $\mathrm{SO}_{2}$ means for all years between 1990 and 2008 have been less than the standard of $0.03 \mathrm{ppm}$. Sulfur dioxide concentrations in the United States have decreased by over 50\% since 1990 (Figure 6-1d). One reason for the decrease is the implementation of pollution control equipment on coal-fired power plants, particularly in the Midwest (EPA, 2008a). There is also a 24-hour standard for $\mathrm{SO}_{2}$ of $0.14 \mathrm{ppm}$ that cannot be exceeded more than once per year. The annual mean 24-hour concentrations for $\mathrm{PM}_{10}$ were calculated using data from 325 sites and ranged from 53.6 to $80.8 \mu \mathrm{g} / \mathrm{m}^{3}$. PM 10 concentrations in the United States have declined by over 25\% since 1990 (Figure 6-1e). The annual mean 24-hour standard of $150 \mu \mathrm{g} / \mathrm{m}^{3}$ was met in all years. However, the annual mean concentrations of $\mathrm{PM}_{10}$ show more fluctuations than the annual mean concentrations of the other criteria air pollutants.

The annual mean 24-hour concentrations for $\mathrm{PM}_{10}$ were calculated using data from 325 sites and ranged from 53.6 to $80.8 \mu \mathrm{g} / \mathrm{m}^{3}$. $\mathrm{PM}_{10}$ concentrations in the United States have declined by over 25\% since 1990 (Figure 6-1e). The annual mean 24-hour $\mathrm{PM}_{10}$ standard of $150 \mu \mathrm{g} / \mathrm{m}^{3}$ was met in all years. However, the annual mean concentrations of $\mathrm{PM}_{10}$ show more fluctuations than the annual mean concentrations of the other criteria air pollutants.

The annual mean concentrations for $\mathrm{PM}_{2.5}$ are based on the seasonally-weighted annual average, and were calculated using data from 725 sites that ranged from 13.8 to $17.6 \mu \mathrm{g} / \mathrm{m}^{3}$. While the means in some years exceeded the standard of $15 \mu \mathrm{g} / \mathrm{m}^{3}$, compliance is determined on a threeyear average. Annual data for $\mathrm{PM}_{2.5}$ were only available from 2000 to 2008. The annual mean concentration of $\mathrm{PM}_{2.5}$ in the US decreased by about 20\% from 2000 to 2008, but was not a consistent decrease between years (Figure 6-1f). The three year average mean for $\mathrm{PM}_{2.5}$ was not less than the standard until 2007. There is also a 24-hour standard for $\mathrm{PM}_{2.5}$.

The primary lead standard is based on the annual maximum 3-month average. These values for the US were calculated using data from 67 sites that ranged from 0.084 to $0.285 \mu \mathrm{g} / \mathrm{m}^{3}$. Lead concentrations in the US have decreased by almost 40\% since 1990 (Figure 6-1g). The decrease of nearly 94 percent in lead between 1980 and 2007 was mostly attributed to the phase-out of leaded gasoline (Cortely, 2008). The new criterion for lead of $0.15 \mu \mathrm{g} / \mathrm{m}^{3}$ is measured as the lead concentration in Total Suspended Particles (TSP). The new criterion is ten times less than the previous criteria of $1.5 \mu \mathrm{g} / \mathrm{m}^{3}$ that was measured as a quarterly average, but the new criterion 
does not have to be met until January 2017 (CFR, 2008). The new three month maximum standard of $0.15 \mu \mathrm{g} / \mathrm{m}^{3}$ would not have been met in 1990, 1991 or 1994 . Based on the current lead monitoring system, 18 of 111 counties in the US violated the new lead criteria of $0.15 \mu \mathrm{g} / \mathrm{m}^{3}$ based on 2005 to 2008 data (Cortely, 2008). These counties were located in Colorado, Texas, Florida, Alabama, Minnesota and multiple areas in the Midwest. These results are indicators, since the EPA is expected to determine lead non-attainment areas based on three years of data.

\subsection{Comparison of Predicted Criteria Pollutants in US to Standards}

The near surface air concentrations from the GATOR-GCMOM modeling results for grid cells extending across the US were compiled for the 2000 base case, the 2050 A1B base case, and the 2050A1B case with SHFCVs. These results are shown in Table 6-3. The maximum $\mathrm{SO}_{2}$ concentration of 9.9 ppbv was predicted to be less than the annual mean standard of $30 \mathrm{ppbv}$ in 2000. The annual mean concentration of $\mathrm{SO}_{2}$ from observed data for 2000 in the US of $4.9 \mathrm{ppbv}$ from Table 6-2 is within the range of the simulated $\mathrm{SO}_{2}$ concentrations. A decrease in the maximum $\mathrm{SO}_{2}$ is predicted from 2000 to 2050 of about 44 percent. Decreases in ambient maximum $\mathrm{SO}_{2}$ concentrations have been observed from 1989-1991 to 2003-2005 in the midwestern part of the US where coal-fired power plants are common (US EPA, 2008a). The large decrease in the US from the 2000 to 2050 A1B base case is due to decreases in the emission growth factors in all three sectors, industry, transportation, and power. The shift to SHFCVs is estimated to result in a small increase in the maximum $\mathrm{SO}_{2}$ of about $0.1 \mathrm{ppbv}$.

Table 6-3

Simulated Atmospheric Surface Concentrations for US Grid Cells

\begin{tabular}{|l|l|c|c|c|c|c|c|}
\hline \multirow{2}{*}{ Chemical } & \multirow{2}{*}{ Units } & \multicolumn{2}{c|}{ 2000 Base Case } & \multicolumn{2}{c|}{ 2050 A1B Base Case } & \multicolumn{2}{c|}{ 2050 A1B with SHFCV } \\
\cline { 3 - 9 } & min & $\max$ & $\min$ & $\max$ & \multicolumn{2}{|c|}{$\min$} & $\max$ \\
\hline $\mathrm{CO}$ & $\mathrm{ppbv}$ & 214.6 & 625.0 & 251.8 & 457.4 & 244.6 & 423.7 \\
$\mathrm{CO}_{2}$ & $\mathrm{ppbv}$ & 379,640 & 411,240 & 468,880 & 503,540 & 465,990 & 500,240 \\
\hline $\mathrm{NO}_{2}$ & $\mathrm{ppbv}$ & 0.09 & 16.8 & 0.08 & 14.2 & 0.07 & 13.2 \\
\hline $\mathrm{O}_{3}$ & $\mathrm{ppbv}$ & 18.3 & 38.2 & 22.2 & 42.7 & 21.8 & 41.2 \\
\hline $\mathrm{SO}_{2}$ & $\mathrm{ppbv}$ & 0.05 & 9.8 & 0.02 & 5.5 & 0.02 & 5.6 \\
\hline $\mathrm{PM}_{10}$ & $\mu \mathrm{g} / \mathrm{m}^{3}$ & 7.335 & 65.242 & 5.547 & 49.143 & 5.484 & 48.6 \\
\hline $\mathrm{PM}_{2.5}$ & $\mu \mathrm{g} / \mathrm{m}^{3}$ & 6.391 & 54.326 & 4.687 & 40.234 & 4.628 & 39.1 \\
\hline $\mathrm{PM}_{10}$ adjusted & $\mu \mathrm{g} / \mathrm{m}^{3}$ & 1.0 & 23.3 & 0.7 & 8.9 & 0.5 & 11.2 \\
\hline
\end{tabular}

Results are from GATOR-GCMOM 10-year simulations from grid cells across US.

Results for $\mathrm{PM}_{10}$ and $\mathrm{PM}_{2.5}$ include water vapor; only the $\mathrm{PM}_{10}$ results can be adjusted.

For $\mathrm{NO}_{2}$, the maximum concentrations for all three cases from the modeling results were less than the annual mean standard of 53 ppbv. From 2000 to the 2050 A1B base case, the maximum concentration of $\mathrm{NO}_{2}$ is estimated to decrease by about 15 percent. The decrease is less than for $\mathrm{SO}_{2}$, since the emission growth factors were predicted to increase in the power and industry sectors, but decrease in the transportation sector. The model results indicate that the highest concentrations in the US are predicted to occur in the northeast in the 2050 base case. Higher concentrations in urban areas, especially in the eastern US, occurred in 2000 to 2005 as well (EPA, 2008b), although the standard was met for the annual average in 2005. The shift to SHFCVs is estimated to result in a small decrease in the maximum $\mathrm{NO}_{2}$ of about 1 ppbv or about 7 percent. Decreased emission growth factors from the 2050 A1B case to the 2050 A1B case 
with SHFCVs occur only in the transportation sector, and were large enough to offset increases for the industry and power sectors.

The standard for $\mathrm{PM}_{2.5}$ of $15 \mu \mathrm{g} / \mathrm{m}^{3}$ is expressed as an annual mean concentration over a three year period. The $\mathrm{PM}_{10}$ and $\mathrm{PM}_{2.5}$ values in the model include water vapor, and an estimate of the percent of the water vapor associated with $\mathrm{PM}_{2.5}$ was not available. The model results show that both the maximum uncorrected $\mathrm{PM}_{10}$ and $\mathrm{PM}_{2.5}$ values are expected to decrease from the 2000 base case to the $2050 \mathrm{~A} 1 \mathrm{~B}$ case. However, the corrected $\mathrm{PM}_{10}$ values are expected to decrease by about 62 percent from 2000 to 2050, but to increase after the shift to SHFCVs by about 2.3 $\mu \mathrm{g} / \mathrm{m}^{3}$, which represents an increase of about 26 percent. Part of the decrease for the $2050 \mathrm{~A} 1 \mathrm{~B}$ case compared to the 2000 base case is due to improved controls of particulate emissions from future gasoline vehicles. The changes are consistent with the growth factors for the shift to SHFCVs in that, while the transportation and power emission growth factors were expected to decrease, the factors for industry increased. The estimated increase in corrected $\mathrm{PM}_{10}$ values is uncertain due to the fraction of water vapor associated with the $\mathrm{PM}_{10}$ fraction.

The other criteria pollutants, $\mathrm{CO}$ and ozone, cannot be compared directly to model results, because the standards are for shorter periods than annual means. The maximum CO concentrations are estimated to decrease from 2000 to 2050 in the US. The emission growth factors for $\mathrm{CO}$ were estimated to increase for industry and power, but decrease for transportation. The maximum CO concentration in the US is estimated to continue decreasing by about 7 percent. The emission growth factors for transportation were estimated to decrease more than the increases for industry and power.

Unlike CO, the maximum ozone concentration is predicted to increase between the 2000 and 2050 A1B case by about 4.5 ppbv, or about 12 percent. After shifting to SHFCVs, the maximum ozone concentration is predicted to decrease by about $1.5 \mathrm{ppbv}$, or 3.5 percent. Changes to ozone in the near surface atmosphere are due to varying emissions of $\mathrm{NO}_{\mathrm{x}}$ and $\mathrm{VOCs}$, and thus involves multiple chemicals and chemical reactions. Model results for daytime ozone for the 2050 A1B base case showed that the estimated surface concentrations in the US were less than $60 \mathrm{ppbv}$, which is less than the 8-hour standard of 75 ppbv. Ozone also has a 1-hour standard, but model results were not available to compare to this criterion.

Formerly, lead sources to the atmosphere were related to motor vehicles due to use of leaded gasoline. Due to the change to unleaded gasoline, the primary current sources of lead are metals processing, particularly lead smelters. Other stationary sources include waste incinerators, power plants, and lead-acid battery manufacturers. Lead-based paint is an important local source. The shift to SHFCVs is expected to result in less lead emissions, due to the decrease in vehicle emissions. The specific amount of the decrease would depend on the method used to generate the hydrogen fuel.

\subsection{Potential Effects of Criteria Pollutants on Health}

\subsubsection{Sulfur Dioxide}

$\mathrm{SO}_{2}$ concentrations in air can impair respiratory function by causing bronchoconstriction, although there is uncertainty with respect to the extent of synergistic effects with other air pollutants. Human clinical studies have shown reduced lung function in 5 to 30 percent of asthmatics when they were exposed to 5-10 minutes of $\mathrm{SO}_{2}$ at concentrations of 0.2-0.3 ppm during moderate to heavy exercise (EPA, 2008c). Exposure to $\mathrm{SO}_{2}$ at concentrations of $0.4 \mathrm{ppm}$ 
for up to 10 minutes resulted in about 20-35 percent of the asthmatics being affected when exercising. Short duration exposure to $\mathrm{SO}_{2}$ concentrations up to1.0 ppm did not cause respiratory effects in healthy non-asthmatics. Asthmatics are more sensitive to $\mathrm{SO}_{2}$ due to pre-existing inflammation, which triggers local nervous system responses that contribute to decreased lung function. Children and adults older than 65 are more likely to be affected by short term exposures to elevated $\mathrm{SO}_{2}$ concentrations. The acute exposure guideline for an 8-hour period (AEGL-1) where even susceptible populations could experience only transient and reversible effects has been determined to be $0.2 \mathrm{ppmv}$. The guideline for concentrations at which serious effects can occur (AEGL-2) is 0.75 ppmv (EPA, 2009b).

Short-term concentrations of air quality parameters were not available from the modeling. However, the annual mean surface $\mathrm{SO}_{2}$ concentrations for the US were predicted to decrease from the 2000 base case levels both in the 2050 A1B base case and the 2050 A1B case with SHFCVs. The annual surface mean on a global basis of $\mathrm{SO}_{2}$ was predicted to increase for the 2050 A1B base case and the 2050 A1B case with SHFCVs, compared to 2000, both the mean concentrations were less than $1 \mathrm{ppm}$. The surface mean on a global basis was estimated to decrease slightly for the 2050 A1B case with SHFCVs.

\subsubsection{Carbon Monoxide}

$\mathrm{CO}$ in air can cause health effects when the $\mathrm{CO}$ binds with reduced iron in heme-containing molecules such as hemoglobin, reducing the oxygen-carrying capacity of the blood (EPA, 2010). Short-term exposures to elevated CO are associated with decreased respiratory function. Susceptible populations include people with coronary heart disease, COPD, diabetes, and anemia. The acute exposure guideline for an 8-hour period (AEGL-2) where susceptible populations could experience serious health effects has been determined to be $27 \mathrm{ppmv}$ (EPA, 2009b). Exposure to high levels (e.g. 600 ppmv for 30 minutes) can result in effects on the central nervous systems including headaches, dizziness, and cognitive difficulties.

The annual mean surface CO concentrations for the US were predicted to decrease from current levels both in the 2050 A1B base case and the 2050 A1B case with SHFCVs, and both values were less $0.5 \mathrm{ppm}$. The annual mean on a global basis was predicted to increase for the 2050 A1B base case and the 2050 A1B case with SHFCVs, compared to 2000. The surface mean CO concentration on a global basis for the 2050 A1B case was about 316 ppbv, and was predicted to decrease after a shift to SHFCVs by about 6 ppbv.

\subsubsection{Nitrogen Dioxide}

$\mathrm{NO}_{2}$ in air can cause respiratory effects, particularly to children. Short term exposure to 1-2 ppm for one hour can cause airway inflammation in healthy individuals (EPA, 2008b). Asthmatics exposed to 0.1 to $0.3 \mathrm{ppm} \mathrm{NO}_{2}$ can experience airway inflammation and hypertensiveness. The effects of air pollutants including $\mathrm{NO}_{2}$ may be influenced by other chemicals such as ozone, $\mathrm{CO}$ or $\mathrm{PM}_{10}$. The acute exposure guideline for an 8-hour period (AEGL-1) where even susceptible populations could experience only transient and reversible effects has been determined to be 0.5 ppmv with a potential for serious effects at 6.7 ppmv for an 8-hour period (AEGL-2) (EPA, 2009b).

The current (2000) annual mean $\mathrm{NO}_{2}$ concentrations across the US are less than $0.1 \mathrm{ppm}$. The model predicted annual mean concentrations for the 2050 A1B base case and 2050 A1B with SHFCVs were less than the 2000 base case, and thus increased health effects are unlikely to 
occur from the shift to SHFCVs. There are estimated to be increased emissions of $\mathrm{NO}_{2}$ at industrial and power plant facilities to support generation of the required hydrogen fuel, so there is a potential for local areas with higher emissions. The duration of local emissions is not simulated by the model.

\subsubsection{Ozone}

Ozone is formed by photochemical reactions between VOCs and nitrogen oxides and is influenced by carbon monoxide and the presence of compounds with hydroxyl radicals such as $\mathrm{NO}_{3}$ and chloride and bromine radicals in coastal areas. There are strong daily and seasonal variations in the precursors of ozone and ozone. Health effects of ground level ozone are related to decreased lung function, mostly from outdoor exposures. Sensitive populations include children, asthmatics, and adults who exercise or work outdoors. Respiratory effects such as coughs can occur after 1-3 hour exposure to $0.12 \mathrm{ppm}$ by healthy adults during heavy exercise and after 6-8 hour exposure to 0.08 ppm by young adults during moderate exercise (EPA, 2006b). In 2008, the 8-hour primary standard for ozone was revised from 0.08 to $0.075 \mathrm{ppm}$. The EPA concluded in their 2006 report that while there are studies in the US and Europe that indicate association between acute exposures to ozone and respiratory or cardiovascular mortality, further research is needed to understand the mechanisms.

The model predicted average surface ozone concentrations in daytime for the 2050 A1B base case were less than $0.075 \mathrm{ppm}$ across the US. The maximum annual mean surface ozone concentration in the US was predicted to decrease by about $1.5 \mathrm{ppm}$ after the shift to SHFCVs. Daytime ozone concentrations at the surface were also predicted to decrease by less than $0.1 \mathrm{ppm}$ on a global basis. Changes in ozone concentrations in the upper atmosphere are discussed in Section 3.4.

\subsubsection{Particulate Matter}

Particulate matter as $\mathrm{PM}_{10}$ and $\mathrm{PM}_{2.5}$ is of concern based on potential effects on the cardiovascular and respiratory system. There is large spatial and temporal variability of particulate emissions, in addition to different methods for measuring and reporting the data. Understanding the specific chemical species associated with the particulate fraction has been used to identify potential sources (EPA, 2009c). The atmospheric lifetime is longer for $\mathrm{PM}_{2.5}$, so those particles can be transported further than $\mathrm{PM}_{10}$, which also contributes to the spatial variability. Both short and long term exposures to elevated $\mathrm{PM}_{2.5}$ were positively associated with increased hospital visits and admissions for cardiovascular emergencies (ischemic heart disease and congestive heart failure) in multi-city studies in the US with mean 24-hour $\mathrm{PM}_{2.5}$ concentrations of 7-18 $\mu \mathrm{g} / \mathrm{m}^{3}$ (EPA, 2009c). Other effects on respiratory systems have been identified, but there are often co-pollutants that could be the primary cause. There is less evidence for health effects of $\mathrm{PM}_{10}$, and most of the studies evaluated the fraction between $\mathrm{PM}_{10}$ and $\mathrm{PM}_{2.5}$. Studies have also investigated potential health effects of gasoline and diesel exhaust, although it is difficult to determine the role of particulates versus specific chemicals.

The model predicted PM concentrations are not reported on a dry basis. The adjusted $\mathrm{PM}_{10}$ concentrations showed a decrease from the 2000 base case to the 2050 A1B base case, but a small increase after shifting to SHFCVs. The shift to HFCVs would reduce the use of both gasoline and diesel vehicles, which would be a general benefit to health. Reduced concentrations 
of fine particles of black carbon due to the shift to SHFCVs were predicted by the model, which are also a health benefit with respect to respiratory effects.

\subsubsection{Lead}

The health effects of lead are now recognized as more important, particularly in children. Once taken into the body, lead distributes throughout the body in the blood and is accumulated in the bones. Depending on the level of exposure, lead can adversely affect the nervous system, kidney function, immune system, reproductive and developmental systems and the cardiovascular system (Cortely, 2008). Lead exposure also affects the oxygen carrying capacity of the blood. The lead effects most commonly encountered in current populations are neurological effects in children and cardiovascular effects (e.g., high blood pressure and heart disease) in adults. Infants and young children are especially sensitive to even low levels of lead, which may contribute to behavioral problems, learning deficits and lowered IQ. In addition to exposure to lead in air, other major exposure pathways include ingestion of lead in drinking water and leadcontaminated food as well as incidental ingestion of lead-contaminated soil and dust. Lead-based paint remains a major exposure pathway in older homes.

The model results did not provide information on lead, per se. The predicted decrease in gasoline and diesel exhaust after shifting to HFCVs is expected to reduce lead emissions from this source.

\subsection{Potential Effects of Criteria Pollutants on Structures}

Criteria pollutants ( $\mathrm{SO}_{2}, \mathrm{NO}_{2}$, ozone, $\mathrm{CO}$, lead, and particulate matter) can have detrimental effects on materials or structures that are exposed to these pollutants over extended periods of time. The exposure to these pollutants occurs through both wet and dry deposition from the atmosphere, and can involve both local deposition and long distance transport of pollutants (Kucera and Fitz, 1995).

Ozone is the principal component of smog and can cause damage to rubber products and fabrics (EPA, 2006). Nitrogen dioxide and sulfur dioxide are acid aerosols that can corrode natural stone and zinc coated materials (Watkiss et al., 2006; EPA, 2006). The impacts from these acid aerosols are of special concern due to the potential for deterioration of numerous historic and cultural monuments and important buildings (Striegel et al., 2003). Nitric acid and $\mathrm{SO}_{2}$ are especially detrimental to zinc, sandstone and limestone. $\mathrm{SO}_{2}$ can also accelerate corrosion of carbon steel in combination with particulate matter (Kucera, 2005). Particulate matter in the atmosphere may consist of ash, soot, smoke, or dust. These materials can soil and discolor structures including painted surfaces, wood and fabrics (EPA, 2006). In addition, particulates can contribute to corrosion of carbon steel and limestone. $\mathrm{NO}_{2}$ can damage glass, and ozone can affect copper and tin metal surfaces (Graedel and Leygraf, 2001).

Deterioration processes affecting stone or concrete buildings and carbonate-based paints include the following:

- carbonate dissolution due to acids and subsequent deposition of salts, which can absorb water and contribute to cracking when subjected to multiple wet-dry or freeze-thaw cycles

- corrosion and weathering of metal sulfides and other minerals

- discoloration of paints 
- formation of gypsum crust on various types of stone

- mechanical cracking due to growth of microorganisms and plants.

Factors affecting the extent of damage to buildings include: air pollutants, extent and acidity of rainfall, relative humidity, exposure to sun and wind, and severity of freeze-thaw cycles.

Deterioration processes affecting metal structures include the following:

- uniform corrosion

- pitting such as chloride-related holes in aluminum or bronze

- selective attack such as de-zincification of brass

- stress corrosion cracking particularly if a metal is bent and in a corrosive setting

- galvanic corrosion where different metals are in contact, even in runoff

- carbon build-up in soot crusts, which act as a cathode in presence of surface moisture

- erosion of soft metals thereby exposing fresh metal that can be corroded.

Other processes contributing to damage of plastics or organic-based materials include leaching of binders and plasticizers and volatilization of solvents. Aluminum and zinc-rich paints or coatings weather and ultimately form water-soluble byproducts that can be removed by subsequent rainfall.

Table 6-4 summarizes building materials and the air pollutants of concern for a given material. As shown in this table, $\mathrm{SO}_{2}$ can have detrimental effects on the most materials. $\mathrm{SO}_{2}$ is one of the main contributors to damage to building materials, because it can dissolve into the moisture layer on the surface of the material where it can form sulfite or sulfate. The aqueous layer then becomes acidic, leading to increased corrosion. This process is influenced by relative humidity, air temperature, and the frequency and intensity of rainfall. Metals such as copper and copper alloys are relatively resistant to corrosion in unpolluted air, but become susceptible to attack under acidic conditions. An investigation by the Swedish Corrosion Institute found that reductions in atmospheric concentrations of sulfur and nitrogen have resulted in decreased corrosion rates to buildings and cultural monuments (Kucera, 2003). 
Table 6-4

Building Materials and Air Pollutants of Concern

\begin{tabular}{|c|c|c|c|c|}
\hline Building Material & $\mathrm{SO}_{2}$ & $\mathrm{NO}_{2}$ & $\mathrm{O}_{3}$ & Rain $[\mathrm{H}+]$ \\
\hline Weathering Steel & $x$ & & & \\
\hline Zinc & $x$ & & $x$ & $x$ \\
\hline Aluminum & $x$ & & & \\
\hline Copper & $x$ & & $x$ & $x$ \\
\hline Cast Bronze & $x$ & & $x$ & $x$ \\
\hline Paint (galvanized) & $x$ & & & \\
\hline Paint (steel) & $x$ & & & \\
\hline Limestone & $x$ & & $x$ & $x$ \\
\hline Sandstone & $x$ & & & $x$ \\
\hline Nickel & $x$ & & $x$ & \\
\hline Tin & & & $x$ & \\
\hline Glass & $x$ & $x$ & & $x$ \\
\hline Rubber and plastic materials & & & $x$ & \\
\hline
\end{tabular}

Source: Screpanti and De Marco, 2009

Equations have been developed for different types of material to estimate the depth of surface recession as a function of $\mathrm{SO}_{2}$ concentration, rainfall acidity, temperature, and relative humidity (Kucera et al, 1997). For example, one program was conducted to measure effects and atmospheric conditions at 39 sites in Europe and North America to derive dose-response functions that can relate effects to $\mathrm{SO}_{2}$ concentrations (Graedel and Leygraf, 2001). Another program monitored 50 sites in Europe for one year to evaluate corrosion of carbon steel, cooper, bronze, zinc, limestone, sandstone, and marble and soiling of surfaces (Kucera, 2005). Doseresponse equations to predict corrosion effects were developed for single pollutants and for combinations of pollutants, which can enhance the rate of losses. An example of combined effects is $\mathrm{NO}_{2}$ and $\mathrm{SO}_{2} . \mathrm{NO}_{2}$ is thought to be less damaging to buildings than $\mathrm{SO}_{2}$, but both contribute to producing acidic solutions. $\mathrm{NO}_{2}$ has synergistic effects with $\mathrm{SO}_{2}$, in that it appears to accelerate the oxidation of sulfite to sulfate (Benedetti et al., 2008). An example of tolerable $\mathrm{SO}_{2}$ levels for various types of materials used for cultural heritage monuments was developed for two scenarios, an urban setting and an average setting, in Europe based on 2005 median air quality conditions, as shown in Table 6-5. These levels were considered appropriate for average conditions with an air temperature of $10.3^{\circ} \mathrm{C}$, relative humidity of 73.2 percent, annual precipitation of $604 \mathrm{~mm} /$ year, and a rain $\mathrm{pH}$ of 5.0. Based on the MULTI-ASSESS project, a target level for $\mathrm{SO}_{2}$ of $10 \mu \mathrm{g} / \mathrm{m}^{3}$ was estimated to be protective of cultural sites in 80 percent of Europe for 2005 conditions, particularly with respect to nitric acid $\left(\mathrm{HNO}_{3}\right)$. 
Table 6-5

Example of Tolerable $\mathrm{SO}_{2}$ Levels

\begin{tabular}{|c|c|c|}
\hline \multirow[b]{2}{*}{ Material } & \multicolumn{2}{|c|}{ Tolerable $\mathrm{SO}_{2}$ Level, $\mu \mathrm{g} / \mathrm{m}^{3}$} \\
\hline & Average Setting & Urban Setting \\
\hline Limestone & 25 & 9 \\
\hline Copper & 5 & 13 \\
\hline Bronze & 21 & 9 \\
\hline Zinc & 11 & 5 \\
\hline Carbon Steel & 11 & 6 \\
\hline \multicolumn{3}{|l|}{ For Conditions } \\
\hline Ozone, $\mu \mathrm{g} / \mathrm{m}^{3}$ & 47 & 33 \\
\hline $\mathrm{NO}_{2}, \mu \mathrm{g} / \mathrm{m}^{3}$ & 19 & 56 \\
\hline $\mathrm{HNO}_{3}, \mu \mathrm{g} / \mathrm{m}^{3}$ & 0.82 & 1.16 \\
\hline $\mathrm{PM}_{10,} \mu \mathrm{g} / \mathrm{m}^{3}$ & 37 & 72 \\
\hline
\end{tabular}

Data from the MULTI-ASSESS Project (Kucera, 2005).

Ozone is an oxidant itself, but also has synergistic effects with $\mathrm{SO}_{2}$. For example, laboratory exposures of zinc, copper, nickel, and calcareous stone materials showed that effects were enhanced by the combination of ozone and $\mathrm{SO}_{2}$ (Kucera and Fitz, 1995). Ozone also contributes to oxidation of exposed iron or steel. One side effect of this process is that the byproducts have a larger volume than the original materials so that clamps, anchors, or internal supports can weather and the surrounding stone can crack (Weaver, 1991). In addition, ozone can cause loss of plasticizers and embrittlement of polymeric materials such as PVC. Ozone is a significant factor contributing to damage to copper and tin materials (Graedel and Leygraf, 2001).

In tropical areas, the high moisture levels can result in colonization of stone by phototrophic microorganisms including algae, lichens, bacteria and fungi, which promote growth of vascular plants that, can cause mechanical deterioration of stone structures (Herrera and Videla, 2004). The bacteria biosolubilize the limestone to obtain needed ions, resulting in releases of organic and inorganic acids that further increase decay of the rock by leaching the binding material of the crystalline structure of the stone (Lewis et al, 1988). A similar process can occur with concrete

Carbon particles from diesel and gasoline vehicles contribute to $\mathrm{PM}_{10}$ and $\mathrm{PM}_{2.5}$ levels in the atmosphere, in addition to other particulate emissions from coal-fired power plants and industries. Such particles can discolor surfaces or deposit soot. In settings where there would be building maintenance only every 20 years, a target level of $10 \mu \mathrm{g} / \mathrm{m}^{3}$ was selected as protective for limestone, painted steel, and white plastic where the reflectance loss was 35 percent or less (Kucera, 2005). For cultural heritage sites, a protective level of $15 \mu \mathrm{g} / \mathrm{m}^{3}$ was suggested.

Comparing the predicted concentrations in the US for the 2050 A1B base case to the above tolerable levels for $\mathrm{SO}_{2}$ concentrations shows that the estimated maximum annual mean surface concentrations are above the desirable levels in an urban setting (5-13 $\mu \mathrm{g} / \mathrm{m}^{3}$ or 1.9 to $3.4 \mathrm{ppbv}$ ). However, this was also true for the 2000 base case. The measured 2008 annual mean in the US (3.3 ppbv) was less than the level to protect limestone in an urban setting, but not less than the estimated levels to protect carbon steel or zinc. The minimum annual mean surface concentration in the US was less than the desired level for protection of metal and limestone building materials. The shift to SHFCVs was predicted to cause only a small increase in $\mathrm{SO}_{2}$ concentrations of about 0.1 ppbv. However, the ambient conditions of the other chemicals used to derive the $\mathrm{SO}_{2}$ levels 
for an urban setting shown in Table 6-5 were higher for ozone for the 2000 and the 2050 A1B base case. The predicted concentrations of ozone after the shift to SHFCVs were estimated to decrease by about 3 percent, but not enough to reach similar ambient conditions. The predicted $\mathrm{NO}_{2}$ levels used for this evaluation were less for the 2000 and the 2050 A1B base case than the ambient conditions used in the above investigation. The shift to SHFCVs resulted in a decrease in $\mathrm{NO}_{2}$ concentrations of about 7\%. Depending on the exposure and meteorological conditions, there could be potential for corrosion loss to structures, but these effects are predicted to be less after the shift to SHFCVs. The estimated $\mathrm{PM}_{10}$ levels for both the $2050 \mathrm{~A} 1 \mathrm{~B}$ base case and the $2050 \mathrm{~A} 1 \mathrm{~B}$ case with HFCVs were less than $15 \mu \mathrm{g} / \mathrm{m}^{3}$, which is the level suggested by Kucera to protect most cultural heritage sites.

\subsection{Summary of Potential Future Effects}

The GATOR-GCMOM results for the criteria pollutants show that surface concentrations of $\mathrm{CO}_{2}$ and ozone in the US are likely to increase from the 2000 base case to the $2050 \mathrm{~A} 1 \mathrm{~B}$ base case due to the increased economic activity, but concentrations of $\mathrm{CO}, \mathrm{NO}_{2}, \mathrm{SO}_{2}$, and $\mathrm{PM}_{10}$ will decrease due to the improved pollution control equipment and energy efficiencies. The shift to SHFCVs in 2050 is predicted to result in decreased concentrations for all the criteria pollutants, except for $\mathrm{SO}_{2}$ and $\mathrm{PM}_{10}$. Ozone was predicted to decrease by about 3.5 percent for the SHFCVs case, and the daytime ozone concentrations in the US were predicted to be less than the 8-hour ozone standard. The higher predicted concentrations for $\mathrm{SO}_{2}$ and $\mathrm{PM}_{10}$ were consistent with estimated increased emissions when the steam-reforming method was used to generate the hydrogen fuel. If renewable methods such as wind-based electrolysis were used to generate the hydrogen, the emissions of these pollutants would be expected to be less. The predicted increase in maximum $\mathrm{SO}_{2}$ concentrations in the US grid cells for the SHFCVs case was small ( $0.12 \mathrm{ppbv}$ ) and represented an increase of about 2 percent. The annual mean surface $\mathrm{SO}_{2}$ concentrations in the US were predicted to be less than $0.2 \mathrm{ppm}$, the level at which transient effects are expected to occur for an 8-hour exposure period. The $\mathrm{PM}_{10}$ concentrations for the SHFCVs case were estimated to increase by about $2.3 \mu \mathrm{g} / \mathrm{m}^{3}$, but only when the concentrations were adjusted to a dry basis. There is considerable uncertainty in the $\mathrm{PM}_{10}$ concentrations, due to spatial and temporal variability in the water vapor content. The unadjusted $\mathrm{PM}_{10}$ concentrations for the SHFCVs case were estimated to be less than those for the 2050 A1B base case. The overall improvement in air quality after shifting to HFCVs in 2050 is projected to result in health benefits and a reduced potential for effects on materials and structures. 



\section{SUMMARY, CONCLUSIONS AND RECOMMENDATIONS}

We examined the effects on climate, the stratospheric ozone layer, and tropospheric composition of converting fossil-fuel onroad vehicles (FFOVs) to hydrogen fuel cell vehicles (HFCVs). The atmospheric model, GATOR-GCMOM, was used for the analysis. The model was first updated and evaluated with respect to its ability to predict sources and sinks of $\mathrm{H}_{2}$. Current and future (2050) emission inventories of all important anthropogenic gas and particle chemicals were then developed. The future inventories included one based on the IPCC SRES A1B scenario and another based on the same scenario but modified with $90 \%$ penetration of HFCVs in developed countries and $45 \%$ penetration in other countries and $\mathrm{H}_{2}$ produced by steam-reforming of natural gas. Subsequently, 10-year simulations were run to examine the effect of converting onroad vehicles in 2050 to steam-reforming-powered HFCVs (SHFCVs). The estimated changes to climate and the tropospheric composition were compared with the results of 10-year simulations examining the effect of converting all current onroad vehicles worldwide to HFCVs where the $\mathrm{H}_{2}$ was produced by electrolysis, with the electricity derived from wind power (WHFCVs).

In addition to the examination of potential global atmospheric changes associated with conversion to HFCVs, the results for near surface concentrations in the US for the six criteria pollutants from the GATOR-GCMOM simulations were compared to annual mean air quality standards. The predicted near surface concentrations of the criteria pollutants and greenhouse gases in the US were also compared to known concentrations that can cause effects on human health or damage to materials and structures.

\subsection{Conclusions}

Major conclusions based on the GATOR-GCMOM simulations are as follows:

1. Converting $100 \%$ of current vehicles worldwide to WHFCVs is expected to reduce levels of $\mathrm{NO}_{\mathrm{x}}, \mathrm{CO}, \mathrm{CO}_{2}$, most organic gases, $\mathrm{OH}$, ozone, PAN, black carbon, and other particle components in the troposphere, but to increase tropospheric $\mathrm{CH}_{4}$ due to the lower $\mathrm{OH}$. However, by cooling the troposphere and warming the stratosphere, thereby stabilizing the stratosphere, reducing water vapor and $\mathrm{HO}_{\mathrm{x}}$ transport to it, and reducing the sizes and lifetimes of stratospheric aerosols and polar stratospheric clouds, WHFCVs are expected to increase upper tropospheric/lower stratospheric ozone, causing a net global ozone column increase, despite a slight upper stratospheric decrease in ozone. Thus, shifting to WHFCVs would benefit the environment by improving air quality and decreasing conditions that favor ozone destruction in the UTLS.

2. Converting vehicles worldwide in 2050 to SHFCVs at $90 \%$ penetration in developed countries and $45 \%$ penetration in other countries is expected to reduce $\mathrm{NO}_{\mathrm{x}}, \mathrm{CO}, \mathrm{CO}_{2}$, 
$\mathrm{CH}_{4}$, some other organic gases, ozone, PAN, black carbon, and other particle components in the troposphere, but may increase some other organic gases there, depending on the exact emission changes. The emissions of some organic gas species differed from the expected changes for conversion to HFCVs produced by steam-reforming. Conversion to SHFCVs is also expected to cool the troposphere and warm the stratosphere, but to a lesser extent than WHFCVs. Finally, SHFCVs are expected to increase upper tropospheric/lower stratospheric ozone while decreasing upper stratospheric ozone, but to a lesser extent in both cases than WHFCVs. Conversion to SHFCVs would also benefit the environment, particularly if organic gas emissions were lower than simulated, which would result in less surface ozone and increased stratospheric ozone.

3. The results here (with respect to WHFCVs and SHFCVs) will likely strengthen over longer simulation periods, as greater reductions in $\mathrm{CO}_{2}$ over a longer simulation period will trigger greater tropospheric cooling and stratospheric warming, causing greater reductions in surface ozone and greater net increases in stratospheric ozone.

4. The predicted criteria pollutant concentrations from the GATOR-GCMOM simulations indicate that near surface annual mean concentrations in the US are likely to increase from the 2000 base case to the $2050 \mathrm{~A} 1 \mathrm{~B}$ base case for $\mathrm{CO}_{2}$ and ozone due to increased economic activity, but to decrease for $\mathrm{CO}, \mathrm{NO}_{2}, \mathrm{SO}_{2}$, and $\mathrm{PM}_{10}$ due to improved pollution control equipment and energy efficiencies. The shift to SHFCVs in 2050 is predicted to result in decreased concentrations for all the criteria pollutants, except for $\mathrm{SO}_{2}$ and $\mathrm{PM}_{10}$. The higher predicted concentrations for $\mathrm{SO}_{2}$ and $\mathrm{PM}_{10}$ were attributed to increased emissions associated with the use of the steam-reforming method to generate $\mathrm{H}_{2}$. If renewable methods such as wind-based electrolysis were used to generate $\mathrm{H}_{2}$, the emissions of $\mathrm{SO}_{2}$ and $\mathrm{PM}_{10}$ would be lower. Because most of the key pollutants are predicted to decrease, shifting to HFCVs is considered to be beneficial to human health, and unlikely to result in damage to buildings and cultural or heritage sites.

5. These results are thought to be robust for larger leakage rates of hydrogen and for greater penetrations of HFCVs, since we believe that the controlling factor for stratospheric ozone impacts is the reduction in fossil-fuel greenhouse gases and the resulting surface cooling, which reduces water vapor emissions, and stratospheric warming, which increases tropopause stability, reducing water vapor transport to the stratosphere. The reduction in water vapor (and ozone-destroying hydrogen oxides that is produced) to the stratosphere due to climate feedbacks should be larger than increases in water vapor and hydrogen oxides produced by leaked hydrogen, causing a net column ozone increase. Further, warmer stratospheric temperatures due to HFCVs should reduce aerosol and polar stratospheric cloud size and lifetime, reducing ozone loss further. While we do not know exactly what hydrogen leakage rate and vehicle penetration would cause net damage, we are confident, based on the results to date that indicate the dominance of climate feedbacks, that all realistic proposed future scenarios of HFCV fleets will not cause damage. As such, no disadvantage to the future large-scale penetration of HFCVs in indicated.

The simplified model is intended to check the plausibility of results from GATOR-GCMOM. Summarize the model's capabilities, it predicts both tropospheric and stratospheric hydrogen mixing ratios, subject to hydrogen releases (from biomass burning, fossil fuel combustion, nitrogen fixation, soil uptake, and oceanic off gassing), and atmospheric sinks and sources 
(oxidation by the $\mathrm{OH}$ radical, and production by photolysis of $\mathrm{HCHO}$, which is produced from atmospheric methane).

The model was validated by a series of analytical tests, and by comparison with known atmospheric burdens, mixing ratios, and residence times of hydrogen. Sensitivity analyses were also performed that confirmed the importance of soil uptake on the global budget.

The major conclusions of this supplemental work are as follows:

1. The time required for hydrogen mixing ratios to attain a steady state condition following initiation of a constant hydrogen leakage rate is over 10 years in the troposphere and over 50 years in the stratosphere. This suggests that the GCMs should be run for periods in excess of 10 years.

2. The hydrogen mixing ratios in the 21st century are likely to increase whether or not the hydrogen economy evolves. These increases may exceed those due to transformation to a hydrogen economy.

3. Hydrogen deposition velocity is an important contributor to the fate of hydrogen, since soil uptake is the single largest pathway of hydrogen loss from the atmosphere. On a global basis, a hydrogen deposition velocity of $0.041 \mathrm{~cm} \cdot \mathrm{s}^{-1}$ that is used by GATORGCMOM is consistent with the work by Novelli (1999). On a local basis, the deposition velocity can vary greatly due to such local changes in soil temperature and soil moisture. This behavior was shown by examining hydrogen uptake in two ecosystems: a boreal forest and the Mojave Desert.

4. Based on laboratory experiments performed by Smith-Downey (2006) under optimal soil temperature and soil moisture conditions, the upper limit of hydrogen uptake by soil was calculated to be approximately $35 \mathrm{nmol} \cdot \mathrm{m}^{-2} \cdot \mathrm{s}^{-1}$, which is equivalent to a deposition velocity of approximately $0.15 \mathrm{~cm}-\mathrm{s}^{-1}$. This value is slightly higher than deposition velocities reported from all previous studies reviewed here, and bounds the upper limit of hydrogen deposition.

5. Current developments in hydrogen uptake by soils were reported in Wuebbles (2009). Laboratory analysis implicated a non-linear dependence on hydrogen mixing rates. Algorithms to describe hydrogen uptake in the model were modified to incorporate these effects. Results showed that soil uptake would increase as molecular hydrogen mixing ratios increase, thereby tending to reduce mixing ratios. An example that was simulated showed that by mid-century mixing ratios would be 30 ppbv lower, and by the end of the century 110 ppbv lower. These are significant differences, and suggest the need to confirm the findings of Wuebbles (2009).

\subsection{Recommendations}

Based on the results of these studies several recommendations are made to extend the analysis of the effects of emissions of hydrogen and to address the uncertainties associated with the technical approach and the results from this study.

1. The GATOR-GCMOM model was used to perform simulations of future conditions for ten years. At the end of the ten year period, it is assumed that the atmospheric chemistry has attained a new steady-state condition, and that concentrations of important constituents have all stabilized. However, it has not been possible to demonstrate the 
validity of this assumption during the project. We recommend that longer simulation time periods be evaluated that would not only allow an assessment of this assumption, but also how longer-duration simulations would influence our conclusions. To accomplish this task, methods to make longer duration simulations feasible would be examined including running GATOR-GCMOM on faster computers, or streamlining the model for faster execution.

2. For this project, GATOR-GCMOM was initialized in a unique way, and the uncertainties in predictions associated with this single initialization were not examined. In general, data sets to uniquely initialize GATOR-GCMOM (or other GCMs) are incomplete, and climate modelers often use different initializations to create an ensemble of simulations. We recommend that tests be completed with multiple simulations of differing initializations to examine the significance on model predictions and project conclusions.

3. Surface concentrations of $\mathrm{SO}_{2}$ and $\mathrm{PM}_{10}$ in the US were predicted to increase for the 2050 A1B case with SHFCVs over the 2050 A1B base case. The predicted surface concentrations in the US were less than the annual mean standard for $\mathrm{SO}_{2}$, but more detailed simulations could be conducted to allow comparison to the 24-hour standards for $\mathrm{SO}_{2}$ and $\mathrm{PM}_{10}$. The ability to provide additional spatial and temporal data could be achieved by running GATOR-GCMOM in a nested grid configuration for the US and saving daily and seasonal concentration data for key criteria pollutants that have 24- or 8hour standards $\left(\mathrm{SO}_{2}, \mathrm{CO}, \mathrm{O}_{3}\right.$, and $\mathrm{PM}_{10}$ and $\left.\mathrm{PM}_{2.5}\right)$. The detailed results would then be compared to the shorter duration air quality standards for near surface atmospheric concentrations of the criteria pollutants.

4. The simplified hydrogen model developed during this project was limited to examining the fate of hydrogen emitted to the atmosphere, as well as sources and sinks of hydrogen. It is recommended that other atmospheric constituents be added to the model to further increase its utility, with a focus on those constituents that can be simulated with a limited number of chemical reactions and source/sink terms. Special emphasis should be placed on exploring ways to further examine the dominant effects of climate feedbacks that appear important to the results of the GATOR-GCMOM simulations.

5. Due to the potential significance of the work done by Wuebbles (2009) that suggests hydrogen uptake by soil is a non-linear function of atmospheric concentrations, we suggest further studies be conducted to examine this process. To our knowledge, there are no other uptake results that are consistent with these. The proposed studies should also include field experiments to determine deposition velocities for different biome types that will supplement the generally sparse data presently available. 


\section{REFERENCES}

Andrae, M. O. and P. Merlet (2001), Emission of trace gases and aerosols from biomass burning, Global Biogeochemical Cycles, 15, 955-966.

Andres, R. J. and A. D. Kasgnoc, 1998. A time-averaged inventory of subaerial volcanic sulfur emissions. J. Geophys. Res. 103, 25: 251-261.

Argonne National Laboratory, 2007 (Argonne 2007). Development and Applications of GREET 2.7 - The Transportation Vehicle-Cycle Model. February 2007. Accessed at: http://www.transportation.anl.gov/pdfs/TA/378.pdf.

Argonne National Laboratory (ANL), 2008a. GREET 1.8b Model. The Greenhouse Gases, Regulated Emissions, and Energy Use in Transportation (GREET) Model. Accessed at: http://www.transportation.anl.gov/modeling_simulation/GREET/index.html.

Argonne National Laboratory (ANL), 2008b. Powertrain Systems Analysis Toolkit Model. Available at http://www.transportation.anl.gov/modeling_simulation/PSAT/index.html.

Argonne National Laboratory, 2009. Summary of Expansions and Revisions of the GREET 1.8c Version.

Barnes, D. H., S. C. Wofsy, B. P. Fehlau, E. W. Gottlieb, J. W. Elkins, G. S. Dutton, and P. C. Novelli, 2003. Hydrogen in the atmosphere: Observations above a forest canopy in a polluted environment. J. Geophys. Res. 108 (D6) doi:10.1029/2001JD001199.

Benedetti, D., E. Bontempi, R. Pedrazzani, A. Zacco, and L.E. Depero, 2008. Transformation in calcium carbonate stones: some examples. Phase Transitions, Vol. 81, No. 2-3, pp. 155-178.

Bond, T. C., D. G. Streets, K. F. Yarber, S. M. Nelson, J-H, Woo, and Z. Klimont, 2004. A technology-based global inventory of black and organic carbon emissions from combustion. J. of Geophys. Res. Vol 109, D 14203, doi:10.1029/2003JD003697.

Bouwman, A., D. Lee, A. Asman, F. Dentener, K. Van der Hoek, and J. Olivier, 1997. A global high-resolution emission inventory for ammonia. Global Biogeochemical Cycles 11:561-587.

Businger, J. A., J. C. Wyngaard, Y. Izumi, and E. F. Bradley (1971), Flux-profile relationships in the atmospheric surface layer, J. Atmos. Sci. 28, 181-189.

Chung, S. H., and J. H. Seinfeld (2005), Climate response of direct radiative forcing of anthropogenic black carbon, J. Geophys. Res., 110, D11102, doi:10.1029/2004JD005441.

CIESIN, 2003. Gridded World Population of the World (GWP) Version 2, CIESIN (Center for Environmenta Earth Science Information Network). Columbia University, Palisades, New York. 
Code of Federal Register (CFR), 2008. 40 CFR Parts 50, 51, 53, and 58 National Ambient Air Quality Standards for Lead; Final Rule, US Environmental Agency. November 12, 2008. Pages 66964 to 67062.

Coletta, W. C., M. Z. Jacobson, and D. M. Golden (2005), Switching to a U.S. hydrogen fuel cell vehicle fleet: The resultant change in emissions, energy use, and greenhouse gasses, J. Power Sources, 150, 150-181

Conrad, R., and W. Seiler (1985), Influences of temperature, moisture, and organic carbon on the flux of $\mathrm{H}_{2}$ and $\mathrm{CO}$ between soil and atmosphere. Field studies in subtropical regions, J. Geophys. Res. 90, 5699 - 5709.

Cortely, J., 2008. Fact Sheet: Final Revisions to the National Ambient Air Quality Standards for Lead. US Environmental Agency.

Ehhalt, D. W., U. Schmidt, and L. E. Heidt (1977), Vertical profiles of molecular hydrogen in the troposphere and stratosphere. J. Geophys. Res., 82, 5907-5911.

Eickhout, B., M. G. J. den Elzen and G. J. J. Kreileman, 2004. The Atmosphere-Ocean System of IMAGE 2.2. National Institute of Public Health and the Environment (RIVM), Bilthoven, the Netherlands. RIVM Report 481508017/2004.

Environment Canada, 2009. Maps of normal ozone.

http://woudc.ec.gc.ca/e/ozone/normalozone.htm.

Evans, S. J., R. Toumi, J. E. Harries, M. P. Chipperfield, and J. M. Russell III (1998), Trends in stratospheric humidity and the sensitivity of ozone to these trends, J. Geophys. Res., 103, 87158725.

Fahey, D. W., et al. (2001) The detection of large $\mathrm{HNO}_{3}$-containing particles in the Winter Arctic Strosphere, Science, 291, 1026-1030.

Fang, M.; Wong, H.-L.; Tam, A.; To, K-L.; Krewitt, W.; Heck, T.; Droste-Franke, B., 2001.

Fornea, 2003. Air pollution, coatings, and cultural resources. Progress in Organic Coatings, Volume 48, pp. 281-288.

Gerst, S., and P. Quay (2001), Deuterium component of the global molecular hydrogen cycle, $J$. Geophys. Res., 106, 5021 - 5031.

Giglio, L. G. R. van der Werf, J. T. Randerson, G. J. Collatz, and P. Kasibhatla, 2006. Global estimation of burned area using MODIS active fire observations, Atmos. Chem. and Physics, 6: 957-974.

Graedel, T.E. \& C. Leygraf, 2001. Scenarios for Atmospheric Corrosion in the 21st Century. The Electrochemical Society Interface, Winter 2001. p. 24-30.

Green, et al., 2007. (Green et al., 2007). Integrated Analysis of Market Transformation Scenarios with HyTrans. Oak Ridge National Laboratory. Oak Ridge, Tennessee.

Hammer, S., L. Ingerborg, and O’Doherty (2007), Lessons from a continuous atmospheric molecular hydrogen $\left(\mathrm{H}_{2}\right)$ record in Heidelberg regarding hydrogen sources and sinks, Presented at EuroH2Hdros.

Hauglustaine, D. A., and D. A. Ehhalt (2002), A three-dimensional model of molecular hydrogen in the troposphere. J. Geophys. Res., 107, 4330, doi:10.1029/2001JD001156. 
Herrera, L.K. and H.A. Videla, 2004. The Importance of Atmospheric Effects on Biodeterioration of Cultural Heritage Constructional Materials. Int. Biodeterioration \& Biodegradation, 54:125-134.

Hogstrom, U. (1988), Non-dimensional wind and temperature profiles in the atmospheric surface layer: A reevaluation, Boundary-Layer Meteor., 42, 55-78.

IMAGE Team, 2001. The IMAGE 2.2 implementation of the SRES scenarios. A comprehensive analysis of emissions, climate change and impacts in the $21^{\text {st }}$ century. National Institute of Public Health and the Environment, Bilthoven, the Netherlands. CD-ROM RIVM Publication 481508018.

Institute of Public Health and the Environment (RIVM) report no. 771060 002/ TNO-MEP report no. R96/119.

Intergovernmental Panel on Climate Change (IPCC), 2000. Special Report on Emissions Scenarios. Summary for Policymakers. A Special Report of Working Group III.

International Institute for Applied Systems Analysis (IIASA), 2007. National Level Population Data for SRES Scenarios. http://www.iiasa.ac.at/Research/POP/IPCC/index.html.

Jacobson, M. Z. (2003), Development of mixed-phase clouds from multiple aerosol size distributions and the effect of the clouds on aerosol removal, J. Geophys. Res., 108 (D8), 4245, doi:10.1029/2002JD002691.

Jacobson, M. Z. (2004), The climate response of fossil-fuel and biofuel soot, accounting for soot's feedback to snow and sea ice albedo and emissivity, J. Geophys. Res., 109, D21201, doi:10.1029/2004JD004945.

Jacobson, M. Z. (2005), Fundamentals of Atmospheric Modeling, Part II, Cambridge University Press, New York, 813 pp.

Jacobson, M. Z. (2007), History of, processes in, and numerical techniques in GATORGCMOM, http://www.stanford.edu/group/efmh/GATOR/index.html.

Jacobson, M. Z. (2008), Effects of wind-powered hydrogen fuel cell vehicles on stratospheric ozone and global climate, J. Geophys. Res. Lett., 35, L19803, doi:10.1029/2008GL035102.

Jacobson, M. Z. (2008a), On the casual link between carbon dioxide and air pollution mortailyt, Geophys. Res. Lett., 35, L03809, doi:10.1029/2007GL031101.

Jacobson, M. Z. (2009), Effects of atmosphere of converting to hydrogen fuel cell vehicles, final report by Stanford University, prepared for U.S. Department of Energy.

Jacobson, M. Z. and D. G. Streets (2009), Influence of future anthropogenic emissions on climate, natural emissions, and air quality. J. of Geophysical Research, Vol. 114, DO8118, doi:10.1029/2008JD011476.

Jacobson, M. Z., W. C. Colella, and D. M. Golden (2005), Cleaning the air and improving health with hydrogen fuel cell vehicles, Science, 308, 1901-1905.

Jacobson, M. Z., Y. J. Kaufmann, Y. Rudich (2007), Examining feedbacks of aerosols to urban climate with a model that treats 3-D clouds with aerosol inclusions, J. Geophys. Res., 112, D24205, doi:10.1029/2007JD008922. 
Jonsson, A. I., V. I. Fomichev, and T. G. Shepherd (2009) An updated analysis of the attribution of stratospheric ozone and temperature changes to changes in ozone-depleting substances and well-mixed greenhouse gases, Atmos. Chem. Phys. Discuss, 9, 14857-14872.

Kammen, D. M. and T. E. Lipman (2003), Letter to the editor, Science, Vol. 302, 10 October.

Kettle, A. J. et al. (1999), A global database of sea surface dimethylsulfide (DMS) measurements and a procedure to predict sea surface DMS as a function of latitude, longitude, and month, Global Biogeochem. Cycles, 13, 399-444.

King, G. M. (2003), Contributions of atmospheric CO and hydrogen dynamics on recent Hawaiian volcanic deposits, Applied Environmental Microbiology. Vol. 69, No. 7, pp 4067-4075.

Klimont, Z., D. G. Streets, S. Gupta, J. Cofala, F. Lixin, and Y. Ichikawa, 2002. Anthropogenic emissions of non-methane volatile organic compounds in China. Atmospheric Environment 36: 1309-1322.

Kucera, V. and S. Fritz, 1995. Direct and indirect air pollution effects on materials including cultural monuments. Water, Air and Soil Pollution, Vol. 85, pp. 153-165.

Kucera, V., 2003. Reduction of air pollutants: A tool for control of atmospheric corrosion. Revista de Metalurgia, Volume 39, No. 1, pp. 55-61.

Kucera, V., D. Pearce, and Y.W. Brodin, 1997. Economic Evaluation of Air Pollution Damage to Materials. Swedish Environmental Protection Agency, No. 4761, Stockholm.

Lallo, M., T. Aalto, T. Laurila, and J. Hatakka (2008), Seasonal cariation in hydrogen deposition to boreal forest soil in southern Finland. GRL, Vol. 35, L04402, doi: 10.1029/2007GL 032357.

Lehman, P. A. (2003), Letter to the editor, Science, Vol. 302, 10 October.

Lewis, F.J., E. May, A.F. Bravery, 1988. Metabolic activity of bacteria isolated from building stone and their relationship to stone decay. In: Houghton, D.R., R.N. Smith, H.O. W. Eggins, (Eds.) Biodeterioration 7. Elsevier, London. pp. 107-112.

Liebl, K., and W. Seiler (1976), $\mathrm{CO}$ and $\mathrm{H}_{2}$ destruction at the soil surface, in Production and Utilization of Gasses, edited by H. G Schlegel, G. Gottschalk, and N Pfenning, pp. 215-229, E. Goltze, Göttingen, Germany.

Louis J. F. (1979), A parametric model of vertical eddy fluxes in the atmosphere, Boundary Layer Meteor., 17, 187-202.

Lovins, A.B. (2003), Letter to the editor, Science, Vol. 302, 10 October.

Ludwig, J., L. T., Marufu, B. Huber, M. O. Andrae, and G. Helas, 2003. Domestic combustion of biomass fuels in developing countries: A major source of atmospheric pollutants. J. Atmos. Chem., 44, 23-37.

Lutz, W. (ed.) 1996. The Future Population of the World: What Can We Assume Today? London: Earthscan

McRae G. J., W. R. Goodin, and J. H. Seinfeld (1982), Development of a second-generation mathematical model for urban air pollution -- I. Model formulation, Atmos. Environ., 16, 679696. 
MODIS/USGS (2006) Land Cover Yearly L3 Global 500 m data, https://lpdaac.usgs.gov/lpdaac/products/modis_product_table/land_cover/yearly_l3_glob, 2005 data processed to $0.01^{\circ}$.

Murray, F., 2009. Presentation on Potential impacts of climate change and regional air pollution on terrestrial biodiversity and landscape use. Murdoch University, Perth, Australia..

National Institute for Public Health and the Environment (RIVM) (2001), The IMAGE 2.2 Implementation of the SRES Scenarios: A Comprehensive Analysis of Emissions, Climate Change and Impacts in the $21^{\text {st }}$ Century [CD-ROM], RIVM Publ. 481508018, Bilthoven, Netherlands.

Novelli, P. C., P. M. Lang, K. A. Masarie, D. F. Hurst, R. E. Myeres, and J. W. Elkins (1999), Molecular hydrogen in the troposphere: Global distribution and budget, J. Geophys. Res., 104, 30427-30444.

Olivier, J. G. J., A. F. Bouwman, C. W. M. Van der Maas, J. J. M. Berdowski, C. Veldt, J. P. J. Bloos, A. J. H. Visschedijk, P. Y. J. Zandveld, and J. L. Haverlag, 1996. Description of EDGAR Version 2.0: A set of global emission inventories of greenhouse gases and ozone-depleting substances for all anthropogenic and most natural sources on a per country basis on $1^{\circ}$ by $1^{\circ}$ grid, National Institute of Public Health and the Environment, RIVM) report no. 771060002 / TNOMEP report no. R96/119.

Olivier, J., J. Peters, C. Granier, G. Petron, J. F. Muller, and S. Wallens, 2003. Present and future surface emissions of atmospheric compounds, POET report \#2, EU project EVK2-1999-00011.

Price, H., L. Jaegle, A., Rice, P. Quay, P. C. Novelli, and R. Gammon (2007), Global budget of molecular hydrogen and its deuterium content: Constraints from ground station, cruise, and aircraft observations, J. Geophys. Res., 112, D22108

Rahn, T., et al. (2003), Extreme deuterium enrichment in stratospheric hydrogen and the global atmospheric budget of H-2, Nature, 474, 915-921.

Rahn, T., J. M. Eiler, N. Kitchen, J. E. Fessenden, and J. T. Randerson (2002), Concentration and deltaD of molecular hydrogen in boreal forests: Ecosystem-scale systematics of atmospheric $\mathrm{H}_{2}$, GRL, 29, No. 18.

Rhee, T. A., C. A. M. Brenningkmeijer, and T. Rockmann (2006), The overwhelming role of soils in the global atmospheric hydrogen cycle, Atmos. Chem. Phys., 6, 1611-1625.

Rohs, S., C. Schiller, M. Riese, A. Engel, U. Schmidt, T. Wetter, I. Levin, T. Nakazawa, and S. Aoki (2006), Long-term changes of methane and hydrogen in the stratosphere in the period 1978-2003 and their impact on the abundance of stratospheric water vapor, J. Geophys. Res. Vol. 111, D14315, doi:10.1029/2006JD006877.

Sanderson, M. G., W. J. Collins, R. G. Derwent, and C. E. Johnson (2003), Simulation of global hydrogen levels using a Lagrangian three-dimensional model, J. Atmos. Chem., 46, 15-28.

Schuler, S. and R. Conrad, 1991. Hydrogen oxidation activities in soil as influenced by $\mathrm{pH}$, temperature, moisture, and season. Biology and Fertility of Soils. 12:127-130.

Schultz, M. G., T. Diehl, G. P. Brasseur, and W. Zittel, 2003. Air pollution and climate-forcing impacts of a global hydrogen economy, Science, 302, 624-627. 
Screpanti, A. and A. De Marco, 2009. Corrosion on cultural heritage buildings in Italy: A role for ozone? Environmental Pollution, Vol. 157, pp. 1513-1520.

Seiler, W., and R. Conrad (1987) Contribution of tropical ecosystems to the global budgets of trace gases, especially CH4, H2, CO, and N2O, in R.E. Dickinson (ed.), The Geophysiology of Amazonia, John Wiley and Sons, New York, pp. 133-157.

Shindell, D. T., and V. Grewe (2002) Separating the influence of halogen and climate changes on ozone recovery in the upper stratosphere, J. Geophys. Res., 107, 4144, 10.1029/2001JD000420.

Simmonds, P. G., R. G. Derwent, S. O'Doherty, D. B. Ryall, L. P. Steele, R. L. Langenfelds, P. Salameh, H. J. Wang, C. H. Dimmer, and L. E. Hudson (2000), Continuous high-frequency observations of hydrogen at the Mace Head baseline atmospheric monitoring station over the 1994-1998 period, J. Geophys. Res., 105(D10), 12,105-12,121.

Smith-Downey N. V., J. T. Randerson, J. M. Eiler (2006), Temperature and moisture dependence of soil H2 uptake measured in the laboratory, J. Geophys. Res. Lett., 33, L14813, doi:10.1029/2006GL026749.

Streets, D. G., T. C. Bond, G. R. Carmichael, S. D. Fernandes, Q. Fu, D. He, Z. Klimont, S. M. Nelson, N. Y. Tsai, M. Q. Wang, J. H. Woo, and K. F. Yarber (2003), An inventory of gaseous and primary aerosol emissions in Asia in the year 2000, J. Geophys. Res., 108(D21), 8809, doi:10.1029/2002JD003093.

Striegel, M.F., E. B. Guin, K. Hallett, D. Sandoval, R. Swingle, K. Knox, F. Best, and S.

Study of Acid Rain in Hong Kong. Final report submitted for the provision of service to the environmental protection department, HKSAR (Tender Ref AS 99-417), Institute for Environment and Sustainable Development, The Hong Kong University of Science and Technology, Clear Water Bay, Hong Kong

Symonds, R. B., W. J. Rose, G. Bluth, and T. M. Gerlach, 1994. Volcanic gas studies: methods, results, and applications. In: Carroll, M.R. and J.R. Holloway (eds), Volatiles in Mamas. Mineralogical Society of America Reviews in Mineralogy 30, 1-66.

Trevors, J. T. (1985), Hydrogen consumption in soil, Plant and Soil, 87, 417-422.

Tromp, T. K., R. L. Shia, M. Allen, J. M. Elier, and Y. L. Yung (2003), Potential environmental impact of a hydrogen economy on the stratosphere, Science, 300, 1740-1742.

U.S. Environmental Protection Agency (EPA), 2000. SPECIATE database v.3, Washington, D.C. Current version 4.2 available at http://www.epa.gov/ttn/chief/software/speciate.

U.S. Environmental Protection Agency (EPA), 2006. The Common Air Pollutants. http://www.epa.gov/air/oaqps/peg_caa/pegcaa11.html (Accessed 4/5/07).

U.S. Environmental Protection Agency (EPA), 2006b. Air Quality Criteria for Ozone and Related Photochemical Oxidants, Volume I. National Center for Environmental Assessment RTP, Research Triangle Park, Raleigh, North Carolina. EPA Report \# EPA/600/R-05/004aF..

U.S. Environmental Protection Agency (EPA), 2008a. Integrated Science Assessment for Sulfur Dioxides- Health Criteria. National Center for Environmental Assessment -RTP, Research Triangle Park, Raleigh, North Carolina. EPA Report \# EPA/600/R-08/047F. 
U.S. Environmental Protection Agency (EPA), 2008b. Integrated Science Assessment for Oxides of Nitrogen - Health Criteria. National Center for Environmental Assessment -RTP, Research Triangle Park, Raleigh, North Carolina. EPA Report \# EPA/600/R-08/071.

United States Environmental Protection Agency (U.S. EPA). 2009a. Air Trends.

http://www.epa.gov/airtrends/ (Accessed 9/28/09)

United States Environmental Protection Agency (U.S. EPA). 2009b. EPA Acute Exposure Guideline Levels (AEGLs). Accessed online October 2009, http://www.epa.gov/oppt/aegl/pubs/chemlist.htm

United States Environmental Protection Agency (U.S. EPA). 2009c. Integrated Science Assessment for Particulate Matter. National Center for Environmental Assessment -RTP, Research Triangle Park, Raleigh, North Carolina. EPA Report \# EPA//600/R-08/139F; Updated on $2 / 10 / 2010$.

United States Environmental Protection Agency (U.S. EPA). 2009d. National Ambient Air Quality Standards. Accessed online at http://epa.gov/air/criteria.html. Site Last updated on 2/20/2009.

United States Environmental Protection Agency (U.S. EPA). 2010. Integrated Science Assessment for Carbon Monoxide. National Center for Environmental Assessment -RTP, Research Triangle Park, Raleigh, North Carolina. EPA Report \# EPA/600/R-09/019F.

van Vuuren, D. P., P. L. Lucas, H. B. M. Hilderink, 2006. Downscaling drivers of global environmental change. Netherlands Environmental Agency (MNP), Bilthoven, the Netherlands Report 550025001/2006.

Walmsley J. L. and M. L. Wesely (1996), Modification of coded parameterizations of surface resistances to gaseous dry deposition, Atmos. Environ., 30A, 1181-1188.

Warneck, P. (1999) Chemistry of the Natural Atmosphere, $2^{\text {nd }}$ edn., International Geophysics Series, Vol. 71, Academic Press, New York.

Warwick, N. J., S. Bekki, E. G. Nisbet, and J. A. Pyle (2004), Geophys. Res. Lett. 31, L05107, doi:10.1029/2003GL019224.

Weaver, M.E., 1991. Acid Rain and Air Pollution vs. the Buildings and Outdoor Sculptures of Montreal. Association for Preservation Technology International (APT) Bulletin, Vol. 23, No. 4, Historic Structures in Contemporary Atmospheres, pp. 13-19.

Wesely M. L. (1989), Parameterization of surface resistances to gaseous dry deposition in regional-scale numerical models, Atmos. Environ., 23, 1293-1304.

World Bank, 2004. World Development Indicators. Oxford University Press, New York.

Wuebbles, D. (2009). Evaluation of the potential environmental impacts of large-scale use and production of hydrogen in energy and transportation applications. Presented at the DOE Hydrogen Program Annual Meeting, Washington D.C.

Xiao, X., R. G. Prinn, P. G. Simmonds, L. P. Steele, P. C. Novelli, J. Huang, R. L. Langenfelds, S. O’Doherty, P. B. Krummel, P. J. Fraser, L. W. Porter, R. F. Weiss, P. Salameh, and R. H. Wang (2007), Optimal estimation of the soil uptake rate of molecular hydrogen from the 
Advanced Global Atmospheric Gases Experiment and other measurements, J. Geophys. Res. Vol. 112, D07303, doi:10.1029/2006JD007241

Yonemura, S., S. Kawashima, and H. Tsuruta (1999), Continuous measurements of $\mathrm{CO}_{2}$ and $\mathrm{H}_{2}$ deposition velocities onto an andisol: uptake control by soil moisture. Tellus, 518, 688-700.

Yonemura, S., S. Kawashima, and H. Tsuruta (2000), Carbon monoxide, hydrogen, and methane uptake by soils in a temperature arable field and a forest, J. Geophys. Res., 105, 14,347-14, 362.

Zhang, Y. (2008), Online coupled meteorological and chemistry models: history, current status, and outlook, Atmos. Chem. Phys. Discuss., 8, 1833-1912.

Zittel, W., M. Altmann, and L-B-S, GmBH, 1996. Molecular hydrogen and water vapour emissions in a global hydrogen economy, Proc. $11^{\text {th }}$ World Hydrogen Energy Conference. T. N. Veziroglu, C. J. Winter, J. P. Baelt, G. Kreysa, (eds). Schon and Wetzel, Frankfurt, Germany. www.hydrogen.org/Knowledge/Vapour.htm.

Zittel, W., M. Altmann, Molecular hydrogen and water vapor emissions in a global hydrogen economy, Proceedings of the $11^{\text {th }}$ World Hydrogen Energy Conference, 71-81. 


\section{APPENDIX A EMISSION-RELATED TABLES}


Table A-1

Emissions for 2000 A1B by Region

\begin{tabular}{|c|c|c|c|c|c|c|c|c|}
\hline \multirow[b]{2}{*}{ Region } & \multicolumn{2}{|c|}{ Domestic } & \multirow[b]{2}{*}{ Industry } & \multirow[b]{2}{*}{ Transport } & \multirow[b]{2}{*}{ Power } & \multirow[b]{2}{*}{$\begin{array}{c}\text { Biomass } \\
\text { Burning }\end{array}$} & \multirow{2}{*}{$\begin{array}{l}\text { Other } \\
\text { Anthropo- } \\
\text { genic }\end{array}$} & \multirow[b]{2}{*}{ Biogenic } \\
\hline & Biofuel & $\begin{array}{l}\text { Fossil } \\
\text { Fuel }\end{array}$ & & & & & & \\
\hline \multicolumn{9}{|c|}{ Species: CO (Unit: Tg) } \\
\hline Canada & 1.48 & 0.10 & 0.31 & 4.91 & 0.03 & 9.26 & 0 & 0 \\
\hline USA & 3.55 & 0.67 & 2.29 & 60.40 & 0.40 & 11.74 & 0 & 0 \\
\hline Central America & 3.63 & 0.04 & 0.24 & 10.22 & 0.02 & 17.17 & 0 & 0 \\
\hline South America & 8.10 & 0.15 & 1.71 & 16.13 & 0.02 & 112.79 & 0 & 0 \\
\hline Northern Africa & 1.12 & 0.05 & 0.23 & 3.30 & 0.02 & 0.38 & 0 & 0 \\
\hline Western Africa & 18.54 & 0.01 & 0.01 & 2.41 & 0.00 & 99.26 & 0 & 0 \\
\hline Eastern Africa & 10.78 & 0.00 & 0.00 & 0.74 & 0.00 & 32.86 & 0 & 0 \\
\hline Southern Africa & 9.02 & 0.54 & 0.30 & 3.64 & 0.04 & 67.55 & 0 & 0 \\
\hline OECD Europe & 3.05 & 1.10 & 5.00 & 29.51 & 0.16 & 9.27 & 0 & 0 \\
\hline Eastern Europe & 0.56 & 1.88 & 1.52 & 5.12 & 0.05 & 0.81 & 0 & 0 \\
\hline Former USSR & 2.75 & 4.10 & 4.73 & 8.35 & 0.21 & 17.45 & 0 & 0 \\
\hline Middle East & 1.28 & 0.84 & 0.55 & 14.92 & 0.06 & 1.42 & 0 & 0 \\
\hline South Asia & 49.40 & 0.37 & 1.59 & 5.19 & 0.12 & 19.14 & 0 & 0 \\
\hline East Asia & 36.33 & 16.76 & 8.14 & 22.99 & 0.18 & 18.84 & 0 & 0 \\
\hline Southeast Asia & 22.65 & 0.11 & 0.40 & 9.50 & 0.04 & 31.76 & 0 & 0 \\
\hline Oceania & 0.79 & 0.07 & 0.37 & 3.47 & 0.03 & 23.50 & 0 & 0 \\
\hline Japan & 0.43 & 0.22 & 4.01 & 4.63 & 0.09 & 0.26 & 0 & 0 \\
\hline World & 173.46 & 27.00 & 31.37 & 205.43 & 1.48 & 473.46 & 0 & 0 \\
\hline \multicolumn{9}{|c|}{ Species: CO2 (Unit: TgC) } \\
\hline Canada & 5.02 & 22.0 & 43.0 & 43.0 & 41.0 & & 4.0 & \\
\hline USA & 43.67 & 159.0 & 340.0 & 494.0 & 639.0 & & 41.0 & \\
\hline Central America & 47.31 & 11.0 & 54.0 & 44.0 & 30.0 & & 7.0 & \\
\hline South America & 94.51 & 19.0 & 99.0 & 83.0 & 25.0 & & 14.0 & \\
\hline Northern Africa & 6.83 & 12.0 & 34.0 & 13.0 & 23.0 & & 5.0 & \\
\hline Western Africa & 374.62 & 2.0 & 9.0 & 9.0 & 3.0 & & 1.0 & \\
\hline Eastern Africa & 149.28 & 1.0 & 2.0 & 3.0 & 1.0 & & 0.0 & \\
\hline Southern Africa & 141.74 & 3.0 & 36.0 & 14.0 & 50.0 & & 6.0 & \\
\hline OECD Europe & 52.59 & 165.0 & 265.0 & 270.0 & 251.0 & & 52.0 & \\
\hline Eastern Europe & 27.37 & 27.0 & 79.0 & 20.0 & 85.0 & & 6.0 & \\
\hline Former USSR & 14.42 & 111.0 & 154.0 & 46.0 & 210.0 & & 31.0 & \\
\hline Middle East & 23.68 & 60.0 & 113.0 & 71.0 & 79.0 & & 26.0 & \\
\hline South Asia & 620.40 & 29.0 & 127.0 & 48.0 & 148.0 & & 2.0 & \\
\hline East Asia & 559.81 & 124.0 & 511.0 & 103.0 & 233.0 & & 28.0 & \\
\hline Southeast Asia & 284.43 & 14.0 & 87.0 & 52.0 & 46.0 & & 17.0 & \\
\hline Oceania & 5.67 & 3.0 & 25.0 & 27.0 & 44.0 & & 2.0 & \\
\hline Japan & 0.00 & 37.0 & 136.0 & 72.0 & 100.0 & & 15.0 & \\
\hline World & 2451.35 & 799.0 & 2114.0 & 1412.0 & 2008.0 & & 257.0 & \\
\hline
\end{tabular}


Table A-1 (continued)

Emissions for 2000 A1B by Region

\begin{tabular}{|c|c|c|c|c|c|c|c|c|}
\hline \multirow[b]{2}{*}{ Region } & \multicolumn{2}{|c|}{ Domestic } & \multirow[b]{2}{*}{ Industry } & \multirow[b]{2}{*}{ Transport } & \multirow[b]{2}{*}{ Power } & \multirow[b]{2}{*}{$\begin{array}{l}\text { Biomass } \\
\text { Burning }\end{array}$} & \multirow{2}{*}{$\begin{array}{l}\text { Other } \\
\text { Anthropo- } \\
\text { genic }\end{array}$} & \multirow[b]{2}{*}{ Biogenic } \\
\hline & Biofuel & $\begin{array}{c}\text { Fossil } \\
\text { Fuel }\end{array}$ & & & & & & \\
\hline \multicolumn{9}{|c|}{ Species: CH4 (Unit: Tg) } \\
\hline Canada & & 0.09 & 0.01 & 2.41 & 0.04 & 0.00 & 0.01 & 2.53 \\
\hline USA & & 0.21 & 0.08 & 21.60 & 0.49 & 0.00 & 0.15 & 22.07 \\
\hline Central America & & 0.22 & 0.01 & 1.31 & 0.04 & 0.00 & 0.32 & 5.54 \\
\hline South America & & 0.49 & 0.02 & 2.08 & 0.07 & 0.00 & 6.34 & 24.76 \\
\hline Northern Africa & & 0.07 & 0.01 & 1.87 & 0.01 & 0.00 & 0.03 & 1.96 \\
\hline Western Africa & & 1.12 & 0.00 & 0.57 & 0.01 & 0.00 & 1.43 & 4.87 \\
\hline Eastern Africa & & 0.65 & 0.00 & 0.00 & 0.00 & 0.00 & 1.42 & 5.92 \\
\hline Southern Africa & & 0.54 & 0.03 & 1.59 & 0.01 & 0.00 & 3.23 & 3.73 \\
\hline OECD Europe & & 0.18 & 0.16 & 3.23 & 0.22 & 0.00 & 0.16 & 17.90 \\
\hline Eastern Europe & & 0.03 & 0.15 & 4.15 & 0.02 & 0.00 & 0.05 & 3.26 \\
\hline Former USSR & & 0.17 & 0.27 & 23.48 & 0.04 & 0.00 & 0.07 & 9.75 \\
\hline Middle East & & 0.08 & 0.07 & 8.56 & 0.06 & 0.00 & 0.11 & 4.65 \\
\hline South Asia & & 2.98 & 0.03 & 3.96 & 0.02 & 0.00 & 0.59 & 29.27 \\
\hline East Asia & & 2.19 & 1.03 & 8.61 & 0.09 & 0.00 & 0.18 & 27.80 \\
\hline Southeast Asia & & 1.37 & 0.01 & 4.30 & 0.04 & 0.00 & 0.71 & 14.96 \\
\hline Oceania & & 0.05 & 0.01 & 1.13 & 0.03 & 0.00 & 1.87 & 4.71 \\
\hline Japan & & 0.03 & 0.03 & 0.50 & 0.06 & 0.00 & 0.10 & 3.08 \\
\hline World & & 10.46 & 1.94 & 89.35 & 1.24 & 0.00 & 16.77 & 186.75 \\
\hline \multicolumn{9}{|c|}{ Species: NO (Unit: Tg) } \\
\hline Canada & 0.027 & 0.042 & 0.163 & 0.685 & 0.249 & 0.152 & 0.000 & 0.000 \\
\hline USA & 0.064 & 0.301 & 2.418 & 8.282 & 4.321 & 0.193 & 0.000 & 0.000 \\
\hline Central America & 0.066 & 0.023 & 0.226 & 0.619 & 0.204 & 0.176 & 0.000 & 0.000 \\
\hline South America & 0.147 & 0.046 & 0.448 & 1.256 & 0.165 & 2.378 & 0.000 & 0.000 \\
\hline Northern Africa & 0.021 & 0.022 & 0.161 & 0.272 & 0.130 & 0.006 & 0.000 & 0.000 \\
\hline Western Africa & 0.336 & 0.003 & 0.040 & 0.189 & 0.015 & 2.595 & 0.000 & 0.000 \\
\hline Eastern Africa & 0.195 & 0.001 & 0.010 & 0.061 & 0.004 & 1.005 & 0.000 & 0.000 \\
\hline Southern Africa & 0.164 & 0.009 & 0.198 & 0.270 & 0.451 & 2.087 & 0.000 & 0.000 \\
\hline OECD Europe & 0.056 & 0.366 & 1.352 & 3.726 & 1.138 & 0.154 & 0.000 & 0.000 \\
\hline Eastern Europe & 0.010 & 0.057 & 0.531 & 0.314 & 0.328 & 0.013 & 0.000 & 0.000 \\
\hline Former USSR & 0.050 & 0.258 & 0.855 & 0.549 & 1.408 & 0.286 & 0.000 & 0.000 \\
\hline Middle East & 0.023 & 0.112 & 0.533 & 1.142 & 0.425 & 0.019 & 0.000 & 0.000 \\
\hline South Asia & 0.893 & 0.048 & 0.708 & 0.937 & 1.258 & 0.269 & 0.000 & 0.000 \\
\hline East Asia & 0.658 & 0.259 & 3.159 & 1.438 & 2.026 & 0.383 & 0.000 & 0.000 \\
\hline Southeast Asia & 0.409 & 0.030 & 0.395 & 0.777 & 0.299 & 0.413 & 0.000 & 0.000 \\
\hline Oceania & 0.014 & 0.008 & 0.113 & 0.397 & 0.286 & 0.702 & 0.000 & 0.000 \\
\hline Japan & 0.008 & 0.058 & 0.589 & 0.741 & 0.568 & 0.004 & 0.000 & 0.000 \\
\hline World & 3.138 & 1.642 & 11.898 & 21.655 & 13.278 & 10.835 & 0.000 & 0.000 \\
\hline
\end{tabular}


Table A-1 (continued)

Emissions for 2000 A1B by Region

\begin{tabular}{|c|c|c|c|c|c|c|c|c|}
\hline \multirow[b]{2}{*}{ Region } & \multicolumn{2}{|c|}{ Domestic } & \multirow[b]{2}{*}{ Industry } & \multirow[b]{2}{*}{ Transport } & \multirow[b]{2}{*}{ Power } & \multirow[b]{2}{*}{$\begin{array}{l}\text { Biomass } \\
\text { Burning }\end{array}$} & \multirow{2}{*}{$\begin{array}{c}\text { Other } \\
\text { Anthropo- } \\
\text { genic }\end{array}$} & \multirow[b]{2}{*}{ Biogenic } \\
\hline & Biofuel & $\begin{array}{c}\text { Fossil } \\
\text { Fuel }\end{array}$ & & & & & & \\
\hline \multicolumn{9}{|c|}{ Species: NO2 (Unit: Tg) } \\
\hline Canada & 0.005 & 0.007 & 0.028 & 0.117 & 0.042 & 0.026 & 0.000 & 0.000 \\
\hline USA & 0.011 & 0.051 & 0.412 & 1.411 & 0.736 & 0.033 & 0.000 & 0.000 \\
\hline Central America & 0.011 & 0.004 & 0.039 & 0.105 & 0.035 & 0.030 & 0.000 & 0.000 \\
\hline South America & 0.025 & 0.008 & 0.076 & 0.214 & 0.028 & 0.405 & 0.000 & 0.000 \\
\hline Northern Africa & 0.004 & 0.004 & 0.027 & 0.046 & 0.022 & 0.001 & 0.000 & 0.000 \\
\hline Western Africa & 0.057 & 0.000 & 0.007 & 0.032 & 0.003 & 0.442 & 0.000 & 0.000 \\
\hline Eastern Africa & 0.033 & 0.000 & 0.002 & 0.010 & 0.001 & 0.171 & 0.000 & 0.000 \\
\hline Southern Africa & 0.028 & 0.001 & 0.034 & 0.046 & 0.077 & 0.356 & 0.000 & 0.000 \\
\hline OECD Europe & 0.010 & 0.062 & 0.230 & 0.635 & 0.194 & 0.026 & 0.000 & 0.000 \\
\hline Eastern Europe & 0.002 & 0.010 & 0.090 & 0.053 & 0.056 & 0.002 & 0.000 & 0.000 \\
\hline Former USSR & 0.009 & 0.044 & 0.146 & 0.094 & 0.240 & 0.049 & 0.000 & 0.000 \\
\hline Middle East & 0.004 & 0.019 & 0.091 & 0.195 & 0.072 & 0.003 & 0.000 & 0.000 \\
\hline South Asia & 0.152 & 0.008 & 0.121 & 0.160 & 0.214 & 0.046 & 0.000 & 0.000 \\
\hline East Asia & 0.112 & 0.044 & 0.538 & 0.245 & 0.345 & 0.065 & 0.000 & 0.000 \\
\hline Southeast Asia & 0.070 & 0.005 & 0.067 & 0.132 & 0.051 & 0.070 & 0.000 & 0.000 \\
\hline Oceania & 0.002 & 0.001 & 0.019 & 0.068 & 0.049 & 0.120 & 0.000 & 0.000 \\
\hline Japan & 0.001 & 0.010 & 0.100 & 0.126 & 0.097 & 0.001 & 0.000 & 0.000 \\
\hline World & 0.535 & 0.280 & 2.027 & 3.689 & 2.262 & 1.846 & 0.000 & 0.000 \\
\hline \multicolumn{9}{|c|}{ Species: N2O (Unit: GgN) } \\
\hline Canada & & 0.200 & 25.900 & 4.400 & 1.200 & & 64.000 & \\
\hline USA & & 1.400 & 132.500 & 56.400 & 19.100 & & 738.300 & \\
\hline Central America & & 0.200 & 3.800 & 0.900 & 0.600 & & 235.000 & \\
\hline South America & & 0.300 & 13.500 & 1.700 & 0.400 & & 909.200 & \\
\hline Northern Africa & & 0.200 & 3.600 & 0.300 & 0.300 & & 128.000 & \\
\hline Western Africa & & 0.000 & 5.600 & 0.200 & 0.000 & & 140.000 & \\
\hline Eastern Africa & & 0.000 & 0.500 & 0.100 & 0.000 & & 204.000 & \\
\hline Southern Africa & & 0.100 & 4.800 & 0.300 & 1.800 & & 231.000 & \\
\hline OECD Europe & & 2.100 & 172.500 & 16.300 & 6.400 & & 388.300 & \\
\hline Eastern Europe & & 0.500 & 46.000 & 0.400 & 2.500 & & 100.100 & \\
\hline Former USSR & & 1.300 & 14.200 & 0.900 & 3.700 & & 284.400 & \\
\hline Middle East & & 0.900 & 8.800 & 1.400 & 1.300 & & 310.200 & \\
\hline South Asia & & 0.500 & 11.500 & 1.000 & 4.800 & & 682.000 & \\
\hline East Asia & & 3.600 & 29.400 & 2.100 & 7.700 & & 2248.500 & \\
\hline Southeast Asia & & 0.200 & 5.600 & 1.000 & 0.000 & & 211.100 & \\
\hline Oceania & & 0.000 & 1.900 & 2.900 & 1.400 & & 393.000 & \\
\hline Japan & & 0.600 & 18.000 & 6.600 & 2.300 & & 52.200 & \\
\hline World & & 12.100 & 498.100 & 96.900 & 53.500 & & 7319.300 & \\
\hline
\end{tabular}


Table A-1 (continued)

Emissions for 2000 A1B by Region

\begin{tabular}{|c|c|c|c|c|c|c|c|c|}
\hline \multirow[b]{2}{*}{ Region } & \multicolumn{2}{|c|}{ Domestic } & \multirow[b]{2}{*}{ Industry } & \multirow[b]{2}{*}{ Transport } & \multirow[b]{2}{*}{ Power } & \multirow[b]{2}{*}{$\begin{array}{l}\text { Biomass } \\
\text { Burning }\end{array}$} & \multirow{2}{*}{$\begin{array}{l}\text { Other } \\
\text { Anthropo- } \\
\text { genic }\end{array}$} & \multirow[b]{2}{*}{ Biogenic } \\
\hline & Biofuel & $\begin{array}{c}\text { Fossil } \\
\text { Fuel }\end{array}$ & & & & & & \\
\hline \multicolumn{9}{|c|}{ Species: SO2 (Unit:Tg) } \\
\hline Canada & 0.004 & 0.014 & 0.163 & 0.088 & 1.482 & 0.078 & 0.000 & 0.000 \\
\hline USA & 0.010 & 0.107 & 2.065 & 1.110 & 10.973 & 0.107 & 0.000 & 0.000 \\
\hline Central America & 0.010 & 0.020 & 1.139 & 0.148 & 1.230 & 0.093 & 0.000 & 0.000 \\
\hline South America & 0.022 & 0.053 & 1.649 & 0.314 & 0.461 & 0.608 & 0.000 & 0.000 \\
\hline Northern Africa & 0.004 & 0.019 & 0.417 & 0.057 & 0.427 & 0.002 & 0.000 & 0.000 \\
\hline Western Africa & 0.050 & 0.004 & 0.161 & 0.036 & 0.030 & 0.536 & 0.000 & 0.000 \\
\hline Eastern Africa & 0.028 & 0.002 & 0.047 & 0.012 & 0.021 & 0.172 & 0.000 & 0.000 \\
\hline Southern Africa & 0.024 & 0.070 & 0.777 & 0.056 & 0.795 & 0.364 & 0.000 & 0.000 \\
\hline OECD Europe & 0.008 & 0.569 & 2.216 & 0.734 & 3.361 & 0.081 & 0.000 & 0.000 \\
\hline Eastern Europe & 0.002 & 0.430 & 2.603 & 0.122 & 3.901 & 0.005 & 0.000 & 0.000 \\
\hline Former USSR & 0.008 & 0.983 & 2.492 & 0.257 & 4.382 & 0.154 & 0.000 & 0.000 \\
\hline Middle East & 0.004 & 0.289 & 2.290 & 0.316 & 1.907 & 0.007 & 0.000 & 0.000 \\
\hline South Asia & 0.132 & 0.102 & 4.006 & 1.028 & 3.186 & 0.093 & 0.000 & 0.000 \\
\hline East Asia & 0.098 & 3.430 & 15.886 & 0.598 & 8.863 & 0.098 & 0.000 & 0.000 \\
\hline Southeast Asia & 0.060 & 0.043 & 1.004 & 0.236 & 0.996 & 0.170 & 0.000 & 0.000 \\
\hline Oceania & 0.002 & 0.010 & 0.191 & 0.076 & 0.773 & 0.123 & 0.000 & 0.000 \\
\hline Japan & 0.002 & 0.063 & 0.624 & 0.310 & 1.186 & 0.001 & 0.000 & 0.000 \\
\hline World & 0.468 & 6.207 & 37.730 & 5.498 & 43.972 & 2.692 & 0.000 & 0.000 \\
\hline \multicolumn{9}{|c|}{ Species: Ethene (Unit:Tg) } \\
\hline Canada & 0.030 & 0.000 & 0.005 & 0.093 & 0.000 & 0.130 & 0.000 & 0.000 \\
\hline USA & 0.072 & 0.000 & 0.034 & 0.676 & 0.000 & 0.159 & 0.000 & 0.000 \\
\hline Central America & 0.074 & 0.000 & 0.006 & 0.128 & 0.000 & 0.355 & 0.000 & 0.000 \\
\hline South America & 0.165 & 0.000 & 0.019 & 0.197 & 0.000 & 1.949 & 0.000 & 0.000 \\
\hline Northern Africa & 0.023 & 0.000 & 0.000 & 0.042 & 0.000 & 0.007 & 0.000 & 0.000 \\
\hline Western Africa & 0.377 & 0.000 & 0.000 & 0.031 & 0.000 & 1.561 & 0.000 & 0.000 \\
\hline Eastern Africa & 0.219 & 0.000 & 0.000 & 0.010 & 0.000 & 0.461 & 0.000 & 0.000 \\
\hline Southern Africa & 0.183 & 0.000 & 0.000 & 0.047 & 0.000 & 0.962 & 0.000 & 0.000 \\
\hline OECD Europe & 0.062 & 0.000 & 0.030 & 0.590 & 0.000 & 0.128 & 0.000 & 0.000 \\
\hline Eastern Europe & 0.011 & 0.000 & 0.016 & 0.067 & 0.000 & 0.013 & 0.000 & 0.000 \\
\hline Former USSR & 0.056 & 0.000 & 0.027 & 0.079 & 0.000 & 0.241 & 0.000 & 0.000 \\
\hline Middle East & 0.026 & 0.000 & 0.005 & 0.184 & 0.000 & 0.026 & 0.000 & 0.000 \\
\hline South Asia & 1.005 & 0.000 & 0.002 & 0.134 & 0.000 & 0.350 & 0.000 & 0.000 \\
\hline East Asia & 0.739 & 0.000 & 0.010 & 0.270 & 0.000 & 0.303 & 0.000 & 0.000 \\
\hline Southeast Asia & 0.461 & 0.000 & 0.012 & 0.230 & 0.000 & 0.625 & 0.000 & 0.000 \\
\hline Oceania & 0.016 & 0.000 & 0.001 & 0.081 & 0.000 & 0.334 & 0.000 & 0.000 \\
\hline Japan & 0.009 & 0.000 & 0.014 & 0.167 & 0.000 & 0.005 & 0.000 & 0.000 \\
\hline World & 3.528 & 0.000 & 0.182 & 3.026 & 0.000 & 7.608 & 0.000 & 0.000 \\
\hline
\end{tabular}


Table A-1 (continued)

Emissions for 2000 A1B by Region

\begin{tabular}{|c|c|c|c|c|c|c|c|c|}
\hline \multirow[b]{2}{*}{ Region } & \multicolumn{2}{|c|}{ Domestic } & \multirow[b]{2}{*}{ Industry } & \multirow[b]{2}{*}{ Transport } & \multirow[b]{2}{*}{ Power } & \multirow[b]{2}{*}{$\begin{array}{l}\text { Biomass } \\
\text { Burning }\end{array}$} & \multirow{2}{*}{$\begin{array}{l}\text { Other } \\
\text { Anthropo- } \\
\text { genic }\end{array}$} & \multirow[b]{2}{*}{ Biogenic } \\
\hline & Biofuel & $\begin{array}{c}\text { Fossil } \\
\text { Fuel }\end{array}$ & & & & & & \\
\hline \multicolumn{9}{|c|}{ Species: Toluene (Unit: Gg) } \\
\hline Canada & 7.092986 & 0.355767 & 54.05762 & 127.6283 & 0.213395 & 45.4768225 & 0 & 0 \\
\hline USA & 16.99141 & 2.7446948 & 693.7676 & 924.803 & 5.515569 & 65.8897034 & 0 & 0 \\
\hline Central America & 17.36194 & 0.0930681 & 47.43545 & 175.3613 & 0.105079 & 49.31104835 & 0 & 0 \\
\hline South America & 38.79969 & 0.4923067 & 154.9731 & 268.9533 & 0.232056 & 299.4845744 & 0 & 0 \\
\hline Northern Africa & 5.399138 & 0.0968264 & 24.74693 & 57.7365 & 0.185981 & 0.365770287 & 0 & 0 \\
\hline Western Africa & 88.71525 & 0.0152633 & 40.88682 & 42.21483 & 0.023953 & 256.0022517 & 0 & 0 \\
\hline Eastern Africa & 51.55648 & 0.0076048 & 15.01115 & 12.96008 & 8.02E-05 & 72.76968663 & 0 & 0 \\
\hline Southern Africa & 43.14017 & 2.2751322 & 21.85245 & 64.07573 & 0.39516 & 167.8248998 & 0 & 0 \\
\hline OECD Europe & 14.60943 & 3.3148182 & 583.2864 & 804.1618 & 1.773309 & 48.37745449 & 0 & 0 \\
\hline Eastern Europe & 2.646636 & 6.910744 & 95.15528 & 90.81307 & 1.025808 & 1.808357635 & 0 & 0 \\
\hline Former USSR & 13.18025 & 17.328121 & 263.4606 & 108.2797 & 1.82024 & 91.64896284 & 0 & 0 \\
\hline Middle East & 6.140197 & 2.5275981 & 81.83879 & 251.0074 & 0.534132 & 2.356884847 & 0 & 0 \\
\hline South Asia & 236.3976 & 1.2358511 & 117.7688 & 181.5815 & 1.153657 & 32.4473497 & 0 & 0 \\
\hline East Asia & 173.8311 & 71.025893 & 210.5658 & 368.7372 & 1.706861 & 34.60841202 & 0 & 0 \\
\hline Southeast Asia & 108.3533 & 0.2965796 & 118.0271 & 313.4619 & 0.362364 & 85.69148874 & 0 & 0 \\
\hline Oceania & 3.811157 & 0.2409495 & 30.45178 & 111.1387 & 0.357058 & 51.46928658 & 0 & 0 \\
\hline Japan & 2.064376 & 0.4118278 & 259.8882 & 228.3116 & 0.805829 & 0.306711578 & 0 & 0 \\
\hline World & 830.0911 & 109.37305 & 2813.174 & 4131.226 & 16.21053 & 1305.839666 & 0 & 0 \\
\hline \multicolumn{9}{|c|}{ Species: Xylenes (Unit: Gg) } \\
\hline Canada & 4.29 & 0.24 & 20.99 & 124.97 & 0.68 & 28.08 & 0 & 0 \\
\hline USA & 10.28 & 1.79 & 265.10 & 908.05 & 21.83 & 40.40 & 0 & 0 \\
\hline Central America & 10.51 & 0.13 & 18.17 & 172.70 & 0.17 & 17.65 & 0 & 0 \\
\hline South America & 23.48 & 0.66 & 60.29 & 264.18 & 0.30 & 116.90 & 0 & 0 \\
\hline Northern Africa & 3.27 & 0.10 & 9.14 & 56.91 & 0.05 & 0.24 & 0 & 0 \\
\hline Western Africa & 53.69 & 0.02 & 15.16 & 41.62 & 0.00 & 103.80 & 0 & 0 \\
\hline Eastern Africa & 31.20 & 0.01 & 5.56 & 12.77 & 0.00 & 32.49 & 0 & 0 \\
\hline Southern Africa & 26.11 & 3.62 & 9.24 & 63.13 & 2.09 & 70.88 & 0 & 0 \\
\hline OECD Europe & 8.84 & 3.74 & 229.36 & 792.07 & 6.56 & 29.71 & 0 & 0 \\
\hline Eastern Europe & 1.60 & 10.78 & 37.19 & 89.45 & 4.17 & 1.19 & 0 & 0 \\
\hline Former USSR & 7.98 & 26.02 & 101.86 & 105.87 & 1.55 & 56.39 & 0 & 0 \\
\hline Middle East & 3.72 & 3.66 & 28.68 & 247.47 & 0.34 & 1.17 & 0 & 0 \\
\hline South Asia & 143.07 & 1.85 & 49.67 & 178.96 & 5.51 & 15.14 & 0 & 0 \\
\hline East Asia & 105.20 & 112.84 & 103.45 & 363.32 & 8.76 & 18.85 & 0 & 0 \\
\hline Southeast Asia & 65.58 & 0.40 & 44.97 & 308.93 & 0.42 & 31.90 & 0 & 0 \\
\hline Oceania & 2.31 & 0.34 & 12.17 & 109.43 & 1.66 & 23.03 & 0 & 0 \\
\hline Japan & 1.25 & 0.49 & 102.46 & 224.86 & 2.16 & 0.18 & 0 & 0 \\
\hline World & 502.37 & 166.68 & 1113.47 & 4064.70 & 56.26 & 588.00 & 0 & 0 \\
\hline
\end{tabular}

Bio burn refers to natural biomass burning.

Biogenic refers to natural emissions such as emissions from the ocean and nitrogen fixation over land.

$\mathrm{CO} 2$ emissions for biomass burning and biogenic emissions not shown. 
Table A-2

Emissions from 2050 A1B by Region

\begin{tabular}{|c|c|c|c|c|c|c|c|c|}
\hline \multirow[b]{2}{*}{ Region } & \multicolumn{2}{|c|}{ Domestic } & \multirow[b]{2}{*}{ Industry } & \multirow[b]{2}{*}{ Transport } & \multirow[b]{2}{*}{ Power } & \multirow[b]{2}{*}{$\begin{array}{c}\text { Biomass } \\
\text { Burning }\end{array}$} & \multirow{2}{*}{$\begin{array}{l}\text { Other } \\
\text { Anthropo- } \\
\text { genic }\end{array}$} & \multirow[b]{2}{*}{ Biogenic } \\
\hline & Biofuel & $\begin{array}{l}\text { Fossil } \\
\text { Fuel }\end{array}$ & & & & & & \\
\hline \multicolumn{9}{|c|}{ Species: CO (Unit: Tg) } \\
\hline Canada & 0.98 & 0.10 & 0.38 & 2.13 & 0.05 & 0.24 & 0 & 0 \\
\hline USA & 3.34 & 0.62 & 2.34 & 22.50 & 0.62 & 8.45 & 0 & 0 \\
\hline Central America & 4.80 & 0.31 & 0.90 & 7.14 & 0.20 & 8.57 & 0 & 0 \\
\hline South America & 9.44 & 0.56 & 6.09 & 10.91 & 0.42 & 206.59 & 0 & 0 \\
\hline Northern Africa & 0.35 & 0.34 & 2.45 & 14.64 & 0.27 & 0.27 & 0 & 0 \\
\hline Western Africa & 26.93 & 0.55 & 0.14 & 10.37 & 0.12 & 61.49 & 0 & 0 \\
\hline Eastern Africa & 17.75 & 0.40 & 0.08 & 7.07 & 0.05 & 25.91 & 0 & 0 \\
\hline Southern Africa & 9.57 & 2.48 & 1.25 & 9.79 & 0.27 & 15.02 & 0 & 0 \\
\hline OECD Europe & 1.94 & 0.50 & 3.77 & 14.16 & 0.32 & 5.36 & 0 & 0 \\
\hline Eastern Europe & 0.41 & 0.30 & 1.83 & 2.57 & 0.15 & 0.46 & 0 & 0 \\
\hline Former USSR & 2.56 & 0.75 & 8.70 & 9.55 & 0.51 & 1.20 & 0 & 0 \\
\hline Middle East & 0.33 & 0.42 & 3.24 & 13.73 & 0.64 & 0.84 & 0 & 0 \\
\hline South Asia & 45.89 & 1.29 & 12.61 & 16.73 & 1.94 & 9.20 & 0 & 0 \\
\hline East Asia & 24.61 & 8.01 & 13.56 & 21.28 & 0.96 & 0.59 & 0 & 0 \\
\hline Southeast Asia & 20.36 & 0.32 & 2.52 & 12.59 & 0.49 & 40.01 & 0 & 0 \\
\hline Oceania & 0.55 & 0.03 & 0.21 & 1.33 & 0.06 & 22.56 & 0 & 0 \\
\hline Japan & 0.25 & 0.18 & 2.68 & 3.28 & 0.13 & 0.66 & 0 & 0 \\
\hline World & 170.05 & 17.17 & 62.76 & 179.77 & 7.20 & 407.42 & 0 & 0 \\
\hline \multicolumn{9}{|c|}{ Species: CO2 (Unit: TgC) } \\
\hline Canada & 6.64 & 23.30 & 28.20 & 55.10 & 76.70 & $\begin{array}{l}\text { Not } \\
\text { shown }\end{array}$ & 2.40 & $\begin{array}{c}\text { Not } \\
\text { shown }\end{array}$ \\
\hline USA & 54.08 & 153.60 & 216.10 & 536.00 & 1004.50 & & 12.70 & \\
\hline Central America & 58.63 & 36.80 & 98.80 & 185.00 & 248.90 & & 6.90 & \\
\hline South America & 106.03 & 105.60 & 199.30 & 303.00 & 506.50 & & 16.60 & \\
\hline Northern Africa & 9.61 & 71.20 & 150.40 & 182.00 & 316.30 & & 10.30 & \\
\hline Western Africa & 458.61 & 75.00 & 60.10 & 116.00 & 139.60 & & 2.30 & \\
\hline Eastern Africa & 222.57 & 55.00 & 30.90 & 78.00 & 555.70 & & 1.50 & \\
\hline Southern Africa & 153.96 & 53.80 & 97.40 & 110.00 & 362.40 & & 6.40 & \\
\hline OECD Europe & 47.85 & 171.90 & 143.90 & 379.00 & 563.70 & & 15.30 & \\
\hline Eastern Europe & 33.43 & 44.30 & 97.30 & 83.00 & 243.80 & & 4.10 & \\
\hline Former USSR & 12.96 & 159.20 & 226.60 & 283.00 & 589.70 & & 19.60 & \\
\hline Middle East & 23.68 & 35.70 & 326.80 & 386.00 & 767.30 & & 22.20 & \\
\hline South Asia & 459.24 & 276.70 & 792.60 & 442.00 & 2343.80 & & 20.00 & \\
\hline East Asia & 339.65 & 289.60 & 829.10 & 440.00 & 1215.00 & & 23.60 & \\
\hline Southeast Asia & 201.13 & 74.00 & 203.80 & 265.00 & 606.80 & & 12.20 & \\
\hline Oceania & 5.95 & 4.90 & 20.30 & 33.60 & 753.60 & & 1.30 & \\
\hline Japan & 0.00 & 32.10 & 64.10 & 72.00 & 164.80 & & 6.00 & \\
\hline World & 2170.34 & 1662.70 & 3585.70 & 3948.70 & 10459.10 & & 183.40 & \\
\hline
\end{tabular}


Table A-2 (continued)

Emissions from 2050 A1B by Region

\begin{tabular}{|c|c|c|c|c|c|c|c|c|}
\hline \multirow[b]{2}{*}{ Region } & \multicolumn{2}{|c|}{ Domestic } & \multirow[b]{2}{*}{ Industry } & \multirow[b]{2}{*}{ Transport } & \multirow[b]{2}{*}{ Power } & \multirow[b]{2}{*}{$\begin{array}{l}\text { Biomass } \\
\text { Burning }\end{array}$} & \multirow{2}{*}{$\begin{array}{c}\text { Other } \\
\text { Anthropo- } \\
\text { genic }\end{array}$} & \multirow[b]{2}{*}{ Biogenic } \\
\hline & Biofuel & $\begin{array}{c}\text { Fossil } \\
\text { Fuel }\end{array}$ & & & & & & \\
\hline \multicolumn{9}{|c|}{ Species: CH4 (Unit: Tg) } \\
\hline Canada & 0.06 & 0.01 & 2.01 & 0.05 & 0.00 & 0.01 & 3.23 & \\
\hline USA & 0.20 & 0.10 & 8.01 & 0.54 & 0.00 & 0.44 & 30.11 & \\
\hline Central America & 0.29 & 0.04 & 2.68 & 0.19 & 0.00 & 0.35 & 10.80 & \\
\hline South America & 0.57 & 0.08 & 9.68 & 0.30 & 0.00 & 13.70 & 37.42 & \\
\hline Northern Africa & 0.02 & 0.05 & 4.02 & 0.15 & 0.00 & 0.01 & 8.40 & \\
\hline Western Africa & 1.62 & 0.06 & 8.10 & 0.12 & 0.00 & 3.62 & 23.36 & \\
\hline Eastern Africa & 1.07 & 0.05 & 0.07 & 0.08 & 0.00 & 1.09 & 19.70 & \\
\hline Southern Africa & 0.58 & 0.17 & 20.48 & 0.11 & 0.00 & 0.65 & 13.90 & \\
\hline OECD Europe & 0.12 & 0.11 & 2.54 & 0.38 & 0.00 & 0.29 & 20.02 & \\
\hline Eastern Europe & 0.03 & 0.04 & 1.60 & 0.08 & 0.00 & 0.02 & 4.71 & \\
\hline Former USSR & 0.15 & 0.11 & 52.39 & 0.24 & 0.00 & 0.06 & 16.08 & \\
\hline Middle East & 0.02 & 0.07 & 65.12 & 0.30 & 0.00 & 0.04 & 18.57 & \\
\hline South Asia & 2.77 & 0.19 & 9.40 & 0.37 & 0.00 & 0.38 & 46.04 & \\
\hline East Asia & 1.48 & 0.60 & 17.49 & 0.43 & 0.00 & 0.03 & 41.29 & \\
\hline Southeast Asia & 1.23 & 0.05 & 9.64 & 0.25 & 0.00 & 2.63 & 29.27 & \\
\hline Oceania & 0.03 & 0.00 & 2.16 & 0.03 & 0.00 & 1.11 & 3.49 & \\
\hline Japan & 0.02 & 0.03 & 0.14 & 0.07 & 0.00 & 0.04 & 4.23 & \\
\hline Asia w/o Japan & 5.48 & 0.84 & 36.53 & 1.04 & 0.00 & 3.04 & 116.61 & \\
\hline World & 10.25 & 1.76 & 215.53 & 3.67 & 0.00 & 24.47 & 330.64 & \\
\hline \multicolumn{9}{|c|}{ Species: NO (Unit: Tg) } \\
\hline Canada & 0.03 & 0.07 & 0.26 & 0.47 & 0.31 & 0.01 & 0.00 & 0.00 \\
\hline USA & 0.09 & 0.44 & 3.92 & 4.66 & 4.55 & 0.19 & 0.00 & 0.00 \\
\hline Central America & 0.13 & 0.15 & 0.96 & 0.96 & 1.61 & 0.23 & 0.00 & 0.00 \\
\hline South America & 0.26 & 0.39 & 2.17 & 1.65 & 2.99 & 3.57 & 0.00 & 0.00 \\
\hline Northern Africa & 0.01 & 0.23 & 1.44 & 2.18 & 1.70 & 0.01 & 0.00 & 0.00 \\
\hline Western Africa & 0.74 & 0.25 & 0.77 & 1.51 & 0.64 & 1.23 & 0.00 & 0.00 \\
\hline Eastern Africa & 0.49 & 0.19 & 0.23 & 1.04 & 0.39 & 0.68 & 0.00 & 0.00 \\
\hline Southern Africa & 0.26 & 0.19 & 0.94 & 1.41 & 2.83 & 0.38 & 0.00 & 0.00 \\
\hline OECD Europe & 0.05 & 0.49 & 1.64 & 2.65 & 1.96 & 0.12 & 0.00 & 0.00 \\
\hline Eastern Europe & 0.01 & 0.17 & 1.28 & 0.35 & 1.38 & 0.01 & 0.00 & 0.00 \\
\hline Former USSR & 0.07 & 0.53 & 2.51 & 1.45 & 2.03 & 0.03 & 0.00 & 0.00 \\
\hline Middle East & 0.01 & 0.41 & 3.32 & 1.85 & 3.00 & 0.02 & 0.00 & 0.00 \\
\hline South Asia & 1.26 & 0.94 & 7.17 & 3.08 & 20.72 & 0.24 & 0.00 & 0.00 \\
\hline East Asia & 0.68 & 1.02 & 8.03 & 2.86 & 9.58 & 0.01 & 0.00 & 0.00 \\
\hline Southeast Asia & 0.56 & 0.27 & 2.08 & 1.66 & 4.59 & 0.70 & 0.00 & 0.00 \\
\hline Oceania & 0.01 & 0.01 & 0.14 & 0.25 & 0.43 & 0.53 & 0.00 & 0.00 \\
\hline Japan & 0.01 & 0.07 & 0.60 & 0.55 & 0.77 & 0.01 & 0.00 & 0.00 \\
\hline World & 4.67 & 5.83 & 37.47 & 28.60 & 59.47 & 7.95 & 0.00 & 0.00 \\
\hline
\end{tabular}


Table A-2 (continued)

Emissions from 2050 A1B by Region

\begin{tabular}{|c|c|c|c|c|c|c|c|c|}
\hline \multirow[b]{2}{*}{ Region } & \multicolumn{2}{|c|}{ Domestic } & \multirow[b]{2}{*}{ Industry } & \multirow[b]{2}{*}{ Transport } & \multirow[b]{2}{*}{ Power } & \multirow[b]{2}{*}{$\begin{array}{l}\text { Biomass } \\
\text { Burning }\end{array}$} & \multirow{2}{*}{$\begin{array}{l}\text { Other } \\
\text { Anthropo- } \\
\text { genic }\end{array}$} & \multirow[b]{2}{*}{ Biogenic } \\
\hline & Biofuel & $\begin{array}{c}\text { Fossil } \\
\text { Fuel }\end{array}$ & & & & & & \\
\hline \multicolumn{9}{|c|}{ Species: NO2 (Unit: Tg) } \\
\hline Canada & 0.004 & 0.011 & 0.044 & 0.079 & 0.053 & 0.001 & 0 & 0 \\
\hline USA & 0.015 & 0.076 & 0.669 & 0.793 & 0.775 & 0.032 & 0 & 0 \\
\hline Central America & 0.022 & 0.026 & 0.164 & 0.164 & 0.275 & 0.039 & 0 & 0 \\
\hline South America & 0.044 & 0.067 & 0.370 & 0.282 & 0.509 & 0.608 & 0 & 0 \\
\hline Northern Africa & 0.001 & 0.039 & 0.245 & 0.372 & 0.290 & 0.001 & 0 & 0 \\
\hline Western Africa & 0.126 & 0.043 & 0.131 & 0.258 & 0.109 & 0.209 & 0 & 0 \\
\hline Eastern Africa & 0.083 & 0.032 & 0.040 & 0.176 & 0.067 & 0.115 & 0 & 0 \\
\hline Southern Africa & 0.045 & 0.033 & 0.160 & 0.240 & 0.482 & 0.065 & 0 & 0 \\
\hline OECD Europe & 0.009 & 0.084 & 0.279 & 0.452 & 0.334 & 0.020 & 0 & 0 \\
\hline Eastern Europe & 0.002 & 0.029 & 0.219 & 0.060 & 0.234 & 0.002 & 0 & 0 \\
\hline Former USSR & 0.012 & 0.091 & 0.428 & 0.248 & 0.345 & 0.005 & 0 & 0 \\
\hline Middle East & 0.001 & 0.070 & 0.565 & 0.315 & 0.511 & 0.003 & 0 & 0 \\
\hline South Asia & 0.215 & 0.160 & 1.222 & 0.526 & 3.530 & 0.041 & 0 & 0 \\
\hline East Asia & 0.115 & 0.174 & 1.368 & 0.487 & 1.632 & 0.002 & 0 & 0 \\
\hline Southeast Asia & 0.095 & 0.046 & 0.354 & 0.283 & 0.782 & 0.119 & 0 & 0 \\
\hline Oceania & 0.002 & 0.002 & 0.024 & 0.043 & 0.073 & 0.091 & 0 & 0 \\
\hline Japan & 0.001 & 0.012 & 0.102 & 0.094 & 0.131 & 0.002 & 0 & 0 \\
\hline World & 0.796 & 0.993 & 6.384 & 4.872 & 10.132 & 1.355 & 0 & 0 \\
\hline \multicolumn{9}{|c|}{ Species: N2O (Unit: GgN) } \\
\hline Canada & & 0.20 & 7.50 & 3.60 & 1.70 & & 70.00 & \\
\hline USA & & 1.70 & 37.60 & 38.00 & 26.70 & & 788.30 & \\
\hline Central America & & 0.80 & 6.90 & 14.00 & 4.40 & & 315.20 & \\
\hline South America & & 1.20 & 32.90 & 22.20 & 7.70 & & 1061.40 & \\
\hline Northern Africa & & 0.90 & 16.40 & 11.90 & 4.20 & & 352.20 & \\
\hline Western Africa & & 1.40 & 54.90 & 11.20 & 1.20 & & 822.00 & \\
\hline Eastern Africa & & 1.20 & 7.70 & 7.60 & 1.10 & & 533.00 & \\
\hline Southern Africa & & 1.20 & 15.70 & 10.30 & 11.30 & & 944.10 & \\
\hline OECD Europe & & 1.90 & 43.30 & 28.10 & 11.80 & & 445.30 & \\
\hline Eastern Europe & & 0.40 & 26.00 & 5.90 & 5.60 & & 113.10 & \\
\hline Former USSR & & 1.10 & 13.60 & 18.70 & 10.40 & & 783.30 & \\
\hline Middle East & & 1.00 & 16.60 & 23.30 & 9.80 & & 821.30 & \\
\hline South Asia & & 3.50 & 62.10 & 36.20 & 60.50 & & 976.40 & \\
\hline East Asia & & 5.50 & 87.00 & 40.30 & 27.30 & & 1559.60 & \\
\hline Southeast Asia & & 0.80 & 29.70 & 23.90 & 11.10 & & 531.30 & \\
\hline Oceania & & 0.00 & 1.40 & 2.30 & 2.20 & & 680.00 & \\
\hline Japan & & 0.50 & 5.30 & 4.80 & 4.00 & & 106.10 & \\
\hline World & & 23.30 & 464.60 & 302.30 & 201.00 & & 10902.60 & \\
\hline
\end{tabular}


Table A-2 (continued)

Emissions from 2050 A1B by Region

\begin{tabular}{|c|c|c|c|c|c|c|c|c|}
\hline \multirow[b]{2}{*}{ Region } & \multicolumn{2}{|c|}{ Domestic } & \multirow[b]{2}{*}{ Industry } & \multirow[b]{2}{*}{ Transport } & \multirow[b]{2}{*}{ Power } & \multirow[b]{2}{*}{$\begin{array}{l}\text { Biomass } \\
\text { Burning }\end{array}$} & \multirow{2}{*}{$\begin{array}{c}\text { Other } \\
\text { Anthropo- } \\
\text { genic }\end{array}$} & \multirow[b]{2}{*}{ Biogenic } \\
\hline & Biofuel & $\begin{array}{l}\text { Fossil } \\
\text { Fuel }\end{array}$ & & & & & & \\
\hline \multicolumn{9}{|c|}{ Species: SO2 (Unit: Tg) } \\
\hline Canada & 0.002 & 0.002 & 0.058 & 0.012 & 0.373 & 0.002 & 0 & 0 \\
\hline USA & 0.008 & 0.014 & 0.493 & 0.131 & 2.910 & 0.086 & 0 & 0 \\
\hline Central America & 0.012 & 0.060 & 2.594 & 0.343 & 1.612 & 0.086 & 0 & 0 \\
\hline South America & 0.026 & 0.102 & 15.835 & 0.603 & 2.072 & 2.066 & 0 & 0 \\
\hline Northern Africa & 0.000 & 0.060 & 3.604 & 0.402 & 2.645 & 0.002 & 0 & 0 \\
\hline Western Africa & 0.072 & 0.070 & 1.715 & 0.243 & 0.453 & 0.614 & 0 & 0 \\
\hline Eastern Africa & 0.048 & 0.057 & 0.478 & 0.172 & 0.877 & 0.258 & 0 & 0 \\
\hline Southern Africa & 0.026 & 0.229 & 7.377 & 0.233 & 3.954 & 0.152 & 0 & 0 \\
\hline OECD Europe & 0.006 & 0.045 & 0.891 & 0.126 & 1.453 & 0.052 & 0 & 0 \\
\hline Eastern Europe & 0.002 & 0.024 & 0.692 & 0.045 & 0.891 & 0.004 & 0 & 0 \\
\hline Former USSR & 0.006 & 0.040 & 1.748 & 0.190 & 1.045 & 0.012 & 0 & 0 \\
\hline Middle East & 0.000 & 0.057 & 3.139 & 0.605 & 1.422 & 0.008 & 0 & 0 \\
\hline South Asia & 0.122 & 0.158 & 11.768 & 2.688 & 18.524 & 0.092 & 0 & 0 \\
\hline East Asia & 0.066 & 0.799 & 16.340 & 0.860 & 7.749 & 0.006 & 0 & 0 \\
\hline Southeast Asia & 0.054 & 0.036 & 2.376 & 0.427 & 5.498 & 0.400 & 0 & 0 \\
\hline Oceania & 0.002 & 0.001 & 0.226 & 0.020 & 0.207 & 0.226 & 0 & 0 \\
\hline Japan & 0.000 & 0.005 & 0.121 & 0.037 & 0.398 & 0.008 & 0 & 0 \\
\hline World & 0.452 & 1.760 & 69.455 & 7.136 & 52.082 & 4.074 & 0 & 0 \\
\hline \multicolumn{9}{|c|}{ Species: Ethene (Unit: Tg) } \\
\hline Canada & 0.020 & 0.000 & 0.004 & 0.028 & 0.000 & 0.155 & 0 & 0 \\
\hline USA & 0.068 & 0.000 & 0.031 & 0.166 & 0.000 & 0.168 & 0 & 0 \\
\hline Central America & 0.098 & 0.000 & 0.005 & 0.073 & 0.000 & 0.289 & 0 & 0 \\
\hline South America & 0.192 & 0.000 & 0.019 & 0.109 & 0.000 & 2.663 & 0 & 0 \\
\hline Northern Africa & 0.007 & 0.000 & 0.000 & 0.173 & 0.000 & 0.011 & 0 & 0 \\
\hline Western Africa & 0.548 & 0.000 & 0.001 & 0.112 & 0.000 & 1.223 & 0 & 0 \\
\hline Eastern Africa & 0.361 & 0.000 & 0.000 & 0.077 & 0.000 & 0.598 & 0 & 0 \\
\hline Southern Africa & 0.195 & 0.000 & 0.000 & 0.106 & 0.000 & 0.389 & 0 & 0 \\
\hline OECD Europe & 0.039 & 0.000 & 0.023 & 0.204 & 0.000 & 0.110 & 0 & 0 \\
\hline Eastern Europe & 0.008 & 0.000 & 0.008 & 0.029 & 0.000 & 0.009 & 0 & 0 \\
\hline Former USSR & 0.052 & 0.000 & 0.015 & 0.076 & 0.000 & 0.250 & 0 & 0 \\
\hline Middle East & 0.007 & 0.000 & 0.008 & 0.156 & 0.000 & 0.019 & 0 & 0 \\
\hline South Asia & 0.934 & 0.000 & 0.005 & 0.396 & 0.000 & 0.601 & 0 & 0 \\
\hline East Asia & 0.501 & 0.001 & 0.007 & 0.216 & 0.000 & 0.302 & 0 & 0 \\
\hline Southeast Asia & 0.414 & 0.000 & 0.021 & 0.255 & 0.000 & 0.601 & 0 & 0 \\
\hline Oceania & 0.011 & 0.000 & 0.000 & 0.023 & 0.000 & 0.485 & 0 & 0 \\
\hline Japan & 0.005 & 0.000 & 0.012 & 0.077 & 0.000 & 0.010 & 0 & 0 \\
\hline Asia & 1.848 & 0.001 & 0.033 & 0.867 & 0.000 & 1.504 & 0 & 0 \\
\hline World & 3.459 & 0.003 & 0.161 & 2.277 & 0.000 & 7.883 & 0 & 0 \\
\hline
\end{tabular}


Table A-2 (continued)

Emissions from 2050 A1B by Region

\begin{tabular}{|c|c|c|c|c|c|c|c|c|}
\hline \multirow[b]{2}{*}{ Region } & \multicolumn{2}{|c|}{ Domestic } & \multirow[b]{2}{*}{ Industry } & \multirow[b]{2}{*}{ Transport } & \multirow[b]{2}{*}{ Power } & \multirow[b]{2}{*}{$\begin{array}{c}\text { Biomass } \\
\text { Burning }\end{array}$} & \multirow{2}{*}{$\begin{array}{l}\text { Other } \\
\text { Anthropo- } \\
\text { genic }\end{array}$} & \multirow[b]{2}{*}{ Biogenic } \\
\hline & Biofuel & $\begin{array}{c}\text { Fossil } \\
\text { Fuel }\end{array}$ & & & & & & \\
\hline \multicolumn{9}{|c|}{ Species: Toluene (Unit: Gg) } \\
\hline Canada & 4.71 & 0.35 & 42.49 & 41.78 & 0.45 & 54.22 & 0 & 0 \\
\hline USA & 15.99 & 2.50 & 624.73 & 270.18 & 7.81 & 69.51 & 0 & 0 \\
\hline Central America & 22.97 & 1.09 & 45.92 & 106.76 & 1.83 & 40.17 & 0 & 0 \\
\hline South America & 45.15 & 1.98 & 159.92 & 159.00 & 4.11 & 409.21 & 0 & 0 \\
\hline Northern Africa & 1.64 & 1.13 & 59.80 & 241.45 & 2.69 & 0.63 & 0 & 0 \\
\hline Western Africa & 128.89 & 1.92 & 197.48 & 161.51 & 1.30 & 200.61 & 0 & 0 \\
\hline Eastern Africa & 84.90 & 1.35 & 78.58 & 110.47 & 0.33 & 94.37 & 0 & 0 \\
\hline Southern Africa & 45.79 & 10.20 & 36.68 & 153.17 & 2.68 & 67.81 & 0 & 0 \\
\hline OECD Europe & 9.26 & 1.49 & 434.16 & 300.98 & 3.68 & 41.50 & 0 & 0 \\
\hline Eastern Europe & 1.96 & 1.06 & 51.08 & 40.82 & 3.19 & 1.35 & 0 & 0 \\
\hline Former USSR & 12.28 & 3.15 & 157.52 & 111.99 & 4.69 & 95.05 & 0 & 0 \\
\hline Middle East & 1.59 & 1.19 & 158.03 & 218.34 & 6.53 & 1.72 & 0 & 0 \\
\hline South Asia & 219.62 & 4.20 & 332.55 & 556.54 & 19.12 & 55.72 & 0 & 0 \\
\hline East Asia & 117.78 & 33.02 & 174.17 & 312.00 & 9.37 & 34.53 & 0 & 0 \\
\hline Southeast Asia & 97.40 & 1.10 & 218.95 & 360.70 & 5.09 & 82.39 & 0 & 0 \\
\hline Oceania & 2.59 & 0.10 & 20.75 & 33.88 & 0.65 & 74.63 & 0 & 0 \\
\hline Japan & 1.16 & 0.45 & 216.57 & 113.68 & 1.34 & 0.65 & 0 & 0 \\
\hline World & 813.68 & 66.28 & 3009.38 & 3293.26 & 74.86 & 1324.08 & 0 & 0 \\
\hline \multicolumn{9}{|c|}{ Species: Xylene (Unit:Gg) } \\
\hline Canada & 2.85 & 0.42 & 17.16 & 37.46 & 0.83 & 33.49 & 0 & 0 \\
\hline USA & 9.67 & 3.01 & 240.96 & 223.31 & 27.48 & 42.62 & 0 & 0 \\
\hline Central America & 13.90 & 1.67 & 19.66 & 98.62 & 2.74 & 14.38 & 0 & 0 \\
\hline South America & 27.33 & 2.86 & 66.14 & 145.94 & 4.95 & 159.72 & 0 & 0 \\
\hline Northern Africa & 0.99 & 1.41 & 21.40 & 232.09 & 2.36 & 0.42 & 0 & 0 \\
\hline Western Africa & 78.01 & 2.75 & 73.13 & 150.28 & 0.23 & 81.34 & 0 & 0 \\
\hline Eastern Africa & 51.38 & 1.96 & 29.24 & 103.09 & 0.26 & 42.14 & 0 & 0 \\
\hline Southern Africa & 27.71 & 16.05 & 17.03 & 142.71 & 12.21 & 28.64 & 0 & 0 \\
\hline OECD Europe & 5.61 & 1.58 & 174.47 & 274.61 & 10.68 & 25.49 & 0 & 0 \\
\hline Eastern Europe & 1.19 & 1.60 & 21.06 & 38.26 & 8.05 & 0.89 & 0 & 0 \\
\hline Former USSR & 7.43 & 4.45 & 61.49 & 101.68 & 4.54 & 58.48 & 0 & 0 \\
\hline Middle East & 0.96 & 1.48 & 46.66 & 208.93 & 3.23 & 0.85 & 0 & 0 \\
\hline South Asia & 132.91 & 5.74 & 138.78 & 529.76 & 61.53 & 25.99 & 0 & 0 \\
\hline East Asia & 71.28 & 51.83 & 93.44 & 287.97 & 25.21 & 18.81 & 0 & 0 \\
\hline Southeast Asia & 58.94 & 1.41 & 85.21 & 341.67 & 9.33 & 30.67 & 0 & 0 \\
\hline Oceania & 1.57 & 0.13 & 8.81 & 31.60 & 2.40 & 33.39 & 0 & 0 \\
\hline Japan & 0.70 & 0.44 & 85.88 & 104.09 & 3.80 & 0.37 & 0 & 0 \\
\hline World & 492.44 & 98.80 & 1200.53 & 3052.06 & 179.84 & 597.69 & 0 & 0 \\
\hline
\end{tabular}

Biomass burn refers to natural biomass burning.

Biogenic refers to natural emissions such as emissions from the ocean and nitrogen fixation over land.

$\mathrm{CO} 2$ emissions for biomass burning and biogenic emissions not shown. 
Table A-3

Growth Factors by Region from 2000 Base Case to $2050 \mathrm{~A} 1 \mathrm{~B}$

\begin{tabular}{|c|c|c|c|c|c|c|c|c|c|c|c|c|c|c|c|c|c|c|c|c|c|c|c|c|c|c|c|}
\hline & ALD2 & $\mathrm{CO}$ & ETH & FORM & ISOP & $\mathrm{NH} 3$ & NO & NO2 & NR & OLE & PAR & PEC & PMC & PMFINE & $\mathrm{PNO} 3$ & POA & PSO4 & SO2 & SULF & TERPB & TOL & $\mathrm{XYL}$ & KET & ALC & $\mathrm{CO} 2$ & $\mathrm{CH} 4$ & $\mathrm{~N} 2 \mathrm{O}$ \\
\hline \multicolumn{28}{|c|}{ Residential Biofuel } \\
\hline Canada & 0.66 & 0.67 & 0.66 & 0.66 & 1.00 & 0.62 & 0.98 & 0.98 & 0.66 & 0.66 & 0.39 & 0.39 & 0.39 & 0.78 & 0.39 & 0.37 & 0.39 & 0.50 & 0.50 & 1.00 & 0.66 & 0.66 & 1.00 & 0.66 & 1.32 & 0.66 & 0.98 \\
\hline USA & 0.94 & 0.94 & 0.94 & 0.94 & 1.00 & 0.89 & 1.43 & 1.43 & 0.94 & 0.94 & 0.55 & 0.58 & 0.58 & 1.18 & 0.58 & 0.55 & 0.58 & 0.80 & 0.80 & 1.00 & 0.94 & 0.94 & 1.00 & 0.94 & 1.24 & 0.94 & 1.43 \\
\hline Central America & 1.32 & 1.32 & 1.32 & 1.32 & 1.00 & 1.34 & 2.01 & 2.01 & 1.32 & 1.32 & 0.78 & 0.20 & 0.20 & 0.59 & 0.20 & 0.15 & 0.20 & 1.20 & 1.20 & 1.00 & 1.32 & 1.32 & 1.00 & 1.32 & 1.24 & 1.32 & 2.01 \\
\hline South America & 1.16 & 1.16 & 1.16 & 1.16 & 1.00 & 1.23 & 1.76 & 1.76 & 1.17 & 1.16 & 0.69 & 0.16 & 0.16 & 0.44 & 0.16 & 0.13 & 0.16 & 1.18 & 1.18 & 1.00 & 1.16 & 1.16 & 1.00 & 1.16 & 1.12 & 1.17 & 1.76 \\
\hline Northern Africa & 0.30 & 0.31 & 0.30 & 0.30 & 1.00 & 0.16 & 0.41 & 0.41 & 0.31 & 0.30 & 0.18 & 1.02 & 1.02 & 2.96 & 1.02 & 0.78 & 1.02 & 0.00 & 0.00 & 1.00 & 0.30 & 0.30 & 1.00 & 0.30 & 1.41 & 0.31 & 0.41 \\
\hline Western Africa & 1.45 & 1.45 & 1.45 & 1.45 & 1.00 & 1.67 & 2.20 & 2.20 & 1.45 & 1.45 & 0.86 & 0.15 & 0.15 & 0.32 & 0.15 & 0.14 & 0.15 & 1.44 & 1.44 & 1.00 & 1.45 & 1.45 & 1.00 & 1.45 & 1.22 & 1.45 & 2.20 \\
\hline Eastern Africa & 1.65 & 1.65 & 1.65 & 1.65 & 1.00 & 1.85 & 2.50 & 2.50 & 1.65 & 1.65 & 0.97 & 0.84 & 0.84 & 1.86 & 0.84 & 0.75 & 0.84 & 1.71 & 1.71 & 1.00 & 1.65 & 1.65 & 1.00 & 1.65 & 1.49 & 1.65 & 2.50 \\
\hline Southern Africa & 1.06 & 1.06 & 1.06 & 1.06 & 1.00 & 1.20 & 1.61 & 1.61 & 1.06 & 1.06 & 0.63 & 0.17 & 0.17 & 0.43 & 0.17 & 0.13 & 0.17 & 1.08 & 1.08 & 1.00 & 1.06 & 1.06 & 1.00 & 1.06 & 1.09 & 1.06 & 1.61 \\
\hline OECD Europe & 0.63 & 0.64 & 0.63 & 0.63 & 1.00 & 0.61 & 0.94 & 0.94 & 0.64 & 0.63 & 0.37 & 1.45 & 1.45 & 3.04 & 1.45 & 1.41 & 1.45 & 0.75 & 0.75 & 1.00 & 0.63 & 0.63 & 1.00 & 0.63 & 0.91 & 0.64 & 0.94 \\
\hline Eastern Europe & 0.74 & 0.74 & 0.74 & 0.74 & 1.00 & 0.60 & 1.22 & 1.22 & 0.74 & 0.74 & 0.44 & 0.89 & 0.89 & 1.82 & 0.89 & 0.80 & 0.89 & 1.00 & 1.00 & 1.00 & 0.74 & 0.74 & 1.00 & 0.74 & 1.22 & 0.74 & 1.22 \\
\hline Former USSR & 0.93 & 0.93 & 0.93 & 0.93 & 1.00 & 0.37 & 1.40 & 1.40 & 0.93 & 0.93 & 0.55 & 3.32 & 3.32 & 6.73 & 3.32 & 3.03 & 3.32 & 0.75 & 0.75 & 1.00 & 0.93 & 0.93 & 1.00 & 0.93 & 0.90 & 0.93 & 1.40 \\
\hline Middle East & 0.26 & 0.26 & 0.26 & 0.26 & 1.00 & 0.30 & 0.38 & 0.38 & 0.26 & 0.26 & 0.15 & 0.00 & 0.00 & 0.00 & 0.00 & 0.00 & 0.00 & 0.00 & 0.00 & 1.00 & 0.26 & 0.26 & 1.00 & 0.26 & 1.00 & 0.26 & 0.38 \\
\hline South Asia & 0.93 & 0.93 & 0.93 & 0.93 & 1.00 & 1.04 & 1.41 & 1.41 & 0.93 & 0.93 & 0.55 & 0.20 & 0.20 & 0.38 & 0.20 & 0.20 & 0.20 & 0.92 & 0.92 & 1.00 & 0.93 & 0.93 & 1.00 & 0.93 & 0.74 & 0.93 & 1.41 \\
\hline East Asia & 0.68 & 0.68 & 0.68 & 0.68 & 1.00 & 0.64 & 1.03 & 1.03 & 0.68 & 0.68 & 0.40 & 0.44 & 0.44 & 0.74 & 0.44 & 0.46 & 0.44 & 0.67 & 0.67 & 1.00 & 0.68 & 0.68 & 1.00 & 0.68 & 0.61 & 0.68 & 1.03 \\
\hline Southeast Asia & 0.90 & 0.90 & 0.90 & 0.90 & 1.00 & 0.96 & 1.37 & 1.37 & 0.90 & 0.90 & 0.53 & 0.18 & 0.18 & 0.35 & 0.18 & 0.18 & 0.18 & 0.90 & 0.90 & 1.00 & 0.90 & 0.90 & 1.00 & 0.90 & 0.71 & 0.90 & 1.37 \\
\hline Oceania & 0.68 & 0.69 & 0.68 & 0.68 & 1.00 & 0.74 & 1.09 & 1.09 & 0.69 & 0.68 & 0.40 & 0.99 & 0.99 & 1.07 & 0.99 & 1.27 & 0.99 & 1.00 & 1.00 & 1.00 & 0.68 & 0.68 & 1.00 & 0.68 & 1.05 & 0.69 & 1.09 \\
\hline Japan & 0.56 & 0.58 & 0.56 & 0.56 & 1.00 & 0.90 & 0.76 & 0.76 & 0.57 & 0.56 & 0.33 & 0.69 & 1.00 & 1.00 & 1.00 & 3.76 & 1.00 & 0.00 & 0.00 & 1.00 & 0.56 & 0.56 & 1.00 & 0.56 & 1.00 & 0.58 & 0.76 \\
\hline World & 0.98 & 0.98 & 0.98 & 0.98 & 1.00 & 1.05 & 1.49 & 1.49 & 0.98 & 0.98 & 0.58 & 0.38 & 0.41 & 0.82 & 0.41 & 0.40 & 0.41 & 0.97 & 0.97 & 1.00 & 0.98 & 0.98 & 1.00 & $\mathrm{~N} / \mathrm{A}$ & 0.89 & 0.98 & N/A \\
\hline \multicolumn{28}{|c|}{ Residential Fossil } \\
\hline Canada & 0.52 & 1.01 & 9.92 & 0.52 & 1.00 & 1.00 & 1.59 & 1.59 & 1.20 & 1.83 & 0.59 & 0.16 & 0.21 & 0.28 & 0.16 & 0.14 & 0.16 & 0.18 & 0.18 & 1.00 & 0.99 & 1.77 & 0.52 & 9.92 & 1.06 & 1.19 & 1.00 \\
\hline USA & 0.48 & 0.93 & 9.73 & 0.48 & 1.00 & 1.00 & 1.47 & 1.47 & 1.15 & 1.75 & 0.54 & 0.09 & 0.14 & 0.28 & 0.09 & 0.08 & 0.09 & 0.13 & 0.13 & 1.00 & 0.91 & 1.68 & 0.48 & 9.73 & 0.97 & 1.15 & 1.21 \\
\hline Central America & 1.89 & 7.93 & 23.83 & 1.89 & 1.00 & 1.00 & 6.63 & 6.63 & 4.45 & 12.92 & 3.98 & 1.34 & 2.48 & 3.67 & 1.34 & 1.46 & 1.34 & 3.00 & 3.00 & 1.00 & 11.71 & 12.80 & 1.89 & 23.83 & 3.35 & 4.23 & 4.00 \\
\hline South America & 1.79 & 3.69 & 6.17 & 1.79 & 1.00 & 1.00 & 8.57 & 8.57 & 3.99 & 4.35 & 2.46 & 1.21 & 1.73 & 2.34 & 1.21 & 1.46 & 1.21 & 1.93 & 1.93 & 1.00 & 4.02 & 4.32 & 1.79 & 6.17 & 5.56 & 3.98 & 4.00 \\
\hline Northern Africa & 3.57 & 7.11 & 100.00 & 3.57 & 1.00 & 1.00 & 10.39 & 10.39 & 6.08 & 14.63 & 5.43 & 0.21 & 0.74 & 2.10 & 0.21 & 0.42 & 0.21 & 3.08 & 3.08 & 1.00 & 11.65 & 14.33 & 3.57 & 100.00 & 5.93 & 5.88 & 4.50 \\
\hline Western Africa & 28.03 & 71.68 & 100.00 & 28.03 & 1.00 & 1.00 & 89.81 & 89.81 & 54.44 & 100.00 & 56.52 & 3.35 & 7.25 & 14.14 & 3.35 & 3.41 & 3.35 & 18.08 & 18.08 & 1.00 & 100.00 & 100.00 & 28.03 & 100.00 & 37.50 & 52.04 & 1.00 \\
\hline Eastern Africa & 50.09 & 100.00 & 100.00 & 50.09 & 1.00 & 1.00 & 100.00 & 100.00 & 90.07 & 100.00 & 88.75 & 3.09 & 6.58 & 16.46 & 3.09 & 2.50 & 3.09 & 28.30 & 28.30 & 1.00 & 100.00 & 100.00 & 50.09 & 100.00 & 55.00 & 86.78 & 1.00 \\
\hline Southern Africa & 15.85 & 4.57 & 100.00 & 15.85 & 1.00 & 1.00 & 21.91 & 21.91 & 4.92 & 4.46 & 3.46 & 0.62 & 1.72 & 9.02 & 0.62 & 0.59 & 0.62 & 3.29 & 3.29 & 1.00 & 4.48 & 4.44 & 15.85 & 100.00 & 17.93 & 5.01 & 12.00 \\
\hline OECD Europe & 0.49 & 0.46 & 9.49 & 0.49 & 1.00 & 1.00 & 1.34 & 1.34 & 0.70 & 0.45 & 0.43 & 0.14 & 0.15 & 0.18 & 0.14 & 0.12 & 0.14 & 0.08 & 0.08 & 1.00 & 0.45 & 0.42 & 0.49 & 9.49 & 1.04 & 0.71 & 0.90 \\
\hline Eastern Europe & 0.66 & 0.16 & 7.27 & 0.66 & 1.00 & 1.00 & 2.96 & 2.96 & 0.25 & 0.15 & 0.14 & 0.02 & 0.03 & 0.04 & 0.02 & 0.01 & 0.02 & 0.06 & 0.06 & 1.00 & 0.15 & 0.15 & 0.66 & 7.27 & 1.64 & 0.26 & 0.80 \\
\hline Former USSR & 0.51 & 0.18 & 4.39 & 0.51 & 1.00 & 1.00 & 2.06 & 2.06 & 0.35 & 0.17 & 0.18 & 0.02 & 0.02 & 0.03 & 0.02 & 0.02 & 0.02 & 0.04 & 0.04 & 1.00 & 0.18 & 0.17 & 0.51 & 4.39 & 1.43 & 0.38 & 0.85 \\
\hline Middle East & 0.80 & 0.50 & 100.00 & 0.80 & 1.00 & 1.00 & 3.65 & 3.65 & 0.99 & 0.41 & 0.55 & 0.46 & 0.40 & 0.64 & 0.46 & 0.14 & 0.46 & 0.20 & 0.20 & 1.00 & 0.47 & 0.40 & 0.80 & 100.00 & 0.60 & 1.05 & 1.11 \\
\hline South Asia & 4.44 & 3.49 & 54.82 & 4.44 & 1.00 & 1.00 & 19.57 & 19.57 & 5.41 & 3.19 & 3.36 & 1.22 & 1.93 & 2.58 & 1.22 & 1.50 & 1.22 & 1.55 & 1.55 & 1.00 & 3.39 & 3.10 & 4.44 & 54.82 & 9.54 & 5.64 & 7.00 \\
\hline East Asia & 2.64 & 0.48 & 45.55 & 2.64 & 1.00 & 1.00 & 3.94 & 3.94 & 0.56 & 0.46 & 0.37 & 0.08 & 0.19 & 0.44 & 0.08 & 0.10 & 0.08 & 0.23 & 0.23 & 1.00 & 0.46 & 0.46 & 2.64 & 45.55 & 2.34 & 0.58 & 1.53 \\
\hline Southeast Asia & 1.93 & 2.92 & 61.55 & 1.93 & 1.00 & 1.00 & 9.02 & 9.02 & 3.72 & 3.63 & 2.61 & 0.31 & 0.65 & 1.29 & 0.31 & 0.36 & 0.31 & 0.84 & 0.84 & 1.00 & 3.71 & 3.53 & 1.93 & 61.55 & 5.29 & 3.73 & 4.00 \\
\hline Oceania & 0.66 & 0.42 & 7.74 & 0.66 & 1.00 & 1.00 & 1.49 & 1.49 & 0.68 & 0.38 & 0.40 & 0.03 & 0.06 & 0.16 & 0.03 & 0.03 & 0.03 & 0.11 & 0.11 & 1.00 & 0.40 & 0.37 & 0.66 & 7.74 & 1.63 & 0.72 & 1.00 \\
\hline Japan & 0.57 & 0.79 & 17.74 & 0.57 & 1.00 & 1.00 & 1.21 & 1.21 & 0.82 & 1.05 & 0.80 & 0.34 & 0.32 & 0.33 & 0.34 & 0.34 & 0.34 & 0.08 & 0.08 & 1.00 & 1.09 & 0.91 & 0.57 & 17.74 & 0.87 & 0.81 & 0.83 \\
\hline World & 1.20 & 0.64 & 22.27 & 1.21 & 1.00 & 1.00 & 3.55 & 3.55 & 0.86 & 0.60 & 0.54 & 0.38 & 0.80 & 1.56 & 0.33 & 0.41 & 0.33 & 0.28 & 0.28 & 1.00 & 0.61 & 0.59 & N/A & $\mathrm{N} / \mathrm{A}$ & 2.08 & 0.90 & 1.93 \\
\hline
\end{tabular}


Table A-3 (continued)

Growth Factors by Region from 2000 Base Case to 2050 A1B

\begin{tabular}{|c|c|c|c|c|c|c|c|c|c|c|c|c|c|c|c|c|c|c|c|c|c|c|c|c|c|c|c|}
\hline & ALD2 & co & ETH & FORM & ISOP & $\mathrm{NH3}$ & NO & NO2 & NR & OLE & PAR & PEC & PMC & PMFINE & $\mathrm{PNO}_{3}$ & POA & PSO4 & so2 & SULF & TERPB & TOL & XYL & KET & ALC & $\mathrm{CO} 2$ & $\mathrm{CH} 4$ & N2O \\
\hline \multicolumn{28}{|l|}{ Industry } \\
\hline Canada & 0.77 & 1.23 & 0.79 & 0.66 & 1.00 & 1.00 & 1.59 & 1.59 & 0.78 & 0.82 & 0.49 & 0.91 & 1.09 & 1.09 & 1.09 & 1.36 & 1.09 & 0.35 & 0.35 & 1.00 & 0.79 & 0.82 & 0.82 & 0.79 & 0.66 & 0.84 & 0.29 \\
\hline USA & 0.90 & 1.02 & 0.91 & 0.74 & 1.00 & 1.00 & 1.62 & 1.62 & 0.37 & 0.91 & 0.48 & 0.74 & 1.86 & 1.86 & 1.86 & 3.73 & 1.86 & 0.24 & 0.24 & 1.00 & 0.90 & 0.91 & 0.91 & 0.91 & 0.64 & 0.37 & 0.28 \\
\hline Central America & 0.90 & 3.78 & 0.90 & 1.26 & 1.00 & 1.00 & 4.26 & 4.26 & 1.86 & 1.08 & 1.14 & 2.14 & 0.86 & 0.86 & 0.86 & 0.48 & 0.86 & 2.28 & 2.28 & 1.00 & 0.97 & 1.08 & 1.08 & 0.90 & 1.83 & 2.04 & 1.82 \\
\hline South America & 1.00 & 3.57 & 1.00 & 1.33 & 1.00 & 1.00 & 4.85 & 4.85 & 4.57 & 1.10 & 3.86 & 1.10 & 0.40 & 0.40 & 0.40 & 0.25 & 0.40 & 9.60 & 9.60 & 1.00 & 1.03 & 1.10 & 1.10 & 1.00 & 2.01 & 4.66 & 2.44 \\
\hline Northern Africa & 2.02 & 10.82 & 1.69 & 3.77 & 1.00 & 1.00 & 8.96 & 8.96 & 1.95 & 2.99 & 1.12 & 2.04 & 2.84 & 2.84 & 2.84 & 3.81 & 2.84 & 8.65 & 8.65 & 1.00 & 2.42 & 2.34 & 2.34 & 1.69 & 4.42 & 2.15 & 4.56 \\
\hline Western Africa & 4.82 & 12.03 & 3.59 & 5.64 & 1.00 & 1.00 & 19.41 & 19.41 & 7.84 & 4.83 & 3.17 & 1.81 & 0.49 & 0.49 & 0.49 & 0.30 & 0.49 & 10.66 & 10.66 & 1.00 & 4.83 & 4.82 & 4.82 & 3.59 & 6.68 & 14.20 & 9.80 \\
\hline Eastern Africa & 5.21 & 35.20 & 3.82 & 7.46 & 1.00 & 1.00 & 24.66 & 24.66 & 100.00 & 5.47 & 8.29 & 5.00 & 2.08 & 2.08 & 2.08 & 1.32 & 2.08 & 10.20 & 10.20 & 1.00 & 5.23 & 5.26 & 5.26 & 3.82 & 15.45 & 100.00 & 15.40 \\
\hline Southern Africa & 1.29 & 4.15 & 1.19 & 1.57 & 1.00 & 1.00 & 4.74 & 4.74 & 12.91 & 2.20 & 10.59 & 1.78 & 1.19 & 1.19 & 1.19 & 1.03 & 1.19 & 9.50 & 9.50 & 1.00 & 1.68 & 1.84 & 1.84 & 1.19 & 2.71 & 12.90 & 3.27 \\
\hline OECD Europe & 0.73 & 0.76 & 0.79 & 0.61 & 1.00 & 1.00 & 1.21 & 1.21 & 0.83 & 0.78 & 0.92 & 0.72 & 0.80 & 0.80 & 0.80 & 0.95 & 0.80 & 0.40 & 0.40 & 1.00 & 0.74 & 0.76 & 0.76 & 0.79 & 0.54 & 0.79 & 0.25 \\
\hline Eastern Europe & 0.49 & 1.20 & 0.49 & 0.71 & 1.00 & 1.00 & 2.42 & 2.42 & 0.40 & 0.55 & 1.08 & 1.45 & 1.33 & 1.33 & 1.33 & 1.19 & 1.33 & 0.27 & 0.27 & 1.00 & 0.54 & 0.57 & 0.57 & 0.49 & 1.23 & 0.39 & 0.57 \\
\hline Former USSR & 0.52 & 1.84 & 0.56 & 0.69 & 1.00 & 1.00 & 2.93 & 2.93 & 2.21 & 0.61 & 1.40 & 1.34 & 1.36 & 1.36 & 1.36 & 1.40 & 1.36 & 0.70 & 0.70 & 1.00 & 0.60 & 0.60 & 0.60 & 0.56 & 1.47 & 2.23 & 0.96 \\
\hline Middle East & 1.48 & 5.89 & 1.47 & 1.31 & 1.00 & 1.00 & 6.22 & 6.22 & 7.17 & 1.67 & 2.56 & 5.20 & 4.72 & 4.72 & 4.72 & 4.07 & 4.72 & 1.37 & 1.37 & 1.00 & 1.93 & 1.63 & 1.63 & 1.47 & 2.89 & 7.60 & 1.89 \\
\hline South Asia & 2.52 & 7.94 & 2.34 & 6.56 & 1.00 & 1.00 & 10.12 & 10.12 & 2.39 & 3.19 & 2.47 & 7.31 & 2.66 & 2.66 & 2.66 & 1.21 & 2.66 & 2.94 & 2.94 & 1.00 & 2.82 & 2.79 & 2.79 & 2.34 & 6.24 & 2.37 & 5.40 \\
\hline East Asia & 0.66 & 1.67 & 0.68 & 1.81 & 1.00 & 1.00 & 2.54 & 2.54 & 2.21 & 0.99 & 4.09 & 0.79 & 0.66 & 0.66 & 0.66 & 0.52 & 0.66 & 1.03 & 1.03 & 1.00 & 0.83 & 0.90 & 0.90 & 0.68 & 1.62 & 2.03 & 2.96 \\
\hline Southeast Asia & 1.74 & 6.34 & 1.72 & 2.18 & 1.00 & 1.00 & 5.26 & 5.26 & 2.19 & 1.90 & 1.44 & 1.33 & 0.95 & 0.95 & 0.95 & 0.73 & 0.95 & 2.37 & 2.37 & 1.00 & 1.86 & 1.89 & 1.89 & 1.72 & 2.34 & 2.24 & 5.30 \\
\hline Oceania & 0.66 & 0.58 & 0.76 & 0.68 & 1.00 & 1.00 & 1.23 & 1.23 & 1.85 & 0.80 & 0.42 & 0.65 & 0.80 & 0.80 & 0.80 & 0.99 & 0.80 & 1.18 & 1.18 & 1.00 & 0.68 & 0.72 & 0.72 & 0.76 & 0.81 & 1.92 & 0.74 \\
\hline Japan & 0.83 & 0.67 & 0.85 & 0.61 & 1.00 & 1.00 & 1.01 & 1.01 & 0.30 & 0.82 & 0.81 & 0.25 & 0.33 & 0.33 & 0.33 & 0.47 & 0.33 & 0.19 & 0.19 & 1.00 & 0.83 & 0.84 & 0.84 & 0.85 & 0.47 & 0.29 & 0.29 \\
\hline World & 0.85 & 2.00 & 0.88 & 1.24 & 1.00 & 1.00 & 3.15 & 3.15 & 2.42 & 1.04 & 2.01 & 1.68 & 1.17 & 1.11 & 1.12 & 0.81 & 1.12 & 1.84 & 1.84 & 1.00 & 1.07 & 1.08 & N/A & N/A & 1.70 & 2.41 & 0.93 \\
\hline \multicolumn{28}{|l|}{ Transportation } \\
\hline Canada & 0.30 & 0.43 & 0.30 & 1.06 & 1.00 & 1.00 & 0.68 & 0.68 & 0.85 & 0.30 & 0.41 & 0.49 & 0.54 & 0.54 & 1.00 & 0.59 & 0.54 & 0.14 & 0.14 & 1.00 & 0.33 & 0.30 & 1.00 & 0.30 & 1.28 & 1.33 & 0.82 \\
\hline USA & 0.24 & 0.37 & 0.25 & 1.61 & 1.00 & 1.00 & 0.56 & 0.56 & 0.83 & 0.25 & 0.44 & 0.44 & 0.43 & 0.43 & 1.00 & 0.43 & 0.43 & 0.12 & 0.12 & 1.00 & 0.29 & 0.25 & 1.00 & 0.25 & 1.09 & 1.09 & 0.67 \\
\hline Central America & 0.56 & 0.70 & 0.57 & 1.79 & 1.00 & 1.00 & 1.56 & 1.56 & 2.40 & 0.59 & 0.74 & 2.06 & 0.97 & 0.97 & 1.00 & 0.58 & 0.97 & 2.32 & 2.32 & 1.00 & 0.61 & 0.57 & 1.00 & 0.57 & 4.20 & 4.77 & 15.56 \\
\hline South America & 0.54 & 0.68 & 0.55 & 1.72 & 1.00 & 1.00 & 1.32 & 1.32 & 2.32 & 0.57 & 0.71 & 1.13 & 0.84 & 0.84 & 1.00 & 0.61 & 0.84 & 1.92 & 1.92 & 1.00 & 0.59 & 0.55 & 1.00 & 0.55 & 3.65 & 4.49 & 13.06 \\
\hline Northern Africa & 4.04 & 4.43 & 4.08 & 7.55 & 1.00 & 1.00 & 8.02 & 8.02 & 7.72 & 4.14 & 4.42 & 7.44 & 2.89 & 2.89 & 1.00 & 1.42 & 2.89 & 7.02 & 7.02 & 1.00 & 4.18 & 4.08 & 1.00 & 4.08 & 14.00 & 12.84 & 39.67 \\
\hline Western Africa & 3.57 & 4.31 & 3.62 & 10.78 & 1.00 & 1.00 & 8.02 & 8.02 & 8.04 & 3.68 & 4.48 & 7.67 & 2.81 & 2.81 & 1.00 & 1.47 & 2.81 & 6.72 & 6.72 & 1.00 & 3.83 & 3.61 & 1.00 & 3.61 & 12.89 & 13.82 & 56.00 \\
\hline Eastern Africa & 7.99 & 9.53 & 8.08 & 23.20 & 1.00 & 1.00 & 17.03 & 17.03 & 17.69 & 8.20 & 9.83 & 17.77 & 10.14 & 10.14 & 1.00 & 5.71 & 10.14 & 14.13 & 14.13 & 1.00 & 8.52 & 8.07 & 1.00 & 8.07 & 26.00 & 30.26 & 76.00 \\
\hline Southern Africa & 2.23 & 2.69 & 2.26 & 6.51 & 1.00 & 1.00 & 5.21 & 5.21 & 5.00 & 2.31 & 2.81 & 5.45 & 2.10 & 2.10 & 1.00 & 1.06 & 2.10 & 4.13 & 4.13 & 1.00 & 2.39 & 2.26 & 1.00 & 2.26 & 7.86 & 8.59 & 34.33 \\
\hline OECD Europe & 0.35 & 0.48 & 0.35 & 1.25 & 1.00 & 1.00 & 0.71 & 0.71 & 1.03 & 0.35 & 0.45 & 0.44 & 0.38 & 0.38 & 1.00 & 0.30 & 0.38 & 0.17 & 0.17 & 1.00 & 0.37 & 0.35 & 1.00 & 0.35 & 1.40 & 1.73 & 1.72 \\
\hline Eastern Europe & 0.42 & 0.50 & 0.43 & 1.13 & 1.00 & 1.00 & 1.13 & 1.13 & 2.09 & 0.44 & 0.53 & 1.42 & 1.33 & 1.33 & 1.00 & 1.21 & 1.33 & 0.37 & 0.37 & 1.00 & 0.45 & 0.43 & 1.00 & 0.43 & 4.15 & 4.84 & 14.75 \\
\hline Former USSR & 0.93 & 1.14 & 0.97 & 2.89 & 1.00 & 1.00 & 2.65 & 2.65 & 3.87 & 1.01 & 1.30 & 1.94 & 2.20 & 2.20 & 1.00 & 2.67 & 2.20 & 0.74 & 0.74 & 1.00 & 1.03 & 0.96 & 1.00 & 0.96 & 6.15 & 6.41 & 20.78 \\
\hline Middle East & 0.84 & 0.92 & 0.84 & 1.71 & 1.00 & 1.00 & 1.62 & 1.62 & 2.69 & 0.84 & 0.91 & 1.31 & 0.60 & 0.60 & 1.00 & 0.28 & 0.60 & 1.91 & 1.91 & 1.00 & 0.87 & 0.84 & 1.00 & 0.84 & 5.44 & 5.08 & 16.64 \\
\hline South Asia & 2.99 & 3.23 & 2.95 & 6.50 & 1.00 & 1.00 & 3.29 & 3.29 & 6.75 & 2.91 & 3.13 & 2.06 & 1.92 & 1.92 & 1.00 & 1.75 & 1.92 & 2.61 & 2.61 & 1.00 & 3.06 & 2.96 & 1.00 & 2.96 & 9.21 & 15.75 & 36.20 \\
\hline East Asia & 0.75 & 0.93 & 0.80 & 2.53 & 1.00 & 1.00 & 1.99 & 1.99 & 2.65 & 0.86 & 1.10 & 2.24 & 1.93 & 1.93 & 1.00 & 1.60 & 1.93 & 1.44 & 1.44 & 1.00 & 0.85 & 0.79 & 1.00 & 0.79 & 4.27 & 4.90 & 19.19 \\
\hline Southeast Asia & 1.10 & 1.32 & 1.11 & 2.58 & 1.00 & 1.00 & 2.14 & 2.14 & 2.69 & 1.12 & 1.27 & 2.30 & 1.25 & 1.25 & 1.00 & 0.71 & 1.25 & 1.81 & 1.81 & 1.00 & 1.15 & 1.11 & 1.00 & 1.11 & 5.10 & 6.34 & 23.90 \\
\hline Oceania & 0.29 & 0.38 & 0.29 & 0.80 & 1.00 & 1.00 & 0.63 & 0.63 & 0.74 & 0.29 & 0.35 & 0.97 & 0.88 & 0.88 & 1.00 & 0.73 & 0.88 & 0.26 & 0.26 & 1.00 & 0.30 & 0.29 & 1.00 & 0.29 & 1.24 & 1.28 & 0.79 \\
\hline Japan & 0.47 & 0.71 & 0.46 & 1.61 & 1.00 & 1.00 & 0.74 & 0.74 & 0.83 & 0.45 & 0.57 & 0.26 & 0.23 & 0.23 & 1.00 & 0.19 & 0.23 & 0.12 & 0.12 & 1.00 & 0.50 & 0.46 & 1.00 & 0.46 & 1.00 & 1.13 & 0.73 \\
\hline World & 0.75 & 0.88 & 0.75 & 2.20 & 1.00 & 1.00 & 1.32 & 1.32 & 1.91 & 0.77 & 0.94 & 1.48 & 1.10 & 1.10 & 1.00 & 0.79 & 1.10 & 1.30 & 1.30 & 1.00 & 0.80 & 0.75 & 1.00 & N/A & 2.80 & 2.97 & 3.12 \\
\hline
\end{tabular}


Table A-3 (continued)

Growth Factors by Region from 2000 Base Case to 2050 A1B

\begin{tabular}{|c|c|c|c|c|c|c|c|c|c|c|c|c|c|c|c|c|c|c|c|c|c|c|c|c|c|c|c|}
\hline & ALD2 & Co & ETH & FORM & ISOP & $\mathrm{NH3}$ & NO & NO2 & NR & OLE & PAR & PEC & PMC & PMFINE & PNO3 & POA & PSO4 & SO2 & SULF & TERPB & TOL & XYL & KET & ALC & $\mathrm{CO} 2$ & $\mathrm{CH} 4$ & $\mathrm{~N} 2 \mathrm{O}$ \\
\hline \multicolumn{28}{|l|}{ Power } \\
\hline Canada & 3.07 & 1.92 & 1.00 & 3.07 & 1.00 & 1.00 & 1.25 & 1.25 & 2.81 & 1.23 & 2.90 & 0.17 & 0.08 & 0.08 & 1.00 & 0.05 & 0.08 & 0.25 & 0.25 & 1.00 & 2.10 & 1.23 & 3.07 & 1.00 & 1.87 & 1.00 & 1.42 \\
\hline USA & 2.34 & 1.54 & 1.00 & 2.34 & 1.00 & 1.00 & 1.05 & 1.05 & 1.62 & 1.26 & 1.72 & 0.09 & 0.05 & 0.05 & 1.00 & 0.04 & 0.05 & 0.27 & 0.27 & 1.00 & 1.42 & 1.26 & 2.34 & 1.00 & 1.57 & 1.00 & 1.40 \\
\hline Central America & 5.34 & 8.82 & 1.00 & 5.34 & 1.00 & 1.00 & 7.89 & 7.89 & 17.63 & 16.13 & 12.01 & 4.56 & 3.32 & 3.32 & 1.00 & 2.52 & 3.32 & 1.31 & 1.31 & 1.00 & 17.40 & 16.13 & 5.34 & 1.00 & 8.30 & 1.00 & 7.33 \\
\hline South America & 17.12 & 17.35 & 1.00 & 17.12 & 1.00 & 1.00 & 18.07 & 18.07 & 17.89 & 16.61 & 17.65 & 1.46 & 0.65 & 0.65 & 1.00 & 0.41 & 0.65 & 4.49 & 4.49 & 1.00 & 17.69 & 16.61 & 17.12 & 1.00 & 20.26 & 1.00 & 19.25 \\
\hline Northern Africa & 8.99 & 12.24 & 1.00 & 8.99 & 1.00 & 1.00 & 13.05 & 13.05 & 13.18 & 42.97 & 12.12 & 5.65 & 5.49 & 5.49 & 1.00 & 6.74 & 5.49 & 6.20 & 6.20 & 1.00 & 14.47 & 42.97 & 8.99 & 1.00 & 13.75 & 1.00 & 14.00 \\
\hline Western Africa & 36.30 & 45.60 & 1.00 & 36.30 & 1.00 & 1.00 & 41.83 & 41.83 & 52.60 & 100.00 & 48.09 & 13.65 & 13.38 & 13.38 & 1.00 & 16.67 & 13.38 & 15.17 & 15.17 & 1.00 & 54.30 & 100.00 & 36.30 & 1.00 & 46.53 & 1.00 & 1.00 \\
\hline Eastern Africa & 59.23 & 100.00 & 1.00 & 59.23 & 1.00 & 1.00 & 89.13 & 89.13 & 100.00 & 100.00 & 100.00 & 45.00 & 41.88 & 41.88 & 1.00 & 45.94 & 41.88 & 41.46 & 41.46 & 1.00 & 100.00 & 100.00 & 59.23 & 1.00 & 100.00 & 1.00 & 1.00 \\
\hline Southern Africa & 100.00 & 6.88 & 1.00 & 100.00 & 1.00 & 1.00 & 6.28 & 6.28 & 9.63 & 5.84 & 11.29 & 0.05 & 0.05 & 0.05 & 1.00 & 0.04 & 0.05 & 4.98 & 4.98 & 1.00 & 6.79 & 5.84 & 100.00 & 1.00 & 7.25 & 1.00 & 6.28 \\
\hline OECD Europe & 2.38 & 2.05 & 1.00 & 2.38 & 1.00 & 1.00 & 1.72 & 1.72 & 2.57 & 1.63 & 2.57 & 0.61 & 0.36 & 0.36 & 1.00 & 0.24 & 0.36 & 0.43 & 0.43 & 1.00 & 2.08 & 1.63 & 2.38 & 1.00 & 2.25 & 1.00 & 1.84 \\
\hline Eastern Europe & 4.58 & 2.71 & 1.00 & 4.58 & 1.00 & 1.00 & 4.19 & 4.19 & 4.70 & 1.93 & 4.85 & 0.79 & 0.78 & 0.78 & 1.00 & 0.96 & 0.78 & 0.23 & 0.23 & 1.00 & 3.11 & 1.93 & 4.58 & 1.00 & 2.87 & 1.00 & 2.24 \\
\hline Former USSR & 2.23 & 2.49 & 1.00 & 2.23 & 1.00 & 1.00 & 1.44 & 1.44 & 2.53 & 2.93 & 2.48 & 0.79 & 0.81 & 0.81 & 1.00 & 1.11 & 0.81 & 0.24 & 0.24 & 1.00 & 2.58 & 2.93 & 2.23 & 1.00 & 2.81 & 1.00 & 2.81 \\
\hline Middle East & 8.48 & 10.17 & 1.00 & 8.48 & 1.00 & 1.00 & 7.06 & 7.06 & 12.44 & 9.60 & 11.57 & 3.39 & 1.66 & 1.66 & 1.00 & 0.98 & 1.66 & 0.75 & 0.75 & 1.00 & 12.23 & 9.60 & 8.48 & 1.00 & 9.71 & 1.00 & 7.54 \\
\hline South Asia & 43.70 & 16.38 & 1.00 & 43.70 & 1.00 & 1.00 & 16.47 & 16.47 & 27.85 & 11.16 & 31.02 & 4.01 & 2.58 & 2.58 & 1.00 & 1.83 & 2.58 & 5.81 & 5.81 & 1.00 & 16.57 & 11.16 & 43.70 & 1.00 & 15.84 & 1.00 & 12.60 \\
\hline East Asia & 17.91 & 5.32 & 1.00 & 17.91 & 1.00 & 1.00 & 4.73 & 4.73 & 12.39 & 2.88 & 14.19 & 0.68 & 0.74 & 0.74 & 1.00 & 1.27 & 0.74 & 0.87 & 0.87 & 1.00 & 5.49 & 2.88 & 17.91 & 1.00 & 5.21 & 1.00 & 3.55 \\
\hline Southeast Asia & 7.90 & 11.60 & 1.00 & 7.90 & 1.00 & 1.00 & 15.33 & 15.33 & 12.39 & 22.17 & 11.25 & 6.76 & 3.33 & 3.33 & 1.00 & 1.97 & 3.33 & 5.52 & 5.52 & 1.00 & 14.04 & 22.17 & 7.90 & 1.00 & 13.19 & 1.00 & 1.00 \\
\hline Oceania & 4.64 & 1.87 & 1.00 & 4.64 & 1.00 & 1.00 & 1.49 & 1.49 & 2.57 & 1.44 & 2.81 & 0.07 & 0.03 & 0.03 & 1.00 & 0.02 & 0.03 & 0.27 & 0.27 & 1.00 & 1.83 & 1.44 & 4.64 & 1.00 & 17.13 & 1.00 & 1.57 \\
\hline Japan & 1.25 & 1.56 & 1.00 & 1.25 & 1.00 & 1.00 & 1.36 & 1.36 & 1.60 & 1.76 & 1.54 & 0.49 & 0.45 & 0.45 & 1.00 & 0.47 & 0.45 & 0.34 & 0.34 & 1.00 & 1.66 & 1.76 & 1.25 & 1.00 & 1.65 & 1.00 & 1.74 \\
\hline World & 14.23 & 4.87 & 1.00 & 5.96 & 1.00 & 1.00 & 4.48 & 4.48 & 5.98 & 3.20 & 6.08 & 1.39 & 0.88 & 0.88 & 1.00 & 0.62 & 0.88 & 1.18 & 1.18 & 1.00 & 4.62 & 3.20 & N/A & 1.00 & 5.21 & 1.00 & 3.76 \\
\hline \multicolumn{28}{|l|}{ Biomass Burning } \\
\hline Canada & 1.19 & 0.03 & 1.19 & 1.19 & 1.00 & 1.16 & 0.04 & 0.04 & 0.03 & 0.02 & 0.01 & 1.19 & 1.19 & 1.19 & 1.19 & 1.12 & 1.19 & 0.03 & 0.03 & 1.00 & 1.19 & 1.19 & 1.19 & 1.19 & 1.17 & 1.08 & 0.04 \\
\hline USA & 1.05 & 0.72 & 1.05 & 1.05 & 1.00 & 1.01 & 0.98 & 0.98 & 0.78 & 0.31 & 0.27 & 1.05 & 1.05 & 1.05 & 1.05 & 0.96 & 1.05 & 0.80 & 0.80 & 1.00 & 1.05 & 1.05 & 1.05 & 1.05 & 1.02 & 1.04 & 0.98 \\
\hline Central America & 0.81 & 0.50 & 0.81 & 0.81 & 1.00 & 0.91 & 1.30 & 1.30 & 0.30 & 0.26 & 0.19 & 0.81 & 0.81 & 0.81 & 0.81 & 0.80 & 0.81 & 0.93 & 0.93 & 1.00 & 0.81 & 0.81 & 0.81 & 0.81 & 0.85 & 0.89 & 1.30 \\
\hline South America & 1.37 & 1.83 & 1.37 & 1.37 & 1.00 & 1.35 & 1.50 & 1.50 & 2.13 & 1.00 & 0.74 & 1.37 & 1.37 & 1.37 & 1.37 & 1.40 & 1.37 & 3.40 & 3.40 & 1.00 & 1.37 & 1.37 & 1.37 & 1.37 & 1.22 & 0.92 & 1.50 \\
\hline Northern Africa & 1.72 & 0.71 & 1.72 & 1.72 & 1.00 & 0.76 & 1.23 & 1.23 & 0.75 & 0.38 & 0.31 & 1.72 & 1.72 & 1.72 & 1.72 & 0.98 & 1.72 & 1.17 & 1.17 & 1.00 & 1.72 & 1.72 & 1.72 & 1.72 & 0.89 & 0.86 & 1.23 \\
\hline Western Africa & 0.78 & 0.62 & 0.78 & 0.78 & 1.00 & 0.82 & 0.47 & 0.47 & 0.72 & 0.36 & 0.26 & 0.78 & 0.78 & 0.78 & 0.78 & 0.79 & 0.78 & 1.15 & 1.15 & 1.00 & 0.78 & 0.78 & 0.78 & 0.78 & 0.77 & 0.79 & 0.47 \\
\hline Eastern Africa & 1.30 & 0.79 & 1.30 & 1.30 & 1.00 & 1.28 & 0.67 & 0.67 & 0.80 & 0.44 & 0.32 & 1.30 & 1.30 & 1.30 & 1.30 & 1.27 & 1.30 & 1.50 & 1.50 & 1.00 & 1.30 & 1.30 & 1.30 & 1.30 & 1.28 & 0.85 & 0.67 \\
\hline Southern Africa & 0.40 & 0.22 & 0.40 & 0.40 & 1.00 & 0.36 & 0.18 & 0.18 & 0.22 & 0.14 & 0.10 & 0.40 & 0.40 & 0.40 & 0.40 & 0.40 & 0.40 & 0.42 & 0.42 & 1.00 & 0.40 & 0.40 & 0.40 & 0.40 & 0.35 & 0.50 & 0.18 \\
\hline OECD Europe & 0.86 & 0.58 & 0.86 & 0.86 & 1.00 & 0.79 & 0.75 & 0.75 & 0.67 & 0.24 & 0.21 & 0.86 & 0.86 & 0.86 & 0.86 & 0.72 & 0.86 & 0.64 & 0.64 & 1.00 & 0.86 & 0.86 & 0.86 & 0.86 & 0.80 & 0.90 & 0.75 \\
\hline Eastern Europe & 0.74 & 0.57 & 0.74 & 0.74 & 1.00 & 0.58 & & & & 0.31 & 0.26 & 0.74 & 0.74 & & & 0.75 & 0.74 & 0.85 & 0.85 & 1.00 & 0.74 & 0.74 & 0.74 & 0.74 & 0.64 & 0.64 & 0.82 \\
\hline Former USSR & 1.04 & 0.07 & 1.04 & 1.04 & 1.00 & 1.00 & 0.10 & 0.10 & 0.07 & 0.04 & 0.03 & 1.04 & 1.04 & 1.04 & 1.04 & 1.04 & 1.04 & 0.08 & 0.08 & 1.00 & 1.04 & 1.04 & 1.04 & 1.04 & 1.00 & 1.02 & 0.10 \\
\hline Middle East & 0.73 & 0.59 & 0.73 & 0.73 & 1.00 & 0.48 & 1.02 & 1.02 & 0.54 & 0.33 & 0.26 & 0.73 & 0.73 & 0.73 & 0.73 & 0.51 & 0.73 & 1.15 & 1.15 & 1.00 & 0.73 & 0.73 & 0.73 & 0.73 & 0.56 & 0.79 & 1.02 \\
\hline South Asia & 1.72 & 0.48 & 1.72 & 1.72 & 1.00 & 1.78 & & & 0.39 & 0.22 & 0.18 & 1.72 & 1.72 & 1.72 & 1.72 & 1.42 & 1.72 & 0.99 & 0.99 & 1.00 & 1.72 & 1.72 & 1.72 & 1.72 & 1.73 & 1.27 & 0.89 \\
\hline East Asia & 1.00 & 0.03 & 1.00 & 1.00 & 1.00 & 0.96 & 0.04 & 0.04 & 0.04 & 0.02 & 0.02 & 1.00 & 1.00 & 1.00 & 1.00 & 0.93 & 1.00 & 0.06 & 0.06 & 1.00 & 1.00 & 1.00 & 1.00 & 1.00 & 0.95 & 0.88 & 0.04 \\
\hline Southeast A & 0.96 & 1.26 & 0.96 & 0.96 & 1.00 & 1.01 & 1.69 & 1.69 & 1.27 & 0.64 & 0.49 & 0.96 & 0.96 & 0.96 & 0.96 & 0.96 & 0.96 & 2.36 & 2.36 & 1.00 & 0.96 & 0.96 & 0.96 & 0.96 & 0.93 & 1.31 & 1.69 \\
\hline Oceania & 1.45 & 0.96 & 1.45 & 1.45 & 1.00 & 1.54 & 0.76 & 0.76 & 1.10 & 0.52 & 0.39 & 1.45 & 1.45 & 1.45 & 1.45 & 1.51 & 1.45 & 1.84 & 1.84 & 1.00 & 1.45 & 1.45 & 1.45 & 1.45 & 1.56 & 1.27 & 0.76 \\
\hline Japan & 2.13 & 2.56 & 2.13 & 2.13 & 1.00 & 1.85 & 2.88 & 2.88 & 3.58 & 1.02 & 0.87 & 2.13 & 2.13 & 2.13 & 2.13 & 1.63 & 2.13 & 6.81 & 6.81 & 1.00 & 2.13 & 2.13 & 2.13 & 2.13 & 1.69 & 1.29 & 2.88 \\
\hline World & 1.03 & 0.86 & 1.04 & 1.06 & 1.00 & 1.02 & 0.73 & 0.73 & 1.00 & 0.45 & 0.34 & 1.02 & 1.03 & 1.03 & 1.02 & 1.00 & 1.02 & 1.51 & 1.51 & 1.00 & 1.01 & 1.02 & N/A & N/A & N/A & 1.46 & N/A \\
\hline
\end{tabular}


Table A-3 (continued)

Growth Factors by Region from 2000 Base Case to 2050 A1B

\begin{tabular}{|c|c|c|c|c|c|c|c|c|c|c|c|c|c|c|c|c|c|c|c|c|c|c|c|c|c|c|c|}
\hline & ALD2 & co & ETH & FORM & ISOP & $\mathrm{NH3}$ & NO & NO2 & NR & OLE & PAR & PEC & PMC & PMFINE & PNO3 & POA & $\begin{array}{ll}\text { PSO4 } \\
\end{array}$ & SO2 & SULF & TERPB & TOL & $\mathrm{XYL}$ & KET & ALC & $\mathrm{CO2}$ & $\mathrm{CH} 4$ & $\mathrm{~N} 2 \mathrm{O}$ \\
\hline \multicolumn{28}{|c|}{ Other Anthropogenic } \\
\hline Canada & 1.00 & 1.00 & 2.42 & 2.42 & 1.00 & 1.05 & 1.00 & 1.00 & 1.00 & 1.00 & 1.00 & 1.00 & 0.92 & 0.92 & 1.00 & 1.00 & 1.00 & 1.00 & 1.00 & 1.00 & 2.42 & 2.42 & 2.42 & 2.42 & 0.60 & 1.28 & 1.09 \\
\hline USA & 1.00 & 1.00 & 2.32 & 2.32 & 1.00 & 1.42 & 1.00 & 1.00 & 1.00 & 1.00 & 1.00 & 1.00 & 0.79 & 0.79 & 1.00 & 1.00 & 1.00 & 1.00 & 1.00 & 1.00 & 2.32 & 2.32 & 2.32 & 2.32 & 0.31 & 1.36 & 1.07 \\
\hline Central America & 1.00 & 1.00 & 9.29 & 9.29 & 1.00 & 1.91 & 1.00 & 1.00 & 1.00 & 1.00 & 1.00 & 1.00 & 3.33 & 3.33 & 1.00 & 1.00 & 1.00 & 1.00 & 1.00 & 1.00 & 9.29 & 9.29 & 9.29 & 9.29 & 0.99 & 1.95 & 1.34 \\
\hline South America & 1.00 & 1.00 & 7.66 & 7.66 & 1.00 & 1.40 & 1.00 & 1.00 & 1.00 & 1.00 & 1.00 & 1.00 & 3.41 & 3.41 & 1.00 & 1.00 & 1.00 & 1.00 & 1.00 & 1.00 & 7.66 & 7.66 & 7.66 & 7.66 & 1.19 & 1.51 & 1.17 \\
\hline Northern Africa & 1.00 & 1.00 & 12.28 & 12.28 & 1.00 & 2.27 & 1.00 & 1.00 & 1.00 & 1.00 & 1.00 & 1.00 & 11.52 & 11.52 & 1.00 & 1.00 & 1.00 & 1.00 & 1.00 & 1.00 & 12.28 & 12.28 & 12.28 & 12.28 & 2.06 & 4.28 & 2.75 \\
\hline Western Africa & 1.00 & 1.00 & 14.19 & 14.19 & 1.00 & 2.99 & 1.00 & 1.00 & 1.00 & 1.00 & 1.00 & 1.00 & 10.29 & 10.29 & 1.00 & 1.00 & 1.00 & 1.00 & 1.00 & 1.00 & 14.19 & 14.19 & 14.19 & 14.19 & 2.30 & 4.80 & 5.87 \\
\hline Eastern Africa & 1.00 & 1.00 & 17.06 & 17.06 & 1.00 & 2.21 & 1.00 & 1.00 & 1.00 & 1.00 & 1.00 & 1.00 & 22.93 & 22.93 & 1.00 & 1.00 & 1.00 & 1.00 & 1.00 & 1.00 & 17.06 & 17.06 & 17.06 & 17.06 & 1.00 & 3.33 & 2.61 \\
\hline Southern Africa & 1.00 & 1.00 & 8.66 & 8.66 & 1.00 & 2.80 & 1.00 & 1.00 & 1.00 & 1.00 & 1.00 & 1.00 & 6.58 & 6.58 & 1.00 & 1.00 & 1.00 & 1.00 & 1.00 & 1.00 & 8.66 & 8.66 & 8.66 & 8.66 & 1.07 & 3.72 & 4.09 \\
\hline OECD Europe & 1.00 & 1.00 & 2.61 & 2.61 & 1.00 & 1.20 & 1.00 & 1.00 & 1.00 & 1.00 & 1.00 & 1.00 & 1.12 & 1.12 & 1.00 & 1.00 & 1.00 & 1.00 & 1.00 & 1.00 & 2.61 & 2.61 & 2.61 & 2.61 & 0.29 & 1.12 & 1.15 \\
\hline Eastern Europe & 1.00 & 1.00 & 12.21 & 12.21 & 1.00 & 1.23 & 1.00 & 1.00 & 1.00 & 1.00 & 1.00 & 1.00 & 3.17 & 3.17 & 1.00 & 1.00 & 1.00 & 1.00 & 1.00 & 1.00 & 12.21 & 12.21 & 12.21 & 12.21 & 0.68 & 1.45 & 1.13 \\
\hline Former USSR & 1.00 & 1.00 & 17.70 & 17.70 & 1.00 & 1.60 & 1.00 & 1.00 & 1.00 & 1.00 & 1.00 & 1.00 & 3.86 & 3.86 & 1.00 & 1.00 & 1.00 & 1.00 & 1.00 & 1.00 & 17.70 & 17.70 & 17.70 & 17.70 & 0.63 & 1.65 & 2.75 \\
\hline Middle East & 1.00 & 1.00 & 7.92 & 7.92 & 1.00 & 3.21 & 1.00 & 1.00 & 1.00 & 1.00 & 1.00 & 1.00 & 4.38 & 4.38 & 1.00 & 1.00 & 1.00 & 1.00 & 1.00 & 1.00 & 7.92 & 7.92 & 7.92 & 7.92 & 0.85 & 4.00 & 2.65 \\
\hline South Asia & 1.00 & 1.00 & 25.56 & 25.56 & 1.00 & 1.30 & 1.00 & 1.00 & 1.00 & 1.00 & 1.00 & 1.00 & 6.57 & 6.57 & 1.00 & 1.00 & 1.00 & 1.00 & 1.00 & 1.00 & 25.56 & 25.56 & 25.56 & 25.56 & 10.00 & 1.57 & 1.43 \\
\hline East Asia & 1.00 & 1.00 & 16.96 & 16.96 & 1.00 & 0.76 & 1.00 & 1.00 & 1.00 & 1.00 & 1.00 & 1.00 & 3.19 & 3.19 & 1.00 & 1.00 & 1.00 & 1.00 & 1.00 & 1.00 & 16.96 & 16.96 & 16.96 & 16.96 & 0.84 & 1.49 & 0.69 \\
\hline Southeast Asia & 1.00 & 1.00 & 12.26 & 12.26 & 1.00 & 2.14 & 1.00 & 1.00 & 1.00 & 1.00 & 1.00 & 1.00 & 4.00 & 4.00 & 1.00 & 1.00 & 1.00 & 1.00 & 1.00 & 1.00 & 12.26 & 12.26 & 12.26 & 12.26 & 0.72 & 1.96 & 2.52 \\
\hline Oceania & 1.00 & 1.00 & 2.53 & 2.53 & 1.00 & 0.86 & 1.00 & 1.00 & 1.00 & 1.00 & 1.00 & 1.00 & 1.00 & 1.00 & 1.00 & 1.00 & 1.00 & 1.00 & 1.00 & 1.00 & 2.53 & 2.53 & 2.53 & 2.53 & 0.65 & 0.74 & 1.73 \\
\hline Japan & 1.00 & 1.00 & 1.91 & 1.91 & 1.00 & 1.96 & 1.00 & 1.00 & 1.00 & 1.00 & 1.00 & 1.00 & 0.75 & 0.75 & 1.00 & 1.00 & 1.00 & 1.00 & 1.00 & 1.00 & 1.91 & 1.91 & 1.91 & 1.91 & 0.40 & 1.38 & 2.03 \\
\hline World & 1.00 & 1.00 & 4.53 & 4.53 & 1.00 & 1.52 & 1.00 & 1.00 & 1.00 & 1.00 & 1.00 & 1.00 & 2.14 & 2.14 & 1.00 & 1.00 & 1.00 & 1.00 & 1.00 & 1.00 & 4.53 & 4.53 & N/A & N/A & 0.71 & 1.77 & 1.49 \\
\hline \multicolumn{28}{|l|}{ Biogenic } \\
\hline Canada & 1.00 & 1.00 & 1.00 & 1.00 & 1.00 & 1.00 & 1.00 & 1.00 & 1.00 & 1.00 & 1.00 & 1.00 & 1.00 & 1.00 & 1.00 & 1.00 & 1.00 & 1.00 & 1.00 & 1.00 & 1.00 & 1.00 & 1.00 & 1.00 & 1.00 & 1.00 & 1.00 \\
\hline USA & 1.00 & 1.00 & 1.00 & 1.00 & 1.00 & 1.00 & 1.00 & 1.00 & 1.00 & 1.00 & 1.00 & 1.00 & 1.00 & 1.00 & 1.00 & 1.00 & 1.00 & 1.00 & 1.00 & 1.00 & 1.00 & 1.00 & 1.00 & 1.00 & 1.00 & 1.00 & 1.00 \\
\hline Central America & 1.00 & 1.00 & 1.00 & 1.00 & 1.00 & 1.00 & 1.00 & 1.00 & 1.00 & 1.00 & 1.00 & 1.00 & 1.00 & 1.00 & 1.00 & 1.00 & 1.00 & 1.00 & 1.00 & 1.00 & 1.00 & 1.00 & 1.00 & 1.00 & 1.00 & 1.00 & 1.00 \\
\hline South America & 1.00 & 1.00 & 1.00 & 1.00 & 1.00 & 1.00 & 1.00 & 1.00 & 1.00 & 1.00 & 1.00 & 1.00 & 1.00 & 1.00 & 1.00 & 1.00 & 1.00 & 1.00 & 1.00 & 1.00 & 1.00 & 1.00 & 1.00 & 1.00 & 1.00 & 1.00 & 1.00 \\
\hline Northern Africa & 1.00 & 1.00 & 1.00 & 1.00 & 1.00 & 1.00 & 1.00 & 1.00 & 1.00 & 1.00 & 1.00 & 1.00 & 1.00 & 1.00 & 1.00 & 1.00 & 1.00 & 1.00 & 1.00 & 1.00 & 1.00 & 1.00 & 1.00 & 1.00 & 1.00 & 1.00 & 1.00 \\
\hline Western Africa & 1.00 & 1.00 & 1.00 & 1.00 & 1.00 & 1.00 & 1.00 & 1.00 & 1.00 & 1.00 & 1.00 & 1.00 & 1.00 & 1.00 & 1.00 & 1.00 & 1.00 & 1.00 & 1.00 & 1.00 & 1.00 & 1.00 & 1.00 & 1.00 & 1.00 & 1.00 & 1.00 \\
\hline Eastern Africa & 1.00 & 1.00 & 1.00 & 1.00 & 1.00 & 1.00 & 1.00 & 1.00 & 1.00 & 1.00 & 1.00 & 1.00 & 1.00 & 1.00 & 1.00 & 1.00 & 1.00 & 1.00 & 1.00 & 1.00 & 1.00 & 1.00 & 1.00 & 1.00 & 1.00 & 1.00 & 1.00 \\
\hline Southern Africa & 1.00 & 1.00 & 1.00 & 1.00 & 1.00 & 1.00 & 1.00 & 1.00 & 1.00 & 1.00 & 1.00 & 1.00 & 1.00 & 1.00 & 1.00 & 1.00 & 1.00 & 1.00 & 1.00 & 1.00 & 1.00 & 1.00 & 1.00 & 1.00 & 1.00 & 1.00 & 1.00 \\
\hline OECD Europe & 1.00 & 1.00 & 1.00 & 1.00 & 1.00 & 1.00 & 1.00 & 1.00 & 1.00 & 1.00 & 1.00 & 1.00 & 1.00 & 1.00 & 1.00 & 1.00 & 1.00 & 1.00 & 1.00 & 1.00 & 1.00 & 1.00 & 1.00 & 1.00 & 1.00 & 1.00 & 1.00 \\
\hline Eastern Europe & 1.00 & 1.00 & 1.00 & 1.00 & 1.00 & 1.00 & 1.00 & 1.00 & 1.00 & 1.00 & 1.00 & 1.00 & 1.00 & 1.00 & 1.00 & 1.00 & 1.00 & 1.00 & 1.00 & 1.00 & 1.00 & 1.00 & 1.00 & 1.00 & 1.00 & 1.00 & 1.00 \\
\hline Former USSR & 1.00 & 1.00 & 1.00 & 1.00 & 1.00 & 1.00 & 1.00 & 1.00 & 1.00 & 1.00 & 1.00 & 1.00 & 1.00 & 1.00 & 1.00 & 1.00 & 1.00 & 1.00 & 1.00 & 1.00 & 1.00 & 1.00 & 1.00 & 1.00 & 1.00 & 1.00 & 1.00 \\
\hline Middle East & 1.00 & 1.00 & 1.00 & 1.00 & 1.00 & 1.00 & 1.00 & 1.00 & 1.00 & 1.00 & 1.00 & 1.00 & 1.00 & 1.00 & 1.00 & 1.00 & 1.00 & 1.00 & 1.00 & 1.00 & 1.00 & 1.00 & 1.00 & 1.00 & 1.00 & 1.00 & 1.00 \\
\hline South Asia & 1.00 & 1.00 & 1.00 & 1.00 & 1.00 & 1.00 & 1.00 & 1.00 & 1.00 & 1.00 & 1.00 & 1.00 & 1.00 & 1.00 & 1.00 & 1.00 & 1.00 & 1.00 & 1.00 & 1.00 & 1.00 & 1.00 & 1.00 & 1.00 & 1.00 & 1.00 & 1.00 \\
\hline East Asia & 1.00 & 1.00 & 1.00 & 1.00 & 1.00 & 1.00 & 1.00 & 1.00 & 1.00 & 1.00 & 1.00 & 1.00 & 1.00 & 1.00 & 1.00 & 1.00 & 1.00 & 1.00 & 1.00 & 1.00 & 1.00 & 1.00 & 1.00 & 1.00 & 1.00 & 1.00 & 1.00 \\
\hline Southeast Asia & 1.00 & 1.00 & 1.00 & 1.00 & 1.00 & 1.00 & 1.00 & 1.00 & 1.00 & 1.00 & 1.00 & 1.00 & 1.00 & 1.00 & 1.00 & 1.00 & 1.00 & 1.00 & 1.00 & 1.00 & 1.00 & 1.00 & 1.00 & 1.00 & 1.00 & 1.00 & 1.00 \\
\hline Oceania & 1.00 & 1.00 & 1.00 & 1.00 & 1.00 & 1.00 & 1.00 & 1.00 & 1.00 & 1.00 & 1.00 & 1.00 & 1.00 & 1.00 & 1.00 & 1.00 & 1.00 & 1.00 & 1.00 & 1.00 & 1.00 & 1.00 & 1.00 & 1.00 & 1.00 & 1.00 & 1.00 \\
\hline Japan & 1.00 & 1.00 & 1.00 & 1.00 & 1.00 & 1.00 & 1.00 & 1.00 & 1.00 & 1.00 & 1.00 & 1.00 & 1.00 & 1.00 & 1.00 & 1.00 & 1.00 & 1.00 & 1.00 & 1.00 & 1.00 & 1.00 & 1.00 & 1.00 & 1.00 & 1.00 & 1.00 \\
\hline World & 1.00 & 1.00 & 1.00 & 1.00 & 1.00 & 1.00 & 1.00 & 1.00 & 1.00 & 1.00 & 1.00 & 1.00 & 1.00 & 1.00 & 1.00 & 1.00 & 1.00 & 1.00 & 1.00 & 1.00 & 1.00 & 1.00 & 1.00 & 1.00 & 1.00 & 1.00 & 1.00 \\
\hline
\end{tabular}


Table A-4

Parameter Definitions for Emission Growth Factor Tables

\begin{tabular}{|c|c|}
\hline Parameter & Definition \\
\hline ALD2 & Higher Aldehydes \\
\hline $\mathrm{CO}$ & Carbon Monoxide \\
\hline ETH & Ethene \\
\hline FORM & Formaldehyde \\
\hline ISOP & Isoprene \\
\hline $\mathrm{NH} 3$ & Ammonia \\
\hline NO & Nitrogen Oxide \\
\hline $\mathrm{NO} 2$ & Nitrogen Dioxide \\
\hline NR & Nonreactive VOCs \\
\hline OLE & Olefins \\
\hline PAR & Paraffins \\
\hline PEC & Particulate Carbon \\
\hline PMC & Particulate-coarse fraction \\
\hline PMFINE & Particulate-fine fraction \\
\hline PNO3 & Nitrate Particles \\
\hline POA & Organic Acid Particles \\
\hline PSO4 & Sulfate Particles \\
\hline $\mathrm{SO} 2$ & Sulfur Dioxode \\
\hline SULF & Sulfur Aerosols \\
\hline TERPB & Monoterpene Bond Group \\
\hline TOL & Toluene \\
\hline$X Y L$ & Xylenes \\
\hline KET & Ketones \\
\hline ALC & Alcohols \\
\hline $\mathrm{CO} 2$ & Carbon Dioxide \\
\hline $\mathrm{CH} 4$ & Methane \\
\hline $\mathrm{N} 2 \mathrm{O}$ & Nitrous Oxide \\
\hline
\end{tabular}




\section{APPENDIX B EFFECTS ON THE ATMOSPHERE OF CONVERTING TO HYDROGEN FUEL CELL VEHICLES. STANFORD UNIVERSITY, NOVEMBER 2009.}




\title{
Final Report by Stanford University
}

\section{Effects on the Atmosphere of Converting to Hydrogen Fuel Cell Vehicles}

\author{
U.S. Department of Energy \\ Primary Contractor: Tetra Tech \\ Subcontractor: Stanford University \\ Principal Investigator at Stanford: Mark Z. Jacobson \\ Dept. of Civil and Environmental Engineering \\ Yang and Yamazaki Environment and Energy Building, Rm. 397 \\ Stanford University \\ Stanford, CA 94305-4020 \\ Tel: 650-723-6386 \\ Email: jacobson@stanford.edu
}

September 2, 2009

\section{Summary}

This was a project to examine the effects on climate, stratospheric ozone, and tropospheric composition of converting fossil-fuel onroad vehicles (FFOVs) to hydrogen fuel cell vehicles (HFCVs). The atmospheric model, GATOR-GCMOM, was used for the analysis. The model was first modified and evaluated with respect to its ability to predict sources and sinks of molecular hydrogen. In particular, biogenic and anthropogenic emissions and dry deposition treatments were updated. Next, current and future (2050) emission inventories of all important anthropogenic gas and particle chemicals were developed as inputs into the model. The future inventories included one based on the IPCC SRES A1B scenario and another based on the same scenario but modified with $90 \%$ penetration of HFCVs in developed countries and $45 \%$ penetration in other countries and $\mathrm{H}_{2}$ produced by steam-reforming of natural gas. Subsequently, 10year simulations were run to examine the effect of converting onroad vehicles in 2050 to steam-reforming-powered HFCVs (SHFCVs). These were compared with 10-year simulations run examining the effect of converting all current onroad vehicles worldwide to HFCVs where the $\mathrm{H}_{2}$ was produced by electrolysis, with the electricity derived from wind power (WHFCVs).

Major conclusions of the project are as follows:

1) Converting $100 \%$ of current vehicles worldwide to WHFCVs is expected to reduce levels of $\mathrm{NO}_{\mathrm{x}}, \mathrm{CO}, \mathrm{CO}_{2}$, most organic gases, $\mathrm{OH}$, ozone, PAN, black carbon, and other particle components in the troposphere, but to increase tropospheric $\mathrm{CH}_{4}$ due to the lower $\mathrm{OH}$. However, by cooling the troposphere and warming the stratosphere, thereby stabilizing the stratosphere, reducing water vapor and $\mathrm{HO}_{\mathrm{x}}$ transport to it, and reducing 
the sizes and lifetimes of stratospheric aerosols and polar stratospheric clouds, WHFCVs are expected to increase upper tropospheric/lower stratospheric ozone, causing a net global ozone column increase. This net increase occurs despite a slight upper stratospheric decrease in ozone.

2) Converting vehicles worldwide in 2050 to SHFCVs at $90 \%$ penetration in developed countries and $45 \%$ penetration in other countries is expected to reduce $\mathrm{NO}_{\mathrm{x}}, \mathrm{CO}, \mathrm{CO}_{2}$, $\mathrm{CH}_{4}$, some other organic gases, ozone, PAN, black carbon, and other particle components in the troposphere, but may increase some other organic gases there, depending on the exact emission changes. SHFCVs are also expected to cool the troposphere and warm the stratosphere, but to a lesser extent than WHFCVs. Finally, SHFCVs are expected to increase upper tropospheric/lower stratospheric ozone while decreasing upper stratospheric ozone, but to a lesser extent in both cases than WHFCVs.

3) The results here (with respect to WHFCVs and SHFCVs) will likely strengthen over longer simulation periods, as greater reductions in $\mathrm{CO}_{2}$ over a longer simulation period will trigger greater tropospheric cooling and stratospheric warming, causing greater reductions in surface ozone and greater net increases in stratospheric ozone.

4) We think the results found are robust for larger leakage rates of hydrogen and for greater penetrations of HFCVs, since we believe that the controlling factor for stratospheric ozone impacts is the reduction in fossil-fuel greenhouse gases and the resulting surface cooling, which reduces water vapor emissions, and stratospheric warming, which increases tropopause stability, reducing water vapor transport to the stratosphere. The reduction in water vapor (and ozone-destroying hydrogen oxides that is produces) to the stratosphere due to climate feedbacks should be larger than increases in water vapor and hydrogen oxides produced by leaked hydrogen, causing a net column ozone increase. Further, warmer stratospheric temperatures due to HFCVs should reduce aerosol and polar stratospheric cloud size and lifetime, reducing ozone loss further. While we do not know exactly what hydrogen leakage rate and vehicle penetration would cause net damage, we are confident, based on results to date that indicate the dominance of climate feedbacks, that all realistic proposed future scenarios of HFCV fleets will not cause damage. As such, we see no disadvantage to the future large-scale penetration of HFCVs.

In the following sections, the model, modifications to it, emissions, and results are discussed in more detail.

\section{Model and Simulation Description}

The model used for this study was GATOR-GCMOM, which solves gas, aerosol, cloud, dynamical, transport, radiation, ocean, land surface, and sea ice processes [Jacobson et al., 2007; Jacobson, 2008a,b; Jacobson and Streets, 2009]. Simulations were run on a $4^{0}$ $\mathrm{S}-\mathrm{N} \times 5^{\circ} \mathrm{W}$-E global domain with 47 layers up to $0.22 \mathrm{hPa}(\approx 60 \mathrm{~km}), 14$ layers in the bottom $1 \mathrm{~km}$, and 31 layers up to $15 \mathrm{~km}$. The model treated the evolution of 134 gases, 347 chemical reactions (including 55 photolysis reactions and 25 heterogeneous reactions), two aerosol size distributions (14 size bins each with 13 chemical components per size bin in one distribution and 16 in the other) and three hydrometeor distributions (liquid, ice, graupel - 30 bins each, and 17 chemical components in each bin) in each model grid cell. The model tracked both particle number and component mass for each size bin of each aerosol and hydrometeor size distribution. Processes affecting gases included emissions, photochemistry, dry deposition, wet deposition, gasto-particle conversion, gas-cloud interactions, and transport. Radiative transfer was solved explicitly over 694 wavelength and probability intervals for heating rates and 86 wavelengths for photolysis rate coefficients. The model included a subgrid surface 
module in each grid cell that treated 10 layers per soil class. It also included a potentialenstrophy, vorticity, mass, and energy-conserving 2-D ocean model of the mixed layer, 10 layers of ocean for energy diffusion and ocean chemistry. These processes, except for gas-to-particle conversion, are discussed below with respect to $\mathrm{H}_{2}$. Other processes are described in detail in the above-mentioned references.

The model treated feedbacks among meteorological, gas, aerosol, cloud, radiative, land surface, and ocean surface process in all nested domains. Since meteorology was coupled online to the other processes, any process that affected meteorology fed back to the other processes and vice versa. The main coupling between gas, aerosol, and cloud processes and meteorology was through radiative transfer. For example, radiative heating rates, used to determine changes in temperature, thus changes in pressure, were calculated by accounting for the optical properties of gases, aerosol particles, and hydrometeor particles. A second coupling was through water vapor. Changes in water vapor due to cloud or aerosol growth/evaporation or through air-ocean or airgroundwater exchange, changed air pressure (since water vapor is a component of air pressure in the model) and the specific heat of air. Conversely, changes in meteorological variables, such as air pressure, wind speed/direction, temperature, and the relative humidity, affected the movement and concentrations of gas, aerosol particles, and hydrometeor particles.

At a deeper level, gases in the model were both affected by and affected photolysis and radiative heating rates. All gases that photolyzed in the model affected radiative heating rates since absorption cross sections of each gas at each wavelength were used both for actinic flux calculations for photolysis (when quantum yields were applied) and irradiance calculations (for heating rates). Thus, when gas concentrations changed, so did photolysis and heating rates. Likewise, aerosol particles, cloud drops, ice crystals, and graupel particles affected gas photolysis and radiative heating rates since particle absorption cross sections were determined as a function of wavelength and included in optical depth calculations for actinic flux and irradiance calculations. Changes in radiative heating rates in turn affected temperatures, which affected the rates of gas and aerosol chemical reactions, water fluxes from the ocean, the relative humidity, air pressure, wind speeds, cloud and aerosol microphysical processes, etc.

Carbon dioxide, like other gases, affected irradiances and radiative heating rates as it is an IR absorber. Its absorption affected the temperature at all altitudes and horizontal locations, and changes in temperature affected local temperature and pressure gradients (thus wind speeds and the transport of all gases and particles), evaporation rates of water from oceans, lakes, soils, and clouds, and the temperature-dependence of many physical and chemical processes in the model, including biogenic emissions. For example, an increase in $\mathrm{CO}_{2}$ increased water evaporation, and both higher temperature and water vapor increase ozone in the troposphere, but higher water vapor decreases ozone in parts of the stratosphere by enhancing the $\mathrm{HO}_{\mathrm{x}}$ photochemical destruction cycle of ozone and increasing the size and lifetime of polar stratospheric clouds.

The change in $\mathrm{CO}_{2}$ also affected $\mathrm{CO}_{2}$ photosynthesis (which depended on $\mathrm{CO}_{2}$ backpressure) in chlorophyll and green plants, thus chlorophyll and leaf respiration rates. Changes in $\mathrm{CO}_{2}$ further changed dissolution and evaporation rates of $\mathrm{CO}_{2}$ into the ocean (which were also affected by the changes in temperature due to $\mathrm{CO}_{2}$ ), $\mathrm{CO}_{2}$ weathering rates, ocean $\mathrm{pH}$ and chemical composition, sea spray $\mathrm{pH}$ and composition, and rainwater $\mathrm{pH}$ and composition. Changes in sea spray composition, in turn, affected the radiative properties of sea spray, thus radiative heating rates. 


\section{Emissions}

The model treated anthropogenic and natural emissions of $\mathrm{H}_{2}$. Anthropogenic emissions were from aircraft, ships, other fossil fuels, biofuels, and biomass burning. Natural emissions were from biological activity in the surface ocean, nitrogen fixation over land, and volcanic outgassing.

Contemporary emissions of fossil-fuel onroad vehicle (FFOV) $\mathrm{H}_{2}$ were derived as follows. The mass emission ratio of $\mathrm{H}_{2}$ : $\mathrm{CO}$ from FFOV was estimated as 0.0285 g$\mathrm{H}_{2} / \mathrm{g}-\mathrm{CO}$, the mean value from Barnes et al. [2003]. The reported uncertainty of this number is $+/-12 \%$, and differences between Barnes et al. and other studies, are up to 33\%. The 1995 onroad vehicle emission rate of CO was $195.7 \mathrm{Tg}-\mathrm{CO} / \mathrm{yr}$ [Olivier et al., 1996], giving a FFOV $\mathrm{H}_{2}$ emission rate for 1995 of $5.58 \mathrm{Tg}-\mathrm{H}_{2} / \mathrm{yr}$. Emissions of $\mathrm{H}_{2}$ from ships, airplanes, and other fossil-fuel sources were similarly estimated by scaling $\mathrm{CO}$ emissions from those sources with the same $\mathrm{H}_{2}$ :CO emission factor as for FFOV. Table 1 provides a summary of the $\mathrm{H}_{2}$ emissions found here.

Natural plus anthropogenic biomass-burning $\mathrm{H}_{2}$ emissions were obtained by combining satellite-derived 8-day fuel burn data [Giglio et al., 2006] with land use data (to determine fire type) and emission factors. The emission factors used were $0.97 \mathrm{~g}$ $\mathrm{H}_{2} / \mathrm{kg}-\mathrm{dm}$ (dm=dry matter) for savannahs, $3.8 \mathrm{~g}-\mathrm{H}_{2} / \mathrm{kg}-\mathrm{dm}$ for tropical forests, $1.8 \mathrm{~g}$ $\mathrm{H}_{2} / \mathrm{kg}-\mathrm{dm}$ for extratropical forests, and $2.4 \mathrm{~g}-\mathrm{H}_{2} / \mathrm{kg}-\mathrm{dm}$ for agricultural waste [Andreae and Merlet, 2002]. Fuel burn data for five separate years were available. About $90 \%$ of biomass-burning emissions today is anthropogenic.

For biofuel burning $\mathrm{H}_{2}$, the spatially-distributed biofuel-burning black carbon (BC) emission rate from Bond et al. [2004] was used, but the global fuel burn rate was increased to 4200 Tg-dry matter $(\mathrm{dm}) / \mathrm{yr}$, which is the mean of the uncertainty range of Ludwig et al. [2003] of 1086-6192 Tg-dm/yr for 1995, multiplied by the 2009 to 1995 world population. The $\mathrm{BC}$ emission rate was then multiplied by the ratio of the biofuel$\mathrm{H}_{2}$ emission factor of $1.8 \mathrm{~g}-\mathrm{H}_{2} / \mathrm{kg}$-dm to that of $\mathrm{BC}(0.59 \mathrm{~g}-\mathrm{BC} / \mathrm{kg}-\mathrm{dm})$ from Andreae and Merlet [2001] to obtain an estimate of the spatially-distributed $\mathrm{H}_{2}$ emission rate.

Hydrogen emissions over the oceans were estimated as about $3.5 \mathrm{Tg}-\mathrm{H}_{2} / \mathrm{yr}$, within the range of literature values [Seiler and Conrad, 1987; Warneck, 1999; Novelli et al., 1999; Sanderson et al., 2003] and distributed in time and space proportionately to dimethylsulfide (DMS) emissions, for which a monthly global dataset of DMS concentration in water was available [Kettle et al., 1999].

Hydrogen emissions from soil, due to nitrogen fixation, have been estimated as 3-4 Tg- $\mathrm{H}_{2} / \mathrm{yr}$ [Seiler and Conrad, 1987; Warneck, 1999; Novelli et al., 1999; Sanderson et al., 2003]. An emission rate of near $3.2 \mathrm{Tg}-\mathrm{H}_{2} / \mathrm{yr}$ was assumed and distributed proportionately in time and space to NO soil emissions, which were calculated based on temperature- and location-dependent parameters [Jacobson and Streets, 2009].

Volcanos emit primarily water vapor, carbon dioxide, and sulfur dioxide. However, their fourth- or fifth-largest emission product is $\mathrm{H}_{2}$, measured by Symonds et al. [1994] at three volcanos to range from $0.49-1.39 \%$ by volume of total emissions. We use the emission factors from Erta Ale, which gives $\mathrm{H}_{2} \mathrm{O}$ as $77.2 \%, \mathrm{CO}_{2}$ as $11.3 \%, \mathrm{SO}_{2}$ as $8.34 \%, \mathrm{H}_{2}$ as $1.39 \%$, and $\mathrm{CO}$ as $0.44 \%$ of total emissions. These emission factors are scaled to the $\mathrm{SO}_{2}$ emission factors for all other volcanos worldwide, determined from Andres and Kosgnoc [1998]. The annual emissions of $\mathrm{H}_{2}$ from volcanos were thus calculated with the global model as about $0.05 \mathrm{Tg}-\mathrm{H}_{2} / \mathrm{yr}$, which compares with the rough estimate of $0.2 \mathrm{Tg}-\mathrm{H}_{2} / \mathrm{yr}$ from Warneck [1999]. 
Table 1 compares hydrogen emissions from the present study with those from several previous studies. Total $\mathrm{H}_{2}$ emissions ( $\left.33 \mathrm{Tg}-\mathrm{H}_{2} / \mathrm{yr}\right)$ are in the range of those from other studies (mean of 42, range of $17-71 \mathrm{Tg}-\mathrm{H}_{2} / \mathrm{yr}$ ). The main difference with respect to most studies is the lower biomass-burning estimate from $\mathrm{H}_{2}$ here, which is based on satellite data of fuel burn combined with measured emission factors for different types of burned vegetation. Most other studies did not calculate the $\mathrm{H}_{2}$ emissions from biomass burning with such data.

Table 1. Contemporary global hydrogen budget. All values in Tg- $\mathrm{H}_{2} / \mathrm{yr}$.

\begin{tabular}{|c|c|c|c|c|c|c|c|c|}
\hline & $\begin{array}{l}\text { This } \\
\text { work }\end{array}$ & P07 & R06 & S03 & H02 & N99 & W99 & SC87 \\
\hline \multicolumn{9}{|l|}{ Emissions } \\
\hline Onroad vehicles & 5.58 & & & & & & & \\
\hline Ships & 0.0031 & & & & & & & \\
\hline Aircraft & 0.0483 & & & & & & & \\
\hline Other fossil & 2.79 & & & & & & & \\
\hline Biofuel burning & 7.48 & 4.4 & & & & & & \\
\hline Total fos.+biofuel & 15.9 & 22.7 & $15 \pm 6$ & 20 & 16 & $15 \pm 10$ & 17 & $20 \pm 10$ \\
\hline Biomass burning & 9.81 & 10.1 & $16 \pm 3$ & 20 & 13 & $16 \pm 11$ & 19 & $20 \pm 10$ \\
\hline Ocean biological & 3.48 & 6.0 & $6 \pm 5$ & 4 & 4 & $3 \pm 2$ & 4 & $4 \pm 2$ \\
\hline Land $\mathrm{N}_{2}$ fixation & 3.35 & 0 & $6 \pm 5$ & 4 & 4 & $3 \pm 1$ & 3 & $3 \pm 2$ \\
\hline Volcanoes & 0.051 & 0 & 0 & 0 & 0 & 0 & 0.2 & 0 \\
\hline Total natural & 6.88 & 6.0 & $12 \pm 10$ & 8 & 8 & $6 \pm 3$ & 7 & $7 \pm 4$ \\
\hline Total emissions & 32.59 & 38.8 & $43 \pm 19$ & 48 & 37 & $37 \pm 24$ & 43.2 & $47 \pm 24$ \\
\hline Net chem. change & $34.48^{\mathrm{a}}$ & $16.3^{b}$ & $45 \pm 9$ & $13.1^{\mathrm{b}}$ & 16 & $21 \pm 11^{b}$ & $22^{b}$ & $32 \pm 12^{b}$ \\
\hline \multicolumn{9}{|l|}{ Sinks } \\
\hline Land dry dep. & 65.88 & 55 & $88 \pm 11$ & 58.3 & 55 & $56 \pm 41$ & 70 & $90 \pm 20$ \\
\hline Ocean diss.-evap & 0.00040 & 0 & 0 & 0 & 0 & 0 & 0 & 0 \\
\hline Wet deposition & 0.00041 & 0 & 0 & 0 & 0 & 0 & 0 & 0 \\
\hline Total sinks & 65.89 & 55 & $88 \pm 11$ & 58.3 & 55 & $56 \pm 41$ & 70 & $90 \pm 20$ \\
\hline Sources minus sinks & $1.18{ }^{\iota}$ & 0.1 & $\mathbf{0}$ & 2.8 & -2 & 2 & -4.8 & -11 \\
\hline & & & & & & & & \\
\hline
\end{tabular}

P07=Price et al. [2007]; R06=Rhee et al. [2006]; S03=Sanderson et al. [2003]; H02=Hauglustaine and Ehhalt [2002]; N99=Novelli et al. [1999]; W99=Warneck [1999]; SC87=Seiler and Conrad [1987].

${ }^{\mathrm{a}}$ Troposphere plus stratosphere (up to $0.22 \mathrm{hPa}(\sim 60 \mathrm{~km})$ )

${ }^{\mathrm{b}}$ Troposphere only

${ }^{\mathrm{c}}$ Does not include escape above $0.22 \mathrm{hPa}(\sim 60 \mathrm{~km})$.

For this project, we developed global gridded emission inventories for 2050 by applying future emission factors to present-day global gridded emissions. The 2000 to 2050 emission factors were developed by Dr. David Streets at Argonne National Laboratory, in a manner similar to that described in Jacobson and Streets [2009]. The emission factors were speciated and a function of 17 world regions. Two future scenarios were developed: a 2050 A1B base scenario and a 2050 A1B scenario with $90 \%$ penetration of HFCVs in developed countries and $45 \%$ penetration in other countries, where $\mathrm{H}_{2}$ was produced by steam-reforming of natural gas. 
Twenty-seven species and Carbon-Bond IV (CB-IV) groups were projected to 2050. These included gases ( $\mathrm{NO}, \mathrm{NO}_{2}, \mathrm{~N}_{2} \mathrm{O}, \mathrm{NH}_{3}, \mathrm{SO}_{2}, \mathrm{H}_{2} \mathrm{SO}_{4}, \mathrm{CO}, \mathrm{CO}_{2}, \mathrm{CH}_{4}, \mathrm{C}_{2} \mathrm{H}_{4}$, $\mathrm{HCHO}$, higher aldehydes, $\mathrm{C}_{5} \mathrm{H}_{8}$, terpenes, nonreactive VOCs, paraffins, olefins, ketones, alcohols, toluene, xylene) and aerosol components (BC, POC, sulfate, nitrate, fine PM, and coarse PM). At first, the IMAGE model [RIVM, 2001] was used to disaggregate IPCC A1B forecasts of $\mathrm{CO}_{2}, \mathrm{CH}_{4}, \mathrm{~N}_{2} \mathrm{O}, \mathrm{SO}_{2}, \mathrm{CO}, \mathrm{VOC}$, and $\mathrm{NO}_{\mathrm{x}}$ into 17 world regions. VOC emissions were then speciated with profiles from Streets et al. [2003] and Klimont et al. [2002] for 82 emitting source types, linking IPCC energy use and other activities to organic emissions.

Once 2050 base A1B emission growth factors were developed, they were applied to the contemporary model inventory to yield a 2050 base A1B inventory. Subsequently, the GREET model at Argonne was used to estimate the 2050 A1B growth factors modified for HFCVs. Table 2 summaries global emissions of several key chemicals under the three scenarios examined.

Whereas, we are fairly confident that the 2050 base A1B scenario represents changes in emissions according to the $\mathrm{A} 1 \mathrm{~B}$ assumptions reasonable, we are less confident in the $2050 \mathrm{~A} 1 \mathrm{~B} \mathrm{H}_{2}$ scenario with respect to organic gas emissions. For example, Table 2 indicates that several organic gases may increase upon a conversion to SHFCVs in 2050. However, we do not believe this is correct and believe the result is an artifact of the GREET model used to derive these numbers. To illustrate, the GREET model estimates that, for a $45 \%$ conversion of the U.S. fleet, $\mathrm{CO}_{2}$ emissions in the U.S. will decrease by about 37\% in the transportation sector (which appears reasonable, since more trucks will be needed to transport the hydrogen from steam-reforming plants), but xylene and formaldehyde emissions will decrease by only 12 and 2\%, respectively, apparently due to the increased transport of hydrogen. However, it does not seem reasonable that hydrogen transport would cause such large increases in xylene and formaldehyde but not $\mathrm{CO}_{2}$. Further, instead of transporting hydrogen, it may be possible to transport hydrogen through pipelines or produce hydrogen on site in service stations, obviating the need for hydrogen transport by vehicles. Unfortunately, we were not able to catch this potential problem before starting the long simulations. The implications of too high of organic emissions are discussed in Section 8. In sum, if organic emissions in the SHFCV scenario were lower, the conclusions found here would be strengthened.

Changes in $\mathrm{H}_{2}$ were calculated separately from some of the derived fields. Specifically, $\mathrm{H}_{2}$ from FFOVs was assumed to be emitted using the ratio of 0.0285 g$\mathrm{H}_{2}$ /g-CO [Barnes et al., 2003], so decreases in FFOV CO emissions resulted in decreases in $\mathrm{H}_{2}$ emissions from vehicles. Simultaneously, though, a 3.0\% leakage of $\mathrm{H}_{2}$ consumed was assumed, and $\mathrm{H}_{2}$ consumption was calculated inversely from the reduction in vehicle $\mathrm{CO}_{2}$ due to conversion to HFCVs in 2050 (2670 Tg- $\mathrm{CO}_{2} / \mathrm{yr}$ ), the $\mathrm{CO}_{2}$ emissions per kilometer from vehicles, the fleet-averaged mileage of vehicles, the density of gasoline, the lower heating values of gasoline and hydrogen, and the efficiencies of gasoline and hydrogen fuel cell vehicles. At a 3.5\% leakage rate $\mathrm{H}_{2}$ decreases from FFOVs evenly offset $\mathrm{H}_{2}$ leaks from HFCVs for the current fleet [Jacobson, 2008b and Table 3]. However, between 2000 and 2050, CO emissions (and thus $\mathrm{H}_{2}$ emissions) from FFOVs are expected to increase proportionately less than are $\mathrm{CO}_{2}$ emission due to better $\mathrm{CO}$ controls relative to $\mathrm{CO}_{2}$ controls (Table 2). As such, the replacement of FFOVs with HFCVs is calculated in Table 2 to result in slightly more $\mathrm{H}_{2}$ emissions than no replacement since future FFOVs will be relatively cleaner per vehicle with respect to $\mathrm{H}_{2}$ emissions. Nevertheless, the $2.5 \mathrm{Tg} / \mathrm{yr}$ increase in $\mathrm{H}_{2}$ is less than $4 \%$ of global atmospheric source plus chemical production of $\mathrm{H}_{2}$ (Table 1).

The $2050 \mathrm{~A} 1 \mathrm{~B}+\mathrm{HFCV} \mathrm{H}_{2}$ from leakage was $3.4 \mathrm{Tg}-\mathrm{H}_{2} / \mathrm{yr}$ and that from combustion of fossil-fuel sources was 13.79 Tg- $\mathrm{H}_{2} / \mathrm{yr}$. Before conversion, $\mathrm{H}_{2}$ from 
fossil-fuel sources was $14.65 \mathrm{Tg}-\mathrm{H}_{2} / \mathrm{yr}$. Thus, conversion to $\mathrm{H}_{2}$ under the present scenario decreased $\mathrm{H}_{2}$ emissions from fossil fuels by $0.86 \mathrm{Tg}-\mathrm{H}_{2} / \mathrm{yr}$ and $\mathrm{H}_{2}$ leakage by $3.4 \mathrm{Tg}-\mathrm{H}_{2} / \mathrm{yr}$, causing a net increase in $\mathrm{H}_{2}$ emissions of $2.6 \mathrm{Tg}-\mathrm{H}_{2} / \mathrm{yr}$. In other words, $\mathrm{H}_{2}$ reductions from reduce fossil-fuel use were about $25 \%$ of $\mathrm{H}_{2}$ increases from leakage.

Table 2. Fossil-fuel emission rates (Tg/yr) of key chemical components in 2000, 2050 under the A1B scenario, and 2050 under the A1B scenario modified by the conversion of vehicles to hydrogen fuel cell vehicles (HFCVs). The 2050 A1B+HFCV scenario assumes $90 \%$ penetration of HFCVs in developed countries and $45 \%$ penetration in other countries and $\mathrm{H}_{2}$ production by steam-reforming of natural gas. Future emission growth factors were derived by Dr. David Streets at Argonne National Laboratory.

\begin{tabular}{|l|l|l|l|}
\hline & 2000 & $2050 \mathrm{~A} 1 \mathrm{~B}$ & 2050 A1B+HFCV \\
\hline $\mathrm{H}_{2}$ & 8.4 & 14.6 & 17.2 \\
\hline $\mathrm{NO}$ & 48.2 & 153 & 149 \\
\hline $\mathrm{NO}_{2}$ & 8.21 & 26.1 & 25.4 \\
\hline $\mathrm{N}_{2} \mathrm{O}$ & 11.1 & 9.7 & 9.6 \\
\hline $\mathrm{CO}$ & 294 & 514 & 484 \\
\hline $\mathrm{CO}_{2}$ & 25,560 & 95,900 & 93,200 \\
\hline Methane & 284 & 357 & 356 \\
\hline Methanol & 4.52 & 13.0 & 13.8 \\
\hline Ethene & 4.42 & 12.6 & 13.4 \\
\hline Formaldehyde & 0.97 & 6.69 & 7.38 \\
\hline Higher aldehydes & 2.91 & 9.14 & 9.29 \\
\hline Toluene & 4.42 & 8.1 & 8.8 \\
\hline Xylene & 6.13 & 9.42 & 10.3 \\
\hline SO & 129 & 212.5 & 213 \\
\hline FF-BC & 3.8 & 6.7 & 5.1 \\
\hline FF-POM & 5.5 & 6.0 & 7.6 \\
\hline BF-BC & 4.1 & 1.5 & 1.5 \\
\hline BF-POM & 38 & 14.6 & 14.6 \\
\hline
\end{tabular}

Table 2 indicates that, under the 2050 base A1B scenario, global emissions of all chemicals, except $\mathrm{N}_{2} \mathrm{O}$ and residential biofuel products, are expected to increase in the global average. However, emissions of many of these chemicals are expected to decrease regionally, particularly over North America and Europe, where emissions are expected to decline.

A comparison of the $2050 \mathrm{~A} 1 \mathrm{~B}$ and 2050 A1B+HFCV columns in Table 2 indicates that a partial conversion to HFCVs, with $\mathrm{H}_{2}$ produced by steam-reforming of natural gas, is expected to decrease emissions of $\mathrm{NO}_{\mathrm{x}}, \mathrm{N}_{2} \mathrm{O}, \mathrm{CO}, \mathrm{CO}_{2}$, and particulate matter compared with no conversion. However, some chemicals ( $\mathrm{SO}_{2}$, ethane, toluene) may increase in some countries and in the global average due to enhanced power plant and, in some cases, vehicle emissions in those countries (relative to FFOVs) due to producing, transporting, and compressing the $\mathrm{H}_{2}$.

Table 3 shows contemporary emissions and emissions resulting from converting $100 \%$ of the world's FFOVs to HFCVs where the $\mathrm{H}_{2}$ is produced by wind-powered electrolysis. Such a conversion is estimated to reduce global fossil, biofuel, and biomassburning emissions of $\mathrm{CO}_{2}$ by $\sim 13.4 \%, \mathrm{NO}_{\mathrm{x}} \sim 13.4 \%$, nonmethane organic gases $\sim 18.9 \%$, black carbon $\sim 8 \% \mathrm{H}_{2} \sim 3.2 \%$ (at 3\% leakage), and $\mathrm{H}_{2} \mathrm{O} \sim 0.2 \%$. Details of the emission changes and resulting effects are given in Jacobson [2008b]. 
Table 3. Global emissions of speciated gases from (a) nonvehicle fossil-fuels, (b) FFOV, and (c) WHFCV, (d) biomass burning, (e) biofuel burning, and total emissions in the (d) baseline and (e) WHFCV cases. From Jacobson [2008b].

\begin{tabular}{|c|c|c|c|c|c|c|c|}
\hline Species & $\begin{array}{c}\text { (a) } \\
\text { Non- } \\
\text { vehicle } \\
\text { fossil- } \\
\text { fuel } \\
\text { (Tg/yr) }\end{array}$ & $\begin{array}{c}\text { (b) } \\
\text { FFOV } \\
\text { (Tg/yr) }\end{array}$ & $\begin{array}{c}\text { (c) } \\
\text { WHFCV } \\
(\mathrm{Tg} / \mathrm{yr})\end{array}$ & $\begin{array}{c}(\mathrm{d}) \\
\text { Biomass } \\
\text { burning } \\
\text { (Tg/yr) }\end{array}$ & $\begin{array}{c}\text { (e) } \\
\text { Biofuel } \\
\text { Burning } \\
\text { (Tg/yr) }\end{array}$ & $\begin{array}{c}(\mathrm{d}) \\
\text { Baseline } \\
\text { total } \\
(\mathrm{a}+\mathrm{b}+\mathrm{d}) \\
(\mathrm{Tg} / \mathrm{yr})\end{array}$ & $\begin{array}{c}(\mathrm{e}) \\
\text { WHFCV } \\
\text { total } \\
(\mathrm{a}+\mathrm{c}+\mathrm{d}) \\
(\mathrm{Tg} / \mathrm{yr})\end{array}$ \\
\hline \multicolumn{8}{|l|}{ Inorganic gases } \\
\hline Carbon monoxide & 119.1 & 195.7 & 0 & 420 & 216 & 950.8 & 755.1 \\
\hline Carbon dioxide & 21,010 & 3760 & 0 & $3200 *$ & $170^{*}$ & 28,140 & 24,380 \\
\hline Nitric oxide & 37 & 16 & 0 & 14 & 2.7 & 69.7 & 53.7 \\
\hline Nitrogen dioxide & 6.35 & 2.75 & 0 & 2.2 & 0.42 & 11.72 & 8.97 \\
\hline Nitrous acid & 0.523 & 0.224 & 0 & 0.25 & 0.048 & 1.045 & 0.821 \\
\hline Nitrous oxide & 11.02 & 0.10 & 0 & 1.1 & 0.17 & 12.39 & 12.29 \\
\hline Sulfur dioxide & 136.2 & 4.0 & 0 & 2.5 & 0.72 & 143.4 & 139.4 \\
\hline Sulfur trioxide & 5.34 & 0.14 & 0 & 0.078 & 0.022 & 5.58 & 5.44 \\
\hline Sulfuric acid & 2.18 & 0.06 & 0 & 0.026 & 0.0074 & 2.27 & 2.21 \\
\hline Ammonia & 58.2 & 0 & 0 & 6.0 & 3.6 & 67.8 & 67.8 \\
\hline Molec. hydrogen & 3.38 & 5.58 & 4.82 & 9.8 & 5.0 & 23.76 & 23 \\
\hline Water vapor & 9590 & 1420 & 1390 & 2770 & 1460 & 15,240 & 15,210 \\
\hline Organic gases & & & & & & 0 & 0 \\
\hline Methane & 275.9 & 0.8 & 0 & 19.7 & 20.2 & 316.6 & 315.8 \\
\hline Paraffin bond grp & 38.0 & 14.7 & 0 & 7.0 & 7.3 & 67 & 52.3 \\
\hline Ethene & 2.54 & 1.83 & 0 & 6.0 & 5.0 & 15.37 & 13.54 \\
\hline Olefin bond grp & 2.75 & 2.10 & 0 & 2.2 & 4.1 & 11.15 & 9.05 \\
\hline Methanol & 2.65 & 1.85 & 0 & 8.3 & 4.2 & 17 & 15.15 \\
\hline Formaldehyde & 0.57 & 0.41 & 0 & 4.9 & 0.36 & 6.24 & 5.83 \\
\hline Higher aldehydes & 1.67 & 1.20 & 0 & 2.8 & 0.39 & 6.06 & 4.86 \\
\hline Benzene & 1.47 & 1.04 & 0 & 1.6 & 5.3 & 9.41 & 8.37 \\
\hline Toluene bond grp & 2.67 & 1.96 & 0 & 1.0 & 3.0 & 8.63 & 6.67 \\
\hline Xylene bond grp & 3.69 & 2.77 & 0 & 0.36 & 1.5 & 8.32 & 5.55 \\
\hline Total organic gas & 331.1 & 28.7 & 0 & 53.9 & 51.4 & 465.1 & 436.4 \\
\hline
\end{tabular}

Biomass- and biofuel-burning $\mathrm{CO}_{2}$ emissions are net burning minus regrowth during year.

\section{Photochemistry}

Hydrogen photochemical production and loss were solved with SMVGEAR II, which treated chemistry among 20 aerosol, liquid, ice, and graupel heterogeneous chemical reactions, 314 kinetic reactions, and 57 photolysis reactions (391 total) [Jacobson, 2008b]. The four chemical sources of $\mathrm{H}_{2}$ in the reaction mechanism were $\mathrm{H}+\mathrm{HO}_{2}$, $\mathrm{CH}_{4}+\mathrm{O}\left({ }^{1} \mathrm{D}\right), \mathrm{H}_{2} \mathrm{COO}^{*}$ (excited formic acid) thermal decomposition, and $\mathrm{HCHO}$ photolysis. The three chemical sinks were reaction with $\mathrm{O}\left({ }^{1} \mathrm{D}\right), \mathrm{OH}$, and $\mathrm{Cl}$.

\section{Dry Deposition}

Dry-deposition speeds $(\mathrm{m} / \mathrm{s})$ at the reference height $z_{r}=10 \mathrm{~m}$ of each gas in each model grid cell were parameterized as the inverse sum of a series of resistances [e.g., McRae et al., 1982; Wesely, 1989], but weighted and summed over all land use classes in each cell with

$$
V_{d}\left(z_{r}\right)=\sum_{l} V_{d, l}\left(z_{r}\right)=\sum_{l} \frac{f_{l}}{R_{a}+R_{b}+R_{s, l}}
$$


where $R_{a}(\mathrm{~s} / \mathrm{m})$ is the aerodynamic resistance (assumed to be the same for all land use classes in each cell) to turbulent transfer between the reference height and the laminar sublayer adjacent to the surface, $R_{b}(\mathrm{~s} / \mathrm{m})$ is the resistance to molecular diffusion through the 0.1 to $0.01-\mathrm{cm}$-thick laminar sublayer (the same for all land use classes in a cell), $R_{s, l}$ $(\mathrm{s} / \mathrm{m})$ is the land-use-class-dependent resistance to chemical, biological, and physical interaction and sticking between the surface and the gas once the gas has collided with the surface, and $f_{l}$ is the fractional area of each land use class in the grid cell, determined from a 0.01 degree global land use data set [MODIS/USGS, 2006]. The summation in each cell was over 11 land use classes specified in Wesely [1989]: (1) urban land, (2) agricultural land, (3) rangeland, (4) deciduous forest, (5) coniferous forest, (6) mixed forest including wetland, (7) salt and fresh water, (8) barren land, mostly desert, (9) nonforested wetland, (10) mixed agricultural and range land, and (11) rocky open areas with low-growing shrubs.

The aerodynamic resistance $(\mathrm{s} / \mathrm{m})$ was approximated from similarity theory with

$$
R_{a}=\frac{\int_{z_{0, h}}^{z_{r}} \phi_{h} \frac{\mathrm{d} z}{z}}{k u_{*}}
$$

where $k$ is the dimensionless von Kármán constant ( 0.40 here), $u_{*}$ is the friction wind speed $(\mathrm{m} / \mathrm{s}), z$ is the height above the surface $(\mathrm{m}), z_{0, h}$ is the thermal roughness length (m), and $\phi_{h}$ is a dimensionless potential temperature gradient. A thermal roughness length and dimensionless potential temperature gradient were used instead of a momentum roughness length and dimensionless wind shear because the transport of trace gases resembles the transport of energy more than it does that of momentum. The integral in Equation 2 is

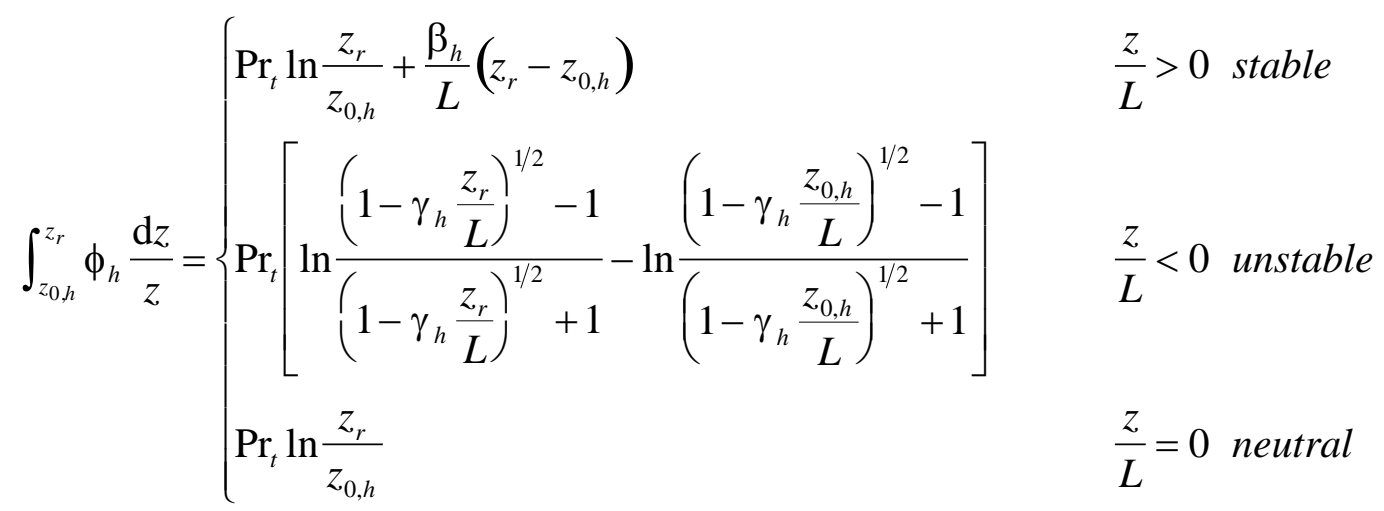

[e.g., Businger et al., 1971], where $\operatorname{Pr}_{t}$ is the turbulent Prandtl number (ratio of eddy diffusion coefficient for momentum to that for energy), $L$ is the Monin-Obukhov length, and $\beta_{h}$ and $\gamma_{h}$ are coefficients. For $k=0.35$, Businger et al. [1971] estimated $\operatorname{Pr}_{t} \approx 0.74$, $\beta_{h}=4.7$, and $\gamma_{h}=9.0$. Hogstrom [1988] noted that, when $k=0.4$, Businger et al.'s constants should be modified to $\operatorname{Pr}_{t} \approx 0.95, \beta_{h}=7.8$, and $\gamma_{h}=11.6$ to obtain a similar relationship to when $k=0.35$. The Monin-Obukhov length $(\mathrm{m})$ is 
$L=\frac{u_{*}^{2} \theta_{v}\left(z_{r}\right)}{k g \theta_{*}}$

where $\theta_{v}$ is the potential virtual temperature $(\mathrm{K})$ at the reference height, $g$ is gravitational acceleration $\left(\mathrm{m} / \mathrm{s}^{2}\right)$, and $\theta *$ is the potential temperature scale, determined as

$\theta_{*}=\frac{k\left|\theta_{v}\left(z_{r}\right)-\theta_{v}\left(z_{0, h}\right)\right|}{\int_{z_{0, h}}^{z_{r}} \phi_{h} \frac{\mathrm{d} z}{\mathrm{z}}}$

Finally, the friction wind speed $(\mathrm{m} / \mathrm{s})$ is

$$
u_{*}=\frac{k\left|\mathrm{v}_{h}\left(z_{r}\right)\right|}{\int_{z_{0, m}}^{z_{r}} \phi_{m} \frac{\mathrm{d} z}{z}}
$$

where $\left|\mathrm{v}_{h}\left(z_{r}\right)\right|$ is the horizontal wind speed $(\mathrm{m} / \mathrm{s})$ at the reference height and

$$
\int_{z_{0, m}}^{z_{r}} \phi_{m} \frac{\mathrm{d} z}{z}= \begin{cases}\ln \frac{z_{r}}{z_{0, m}}+\frac{\beta_{m}}{L}\left(z_{r}-z_{0, m}\right) & \frac{z}{L}>0 \text { stable } \\ \ln \frac{\left(1-\gamma_{m} \frac{z_{r}}{L}\right)^{1 / 4}-1}{\left(1-\gamma_{m} \frac{z_{r}}{L}\right)^{1 / 4}+1}-\ln \frac{\left(1-\gamma_{h} \frac{z_{0, m}}{L}\right)^{1 / 4}-1}{\left(1-\gamma_{h} \frac{z_{0, m}}{L}\right)^{1 / 4}+1} & \\ +2 \tan ^{-1}\left(1-\gamma_{m} \frac{z_{r}}{L}\right)^{1 / 4}-2 \tan ^{-1}\left(1-\gamma_{m} \frac{z_{0, m}}{L}\right)^{1 / 4} & \frac{z}{L}<0 \text { unstable } \\ \ln \frac{z_{r}}{z_{0, m}} & \frac{z}{L}=0 \text { neutral }\end{cases}
$$

is the integral of the dimensionless wind shear [e.g. Businger et al., 1971], which uses the roughness length for momentum $\left(\mathrm{z}_{0, m}, \mathrm{~m}\right)$. The parameter values $k=0.4, \beta_{m}=6.0$ and $\gamma_{m}=19.3$ give similar results as when $k=0.35, \beta_{m}=4.7$, and $\gamma_{m}=15.0$ [Hogstrom, 1988]. Because $L$ depends on $u_{*}$ and $\theta_{*}$ which, in turn, depend on $L$, the noniterative parameterization of Louis [1979], as described in Jacobson [2005, Section 8.42.4] is used first to estimate $u_{*}, \theta_{*}$, and $L$. Then, $L$ is then substituted into Equations 3 and 7 to determine the integrals for dry-deposition calculations. as

The resistance to molecular diffusion in the laminar sublayer $(\mathrm{s} / \mathrm{m})$ was estimated

$$
R_{b}=\ln \left(\frac{z_{0, m}}{z_{0, h}}\right) \frac{(\mathrm{Sc} / \mathrm{Pr})^{2 / 3}}{k u_{*}}
$$


where $\mathrm{Sc}=v_{a} / D$ is the Schmidt number. Here, $v_{a}$ is the kinematic viscosity of air $\left(\mathrm{m}^{2} / \mathrm{s}\right)$ and $D$ is the molecular diffusion coefficient of the gas $\left(\mathrm{m}^{2} / \mathrm{s}\right)$. The Prandtl number is $\operatorname{Pr}=\eta c_{p, m} / \kappa_{a}$, where $\eta_{a}$ is the dynamic viscosity of air $(\mathrm{kg} / \mathrm{m} / \mathrm{s}), c_{p, m}$ is the specific heat of moist air at constant pressure $(\mathrm{J} / \mathrm{kg} / \mathrm{K})$, and $\kappa_{a}$ is the thermal conductivity of moist air $(\mathrm{J} / \mathrm{m} / \mathrm{s} / \mathrm{K})$.

The resistance of gases to surface interactions in a given land use class $l$ of a model grid cell was calculated with

$$
R_{s, l}=\left\{\left[\frac{1}{R_{\text {stom }}+R_{\text {meso }}}+\frac{1}{R_{\text {cut }}}+\frac{1}{R_{\text {conv }}+R_{\text {surf }}}+\frac{1}{R_{\text {canp }}+R_{\text {soil }}}\right] f_{v, l}+\frac{1}{R_{\text {soil }}}\left(1-f_{v, l}\right)\right\}^{-1}
$$

which separates each land use class into a vegetated and nonvegetated portion. Here, $f_{v, l}$ is the vegetation fraction (between 0 and 1 ) within land use class $l$ of a grid cell, determined by overlaying 0.01 degree global land use data [MODIS/USGS, 2006]with 0.1 degree global vegetation fraction data derived from NDVI data from the MODIS satellite and an equation converting NDVI to vegetation fraction. The summation

$$
f_{v}=\sum_{l} f_{l} f_{v, l}
$$

is the overall vegetation fraction (0-1) of a grid cell. In Equation 9, $R_{\text {stom }}$ is the leaf stomatal resistance, $R_{\text {meso }}$ is the leaf mesophyll resistance, $R_{\text {cut }}$ is the leaf cuticle resistance (resistance in outer surface of plants), $R_{\text {conv }}$ is the resistance due to buoyant convection in canopies, $R_{\text {surf }}$ is the resistance to reaction and dissolution on leaves, twigs, bark, and other exposed surfaces, $R_{\text {canp }}$ is the resistance to transfer to the ground through a canopy, and $R_{\text {soil }}$ is the resistance to biological, chemical, and physical interactions at soil and leaf litter surfaces on the ground. $R_{\text {stom }}, R_{\text {meso }}$, and $R_{\text {cut }}$ are resistances in the upper canopy; $R_{\text {conv }}$ and $R_{\text {surf }}$ are resistances in the lower canopy, and $R_{\text {canp }}$ and $R_{\text {soil }}$ are resistances at the ground.

The treatments of the individual resistances are based on the work of Wesely [1989] and Walmsley and Wesely [1996], as described in Jacobson [2005, Section 20.2]. Here, expressions for the soil resistance are provided for $\mathrm{H}_{2}, \mathrm{CH}_{4}$, and $\mathrm{CO}$ that account for variations in soil moisture $\left(w, \mathrm{~m}^{3}\right.$-liquid water $/ \mathrm{m}^{3}$-soil). The expressions take the form of $R_{\text {soil }}=1 / V_{s}$, where $V_{s}$ is a measured or derived dry deposition speed $(\mathrm{m} / \mathrm{s})$ over a soil surface. For molecular hydrogen, soil deposition speeds are parameterized as

$$
V_{s, \mathrm{H} 2}= \begin{cases}0.00177-0.004139 w & \text { grassland } \\ 0.00197-0.004190 w & \text { forests } \\ 0.0001235-0.0000472 \ln (w)+0.000027 \ln ^{2}(w) & \text { savannah } \\ 0.00316-0.00988 w & \text { ag land (late Aut, Win) } \\ 0.00218-0.00548 w & \text { ag land (rest of year) }\end{cases}
$$

where the expressions for grassland and savannah were the same as those in Sanderson et al. [2003] and those for forests and agricultural land were obtained from Yonemura et 
al. [2000]. These expressions are not allowed to fall below zero. For deserts, the deposition speed was estimated as that over forests divided by 2.9 based on data from Smith-Downey et al. [2006] indicating that the deposition speed in a forest with a soil carbon content of $55 \%$ is about 2.9 times that in a desert with a carbon content near $0 \%$.

Equation 11 was based on data obtained above $w=0.15 \mathrm{~m}^{3} / \mathrm{m}^{3}$. Below $w=0.15$ $\mathrm{m}^{3} / \mathrm{m}^{3}$, water stress reduces biological uptake of gases in soil [Yonemura et al., 2000]. However, since some data indicate no effect of drying soil until much lower moisture values [e.g., Conrad and Seiler, 1985], we only limit deposition speeds below $w=0.05$ $\mathrm{m}^{3} / \mathrm{m}^{3}$. In such cases, we multiply Equation 11 (and similarly for $\mathrm{CH}_{4}$ and CO) below $w=0.05 \mathrm{~m}^{3} / \mathrm{m}^{3}$ by $w / 0.05$ to ensure no uptake at zero soil moisture.

For methane, the expressions were

$$
V_{s, \mathrm{CH} 4}= \begin{cases}0.014 V_{s, \mathrm{H} 2} & \text { grassland } \\ 0.00011-0.000232 w & \text { forests } \\ 0.014 V_{s, \mathrm{H} 2} & \text { savannah } \\ 0.0000506-0.000159 w & \text { ag land (late Aut, Win) } \\ 0.0000225-0.0000422 w & \text { ag land (rest of year) }\end{cases}
$$

where the equations for forests and agricultural land were obtained from Yonemura et al. [2000]. The $\mathrm{CH}_{4}$ speeds over grassland and savannah were scaled to the $\mathrm{H}_{2}$ speeds using an approximate annually-averaged ratio of $\mathrm{CH}_{4}: \mathrm{H}_{2}$ speeds over agricultural land, obtained from Equations 11 and 12.

For carbon monoxide, the expressions were

$$
V_{\mathrm{s}, \mathrm{CO}}= \begin{cases}0.606 V_{s, \mathrm{H} 2} & \text { grassland } \\ 0.001-0.00232 w & \text { forests } \\ 0.389 V_{\mathrm{s}, \mathrm{H} 2} & \text { savannah } \\ 0.00186-0.00587 w & \text { ag land (late Aut, Win) } \\ 0.00169-0.00456 w & \text { ag land (rest of year) }\end{cases}
$$

where the equations for forests and agricultural land were obtained from Yonemura et al. [2000]. The CO deposition speeds over grassland and savannah were scaled to the respective $\mathrm{H}_{2}$ deposition speeds using an approximate $\mathrm{CO}: \mathrm{H}_{2}$ deposition speed ratio for these respective lands from Conrad and Seiler [1985]. For deserts, the deposition speeds of $\mathrm{CH}_{4}$ and $\mathrm{CO}_{2}$ were estimated as those over forests divided by 2.9, as discussed with respect to $\mathrm{H}_{2}$. When the equations above were used in Equation 9, the canopy resistance was reduce by 95\% since the measured soil deposition speeds in, for example, forests, should account for much of the canopy resistance.

The temperature dependence of bacterial uptake of gases was modeled with 
$V_{s}(T)=\frac{V_{s}}{1+\exp (-0.1718 T+46.938)}$

where $T$ is in Kelvin [Smith-Downey et al., 2006]. This equation is valid between 288.15 and $313.15 \mathrm{~K}$.

Equation 1 is the deposition speed at the reference height $\left(z_{r}\right)$. However, generally, most of a model's lowest layer is above the reference height, and the deposition speed decreases with height as a function of stability. McRae et al. [1982] derived an equivalent deposition speed $V_{d}(\mathrm{~m} / \mathrm{s})$, which, when applied to the average concentration in the lowest model layer, gives the deposition flux to the surface better than does a deposition speed at the reference height. This effective deposition speed is

$$
V_{d}=\frac{V_{d}\left(z_{r}\right)}{1+\frac{V_{d}\left(z_{r}\right)}{k u_{*}\left(z_{c}-z_{r}\right)} \int_{z_{r}}^{z_{c}} \int_{z_{r}}^{z} \phi_{p}\left(\frac{x}{L}\right) \frac{\mathrm{d} x}{x} \mathrm{~d} z}
$$

where $z_{c}$ is the height (m) at the top of the lowest model layer and

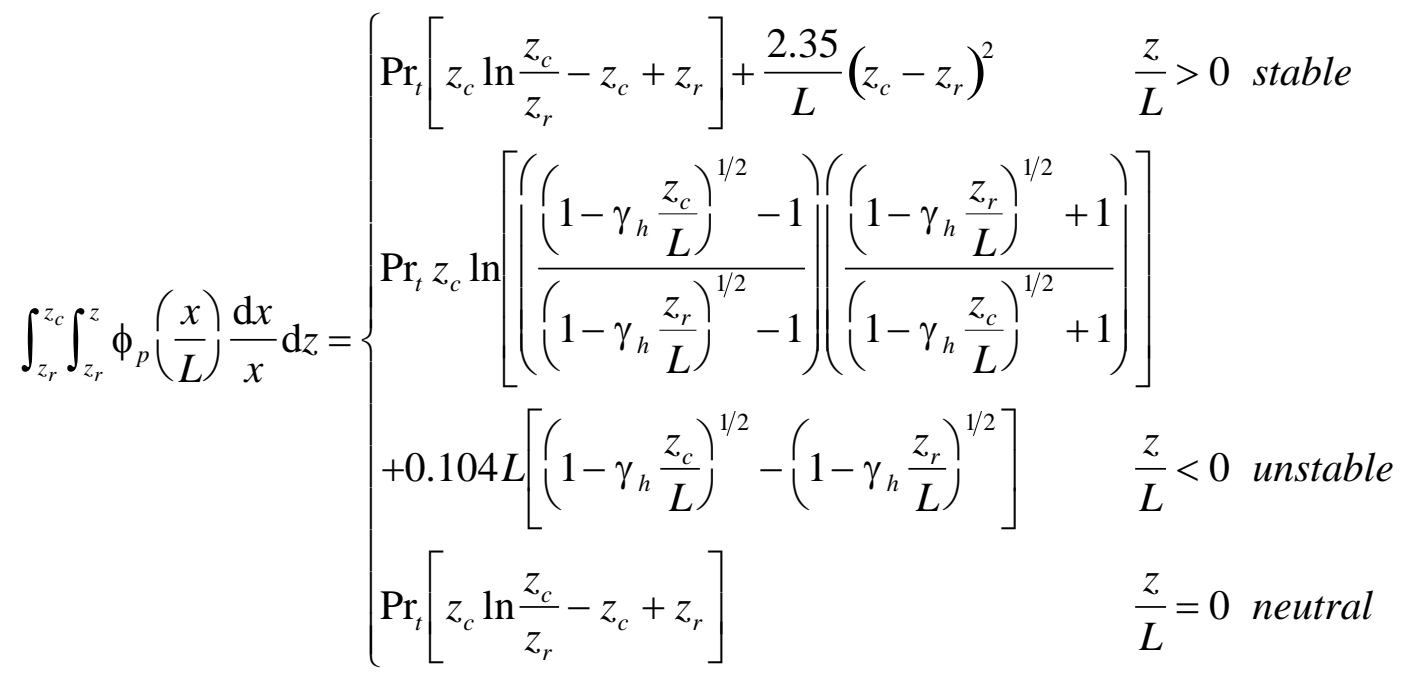

All variables in the equation were previously defined.

\section{Wet Deposition}

Previous studies have not considered wet deposition of hydrogen because it is relatively insoluble in rainwater. Nevertheless, it is slightly soluble, and its removal rate was calculated with the method described in Jacobson [2003, Section 4.12], which accounts for the layer-by-layer transfer of gases between the atmosphere and cloud and precipitation liquid water in a mass-conserving manner. The effective Henry's constant used was $0.00078 \mathrm{~mol} / \mathrm{kg} / \mathrm{atm}$. Table 1 summarizes the global total wet deposited annual mass of $\mathrm{H}_{2}$.

\section{Summary Analysis of $\mathbf{H}_{2}$ Sources and Sinks}

Table 1 compares the hydrogen source and sink budget from the present study with those from several previous studies. Emission sources and surface sinks are generally similar to those from most previous studies, but the net atmospheric chemical change of $\mathrm{H}_{2}$ differs because the present study treated chemistry of the stratosphere and 
troposphere whereas all the other studies considered tropospheric chemistry only. One sink not included in the table is escape from the stratosphere to higher altitudes or space.

The global atmospheric burden up to $0.22 \mathrm{hPa}(\sim 60 \mathrm{~km})$ of hydrogen ranges was calculated to be about $188 \mathrm{Tg}$ based on a mean well-mixed initial mixing ratio of 530 ppbv and an Earth surface area of $5.10064 \times 10^{14} \mathrm{~m}^{2}$. Simmonds et al. [2000] estimates a burden on a single day (January 1, 1996) of $182 \mathrm{Tg}$, based on mean hemispheric mixing ratios of 504 and 520 ppbv between the Northern and Southern Hemisphere, respectively, on that day.

Figure 1 shows annually-averaged dry deposition speeds worldwide of molecular hydrogen calculated by GATOR-GCMOM. Figure 2 shows fluxes of hydrogen to the surface for the same period. Figure 3 shows near-surface mixing ratios of $\mathrm{H}_{2}$ average over a year of simulation. The greater annual mixing ratio in the Southern Hemisphere relative to the Northern Hemisphere is consistent with results from Price et al. [2007], who show low mixing ratios of $\mathrm{H}_{2}$ over Russia and northeastern Canada most of the year, for example.

Figure 1: Annually-averaged dry deposition speeds $(\mathrm{cm} / \mathrm{s})$ of $\mathrm{H}_{2}$ from the model calculated with the method described herein. Numbers in parentheses are the globallyand land-averaged values, respectively, from the figure.

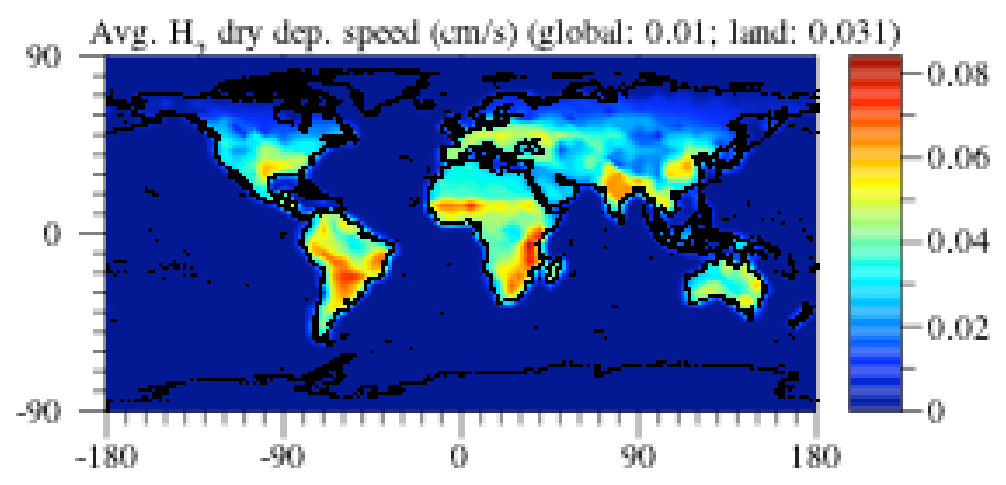

Figure 2: Annually-averaged dry deposition fluxes (nmoles $/ \mathrm{m}^{2} / \mathrm{s}$ ) of $\mathrm{H}_{2}$ determined from the model. Numbers in parentheses are the globally- and land-averaged values, respectively, from the figure.

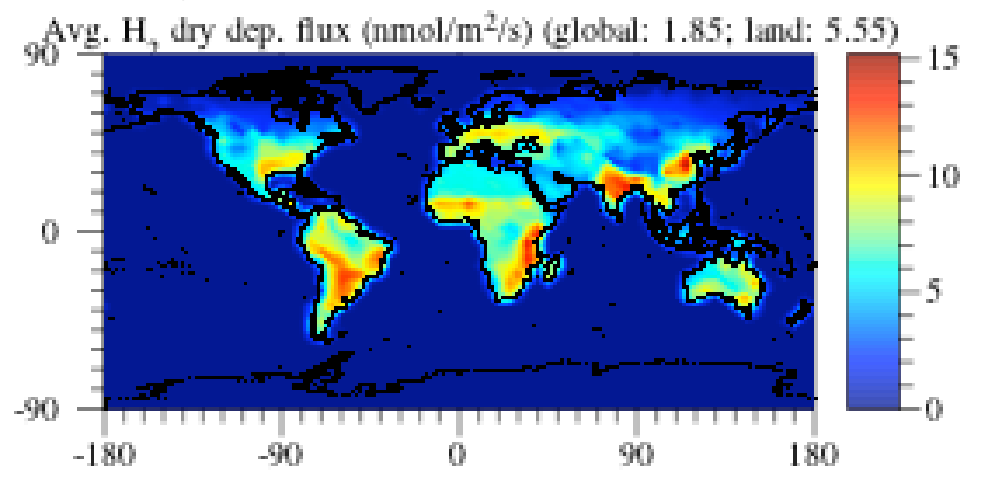


Figure 3: Annually-averaged modeled near-surface $\mathrm{H}_{2}$ (ppbv). Numbers in parentheses are the globally- and land-averaged values, respectively, from the figure.

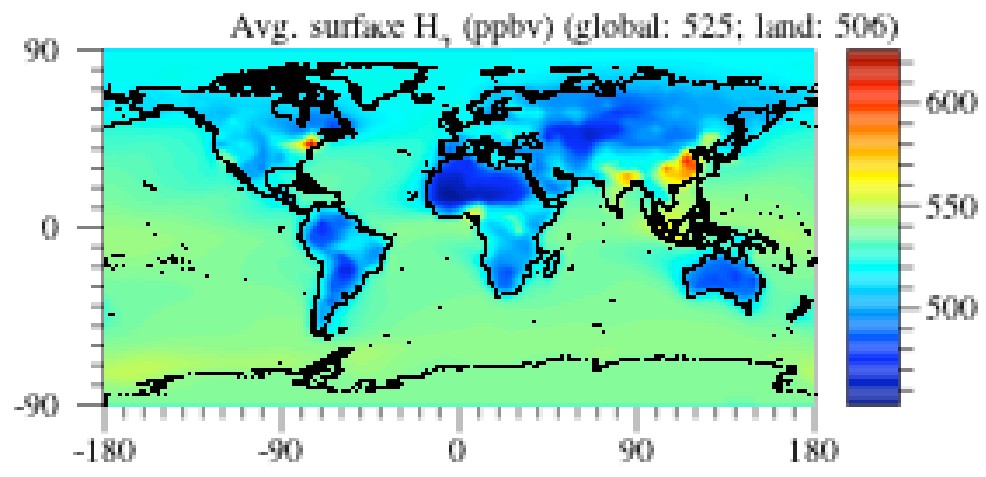

\section{Effects of Converting from FFOVs to Wind-Powered HFCVs Today}

Ten-year model simulations were performed examining the effect of converting the world's FFOV to hydrogen fuel cell vehicles (HFCVs), where the $\mathrm{H}_{2}$ is produced by wind-powered electrolysis (WHFCVs). Results were published in Jacobson [2008b]. Table 3 summarizes emission changes from this set of scenarios.

WHFCV decreased the ambient global column of the vehicle-emitted chemicals, $\mathrm{H}_{2}, \mathrm{CO}_{2}, \mathrm{NO}, \mathrm{NO}_{2}, \mathrm{CO}, \mathrm{HCHO}, \mathrm{CH}_{3} \mathrm{CHO}$, benzene, toluene, black carbon (BC), and primary organic matter (POM) relatively proportionately to their emission reductions. WHFCV also decreased column secondary organic matter (SOM), S(VI), $\mathrm{HNO}_{3}$, and $\mathrm{NO}_{3}{ }^{-}$by $6 \%, 3 \%, 2 \%$, and $19 \%$, respectively due to reductions in aerosol-precursor gases.

The decrease in tropospheric ozone precursors due to WHFCV decreased surface ozone by about $\sim 1$ ppbv globally and up to 5 ppbv regionally. WHFCV, though, increased column ozone by about $0.25 \%$, by increasing upper-tropospheric/lowerstratospheric (UTLS) ozone. Ozone increased in the UTLS between 200-50 hPa $(\sim 11.8$ to $19.3 \mathrm{~km})$, peaking at $80 \mathrm{hPa}(\sim 17 \mathrm{~km})$, primarily in the Northern Hemisphere (Fig 4). The increase correlates very well with an up to $4 \% \mathrm{OH}$ decrease in the same region. Since $\mathrm{HO}_{\mathrm{x}}$ is the main family to destroy UTLS ozone, $\mathrm{OH}$ loss should increase ozone there. $\mathrm{OH}$ is produced primarily by aldehyde and HONO photolysis and $\mathrm{O}\left({ }^{1} \mathrm{D}\right)+\mathrm{H}_{2} \mathrm{O}$ reaction. WHFCV reduced column formaldehyde and acetaldehyde by 3.9 and $1.6 \%$, respectively, column HONO, and tropospheric $\mathrm{O}\left({ }^{1} \mathrm{D}\right)$ by reducing tropospheric ozone by $6 \%$ (Fig. 4). These reductions outweighed a slight (0.1\%) tropospheric $\mathrm{H}_{2} \mathrm{O}$ increase, causing a net $\mathrm{OH}$ loss.

Figure 4. Zonally- and 10-year averaged differences in ozone, temperature, and water vapor due to converting all FFOV to WHFCVs today.
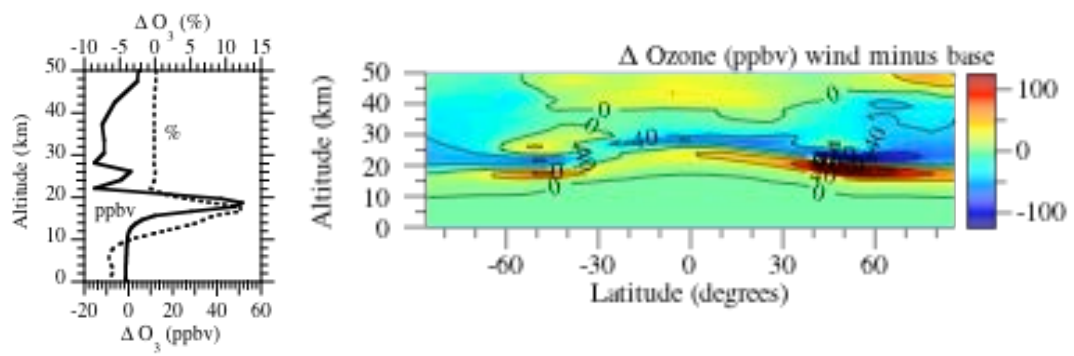

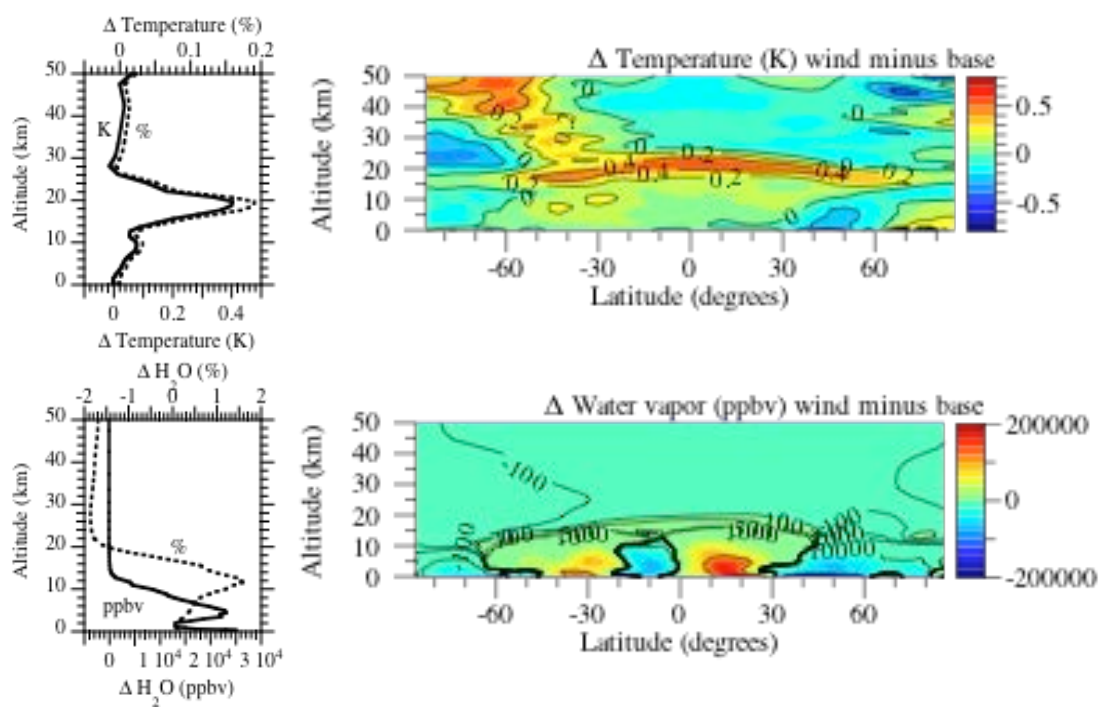

Although $\mathrm{CH}_{4}$ emissions decreased by $\sim 0.25 \%$, column $\mathrm{CH}_{4}$ increased slightly $(+0.25 \%)$ due primarily to a tropospheric $\mathrm{CH}_{4}$ increase caused by an $\mathrm{OH}$ loss. Tropospheric $\mathrm{OH}$ and $\mathrm{O}_{3}$ losses reduced chemical losses of isoprene and monoterpenes, increasing their concentrations and reducing secondary organic matter.

Greenhouse gases (GHGs) warm the surface and cool the stratosphere, thus their removal does the reverse, but over years to decades. Aerosol particles consist of warming components (e.g., $\mathrm{BC}$, some $\mathrm{POM}$ ) and cooling components (e.g., $\mathrm{S}(\mathrm{VI}), \mathrm{NO}_{3}{ }^{-}$, most POM and SOM). Cooling components dominate, so overall, aerosol particles caused net surface cooling, and their removal (with WHFCV) caused surface warming by reducing aerosol and cloud optical depths and increasing surface solar radiation. WHFCV decreased both GHG and aerosol emissions, so the net impact depended on the period during which changes occurred. For the 10-y simulations, a slight surface cooling and stronger UTLS warming occurred (Fig. 4), indicating that the GHG effect began to dominate by 10 years. UTLS warming occurred globally and was enhanced by the ozone increase there. Over a longer simulation, the surface cooling and stratospheric warming due to WHFCVs should strengthen.

Tropospheric cooling and stratospheric warming increases the stability of UTLS, reducing transport of water vapor to the stratosphere. This explains the decrease in upper tropospheric and stratospheric water vapor in Fig. 4. Over longer simulations, surface cooling would also reduce lower tropospheric water vapor regionally to a greater extent, reducing water vapor transport to the stratosphere further.

In the middle and upper stratosphere (above $25 \mathrm{~km}$ ), an increase in temperature or decrease in water vapor decreases ozone, when only chemical reactions and their temperature and water-vapor dependence, are considered [Fig. 5]. The inverse correlation between temperature, in particular, and ozone in the upper stratosphere is well known [e.g., Evans et al., 1998; Jonsson et al., 2009; Jacobson, 2008a] as is the inverse correlation between stratospheric water vapor and ozone [e.g., Shindell and Grewe, 2002; Jacobson, 2008a].

Figure 5. (a) Mixing ratio of ozone as a function of water vapor mixing ratio after 12 hours of a box-model chemistry-only simulation initialized at 0430 under several initial $\mathrm{NO}_{\mathrm{x}}$ and nonmethane organic gas (NMOG) mixing ratio combinations (ppbv) (given in the figure) at $298.15 \mathrm{~K}$ (solid lines) and $299.15 \mathrm{~K}$ (dashed lines), under near-surface photolysis conditions. The simulations assumed sinusoidally varying photolysis between 
0600 and 1800. (b) Stratospheric (25 km) mixing ratio of ozone as a function of water vapor mixing ratio after 36 hours of a box-model chemistry-only simulation initialized at 0430. Chemistry was solved among 128 gases and 395 inorganic, organic, sulfur, chlorine, and bromine reactions (including 57 photolysis reactions), assuming sinusoidally varying photolysis between 0600 and 1800. Results are shown for 221.55 $\mathrm{K}$, except an additional ozone curve at $220.05 \mathrm{~K}$ is shown as well. From Jacobson [2008a and its Suppl. Info.]
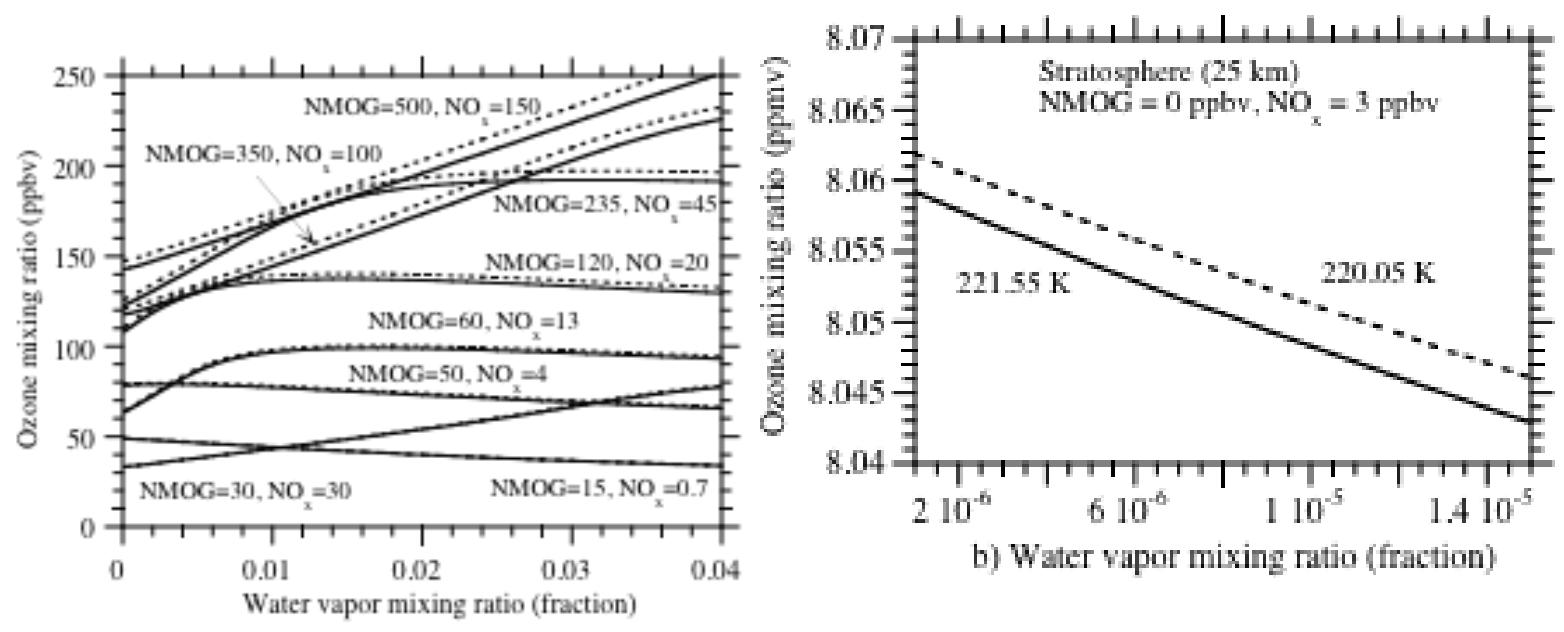

b) Water vapor mixing ratio (fraction)

In the present case, WHFCVs increased upper stratospheric temperatures, on average, thereby decreasing ozone there (Fig. 4). The small percent decrease in water vapor in the stratosphere due to WHFCVs (Fig. 4) increased ozone less than higher temperature decreased ozone, resulting in a net ozone decrease.

In the upper troposphere and lower stratosphere (UTLS), however, ozone increased. The increase was greater than was the upper-stratospheric ozone decrease, causing a net ozone column increase. UTLS ozone increases due to reducing GHGs from WHFCVs in Fig. 4 here [from Jacobson, 2008b] were consistent with results from Jacobson [2008a], where the effects of $\mathrm{CO}_{2}$ in isolation on ozone, particulate matter, and temperatures were examined. Most of the UTLS ozone increase here was due to the water vapor effect, as, between 18-25 km, water vapor decreased due to WHFCVs (Fig. 4), enhancing ozone due to chemistry alone (Fig. 5a). The increase in ozone due to a reduction in water vapor is due to a reduction in $\mathrm{OH}$ and $\mathrm{HO}_{2}$ produced by water vapor, reducing the catalytic ozone loss due to these chemicals. Shindell and Grewe [2002] found that, for net increases in stratospheric water vapor, ozone column should decrease, implying that for net decreases in stratospheric water vapor, ozone column should increase, a result consistent with that found here.

In the UTLS, under low $\mathrm{NO}_{\mathrm{x}}$ and organic gas mixing ratios, higher temperature (Fig. 4) have less effect on ozone than in the upper stratosphere (e.g., Fig. 5a, which applies to the surface, versus Fig. 5b), particularly since the $\mathrm{O}+\mathrm{O}_{3}$ reaction is less important than in the upper stratosphere [Evans et al., 1998].

A second, lesser reason for the UTLS ozone gains due to WHFCVs was that the warmer UTLS temperatures due to removing WHFCVs reduced the prevalence of aerosol and ice cloud surface area on which ozone-destroying halogen gases could form and by reducing nitric acid available for nitric acid trihydrate (NAT) ice crystals to form. WHFCV reduced aerosol surface area by reducing BC, POM, and S(VI) emissions and increasing precipitation. The reduced UTLS aerosol surface area decreased 
heterogeneous reactions, decreasing ambient $\mathrm{Cl}_{2}$ and $\mathrm{HOCl}$ [Jacobson, 2008b], which would otherwise go on to destroy ozone.

Fahey et al. [2001] observed large particles containing nitric acid sedimenting in the Arctic winter stratosphere. They hypothesized that greenhouse gases, which increase water vapor and cool the stratosphere, increase the prevalence of ice clouds on which ozone-destroying reactions occur and on the sedimentation rate of nitric acid particles, enhancing denitrification. The denitrification reduces the ability of active chlorine to combine with nitric acid to form chlorine nitrate $\left(\mathrm{ClONO}_{2}\right)$, thereby extending ozone loss. Their hypothesis, that an increase in greenhouse gases destroys stratospheric ozone through these mechanisms implies that the reverse, removal of greenhouse gases, should increase such ozone. This result is consistent with what was found here with respect to the effect of converting to WHFCVs.

8. Effects of Converting from FFOVs to Steam-Reforming-Powered HFCVs in 2050 Ten-year model simulations were performed examining the effect of converting $90 \%$ of FFOV in developed countries and 45\% of FFOVs vehicles in other countries in 2050 to hydrogen fuel cell vehicles, where the $\mathrm{H}_{2}$ is produced by steam-reforming of natural gas (SHFCVs). Key emissions for these simulations are given in Table 2.

Figure 6 shows simulation-averaged differences in several modeled gases and aerosol components and temperature due to the conversion to SHFCVs. Most of the chemicals shown were emitted directly. Some, such as ozone and sulfate aerosol (S(VI)), formed in the atmosphere due to chemical reaction and gas-to-particle conversion. The figure indicates a significant regional variation in changes, which reflects the fact that emission factors derived for Table 2 varied in each region of the world. In general, mixing ratios or concentrations of most emitted chemicals decreased in the global average. Decreases occurred primarily in North America and Europe, and for some chemicals, in China. Increases occurred in South America, Africa, and parts of Asia, including India. Some chemicals, such as $\mathrm{H}_{2}$ and $\mathrm{SO}_{2}$, increased in the U.S. and Europe due to the higher penetration of SHFCVs there, thus the higher leakage rate of $\mathrm{H}_{2}$ and power plant emissions of $\mathrm{SO}_{2}$ there (Table 2) due to power requirements for compressing $\mathrm{H}_{2}$. Due to the decrease in $\mathrm{NO}_{\mathrm{x}}$ and organics in particular, surface ozone decreased in the global average due to the conversion to SHFCVs (Fig. 6). Further, surface temperature decreased due to the conversion, with most decreases occurring at high latitudes (Fig. 6). Decreases occurred primarily due to the reduction in $\mathrm{CO}_{2}$ and black carbon (Fig. 6), both of which are strong global warming agents.

Figure 6. Ten-year-average differences in several gas and aerosol parameters and temperature near the surface due to the conversion of FFOVs to SHFCVs in 2050. Numbers in parentheses are globally-averaged changes in the figure.

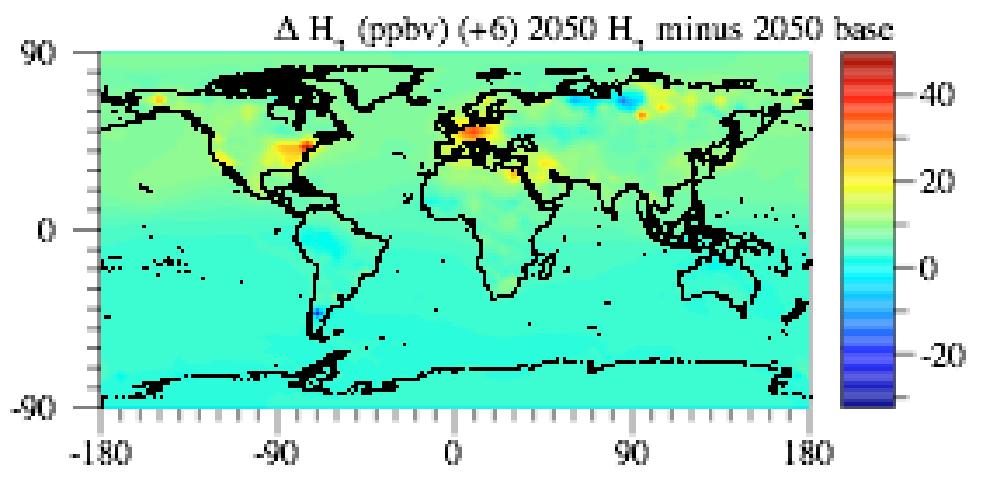



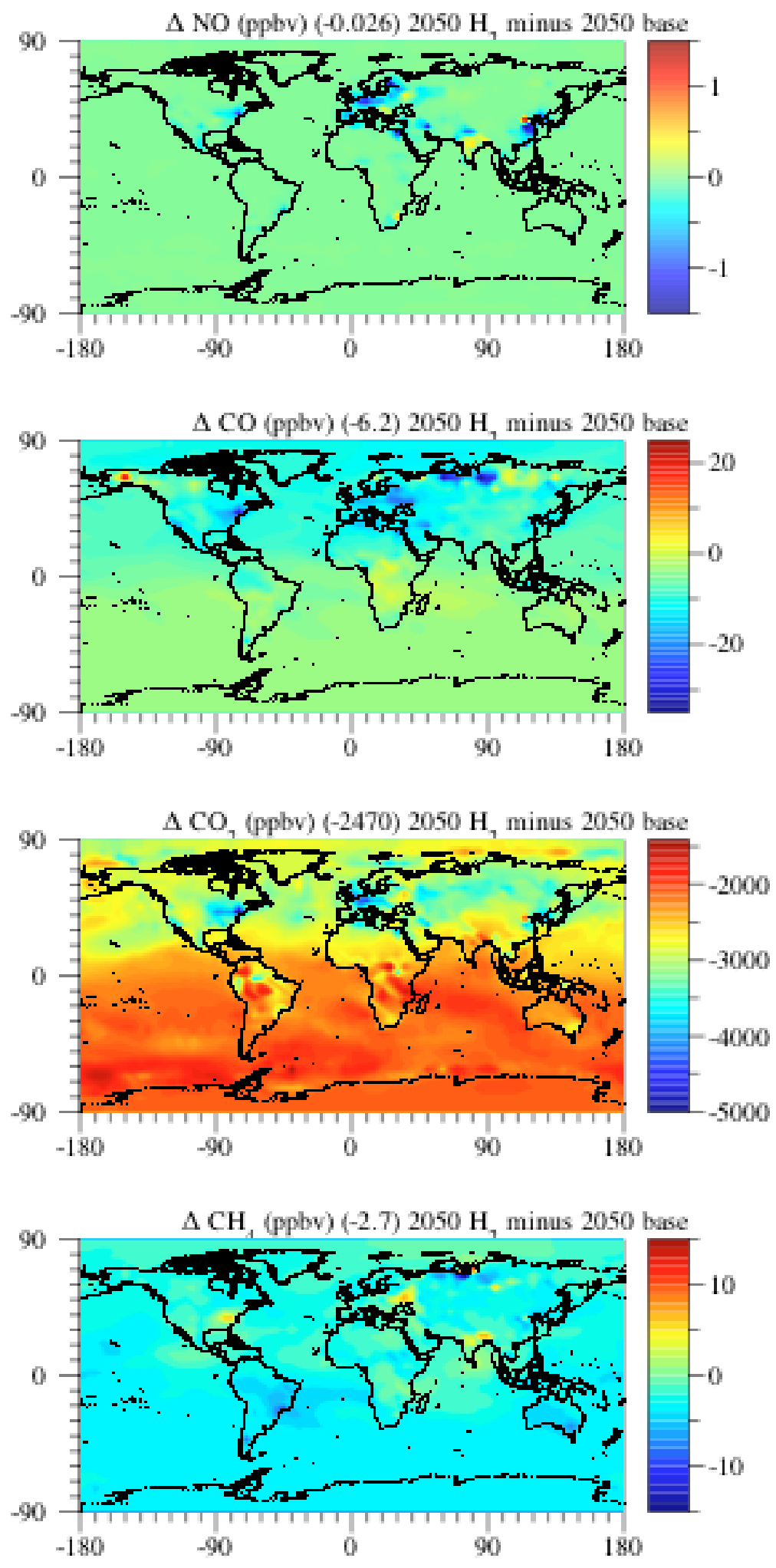

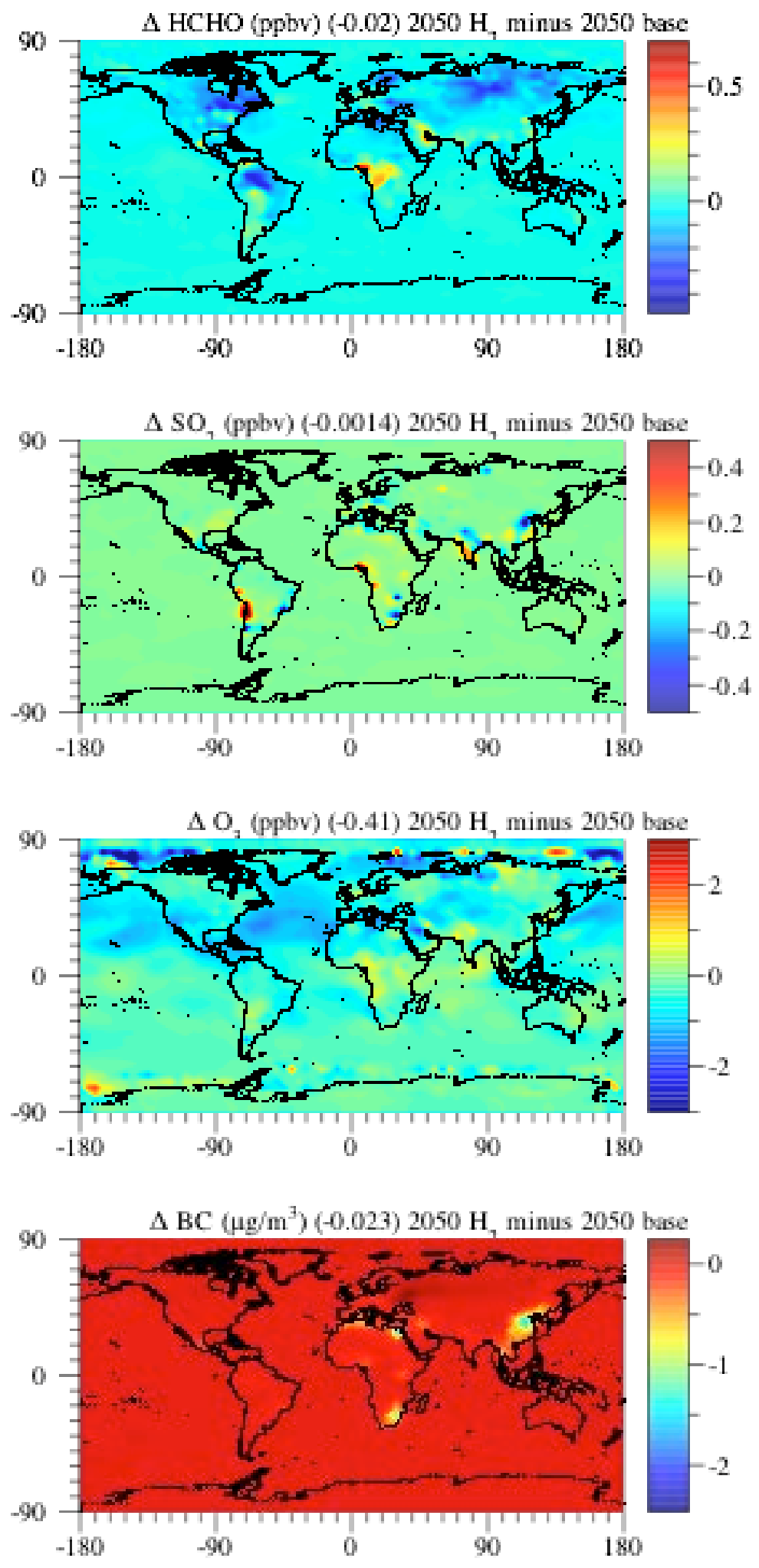

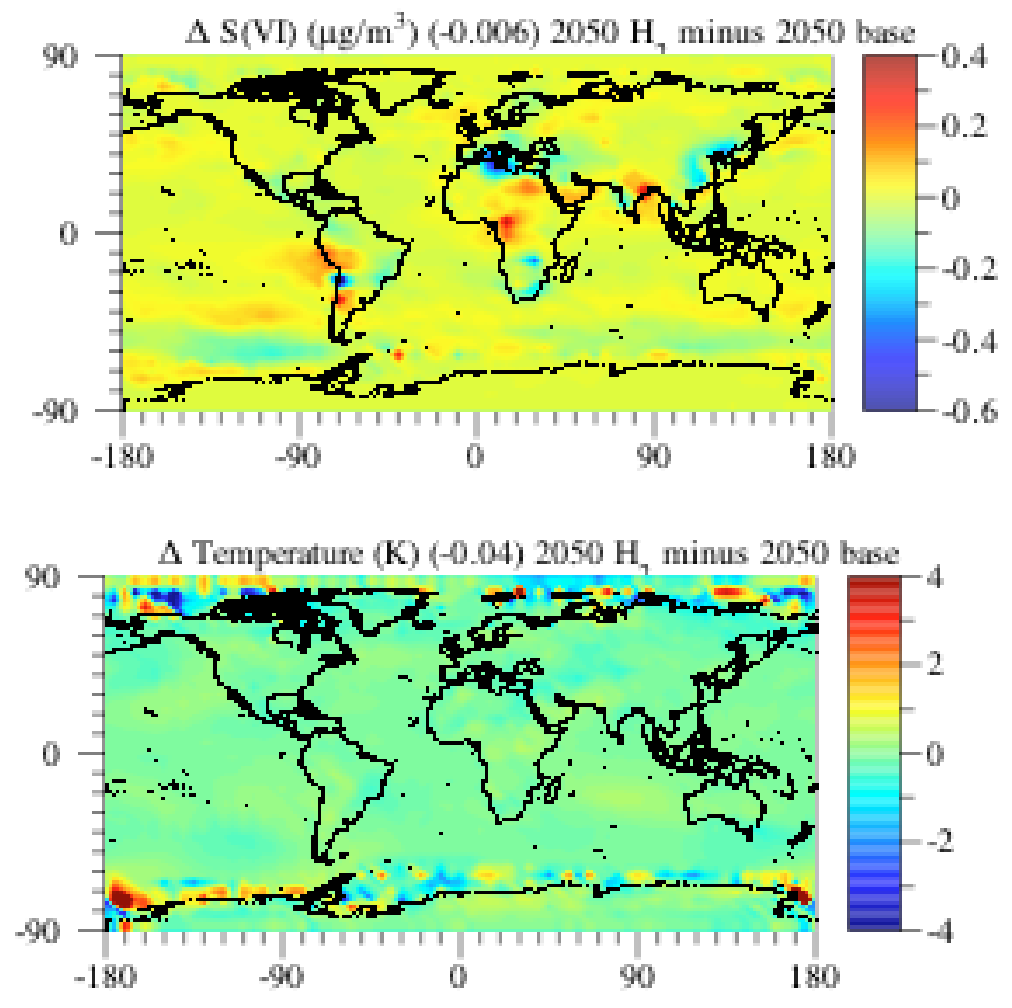

Figure 7 shows simulation- and zonally-averaged differences in several parameters due to the conversion. These plots give an indication of the effects of a switch from FFOVs to SHFCVs on tropospheric and stratospheric composition and climate.

Tropospheric changes in the major emitted chemicals, $\mathrm{H}_{2}, \mathrm{NO}, \mathrm{CO}, \mathrm{CO}_{2}, \mathrm{CH}_{4}$, $\mathrm{HCHO}$, toluene, $\mathrm{SO}_{2}$, and $\mathrm{BC}$, reflect changes, for the most part, in emissions of these chemicals, as determined from Table 2 . An exception was $\mathrm{CH}_{4}$, whose emissions did not change much in Table 2 but whose column abundance decreased in the global average due to a slight increase in $\mathrm{OH}$ in many regions, which itself was caused by a significant decrease in $\mathrm{CO}$ due to SHFCVs. $\mathrm{CO}$ is oxidized by $\mathrm{OH}$, removing $\mathrm{OH}$, so a reduction in $\mathrm{CO}$ increases $\mathrm{OH}$. This result differs from in Jacobson [2009], where OH decreased slightly due to a conversion to wind-powered HFCVs (WHFCVs), causing an increase in $\mathrm{CH}_{4}$. The reason $\mathrm{OH}$ decreased in that case was that, although $\mathrm{CO}$ emissions also decreased in that case, so did aldehyde emissions, and aldehydes are significant sources of $\mathrm{OH}$, so reducing aldehydes decreased $\mathrm{OH}$. Also, a reduction in stratospheric water vapor reduced stratospheric $\mathrm{OH}$. In the present scenario, aldehyde emissions increased slightly, producing $\mathrm{OH}$ that offset $\mathrm{OH}$ reduction due to a reduction in water vapor (Fig. 7). However, over a longer simulation period, it is expected that further cooling due to greater accumulated reductions in $\mathrm{CO}_{2}$ will reduce water vapor further, reducing $\mathrm{OH}$ causing a net increase in $\mathrm{CH}_{4}$.

The decrease in $\mathrm{CO}_{2}$ emissions due to the conversion to SHFCVs decreased tropospheric $\mathrm{CO}_{2}$ more than it decreased stratospheric $\mathrm{CO}_{2}$. The decrease in tropospheric $\mathrm{CO}_{2}$ cooled the surface by $0.04 \mathrm{~K}$ (Fig. 6) and warmed the stratosphere, on average, although regional cooling occurred at high northern latitudes (Fig. 7). A comparison of the temperature change panels in Figs. 4 and 6 indicate similar locations of cooling and warming due to contemporary WHFCVs and 2050 SHFCVs, particularly in the Southern 
Hemisphere, but a greater change due to WHFCVs. Over a longer simulation, the surface cooling and stratospheric warming should strengthen in both cases.

The decrease in $\mathrm{NO}_{\mathrm{x}}, \mathrm{CO}$, and $\mathrm{CH}_{4}$ in particular decreased surface and midtropospheric ozone due to a conversion to SHFCVs (Figs. 5 and 6). The conversion also increased upper-tropospheric/lower stratospheric ozone, on average, and decreased upper stratospheric ozone (Fig. 7) in a manner similar to in the WHFCV case (Fig. 4) and for similar reasons. Again, $\mathrm{O}_{3}$ changes in the WHFCV case were greater in magnitude than in the SHFCV case. In both cases, effects should strengthen over a longer simulation period as greater accumulated reductions in $\mathrm{CO}_{2}$ over a longer simulation will trigger greater tropospheric cooling and stratospheric warming, increased stratospheric stability, reduced surface evaporation of water, and reduced UTLS water vapor, causing greater increases in UTLS ozone and greater decreases in upper stratospheric ozone, and greater net increases in overall ozone.

As discussed in Section 3, we believe the organic gas emissions under the 2050 A1B $\mathrm{H}_{2}$ scenario were probably too high. If they were lower, as we expect they should be, then the results here would be strengthened, since a reduction in aldehydes, in particular, will decrease tropospheric and some stratospheric $\mathrm{OH}$, decreasing surface ozone and increasing stratospheric ozone further.

Figure 7. Ten-year averaged differences in modeled parameters in the zonal average due to the conversion of FFOVs to SHFCVs in 2050.
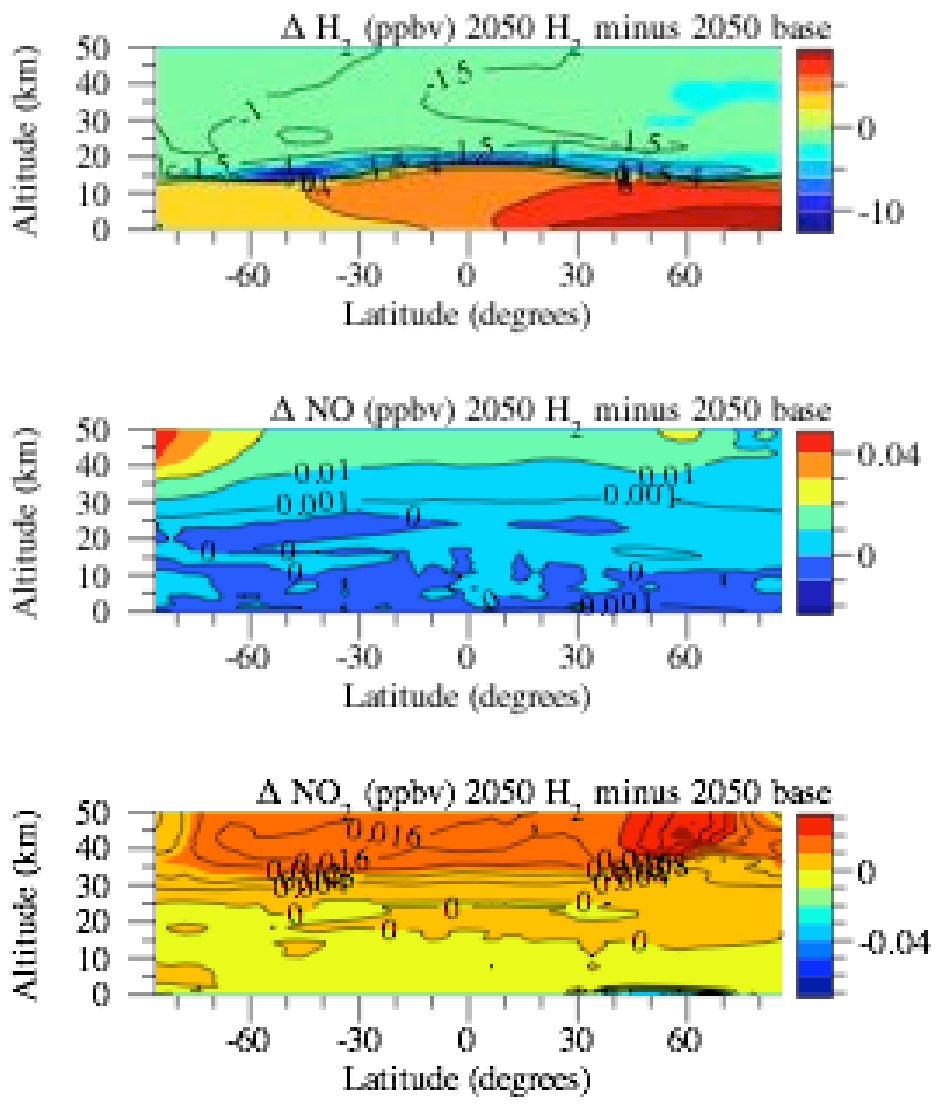

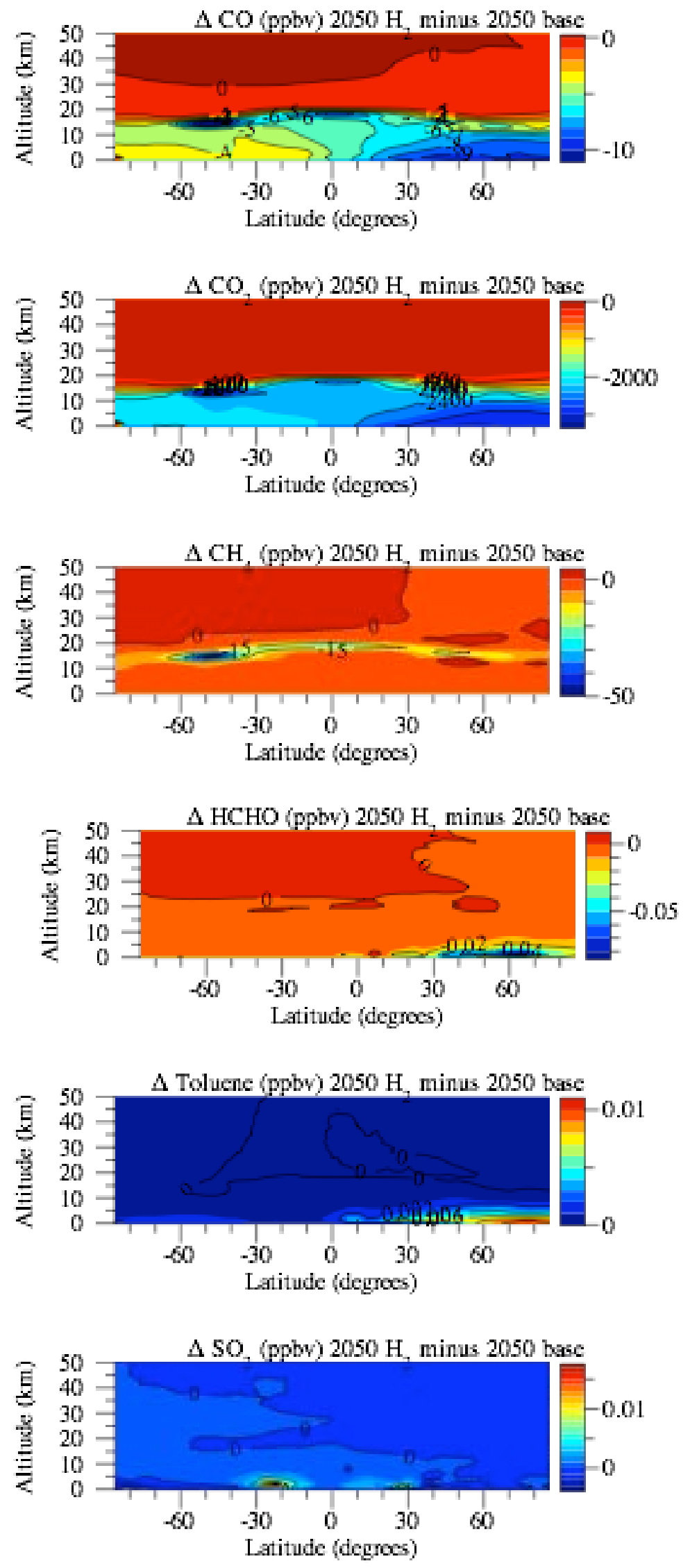

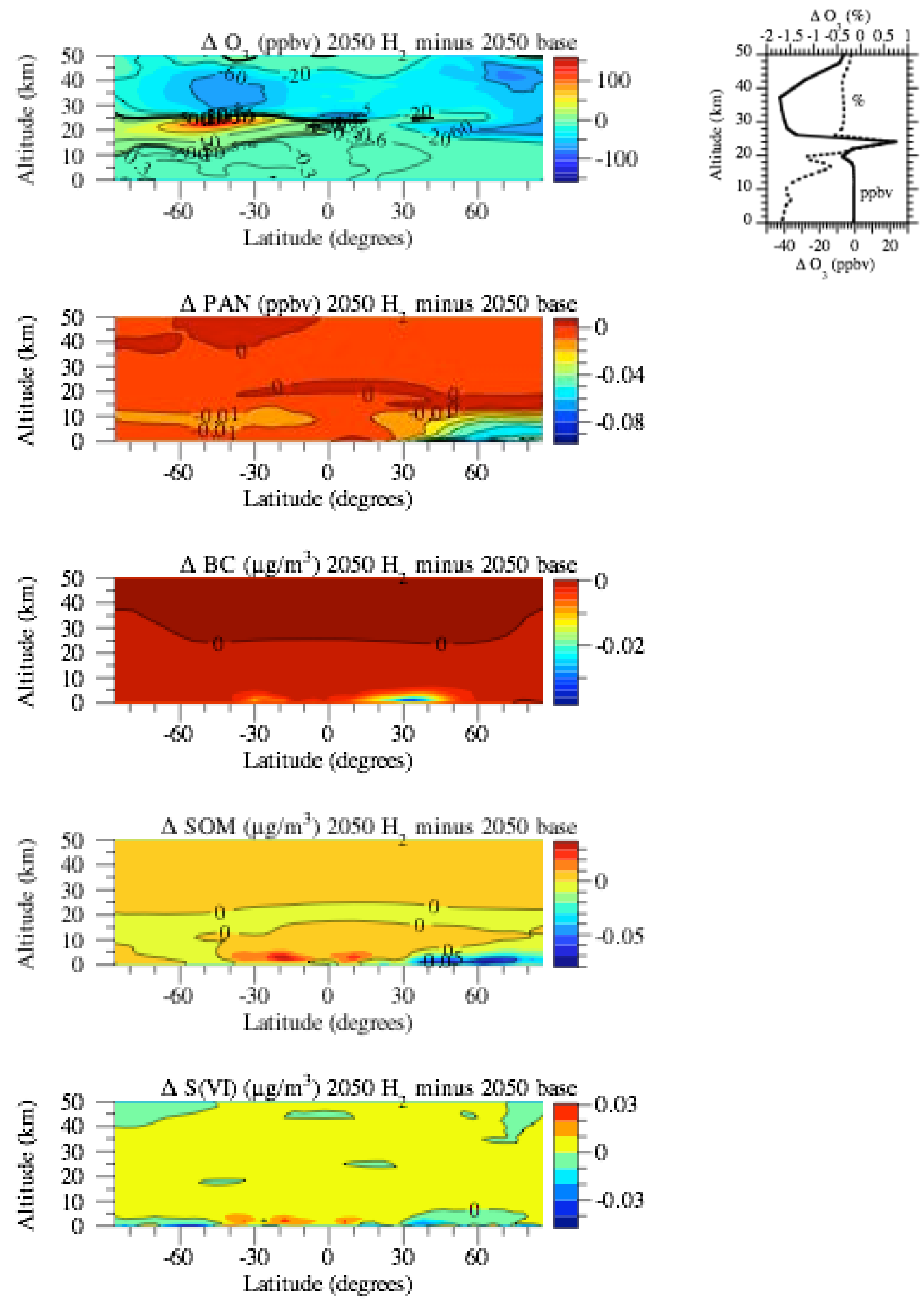

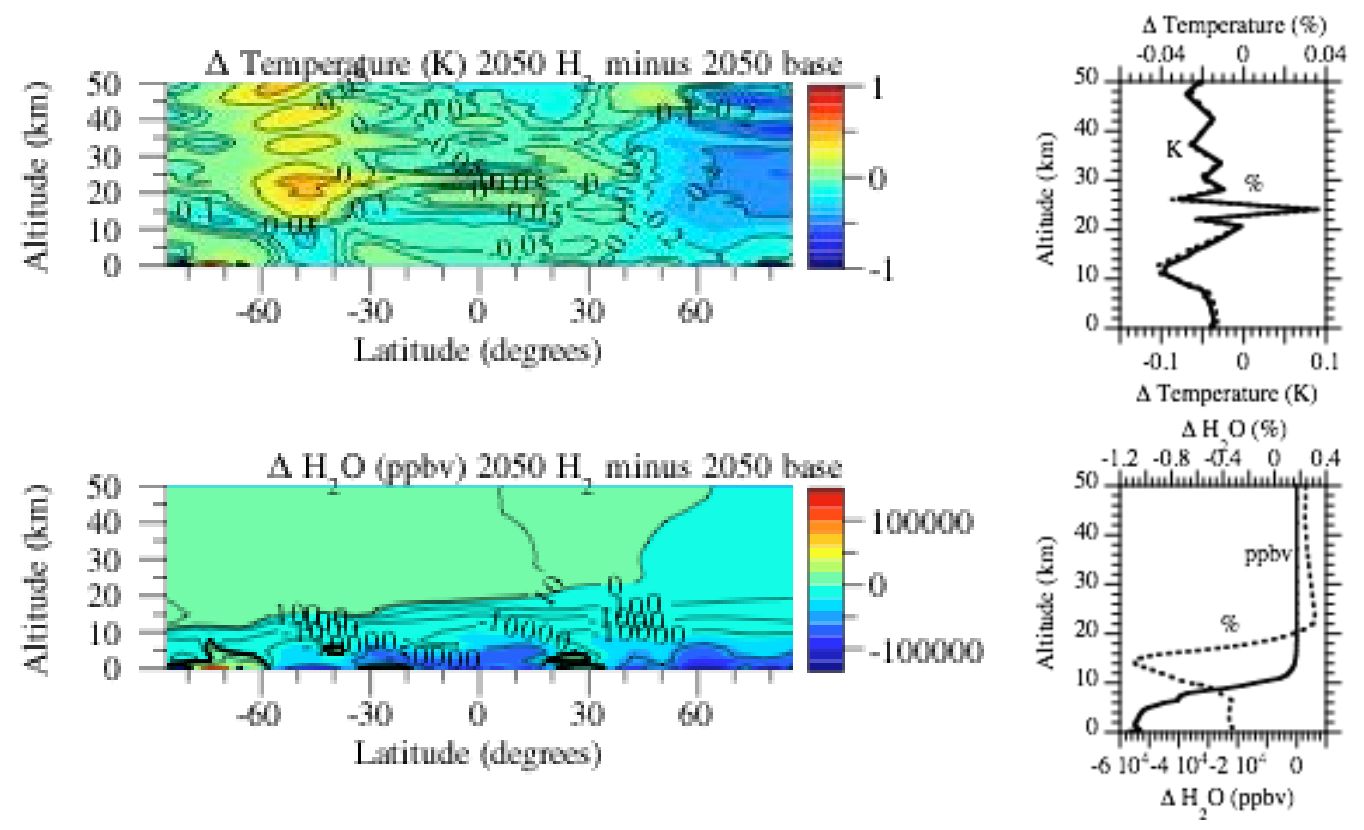

\section{Conclusion}

For this project, we examined the effects on climate, the stratospheric ozone layer, and tropospheric composition of converting fossil-fuel onroad vehicles (FFOVs) to hydrogen fuel cell vehicles (HFCVs). The atmospheric model, GATOR-GCMOM, was used for the analysis. The model was first updated and evaluated with respect to its ability to predict sources and sinks of $\mathrm{H}_{2}$. Current and future (2050) emission inventories of all important anthropogenic gas and particle chemicals were then developed. The future inventories included one based on the IPCC SRES A1B scenario and another based on the same scenario but modified with $90 \%$ penetration of HFCVs in developed countries and $45 \%$ penetration in other countries and $\mathrm{H}_{2}$ produced by steam-reforming of natural gas. Subsequently, 10-year simulations were run to examine the effect of converting onroad vehicles in 2050 to steam-reforming-powered HFCVs (SHFCVs). These were compared with 10-year simulations run examining the effect of converting all current onroad vehicles worldwide to HFCVs where the $\mathrm{H}_{2}$ was produced by electrolysis, with the electricity derived from wind power (WHFCVs).

Major conclusions of the project are as follows:

1) Converting $100 \%$ of current vehicles worldwide to WHFCVs is expected to reduce levels of $\mathrm{NO}_{\mathrm{x}}, \mathrm{CO}, \mathrm{CO}_{2}$, most organic gases, $\mathrm{OH}$, ozone, PAN, black carbon, and other particle components in the troposphere, but to increase tropospheric $\mathrm{CH}_{4}$ due to the lower $\mathrm{OH}$. However, by cooling the troposphere and warming the stratosphere, thereby stabilizing the stratosphere, reducing water vapor and $\mathrm{HO}_{\mathrm{x}}$ transport to it, and reducing the sizes and lifetimes of stratospheric aerosols and polar stratospheric clouds, WHFCVs are expected to increase upper tropospheric/lower stratospheric ozone, causing a net global ozone column increase. This net increase occurs despite a slight upper stratospheric decrease in ozone.

2) Converting vehicles worldwide in 2050 to SHFCVs at $90 \%$ penetration in developed countries and $45 \%$ penetration in other countries is expected to reduce $\mathrm{NO}_{\mathrm{x}}, \mathrm{CO}, \mathrm{CO}_{2}$, $\mathrm{CH}_{4}$, some other organic gases, ozone, PAN, black carbon, and other particle components in the troposphere, but may increase some other organic gases there, depending on the exact emission changes. SHFCVs are also expected to cool the troposphere and warm the stratosphere, but to a lesser extent than WHFCVs. Finally, 
SHFCVs are expected to increase upper tropospheric/lower stratospheric ozone while decreasing upper stratospheric ozone, but to a lesser extent in both cases than WHFCVs.

3) The results here (with respect to WHFCVs and SHFCVs) will likely strengthen over longer simulation periods, as greater reductions in $\mathrm{CO}_{2}$ over a longer simulation period will trigger greater tropospheric cooling and stratospheric warming, causing greater reductions in surface ozone and greater net increases in stratospheric ozone.

4) We think the results found are robust for larger leakage rates of hydrogen and for greater penetrations of HFCVs, since we believe that the controlling factor for stratospheric ozone impacts is the reduction in fossil-fuel greenhouse gases and the resulting surface cooling, which reduces water vapor emissions, and stratospheric warming, which increases tropopause stability, reducing water vapor transport to the stratosphere. The reduction in water vapor (and ozone-destroying hydrogen oxides that are produced) to the stratosphere due to climate feedbacks should be larger than increases in water vapor and hydrogen oxides produced by leaked hydrogen, causing a net column ozone increase. Further, warmer stratospheric temperatures due to HFCVs should reduce aerosol and polar stratospheric cloud size and lifetime, reducing ozone loss further. While we do not know exactly what hydrogen leakage rate and vehicle penetration would cause net damage, we are confident, based on results to date that indicate the dominance of climate feedbacks, that all realistic proposed future scenarios of HFCV fleets will not cause damage. As such, we see no disadvantage to the future large-scale penetration of HFCVs.

\section{Acknowledgments}

This work was funded by the Department of Energy under DE-FG36-07G017108. We would also like to thank Dr. David Streets of Argonne National Laboratory for providing emission growth factors and John Ten Hoeve from Stanford University for providing some land use model data sets.

\section{References}

Andreae, M. O. and P. Merlet (2001), Emission of trace gases and aerosols from biomass burning, Global Biogeochemical Cycles, 15, 955-966.

Andres, R. J., and A. D. Kasgnoc (1998), A time-averaged inventory of subaerial volcanic sulfur emissions, J. Geophys. Res., 103, 25,251-25,261.

Conrad, R., and W. Seiler (1985), Influence of temperature, moisture, and organic carbon on the flux of $\mathrm{H}_{2}$ and $\mathrm{CO}$ between soil and atmosphere: Field studies in subtropical regions, J. Geophys. Res., 90, 5699-5709.

Barnes, D.H., S.C. Wofsy, B.P. Fehlau, E.W. Gottlieb, J.W. Elkins, G.S. Dutton, and P.C. Novelli (2003), Hydrogen in the atmosphere: Observations above a forest canopy in a polluted environment, J. Geophys. Res., 108 (D6) doi:10.1029/2001JD001199.

Bond, T.C., Streets, D.G., Yarber, K.F., Nelson, S.M., Woo, J.-H. \& Klimont, Z. (2004), A technology-based global inventory of black and organic carbon emissions from combustion, J. Geophys. Res., 109, D14203, doi: 10.1029/2003JD003697.

Businger, J. A., J.C. Wyngaard, Y. Izumi, and E.F. Bradley (1971), Flux-profile relationships in the atmospheric surface layer, J. Atmos. Sci. 28, 181-189.

Colella, W.C., M.Z. Jacobson, and D.M. Golden (2005), Switching to a U.S. hydrogen fuel cell vehicle fleet: The resultant change in emissions, energy use, and greenhouse gases, J. Power Sources, 150, 150-181.

Giglio, L., G.R. van der Werf, J.T. Randerson, G.J. Collatz, and P. Kasibhatla (2006), Global estimation of burned area using MODIS active fire observations, Atmos. Chem. and Physics, 6, 957-974. 
Evans, S.J., R. Toumi, J.E. Harries, M.P. Chipperfield, and J.M. Russell III (1998), Trends in stratospheric humidity and the sensitivity of ozone to these trends, $J$. Geophys. Res., 103, 8715-8725.

Fahey, D.W., et al. (2001) The detection of large $\mathrm{HNO}_{3}$-containing particles in the Winter Arctic Stratosphere, Science, 291, 1026-1030.

Hauglustaine, D.A., and D.A. Ehhalt (2002), A three-dimensional model of molecular hydrogen in the troposphere, J. Geophys. Res., 107, 4330, doi:10.1029/2001JD001156.

Hogstrom, U. (1988), Non-dimensional wind and temperature profiles in the atmospheric surface layer: A reevaluation, Boundary-Layer Meteor., 42, 55-78.

Jacobson, M. Z. (2003), Development of mixed-phase clouds from multiple aerosol size distributions and the effect of the clouds on aerosol removal, J. Geophys. Res., 108 (D8), 4245, doi:10.1029/2002JD002691.

Jacobson, M.Z. (2005) Fundamentals of Atmospheric Modeling, Part II, Cambridge University Press, New York, 813 pp.

Jacobson, M.Z. (2008a) On the causal link between carbon dioxide and air pollution mortality, Geophys. Res. Lett., 35, L03809, doi:10.1029/2007GL031101.

Jacobson, M.Z. (2008b) Effects of wind-powered hydrogen fuel cell vehicles on stratospheric ozone and global climate, Geophys. Res. Lett., 35, L19803, doi:10.1029/2008GL035102.

Jacobson, M.Z., W.C. Colella, and D.M. Golden (2005), Cleaning the air and improving health with hydrogen fuel cell vehicles, Science, 308, 1901-1905.

Jacobson, M.Z., Y.J. Kaufmann, Y. Rudich (2007), Examining feedbacks of aerosols to urban climate with a model that treats 3-D clouds with aerosol inclusions, $J$. Geophys. Res., 112, D24205, doi:10.1029/2007JD008922.

Jacobson, M.Z. (2008), Effects of wind-powered hydrogen fuel cell vehicles on stratospheric ozone and global climate, Geophys. Res. Lett., 35, L19803, doi:10.1029/2008GL035102.

Jacobson, M.Z., and D.G. Streets (2009) The influence of future anthropogenic emissions on climate, natural emissions, and air quality, J. Geophys. Res., 114, D08118, doi:10.1029/2008JD011476.

Jonsson, A.I., V.I. Fomichev, and T.G. Shepherd (2009) An updated analysis of the attribution of stratospheric ozone and temperature changes to changes in ozonedepleting substances and well-mixed greenhouse gases, Atmos. Chem. Phys. Discuss, 9, 14857-14872.

Kettle, A. J. et al. (1999), A global database of sea surface dimethylsulfide (DMS) measurements and a procedure to predict sea surface DMS as a function of latitude, longitude, and month, Global Biogeochem. Cycles, 13, 399-444.

Klimont, Z., D.G. Streets, S. Gupta, J. Cofala, L. Fu, and Y. Ichikawa (2002), Anthropogenic emissions of non-methane volatile organic compounds (NMVOC) in China, Atmos. Environ., 36, 1309-1322.

Louis J.-F. (1979), A parametric model of vertical eddy fluxes in the atmosphere, Boundary Layer Meteor., 17, 187-202.

Ludwig, J., L.T. Marufu, B. Huber, M.O. Andreae, and G. Helas (2003) Domestic combustion of biomass fuels in developing countries: A major source of atmospheric pollutants, J. Atmos. Chem., 44, 23-37.

McRae G. J., W.R. Goodin, and J.H. Seinfeld (1982), Development of a secondgeneration mathematical model for urban air pollution -- I. Model formulation, Atmos. Environ., 16, 679-696.

MODIS/USGS (2006) Land Cover Yearly L3 Global $500 \mathrm{~m}$ data, https://lpdaac.usgs.gov/lpdaac/products/modis_product_table/land_cover/yearly_l3 glob, 2005 data processed to $0.01^{\circ}$.

National Institute for Public Health and the Environment (RIVM) (2001), The IMAGE 2.2 Implementation of the SRES Scenarios: A Comprehensive Analysis of Emissions, 
Climate Change and Impacts in the $21^{\text {st }}$ Century [CD-ROM], RIVM Publ. 481508018, Bilthoven, Netherlands.

Novelli, P.C., P.M. Lang, K.A. Masarie, D.F. Hurst, R. Myers, and J.W. Elkins (1999), Molecular hydrogen in the troposphere: Global distribution and budget, J. Geophys. Res., 104, 30427-30444.

Olivier, J. G. J., A. F. Bouwman, C. W. M. Van der Maas, J. J. M. Berdowski, C. Veldt, J. P. J. Bloos, A. J. H. Visschedijk, P. Y. J. Zandveld, and J. L. Haverlag (1996), Description of EDGAR Version 2.0: A set of global emission inventories of greenhouse gases and ozone-depleting substances for all anthropogenic and most natural sources on a per country basis on $1^{\circ} \times 1^{\circ}$ grid, National Institute of Public Health and the Environment, RIVM) report no. 771060002 / TNO-MEP report no. R96/119.

Price, H., L. Jaegle, A. Rice, P. Quay, P.C. Novelli, and R. Gammon (2007), Global budget of molecular hydrogen and its deuterium content: Constraints from ground station, cruise, and aircraft observations, J. Geophys. Res., 112, D22108

Rhee, T.S., C.A.M. Brenningkmeijer, and T. Rockmann (2006), The overwhelming role of soils in the global atmospheric hydrogen cycle, Atmos. Chem. Phys., 6, 16111625.

Sanderson, M.G., W.J. Collins, R.G. Derwent, and C.E. Johnson (2003), Simulation of global hydrogen levels using a Lagrangian three-dimensional model, J. Atmos. Chem., 46, 15-28.

Schultz, M.G., T. Diehl, G.P. Brasseur, and W. Zittel, 2003. Air pollution and climateforcing impacts of a global hydrogen economy, Science, 302, 624-627.

Seiler, W., and R. Conrad (1987) Contribution of tropical ecosystems to the global budgets of trace gases, especially CH4, H2, CO, and N2O, in R.E. Dickinson (ed.), The Geophysiology of Amazonia, John Wiley and Sons, New York, pp. 133-157.

Shindell, D.T., and V. Grewe (2002) Separating the influence of halogen and climate changes on ozone recovery in the upper stratosphere, J. Geophys. Res., 107, 4144, 10.1029/2001JD000420.

Simmonds, P. G., R. G. Derwent, S. O'Doherty, D. B. Ryall, L. P. Steele, R. L. Langenfelds, P. Salameh, H. J. Wang, C. H. Dimmer, and L. E. Hudson (2000), Continuous high-frequency observations of hydrogen at the Mace Head baseline atmospheric monitoring station over the 1994-1998 period, J. Geophys. Res., 105(D10), 12,105-12,121.

Smith-Downey N. V., J. T. Randerson, J. M. Eiler (2006), Temperature and moisture dependence of soil $\mathrm{H}_{2}$ uptake measured in the laboratory, Geophys. Res. Lett., 33, L14813, doi:10.1029/2006GL026749.

Streets, D.G., T.C. Bond, G.R. Carmichael, S.D. Fernandes, Q. Fu, D. He, Z. Klimont, S.M. Nelson, N.Y. Tsai, M.Q. Wang, J.-H. Woo, and K.F. Yarber (2003), An inventory of gaseous and primary aerosol emissions in Asia in the year 2000, $J$. Geophys. Res., 108(D21), 8809, doi:10.1029/2002JD003093.

Symonds, R.B., W.I. Rose, G. Bluth, and T.M. Gerlach (1994), Volcanic gas studies: methods, results, and applications, in Carroll, M.R., and J.R. Holloway, eds., Volatiles in Mamas: Mineralogical Society of America Reviews in Mineralogy, 30, 1-66.

Tromp, T.K., R.-L. Shia, M. Allen, J.M. Eiler, and Y.L. Yung (2003), Potential environmental impact of a hydrogen economy on the stratosphere, Science, 300, 1740-1742.

Warneck, P. (1999) Chemistry of the Natural Atmosphere, $2^{\text {nd }}$ edn., International Geophysics Series, Vol. 71, Academic Press, New York.

Warwick, N.J., S. Bekki, E.G. Nisbet, and J.A. Pyle (2004), Geophys. Res. Lett. 31, L05107, doi:10.1029/2003GL019224.

Walmsley J. L. and M.L. Wesely (1996), Modification of coded parameterizations of surface resistances to gaseous dry deposition, Atmos. Environ., 30A, 1181-1188. 
Wesely M. L. (1989), Parameterization of surface resistances to gaseous dry deposition in regional-scale numerical models, Atmos. Environ., 23, 1293-1304.

Yonemura, S., S. Kawashima, and H. Tsuruta (2000), Carbon monoxide, hydrogen, and methane uptake by soils in a temperate arable field and a forest, J. Geophys. Res., 105, 14,347-14,362. 


\title{
APPENDIX C \\ DEVELOPMENT, VERIFICATION, AND APPLICATIONS OF A SIMPLIFIED HYDROGEN MODEL. TETRA TECH, INC., JANUARY 2010.
}

\begin{abstract}
A model of hydrogen dynamics in the troposphere and stratosphere has been developed. The model is intended to complement more complex three-dimensional models, such as GATORGCMOM (Jacobson, 2009).
\end{abstract}

The model presented here, while unable to simulate the wide array of processes parameterized in numerical three-dimensional models, can simulate atmospheric hydrogen mixing ratios over time periods that extend from well into the past to well into the future (for example, from the beginning of the industrial revolution to the end of the $21^{\text {st }}$ century) in a matter of minutes while at the other extreme, GATOR-GCMOM can take weeks of real time to simulate a decade.

The simplified model can predict how atmospheric hydrogen mixing ratios will be affected by conversion to an alternative hydrogen economy (e.g., to hydrogen fuel cell vehicles). Model verification and validation tests have been completed, and are reported here as well. Multiple sources and sinks of hydrogen are included in the global model.

The model also predicts the total atmospheric burden and lifetime of hydrogen. The historical period from 1992 to present shows that the model can predict the recent hydrogen mixing ratios in the troposphere, (approximately 531 ppbv globally averaged). Hypothetical market conversion scenarios are simulated, and predicted hydrogen mixing ratios have been simulated up to the end of the $21^{\text {st }}$ century.

\section{Introduction}

Research over the past decade on hydrogen fuel cell vehicles (HFCVs) has been carried out to examine whether HFCVs can provide a low carbon alternative to gasoline powered vehicles. Several researchers have voiced concerns that the amount of fugitive hydrogen released to the atmosphere would substantially increase, primarily by leakage into the troposphere from production, distribution and storage of hydrogen and could adversely impact the stratosphere.

Tromp et al. (2003) estimated $10 \%$ to $20 \%$ of the amount of molecular hydrogen anthropogenically generated could be leaked into the troposphere, which is equivalent to between 60 and $120 \mathrm{Tg}$ /year, assuming a 100 percent change in the future of all technologies based on oil or gasoline. Tromp et al. predict these emission increases, and associated atmospheric chemistry reactions, could cause tropospheric hydrogen concentrations to increase 
up to 2300 ppbv, from its present value of 530 ppbv. Warrwick et al. (2004) provided another estimate of emission rates based on leakage rates of $1 \%$ to $12 \%$ and assuming that hydrogen would supply $33 \%$ to $100 \%$ of all present day energy needs. Their fugitive emission estimates of leakage ranged from $8.8 \mathrm{Tg} /$ year to $260 \mathrm{Tg} /$ year. A summary of estimates of potential leakage rates generated by various researchers is shown in Table $\mathrm{C}-1$.

Table C-1

Estimates of Anthropogenic Hydrogen Generation and Leakage from Anthropogenic Production, Distribution, and Storage Operations

\begin{tabular}{|c|c|c|c|}
\hline Reference & \% Leakage & Estimated Global $\mathrm{H}_{2}$ Production, Tg/yr & Leakage, Tg/yr \\
\hline Jacobson (2009) & $3 \%$ & 160 & 4.82 \\
\hline Tromp et al. (2003) & $10 \%-20 \%$ & $\begin{array}{c}600 \text { (100\% of all technologies based on oil or } \\
\text { gasoline combustion are replaced by } \\
\text { hydrogen fuel cells) }\end{array}$ & $60-120$ \\
\hline Kammen and Lipman (2003) & $1 \%-2 \%$ & 200 (30\% penetration) & $2-4$ \\
\hline Lovins (2003) & $1 \%$ & Below natural background sources & $\begin{array}{c}10 \text { - } 100 \text { times lower than Tromp } \\
\text { et al. (2003) }\end{array}$ \\
\hline Coletta et al. (2005) & $3 \%$ & 150 & 4.5 \\
\hline Warrwick et al. (2003) & $1 \%-12 \%$ & $\begin{array}{c}880-2600 \text { (Supplies } 33 \% \text { to } 100 \% \text { of all } \\
\text { present day energy needs) }\end{array}$ & $10-260$ \\
\hline
\end{tabular}

As part of ongoing research (Jacobson, 2009) has shown how a hydrogen economy could influence the environment (such as by affecting atmospheric emissions and concentrations of carbon dioxide, methane, carbon black, hydrogen and other constituents). The three-dimensional model GATOR-GCMOM which solves dynamical, gas, aerosol, cloud, transport, radiation and surface processes (Jacobson et al., 2005, 2007 and Jacobson, 2005, 2007, 2008) was used to simulate effects of converting the world's fossil-fuel vehicles (FFOV) to hydrogen fuel cell vehicles (HFCV) by steam reforming of natural gas to produce hydrogen and by wind power to generate hydrogen from electricity. Since multiyear model simulations can take weeks to complete, a simplified model that can address a portion of the problem (atmospheric hydrogen responses) may provide additional perspectives into how atmospheric hydrogen mixing ratios would respond to alternative emission rate scenarios, and would allow sensitivities to be examined. The remaining part of this paper describes the model; the verification and validation tests that have been completed; and evaluation of additional anthropogenic hydrogen emissions associated with a hydrogen economy.

\section{The Mathematical Model}

\section{Conceptual Model}

Figure C-1 illustrates a global conceptual model of the hydrogen cycle. This version of the hydrogen cycle is intended to be consistent with the mathematical model to be described. The atmosphere is subdivided into the troposphere and stratosphere. Within the troposphere and stratosphere the predicted hydrogen mixing ratios are assumed to be spatially constant but temporally variable. Major sources of hydrogen to the troposphere include sources at the earth's surface (biomass burning, fossil fuel combustion, nitrogen fixation, and oceanic off-gassing), as well as hydrogen produced in the atmosphere from reactions involving methane $\left(\mathrm{CH}_{4}\right)$ and nonmethane hydrocarbons (NMHC) (Novelli et al. 1999). In the troposphere, hydrogen is removed by reaction with the hydroxyl radical, insertion (diffusion) into the stratosphere, and uptake at the 
soil-atmosphere interface. In the stratosphere, processes similar to those in the troposphere both produce and destroy hydrogen.

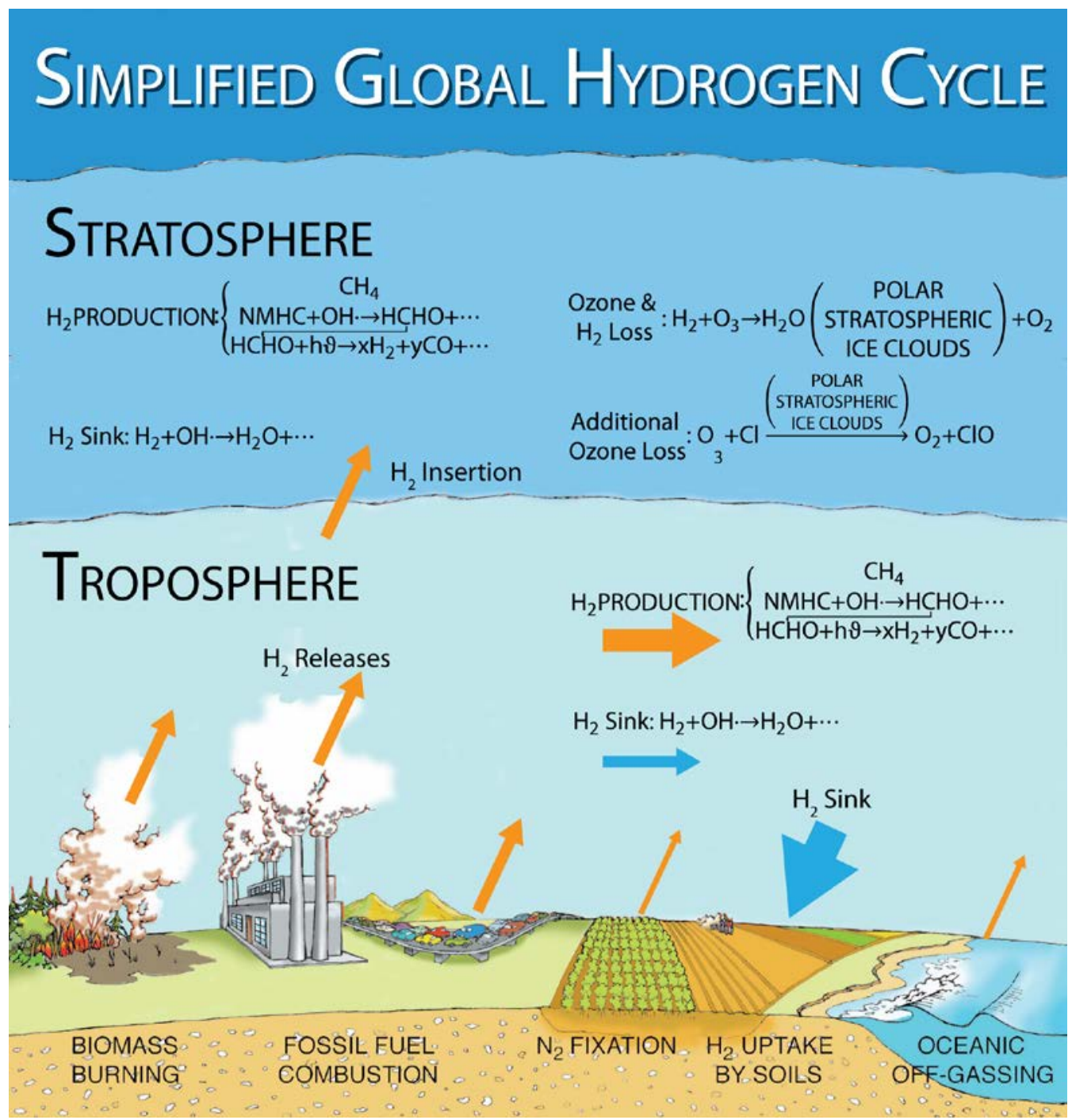

\section{Figure C-1 Global Hydrogen Cycle}

A number of researchers have developed global tropospheric hydrogen budgets in an attempt to quantify sources and sinks of hydrogen. Examples are shown in Figure C-2, and includes the work of Novelli (1999), Rhee (2006), Hauglustaine and Ehhalt (2002), Price (2007), Xiao et al. (2007), and Jacobson (2009). Jacobson did not include separate categories for photochemical production and oxidation by $\mathrm{OH}$ radicals, but rather combined them (40.3 Tg/yr). Also, uptake rates calculated by Smith-Downey et al. (2006) for a boreal forest and the Mohave desert were extrapolated to a global uptake rate to compare with the other investigated results. Not unexpectedly, hydrogen uptake from Mohave desert soils were lower than from other global sources, but still high enough to show that uptake of hydrogen in desert soils is not insignificant.

Five source categories are shown in Figure C-2 (photochemical production is the sum of production from methane and non-methane hydrocarbons). The two loss terms are by $\mathrm{OH}$ oxidation and by soil uptake The soil uptake rate is a much greater loss rate than is oxidation by 
hydroxyl radicals, and research continues to better characterize this loss mechanism (for example, Smith-Downey et al. (2006, 2008) and Jacobson (2009).

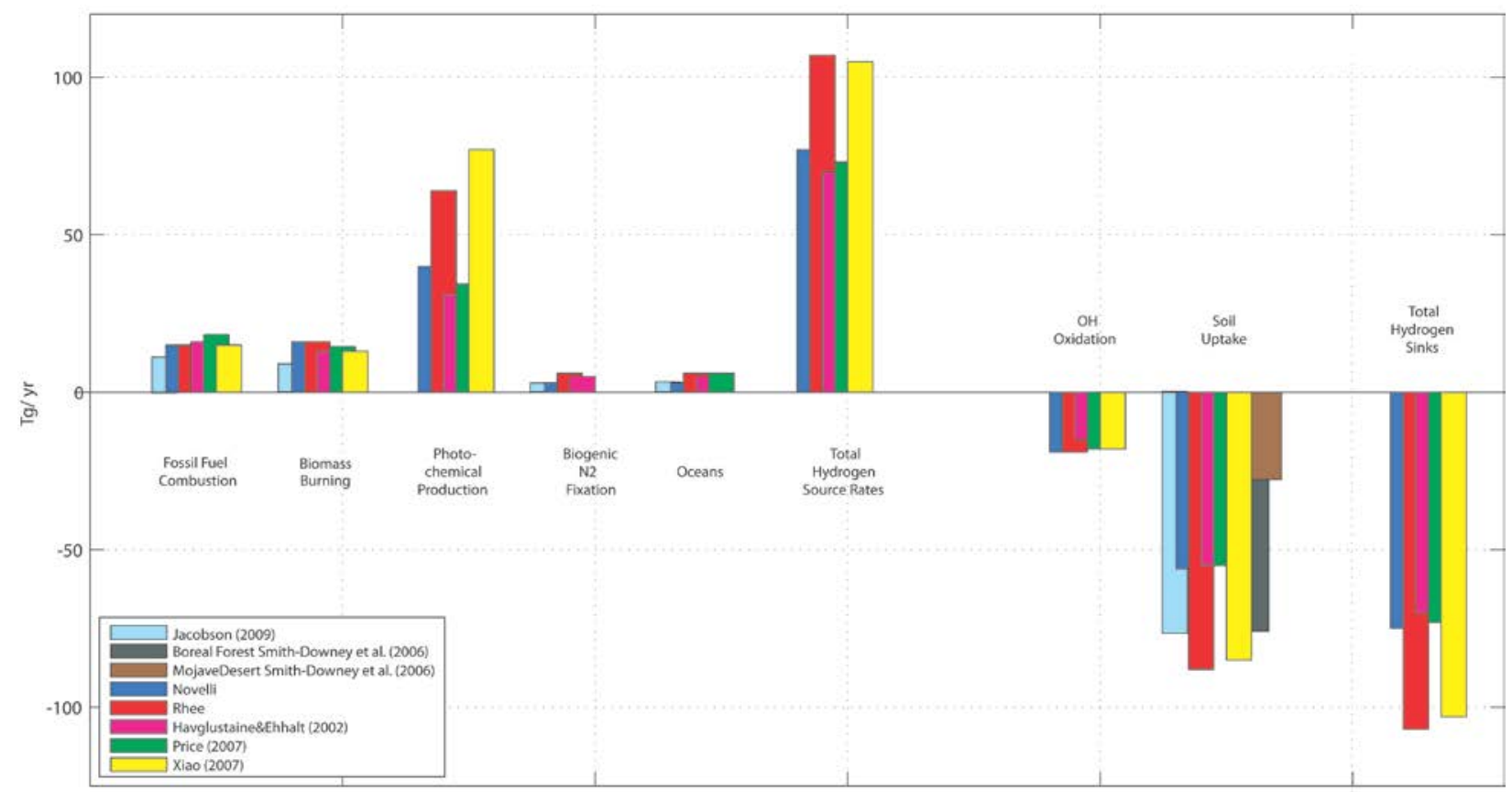

Figure C-2 Sources and Sinks for Global Hydrogen Budget

Several researchers have also provided estimates of total tropospheric hydrogen burdens and residence times. Only one researcher provided data that allowed estimates to be made of stratospheric hydrogen burden. These data are shown in Table C-2.

Table C-2

Atmospheric Burdens and Residence Time Estimates of Hydrogen from Various Researchers

\begin{tabular}{|c|c|c|c|c|c|c|c|c|}
\hline Category & $\begin{array}{l}\text { Novelli et } \\
\text { al. (1999) }\end{array}$ & $\begin{array}{l}\text { Xiao et al. } \\
\# 1 \text { (2007) }\end{array}$ & $\begin{array}{l}\text { Xiao et al. } \\
\# 2 \text { (2007) }\end{array}$ & $\begin{array}{l}\text { Rhee } \\
\text { et al. } \\
\text { (2006) }\end{array}$ & $\begin{array}{l}\text { Warneck } \\
\text { (1988) }\end{array}$ & $\begin{array}{l}\text { Hauglustaine } \\
\text { and Ehhalt } \\
\text { (2002) }\end{array}$ & $\begin{array}{c}\text { Price } \\
\text { et al. (2007) }\end{array}$ & $\begin{array}{c}\text { Jacobson } \\
(2009)\end{array}$ \\
\hline $\begin{array}{l}\text { Tropospheric mass, } \\
\text { Tg }\end{array}$ & 155 & 149 & 151 & 150 & 163 & 136 & 141 & NA \\
\hline $\begin{array}{l}\text { Stratospheric } \\
\text { mass, } \mathrm{Tg}\end{array}$ & NA & 42 & 43 & NA & NA & NA & NA & NA \\
\hline $\begin{array}{l}\text { Total atmospheric } \\
\text { mass, } \mathrm{Tg}\end{array}$ & NA & 191 & 194 & NA & NA & NA & NA & 188 \\
\hline $\begin{array}{l}\text { Tropospheric } \\
\text { residence time, } \\
\text { year }\end{array}$ & 2.1 & 1.4 & 1.4 & 1.4 & 1.8 & 1.9 & 1.9 & NA \\
\hline $\begin{array}{l}\text { Stratospheric } \\
\text { residence time, } \\
\text { years }\end{array}$ & NA & NA & NA & NA & NA & NA & NA & NA \\
\hline $\begin{array}{l}\text { Atmospheric } \\
\text { residence time }\end{array}$ & NA & 1.8 & 1.8 & NA & NA & NA & NA & 2.85 \\
\hline
\end{tabular}

NA = not available 


\section{Model Formulations}

The mathematical model solves for the total mass or burden of hydrogen in the troposphere and stratosphere over time, and assumes that both the troposphere and stratosphere are well-mixed with respect to hydrogen mixing ratio. This assumption was made based on the work of researchers such as Novelli et al. (1999) who analyzed tropospheric hydrogen concentrations from approximately 1990 to 1996 at 50 locations around the world. They found that the globally averaged tropospheric hydrogen mixing ratio was $530 \pm 6$ ppbv, with a tropospheric lifetime of about two years. Other researchers (e.g., Tromp et al. 2003 as shown in Figure C-3) have demonstrated the uniformity of hydrogen mixing ratios at altitudes of up to $25 \mathrm{~km}$, and a slight decrease above that level up to 40 kms. Warneck (1999) and Ehhalt et al. (1977) also examined the vertical distribution of molecular hydrogen based on data from a number of investigations and found the vertical distribution of hydrogen was also uniform up to nearly $30 \mathrm{~km}$. The model presented here does not differentiate between the northern and southern hemispheres where hydrogen mass differs by about 3\%.

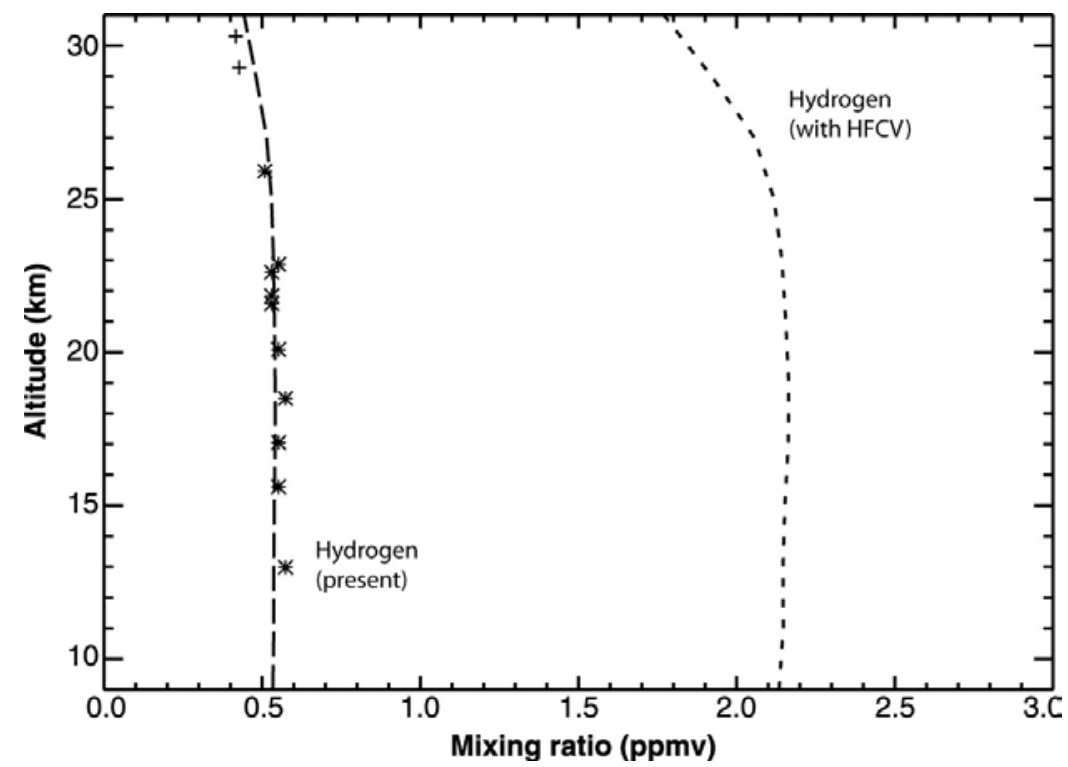

Figure C-3 Present and Projected Atmospheric Hydrogen mole fractions based on Tromp et al. (2003)

The mathematical equations used to simulate the fate of hydrogen in the troposphere and stratosphere are shown below. See the Addendum for typical values of these terms. The two most important equations needed for this analysis are for the burdens of hydrogen in the troposphere and stratosphere:

Troposphere

$$
\begin{aligned}
& \frac{\mathrm{dM}}{\mathrm{dt}}=\left\{\dot{\mathrm{M}}_{\text {in }, \mathrm{ff}}+\dot{\mathrm{M}}_{\text {in, biomass }}+\dot{\mathrm{M}}_{\text {in, nitrogen }}+\dot{\mathrm{M}}_{\text {in }, \text { ocean }}+\dot{\mathrm{M}}_{\text {in, } \mathrm{CH} 4}+\dot{\mathrm{M}}_{\text {in, NMHC }}+\dot{\mathrm{M}}_{\text {in }, \mathrm{HE}}\right\} \\
& -\left\{\dot{\mathrm{M}}_{\text {out } \mathrm{OH}}+\dot{\mathrm{M}}_{\text {out }, \mathrm{soil}}+\dot{\mathrm{M}}_{\text {insertion }}\right\}
\end{aligned}
$$




\section{Stratosphere}

$$
\frac{\mathrm{dMs}}{\mathrm{dt}}=\left\{\dot{\mathrm{M}}_{\text {insertion }}+\dot{\mathrm{M}}_{\mathrm{in}, \mathrm{CH} 4}-\dot{\mathrm{M}}_{\mathrm{out}, \mathrm{OH}, \mathrm{s}}\right\}
$$

Subject to these initial conditions:

$\mathrm{M}\left(\mathrm{t}_{0}\right)=\mathrm{M}_{0}$, burden of hydrogen in troposphere at initialization of simulation, Tg

$\mathrm{M}_{\mathrm{s}}\left(\mathrm{t}_{0}\right)=\mathrm{M}_{0, \mathrm{~s}}$, burden of hydrogen in stratosphere at initialization of simulation, Tg (2b) where

$$
\begin{aligned}
& \mathrm{M}, \mathrm{M}_{\mathrm{s}} \quad \text { = Mass of hydrogen in troposphere (stratosphere), } \mathrm{Tg} \\
& \dot{\mathrm{M}}_{\text {in,ff }} \quad \text { = Emissions rate of hydrogen into troposphere by incomplete } \\
& \text { combustion of fossil fuels, } \mathrm{Tg} / \mathrm{yr} \\
& \dot{\mathrm{M}}_{\text {in,biomass }} \quad \text { = Emission rate of hydrogen into troposphere from biomass } \\
& \text { burning, } \mathrm{Tg} / \mathrm{yr} \\
& \dot{\mathrm{M}}_{\mathrm{in}, \text { nitrogen }} \quad \text { = Emission rate of hydrogen into troposphere from nitrogen } \\
& \text { fixation, } \mathrm{Tg} / \mathrm{yr} \\
& \dot{\mathrm{M}}_{\text {in,ocean }} \quad \text { = Emission rate of hydrogen into troposphere from world's oceans, } \\
& \mathrm{Tg} / \mathrm{yr} \\
& \dot{\mathrm{M}}_{\mathrm{in}, \mathrm{CH} 4}\left(\dot{\mathrm{M}}_{\mathrm{in}, \mathrm{CH} 4, \mathrm{~s}}\right) \quad=\text { Generation rate of hydrogen in troposphere (stratosphere) from } \\
& \text { photolysis reactions involving atmospheric methane, } \mathrm{Tg} / \mathrm{yr} \\
& \dot{\mathrm{M}}_{\mathrm{in}, \mathrm{NMHC}} \quad \text { = Generation rate of hydrogen in troposphere from photolysis } \\
& \text { reactions with non-methane hydrocarbons, Tg/yr } \\
& \dot{\mathrm{M}}_{\text {in,HE }} \\
& \text { = Leakage rate of hydrogen into troposphere from anthropogenic } \\
& \text { hydrogen production, distribution, and storage associated with a } \\
& \text { hydrogen economy, Tg/yr } \\
& \dot{\mathrm{M}}_{\text {out,OH }}\left(\dot{\mathrm{M}}_{\text {out,OH,s}}\right)=\text { Destruction of hydrogen in troposphere (stratosphere) due to } \\
& \text { reaction with hydroxyl radicals, } \mathrm{Tg} / \mathrm{yr}
\end{aligned}
$$




$$
\begin{array}{ll}
\dot{\mathrm{M}}_{\text {out,soil }} & \begin{array}{l}
\text { Uptake rate of tropospheric hydrogen by soil (and by other } \\
\text { surface features), Tg/yr }
\end{array} \\
& =\begin{array}{l}
\text { Insertion rate of hydrogen (i.e., large scale diffusion processes) } \\
\text { from troposphere to stratosphere, Tg/yr }
\end{array}
\end{array}
$$

The terms in Equations (1a) and (1b) are time-variable so their relative contributions can change over time. An example of this is the $\dot{\mathrm{M}}_{\text {in,He }}$ term. This influx may increase in the future if a hydrogen economy evolves. Also, since past researchers (e.g., Tromp et al., 2003) have estimated large leakage rates of hydrogen may occur in the future, the impacts on atmospheric hydrogen can be evaluated for alternative estimates of leakage.

The Equations (1a) and (1b) are solved in terms of time variable hydrogen mixing ratios which are related to total hydrogen mass as follows:

$$
\mathrm{f}_{\mathrm{H} 2}=\frac{\mathrm{M} \cdot 10^{21}}{\mathrm{~V}_{\text {trop }} \cdot \mathrm{MW}_{\mathrm{H} 2} \cdot \overline{\mathrm{C}} \text { air }}
$$

and

$$
\mathrm{f}_{\mathrm{H} 2, \mathrm{~s}}=\frac{\mathrm{M}_{\mathrm{s}} \cdot 10^{21}}{\mathrm{~V}_{\mathrm{strat}} \cdot \mathrm{MW}_{\mathrm{H} 2} \cdot \overline{\mathrm{C}} \text { air }}
$$

where

$$
\begin{array}{ll}
\mathrm{f}_{\mathrm{H} 2}\left(\mathrm{f}_{\mathrm{H} 2, \mathrm{~s}}\right) & =\begin{array}{l}
\text { Mixing ratio (or mole fraction) of hydrogen in troposphere } \\
\end{array} \\
& \text { (stratosphere), ppbv } \\
\mathrm{V}_{\text {trop }}\left(\mathrm{V}_{\text {strat }}\right) & \text { Volume of troposphere (stratosphere), } \mathrm{m}^{3} \\
\mathrm{MW}_{\mathrm{H} 2} & =\text { Molecular weight of hydrogen } \\
\bar{C}_{\text {Cair }}\left(\overline{\text { Cair }}_{\mathrm{s}}\right) & = \\
& \text { Average molar concentration of air in troposphere (stratosphere), } \\
& \text { moles } / \mathrm{m}^{3}
\end{array}
$$

Once $\mathrm{f}_{\mathrm{H} 2}$ and $\mathrm{M}$ are calculated, $\mathrm{f}_{\mathrm{H} 2 \mathrm{~s}}$ and $\mathrm{M}_{\mathrm{s}}$ are calculated over the same time period. The simulations typically begin at some historical time, such as 1992, to allow the effects of an arbitrarily chosen initial condition to be dissipated before model results are interpreted.

By comparing Equations (1a) and (1b) it is noted that the hydrogen mass balance for the stratosphere contains only three flux rates, while the hydrogen mass balance for the troposphere contains 10. Five of the terms in Equation (1a) ( $\dot{\mathrm{M}}_{\text {in,ff }}, \dot{\mathrm{M}}_{\text {in,biomass }}, \dot{\mathrm{M}}_{\text {in,nitrogen }}, \dot{\mathrm{M}}_{\text {in,ocean }}$, and 
$\dot{\mathrm{M}}_{\mathrm{in}, \mathrm{HE}}$ ) pertain to surface releases, and one term pertains to surface losses ( $\dot{\mathrm{M}}_{\text {out,soil }}$ ). The source term $\dot{\mathrm{M}}_{\mathrm{in,NMHC}}$ is assumed negligible in the stratosphere (Rohs et al., 2006).

Several of the flux terms for the troposphere were modified from the work of Novelli et al. (1999), where they used those formulations to estimate hydrogen emission rates and loss rates to the troposphere (they did not include the stratosphere) at a single point in time (representative of 1992-1996 averages), and they did not create a mathematic model to predict hydrogen mixing ratios over time. The particular tropospheric terms they generated are fossil fuel combustion, biomass combustion, nitrogen fixation, off-gassing from oceans, methane reactions, NMHC reactions, hydroxide oxidation, and soil uptake. Each of these expressions was modified for use in Equation (1a) to account for time variability.

The insertion term in Equation (1b) is expressed as:

$$
\dot{\mathrm{M}}_{\text {insertion }}=\frac{\mathrm{f}_{\mathrm{H} 2}}{\mathrm{f}_{\mathrm{H} 2 \mathrm{REF}}} \cdot \dot{\mathrm{M}}_{\text {insertion, REF }}
$$

where

$$
\begin{array}{ll}
\dot{\mathrm{M}}_{\text {insertion, REF }} & =\text { Known reference rate of insertion at some specified time, } \mathrm{Tg} / \mathrm{yr} \\
\mathrm{f}_{\mathrm{H} 2, \mathrm{REF}} & =\text { Reference tropospheric hydrogen mixing ratio, ppbv }
\end{array}
$$

There are few estimates of reference insertion rates, but they generally fall between $0.6 \mathrm{Tg} / \mathrm{yr}$ to 1.6 Tg/yr (Zittel and Altmann, 1996).

The remaining source and sink terms for the troposphere are:

$$
\begin{aligned}
& \dot{\mathrm{M}}_{\text {in,biomass }}=\dot{\mathrm{M}}_{\text {in,biomass }}\left(1+\alpha_{\text {biomass }}\right)^{\left(\mathrm{t}-\mathrm{t}_{0}\right)} \\
& \dot{\mathrm{M}}_{\mathrm{in}, \text { nitrogen }}=\dot{\mathrm{M}}_{\mathrm{in}, \text { nitrogen }}\left(1+\alpha_{\mathrm{N} 2}\right)^{\left(t-t_{0}\right)} \\
& \dot{\mathrm{M}}_{\mathrm{in}, \text { ocean }}=\left(\frac{\mathrm{f}_{\mathrm{H} 2}^{\text {ref }}}{\mathrm{f}_{\mathrm{H} 2}}\right) \cdot \dot{\mathrm{M}}_{\mathrm{in}, \text { ref,ocean }} \\
& \dot{\mathrm{M}}_{\mathrm{in}, \mathrm{NMHC}}=\left\{\begin{array}{c}
\quad \dot{\mathrm{M}}_{\mathrm{in}, \mathrm{NMHC}}\left(1+\alpha_{\mathrm{NMHC}}\right. \\
\beta \mathrm{M}_{\mathrm{in}, \mathrm{NMHC}}^{0}\left(1+\alpha_{\mathrm{NMHC}}\right)^{\left(\mathrm{t}_{\mathrm{HE}}-\mathrm{t}_{0}\right)}\left(1+\alpha_{\mathrm{NMHC}}\right)^{\left(\mathrm{t}-\mathrm{t}_{\mathrm{HE}}\right)}, \mathrm{t}_{\mathrm{HE}}<\mathrm{t}
\end{array}\right.
\end{aligned}
$$




$$
\begin{aligned}
& \dot{\mathrm{M}}_{\mathrm{in}, \mathrm{CH} 4}=\left\{\begin{array}{c}
\mathrm{k}_{5 \mathrm{t}}[\mathrm{OH}]_{\mathrm{t}}\left(\mathrm{G}_{\mathrm{CH} 4, \mathrm{t}}+\Delta \mathrm{G}_{\mathrm{CH} 4, \mathrm{t}}\right)\left(0.95 \cdot \mathrm{F}_{\mathrm{HCOH}}\right) \mathrm{M}_{\mathrm{ratio}} \cdot \phi_{2} \\
\Delta \mathrm{G}_{\mathrm{CH} 4, \mathrm{t}}=\Delta_{\mathrm{in}, \mathrm{CH} 4, \mathrm{t}} \frac{\tau_{\mathrm{CH} 4}}{\ln (2)}\left[1-\exp \left(\frac{-\ln (2)}{\tau_{\mathrm{CH} 4}}\left(\mathrm{t}-\mathrm{t}_{\mathrm{HE}}\right)\right)\right], \mathrm{t}>\mathrm{t}_{\mathrm{HE}} \\
\Delta \mathrm{G}_{\mathrm{CH} 4, \mathrm{t}}=0, \mathrm{t}<\mathrm{t}_{\mathrm{HE}}
\end{array}\right. \\
& \dot{\mathrm{M}}_{\mathrm{in}, \mathrm{ff}}=\left\{\begin{array}{c}
\dot{\mathrm{M}}_{\mathrm{in}, \mathrm{ff}}^{0}\left(1+\alpha_{\mathrm{ff}}\right)^{\left(\mathrm{t}-\mathrm{t}_{0}\right)}, \mathrm{t}_{0}<\mathrm{t}<\mathrm{t}_{\mathrm{HE}} \\
\dot{\mathrm{M}}_{\mathrm{in}, \mathrm{ff}}\left(1+\alpha_{\mathrm{ff}}\right)^{\left(\mathrm{t}_{\mathrm{HE}}-\mathrm{t}_{0}\right)}\left(1+\alpha_{\mathrm{ff}}\right)^{\left(\mathrm{t}-\mathrm{t}_{\mathrm{HE}}\right)}, \mathrm{t}_{\mathrm{HE}}<\mathrm{t}
\end{array}\right.
\end{aligned}
$$

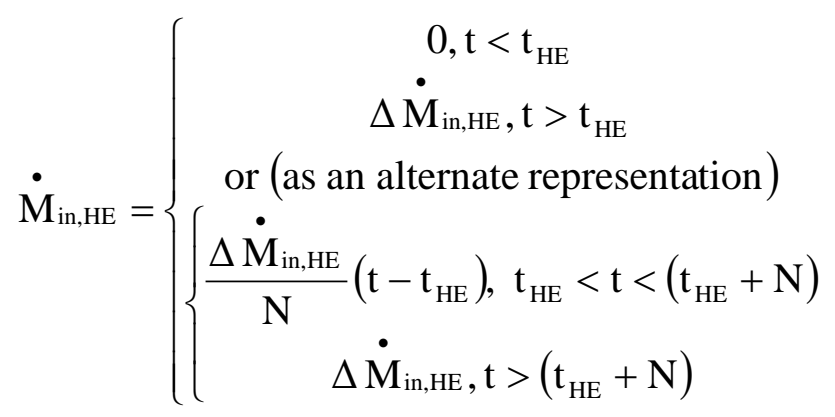

$$
\begin{aligned}
& \dot{\mathrm{M}}_{\mathrm{out}, \mathrm{OH}}=\mathrm{k}_{1 \mathrm{t}}[\mathrm{OH}]_{\mathrm{t}} \mathrm{M} \\
& \dot{\mathrm{M}}_{\text {out,soil }}=\mathrm{V}_{\mathrm{d}} \cdot \frac{\mathrm{nm}}{\mathrm{Av}} \mathrm{f}_{\mathrm{H} 2} \mathrm{Ae} \cdot \mathrm{MW}_{\mathrm{H} 2} \cdot 10^{-11}(365.25)(86400)
\end{aligned}
$$

For the stratosphere, the following source and sink terms are appropriate:

$$
\begin{aligned}
& \dot{\mathrm{M}}_{\mathrm{in}, \mathrm{CH} 4,5}=\mathrm{k}_{5, \mathrm{~s}}[\mathrm{OH}]_{\mathrm{s}}\left(\mathrm{G}_{\mathrm{CH} 4, \mathrm{~s}}\right) \cdot \mathrm{F}_{\mathrm{HCH} 6} \cdot \mathrm{M}_{\text {ratio }} \cdot \phi_{2 s} \\
& \dot{\mathrm{M}}_{\mathrm{out}, \mathrm{OH}, \mathrm{s}}=\mathrm{k}_{1, \mathrm{~s}}[\mathrm{OH}]_{\mathrm{s}} \mathrm{M}_{\mathrm{s}}
\end{aligned}
$$

The methane burden in the troposphere and stratosphere are required:

$$
\begin{aligned}
& \mathrm{G}_{\mathrm{CH} 4}=\mathrm{G}_{\mathrm{CH} 4}(0) \cdot \frac{\mathrm{f}_{\mathrm{CH} 4}}{\mathrm{f}_{\mathrm{CH} 4}(0)} \\
& \mathrm{f}_{\mathrm{CH} 4}=\mathrm{f}_{\mathrm{CH} 4}\left(\mathrm{t}_{0}\right)+\mathrm{A}\left(1-\cos \frac{2 \pi}{\mathrm{T}}\left(\mathrm{t}-\mathrm{t}_{0}\right)\right)+\left(\mathrm{f}_{\mathrm{CH}_{\mathrm{f}}}-\mathrm{f}_{\mathrm{CH}_{0}}\right) \frac{\left(\mathrm{t}-\mathrm{t}_{0}\right)}{\mathrm{t}_{\mathrm{t}}-\mathrm{t}_{0}}, \mathrm{t}<\mathrm{t}_{\mathrm{HE}} \\
& \mathrm{G}_{\mathrm{CH} 4}(0)=\mathrm{f}_{\mathrm{CH} 4}(0) \overline{\mathrm{C}}_{\mathrm{a}}^{\text {molar }} \cdot \mathrm{V}_{\text {trop }} \cdot \mathrm{MW}_{\mathrm{CH} 4} \cdot 10^{-21}
\end{aligned}
$$


The stratospheric methane burden is scaled from the tropospheric burden, based on known historical burdens in both stratosphere and troposphere.

The rate constants for production of hydrogen from methane and loss of hydrogen by reaction with the hydroxyl radical are temperature dependent and are given by:

$$
\begin{aligned}
& \mathrm{k}(\mathrm{T})=\mathrm{A}_{\mathrm{fac}} \cdot \exp \left[-\left(\frac{\mathrm{E}}{\mathrm{R}}\right) \frac{1}{\mathrm{~T}}\right] \\
& \text { where } \\
& \mathrm{k} \quad=\text { Rate constant for either } \mathrm{OH} \text { oxidation of molecular hydrogen } \\
& \left(k_{1}\right) \text { or for formation of hydrogen from methane }\left(k_{5}\right) \text { at } \\
& \text { temperature } \mathrm{T} \\
& \mathrm{T} \quad=\text { Temperature, Kelvin } \\
& \mathrm{A}_{\text {fac1 }}, \mathrm{A}_{\text {fac5 }} \quad=\text { Arrhenius factors } \\
& \left(\frac{E}{R}\right)_{1},\left(\frac{E}{R}\right)_{5} \quad=\text { Activation temperatures }
\end{aligned}
$$

\section{Model Validation}

Model validation, as defined here, is the process of comparing model predictions against one or more other models (typically more simplified ones) to see that results match to the degree of accuracy expected. One of the several validation exercises that were completed in the development of this model is described below. This exercise focused on solving Equation (1a) using an ordinary differential equation solver and comparing this solution to an analytic solution to that equation (where hydrogen emissions are assumed to be constant) that can be expressed as:

$$
\begin{aligned}
& \frac{d M}{d t}=z_{1}-A z_{2} \cos \left(\frac{2 \pi}{T} t\right)+z_{2} \cdot \text { slope } \cdot t-z_{3} M \\
& \text { where } \\
& \mathrm{z}_{1}, \mathrm{z}_{2}, \mathrm{z}_{3} \quad=\text { Composite constants that contain information about hydrogen } \\
& \text { source and sink terms } \\
& \mathrm{T} \quad \text { = Induced periodicity } \\
& \text { slope } \quad=\text { Constant slope for hydrogen burden changes }
\end{aligned}
$$

Equation (8) was solved using two techniques, and those results were compared to the solution to equation (1a) for the same conditions. The two test solutions are:

- An analytical solution to a non-homogenous first-order ordinary differential equation, and 
- A second solution using Laplace transforms, and numerically inverting them, expressing the solution as an integral, and using quadrature to solve the integral equation.

Because each of the two analytical solutions gave exact results, and the error tolerance for the ordinary differential equation solver was specified to be very strict, the three solutions matched very closely.

\section{Model Verification}

Model verification, as defined here, is the process of successfully comparing model predictions against observed data. The observed data used were the present-day atmospheric hydrogen mixing ratios, the atmospheric burden of hydrogen, and its residence time. The validated model was applied with estimates of present-day hydrogen emissions rates from Novelli et al. (1999), shown earlier in Table C-2. The Novelli et al. (1999) emission estimates were used because of the detailed analysis completed by those researchers to develop their estimates, and the fact that many researchers since then have based many of their results on the work of Novelli et al. (1999).

Using the data shown previously, the predictions are shown in Figure C-4 and Figure C-5. The simulation period was from 1992 to 2010 . This duration is intended to be long enough so that tropospheric and stratospheric concentrations reach a steady-state condition, with the exception of a seasonal variability.

(a) Hydrogen Burden

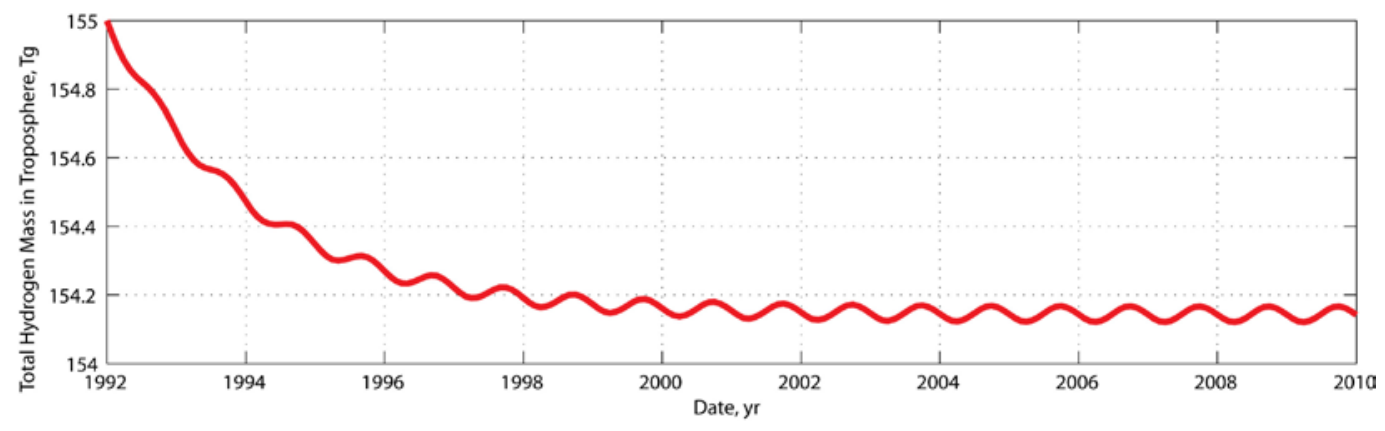

(b) Hydrogen Mixing Ratio

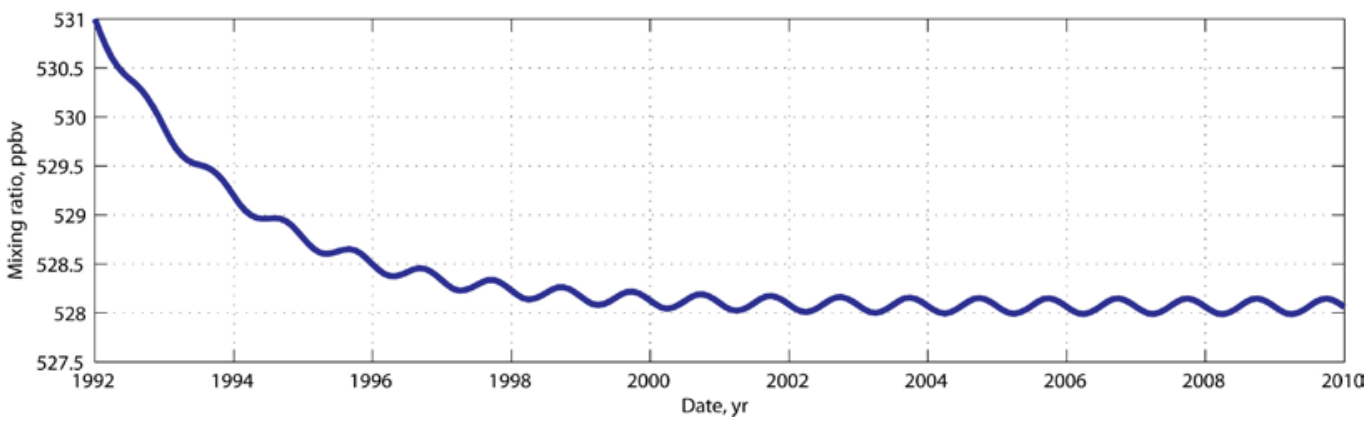

Figure C-4 Predicted Hydrogen Burden and Mixing Ratio in Troposphere under Present Day Conditions. Note: The initial decrease in mixing ratio and mass were caused by the initial condition chosen, and after about eight years, the influence of the initial condition is negligible. 

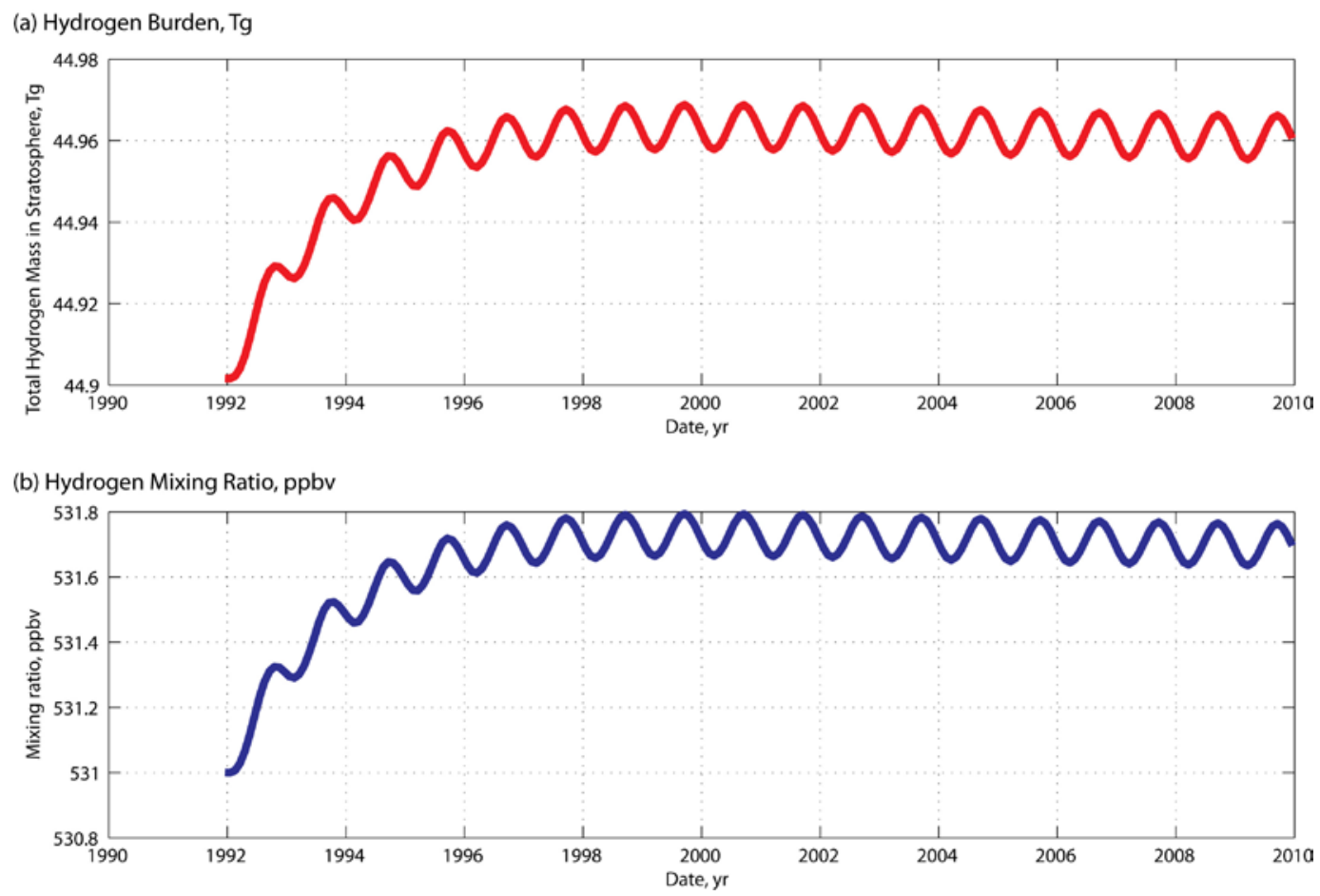

Figure C-5 Predicted Hydrogen Burden and Mixing Ratios in Stratosphere under Present Day Conditions. Note: The initial decrease in mixing ratio and mass were caused by the initial condition chosen, and after about eight years, the influence of the initial condition is negligible.

Initial molecular hydrogen mixing ratios were set at $531 \mathrm{ppbv}$ as the starting guess in 1992 in both the troposphere and stratosphere. The total hydrogen mass was then calculated. As shown in Figure C-4(a) and Figure C-5(a), the concentrations drifted from the initial conditions to about $528 \mathrm{ppbv}$ in the troposphere and to about $532 \mathrm{ppbv}$ in the stratosphere. The burden in the troposphere was slightly more than $154 \mathrm{Tg}$, while in the stratosphere the burden was about 45 Tg. The time to attain the steady state condition was about eight years. Comparing these predictions to the estimates in Table C-1, the agreement is good (Table C-3). The hydrogen burdens, mixing ratios, and residence times all closely compare. Stratospheric residence time predictions were not compared to Table C-1, as no such data for comparison were available. 
Table C-3

Comparison of Predicted Hydrogen Results vs. Values Calculated by Other Researchers Shown Previously in Table C-2

\begin{tabular}{|c|c|c|}
\hline Category & Table C-2 & Predicted Here \\
\hline Hydrogen burden in troposphere, $\mathrm{Tg}$ & $136-155$ & 154 \\
\hline Hydrogen burden in stratosphere, $\mathrm{Tg}$ & $42-43$ & 45 \\
\hline Global hydrogen burden, $\mathrm{Tg}$ & 188 & 199 \\
\hline $\begin{array}{l}\text { Present day hydrogen mixing ratio in troposphere (Novelli et al., 1999), } \\
\text { ppbv }\end{array}$ & 531 & 528 \\
\hline Troposphere residence time, years & $1.4-2.1$ & 2.1 \\
\hline Stratosphere residence time, years & NA & 8.5 \\
\hline $\begin{array}{l}\text { Present day mixing ratio of hydrogen in stratosphere (1988-2004). } \\
\text { (Rohs et al., 2006), ppbv }\end{array}$ & $490-555$ & 532 \\
\hline
\end{tabular}

NA = not available

To further illustrate the comparison between observed tropospheric hydrogen mixing ratios and model results in Figure C-5(b), atmospheric hydrogen data at two locations (Tasmania in the southern hemisphere; Ireland in the northern hemisphere) are shown in Figure C-6. The average value of the two time series are also shown. The average mixing ratios have an amplitude much smaller than either time series, indicating that the two series are hemispherically out of phase.

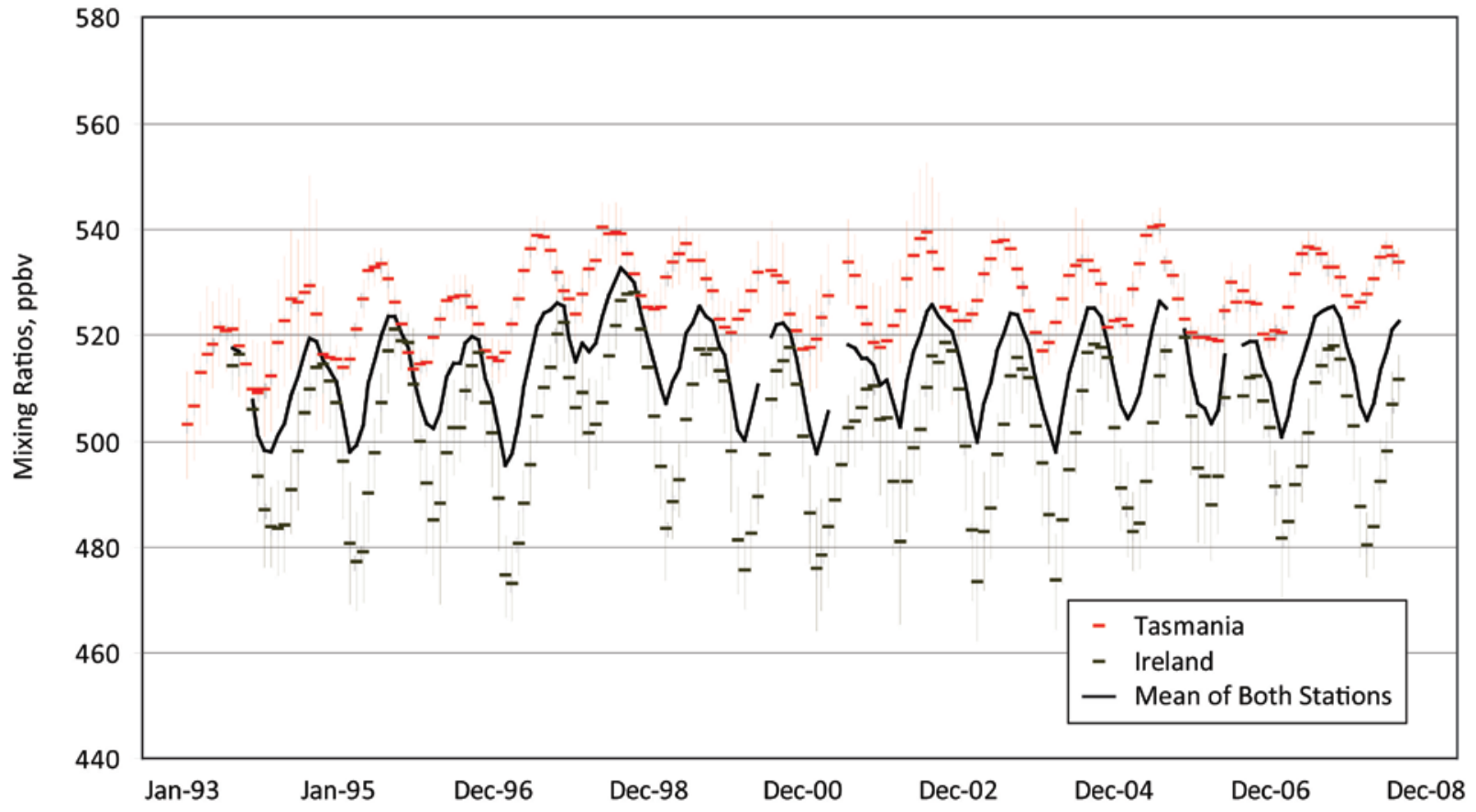

Figure C-6 Tropospheric Hydrogen Mixing Ratios from 1993-2008 in Tasmania and Ireland.

\section{Model Applications}

The model applications focus on how changes in either uncertain data or hydrogen emissions can affect hydrogen mixing ratios and hydrogen burdens in the troposphere or stratosphere. 


\section{Sensitivity to Deposition Velocity}

To begin we examine the deposition velocity, $\mathrm{V}_{\mathrm{d}}$. The deposition velocity, based on results of previous research, has a wide range (Figure C-7), and prior researchers have shown that the soil uptake process is the largest hydrogen sink, as shown previously in Figure C-2. Estimates of hydrogen uptake by the soil (and associated surface processes) range from 50 to $100 \mathrm{Tg} / \mathrm{yr}$, while the remaining largest sink (oxidation by the $\mathrm{OH}$ radical) is approximately $20 \mathrm{Tg} / \mathrm{yr}$.

As shown by the study results shown in Figure C-7, deposition velocity ranges from 0 to 0.131 $\mathrm{cm} / \mathrm{sec}$. Since these field studies represent various land use types, variability is not unexpected. Added to the plot are the global estimate and global upper and lower limits proposed by Novelli (1999). These estimates are very consistent with the field studies (when taken in their entirety), and add validity to the choice used $(0.04 \mathrm{~cm} / \mathrm{sec})$ for the global hydrogen cycle simulations presented here. A second set of researchers has also developed estimates of soil uptake, but expressed their results as nmol/ $/ \mathrm{m}^{2} / \mathrm{sec}$ (Figure C-8). Novelli's global estimate of $0.04 \mathrm{~cm} / \mathrm{sec}$ is equivalent to approximately $9.7 \mathrm{nmol} / \mathrm{m}^{2} / \mathrm{sec}$ and is plotted on Figure C-8. Novelli's estimate once again was generally between the upper and lower limits of the study results.

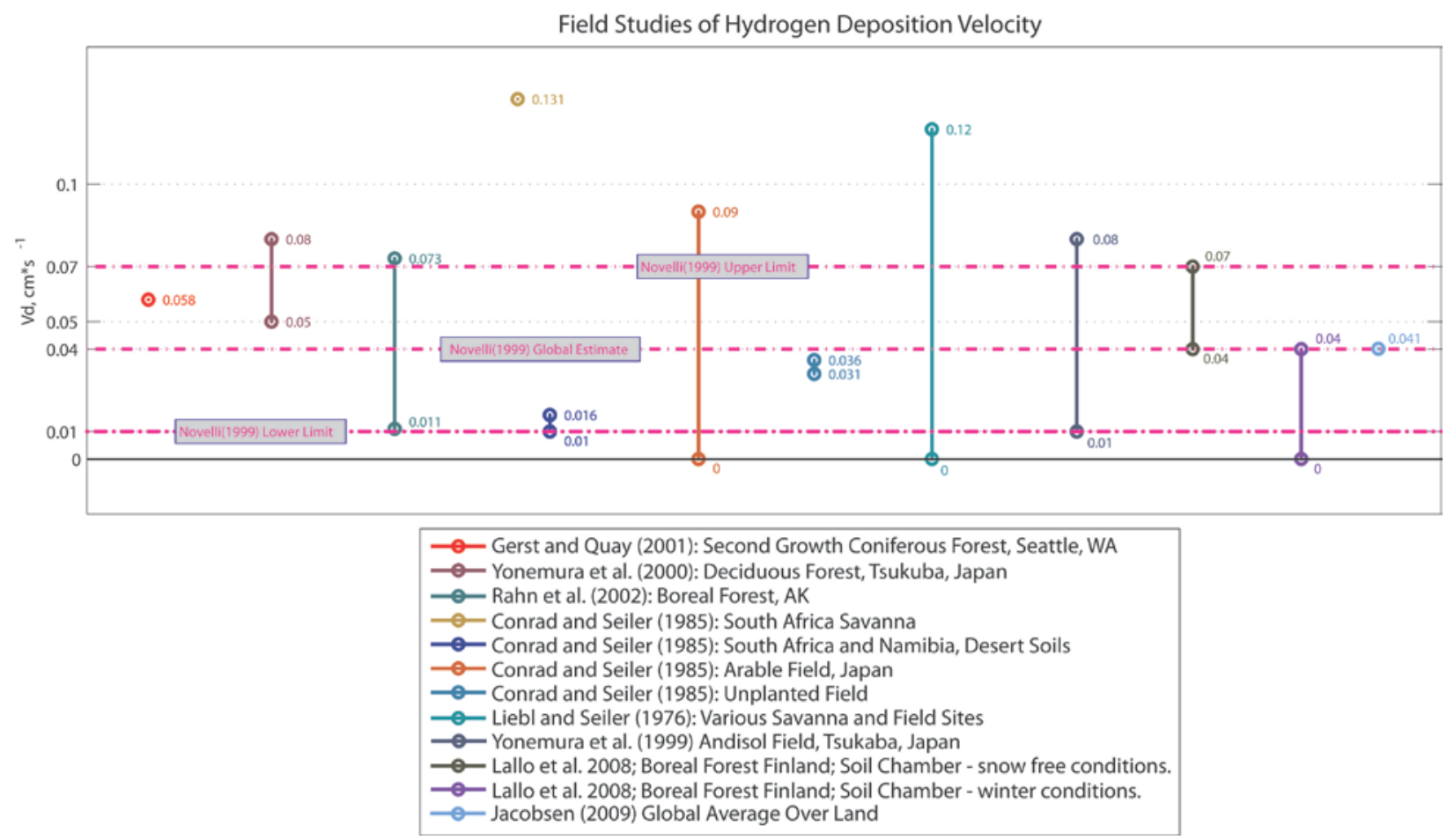

Figure C-7 Studies of Hydrogen Deposition Velocity. Note: The recent modeling results of Jacobson (2009) for global average deposition are shown for comparison. 


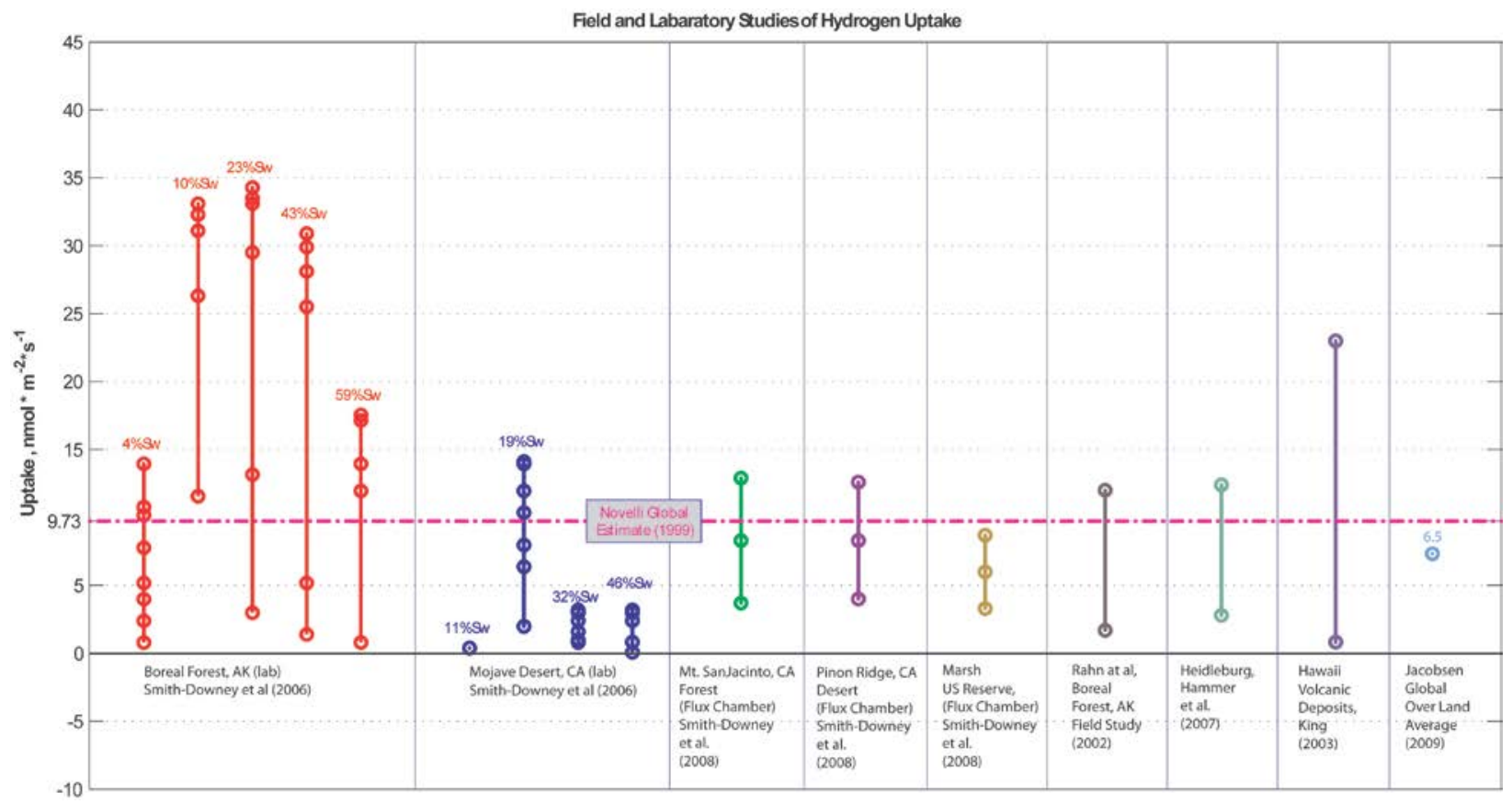

Figure C-8 Studies of Hydrogen Uptake. Note: The recent modeling results of Jacobson (2009) are shown for comparison.

The sensitivity of predicted tropospheric and stratospheric hydrogen mixing ratios to deposition velocity is shown in Figure C-9. Predictions are shown for deposition velocities of $0.01 \mathrm{~cm} / \mathrm{sec}$, $0.04 \mathrm{~cm} / \mathrm{sec}$ (global average as estimated by several researchers), and $0.07 \mathrm{~cm} / \mathrm{sec}$. The predicted hydrogen mixing ratios are quite sensitive to the deposition velocity. Both ends of the range of $\mathrm{V}_{\mathrm{d}}$ produce predictions that are well outside the present day hydrogen mixing ratios, indicating such deposition velocities are not realistic on a global scale. These results are consistent with those presented previously in Figure C-7 and Figure C-8. 
(a) Stratosphere

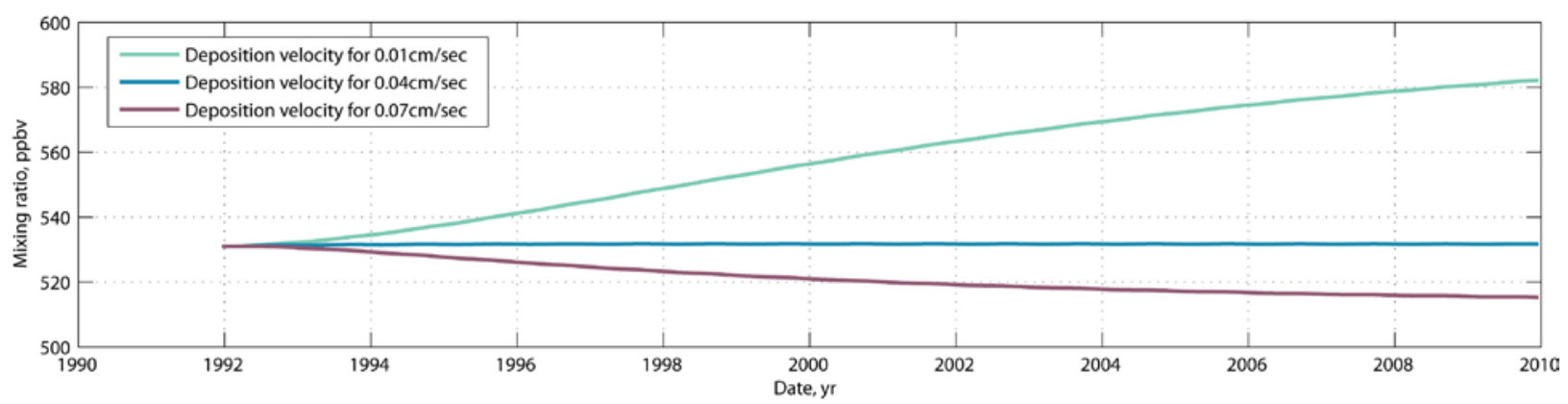

(b) Troposphere

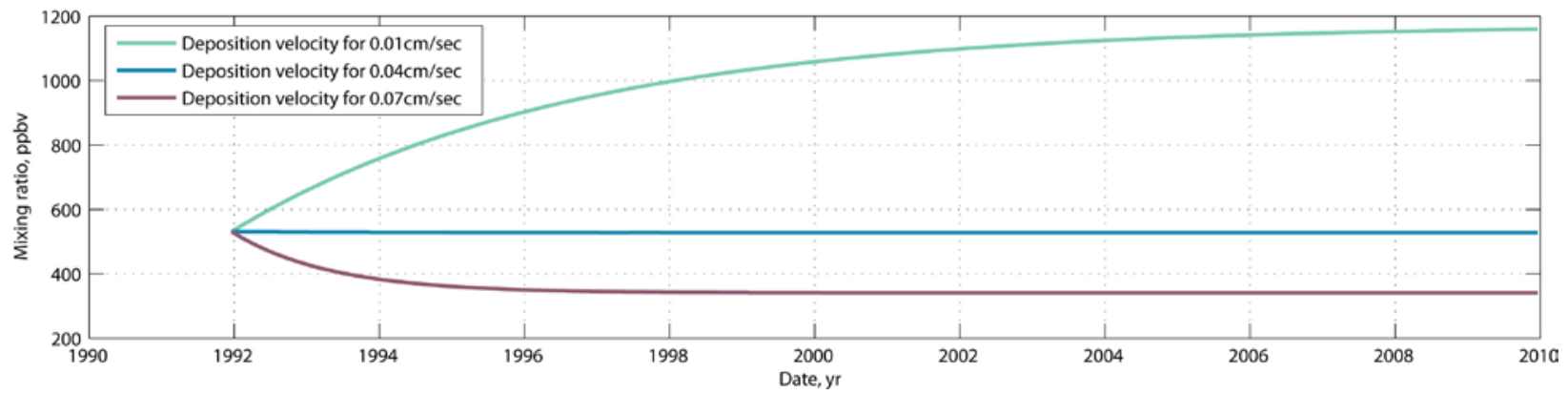

Figure C-9 Sensitivity of Hydrogen Mixing Ratio to Deposition Velocity.

A more complete sensitivity analyses is shown in Table C-4. Each variable is perturbed one at a time, with +- $10 \%$ change from a base case. The sensitivity analysis shows how atmospheric hydrogen mixing ratios are changed as each variable is perturbed. Not unexpectedly, hydrogen response is most sensitive to deposition velocity change. 
Table C-4

Parameter-by-Parameter Sensitivity Analysis for Hydrogen Model (Once Steady-state Conditions are Attained)

\begin{tabular}{|c|c|c|c|c|c|c|c|}
\hline \multirow[b]{2}{*}{ Variable Perturbed } & \multirow[b]{2}{*}{ Base Case Value } & \multirow{2}{*}{$\begin{array}{c}\text { Base Case } \\
-10 \%\end{array}$} & \multirow{2}{*}{$\begin{array}{c}\text { Base Case } \\
\quad+10 \%\end{array}$} & \multicolumn{2}{|c|}{$\begin{array}{c}\text { Tropospheric } \\
\text { Response } \\
\text { (ppbv) }\end{array}$} & \multicolumn{2}{|c|}{$\begin{array}{c}\text { Stratospheric } \\
\text { Response } \\
\text { (ppbv) }\end{array}$} \\
\hline & & & & $-10 \%$ & $+10 \%$ & $-10 \%$ & $+10 \%$ \\
\hline $\begin{array}{l}\text { Initial Hydrogen Mixing } \\
\text { Ratio in Troposphere }\end{array}$ & 528 ppbv & 478 ppbv & 584 ppbv & 0 & 0 & 0 & 0 \\
\hline $\begin{array}{l}\text { Initial Hydrogen Mixing } \\
\text { Ratio in Stratosphere }\end{array}$ & 531 ppbv & 478 ppbv & 584 & 0 & 0 & 0 & 0 \\
\hline Deposition Velocity & $0.04 \mathrm{~cm} \cdot \mathrm{s}^{-1}$ & $0.036 \mathrm{~cm} \cdot \mathrm{s}^{-1}$ & $0.044 \mathrm{~cm} \cdot \mathrm{s}^{-1}$ & +52 & -46 & +5 & -3 \\
\hline $\mathrm{k}_{1}$ (troposphere) & $4.02 \cdot 10^{-15} \mathrm{~cm}^{3} \cdot$ molecule $^{-1} \cdot \mathrm{s}^{-1}$ & $3.6 \cdot 10^{-15}$ & $4.422 \cdot 10^{-15}$ & \multirow{2}{*}{+43} & \multirow{2}{*}{-17} & \multirow{2}{*}{+59} & \multirow{2}{*}{-51} \\
\hline $\mathrm{k}_{1}$ (stratosphere) & $1.03 \cdot 10^{-15} \mathrm{~cm}^{3} \cdot \mathrm{molecule}^{-1} \cdot \mathrm{s}^{-1}$ & $0.927 \cdot 10^{-15}$ & $1.13 \cdot 10^{-5}$ & & & & \\
\hline $\mathrm{k}_{5}$ (troposphere) & $4.04 \cdot 10^{-15} \mathrm{~cm}^{3} \cdot$ molecule $^{-1} \cdot \mathrm{s}^{-1}$ & $3.64 \cdot 10^{-15}$ & $4.44 \cdot 10^{-15}$ & \multirow{2}{*}{-19} & \multirow{2}{*}{+12} & \multirow{2}{*}{-45} & \multirow{2}{*}{+50} \\
\hline $\mathrm{k}_{5}$ (stratosphere) & $1.2 \cdot 10^{-15} \mathrm{~cm}^{3} \cdot$ molecule $^{-1} \cdot \mathrm{s}^{-1}$ & $1.08 \cdot 10^{-15}$ & $1.32 \cdot 10^{-15}$ & & & & \\
\hline $\mathrm{OH}$ (troposphere) & $9.70 \cdot 10^{5}$ molecule $\cdot \mathrm{cm}^{-3}$ & $8.77 \cdot 10^{5}$ & $1.07 \cdot 10^{6}$ & \multirow{2}{*}{-2.3} & \multirow{2}{*}{+2.6} & \multirow{2}{*}{+6} & \multirow{2}{*}{-4} \\
\hline $\mathrm{OH}$ (stratosphere) & $4.00 \cdot 10^{6}$ molecule $\cdot \mathrm{cm}^{-3}$ & $3.6 \cdot 10^{6}$ & $4.4 \cdot 10^{6}$ & & & & \\
\hline $\begin{array}{l}\text { Initial Methane } \\
\text { Concentration in } \\
\text { Troposphere }\end{array}$ & $1660 \mathrm{ppbv}$ & 1494 & 1826 & -15 & +20 & -52 & +44 \\
\hline $\begin{array}{l}\text { All Sources of Hydrogen } \\
\text { Emitted to Troposphere }\end{array}$ & $37 \mathrm{Tg} / \mathrm{yr}$ & 33.3 Tg/yr & 40.7 Tg/yr & -27 & +31 & -2 & +4 \\
\hline $\begin{array}{l}\text { Insertion of Hydrogen } \\
\text { into Stratosphere } \\
\text { (Reference Flux) }\end{array}$ & $0.6 \mathrm{Tg} / \mathrm{yr}$ & $0.54 \mathrm{Tg} / \mathrm{yr}$ & $0.66 \mathrm{Tg} / \mathrm{yr}$ & $<+1$ & $\sim-0.3$ & -4.3 & +6 \\
\hline
\end{tabular}

\section{Time Frame Estimates for Atmospheric Response to Hydrogen Leakage Rates}

As hydrogen leaks into the troposphere as a result of production, transport, and usage during transition to a hydrogen economy, important questions arise including these two:

- What will be the future mixing ratios of hydrogen in the troposphere and stratosphere?

- How long will it take for mixing ratios to stabilize, given a constant emissions rate?

To answer these questions, three different hydrogen leakage rates were examined: $4.5 \mathrm{Tg} / \mathrm{yr}, 50$ $\mathrm{Tg} / \mathrm{yr}$, and $120 \mathrm{Tg} / \mathrm{yr}$. These are intended to represent a potential range of emissions, based on the data presented earlier in Table C-1. The emissions were assumed to increase gradually over a 10 year period to each of the three amounts specified and to remain steady after that. The results are presented in Figure C-10 for both the troposphere and stratosphere. Note that all results are presented as differences with respect to the no leakage case (that is, the model was run twice, and the results were subtracted). In the troposphere, the response time to attain a steady tropospheric mixing ratios is about 15 years (from 2020 to 2035), while in the stratosphere the response time is over 30 years (that is, by 2050 hydrogen levels are still increasing, but slowly).

Increases in mixing ratios in the troposphere range from about $10 \mathrm{ppbv}$ to over $800 \mathrm{ppbv}$ depending on the leakage rate. The increase of $800 \mathrm{ppbv}$ is very significant, as today's troposphere concentrations are $531 \mathrm{ppbv}$. For the stratosphere, changes in mixing ratio concentrations at steady-state are considerably smaller, and range from 2 ppbv to over 80 ppbv. 

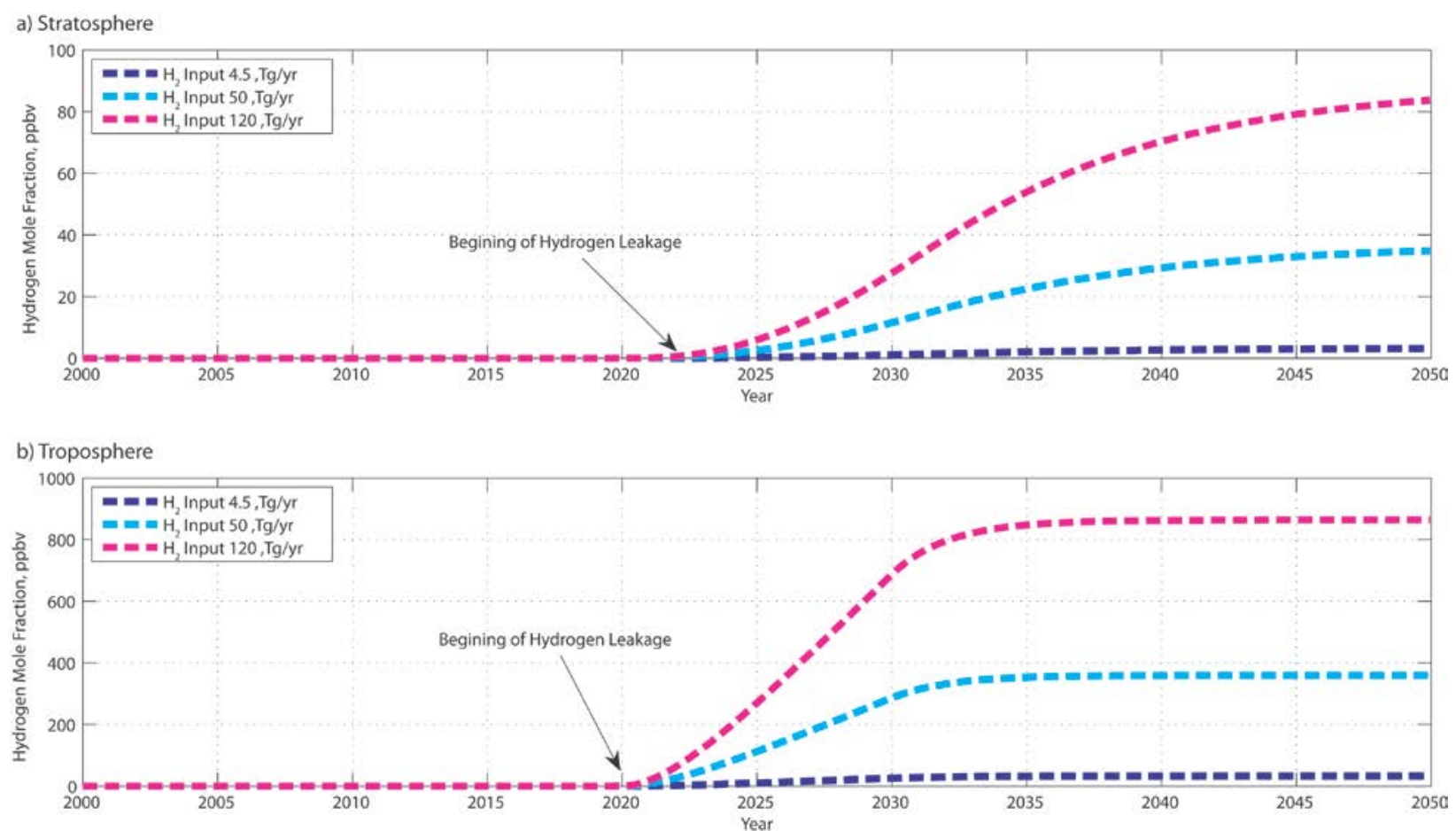

Figure C-10 Influence of hydrogen leakage rates on incremental tropospheric and stratospheric hydrogen mixing ratios. Note: Hydrogen leakage was assumed to increase linearly over a 10 year period, and to remain constant thereafter.

\section{Approximate Response of Tropospheric Hydrogen Burden to Net Changes in Hydrogen Input from Hydrogen Economy}

An important metric of the hydrogen economy is how the burden (and therefore mixing ratio) of hydrogen will change in the troposphere at a future steady-state condition. While this could be calculated from the hydrogen model developed here, we first approximate the steady-state response using a set of simplifying assumptions that include:

- The major changes in sources of hydrogen in the hydrogen economy are the leakage associated with anthropogenic activities, and the change in fossil fuel emissions.

- The major changes in loss terms from the troposphere are limited to soil deposition and oxidation by the hydroxyl radical.

By making these assumptions and evaluating Equation (1a) for two conditions (without a hydrogen economy and with a hydrogen economy), the following simplified equation results for tropospheric hydrogen burden changes:

$$
\Delta \mathrm{M}_{\text {trop }}=\frac{\left(\dot{\mathrm{M}}_{\mathrm{IN}, \mathrm{HE}}-\Delta \dot{\mathrm{M}}_{\mathrm{IN}, \mathrm{ff}}\right) /(86400 \cdot 365.25)}{\mathrm{k}_{1 \mathrm{~T}}[\mathrm{OH}]_{\mathrm{T}}+\left(\frac{\mathrm{nm}}{\mathrm{Av} \cdot \overline{\mathrm{C}}_{\text {air }}}\right) \frac{\mathrm{V}_{\mathrm{d}} \cdot \mathrm{Ae}}{\mathrm{V}_{\text {ol,trop }}} \cdot 10^{10}}
$$

where 
$\Delta \mathrm{M}_{\mathrm{IN}, \mathrm{ff}} \quad$ = change in hydrogen emissions fossil fuel sources, a portion of which is related to the hydrogen economy, Tg/yr.

and

$$
\Delta \mathrm{f}_{\mathrm{H} 2}=\frac{\Delta \mathrm{M}_{\text {trop }} \cdot 10^{21}}{\mathrm{~V}_{\text {trop }} \cdot \mathrm{MW}_{\mathrm{H} 2} \cdot \overline{\mathrm{C}}_{\text {air }}}
$$

where

$$
\begin{array}{ll}
\Delta \mathrm{f}_{\mathrm{H} 2} & =\text { change in mixing ratio of hydrogen in the troposphere, ppbv } \\
\mathrm{V}_{\text {trop }} & =\text { volume of troposphere, } 6.7 \cdot 10^{18} \mathrm{~m}^{3} \\
\mathrm{MW}_{\mathrm{H} 2} & =\text { molecular weight of hydrogen, } 2 \mathrm{gm} / \mathrm{mole} \\
\overline{\mathrm{C}}_{\text {air }} & =\text { molar concentration of air, } 21.7 \text { moles }-\mathrm{m}^{3} \\
\mathrm{~nm} & =6.7 \cdot 10^{19} \text { molecules } / \mathrm{cm}^{3} \\
\mathrm{Av} & =9.7 \cdot 10^{5} \mathrm{molecules}^{*} \mathrm{~cm}^{-3} \\
\mathrm{OH} & =4.02 \cdot 10^{-15} \mathrm{~cm}^{3} \cdot \mathrm{molecule}^{-1} \cdot \mathrm{s}^{-1} \\
\mathrm{k}_{1 \mathrm{~T}} &
\end{array}
$$

To show the range of applicability of Equation (9a), the results were compared to the exact solution, and are shown in Figure C-11. Cases are shown where $\Delta \mathrm{M}_{\mathrm{IN}, \mathrm{ff}}=-10 \mathrm{Tg} / \mathrm{yr}, 0 \mathrm{Tg} / \mathrm{yr}$, and $10 \mathrm{Tg} / \mathrm{yr}$, and demonstrate an excellent comparison for the range of leakage rates examined, which likely exceeds an upper limit of hydrogen leakage in the future. In the denominator of Equation (9a) the deposition term is approximately three times larger than the OH-oxidation term, once again indicating the importance of the deposition velocity on atmospheric hydrogen.

An example of the use of Equations (9a) and (9b) is when $\dot{\mathrm{M}}_{\mathrm{IN}, \mathrm{HE}}-\Delta \dot{\mathrm{M}}_{\mathrm{IN}, \mathrm{ff}}=50 \mathrm{Tg} / \mathrm{yr}$. Under these circumstances $\Delta \mathrm{M}_{\text {trop }}=113 \mathrm{Tg}$ from Equation (9a), and $\Delta \mathrm{f}_{\mathrm{H} 2}=390 \mathrm{ppbv}$ from Equation (9b).

Equation (9a) can also be used to compare with some of Wuebbles (2009) results. In going to an A1FI hydrogen economy Wuebbles projects that the increase in hydrogen emissions between the two A1FI scenarios is $45 \mathrm{Tg} / \mathrm{yr}$ (see page 16 of Wuebbles (2009)). Assuming steady-state and using Equations (9a) and (9b), the increase in mixing ratios of hydrogen is calculated to be 280 ppbv. This is at the lower end of the range predicted by Wuebbles (300-600 ppbv; see page 19). Given the simplicity of the approach used when comparing to Wuebbles (2009), the comparison generally validates both, Wuebbles (2009) and the simpler approach developed here. 


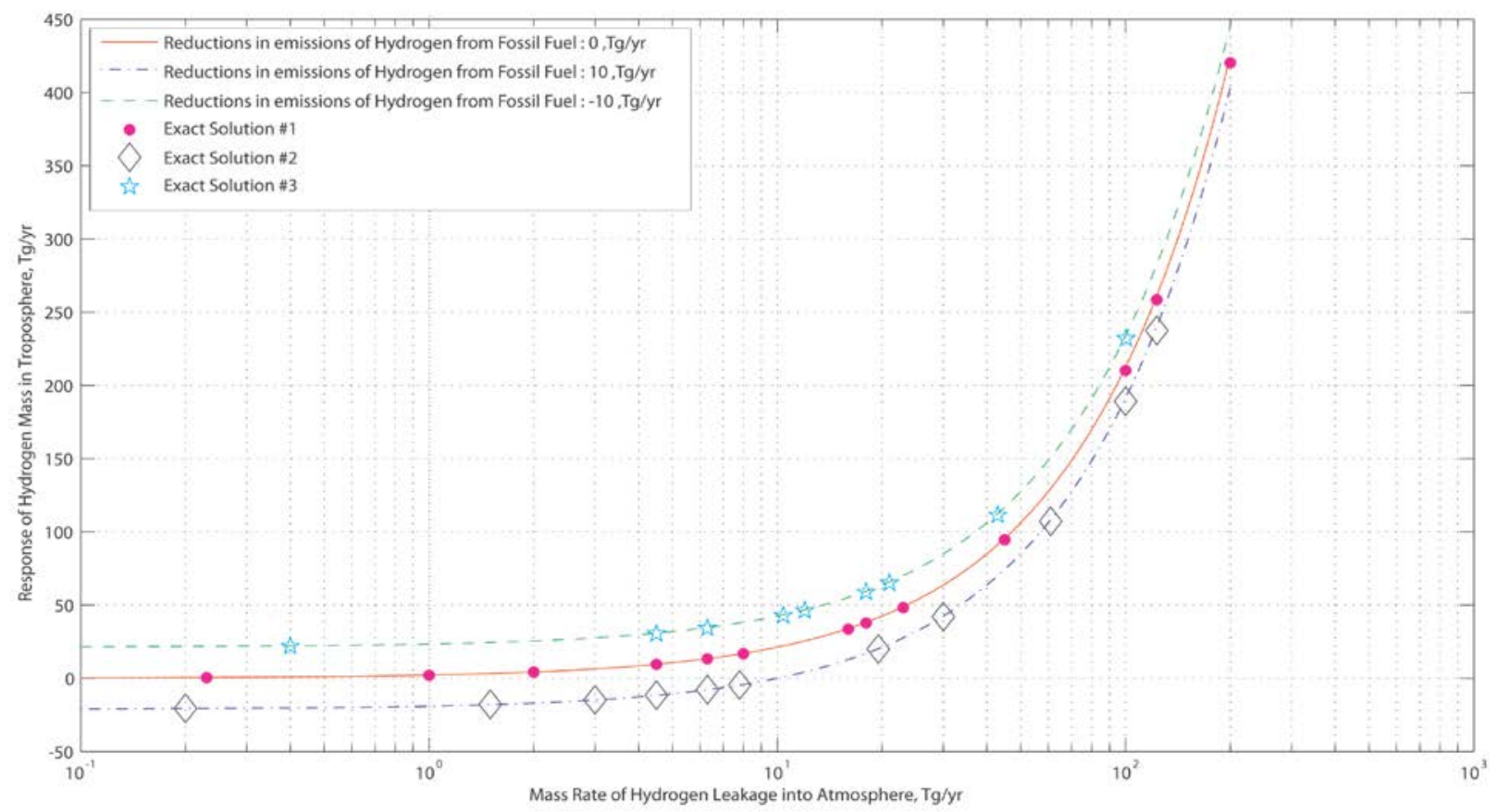

Figure C-11 Comparison of Exact and Approximate Changes of Hydrogen Mass in Troposphere

\section{Investigation of Time-variable Hydrogen Emission Rates}

We do not expect emissions of hydrogen to the atmosphere to remain constant over the $21^{\text {st }}$ century as our economy grows, whether or not a hydrogen economy evolves. This is illustrated in Figure C-12, where hydrogen emissions from fossil fuel sources and biomass are assumed to increase by $1 \% / \mathrm{yr}$ and $0.5 \% / \mathrm{yr}$, respectively. At the year $2050,4.8 \mathrm{Tg} / \mathrm{yr}$ of hydrogen is assumed to leak into the atmosphere as a result of the initiation of a hydrogen economy. The only difference between Figure C-12(a) and Figure C-12(b) is that Figure C-12(b) includes a compensating reduction in hydrogen emissions associated with a reduction in fossil fuel vehicles, while no such compensation is included in Figure C-12(a). The effects of this difference are evident beginning in 2050, when the hydrogen leakage is assumed to begin. The increased hydrogen mixing ratio associated with the hydrogen economy is about 15 ppbv when compensation is considered, but about twice that when compensation is not considered. Relative to the projected increase of hydrogen mixing ratios from $530 \mathrm{ppbv}$ to $715 \mathrm{ppbv}$ without a hydrogen economy, the increases in mixing ratios is small. 

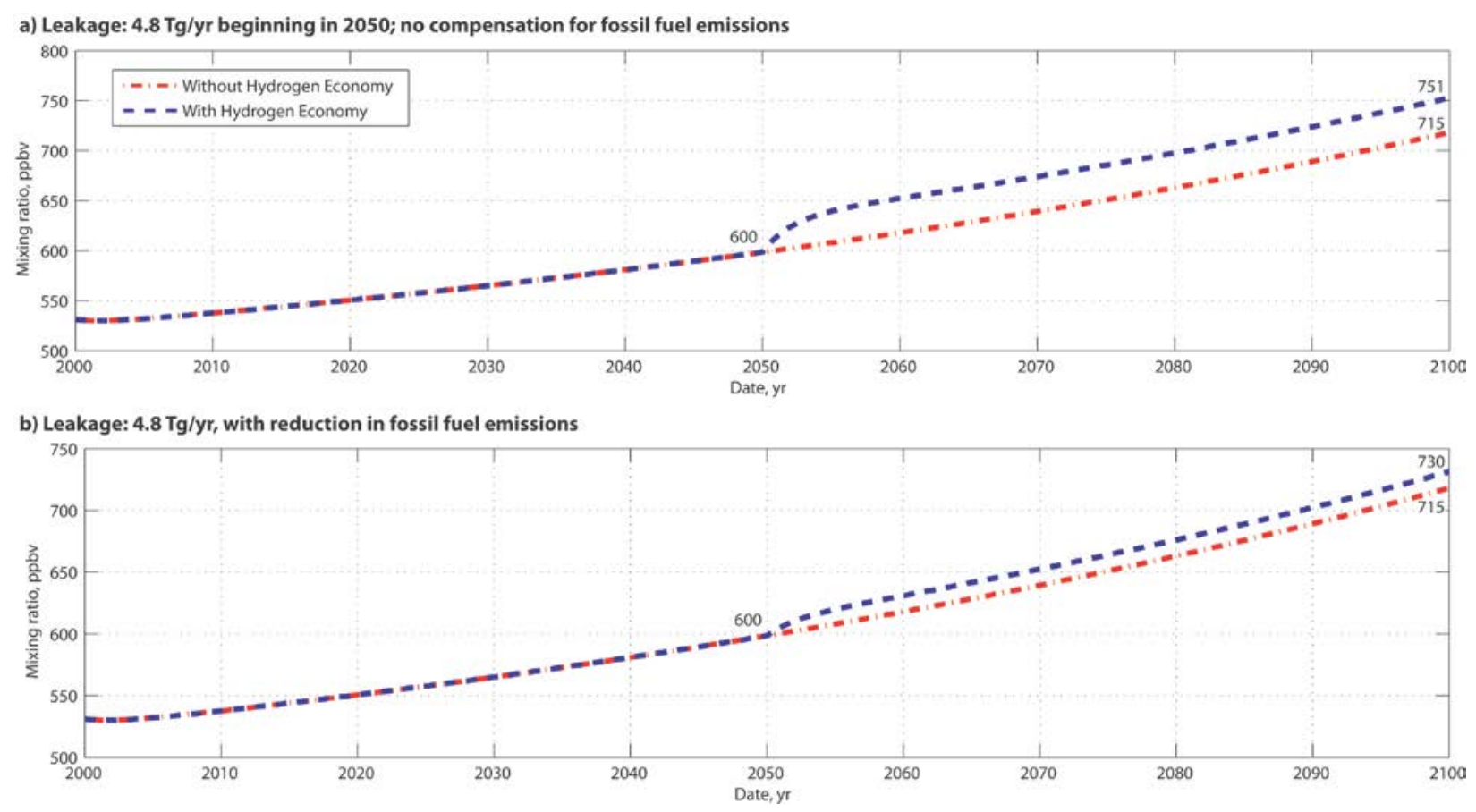

Figure C-12 Effects of time variable source terms and hydrogen leakage on hydrogen mixing ratios in the troposphere.

\section{Recent Developments and Implications in Soil Uptake of Hydrogen}

The previous work presented in this paper, and by other researchers as well, assumes that hydrogen uptake by soil (and uptake by other near-surface features) is linearly proportional to the hydrogen concentrations at the atmospheric-soil interface. All results presented to this point are based on this assumption.

Only a few researchers are known to have examined the effect of hydrogen mixing ratios on soil uptake of hydrogen. Schuler and Conrad (1991) examined hydrogen uptake at $10^{3} \mathrm{ppbv}$ and 3:10 ${ }^{6}$ ppbv for two soil types. The mixing ratios used are well above that in the troposphere ( $\sim 531 \mathrm{ppbv}$ ). For an acidic cambisol soil, the ratio of peak uptake rates was 1600:1 at the two hydrogen mixing ratios. For a composite soil, the ratio of peak uptake rates was 1200:1 at the two hydrogen mixing ratios. In both cases uptake increases were less than linear (3000:1), indicating no non-linear enhancement in uptake. However, the range of hydrogen mixing ratios is very large, and there is no indication of whether an intermediate peak would have been attained.

Trevors (1985) examined the hydrogen consumption in aerobic and anaerobic soils at a range of hydrogen concentrations that varied by a factor of 5 . In both cases, hydrogen consumed increased with hydrogen concentrations, and also over time. After about 72 hours a linear relationship was attained between hydrogen consumed and hydrogen concentration applied. The experiments did not provide evidence of non-linear uptake from exposure to higher hydrogen concentrations.

Presently, global uptake of hydrogen by soil is calculated by:

$$
\dot{\mathrm{M}}_{\text {out,soil }}=\mathrm{V}_{\mathrm{d}} \cdot \frac{\mathrm{nm}}{\mathrm{Av}} \cdot \mathrm{f}_{\mathrm{H} 2} \cdot \mathrm{Ae} \cdot \mathrm{MW}_{\mathrm{H} 2} \cdot 10^{-11}(365.25)(86400)
$$


where

$$
\begin{array}{ll}
\dot{\mathrm{M}}_{\text {out,soil }} & =\text { global uptake rate of atmospheric hydrogen by soil, Tg/yr } \\
\mathrm{V}_{\mathrm{d}} & =\text { global average deposition velocity of hydrogen, } 0.04 \mathrm{~cm} \cdot \mathrm{s}^{-1} \\
\mathrm{~nm} & =\text { average surface number density, } 2.7 \cdot 10^{19} \text { molecules }^{*} \mathrm{~cm}^{-3} \\
= & \text { globally averaged mixing ratio of hydrogen at atmosphere }- \text { soil } \\
\mathrm{f}_{\mathrm{H} 2} & \text { surface }(\sim 531 \text { ppbv at present }) \\
= & \text { surface area of earth where hydrogen deposition occur, } 9 \cdot 10^{7} \\
& \text { Ae }
\end{array}
$$

As an example application of Equation 11, using the data above, the soil uptake rate becomes:

$$
\dot{\mathrm{M}}_{\text {out }, \text { soil }}=54.1 \mathrm{Tg} / \mathrm{yr}
$$

However, a recent study by Wuebbles (2009) has shown that hydrogen uptake by soils is a nonlinear function of the atmospheric hydrogen mixing ratios. Figure $\mathrm{C}-13$ shows the relative soil uptake developed by Wuebbles and compares it to the value used by other investigators.

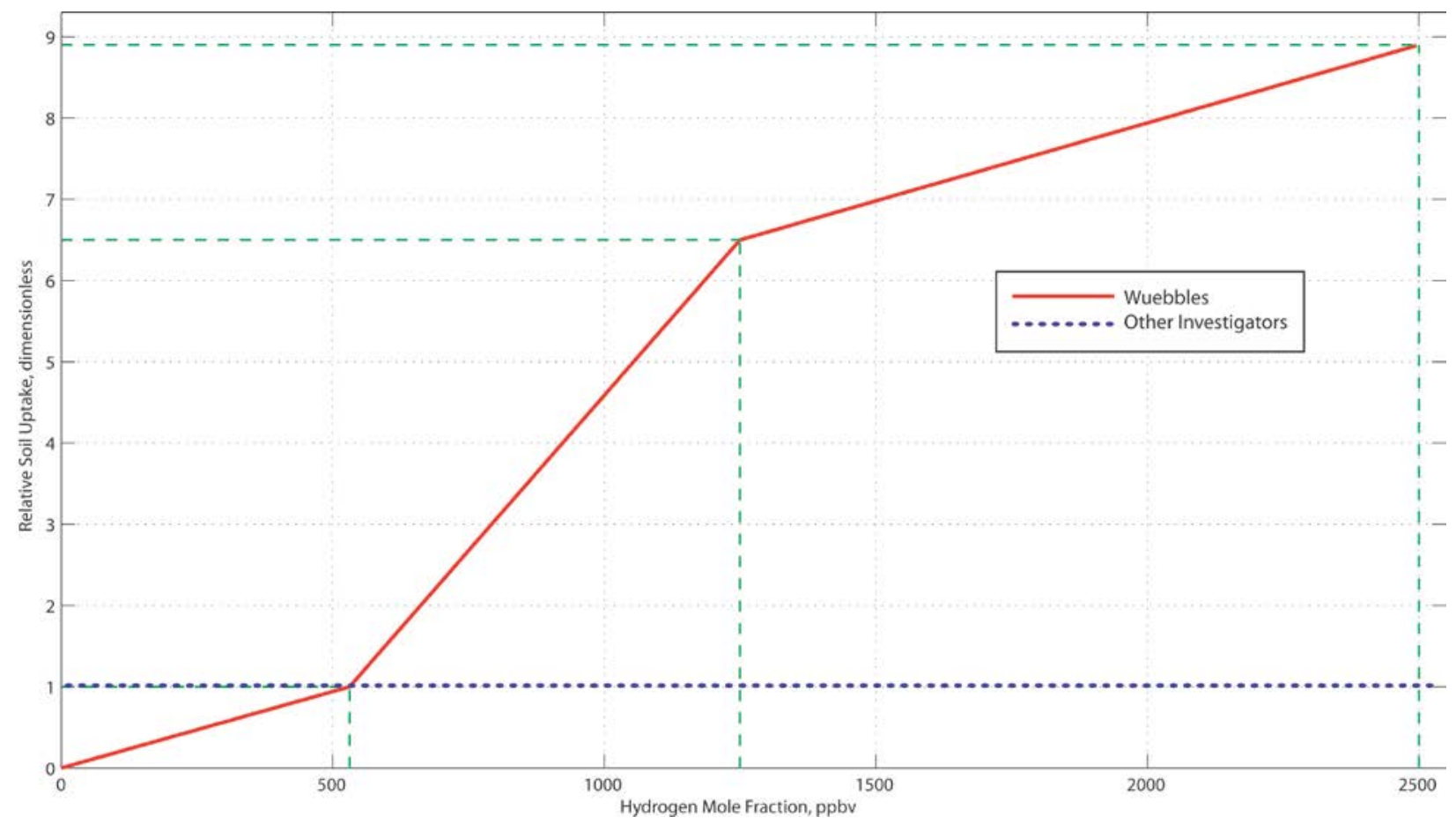

Figure C-13 Relative soil uptake versus hydrogen concentration. 
There is a significant difference in uptake (Figure C-13) as the hydrogen mixing ratio moves away from today's present value of about $531 \mathrm{ppbv}$. Since hydrogen concentrations are likely to increase in the future rather than decrease, the curve to the right of $531 \mathrm{ppbv}$ is of most interest. The uptake rate would double if the hydrogen mole fraction were to increase to $650 \mathrm{ppbv}$. The hydrogen uptake rates (both linear and non-linear approaches) are shown in Figure C-14. They are only identical to each other at $531 \mathrm{ppbv}$ (where the global uptake is about $54 \mathrm{Tg} / \mathrm{yr}$ ). At the hydrogen mole fraction where uptake doubles to $108 \mathrm{Tg} / \mathrm{yr}$ for non-linear uptake, the predicted linear uptake rate has increased to about $70 \mathrm{Tg} / \mathrm{yr}$.

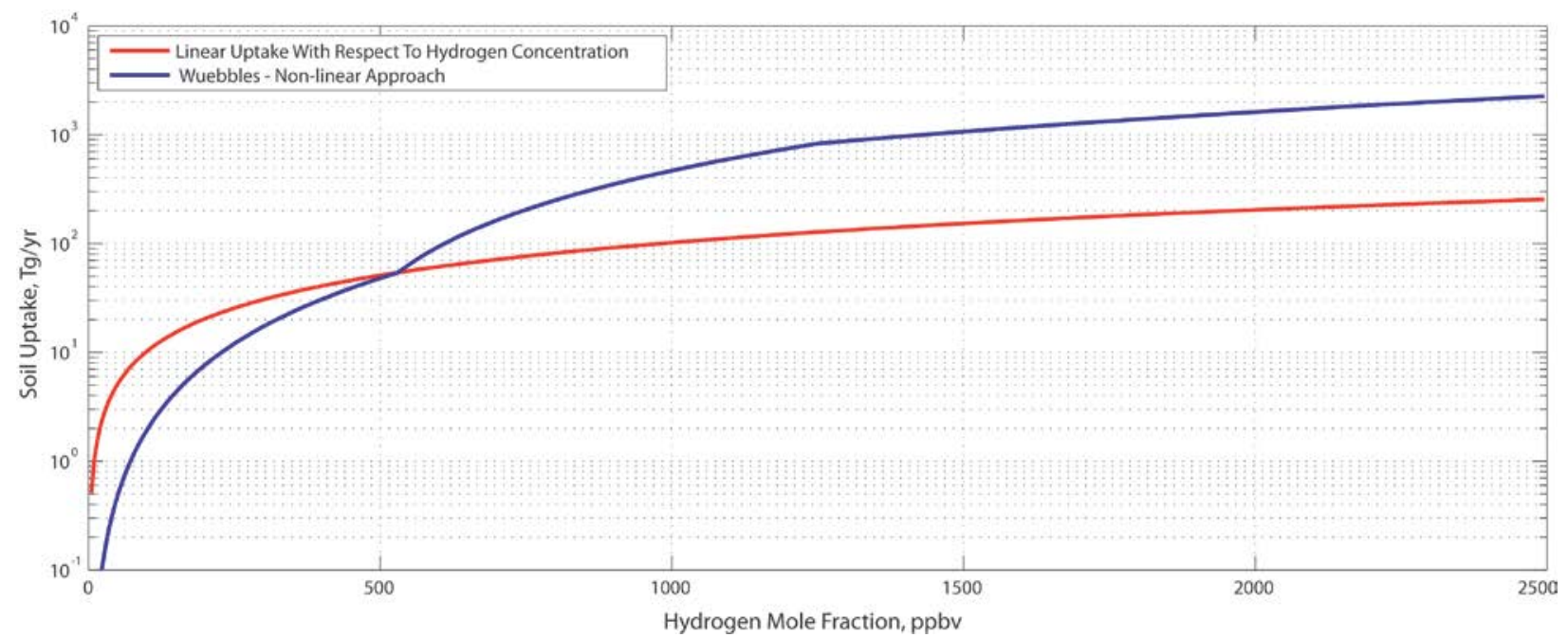

Figure C-14 Global soil uptake of hydrogen using two approaches: (a) linear uptake with respect to hydrogen concentration and; (b) Wuebbles-non-linear approach.

Because of the anticipated importance of the non-linear uptake, this feature was added to the global hydrogen model as an optional approach. The first step in developing this method was to fit the relative uptake rate data to a smooth curve that minimizes the mean square error (MSE). The smooth curve used to describe $\alpha$ (the relative uptake) was chosen to be:

$$
\alpha=a \operatorname{erf}\left(\frac{\mathrm{f}_{\mathrm{H} 2}}{\mathrm{~b}}-\mathrm{c}\right)+\mathrm{a} \operatorname{erf}(\mathrm{c})
$$

where

$$
\begin{array}{ll}
\mathrm{a}, \mathrm{b}, \mathrm{c} & =\text { unknown coefficients to be determined by minimization of error } \\
\mathrm{f}_{\text {H2 }} & =\text { mixing ratio for hydrogen, ppbv }
\end{array}
$$

The MSE is expressed as:

$$
\text { MSE }=\sum_{\mathrm{i}=1}^{3}\left[\mathrm{a} \operatorname{erf}\left(\frac{\mathrm{f}_{\mathrm{H}_{\mathrm{i}}}}{\mathrm{b}}-\mathrm{c}\right)+\mathrm{a} \operatorname{erf}(\mathrm{c})-\alpha_{\mathrm{i}}\right]^{2}
$$

where 


$$
\mathrm{f}_{\mathrm{H}_{\mathrm{i}}}, \alpha_{\mathrm{i}} \quad=\text { data pairs determined from laboratory analysis }
$$

We note that Equation (11a) automatically satisfies the $(0,0)$ data point, so that point is not used in the summation given by Equation (11b). The unknowns a, b, and c were found by first finding a good initial guess for Newton's method by solving (11b) approximately $10^{6}$ times, sorting to find the minimum value, and using those values of a, b, and c as initial conditions. Newton's method then converged in three iterations. The results are shown in Figure C-15. The MSE calculated a, b, and c, allowed Equation (11a) to pass through each of the data points very accurately. We see that the two curves are identical only at the four points. However a smooth curve might actually be a better representation of $\alpha$ between data points than a piece-wise continuous function.

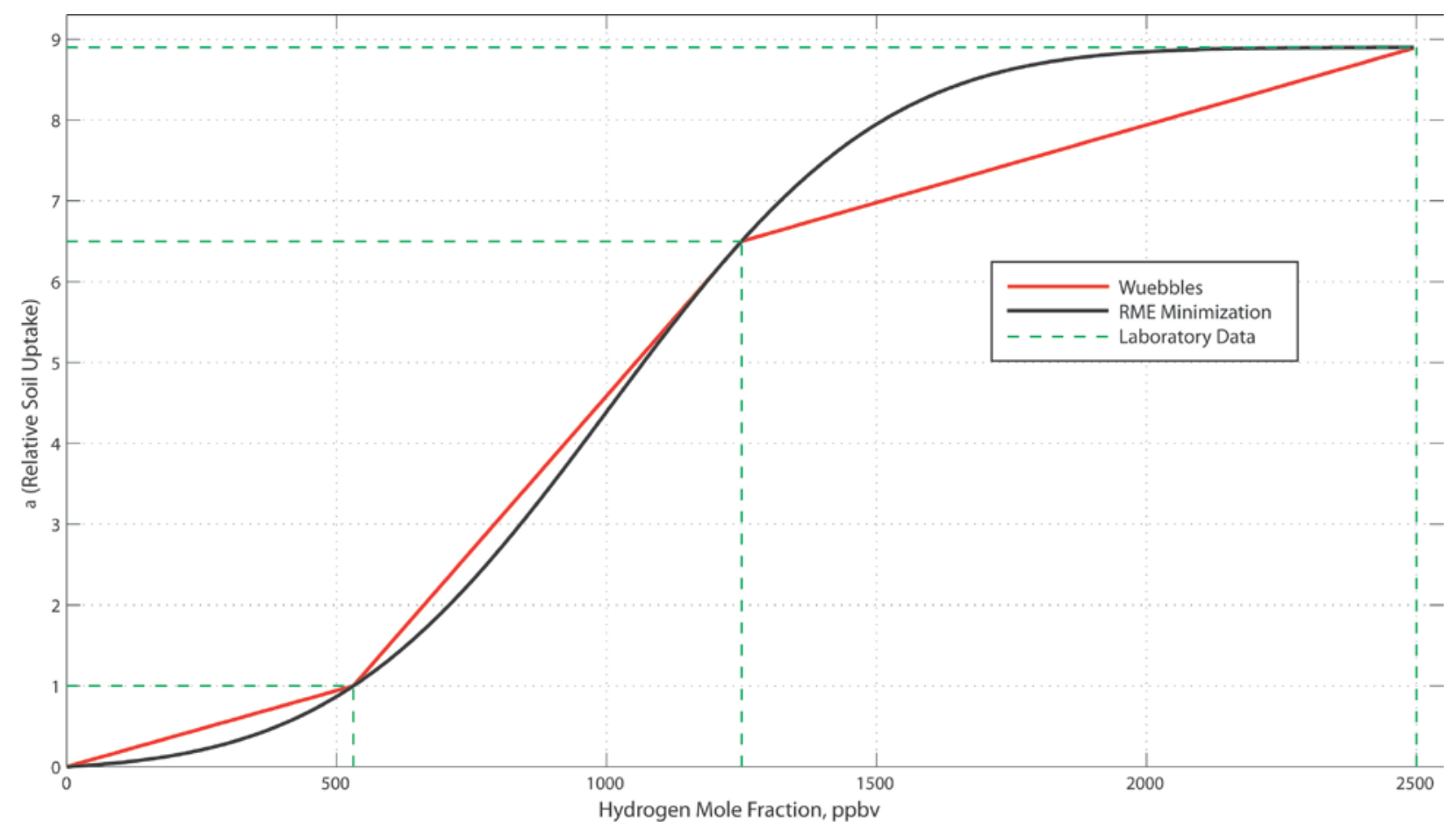

Figure C-15 Relative soil uptake versus hydrogen concentration: Wuebbles approach, and nonlinear best fit Wuebbles data.

As noted by Equation 10, the global uptake rate is linearly proportional to the hydrogen mixing ratio. It is of interest to examine how the uptake rate based on the work of Wuebbles would influence atmospheric hydrogen mixing ratios. To do this, the uptake rate is re-calculated as follows:

$$
\begin{aligned}
& \dot{\mathrm{M}}_{\text {out,soil,w }}=\alpha \dot{\mathrm{M}}_{\text {out,soil }} \\
& =\left[\mathrm{a} \cdot \operatorname{erf}\left(\frac{\mathrm{f}_{\mathrm{H} 2}}{\mathrm{~b}}-\mathrm{c}\right)+\mathrm{a} \cdot \operatorname{erf}(\mathrm{c})\right] \cdot \dot{\mathrm{M}}_{\text {out,soil }}
\end{aligned}
$$

where a, b, and c were calculated as shown previously. 
To demonstrate the significance of this alternative formulation, Figure C-12(a) was re-created using the alternative uptake rate in Equation (12a). The results are shown in Figure C-16.

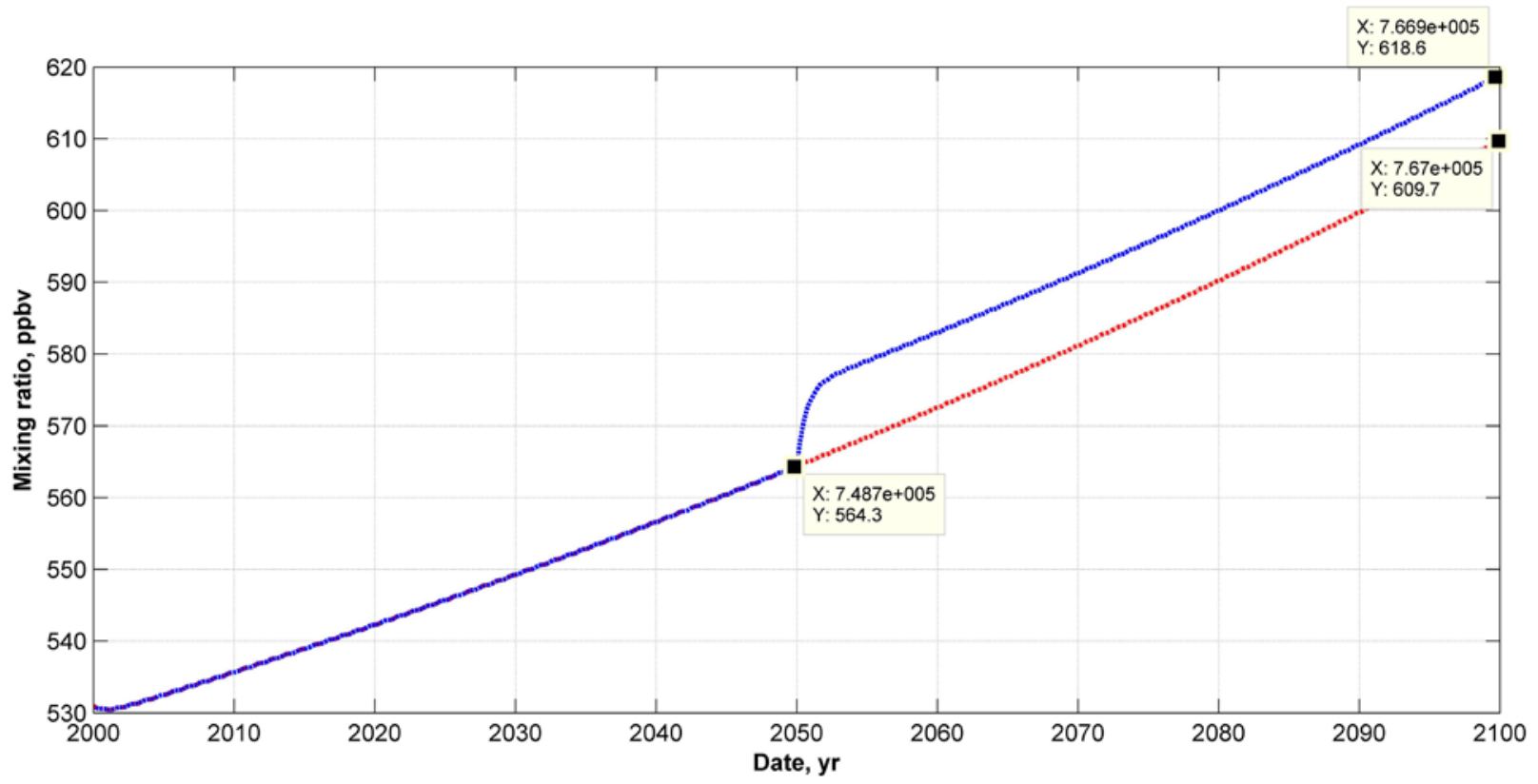

Figure C-16 Projected Hydrogen Mixing Ratios During the $21^{\text {st }}$ Century for Hydrogen Uptake Governed by the Work of Wuebbles (2009).

When the results of Figure C-16 are compared against the results in Figure C-12(b), where the only difference between the two simulations is the uptake algorithm, it is seen that hydrogen mixing ratios are predicted to decrease by about 35 ppbv in mid century and 110 ppbv by the end of the century, compared to what they otherwise would be. This is a significant finding, and suggests more work is needed to confirm this effect.

\section{Summary and Conclusions}

A global hydrogen balance model has been developed that is simplified compared to numerical three-dimensional models such as GATOR-GCMOM. However, by its very simplicity, it has advantages over the complex models, such as being able to simulate long periods of time; and seeing clearly how atmospheric hydrogen mixing ratios evolve over time. To simulate a century of time, the simplified model takes about five minute of computing time; GATOR-GCMOM cannot simulate such long periods of time without spending months of computational time.

The simplified model is intended only to supplement the more sophisticated models, and to check the plausibility of their results, which was done during this project. Further the model does not evaluate impacts on human health or the environment.

To summarize the model's capabilities, it predicts both tropospheric and stratospheric hydrogen mixing ratios, subject to hydrogen releases (from biomass burning, fossil fuel combustion, nitrogen fixation, soil uptake, and oceanic off gassing), and atmospheric sinks and sources (oxidation by the $\mathrm{OH}$ radical, and production by photolysis of $\mathrm{HCHO}$, which is produced from atmospheric methane). 
The model has been validated by a series of analytical tests, and by comparison with known atmospheric burdens, mixing ratios, and residence times of hydrogen. Sensitivity analyses were also performed that confirmed the importance of soil uptake on the global budget.

The major conclusions of this work are as follows:

- The time required for hydrogen mixing ratios to attain a steady state condition following initiation of a constant hydrogen leakage rate is over 10 years in the troposphere and over 50 years in the stratosphere. This suggests that the more sophisticated models should be run for periods in excess of 10 years.

- The hydrogen mixing ratios in the $21^{\text {st }}$ century are likely to increase whether or not the hydrogen economy evolves. Those increases may exceed those due to a hydrogen economy.

- Current developments in hydrogen uptake as reported in Wuebbles (2009), where a nonlinear dependence on hydrogen mixing rates was implicated from laboratory analysis, the algorithm to describe hydrogen uptake in the model was modified to incorporate these effects. Results showed that soil uptake world increase as molecular hydrogen mixing ratios increase, thereby tending to reduce mixing ratios. An example that was run showed that by mid-century mixing ratios would be 60 ppbv lower, and by the end of the century 190 ppbv lower. These are significant differences, and suggest the need to confirm the research of Wuebbles (2009).

\section{Glossary of Terms}

\section{$\mathrm{Tg}$}

$\mathrm{Tg} / \mathrm{yr}$

ppbv

$\mathrm{M}, \mathrm{M}_{\mathrm{s}}$

$\dot{\mathrm{M}}_{\mathrm{in}, \mathrm{ff}}$

$\dot{\mathrm{M}}_{\text {in,biomass }}$

$\dot{\mathrm{M}}_{\text {in,nitrogen }}$

$\dot{\mathrm{M}}_{\text {in,ocean }}$
$=$ Teragram

$=$ Teragrams per year

= parts per billion by volume

= Mass of hydrogen in troposphere (stratosphere), Tg

= Emission rate of hydrogen into troposphere by fossil fuel combustion, $\mathrm{Tg} / \mathrm{yr}$

$=$ Emission rate of hydrogen into troposphere from biomass burning, $\mathrm{Tg} / \mathrm{yr}$

= Emissions rate of hydrogen into troposphere from nitrogen fixation, Tg/yr

$=$ Emissions rate of hydrogen into troposphere from oceans, $\mathrm{Tg} / \mathrm{yr}$ 


$$
\begin{aligned}
& \dot{\mathrm{M}}_{\mathrm{in}, \mathrm{CH} 4}\left(\dot{\mathrm{M}}_{\mathrm{in}, \mathrm{CH} 4, \mathrm{~s}}\right)=\text { Generation rate of hydrogen in troposphere (stratosphere) from } \\
& \text { photolysis reactions with methane, } \mathrm{Tg} / \mathrm{yr} \\
& \dot{\mathrm{M}}_{\mathrm{in}, \mathrm{NMHC}} \\
& \dot{\mathrm{M}}_{\text {in,leak }} \\
& =\text { Generation rate of hydrogen in troposphere from photolysis } \\
& \text { reactions with NMHCs, Tg/yr } \\
& \text { = Hydrogen leakage rate into troposphere from anthropogenic } \\
& \text { hydrogen production, distribution, and consumption, Tg/yr } \\
& \dot{\mathrm{M}}_{\mathrm{out}, \mathrm{OH}}\left(\dot{\mathrm{M}}_{\mathrm{out}, \mathrm{OH}, \mathrm{s}}\right) \quad=\text { Destruction rate of hydrogen in troposphere (stratosphere) by } \\
& \text { reaction with } \mathrm{OH} \text { radicals, } \mathrm{Tg} / \mathrm{yr} \\
& \dot{\mathrm{M}}_{\text {insertion }} \\
& \dot{\mathrm{M}}_{\text {in, soil }} \\
& \mathrm{M}_{0}, \mathrm{M}_{0, \mathrm{~s}} \\
& \dot{\mathrm{M}}_{\text {in,ref,ocean }} \\
& =\text { Reference rate of hydrogen emissions from ocean at time } t_{\text {ref }} \text {, } \\
& \mathrm{Tg} / \mathrm{yr} \\
& \mathrm{f}_{\mathrm{H} 2}, \mathrm{f}_{\mathrm{H} 2, \mathrm{~s}} \\
& =\text { Mixing ratio of hydrogen in troposphere (and stratosphere), ppbv } \\
& \mathrm{V}_{\text {trop }}\left(\mathrm{V}_{\text {strat }}\right) \quad=\text { Volume of troposphere (stratosphere), } \mathrm{m}^{3} \\
& \mathrm{MW}_{\mathrm{H} 2} \quad \text { = Molecular weight of hydrogen } \\
& \overline{\text { Cair, }} \overline{\text { Cair, }}{ }_{\mathrm{s}} \quad \text { = Average molar concentration of air in troposphere (stratosphere) } \\
& \text { used in model simulations, moles } / \mathrm{m}^{3} \\
& \mathrm{r}_{\mathrm{ff}} \quad=\text { Coefficient for fossil fuel emissions of hydrogen that equals one } \\
& \text { for } \mathrm{t}<\mathrm{t}_{\mathrm{HE}} \text {, but may change for } \mathrm{t}>\mathrm{t}_{\mathrm{HE}} \\
& \beta \quad=\text { Fractional hydrogen emissions change associated with NMHC } \\
& \text { after hydrogen economy begins, dimensionless }
\end{aligned}
$$




$$
\begin{aligned}
& \alpha_{\mathrm{ff}} \quad=\text { Coefficient that reflects growth rates of fossil fuel emissions of } \\
& \text { hydrogen, dimensionless } \\
& \alpha_{\text {nmhc }} \quad=\text { Coefficient that reflects growth rates (or reduction rates) of } \\
& \text { atmospheric NMHCs, dimensionless } \\
& \alpha_{\text {biomass }} \\
& \alpha_{\text {nitrogen }} \\
& \mathrm{t} \\
& t_{\text {he }} \\
& \mathrm{t}_{0} \\
& \mathrm{t}_{\text {ref }} \\
& \mathrm{G}_{\mathrm{CH} 4, \mathrm{t}}\left(\mathrm{G}_{\mathrm{CH} 4, \mathrm{~s}}\right) \quad=\text { Tropospheric (stratospheric) burden of methane, } \mathrm{Tg} \\
& \dot{\mathrm{M}}_{\text {in,he }} \\
& \mathrm{N} \\
& \mathrm{f}_{\mathrm{H} 2 \text { ref -insertion }} \\
& \mathrm{OH}\left(\mathrm{OH}_{\mathrm{s}}\right) \quad \text { = Tropospheric (stratospheric) hydroxyl radical concentration, } \\
& \text { molecules } / \mathrm{cm}^{3} \\
& \mathrm{k}_{1 \mathrm{t}}\left(\mathrm{k}_{1 \mathrm{~s}}\right) \quad=\text { Rate constant for loss of hydrogen by reaction with } \mathrm{OH} \text { in } \\
& \text { troposphere (stratosphere), } \mathrm{cm}^{3}-\mathrm{molecule}^{-1} \cdot \mathrm{s}^{-1} \\
& \mathrm{k}_{5 \mathrm{t}}\left(\mathrm{k}_{5 \mathrm{~s}}\right) \quad=\text { Rate constant for production of hydrogen in troposphere } \\
& \text { (stratosphere), } \mathrm{cm}^{3} \cdot \mathrm{molecule}^{-1} \cdot \mathrm{s}^{-1} \\
& \mathrm{~V}_{\mathrm{d}} \quad=\text { Deposition velocity of hydrogen, } \mathrm{cm} \cdot \mathrm{s}^{-1}
\end{aligned}
$$




$$
\begin{array}{ll}
\mathrm{nm} & =\text { Average surface number density of molecules, molecules } \cdot \mathrm{cm}^{-3} \\
\mathrm{Av} & =\text { Avagadro's number, } 6 \cdot 0233 \cdot 10^{23} \text { molecules } / \mathrm{mole} \\
\mathrm{A}_{\mathrm{e}} & \text { Area of earth where deposition of hydrogen occurs, } \mathrm{km}^{2} \\
\mathrm{~F}_{\text {hcho }} & =\text { Fraction of (formaldehyde) HCHO photolyzed in the } \\
& \text { troposphere, dimensionless } \\
\mathrm{MW}_{\text {ratio }} & \text { Molecular rate ratio of hydrogen to methane, dimensionless } \\
\Delta_{\text {in,CH4,t }} & \text { Emissions rate change in methane to troposphere associated with } \\
& \text { hydrogen economy, Tg/yr } \\
\tau_{\mathrm{CH} 4} & \text { Half-life of methane in stratosphere, years } \\
\mathrm{A}_{\text {fac1 }}, \mathrm{A}_{\text {fac }} & =\text { Arrhenius factor for } \mathrm{k}_{1}\left(\mathrm{k}_{5}\right), \mathrm{cm}^{3} \cdot \text { molecule }{ }^{-1} \cdot \mathrm{s}^{-1} \\
(\mathrm{E} / \mathrm{R})_{1},(\mathrm{E} / \mathrm{R})_{5} & =\text { Activation temperature for } \mathrm{k}_{1}\left(\mathrm{k}_{5}\right), \text { Kelvin } \\
\mathrm{T}_{\mathrm{t}}, \mathrm{T}_{\mathrm{s}} & =\text { average temperature of troposphere (stratosphere), Kelvin } \\
\phi_{2}, \phi_{2, \mathrm{~S}} & =
\end{array}
$$




\section{Addendum}

\section{Typical Range of Model Input Variables}

Table C-5

Typical Range of Model Input Variables

\begin{tabular}{|c|c|c|c|c|}
\hline Variable & Units & Comment & Typical Value & $\begin{array}{l}\text { Typical } \\
\text { Range }\end{array}$ \\
\hline Start Time & Year & $\begin{array}{l}\text { Simulation starts on January } 1 \text { of } \\
\text { the specified year }\end{array}$ & 1992 & $1700-2010$ \\
\hline End Time & Year & $\begin{array}{l}\text { Simulation ends on January } 1 \text { of } \\
\text { the specified year }\end{array}$ & $\begin{array}{l}2050 \text { (Must be } \\
\text { after start time) }\end{array}$ & $\begin{array}{l}\text { Start time to } \\
2100\end{array}$ \\
\hline $\begin{array}{l}\text { Initial Hydrogen mixing ratio in } \\
\text { Troposphere }\end{array}$ & ppbv & $\begin{array}{l}\text { The value selected should be } \\
\text { consistent with start time }\end{array}$ & 531 & $200-550$ \\
\hline $\begin{array}{l}\text { Initial Hydrogen mixing ratio in } \\
\text { Stratosphere }\end{array}$ & ppbv & $\begin{array}{l}\text { The value selected should be } \\
\text { consistent with start time }\end{array}$ & 531 & $200-550$ \\
\hline Deposition Velocity & $\mathrm{cm} / \mathrm{sec}$ & $\begin{array}{l}\text { Global average value should be } \\
\text { used }\end{array}$ & 0.04 & $0.01-0.07$ \\
\hline Temperature in Troposphere & Kelvin & $\begin{array}{l}\text { Average temperature in } \\
\text { troposphere used for rate } \\
\text { calculations }\end{array}$ & 277 & $267-287$ \\
\hline Temperature in Stratosphere & Kelvin & $\begin{array}{l}\text { Average temperature in } \\
\text { stratosphere used for rate } \\
\text { calculations }\end{array}$ & 233 & $223-243$ \\
\hline $\begin{array}{l}\text { A-Factor (Arrhenius) for } \mathrm{k}_{1}(\mathrm{OH} \\
\text { oxidation of } \mathrm{H}_{2} \text { ) }\end{array}$ & $\mathrm{cm}^{3} \cdot$ molecule $^{-1} \cdot \mathrm{s}^{-1}$ & Arrhenius factor at 277 Kelvin & $5.50 \mathrm{e}-12$ & $\begin{array}{l}2 \mathrm{e}-12 \text { to } \\
1.1 \mathrm{e}-11\end{array}$ \\
\hline $\begin{array}{l}\text { A-Factor (Arrhenius) for } \mathrm{k}_{5} \\
\text { (Production of } \mathrm{H}_{2} \text { from } \mathrm{CH}_{4} \text { ) }\end{array}$ & $\mathrm{cm}^{3} \cdot$ molecule $^{-1} \cdot \mathrm{s}^{-1}$ & Arrhenius factor at 227 Kelvin & $2.45 e-12$ & $\begin{array}{l}1.2 \mathrm{e}-12 \text { to } \\
5 \mathrm{e}-12\end{array}$ \\
\hline $\begin{array}{l}\text { E/R (Activation Temperature) } \\
\text { for } \mathrm{k}_{1}\end{array}$ & Kelvin & $\begin{array}{l}\text { Used in Arrhenius calculation of } \\
\text { rate dependency on temperature }\end{array}$ & 2000 & $1800-2200$ \\
\hline $\begin{array}{l}\text { E/R (Activation Temperature) } \\
\text { for } k_{5}\end{array}$ & Kelvin & $\begin{array}{l}\text { Used in Arrhenius calculation of } \\
\text { rate temperature dependency on } \\
\text { temperature }\end{array}$ & 1775 & $1550-1950$ \\
\hline $\begin{array}{l}\text { OH Concentration in } \\
\text { Troposphere }\end{array}$ & molecule $\cdot \mathrm{cm}^{-3}$ & $\begin{array}{l}\text { Constant throughout the simulation } \\
\text { period }\end{array}$ & $9.70 e+05$ & $\begin{array}{l}8 \mathrm{e}+5 \text { to } \\
1.2 \mathrm{e}+6\end{array}$ \\
\hline $\begin{array}{l}\text { OH Concentration in } \\
\text { Stratosphere }\end{array}$ & molecule $\cdot \mathrm{cm}^{-3}$ & $\begin{array}{l}\text { Constant throughout the simulation } \\
\text { period }\end{array}$ & $4.00 \mathrm{e}+06$ & $1 e+6$ to $8 e+6$ \\
\hline $\begin{array}{l}\text { Area of the Earth's Surface, } \\
\text { where } \mathrm{H}_{2} \text { Uptake by soil occurs }\end{array}$ & $\mathrm{km}^{2}$ & $\begin{array}{l}\text { This area is less than the area of } \\
\text { dry land }\end{array}$ & $9.00 e+07$ & $\begin{array}{l}4 \mathrm{e}+7 \text { to } \\
1.2 \mathrm{e}+8\end{array}$ \\
\hline $\begin{array}{l}\text { Volume of troposphere } \\
\text { (stratosphere) }\end{array}$ & $\mathrm{m}^{3}$ & Assumed Constant & $\begin{array}{r}2.3 \cdot 10^{18} \\
\left(2.1 \cdot 10^{19}\right)\end{array}$ & - \\
\hline
\end{tabular}


Table C-5 (continued)

Typical Range of Model Input Variables

\begin{tabular}{|c|c|c|c|c|}
\hline Variable & Units & Comment & $\begin{array}{l}\text { Typical } \\
\text { Value }\end{array}$ & $\begin{array}{l}\text { Typical } \\
\text { Range }\end{array}$ \\
\hline $\begin{array}{l}\text { Reference Altitude of } 1 \text { e- } \\
\text { folding for pressure and } \\
\text { density }\end{array}$ & $\mathrm{km}$ & $\begin{array}{l}\text { Pressure and density decrease by } \\
\text { exp(-1) of surface value at this } \\
\text { altitude }\end{array}$ & 7 & $6.8-7.2$ \\
\hline Air Density at surface of Earth & $\mathrm{g} / \mathrm{m}^{3}$ & $\begin{array}{l}\text { At annual surface temperature and } \\
\text { pressure }\end{array}$ & 1225 & $1100-1300$ \\
\hline $\begin{array}{l}\text { Atmospheric Pressure at } \\
\text { Surface of Earth }\end{array}$ & $\mathrm{Pa}$ & Approximately $1 \mathrm{~atm}$ & 101338 & $\begin{array}{l}101000- \\
102000\end{array}$ \\
\hline Thickness Of Troposphere & $\mathrm{km}$ & Average global thickness & 13.16 & 12 to 14 \\
\hline Top of Stratosphere & $\mathrm{km}$ & $\begin{array}{l}\text { Measured from the surface of the } \\
\text { earth }\end{array}$ & 50 & $48-52$ \\
\hline $\begin{array}{l}\text { Molecular density at surface } \\
\text { of earth }\end{array}$ & molecules $\cdot \mathrm{cm}^{-3}$ & - & $2.7 \cdot 10^{19}$ & - \\
\hline Avagadro's number & molecules $\cdot \mathrm{mole}^{-1}$ & - & $6.022 \cdot 10^{23}$ & - \\
\hline $\begin{array}{l}\text { Mole Density of air at altitude } \\
\text { where } 50 \% \text { of air mass is } \\
\text { below this altitude }\end{array}$ & $\mathrm{mole} / \mathrm{m}^{3}$ & $\begin{array}{l}\text { Used to represent average value } \\
\text { for model calculations }\end{array}$ & 21.7 & $21-23$ \\
\hline $\begin{array}{l}\text { Mole Density of air in } \\
\text { Stratosphere Consistent with } \\
\text { Producing Relationship } \\
\text { between Hydrogen Mixing } \\
\text { Ratio and Hydrogen Burden }\end{array}$ & $\mathrm{mole} / \mathrm{m}^{3}$ & $\begin{array}{l}\text { This value is estimated from model } \\
\text { simulations }\end{array}$ & 2.25 & $2.0-2.4$ \\
\hline $\begin{array}{l}\text { Start Time Of Hydrogen } \\
\text { Economy (HE) }\end{array}$ & Year & $\begin{array}{l}\text { This is the date when atmospheric } \\
\text { emissions of hydrogen associated } \\
\text { with HE is assumed to begin }\end{array}$ & 2020 & $2010-2060$ \\
\hline \multicolumn{5}{|l|}{$\begin{array}{l}\text { Options for Calculating } \\
\text { additional flux of Hydrogen } \\
\text { associated with HE: }\end{array}$} \\
\hline $\begin{array}{l}\text { - emission rate of } \mathrm{H}_{2} \text { is } \\
\text { constant }\end{array}$ & $\mathrm{Tg} / \mathrm{yr}$ & $\begin{array}{l}\text { Mass of hydrogen is input over } 1 \\
\text { year, and constant there after }\end{array}$ & 4.5 & $2-200$ \\
\hline $\begin{array}{l}\text { - mass of } \mathrm{H}_{2} \text { has a linearly } \\
\text { increasing Flux over } \mathrm{N} \\
\text { years,(Thereafter it remains } \\
\text { constant) }\end{array}$ & $\mathrm{Tg} / \mathrm{yr}$ & $\begin{array}{l}\text { Mass of hydrogen is input over } \mathrm{N} \\
\text { years, and constant there after }\end{array}$ & 1.0 & $1-60$ \\
\hline $\begin{array}{l}\text { - N, Years of Linear } \\
\text { Increasing hydrogen } \\
\text { emissions associated with HE }\end{array}$ & year & $\begin{array}{l}\text { This scenario is appropriate when } \\
\text { the leakage rate increases over } \\
\text { time as the HE matures }\end{array}$ & 5 & 1 to 40 \\
\hline $\begin{array}{l}\text { fractional hydrogen loading } \\
\text { change associated with } \\
\text { NMHC loading adjustment }\end{array}$ & Dimensionless & $\begin{array}{l}\text { Once the HE begins, the hydrogen } \\
\text { emitted associated with NMHC } \\
\text { loading may change by a few } \\
\text { percent. }\end{array}$ & 1 & 0.9 to 1.1 \\
\hline $\begin{array}{l}\text { fractional hydrogen associate } \\
\text { with fossil fuel loading } \\
\text { adjustment }\end{array}$ & Dimensionless & $\begin{array}{l}\text { Once the HE begins, the hydrogen } \\
\text { emitted associated with fossil fuel } \\
\text { combustion loading may change } \\
\text { by a few percent. }\end{array}$ & 1 & 0.9 to 1.1 \\
\hline
\end{tabular}


Table C-5 (continued)

Typical Range of Model Input Variables

\begin{tabular}{|c|c|c|c|c|}
\hline Variable & Units & Comment & Typical Value & $\begin{array}{l}\text { Typical } \\
\text { Range }\end{array}$ \\
\hline $\begin{array}{l}\text { Methane Emission } \\
\text { Reduction Rate at } \\
\text { Beginning of Hydrogen } \\
\text { Economy, }\end{array}$ & $\mathrm{Tg} / \mathrm{Yr}$ & $\begin{array}{l}\text { Methane emissions may change by a } \\
\text { known amount once the HE starts. } \\
\text { From the change in methane } \\
\text { emissions, the change in hydrogen } \\
\text { formed in the troposphere is } \\
\text { calculated by the model }\end{array}$ & 0 & $\begin{array}{l}\text { Negative } 5 \text { to } \\
+5 \text { (minus } \\
\text { denotes } \\
\text { decrease in } \\
\text { emissions) }\end{array}$ \\
\hline $\begin{array}{l}\text { Initial Methane mixing ratio } \\
\text { in Troposphere }\end{array}$ & ppbv & $\begin{array}{l}\text { Methane mixing ratio is specified for } \\
\text { the starting time of simulation }\end{array}$ & 1660 & 800 to 3200 \\
\hline $\begin{array}{l}\text { Annual Amplitude }(1 / 2 \\
\text { annual range) of methane } \\
\text { mixing ratio }\end{array}$ & ppbv & $\begin{array}{l}\text { Methane mixing ratios vary over the } \\
\text { course of a year. A typical range is } 22 \\
\text { ppbv. }\end{array}$ & 11 & 5 to 20 \\
\hline Linear slope for methane & ppbv/yr & $\begin{array}{l}\text { Atmospheric methane concentrations } \\
\text { have typically been increasing in the } \\
\text { recent past, and may continue to } \\
\text { increase throughout the period of } \\
\text { simulation. }\end{array}$ & 0 & -50 to 50 \\
\hline $\begin{array}{l}\text { Methane Half-Life in } \\
\text { Troposphere }\end{array}$ & Year & $\begin{array}{l}\text { The half life is approximately } \ln (2) \\
\text { times the lifetime. Often, data are } \\
\text { available in terms of lifetime }\end{array}$ & 6 & 4 to 8 \\
\hline $\begin{array}{l}\text { Fraction of } \mathrm{HCHO} \text { in } \\
\text { Troposphere not lost to } \\
\text { deposition }\end{array}$ & Fraction & $\begin{array}{l}\text { A small fraction of atmospheric } \\
\text { methane is taken up at the earth's } \\
\text { surface (typically } 5 \% \text { ) }\end{array}$ & 0.95 & 0.9 to 1.0 \\
\hline $\begin{array}{l}\text { Fraction of } \mathrm{HCHO} \\
\text { Photolyzed In Troposphere }\end{array}$ & Fraction & $\begin{array}{l}\text { The higher the fraction of } \mathrm{HCHO} \\
\text { photolyzed, the greater the hydrogen } \\
\text { production }\end{array}$ & 0.65 & 0.5 to 0.8 \\
\hline $\begin{array}{l}\text { Mean Yield of Hydrogen In } \\
\text { Troposphere from HCHO } \\
\text { photolysis }\end{array}$ & Fraction & $\begin{array}{l}\text { The higher the yield, the more } \\
\text { hydrogen is produced }\end{array}$ & 0.6 & 0.5 to 0.7 \\
\hline $\begin{array}{l}\text { Hydrocarbon Fraction In } \\
\text { Stratosphere not lost to } \\
\text { deposition (ALWAYS 1) }\end{array}$ & Fraction & $\begin{array}{l}\text { No depositional loss from } \\
\text { stratosphere }\end{array}$ & 1 & 1 to 1 \\
\hline $\begin{array}{l}\text { Fraction of } \mathrm{HCHO} \\
\text { Photolyzed In Stratosphere }\end{array}$ & Fraction & $\begin{array}{l}\text { The higher the fraction of } \mathrm{HCHO} \\
\text { photolyzed, the greater the hydrogen } \\
\text { production }\end{array}$ & 0.65 & 0.5 to 0.8 \\
\hline $\begin{array}{l}\text { Mean Yield of Hydrogen In } \\
\text { Stratosphere from HCHO } \\
\text { photolysis }\end{array}$ & Fraction & $\begin{array}{l}\text { The higher the yield, the more } \\
\text { hydrogen is produced }\end{array}$ & 0.6 & 0.5 to 0.7 \\
\hline $\begin{array}{l}\text { Mass Ratio of Hydrogen / } \\
\text { Methane }\end{array}$ & Dimensionless & Molecular weight ratios & 0.125 & 0.125 \\
\hline $\begin{array}{l}\text { Biogenic N2 Fixation, Initial } \\
\text { Mass Flux }\end{array}$ & $\mathrm{Tg} / \mathrm{yr}$ & $\begin{array}{l}\text { Mass flux of hydrogen from this } \\
\text { source at the beginning of the } \\
\text { simulation }\end{array}$ & 3 & 0 to 6 \\
\hline $\begin{array}{l}\text { Biogenic N2 Fixation, } \\
\text { alphaN2Fix }\end{array}$ & dimensionless & $\begin{array}{l}\text { Rate of annual increase from this } \\
\text { source (for example, } 0.02 \text { in annual } \\
\text { fractional increase, compounded } \\
\text { annually ) }\end{array}$ & 0 & -0.05 to 0.05 \\
\hline $\begin{array}{l}\text { Photochemical production - } \\
\text { NMHC, Initial Mass Flux }\end{array}$ & $\mathrm{Tg} / \mathrm{yr}$ & $\begin{array}{l}\text { Mass flux of hydrogen from this } \\
\text { source at the beginning of the } \\
\text { simulation }\end{array}$ & 14 & 10 to 20 \\
\hline
\end{tabular}


Table C-5 (continued)

Typical Range of Model Input Variables

\begin{tabular}{|c|c|c|c|c|}
\hline Variable & Units & Comment & Typical Value & $\begin{array}{l}\text { Typical } \\
\text { Range }\end{array}$ \\
\hline $\begin{array}{l}\text { Photochemical production } \\
\text { - NMHC, alphaNMHC }\end{array}$ & Dimensionless & $\begin{array}{l}\text { Rate of annual increase from this } \\
\text { source (for example, } 0.02 \text { in annual } \\
\text { fractional increase, compounded } \\
\text { annually ) }\end{array}$ & 0 & -0.05 to 0.05 \\
\hline $\begin{array}{l}\text { Biogenic N2 Fixation, } \\
\text { Initial Mass Flux }\end{array}$ & $\mathrm{Tg} / \mathrm{yr}$ & $\begin{array}{l}\text { Mass flux of hydrogen from this } \\
\text { source at the beginning of the } \\
\text { simulation }\end{array}$ & 3 & 0 to 6 \\
\hline $\begin{array}{l}\text { Biogenic N2 Fixation, } \\
\text { alphaN2Fix }\end{array}$ & Dimensionless & $\begin{array}{l}\text { Rate of annual increase from this } \\
\text { source (for example, } 0.02 \text { in annual } \\
\text { fractional increase, compounded } \\
\text { annually ) }\end{array}$ & 0 & -0.05 to 0.05 \\
\hline $\begin{array}{l}\text { Photochemical production } \\
\text { - NMHC, Initial Mass Flux }\end{array}$ & $\mathrm{Tg} / \mathrm{yr}$ & $\begin{array}{l}\text { Mass flux of hydrogen from this } \\
\text { source at the beginning of the } \\
\text { simulation }\end{array}$ & 14 & 10 to 20 \\
\hline $\begin{array}{l}\text { Photochemical production } \\
\text { - NMHC, alphaNMHC }\end{array}$ & Dimensionless & $\begin{array}{l}\text { Rate of annual increase from this } \\
\text { source (for example, } 0.02 \text { in annual } \\
\text { fractional increase, compounded } \\
\text { annually ) }\end{array}$ & 0 & -0.05 to 0.05 \\
\hline $\begin{array}{l}\text { Fossil Fuel Combustion, } \\
\text { Initial Mass Flux }\end{array}$ & $\mathrm{Tg} / \mathrm{yr}$ & $\begin{array}{l}\text { Mass flux of hydrogen from this } \\
\text { source at the beginning of the } \\
\text { simulation }\end{array}$ & 15 & 10 to 20 \\
\hline $\begin{array}{l}\text { Fossil Fuel Combustion, } \\
\text { alphaFF }\end{array}$ & Dimensionless & $\begin{array}{l}\text { Rate of annual increase from this } \\
\text { source (for example, } 0.02 \text { in annual } \\
\text { fractional increase, compounded } \\
\text { annually ) }\end{array}$ & 0 & -0.10 to 0.10 \\
\hline $\begin{array}{l}\text { Biomass Burning, Initial } \\
\text { Mass Flux }\end{array}$ & $\mathrm{Tg} / \mathrm{yr}$ & $\begin{array}{l}\text { Mass flux of hydrogen from this } \\
\text { source at the beginning of the } \\
\text { simulation }\end{array}$ & 16 & 10 to 20 \\
\hline $\begin{array}{l}\text { Biomass Burning, } \\
\text { (alphaBiomass) }\end{array}$ & Dimensionless & $\begin{array}{l}\text { Rate of annual increase from this } \\
\text { source (for example, } 0.02 \text { in annual } \\
\text { fractional increase, compounded } \\
\text { annually ) }\end{array}$ & 0 & -0.05 to 0.05 \\
\hline Oceans, Initial Mass Flux & $\mathrm{Tg} / \mathrm{yr}$ & $\begin{array}{l}\text { Mass flux of hydrogen from this } \\
\text { source at the beginning of the } \\
\text { simulation }\end{array}$ & 3 & 0 to 6 \\
\hline $\begin{array}{l}\text { If Ocean Flux Is Non- } \\
\text { Constant Value: fH2Ref }\end{array}$ & ppbv & $\begin{array}{l}\text { Reference hydrogen mixing ratio that } \\
\text { corresponds to the initial hydrogen } \\
\text { flux from the ocean }\end{array}$ & 531 & $200-550$ \\
\hline $\begin{array}{l}\text { If Ocean Flux Is Non- } \\
\text { Constant Value: } N \\
(0<N<1)\end{array}$ & Dimensionless & $\begin{array}{l}\text { The ocean flux of hydrogen is } \\
\text { assumed to slowly decrease as } \\
\text { tropospheric mixing ratios increase }\end{array}$ & 0.5 & -0.10 to 0.10 \\
\hline $\begin{array}{l}\text { Estimated Diffusive Flux } \\
\text { from Troposphere to } \\
\text { Stratosphere }\end{array}$ & $\mathrm{Tg} / \mathrm{yr}$ & $\begin{array}{l}\text { Mass flux of hydrogen that enters } \\
\text { the stratosphere from the } \\
\text { troposphere }\end{array}$ & 0.6 & 0.1 to 1.6 \\
\hline $\begin{array}{l}\text { fH2Ref for Diffusive Flux } \\
\text { from Troposphere to } \\
\text { Stratosphere }\end{array}$ & ppbv & $\begin{array}{l}\text { This is the hydrogen mixing ratio } \\
\text { corresponding to the diffusive flux } \\
\text { transfer shown directly above }\end{array}$ & 531 & 200 to 550 \\
\hline
\end{tabular}

\section{References}

Coletta, W. C., M. Z. Jacobson, and D. M. Golden (2005), Switching to a U.S. hydrogen fuel cell vehicle fleet: The resultant change in emissions, energy use, and greenhouse gasses, J. Power Sources, 150, 150-181 
Conrad, R., and W. Seiler (1985), Influences of temperature, moisture, and organic carbon on the flux of $\mathrm{H}_{2}$ and $\mathrm{CO}$ between soil and atmosphere. Field studies in subtropical regions, J. Geophys. Res. 90, 5699 - 5709.

Ehhalt, D. W., U. Schmidt, and L. E. Heidt (1977), Vertical profiles of molecular hydrogen in the troposphere and stratosphere. J. Geophys. Res., 82, 5907-5911.

Gerst, S., and P. Quay (2001), Deuterium component of the global molecular hydrogen cycle, $J$. Geophys. Res., 106, 5021 - 5031.

Hammer, S., L. Ingerborg, and O’Doherty (2007), Lessons from a continuous atmospheric molecular hydrogen $\left(\mathrm{H}_{2}\right)$ record in Heidelberg regarding hydrogen sources and sinks, Presented at EuroH2Hdros.

Hauglustaine, D. A., and D. A. Ehhalt (2002), A three-dimensional model of molecular hydrogen in the troposphere. J. Geophys. Res., 107, 4330, doi:10.1029/2001JD001156.

Jacobson, M. Z. (2005), Fundamentals of Atmospheric Modeling, Part II, Cambridge University Press, New York, 813 pp.

Jacobson, M. Z., W. C. Colella, and D. M. Golden (2005), Cleaning the air and improving health with hydrogen fuel cell vehicles, Science, 308, 1901-1905.

Jacobson, M. Z., Y. J. Kaufmann, Y. Rudich (2007), Examining feedbacks of aerosols to urban climate with a model that treats 3-D clouds with aerosol inclusions, J. Geophys. Res., 112, D24205, doi:10.1029/2007JD008922.

Jacobson, M. Z. (2007), History of, processes in, and numerical techniques in GATORGCMOM, http://www.stanford.edu/group/efmh/GATOR/index.html.

Jacobson, M. Z. (2008), Effects of wind-powered hydrogen fuel cell vehicles on stratospheric ozone and global climate, J. Geophys. Res. Lett., 35, L19803, doi:10.1029/2008GL035102.

Jacobson, M. Z. (2009), Effects of atmosphere of converting to hydrogen fuel cell vehicles, final report by Stanford University, prepared for U.S. Department of Energy.

Kammen, D. M. and T. E. Lipman (2003), Letter to the editor, Science, Vol. 302, 10 October.

King, G. M. (2003), Contributions of atmospheric CO and hydrogen dynamics on recent Hawaiian volcanic deposits, Applied Environmental Microbiology. Vol. 69, No. 7, pp 4067-4075.

Lallo, M., T. Aalto, T. Laurila, and J. Hatakka (2008), Seasonal cariation in hydrogen deposition to boreal forest soil in southern Finland. GRL, Vol. 35, L04402, doi: 10.1029/2007GL 032357.

Lehman, P. A. (2003), Letter to the editor, Science, Vol. 302, 10 October.

Liebl, K., and W. Seiler (1976), $\mathrm{CO}$ and $\mathrm{H}_{2}$ destruction at the soil surface, in Production and Utilization of Gasses, edited by H. G Schlegel, G. Gottschalk, and N Pfenning, pp. 215-229, E. Goltze, Göttingen, Germany.

Lovins, A. B. (2003), Letter to the editor, Science, Vol. 302, 10 October.

Novelli, P. C., P. M. Lang, K. A. Masarie, D. F. Hurst, R. E. Myeres, and J. W. Elkins (1999), Molecular hydrogen in the troposphere: Global distribution and budget, J. Geophys. Res., 104, 30427-30444. 
Price, H., L. Jaegle, A., Rice, P. Quay, P. C. Novelli, and R. Gammon (2007), Global budget of molecular hydrogen and its deuterium content: Constraints from ground station, cruise, and aircraft observations, J. Geophys. Res., 112, D22108

Rahn, T., et al. (2003), Extreme deuterium enrichment in stratospheric hydrogen and the global atmospheric budget of H-2, Nature, 474, 915-921.

Rahn, T., J. M. Eiler, N. Kitchen, J. E. Fessenden, and J. T. Randerson (2002), Concentration and deltaD of molecular hydrogen in boreal forests: Ecosystem-scale systematics of atmospheric $\mathrm{H}_{2}$, GRL, 29, No. 18.

Rhee, T. A., C. A. M. Brenningkmeijer, and T. Rockmann (2006), The overwhelming role of soils in the global atmospheric hydrogen cycle, Atmos. Chem. Phys., 6, 1611-1625.

Rohs, S., C. Schiller, M. Riese, A. Engel, U. Schmidt, T. Wetter, I. Levin, T. Nakazawa, and S. Aoki (2006), Long-term changes of methane and hydrogen in the stratosphere in the period 1978-2003 and their impact on the abundance of stratospheric water vapor, J. Geophys. Res. Vol. 111, D14315, doi:10.1029/2006JD006877.

Schuler, S. and R. Conrad, 1991. Hydrogen oxidation activities in soil as influenced by $\mathrm{pH}$, temperature, moisture, and season. Biology and Fertility of Soils. 12:127-130.

Schultz, M. G., T. Diehl, G. P. Brasseur, and W. Zittel, 2003. Air pollution and climate-forcing impacts of a global hydrogen economy, Science, 302, 624-627.

Smith-Downey N. V., J. T. Randerson, J. M. Eiler (2006), Temperature and moisture dependence of soil H2 uptake measured in the laboratory, J. Geophys. Res. Lett., 33, L14813, doi:10.1029/2006GL026749.

Trevors, J. T. (1985), Hydrogen consumption in soil, Plant and Soil, 87, 417-422.

Tromp, T. K., R. L. Shia, M. Allen, J. M. Elier, and Y. L. Yung (2003), Potential environmental impact of a hydrogen economy on the stratosphere, Science, 300, 1740-1742.

Warneck, P. 1999. Chemistry of the Natural Atmosphere. $2^{\text {nd }}$ Edition, Int.Geophys. Series, vol. 71.

Warwick, N. J., S. Bekki, E. G. Nisbet, and J. A. Pyle (2004), Geophys. Res. Lett. 31, L05107, doi:10.1029/2003GL019224.

Wuebbles, D. (2009). Evaluation of the potential environmental impacts of large-scale use and production of hydrogen in energy and transportation applications. Presented at the DOE Hydrogen Program Annual Meeting, Washington D.C.

Xiao, X., R. G. Prinn, P. G. Simmonds, L. P. Steele, P. C. Novelli, J. Huang, R. L. Langenfelds, S. O’Doherty, P. B. Krummel, P. J. Fraser, L. W. Porter, R. F. Weiss, P. Salameh, and R. H. Wang (2007), Optimal estimation of the soil uptake rate of molecular hydrogen from the Advanced Global Atmospheric Gases Experiment and other measurements, J. Geophys. Res. Vol. 112, D07303, doi:10.1029/2006JD007241

Yonemura, S., S. Kawashima, and H. Tsuruta (1999), Continuous measurements of $\mathrm{CO}_{2}$ and $\mathrm{H}_{2}$ deposition velocities onto an andisol: uptake control by soil moisture. Tellus, 518, 688-700.

Yonemura, S., S. Kawashima, and H. Tsuruta (2000), Carbon monoxide, hydrogen, and methane uptake by soils in a temperature arable field and a forest, J. Geophys. Res., 105, 14,347-14, 362. 
Zittel, W., M. Altmann, Molecular hydrogen and water vapor emissions in a global hydrogen economy, Proceedings of the $11^{\text {th }}$ World Hydrogen Energy Conference, 71-81. 


\section{APPENDIX D \\ REVIEW OF METHODS OF PREDICTING SOIL UPTAKE OF HYDROGEN: EXPERIMENTAL AND MODELING APPROACHES, WITH AN ANALYSIS OF UNCERTAINTIES. TETRA TECH, INC., JANUARY 2010.}

\section{Introduction}

Soil uptake of tropospheric hydrogen is an important component of the global hydrogen cycle. Calculated global hydrogen uptake by soils is estimated to range from approximately $50 \mathrm{Tg} / \mathrm{yr}$ to $90 \mathrm{Tg} / \mathrm{yr}$ (Novelli et al. 1999). The other major loss mechanism for tropospheric hydrogen is hydrogen oxidation by the hydroxyl radical. This mechanism contributes about $20 \mathrm{Tg} / \mathrm{yr}$. Therefore, in order to simulate the global hydrogen cycle, the soil sink needs to be accurately represented. In this appendix, studies of soil uptake of hydrogen are summarized, and modeling algorithms that simulate soil uptake are reviewed.

As a result of this work, several changes have been incorporated into GATOR-GCMOM, and an approach has been developed to incorporate uncertainty in predictions of hydrogen uptake. The approach was demonstrated by application to two separate ecosystem types: the Mojave Desert, $\mathrm{CA}$ and a boreal forest in AK.

\section{Laboratory and Field Studies of Atmospheric Hydrogen Uptake by Soils}

Table D-1 provides a summary of field and laboratory studies of hydrogen deposition and uptake over the past 30 years at locations around the world. Because some studies calculated deposition $\left(\mathrm{cm} \cdot \mathrm{s}^{-1}\right)$ and others calculated uptake $\left(\mathrm{nmol} \cdot \mathrm{m}^{-2} \cdot \mathrm{s}^{-1}\right)$ the relationship between uptake and deposition is needed to compare study results, and is given by:

$$
\text { Uptake }=\mathrm{V}_{\mathrm{d}} \cdot \mathrm{f}_{\mathrm{H}_{2}} \cdot \mathrm{C}_{\text {air }}^{\mathrm{mol}} \cdot 10^{-2}
$$

where

$$
\begin{array}{ll}
\text { Uptake } & =\text { hydrogen uptake by soil, } \mathrm{nmol} \cdot \mathrm{m}^{-2} \cdot \mathrm{s}^{-1} \\
\mathrm{~V}_{\mathrm{d}} & =\text { hydrogen deposition velocity, } \mathrm{cm} \cdot \mathrm{s}^{-1} \\
\mathrm{f}_{\mathrm{H}_{2}} & =\text { mixing ratio of hydrogen, ppbv }
\end{array}
$$




$$
\begin{aligned}
& \mathrm{C}_{\text {air }}^{\mathrm{mol}} \quad=\text { molar density of air at earth’s surface, approximately } 43.4 \\
& \text { moles } \cdot \mathrm{m}^{-3}
\end{aligned}
$$

Hydrogen deposition velocities for the studies examined range from essentially zero at the lower end of the data to $0.14 \mathrm{~cm} \cdot \mathrm{s}^{-1}$ at the upper end $\left(0\right.$ to $\left.31.9 \mathrm{nmol} \cdot \mathrm{m}^{-2} \cdot \mathrm{s}^{-1}\right)$. Researchers have found that among the factors that influence hydrogen uptake are soil temperature, soil moisture content, snow cover, organic soil content (weakly), night-time inversions, and for Hawaiian volcanic deposits, the age of the deposits. 
Table D-1

Studies to Determine Hydrogen Deposition Velocity and Hydrogen Uptake by Soils

\begin{tabular}{|c|c|c|c|c|c|}
\hline Reference & Environmental Setting & $\begin{array}{l}\text { Factors That } \\
\text { Influenced Deposition }\end{array}$ & Approach Used & $\mathrm{V}_{\mathrm{d}}, \mathbf{c m} \cdot \mathbf{s}^{-1}$ & Uptake, $\mathrm{nmol} \cdot \mathrm{m}^{-2} \cdot \mathrm{s}^{-1}$ \\
\hline Gerst and Quay (2001) & $\begin{array}{l}\text { Second growth coniferous forest } \\
\text { Seattle, Washington }\end{array}$ & - Soil temperature & In-situ static flux chamber & $0.03-0.06$ & $6.9-13.9$ \\
\hline \multirow{2}{*}{ Yonemura et al. (2000) } & \multirow{2}{*}{$\begin{array}{l}\text { Arable field and forest soil in } \\
\text { temperate Japan }\end{array}$} & \multirow{2}{*}{$\begin{array}{l}\text { - Soil moisture } \\
\text { - Plowing of soil } \\
\text { - Soil temperature } \\
\end{array}$} & \multirow{2}{*}{$\begin{array}{l}\text { Closed chamber for } 1 \text { year; Deposition } \\
\text { velocities were calculated by curve-fitting data } \\
\text { assuming linear kinetics }\end{array}$} & $0-0.09$, arable field* & $0-20.5$ \\
\hline & & & & $0.05-0.08$, forest $^{\star}$ & $11.4-18.2$ \\
\hline Rahn et al. (2002) & Boreal forest in interior Alaska & $\begin{array}{l}\text { - Soil moisture } \\
\text { - Burned areas } \\
\text { - Soil organic carbon }\end{array}$ & $\begin{array}{l}\text { Hydrogen uptake is calculated by correlating to } \\
\mathrm{CO}_{2} \text { uptake during night-time inversions using a } \\
\text { diffuser limited approach }\end{array}$ & $0.009-0.05$ & $2-12^{\star *}$ \\
\hline \multirow[b]{2}{*}{ Conrad and Seiler (1985) } & \multirow{2}{*}{$\begin{array}{l}\text { Subtropical regions in South Africa } \\
\text { and Spain }\end{array}$} & \multirow{2}{*}{$\begin{array}{l}\text { - Soil temperature } \\
\text { - Soil moisture } \\
\text { (irrigation) }\end{array}$} & \multirow[b]{2}{*}{ Static and equilibrium in-situ flux chamber } & $0.12-0.14^{\star}$ (Savanna soil) & 27.4-31.9 \\
\hline & & & & $\begin{array}{l}0.01-0.08^{\star}(\text { desert and } \\
\text { semi-desert soils) }\end{array}$ & 2.3-18.4 \\
\hline Liebl and Seiler (1976) & Savanna and field sites & - & - & $0.012^{\star}$ & $0-27.4$ \\
\hline Yonemura et al. (1999) & Andisol field in Japan & $\begin{array}{l}\text { - Soil moisture } \\
\text { - Plowing of soil }\end{array}$ & Open-flow chamber method & $0-0.10^{*}$ & $0-23$ \\
\hline \multirow{2}{*}{ Lallo et al. (2008) } & \multirow{2}{*}{$\begin{array}{l}\text { Boreal forest soil in southern } \\
\text { Sweden }\end{array}$} & \multirow{2}{*}{$\begin{array}{l}\text { - Soil temperature } \\
\text { - Soil water content } \\
\text { - Snow cover } \\
\text { - Organic peat and } \\
\text { mineral content }\end{array}$} & \multirow{2}{*}{ Flux chamber } & $0.04-0.07^{*}$ (snow free) & $9.1-16.1$ \\
\hline & & & & $0-0.04^{\star}$ (winter) & $0-9.1$ \\
\hline \multirow{2}{*}{$\begin{array}{l}\text { Smith-Downey et } \\
\text { al. (2006) }\end{array}$} & \multirow{2}{*}{$\begin{array}{l}\text { Soil collected for laboratory analysis } \\
\text { from black spruce forest AK, and } \\
\text { Mojave Desert (CA) }\end{array}$} & \multirow{2}{*}{$\begin{array}{l}\text { - Soil temperature } \\
\text { - Soil moisture }\end{array}$} & \multirow{2}{*}{$\begin{array}{l}\text { Flow-through apparatus was used to determine } \\
\text { hydrogen flux rates for different soil types }\end{array}$} & Boreal forest: 0-0.19 & Boreal forest: $0-33^{\star \star}$ \\
\hline & & & & Mojave Desert: 0-0.05 & Mojave Desert: 0-9.2 \\
\hline \multirow{3}{*}{$\begin{array}{l}\text { Smith-Downey et al. } \\
\text { (2008) }\end{array}$} & \multirow{3}{*}{$\begin{array}{l}\text { Three sites in southern CA: forest } \\
\text { ecosystem, desert ecosystem, } \\
\text { freshwater marsh }\end{array}$} & \multirow{3}{*}{$\begin{array}{l}\text { - Soil temperature } \\
\text { - Soil moisture }\end{array}$} & \multirow{3}{*}{$\begin{array}{l}\text { Flux chambers applied during duration of } \\
\text { experiment }\end{array}$} & 0.063 (forest) $^{\star}$ & 7.9 (forest) \\
\hline & & & & 0.051 (desert) & 7.6 (desert) \\
\hline & & & & 0.035 (marsh) & 7.5 (marsh) \\
\hline Rahn et al. (2000) & Boreal forest, Delta Junction, AK & $\begin{array}{l}\text { - Relationship between } \\
\mathrm{CO}_{2} \text { and } \mathrm{H}_{2} \\
\text { - Flux of } \mathrm{CO}_{2} \text { into soil } \\
\end{array}$ & Nighttime inversion analysis & $9 \cdot 10^{-3}-5 \cdot 10^{-2 \hbar}$ & $2-12$ \\
\hline \multirow{2}{*}{ Hammer et al. (2007) } & \multirow{2}{*}{ Heidelberg, Germany } & \multirow{2}{*}{$\begin{array}{l}\text { - Strength of nighttime } \\
\text { inversions }\end{array}$} & \multirow{2}{*}{$\begin{array}{l}\text { During nocturnal inversions the uptake of } \\
\text { hydrogen was related to the uptake of radon }\end{array}$} & 0.06 (annual average) & 8.3 (annual average) $)^{\star \star}$ \\
\hline & & & & $0.02-0.08$ (range) & 3-13 (range) \\
\hline King, G.M. (2003) & $\begin{array}{l}\text { A series of sites in Hawaiian volcanic } \\
\text { deposits }\end{array}$ & - Deposit age & In-situ techniques and intact cores & $0.013-0.13$ & $2.3-22.5^{\star \star}$ \\
\hline
\end{tabular}

${ }^{*} V_{d}$ was calculated for this study

**Uptake was calculated for this study 
A number of different approaches were developed and used by the investigators referenced in Table D-1 to estimate deposition velocities or hydrogen uptake. Gerst and Quay (2001) followed the method of Conrad and Seiler (1985) to calculate deposition velocity using an in-situ flux chamber:

$$
\mathrm{V}_{\mathrm{d}}=\frac{\left(\frac{\mathrm{V}}{\mathrm{A}}\right) \frac{\mathrm{df}_{\mathrm{H}_{2}}}{\mathrm{dt}}}{\mathrm{f}_{\mathrm{H}_{2}}}
$$

where

$\mathrm{V}$

A

$\mathrm{f}_{\mathrm{H}_{2}}$
= volume of flux chamber

$=$ surface area of exposed soil

$=$ mole fraction of time variable hydrogen in chamber

$V_{d}$ was calculated using the initial and final $f_{\mathrm{H}_{2}}$ values to estimate the time rate of change of $f_{\mathrm{H}_{2}}$, and the mean $\mathrm{f}_{\mathrm{H}_{2}}$ value was used in the denominator of Equation (2).

During night-time inversion conditions, the flux of hydrogen into soils $\left(\mathrm{F}_{\mathrm{H}_{2}}\right)$ was calculated by Rahn et al. (2002), based on the following formulation:

$$
\mathrm{F}_{\mathrm{H}_{2}}=\mathrm{F}_{\mathrm{CO}_{2}} \frac{\mathrm{D}_{\mathrm{H}_{2}}}{\mathrm{D}_{\mathrm{CO}_{2}}} \frac{\mathrm{d}\left[\mathrm{H}_{2}\right]}{\mathrm{d}\left[\mathrm{CO}_{2}\right]}
$$

where

$$
\begin{array}{ll}
\mathrm{F}_{\mathrm{CO}_{2}} & =\text { flux of carbon dioxide into soil (measured by flux chamber) } \\
\mathrm{D}_{\mathrm{H}_{2}}, \mathrm{D}_{\mathrm{CO}_{2}} & =\text { diffusion coefficients } \\
\frac{\mathrm{d}\left[\mathrm{H}_{2}\right]}{\mathrm{d}\left[\mathrm{CO}_{2}\right]} & =\text { relative gradients of hydrogen and carbon dioxide calculated } \\
& \text { from measurements during night-time inversions }
\end{array}
$$

Yonemura et al. (1999) calculated deposition velocity using an open-flow method to calculate hydrogen flux into the soil, and then converted the flux to deposition velocity using Equation (1). Smith-Downey et al. (2006) determined hydrogen uptake in the laboratory using soils from boreal forest and desert ecosystems. They developed an experimental apparatus to determine the hydrogen uptake for the two soil types, and controlled both temperature and moisture contents of the soil samples. The hydrogen uptake flux was then calculated from: 


$$
\mathrm{F}_{\mathrm{H}_{2}}=\frac{\left(\left[\mathrm{H}_{2}\right]_{\text {in }}-\left[\mathrm{H}_{2}\right]_{\text {out }}\right) \cdot \mathrm{f} \cdot \mathrm{P}}{\mathrm{V}_{\text {soil }} \cdot \mathrm{R} \cdot \mathrm{T}}
$$

where

$$
\begin{array}{ll}
{\left[\mathrm{H}_{2}\right]_{\text {in }}} & =\text { hydrogen concentration incoming to soil sample } \\
{\left[\mathrm{H}_{2}\right]_{\text {out }}} & =\text { hydrogen concentration in gas leaving soil sample } \\
\mathrm{f} & =\text { volumetric flow rate } \\
\mathrm{P} & =\text { atmospheric pressure } \\
\mathrm{V}_{\text {soil }} & =\text { soil volume in sample } \\
\mathrm{R} & =\text { universal gas constant }
\end{array}
$$

The results indicated temperature and soil moisture content together influenced hydrogen uptake. The uptake data set generated by Smith-Downey et al. (2006) is extensive compared with other datasets reviewed.

Smith-Downey et at. (2008) later developed field techniques to determine hydrogen uptake in forest, desert, and marsh ecosystems. Using a flux chamber, the hydrogen concentrations in the chamber were calculated from:

$$
\mathrm{H}_{2}(\mathrm{t})=\mathrm{H}_{2}(0) \mathrm{e}^{-\mathrm{bt}}
$$

where

$$
\begin{array}{ll}
\mathrm{b} & =\text { fitting parameter } \\
\mathrm{t} & =\text { time since beginning of experiment }
\end{array}
$$

The flux was then calculated from:

$$
\mathrm{F}_{\mathrm{H}_{2}}=\mathrm{H}_{2}(0)(-\mathrm{b}) \frac{\mathrm{P} \cdot \mathrm{V}}{\mathrm{R} \cdot \mathrm{T} \cdot \mathrm{A}}
$$

Hammer et al. (2007) used data collected during night-time inversions to calculate hydrogen uptake flux, where ${ }^{222} \mathrm{Rn}$ was used to parameterize vertical mixing. The hydrogen flux was calculated from:

$$
\mathrm{F}_{\mathrm{H}_{2}}=\mathrm{F}_{\mathrm{Rn}} \frac{\Delta \mathrm{H}_{2}}{\Delta \mathrm{Rn}}
$$

where

$$
\mathrm{F}_{\mathrm{Rn}} \quad=\text { flux of }{ }^{222} \mathrm{Rn}
$$


$\Delta \mathrm{H}_{2}$

$\Delta \mathrm{Rn}$
= change in hydrogen concentration during nocturnal inversion

$=$ change in ${ }^{222} \mathrm{Rn}$ concentration during nocturnal inversion

\section{Modeling Techniques to Estimate Hydrogen Uptake by Soils}

On a global scale, the hydrogen uptake by soil was estimated by Novelli et al. (1999) using the following formula:

$$
\text { Uptake }=\mathrm{V}_{\mathrm{d}} \cdot \mathrm{n} \cdot \mathrm{f}_{\mathrm{H}_{2}} \cdot \mathrm{A}_{\mathrm{e}}
$$

where

$\mathrm{n}=$ number density of air molecules at surface

$\mathrm{f}_{\mathrm{H}_{2}} \quad$ = hydrogen mixing ratio at surface

$\mathrm{A}_{\mathrm{e}} \quad$ = effective soil area of earth's surface conducive to hydrogen uptake

Jacobson's GATOR-GCMOM model also uses a depositional velocity approach, but with more complexity to accommodate the spatial discretization present in the model and to accommodate multiple land uses. GATOR-GCMOM was modified during this project to specifically include the results of previous research on hydrogen uptake. The basic equation for deposition velocity was formulated as the inverse sum of a series of resistances, weighted over land use types:

$$
\mathrm{V}_{\mathrm{d}}\left(\mathrm{z}_{\mathrm{r}}\right)=\sum_{\mathrm{l}} \mathrm{V}_{\mathrm{d}, \mathrm{l}}\left(\mathrm{z}_{\mathrm{r}}\right)=\sum_{\mathrm{l}} \frac{\mathrm{f}_{\mathrm{l}}}{\mathrm{R}_{\mathrm{a}}+\mathrm{R}_{\mathrm{b}}+\mathrm{R}_{\mathrm{s}, \mathrm{l}}}
$$

where

$$
\begin{array}{ll}
\mathrm{R}_{\mathrm{a}} & \text { aerodynamic resistance to turbulent transfer } \\
\mathrm{R}_{\mathrm{b}} & \text { resistance to molecular diffusion across a thin laminar layer } \\
& \text { adjacent to the atmosphere-surface interface } \\
= & \text { land use class l resistance that occurs once hydrogen has reached } \\
& \text { the surface } \\
\mathrm{R}_{\mathrm{s}, \mathrm{l}} & = \\
\mathrm{f}_{\mathrm{l}} & \text { area fraction of land use class l in discretized cell } \\
\mathrm{Z}_{\mathrm{r}} & \text { reference height }
\end{array}
$$

For this project neither the parameterizations for $R_{a}$ and $R_{b}$ were examined. Rather the focus was on $\mathrm{R}_{\mathrm{s}, \mathrm{l}}$, which was reformulated in terms of vegetated and non-vegetated fractions:

$$
\mathrm{R}_{\mathrm{s}, \mathrm{l}}=\left\{\left[\mathrm{X}+\frac{1}{\mathrm{R}_{\text {canp }}+\mathrm{R}_{\text {soil }, \mathrm{l}}}\right] \mathrm{f}_{\mathrm{v} . \mathrm{l}}+\frac{1}{\mathrm{R}_{\text {soil }, \mathrm{l}}}\left(1-\mathrm{f}_{\mathrm{v}, \mathrm{l}}\right)\right\}^{-1}
$$


where
$f_{v, l}$
$=$ fraction vegetated
$\mathrm{R}_{\text {soil, }, 1}$
$=$ resistance of soil and leaf litter at the ground surface
X
= inverse sum of resistance (such as resistance by leaves) that were not examined for this project
$\mathrm{R}_{\text {canp }} \quad$ = resistance to transfer to the ground through a canopy

The soil resistance, $\mathrm{R}_{\text {soil }}$, is related to the deposition velocity by:

$$
\mathrm{R}_{\text {soil }}=\frac{1}{\mathrm{~V}_{\mathrm{d}}}
$$

where

$\mathrm{V}_{\mathrm{d}} \quad$ dry deposition velocity over a soil surface

For this project the deposition velocities were parameterized as:

$$
\mathrm{V}_{\mathrm{d}}= \begin{cases}0.177-0.4139 \mathrm{w} & \text { grassland } \\ 0.197-0.4190 \mathrm{w} & \text { forests } \\ 0.01235-0.00472 \ln (\mathrm{w})+0.0027 \ln ^{2}(\mathrm{w}) & \text { savannah } \\ 0.0316-0.988 \mathrm{w} & \text { ag land (late Aut, Win) } \\ 0.218-0.548 \mathrm{w} & \text { ag land (rest of year) }\end{cases}
$$

where

$$
\mathrm{W} \quad=\text { water content of soil }
$$

These expressions were obtained from previous work of other researchers such as reported in Smith-Downey et al. (2006) and in Conrad and Seiler (1995). $\mathrm{V}_{\mathrm{d}}$ has an additional limitation imposed not reflected in Equation (11): deposition is constrained to approach zero at very low soil water content.

A temperature dependence was also added to $V_{d}$, based on the work of Smith-Downey et al. (2006):

$$
V_{d}(T)=\frac{V_{d}\left(T_{R}\right)}{1+\exp (-0.1718 T+46.938)}
$$

where 
$V_{d}\left(T_{R}\right)=$ deposition velocity at reference temperature $T_{R}$

Smith-Downey et al. (2008) developed a model to simulate the hydrogen uptake of soil as a function of soil diffusivity and biological uptake capacity. The basic model developed was a onedimensional, time-variable diffusive-transport equation:

$$
\frac{\partial\left[\mathrm{H}_{2}\right]}{\partial \mathrm{t}}=\frac{\partial}{\partial \mathrm{z}}\left(\mathrm{D}_{\mathrm{s}} \frac{\partial\left[\mathrm{H}_{2}\right]}{\partial \mathrm{z}}\right)-\frac{\lambda\left[\mathrm{H}_{2}\right]}{\varepsilon}
$$

Where the flux at the surface is proportional to the hydrogen concentration and:

$$
\begin{array}{ll}
\mathrm{D}_{\mathrm{s}} & =\text { diffusivity of hydrogen in soil, } \mathrm{L}^{2} \mathrm{~T}^{-1} \\
\lambda & =\text { biological uptake rate, } \mathrm{T}^{-1} \\
\varepsilon & \quad=\text { fractional air space }
\end{array}
$$

The model was applied by Smith-Downey et al. (2008) to a multiple layered soil system. Hydrogen diffusion limitations into soil were found to exert an important limit on fluxes. Researchers also found that minimum soil moisture levels are needed to initiate microbial uptake.

Compared to other approaches to predict hydrogen uptake by soils, the approach of SmithDowney et al. (2008) appears to be unique in that the approach examines the properties of the soil over depth and considers the diffusive flux into the soil and the microbial uptake that occurs simultaneously. Several examples are shown below. For the first, the time variable term in Equation (13) is not needed for the uptake analysis, based on the predictions shown in Figure D1. The predictions in this figure show how long it takes for steady-state to be attained for hydrogen mixing ratios in the subsurface. The depths examined are $10 \mathrm{~cm}, 30 \mathrm{~cm}$, and $50 \mathrm{~cm}$. Initially (at time equal zero) the hydrogen concentrations in the subsurface are assumed to be zero. Once steady-state is attained the hydrogen concentration at the depths shown approach constant values. As shown, the elapsed time is on the order of several hours for each of the three depths examined. From a practical point of view this result indicates that the time variability term is really not needed in Equation (13), since hydrogen mixing ratios in the subsurface should adapt to slowly changing ambient conditions. 


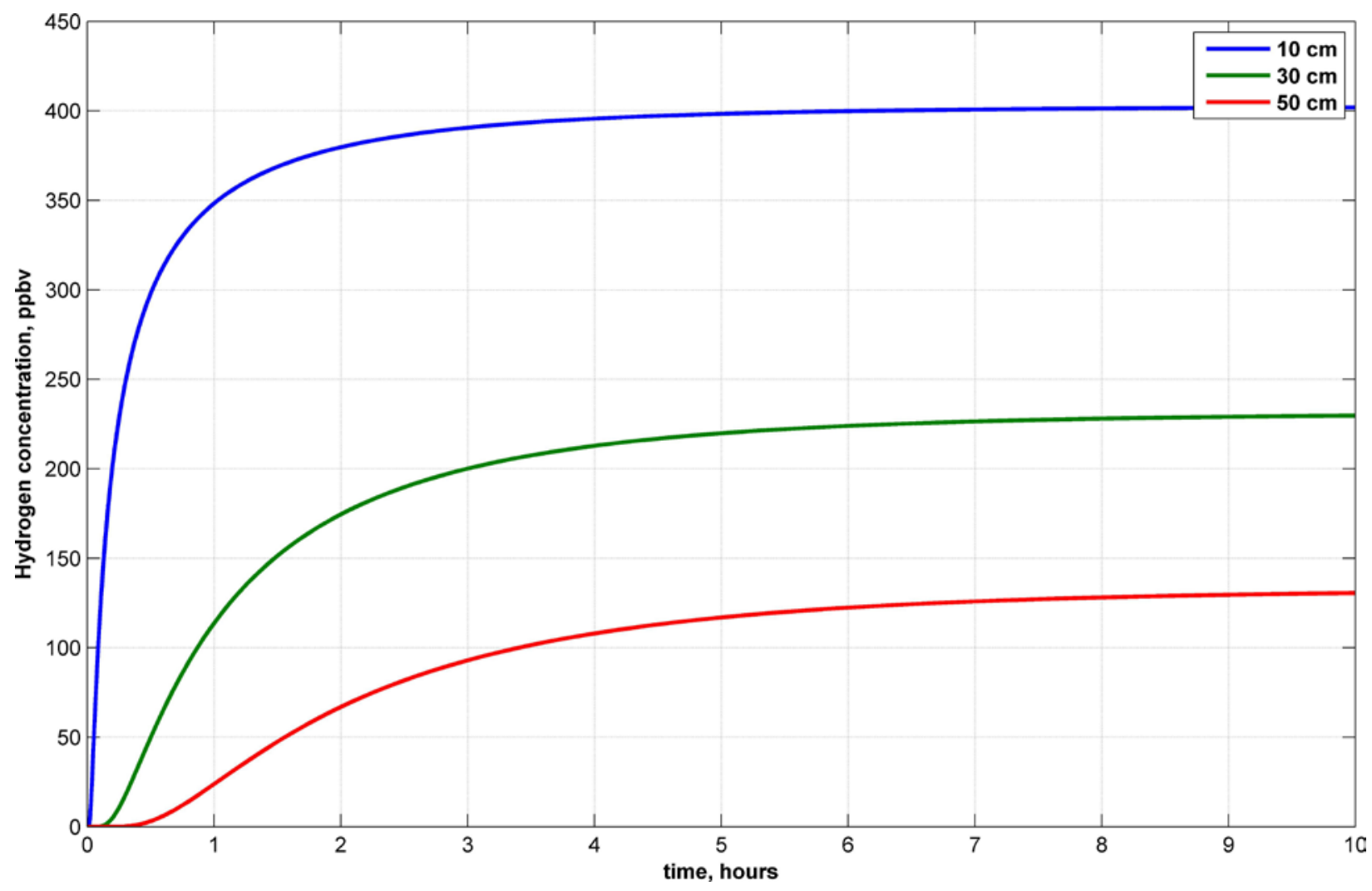

Figure D-1 Representative time required for diffusion of hydrogen in soil. Note: Data used are representative of soil conditions and these results are not universal.

Figure D-2(a) illustrates the reduction in hydrogen mixing ratios over depth for different soil temperatures and soil moisture contents. For the conditions examined, concentrations drop dramatically over depth. Within about $4 \mathrm{~cm}$, the hydrogen is essentially depleted. Figure D-2(b) illustrates how hydrogen flux into soils depends on soil temperature. Temperature limitations are exerted for temperatures below $20^{\circ} \mathrm{C}$ (that is, once temperature exceeds $20^{\circ} \mathrm{C}$, the curves overlap). Figure D-3 illustrate the effects of snow cover on the hydrogen mixing ratio and flux into the soil. With no snow cover, the hydrogen mixing ratio at the soil's surface is 531ppbv, the atmospheric mixing ratio. However as the snow cover increases, diffusion of hydrogen through the snow strongly influences the hydrogen mixing ratio, and the flux of hydrogen into the soil. At about $20 \mathrm{~cm}$ snow cover, the hydrogen mixing ratio at the soil surface is less than $30 \%$ of background, and the flux of hydrogen into the soil likewise dramatically decreases. 

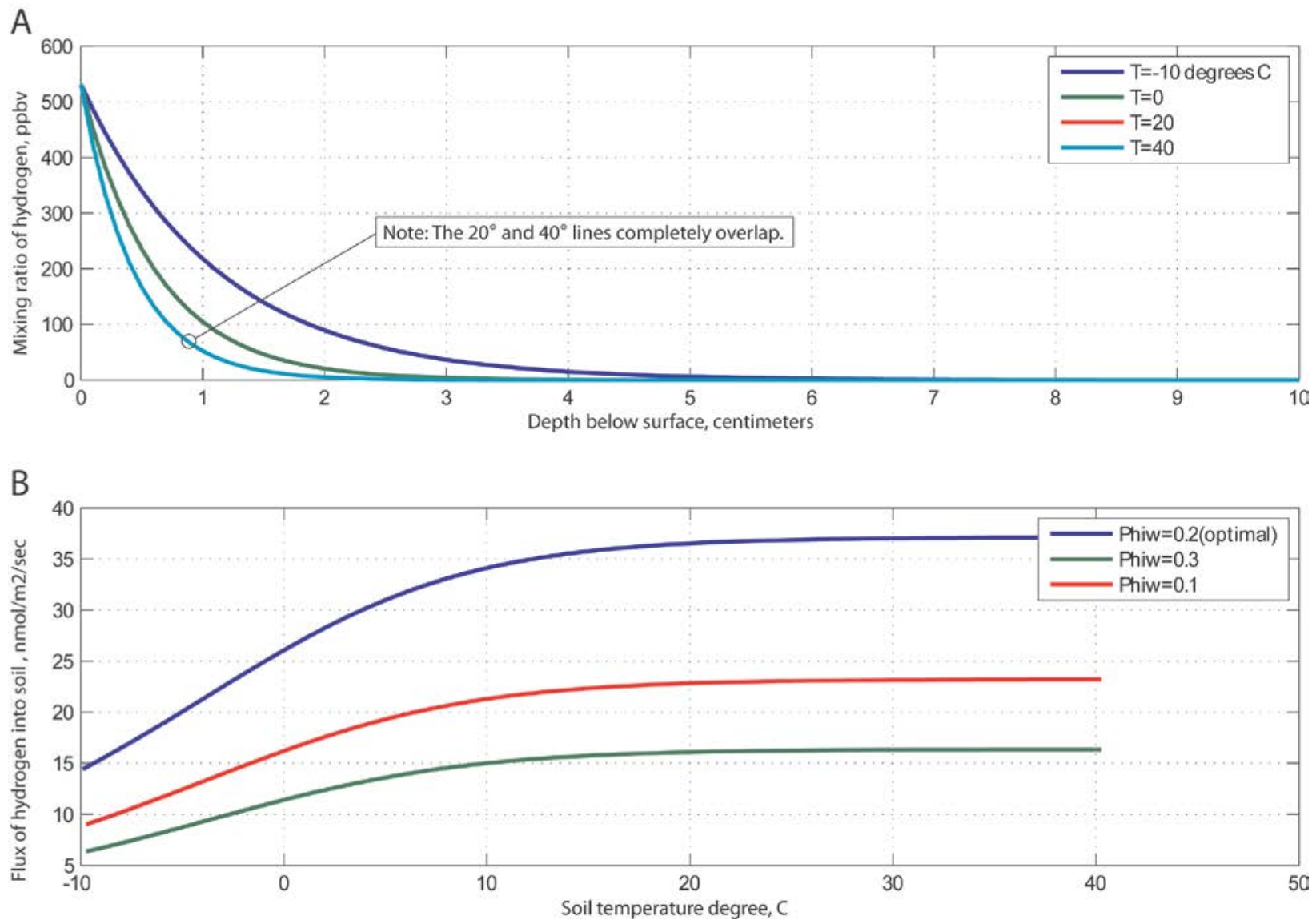

Figure D-2 $\quad$ A) Hydrogen profile over depth for different soil temperatures. B) Hydrogen flux into soil under three soil moisture conditions. 


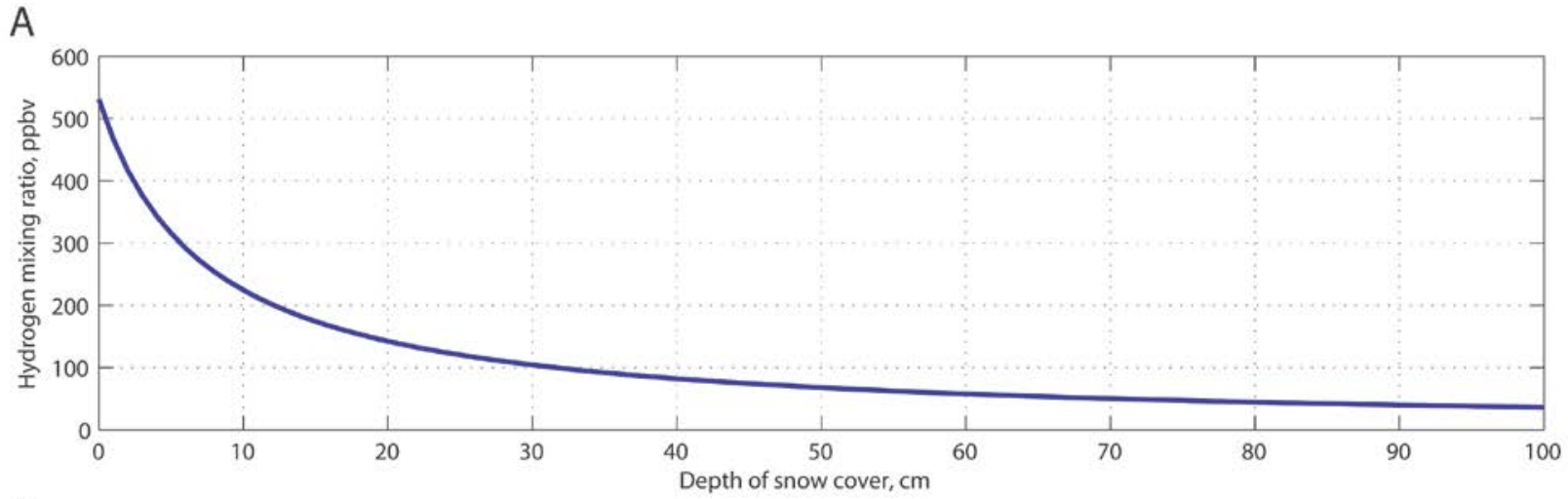

B

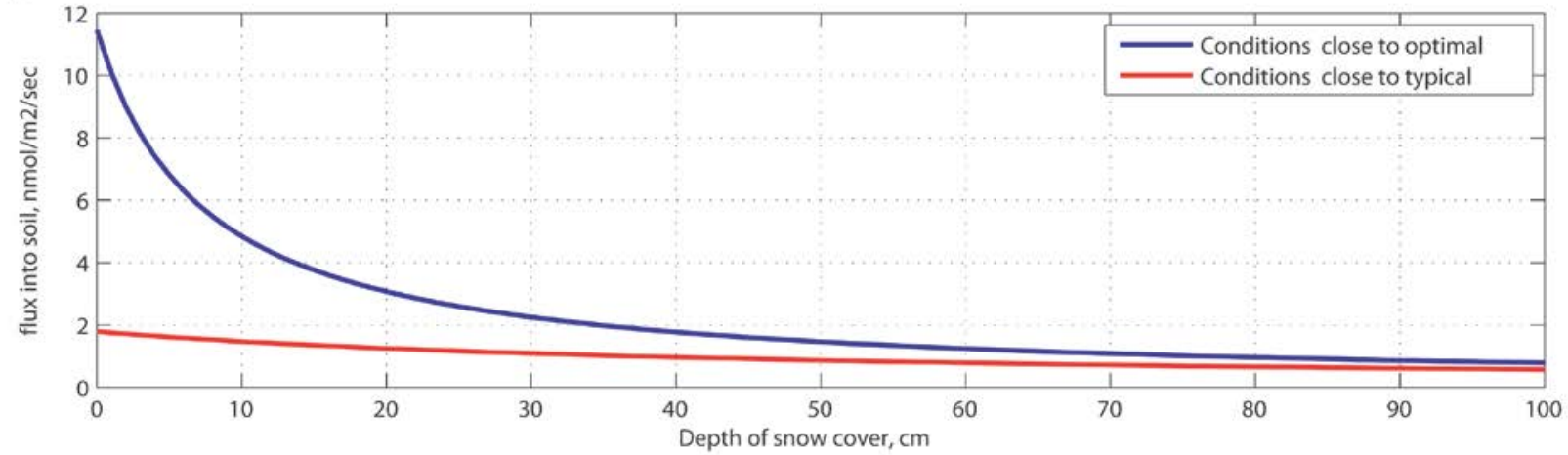

Figure D-3 A) Hydrogen mixing ratio beneath snow cover for different snow cover depths. B) Hydrogen flux into soil beneath snow cover.

\section{Development of Probabilistic Framework to Estimate Hydrogen Uptake by Soil}

Although atmospheric hydrogen uptake by soils has been studied for several decades, as described in this report, the number of studies is small, and relatively few uptake rates or deposition velocities have been estimated. Also a framework has not been developed that can rigorously accommodate uncertainties. Here a Monte Carlo framework is presented that begins to address this issue. While it is not feasible to include the Monte Carlo approach in complex models such as GATOR-GCMOM, the results here can provide valuable insight into the issue of uptake variability.

The following formula is used to calculate uptake, and was motivated by the work of SmithDowney et at. (2006).

$$
M_{\mathrm{H}_{2}, \text { soil }}=\mathrm{G}\left(\mathrm{S}_{\mathrm{w}}\right) \mathrm{F}\left(\mathrm{T}_{\mathrm{k}}\right) \mathrm{M}_{\mathrm{H}_{2} \text {, soil, max }}^{*} \cdot \frac{\left[\mathrm{H}_{2}\right]_{\text {trop }}}{\left[\mathrm{H}_{2}{ }^{*}\right]_{\text {trop }}}
$$

where

$\mathrm{G}\left(\mathrm{S}_{\mathrm{w}}\right) \quad$ = soil moisture limitation expression, dimensionless

$\mathrm{F}\left(\mathrm{T}_{\mathrm{k}}\right) \quad$ = soil temperature limitation expression, dimensionless 


$$
\begin{array}{ll}
\mathrm{M}_{\mathrm{H}_{2} \text {,soil,max }}^{*} & =\text { hydrogen uptake at optimal conditions, } \mathrm{nmol} \cdot \mathrm{m}^{-2} \cdot \mathrm{s}^{-1} \\
{\left[\mathrm{H}_{2}\right]_{\text {trop }}} & =\text { hydrogen concentration in troposphere, ppbv } \\
{\left[\mathrm{H}_{2}{ }^{*}\right]_{\text {trop }}} & =\text { hydrogen concentration associated with the maximum uptake } \\
& \text { rate (e.g., at optimal conditions in laboratory), ppbv }
\end{array}
$$

The limiting function $\mathrm{G}\left(\mathrm{S}_{\mathrm{w}}\right)$ is formulated to include moisture limitations at both low and high soil moisture content, consistent with the findings of previous researchers. The expression is:

$$
G\left(S_{w}\right)=\alpha\left(\frac{S_{w}-S_{\min }}{S_{w}+S_{h 1}}\right)\left(\frac{S_{\text {max }}-S_{w}}{S_{w}+S_{h 2}}\right)\left(\frac{S_{h 2}}{S_{\text {max }}}\right)
$$

where

$$
\begin{aligned}
& \alpha=\left\{\max \left(\frac{\mathrm{S}_{\mathrm{w}}-\mathrm{S}_{\min }}{\mathrm{S}_{\mathrm{w}}+\mathrm{S}_{\mathrm{h} 1}}\right)\left(\frac{\mathrm{S}_{\text {max }}-\mathrm{S}_{\mathrm{w}}}{\mathrm{S}_{\mathrm{w}}+\mathrm{S}_{\mathrm{h} 2}}\right)\left(\frac{\mathrm{S}_{\mathrm{h} 2}}{\mathrm{~S}_{\max }}\right)\right\}^{-1} \\
& \mathrm{~F}\left(\mathrm{~T}_{\mathrm{k}}\right)=\left[1+\exp \left(-0.1718 \mathrm{~T}_{\mathrm{k}}+46.938\right)\right]^{-1}
\end{aligned}
$$

$\mathrm{S}_{\mathrm{w}}$ and $\mathrm{T}_{\mathrm{k}}$ will be treated as random variables. The random variables are assumed to be truncated normal distributions, denoted by these probability density functions:

$$
\begin{aligned}
& \operatorname{pdf}\left(\mathrm{S}_{\mathrm{w}}\right)=\delta_{\mathrm{s}} \text { normpdf }\left(\mathrm{S}_{\mathrm{w}} ; \mu_{\mathrm{sw}}, \sigma_{\mathrm{sw}}\right) \\
& \mathrm{S}_{\min }<\mathrm{S}_{\mathrm{w}}<\mathrm{S}_{\max } \\
& \operatorname{pdf}\left(\mathrm{T}_{\mathrm{k}}\right)=\delta_{\mathrm{T}} \operatorname{normpdf}\left(\mathrm{T}_{\mathrm{k}} ; \mu_{\mathrm{T}_{\mathrm{k}}}, \sigma_{\mathrm{T}_{\mathrm{k}}}\right) \\
& \mathrm{T}_{\mathrm{k} \min }<\mathrm{T}_{\mathrm{k}}<\mathrm{T}_{\mathrm{kmax}} \\
& \text { where } \\
& \operatorname{pdf}\left(\mathrm{S}_{\mathrm{w}}\right), \operatorname{pdf}\left(\mathrm{T}_{\mathrm{k}}\right) \quad=\text { probability density functions for } \mathrm{S}_{\mathrm{w}} \text { and } \mathrm{T}_{\mathrm{k}} \text {, respectively } \\
& \mu_{\mathrm{Sw}}, \mu_{\mathrm{T}_{\mathrm{k}}} \quad=\text { mean values of the distributions } \\
& \sigma_{\mathrm{S}_{\mathrm{w}}}, \sigma_{\mathrm{T}_{\mathrm{k}}}
\end{aligned}
$$

In order to ensure that the cumulative probabilities of $S_{\mathrm{w}}$ and $\mathrm{T}_{\mathrm{k}}$ are unity, $\delta_{\mathrm{s}}$ and $\delta_{\mathrm{T}_{\mathrm{k}}}$ are set as follows: 


$$
\begin{aligned}
& \delta_{\mathrm{s}}=\left[\int_{\mathrm{S}_{\min }}^{\mathrm{S}_{\max }} \operatorname{normpdf}\left(\mathrm{S}_{\mathrm{w}} ; \mu_{\mathrm{Sw}}, \sigma_{\mathrm{Sw}}\right) \mathrm{dS} \mathrm{S}_{\mathrm{w}}\right]^{-1} \\
& =\left[\operatorname{cdfnorm}\left(\mathrm{S}_{\max } ; \mu_{\mathrm{Sw}}, \sigma_{\mathrm{Sw}}\right)-\operatorname{cdfnorm}\left(\mathrm{S}_{\min } ; \mu_{\mathrm{Sw}}, \sigma_{\mathrm{Sw}}\right)\right]^{-1} \\
& \delta_{\mathrm{T}_{\mathrm{k}}}=\left[\int_{\mathrm{T}_{\min }}^{\mathrm{T}_{\max }} \operatorname{normpdf}\left(\mathrm{T}_{\mathrm{k}} ; \mu_{\mathrm{T}_{\mathrm{k}}}, \sigma_{\mathrm{T}_{\mathrm{k}}}\right) \mathrm{d} \mathrm{T}_{\mathrm{k}}\right]^{-1} \\
& =\left[\operatorname{cdfnorm}\left(\mathrm{T}_{\mathrm{kmax}}, \mu_{\mathrm{T}_{\mathrm{k}}}, \sigma_{\mathrm{T}_{\mathrm{k}}}\right)-\operatorname{cdfnorm}\left(\mathrm{T}_{\mathrm{kmin}}, \mu_{\mathrm{T}_{\mathrm{k}}}, \sigma_{\mathrm{T}_{\mathrm{k}}}\right)\right]^{-1}
\end{aligned}
$$

where

$$
\text { cdfnorm = cumulative normal distribution function }
$$

Examples of $G\left(S_{w}\right)$ and $F\left(T_{k}\right)$ are shown in Figure D-4. As mentioned earlier $F\left(T_{k}\right)$ is from Smith-Downey (2006), but the expression for $G\left(S_{w}\right)$ was developed for this work. While $F\left(T_{k}\right)$ is applicable globally, the expression for $G\left(S_{w}\right)$ depends on site specific conditions. Two expressions for $\mathrm{G}_{\mathrm{w}}$ are shown in Figure D-4b: boreal forest ecosystem and Mojave Desert ecosystem. Both exhibit the same general behavior of having a peak value, and minimal values at both very low soil moisture contents and high soil moisture contents. Based on soil temperature and moisture data appropriate for the boreal forest (63 $53^{\prime} \mathrm{N}, 145^{\circ} 44^{\prime} \mathrm{W}$ ) and Mojave Desert (34 $08^{\prime} \mathrm{N}, 116^{\circ} 27^{\prime} \mathrm{W}$, Mojave, CA) (Smith-Downey et al. 2006), the density functions have been created, and are shown in Figure D-5. 

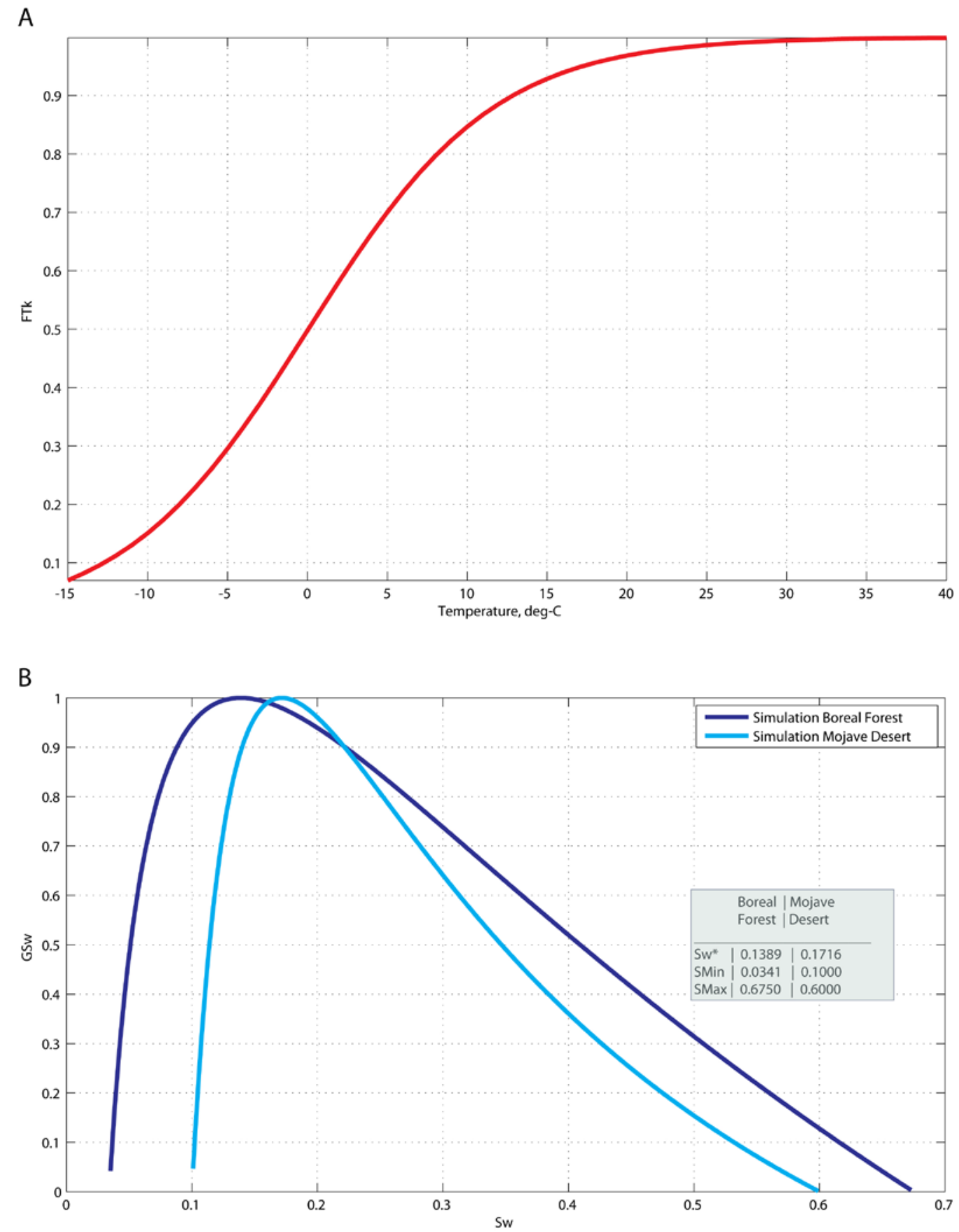

Figure D-4 $\quad$ A) Soil temperature limitation function. B) Soil moisture limitation function 

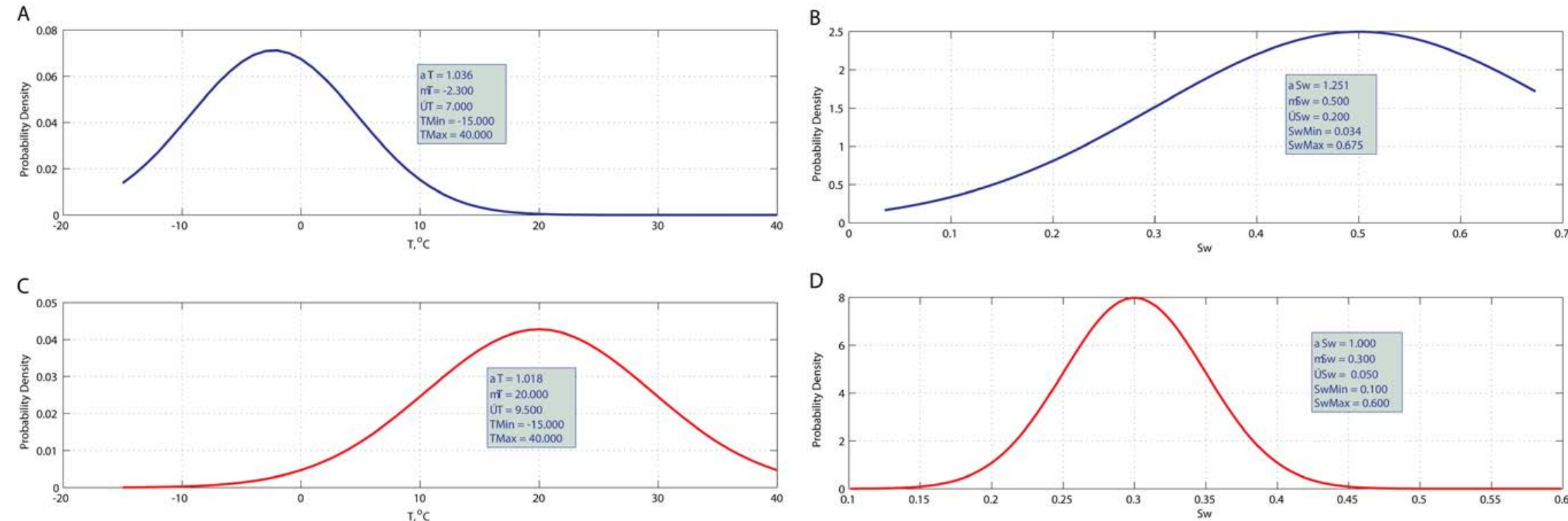

Figure D-5 $\quad$ A) Truncated normal probability density of the temperature in the boreal forest. B) Truncated normal probability density of soil moisture in the boreal forest. C) Truncated normal probability density of the temperature in the Mojave Desert. D) Truncated normal probability density of soil moisture in the Mojave Desert. 
There are significant differences in the probability density functions for the two ecosystems. Temperatures in the Mojave Desert are infrequently below freezing, while in the Alaskan boreal forest temperatures are more often below freezing than not. The soil moisture content in the Mojave Desert is typically lower than in the boreal forest, and exhibits a more narrow range.

The hydrogen uptake rates over the range of soil moisture and temperature conditions for the two biomes are shown in Figure D-6. The hydrogen uptake rates for the boreal forest are significantly higher than in the Mojave Desert. The units of the uptake rates are expressed in $\mathrm{Tg} / \mathrm{yr}$, assuming each of the ecosystems has global coverage. While not true, this helps to put into perspective the significance of the uptake from each ecosystem compared with estimates of actual global uptake ( 50 to $90 \mathrm{Tg} / \mathrm{yr}$ ). Even the lower end of predicted uptake rates in the boreal forest ( $50 \mathrm{Tg} / \mathrm{yr}$ ) are approximately comparable to the maximum uptake rates shown for the Mojave Desert (45 $\mathrm{Tg} / \mathrm{yr})$. During extremely low or extremely high soil moisture levels, uptake becomes very small ( 5 Tg/yr). 
A

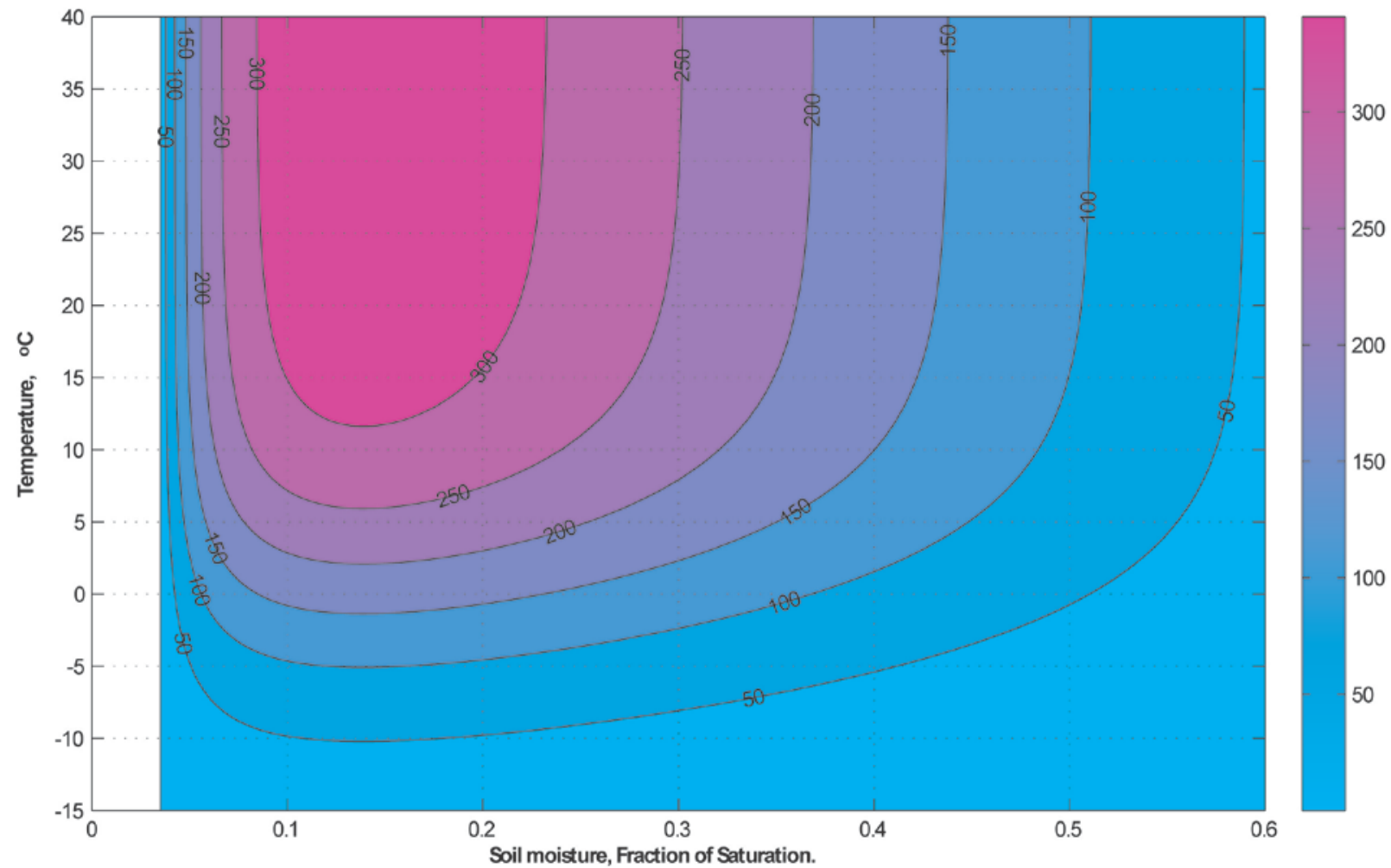

B

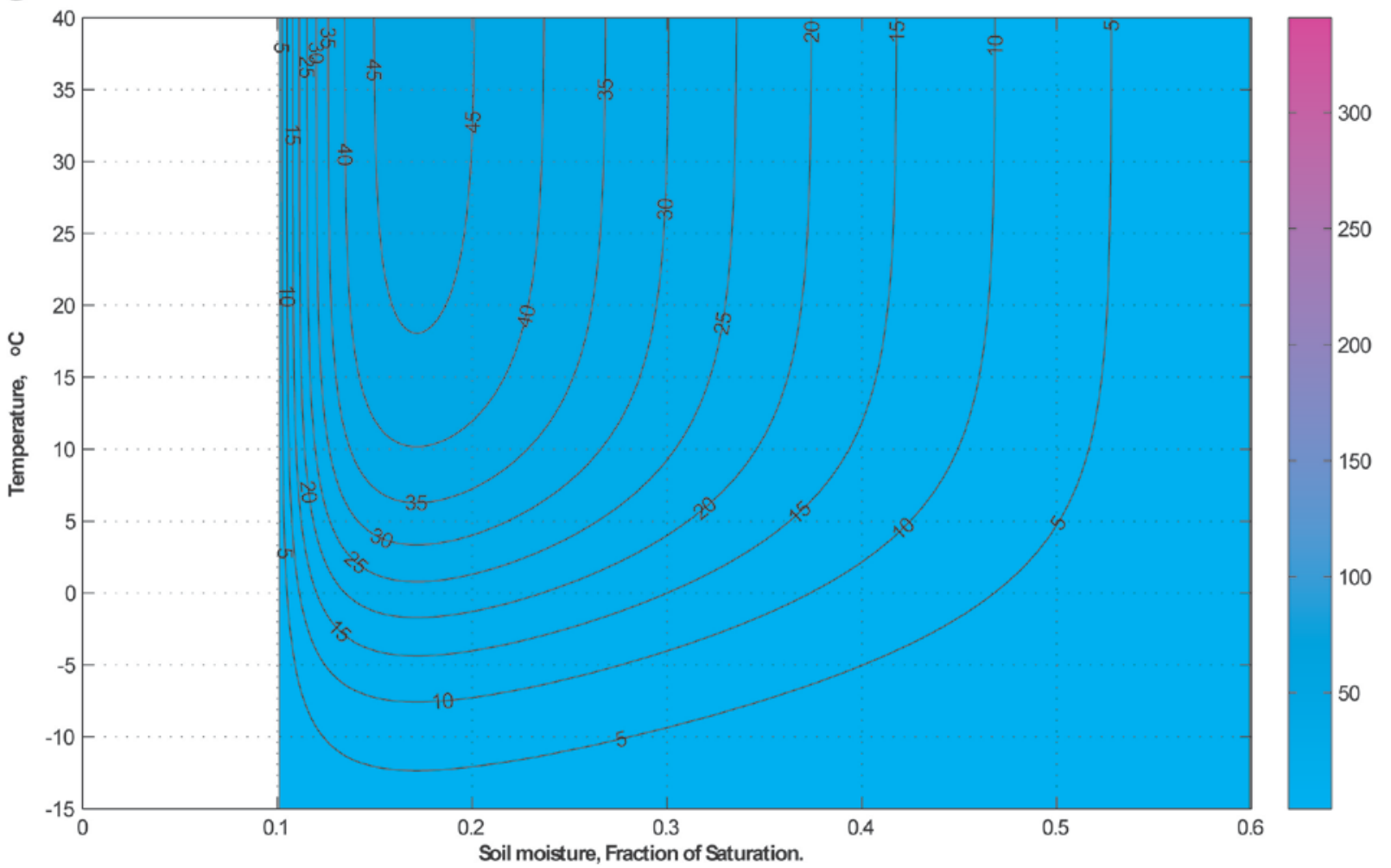

Figure D-6 $\quad$ A) Hydrogen uptake in boreal forest limited by soil moisture and temperature. B) Soil uptake of hydrogen in Mojave Desert limited by soil moisture and temperature. 
The cumulative distribution of hydrogen uptake in the boreal forest and Mojave Desert are shown in Figure D-7. The far greater uptake rates in the boreal forest are clearly shown.
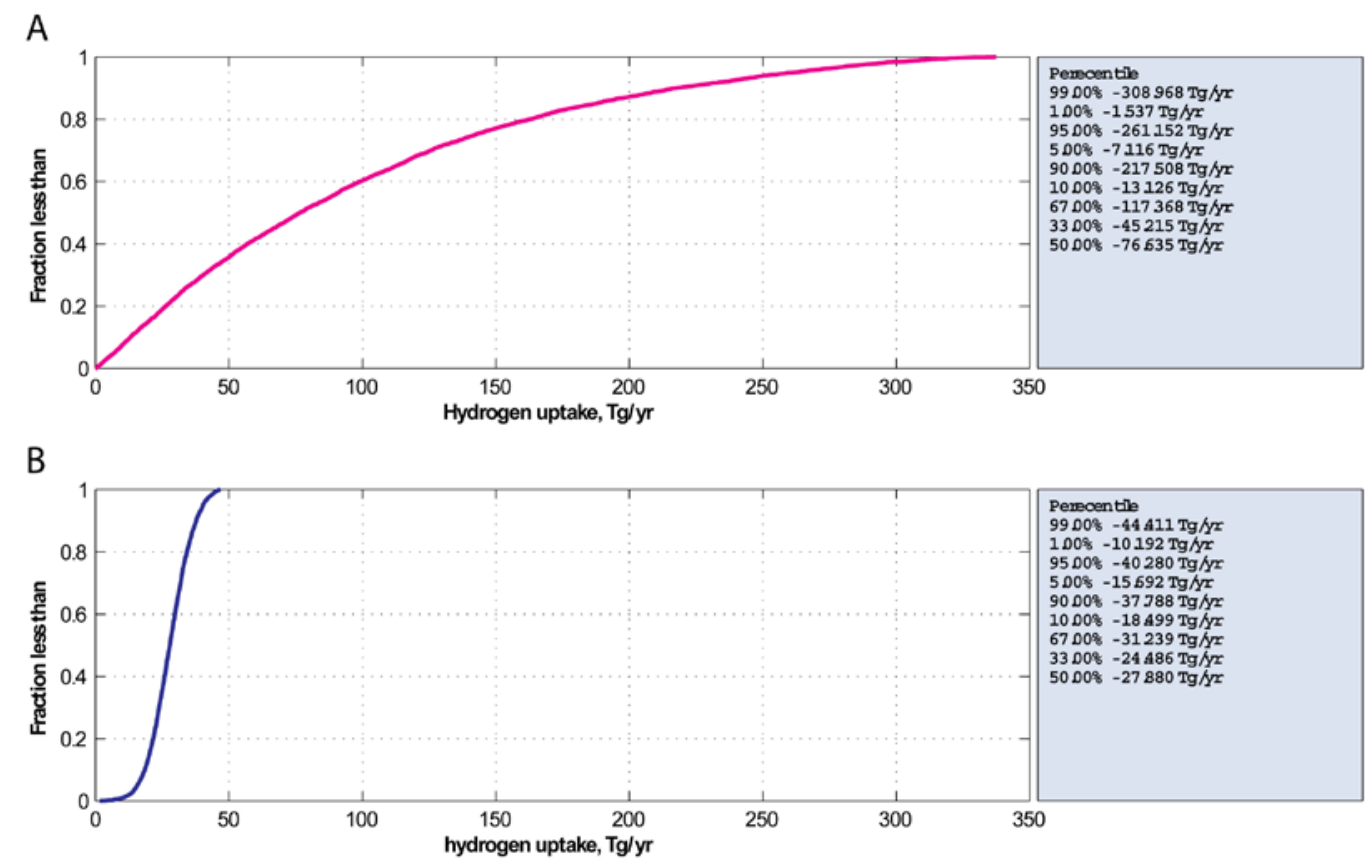

\section{Figure D-7 $\quad$ A) Distribution of soil uptake of hydrogen in boreal forest. B) Distribution of soil uptake of hydrogen in Mojave Desert.}

While hydrogen uptake in the Mojave Desert ranges from near zero to $50 \mathrm{Tg} / \mathrm{yr}$, in the boreal forest, conditions are such that uptake rates are greater than $50 \mathrm{Tg} / \mathrm{yr}$ for over $60 \%$ of the conditions simulated. Given that the global uptake rate reported by Novelli et al. (1999) is 54 Tg/yr, the results in Figure D-7 are very plausible in that they bound Novelli's estimate.

\section{Summary and Conclusions}

The literature on hydrogen uptake by soils has been reviewed. While research has been conducted for well over 20 years, the data collected and analyzed are sparse.

Several mathematic models that simulate hydrogen uptake were reviewed, and independent testing was performed. The uptake algorithms for one of the models (GATOR-GCMOM) were modified to account for soil moisture and temperature limitations.

Because of the uncertainties in the actual rates of hydrogen uptake, uncertainties in uptake were examined using a Monte Carlo framework, where soil moisture and soil temperature were treated as random variables. The framework was applied to two ecosystems (boreal forest and desert). The approach could potentially be incorporated into a probabilistic modeling framework.

\section{References}

Conrad, R., and W. Seiler (1985), Influences of temperature, moisture, and organic carbon on the flux of $\mathrm{H}_{2}$ and $\mathrm{CO}$ between soil and atmosphere. Field studies in subtropical regions, J. Geophys. Res. 90, 5699-5709. 
Ehhalt, D. H., and L. E. Heidt (1973b), The concentration of molecular $\mathrm{H}_{2}$, and $\mathrm{CH}_{4}$ in the stratosphere. Pure Appl. Geophys. 106-108, 1352-1360.

Ehhalt, H. D., U. Schmidt, and L. E. Heidt (1977), Vertical profiles of molecular hydrogen in the troposphere and stratosphere. J .Geophys. Res. 82, 5907-5910.

Gerst, S., and P. Quay (2001), Deuterium component of the global molecular hydrogen cycle, $J$. Geophys. Res., 106, 5021-5031.

Hammer, S., L. Ingerborg, and O’Doherty (2007), Lessons from a continuous atmospheric molecular hydrogen $\left(\mathrm{H}_{2}\right)$ record in Heidelberg regarding hydrogen sources and sinks, Presented at EuroH2Hdros.

King, G. M. (2003), Contributions of atmospheric CO and hydrogen dynamics on recent Hawaiian volcanic deposits, Applied Environmental Microbiology. Vol. 69, No. 7, pp 40674075.

Lallo, M., T. Aalto, T. Laurila, and J. Hatakka (2008), Seasonal cariation in hydrogen deposition to boreal forest soil in southern Finland. GRL, Vol. 35, L04402, doi: 10.1029/2007GL 032357.

Liebl, K., and W. Seiler (1976), $\mathrm{CO}$ and $\mathrm{H}_{2}$ destruction at the soil surface, in Production and Utilization of Gasses, edited by H. G Schlegel, G. Gottschalk, and N Pfenning, pp. 215-229, E. Goltze, Göttingen, Germany.

Novelli, P.C., P.m. Lang, K/A/ Masarie, D/F/ Hurst, RE/ Myeres, and J.W. Elkins (1999), Molecular hydrogen in th4 troposhere: Global distribution and budget, J. Geophys. Res., 104, 30427-30444.

Rahn, T., et al. (2003), Extreme deuterium enrichment in stratospheric hydrogen and the global atmospheric budget of $\mathrm{H}_{2}$, Nature, 474, 915-921.

Rahn, T., J. M. Eiler, N. Kitchen, J. E. Fessenden, and J.T. Randerson (2002), Concentration and deltaD of molecular hydrogen in boreal forests: Ecosystem-scale systematics of atmospheric $\mathrm{H}_{2}$, GRL, 29, No. 18.

Smith-Downey N.V., J.T. Randerson, J.M. Eiler (2006), Temperature and moisture dependence of soil $\mathrm{H}_{2}$ uptake measured in the laboratory, J. Geophys. Res. Lett., 33, L14813, doi:10.1029/2006GL026749.

Smith-Downey, N. T., J. T. Randerson, and J. M. Eiler (2008), Molecular hydrogen uptake by soils in forest, desert, and marsh ecosystems in California, J. Geophys. Res. 113, G03037, doi:10.1029/2088JG00701.

Yonemura, S., S. Kawashima, and H. Tsuruta (1999), Continuous measurements of $\mathrm{CO}_{2}$ and $\mathrm{H}_{2}$ deposition velocities onto an andisol: uptake control by soil moisture. Tellus, 518, 688-700.

Yonemura, S., S. Kawashima, and H. Tsuruta (2000), Carbon monoxide, hydrogen, and methane uptake by soils in a temperature arable field and a forest, J. Geophys. Res., 105, 14,347-14, 362. 



\section{APPENDIX E \\ PLOTS OF TEN-YEAR ZONAL DIFFERENCES IN SELECTED CONSTITUENTS: MAXIMUM AND MINIMUM BY ALTITUDE AND LATITUDE.}




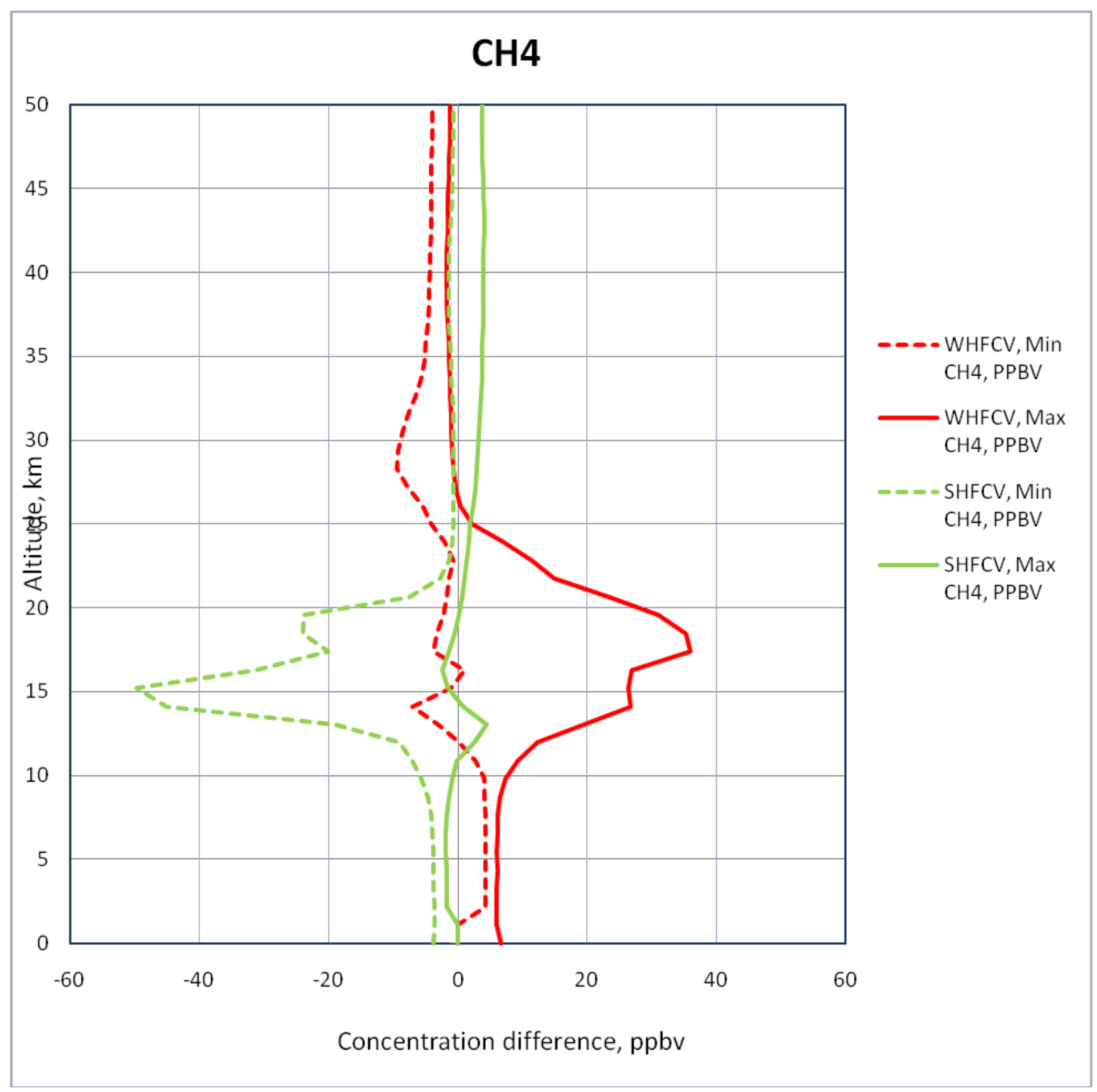

E-2 


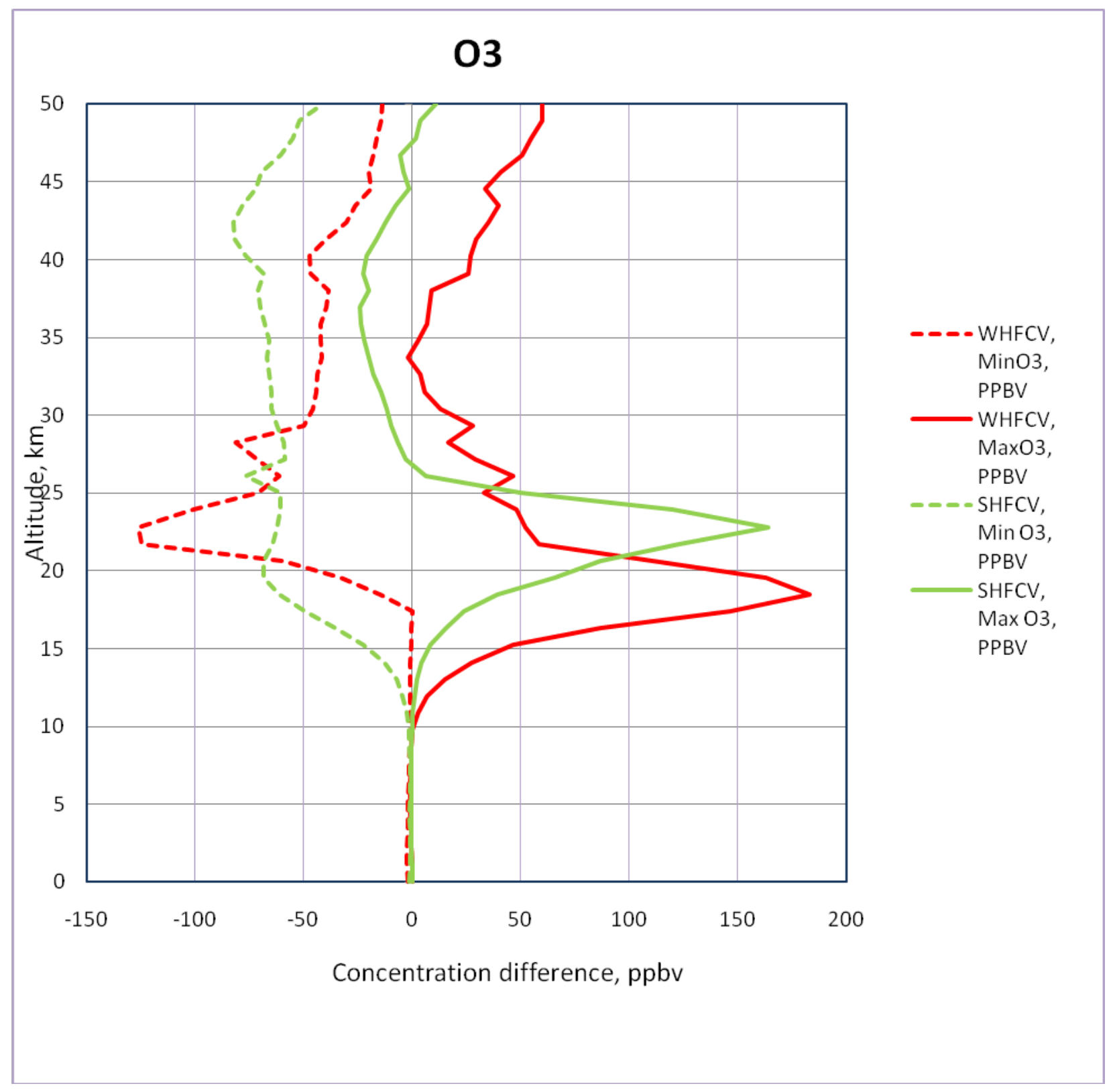




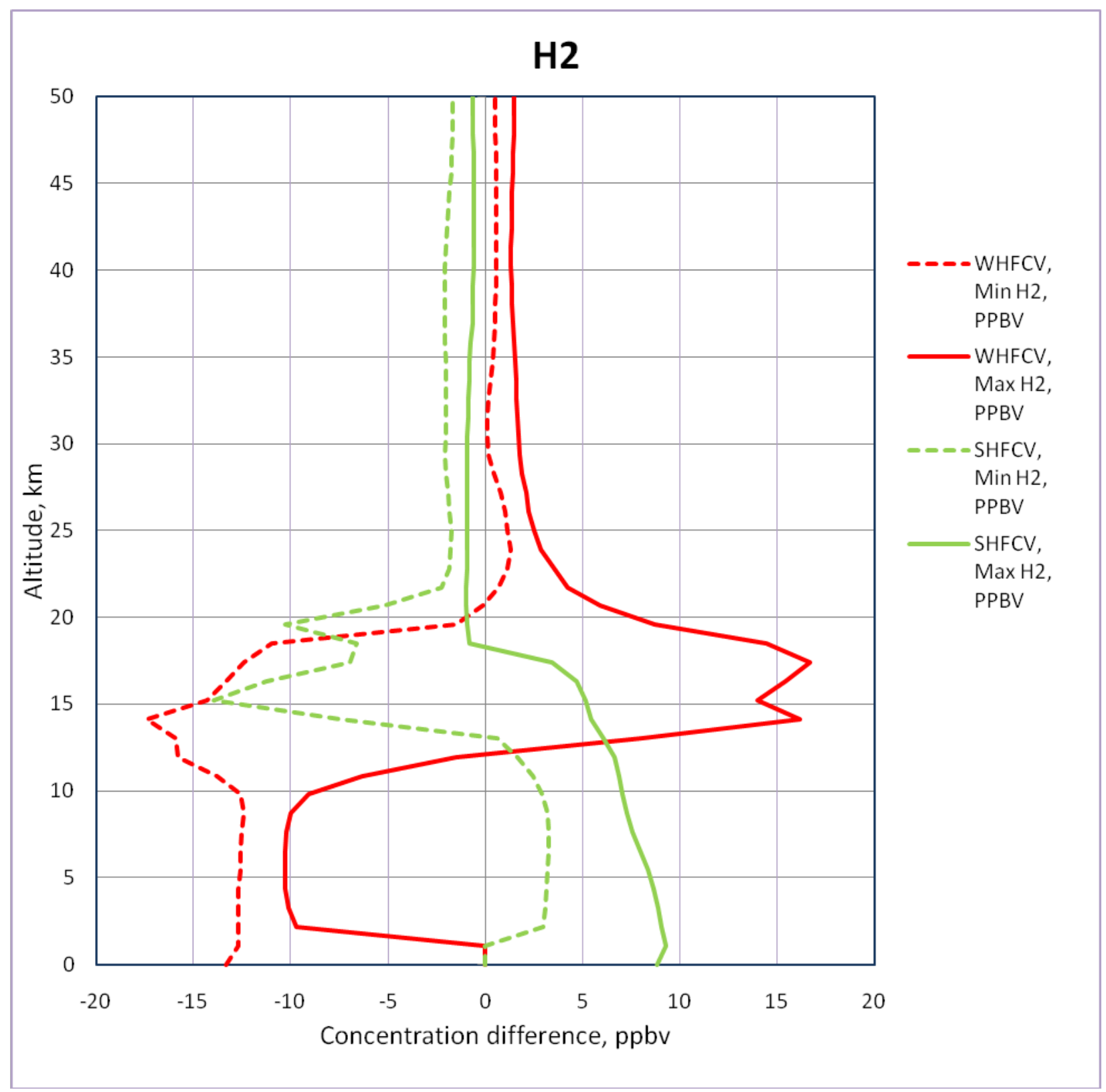




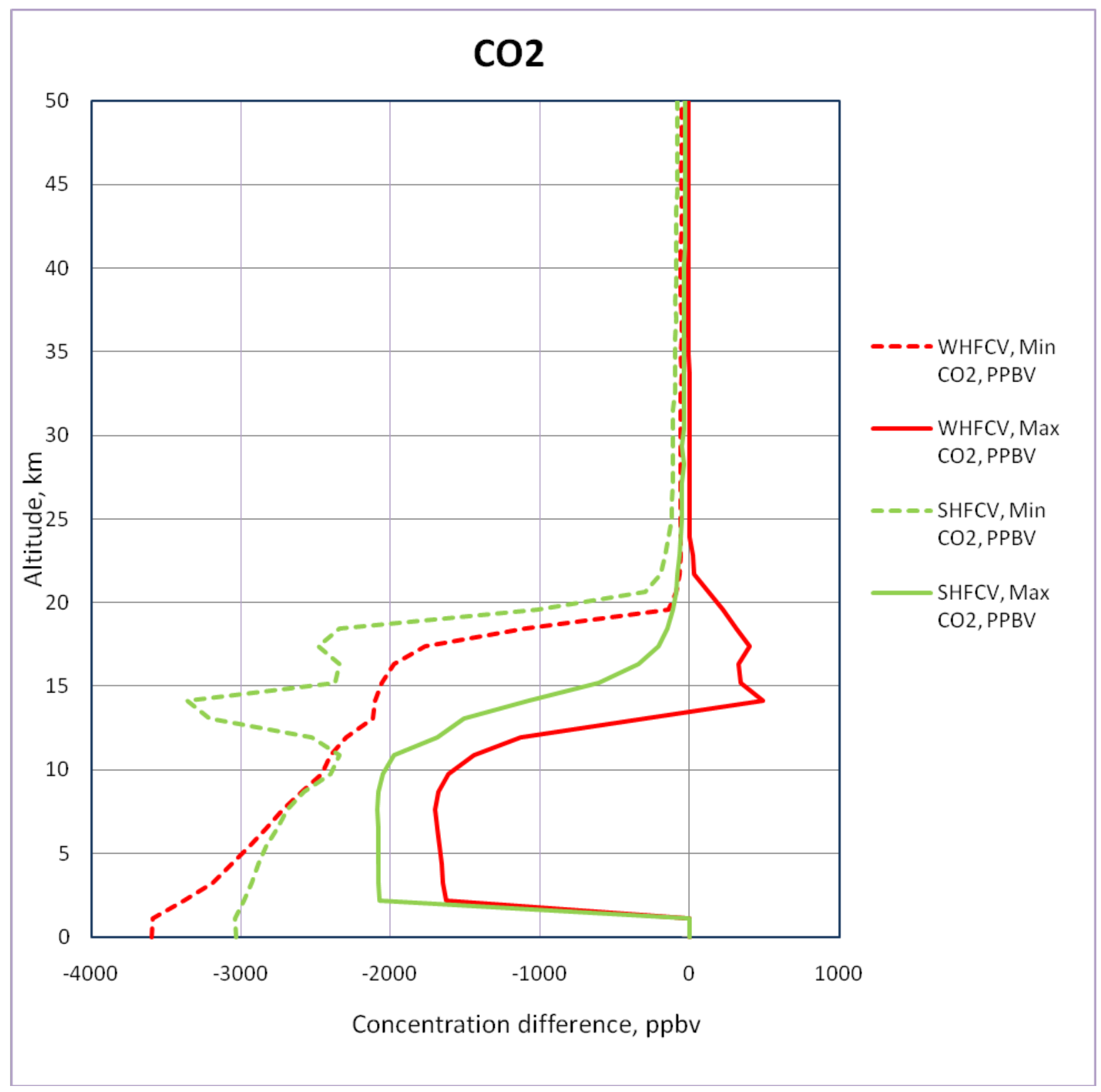




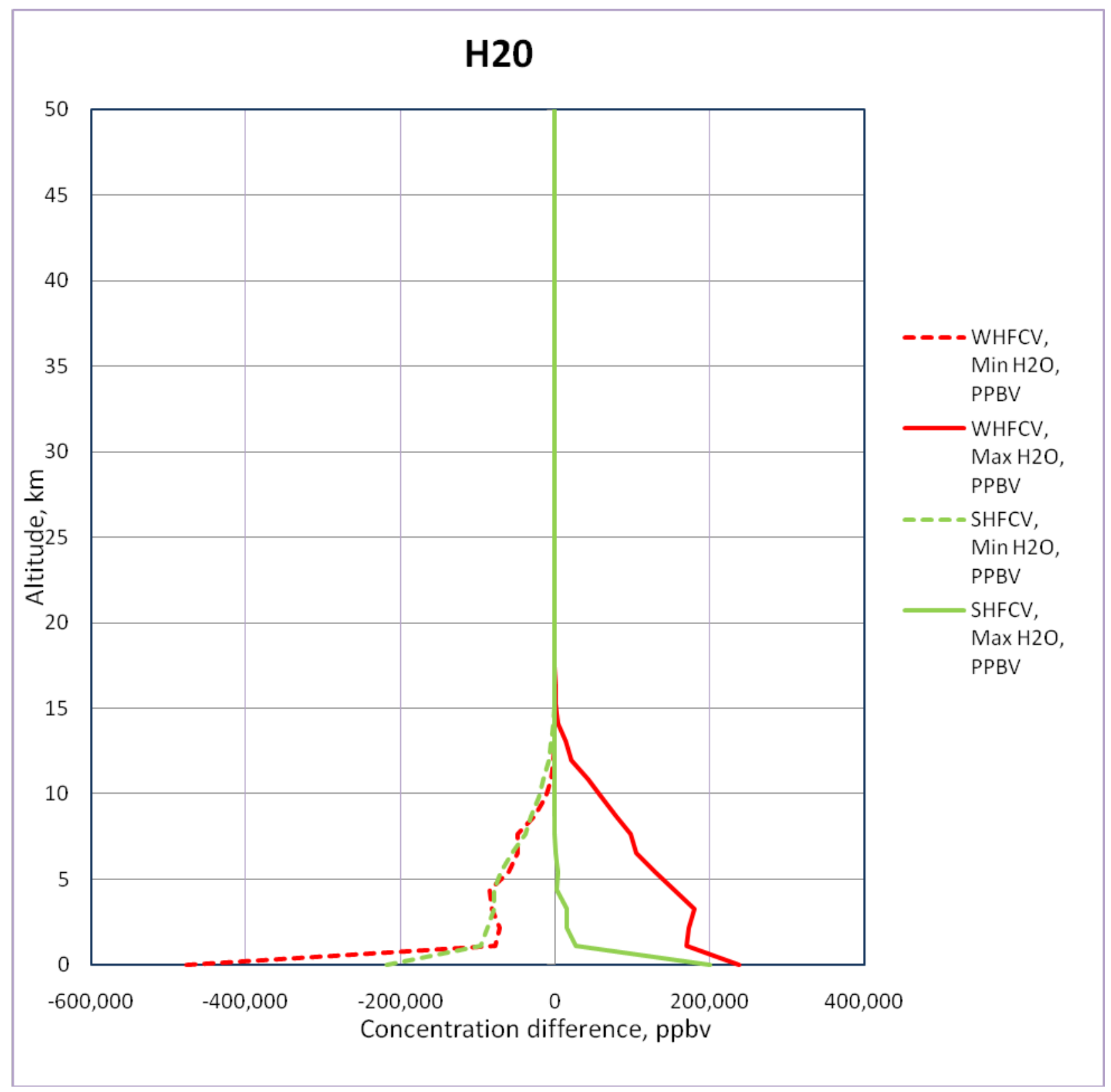




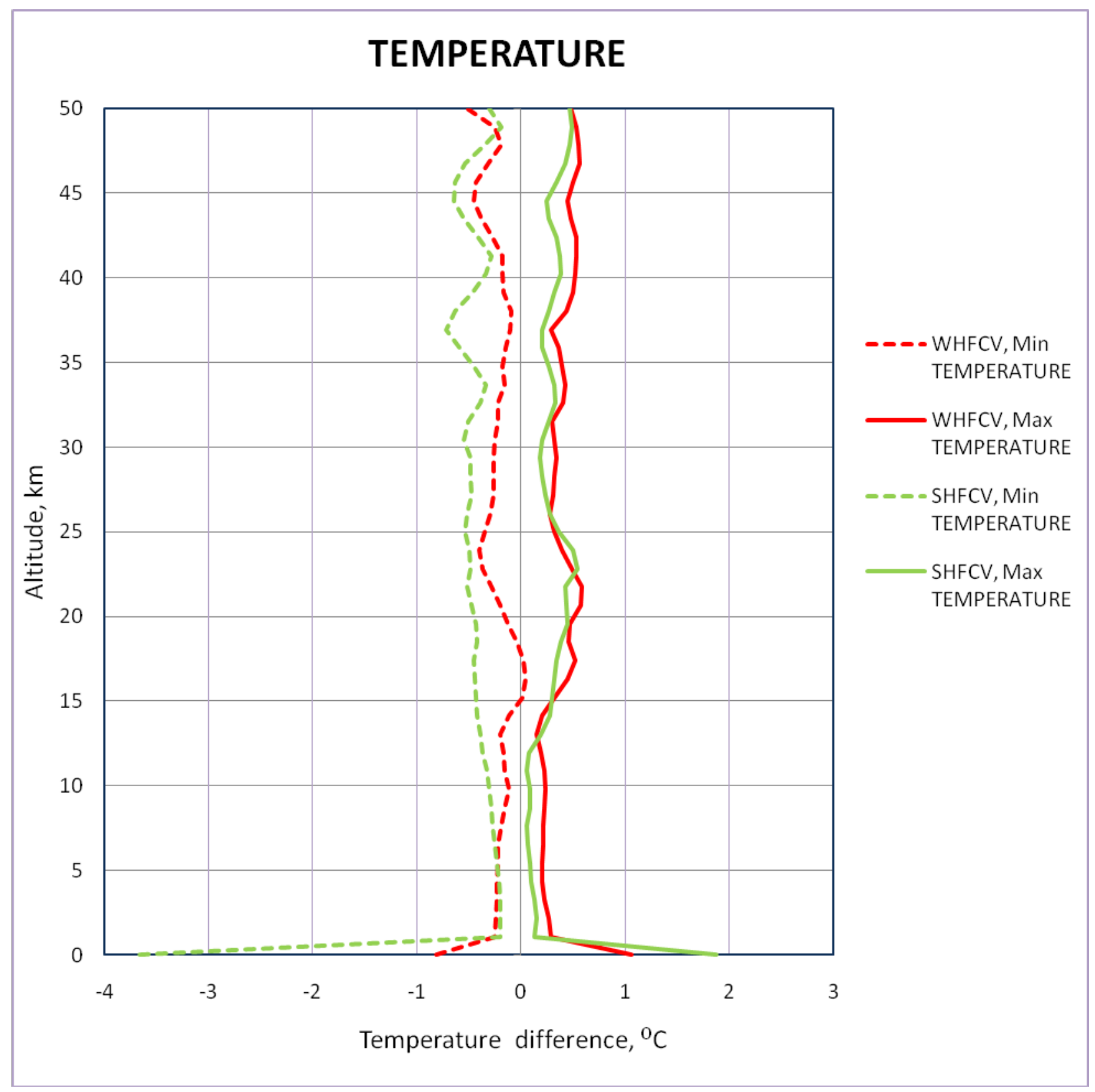




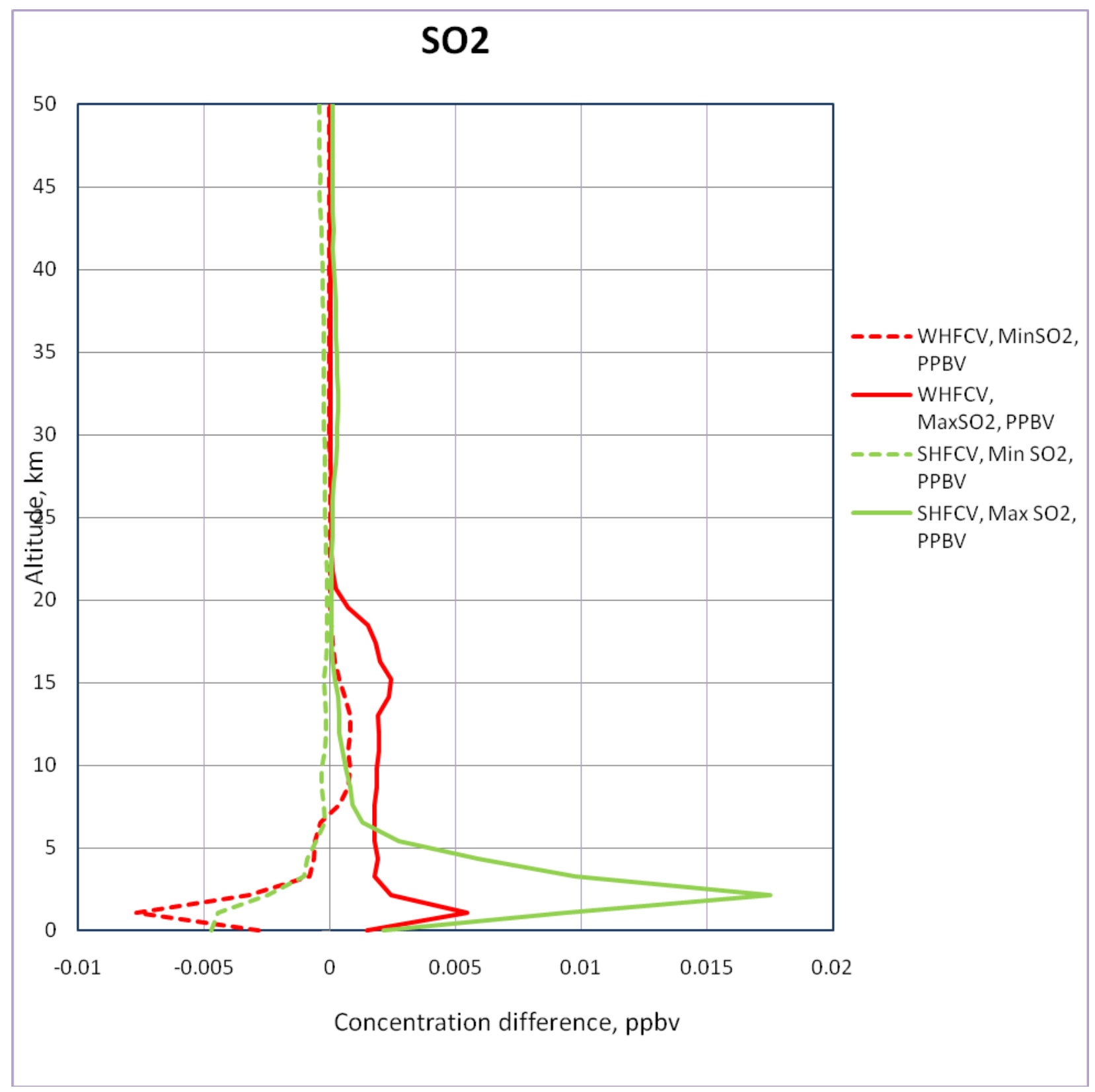




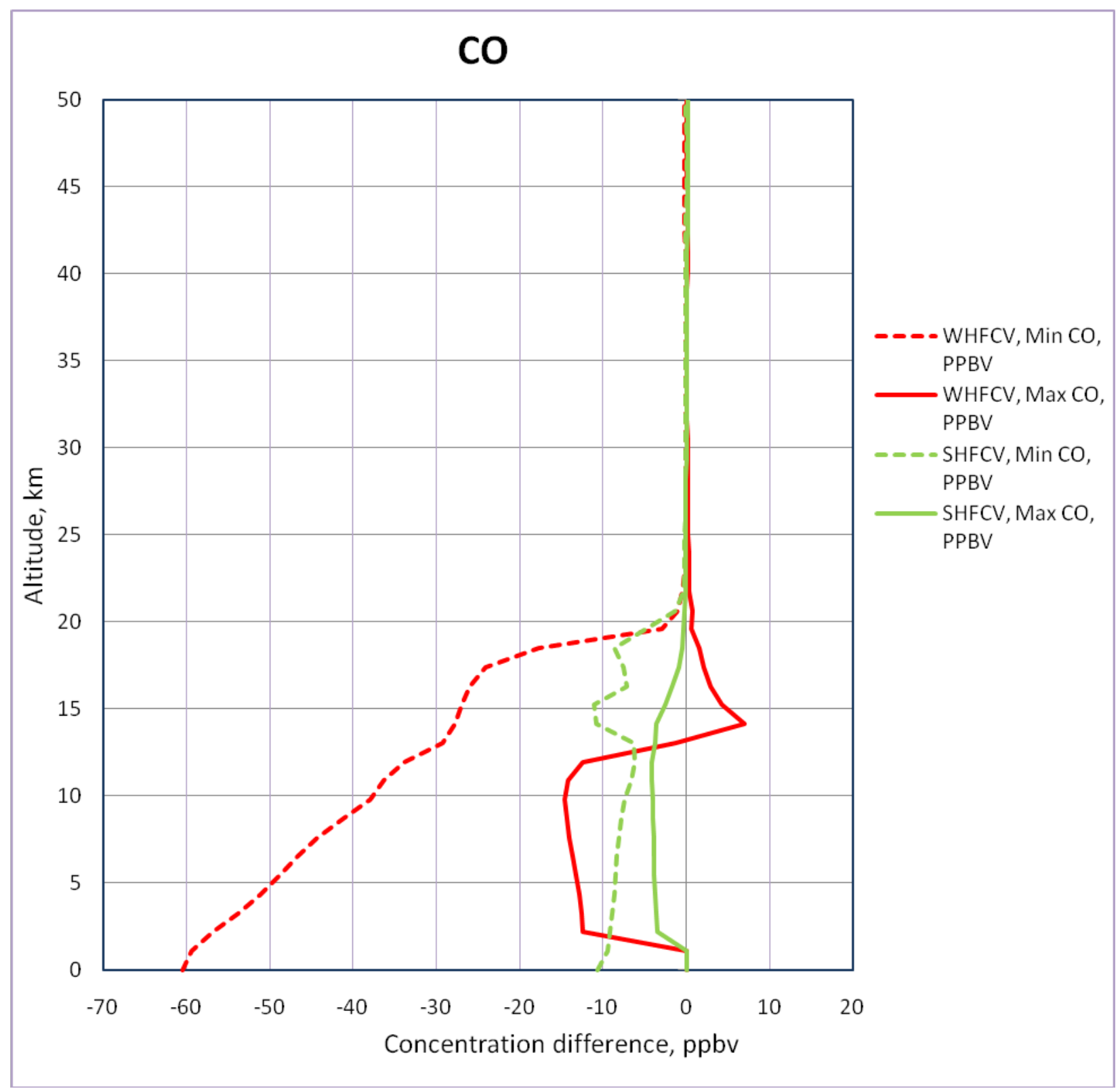




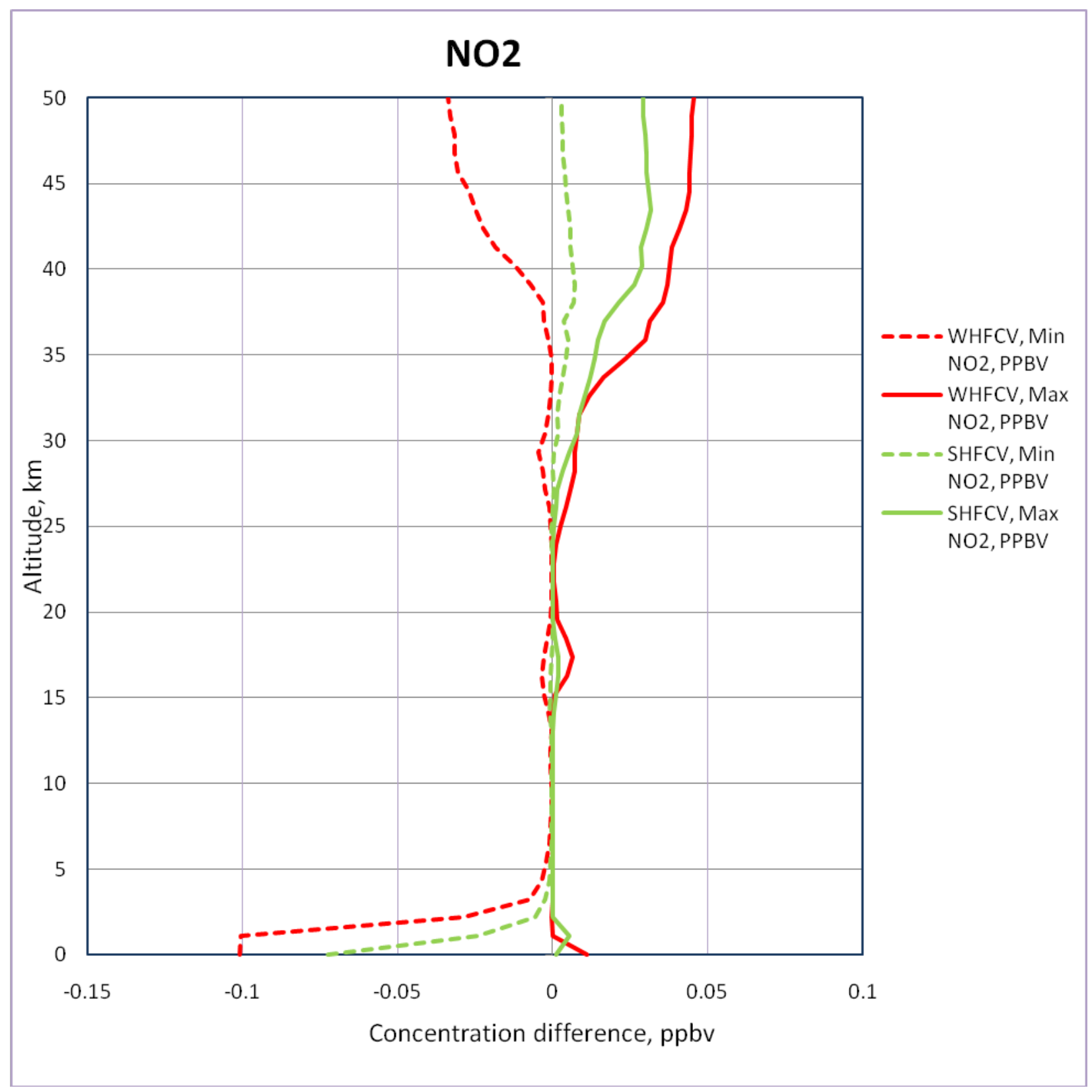

E-10 

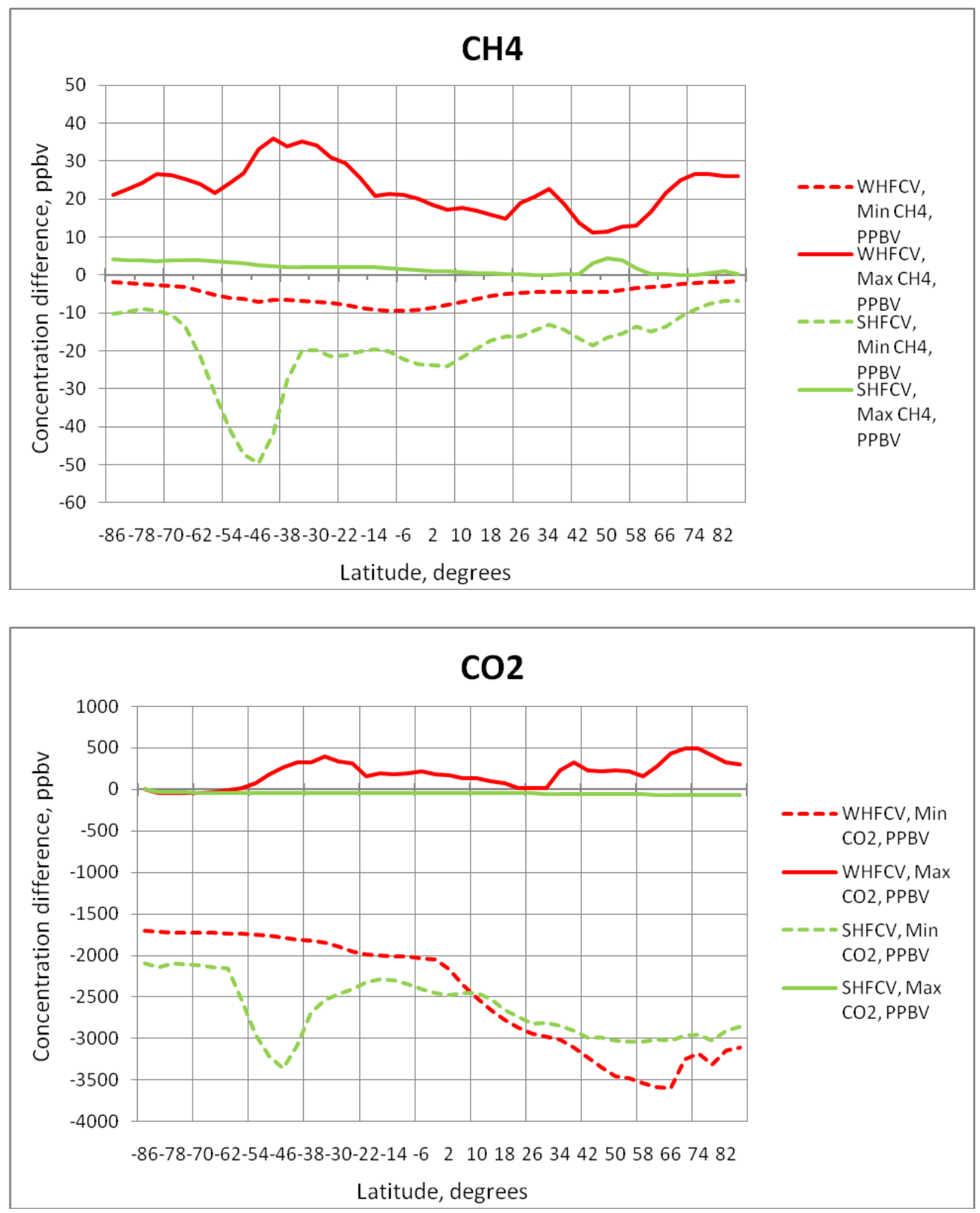

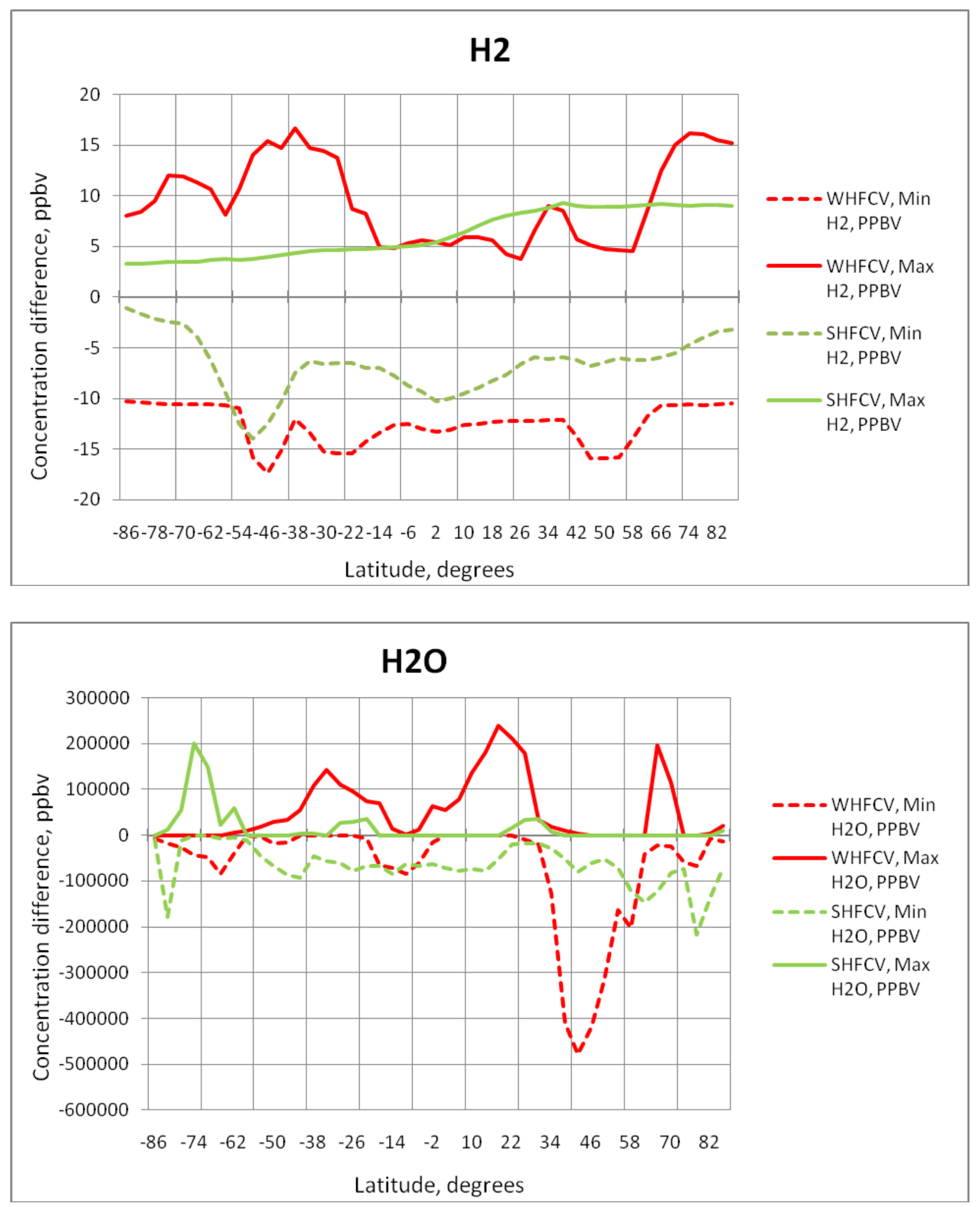

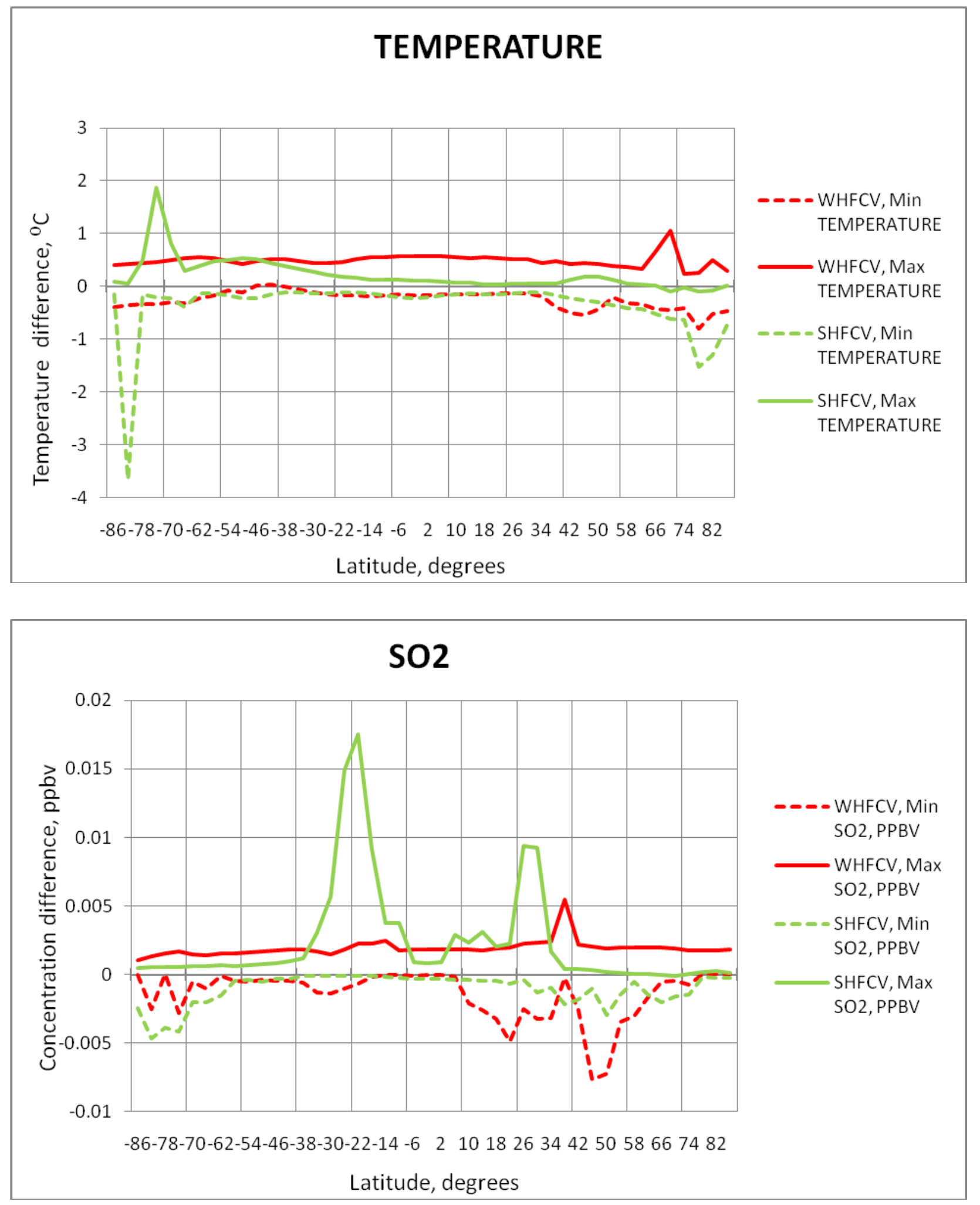

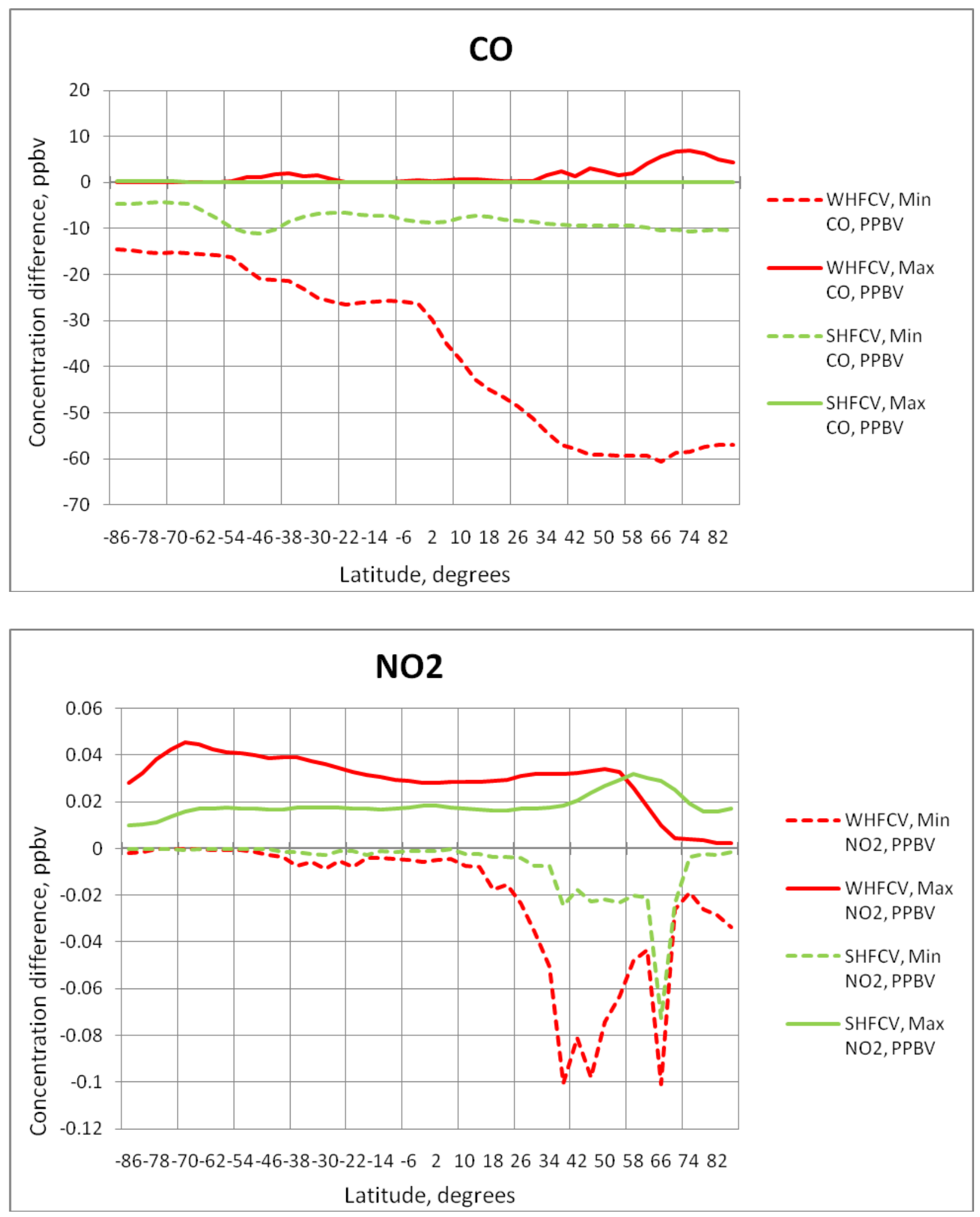